\title{
Analysis of Federal Policy Options for Improving U.S. Lighting Energy Efficiency: Commercial and Residential Buildings
}

Barbara A. Atkinson, James E. McMahon, Evan Mills, Peter Chan, Terry W. Chan, Joseph H. Eto, Judith D. Jennings, Jonathan G. Koomey, Kenmy W. Lo, Matthew Lecar, Lynn Price, Francis Rubinstein, Osman Sezgen. Tom Wenzel

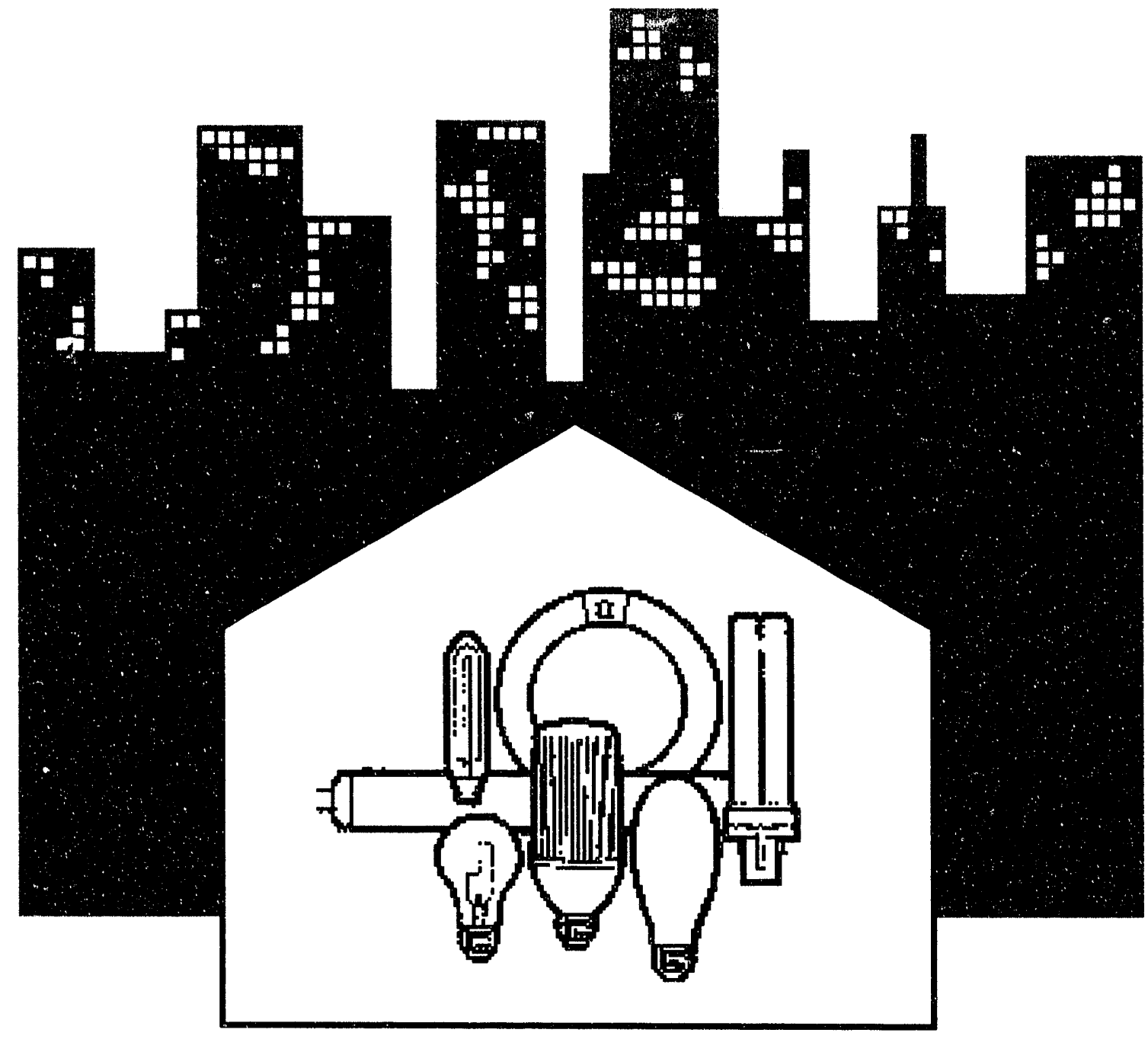

Energy \& Environment Division - Lawrence Berkeley Laboratory One Cyclotron Road, 90-4000

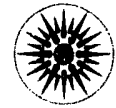
Berkeley, CA, USA 94720

$$
\begin{gathered}
\text { LBL-31469 } \\
\text { UC-350 }
\end{gathered}
$$




\section{DISCLAIMER}

This document was prepared as an account of work sponsored by the United States Government. Neither the United States Government nor any agency thereof, nor The Regents of the University of California, nor any of their employees, makes any warranty, express or implied, or assurnes any legal liability or responsibility for the accuracy, completeness, or usefulness of any information, apparatus, product, or process disclosed, or represents that its use would not infringe privately owned rights. Reference herein to any specific commercial product, process, or service by its trade name, trademark, manufacturer, or otherwise, does not necessarily constitute or imply its endorsement, recommendation, or favoring by the United States Government or any agency thereof, or The Regents of the University of California. The views and opinions of authors expressed herein do not necessarily state or reflect those of the United States Government or any agency thereof or The Regents of the University of California and shall not be used for advertising or product endorsement purposes.

This report has been reproduced directly from the best available copy.

Available to DOE and DOE Contractors from the Office of Scientific and Technical Information

P.O. Box 62, Oak Ridge, TN 37831

Prices available from (615) 576-8401, FTS 626-8401

Available to the public from the

National Technical Information Service

U.S. Department of Commerce

5285 Port Royal Road, Springfield, VA 22161

Lawrence Berkeley Laboratory is an equal opportunity employer. 


\title{
Analysis of Federal Policy Options for \\ Improving U.S. Lighting Energy Efficiency: \\ Commercial and Residential Buildings
}

\author{
Barbara A. Atkinson, James E. McMahon, Evan Mills \\ Peter Chan, Terry W. Chan, Joseph H. Eto, Judith D. Jennings, \\ Jonathan G. Koomey, Kenny W. Lo, Matthew Lecar, \\ Lynn Price, Francis Rubinstein, Osman Sezgen, Tom Wenzel
}

Energy \& Environment Division

Lawrence Berkeley Laboratory

One Cyclotron Road, 90-4000

Berkeley, CA, USA 94720

LBL-31469

December 1992 


\section{ACKNOWLEDGMENTS}

Rudy Verderber of LBL's Lighting Systems Research Group and Issac Turiel of the Energy Conservation Policy Group provided valuable technical support on this project. Greg Rosenquist performed environmental and peak load analyses, and Sajid Hakim assisted with table production. We thank Nan Wishner for copy editing and Ted Gartner, Dorothy Harvey, Kristen Nickel, and Esther Malveaux who produced the final document.

The following individuals reviewed a draft version of this report. Review of the document does not necessarily constitute an endorsement of the results; the authors are solely responsible for its content.

Charles L. Amick Chairman, NEMA Indoor Lighting Section Technical Committee, Thomas Industries, Inc., Tupelo, MI

Peter Bleasby

Director of Codes and Standards, OSRAM Corporation, Montgomery, NY

Karl Brown

Research Manager, California Institute for Energy Efficiency, Berkeley, CA

Diana Campbell

Froject Manager, Lighting Design Lab, Seattle, WA

Mark Fishbaugher

Fishbaugher \& Associates, Cheshire, OR

Miriam Goldberg

Team Leader, Analytic Data Bases,

U.S. DOE Energy Information Administration, Washington, DC

Alfred Gough

President, Lighting Research Institute, Littleton, CO

Jeffrey Harris

Staff Scientist, Lawrence Berkeley Laboratory, Washington, DC

Karl Johnson

Electric Power Research Institute, Palo Alto, CA

Joseph Kolarik

Thomas Industries, Inc., Tupelo, MI

Jerome La Montagne

Senior Project Engineer, Department of Applied Science, Brookhaven National Laboratory, Upton, Long Island, NY

Steven Nadel

American Council for an Energy-Efficient Economy, Washington, D.C.

Fred Nichoison

Group Manager, Lighting Division, National Electric Manufacturers Association, Washington, D.C.

Barbara Pierce Department of Applied Science, Brookhaven National Laboratory, Upton, Long Island, NY

Mary Ann Piette Staff Scientist, Lawrence Berkeley Laboratory, Berkeley, CA Mark Rea Director, Lighting Research Center, Troy, NY

A.C. Rousseau Manager, Technical Relations, Philips Lighting Co., Lewiston, ME

This work was supported by the Assistant Secretary for Conservation and Renewable Energy, Office of Building Technologies of the U.S. Department of Energy, under Contract No. DE-AC03-76SF00098. 


\section{SYNOPSIS}

In 1990, lighting systems in the United States consumed approximately $515 \mathrm{TWh}$ (19 percent of national electricity use) or 5.9 primary Quads (7 percent of national energy use) at a cost of $\$ 36$ billion to consumers. In response to a request by the U.S. Department of Energy, this report analyzes selected policy options for reducing electricity use, peak demand, power-plant emissions, and associated costs by improving the end-use energy efficiency of lighting. This study focuses on the potential for energy savings beyond those anticipated from current market trends, programs, and state standards. The analysis is limited to the main lighting energy uses within the commercial and residential sectors, which constitute 69 percent of national lighting energy use (and 74 percent of the cost).

The investigation begins with a component-level engineering analysis of specific lighting technologies (including engineering performance and life-cycle cost) and a review of past U.S. experience with lighting programs and policies. A variety of prospective policy strategies is then identified, including:

- Mandatory component performance and prescriptive standards

- Mandatory system performance standards

- Voluntary component standards

- Federal incentive programs

- consumer rebates

- consumer tax credits

- Education/information programs

- consumer/designer education

- component labeling

The policy cases are developed to incorporate a range of existing and emerging efficient lighting technologies (lamps, fixtures, and controls) as well as whole-building installed wattage limits for lighting. Eleven lamp product classes and four fixture product classes are examined for the commercial sector, and four lamp product classes are studied for the residential sector. Ballasts are considered in detail in a separate analysis in support of a forthcoming DOE rulemaking.

In the next stage of the analysis, technologies are applied in the policy cases at the natural rates of capital turnover, building renovation, and new construction and with the constraint that current lighting levels are maintained. The national demand for lighting energy is modeled through the year 2030 for eleven commercial building types using the Electric Power Research Institute's Commercial End-Use Forecasting Model (COMMEND 3.2) and for three residential building types using the LBL Residential Energy Model (LBL-REM). The analysis excludes interactions between lighting and space-conditioning energy use, but the topic is treated in an appendix.

Projections of lighting energy demand are accompanied by several supplemental analyses. Cost effectiveness is measured in terms of the net present value of equipment and energy expenditures. 
An assessment of utility impacts translates electricity savings into avoided electrical generating capacity, and a manufacturer analysis describes the current disposition of the lighting industry and explores the likely effect of policies on the producers of lighting equipment. Energy savings are translated into associated power-sector emissions of sulfur dioxide, nitrogen oxides, and carbon dioxide.

As an upper bound to future commercial lighting demand, a "No-Programs" Baseline reflects a case in which changing electricity prices are the only influence on energy efficiency. To provide more realistic future reference points from which to measure energy savings, "High-" and "Low-Efficiency" Baselines define likely trends in lighting energy demand if none of the policies examined in the study are implemented, but presently projected efforts by utilities, state standards, and existing national programs (e.g., EPA's Green Lights Program and FEMP's Federal Relighting Initiative) continue. The High-Efficiency Baseline is considered to be the "most likely" scenario, given current programs and market trends.

In the No-Programs Baseline, commercial lighting demand is estimated to grow 107 percent by the year 2030 compared to levels in the base year, 1986. This trend is driven by an approximate doubling of floor space and is almost synonymous with a "frozen-efficiency" scenario and with the current U.S. Department of Energy's Annual Energy Outlook (AEO) forecast. By 2030, commercial lighting energy demand would rise by 59 percent in the High-Efficiency Baseline (to $401 \mathrm{TWh}, 76 \mathrm{GW}$ peak, and $\$ 33$ billion/year in 1990 dollars) and by 96 percent in the Low-Efficiency Baseline (to $495 \mathrm{TWh}, 93 \mathrm{GW}$ peak, and $\$ 40$ billion/year).

For the residential sector, insufficient information about the sensitivity of lighting energy demand to electricity prices requires the use of a true Frozen-Efficiency Baseline. Residential lighting electricity demand in the year 2030 would grow by 38 percent (to $168 \mathrm{TWh}, 18 \mathrm{GW}$ peak, and $\$ 15$ billion/year) in the Frozen-Efficiency Baseline compared with the base year, 1990. In the High-Efficiency Baseline, demand would rise by 14 percent (to $139 \mathrm{TWh}, 15 \mathrm{GW}$ peak, $\$ 13$ billion/year).

Energy, economic, and environmental impacts for three selected policy cases in the two sectors are summarized in Tables S.1 and S.2. The first case featured is the standards for fluorescent and incandescent lamps established by the Energy Policy Act of 1992 (P.L. 102-486). The Minimum Life-Cycle Cost Combination represents the maximum economic savings potential for each sector and the Research \& Development Combination represents the technical potential. Energy savings in the year 2030 for these two cases vary from 49 to 71 percent for the commercial sector and from 21 to 64 percent for the residential sector, depending on the baseline from which savings are measured. Lighting energy intensities for commercial and residential baselines and selected policy cases are presented in Figures S.1 and S.2. 
Table S.1 Summary of Cumulative Impacts of Selected Commercial Lighting Policies Measured with Respect to the High- (Low-) Efficiency Baseline"

\begin{tabular}{|c|c|c|c|}
\hline Type of Impact & $\begin{array}{l}\text { Energy Policy Act } \\
\text { of } 1992 \\
\text { Lamp Standards }\end{array}$ & $\begin{array}{l}\text { Minimum Life- } \\
\text { Cycle Cost } \\
\text { Combination } \\
\text { [Max. Econ. Pot'l] }\end{array}$ & $\begin{array}{l}\text { Research \& } \\
\text { Development } \\
\text { Combination } \\
\text { [Technical Potential] }\end{array}$ \\
\hline $\begin{array}{l}\text { Lighting Energy Intensity in } 2030: \\
\text { Energy Use Intensity, EUI (kWh/ft'-year) }\end{array}$ & $2.76(2.93)$ & $1.59(1.59)$ & $1.11(1.11)$ \\
\hline $\begin{array}{l}\text { Primary Energy Savings (Quads) } \\
(1995-2030)\end{array}$ & $13(31)$ & $53(77)$ & $69(93)$ \\
\hline $\begin{array}{l}\text { Electricity Savings in } 2030 \text { (TWh) } \\
\text { (Percent Savings) }\end{array}$ & $\begin{array}{c}45(117) \\
11 \%(24 \%)\end{array}$ & $\begin{array}{l}197(291) \\
49 \%(59 \%)\end{array}$ & $\begin{array}{l}258(351) \\
64 \%(71 \%)\end{array}$ \\
\hline Peak Power Savings by $2030\left(\mathrm{GW}, 10^{\circ} \mathrm{W}\right)$ & $9(23)$ & $37(54)$ & $49(66)$ \\
\hline $\begin{array}{l}\text { Net Present Yalue }(\$ 1990 \text { billion })^{*} \\
\text { Avoided Emissions }(1995-2030)\end{array}$ & $23(55)$ & $40(88)$ & $76(126)$ \\
\hline $\begin{array}{ll}- & \mathrm{CO}_{2} \text { (Billion tons) } \\
- & \mathrm{SO}_{2} \text { (Million tons) } \\
- & \mathrm{NO}_{\mathrm{x}} \text { (Million tons) }\end{array}$ & $\begin{array}{l}1.1(2.7) \\
2.2(5.6) \\
2.0(5.1)\end{array}$ & $\begin{array}{l}4.3(7.2) \\
8.3(14.1) \\
7.8(13.1)\end{array}$ & $\begin{array}{l}5.0(8.4) \\
9.0(17.6) \\
8.7(16.0)\end{array}$ \\
\hline
\end{tabular}

Excludes interactions with heating, ventilating, and air conditioning (HVAC) energy use.

${ }^{+}$Real electricity prices increase only slightly between 1995 and 2030 . Real discount rate $=4$ percent.

Table S.2 Summary of Cumulative Impacts of Selected Residential Lighting Policies Measured with Respect to the High- (Frozen-) Efficiency Baseline ${ }^{\circ}$

\begin{tabular}{|c|c|c|c|}
\hline Type of Impect & $\begin{array}{l}\text { Energy Policy Act } \\
\text { of } 1992 \\
\text { Lamp Standards }\end{array}$ & $\begin{array}{l}\text { Mhinimum Life- } \\
\text { Cycle Cost } \\
\text { Combination } \\
\text { [Max. Econ. Pot'l] }\end{array}$ & $\begin{array}{l}\text { Research \& } \\
\text { Development } \\
\text { Combination } \\
\text { [Technical Potential] }\end{array}$ \\
\hline $\begin{array}{l}\text { Lighting Energy Intensity in 2030: } \\
\text { Unit Energy Consumption, UEC } \\
\text { (kWh/household-year) }\end{array}$ & $1,039(1,249)$ & 839 (839) & 467 (467) \\
\hline $\begin{array}{l}\text { Primary Energy Savings (Quads) } \\
(1995-2030)\end{array}$ & $1(2)$ & $11(22)$ & $29(40)$ \\
\hline $\begin{array}{l}\text { Electricity Savings in } 2030 \text { (TWh) } \\
\text { Percent Savings } \\
\text { Peak Power Savings by } 2030\left(\mathrm{GW}, 10^{\circ} \mathrm{W}\right) \\
\text { Net Present Value ( } \$ 1990 \text { billion }^{+} \\
\text {Avoided Emissions }(1995-2030)\end{array}$ & $\begin{aligned} 4 & (6) \\
3 \% & (4 \%) \\
0.4 & (0.6) \\
1 & (2)\end{aligned}$ & $\begin{array}{l}29(58) \\
21 \%(35 \%) \\
3.2(6.4) \\
34(39)\end{array}$ & $\begin{array}{l}78(107) \\
56 \%(64 \%) \\
8.6(11.7) \\
20(26)\end{array}$ \\
\hline $\begin{array}{l}-\mathrm{CO}_{2} \text { (Billion tons) } \\
-\mathrm{SO}_{2} \text { (Million tons) } \\
-\mathrm{NO}_{\mathrm{x}} \text { (Million tons) }\end{array}$ & $\begin{array}{l}0.1(0.2) \\
0.3(0.4) \\
0.2(0.4)\end{array}$ & $\begin{array}{l}0.9(1.8) \\
2.3(4.3) \\
1.9(3.8)\end{array}$ & $\begin{array}{l}2.5(3.4) \\
6.1(8.4) \\
5.1(7.1)\end{array}$ \\
\hline
\end{tabular}

Excludes interactions with heating, ventilating, and air conditioning (HVAC) energy use.

${ }^{+}$Real electricity prices increase only slightly between 1995 and 2030. Real discount rate $=6$ percent. 
The results show that new federal policies offer significant cost-effective opportunities for further reducing lighting energy demand. The extent of savings ranges considerably, from up to 15 percent for incentive/information policies to almost 65 percent for comprehensive mandatory standards. Voluntary standards achieve approximately two-thirds as much savings as do mandatory standards. The economic benefits (net present values) and emissions reductions are also greater for mandatory standards than for voluntary standards or incentive/information policies. Notably, the magnitude of the prospective benefits exceeds those from the entire set of existing federal NAECA standards for residential appliances.

The magnitude of these savings is in some standards cases greater than even the maximum likely savings from current programs and policies (i.e., the difference between the High-Efficiency and No-Programs Baselines). Furthermore, savings from the Energy Policy Act of 1992 lamp standards achieve one-fourth of the potential commercial energy savings from prospective comprehensive standards (i.e. the Minimum Life Cycle Cost Combination case) and a one-seventh of the prospective savings for the residential sector. For the commercial and residential sectors combined, the difference in net present value for the two cases is approximately $\$ 50$ billion.

New federal policies would reduce uncertainties for utilities in projecting future energy demand and for lighting equipment manufacturers in anticipating demand for their products. The policy options considered here are generally complementary; a mixture of strategies promises to be the most technically and institutionally sound approach. Continued research and development is essential for a continued supply of conservation resources. 
Figure S.1

Annual LIghting Energy Use Intensity

Baselines and Illustrative Policy Cases

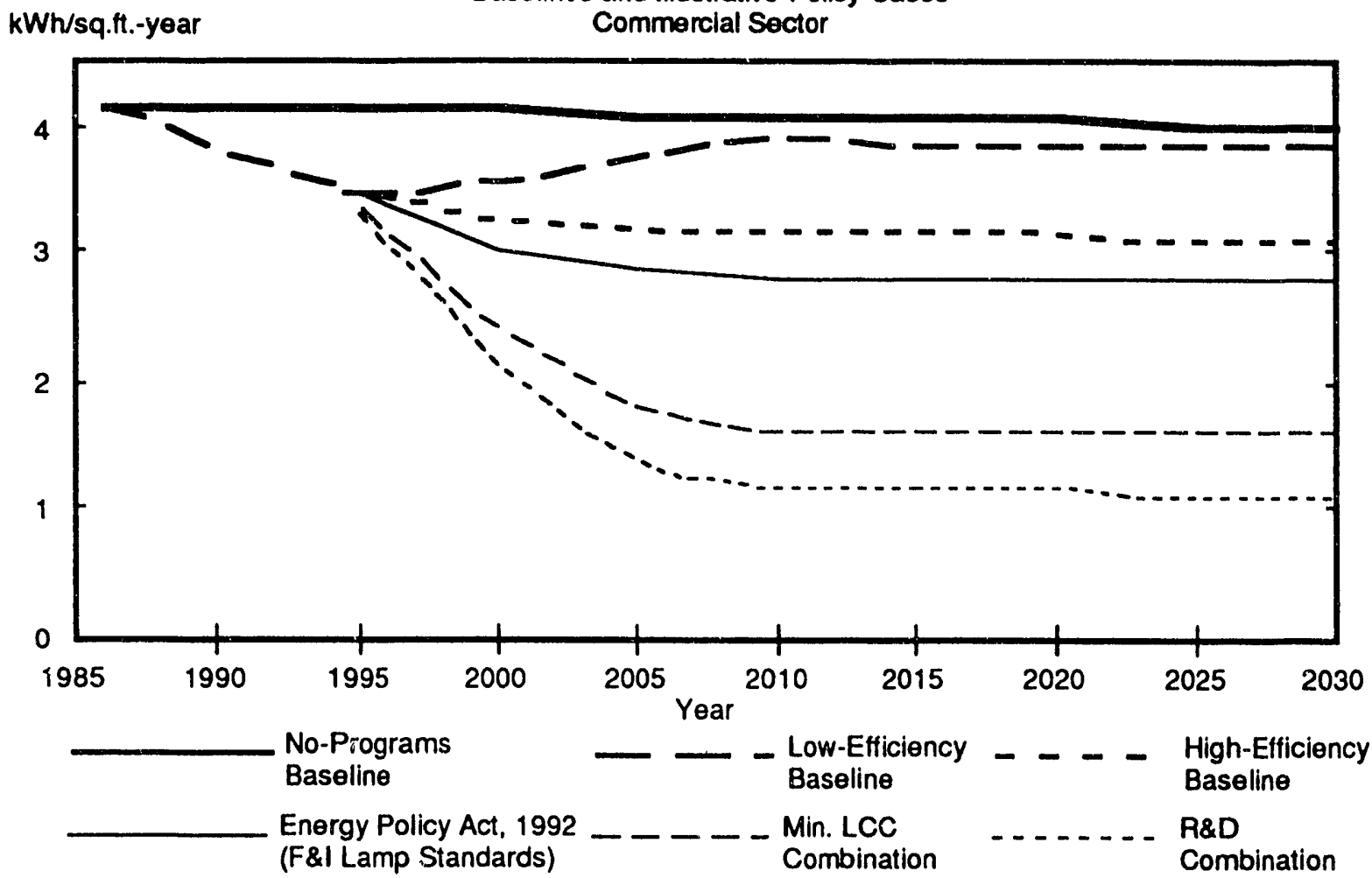

Figure S.2

kWh / household-year

Lighting Unit Energy Consumption In 2030

Baselines and Illustrative Policy Cases

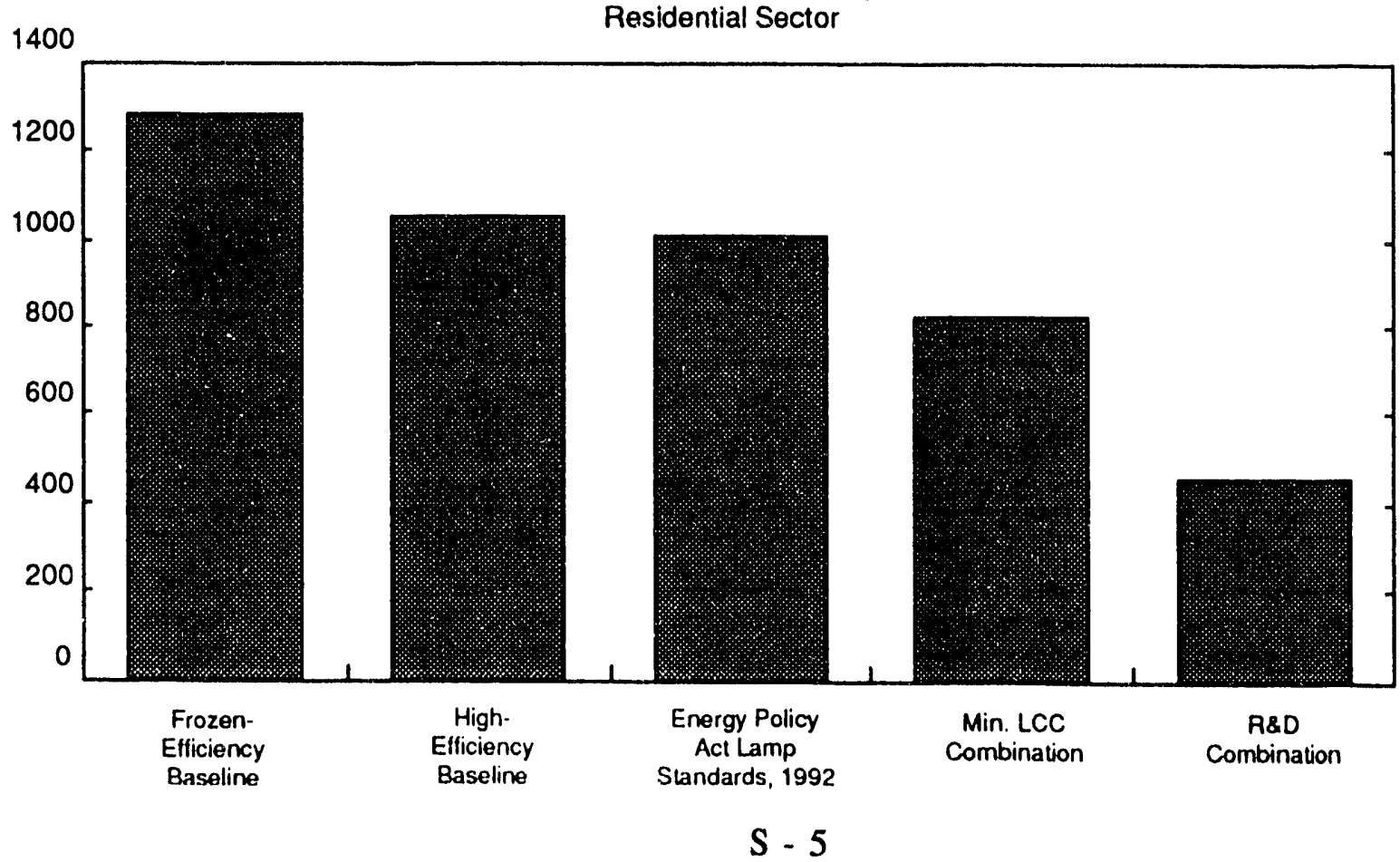




\section{TABLE OF CONTENTS}

SYNOPSIS

EXECUTIVE SUMMARY $\ldots \ldots \ldots \ldots \ldots \ldots \ldots \ldots \ldots \ldots \ldots \ldots \ldots \ldots \ldots \ldots \ldots$

INTRODUCTION: PURPOSE AND SCOPE $\ldots \ldots \ldots \ldots \ldots \ldots \ldots \ldots \ldots \ldots \ldots \ldots \ldots$ i

BOUNDING THE UNCERTAINTY $\ldots \ldots \ldots \ldots \ldots \ldots \ldots \ldots \ldots \ldots \ldots \ldots \ldots$ ii

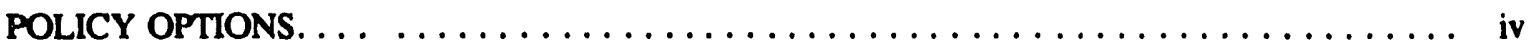

Provisions of the Energy Policy Act of $1992 \ldots \ldots \ldots \ldots \ldots \ldots \ldots$ viii

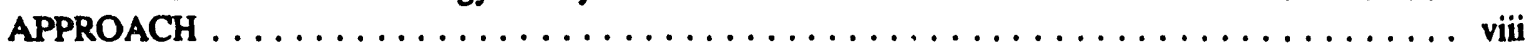

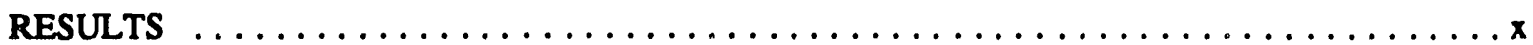

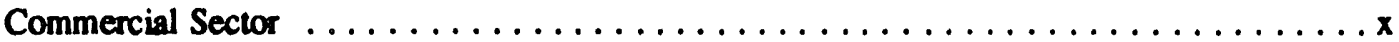

Residential Sector .............................. xvi

Comparisons to Other Studies $\ldots \ldots \ldots \ldots \ldots \ldots \ldots \ldots \ldots \ldots \ldots \ldots \ldots$ xvi

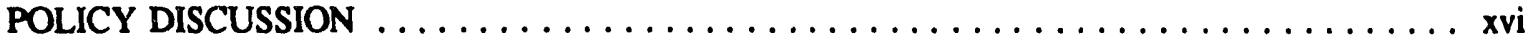

Advantages and Disadvantages of Specific Policy Options $\ldots \ldots \ldots \ldots \ldots \ldots \ldots \ldots$ xx

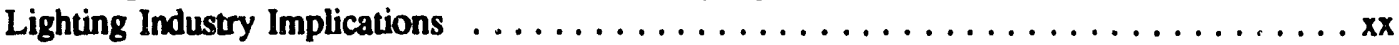

Implications for Policy Making $\ldots \ldots \ldots \ldots \ldots \ldots \ldots \ldots \ldots \ldots \ldots \ldots \ldots \ldots \ldots$

Policy Approaches Not Examined in the Analysis ................. xxiv

Analytic and Research Needs $\ldots \ldots \ldots \ldots \ldots \ldots \ldots \ldots \ldots \ldots \ldots \ldots \ldots$ xxvi

CONCLUSIONS $\ldots \ldots \ldots \ldots \ldots \ldots \ldots \ldots \ldots \ldots \ldots \ldots \ldots \ldots \ldots \ldots \ldots \ldots \ldots \ldots \ldots \ldots \ldots$

$1 \quad$ INTRODUCTION $\ldots \ldots \ldots \ldots \ldots \ldots \ldots \ldots \ldots \ldots \ldots \ldots \ldots \ldots \ldots \ldots \ldots \ldots$

1.1 WHY ENERGY-EFFICIENT LIGHTING? $\ldots \ldots \ldots \ldots \ldots \ldots \ldots \ldots \ldots \ldots \ldots$

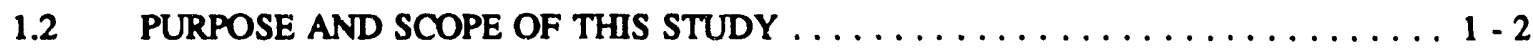

1.3 STRUCTURE OF THE REPORT $\ldots \ldots \ldots \ldots \ldots \ldots \ldots \ldots \ldots \ldots \ldots \ldots \ldots$

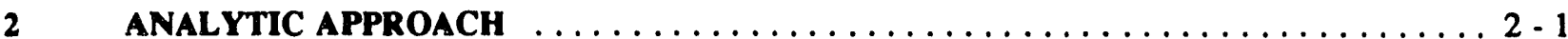

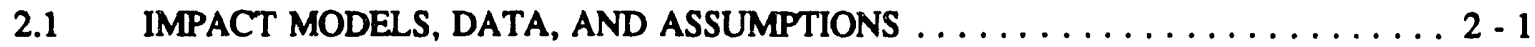

2.1.1 Engineering Analysis ....................... 2 - 1

2.1.2 Commercial Sector and EPRI COMMEND Model ............. 2 - 7

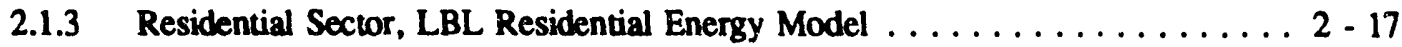

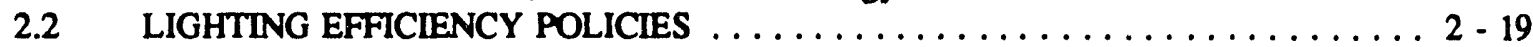

2.2.1 Component Performance/Prescriptive Standards

(Commercial and Residential Sectors) .................... 2 - 19

2.2.2 Voluntary Component Performance Standards (Commencial Sector) . . . . . 2 20

2.2.3 System Performance Standards (Commercial Sector) . . . . . . . . . . . . 2 - 21

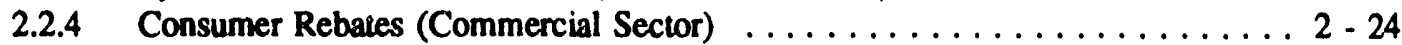

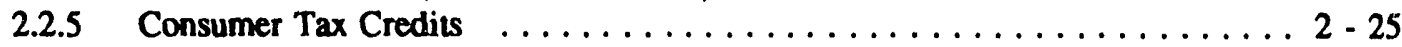

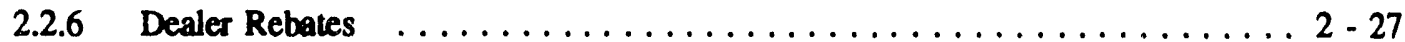

2.2.7 Manufacturer Tax Credits ....................... 2 - 28

2.2.8 Consumer Education (Commercial Sector) ................ 2 - 28

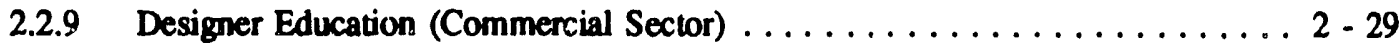

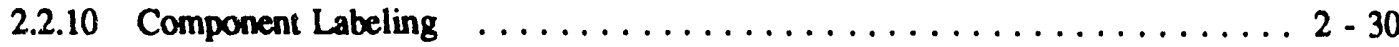




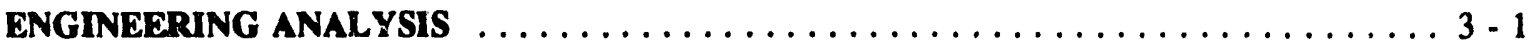

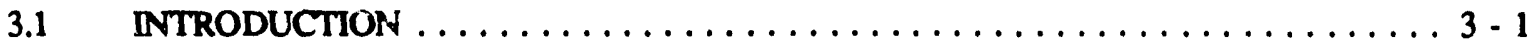

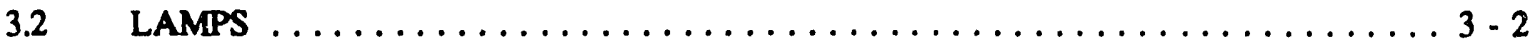

3.2.1 Commencial Sector Product Classes and Design Options ........... 3 - 2

3.2.2 Residential Sector Product Classes . . . . . . . . . . . . . . . 3 - 4

3.2.3 Energy Use, Efficacy, Equipment Costs, Replacement Costs, and Operating

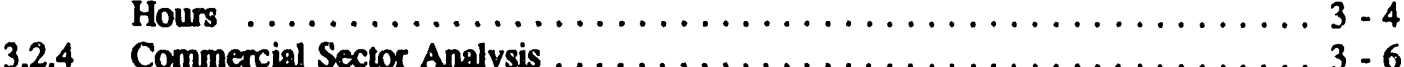

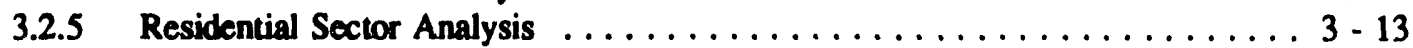

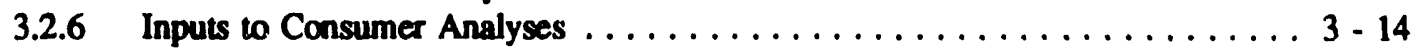

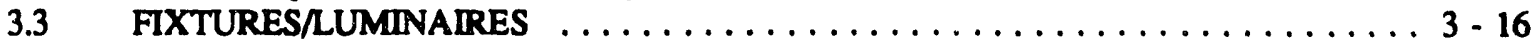

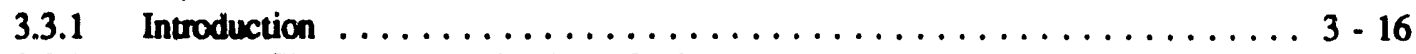

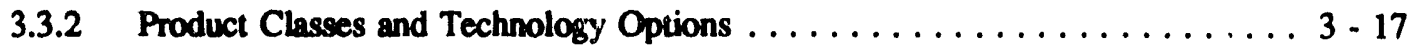

3.3.3 Energy Use Data ........................... $3-23$

3.3.4 Cost-Efficiency Data ......................... 3-26

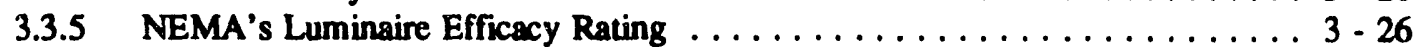

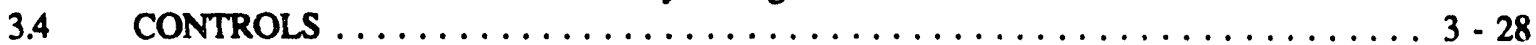

3.4.1 Analysis Method .......................... 3-29

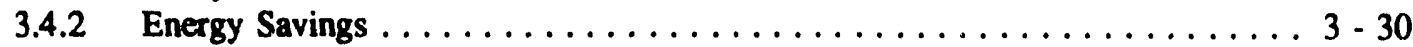

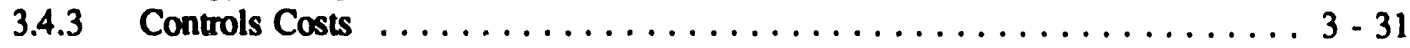

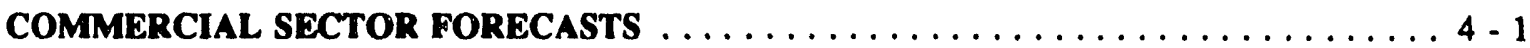

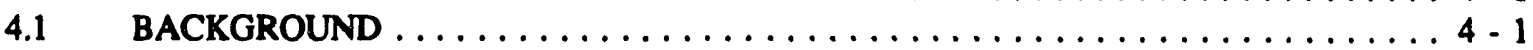

4.2 OVERVIEW OF THE COMMERCIAL SECTOR ANALYSIS $\ldots \ldots \ldots \ldots \ldots \ldots \ldots 4-2$

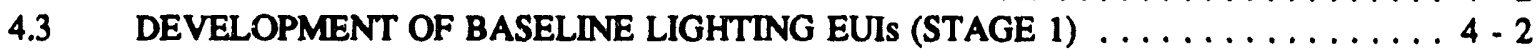

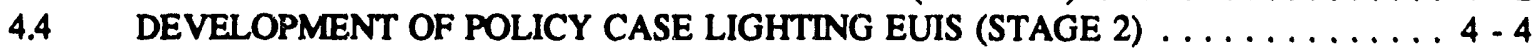

4.5 ESTIMATION OF THE NET PRESENT VALUES OF POLICY CASES $\ldots \ldots \ldots \ldots 4-6$

4.6 RESULTS OF THE COMMERCIAL ENERGY MODEL $\ldots \ldots \ldots \ldots \ldots \ldots \ldots \ldots$ - 8

4.6.1 Fluorescent Lamp Policies . . . . . . . . . . . . . . . . . . . . 4 - 19

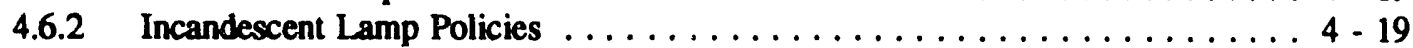

4.6.3 Fixture Policies ........................... 4 - 19

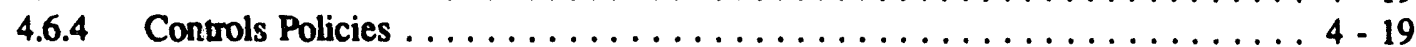

4.6.5 Comparison of Policies ............................ 4 4 . 19

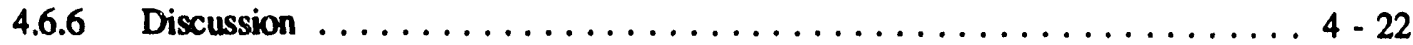

5 RESIDENTIAL SECTOR FORECASTS $\ldots \ldots \ldots \ldots \ldots \ldots \ldots \ldots \ldots \ldots \ldots \ldots$

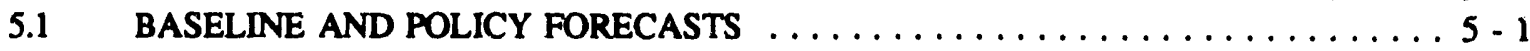

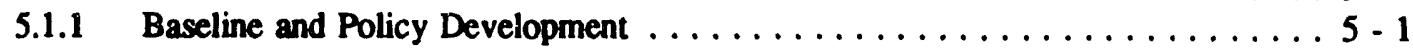

5.1.2 Policy Case UECs, Costs, and Lifetimes ................. 5 - 2

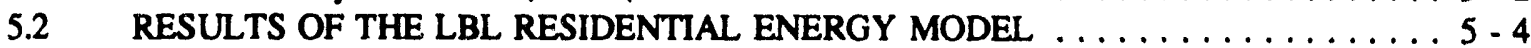

5.3 ECONOMIC ANALYSIS FOR THE RESIDENTIAL SECTOR $\ldots \ldots \ldots \ldots \ldots \ldots \ldots .5-7$

6 IMPACTS OF POLICIES ON MANUFACTURERS $\ldots \ldots \ldots \ldots \ldots \ldots \ldots \ldots \ldots \ldots$

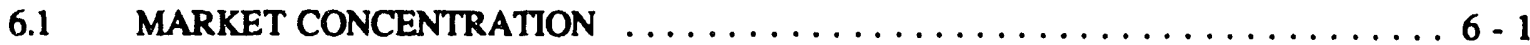

6.1.1 Lamps ......................... 6 - 1

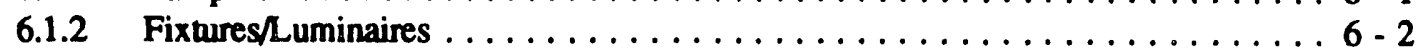

6.1.3 Controls .......................... 6 - 3

6.2 IMPACT OF PROPOSED DESIGN OPTIONS ON MANUFACTURERS $\ldots \ldots \ldots \ldots 6-3$

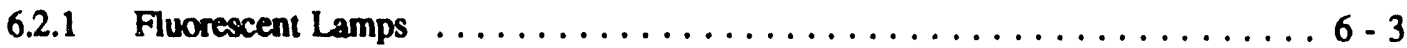

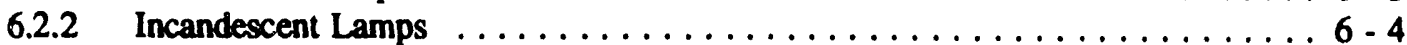

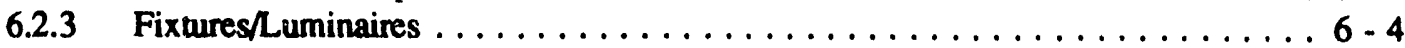

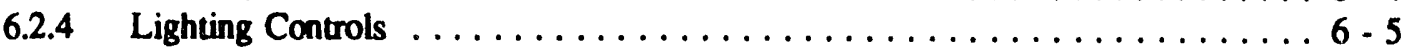

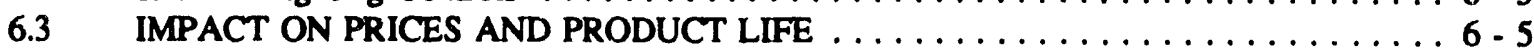

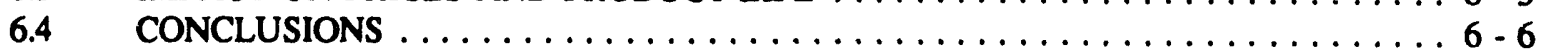


7 IMPACTS OF POLICIES ON ELECTRIC PEAK DEMAND $\ldots \ldots \ldots \ldots \ldots \ldots \ldots \ldots \ldots 7$.

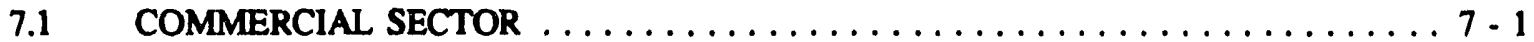

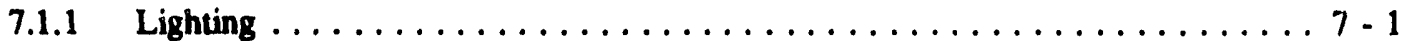

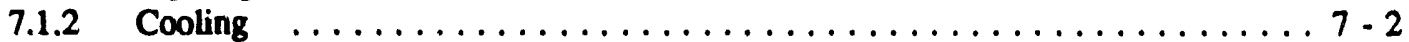

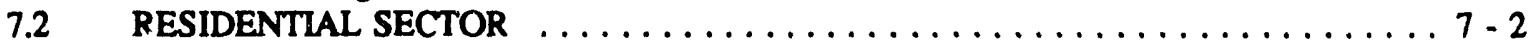

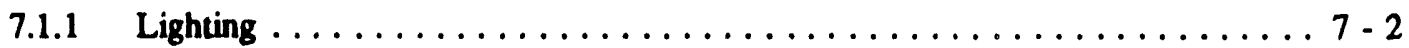

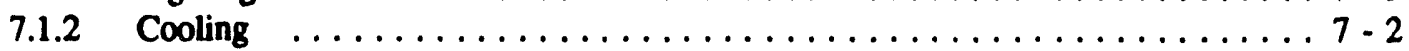

8 ENVIRONMENTAL IMPACTS $\ldots \ldots \ldots \ldots \ldots \ldots \ldots \ldots \ldots \ldots \ldots \ldots \ldots \ldots$

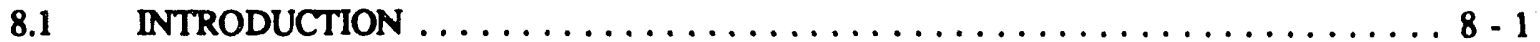

8.2 METHODS OF ESTIMATING ENVIRONMENTAL IMPACTS $\ldots \ldots \ldots \ldots \ldots \ldots 8-1$

8.2.1 Sulfur and Nitrogen Oxide Emissions $\ldots \ldots \ldots \ldots \ldots \ldots \ldots \ldots \ldots . \ldots .2$

8.2.2 Carbon Dioxide Emissions ..................... 8 - 3

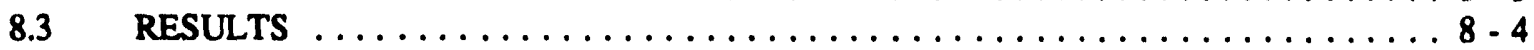

9 COMPARISON WTT" OTHER ESTIMATES OF POTENTIAL LIGHTING

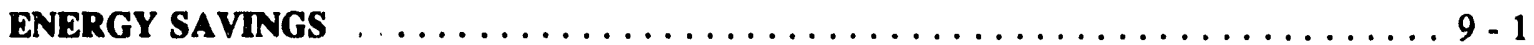

9.1 ACHIEVING MEANINGFUL COMPARISONS $\ldots \ldots \ldots \ldots \ldots \ldots \ldots \ldots \ldots$

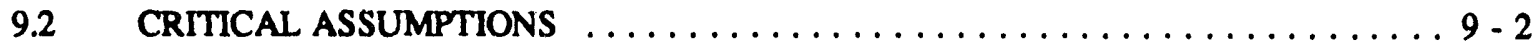

9.3 COMPARISONS WITH OTHER PROJECTIONS $\ldots \ldots \ldots \ldots \ldots \ldots \ldots \ldots \ldots . \ldots \ldots$

9.3.1 EIA's Lighting in Commercial Buildings $\ldots \ldots \ldots \ldots \ldots \ldots \ldots \ldots$. 6

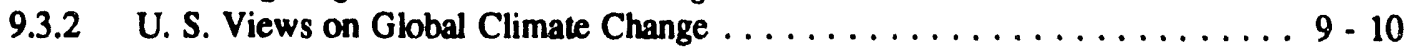

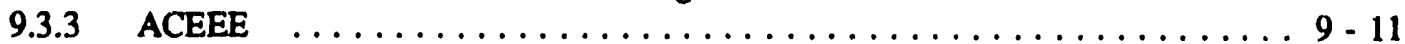

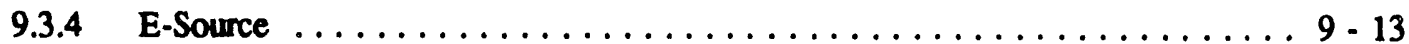

9.3.5 Electric Power Research Institute $\ldots \ldots \ldots \ldots \ldots \ldots \ldots \ldots \ldots \ldots \ldots$

10 RESEARCH AND DEVELOPMENT NEEDS $\ldots \ldots \ldots \ldots \ldots \ldots \ldots \ldots \ldots \ldots \ldots \ldots$

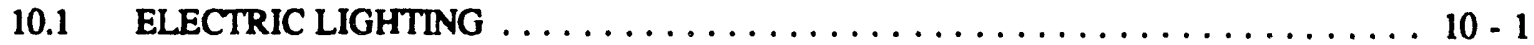

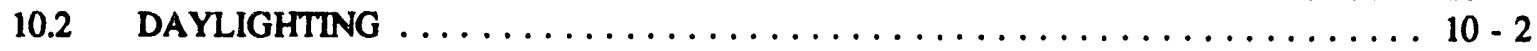

\section{APPENDICES}

APPENDIX A LIGHTING TECHNOLOGY OPTIONS $\ldots \ldots \ldots \ldots \ldots \ldots \ldots \ldots \ldots \ldots \ldots$ A -1

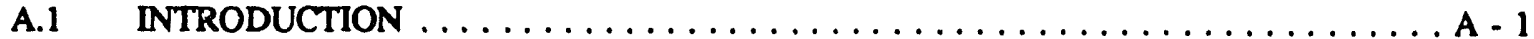

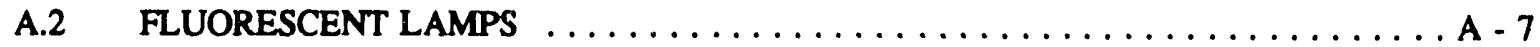

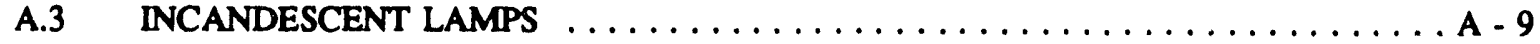

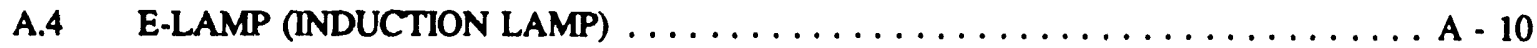

A.5 ADVANCED FLUORESCENT FIXTURE TECHNOLOGIES $\ldots \ldots \ldots \ldots \ldots \ldots$ A -11

APPENDIX B ENGINEERING ANALYSIS TABLES $\ldots \ldots \ldots \ldots \ldots \ldots \ldots \ldots \ldots \ldots \ldots$

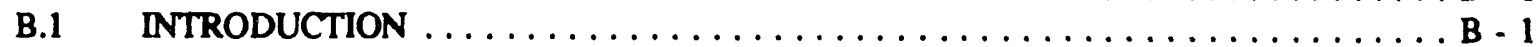

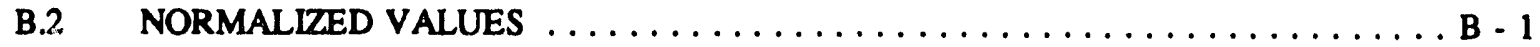

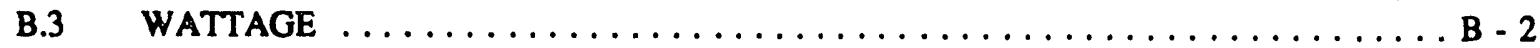

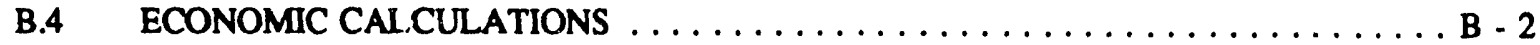

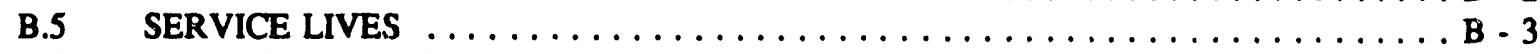

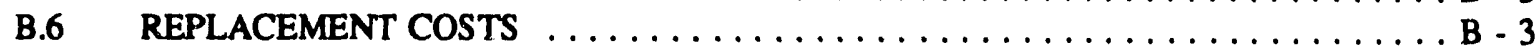

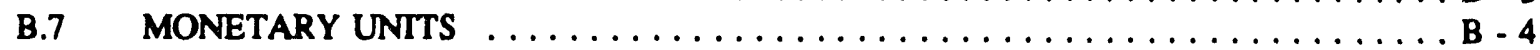

B.8 EQUIPMENT PRICE SELECTION, COMMERCIAL SECTOR $\ldots \ldots \ldots \ldots \ldots \ldots \ldots$ B - 4

B.9 EQUIPMENT PRICE SELECTION, RESIDENTIAL SECTOR $\ldots \ldots \ldots \ldots \ldots \ldots \ldots$. 5

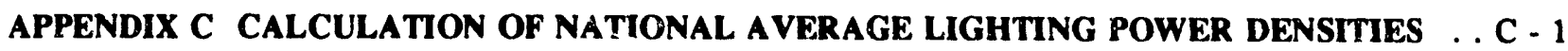

APPENDIX D LIGHTING TECHNOLOGY SPREADSHEETS FOR THE COMMERCIAL

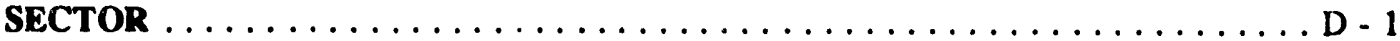


APPENDIX E THE DEMAND FORECASTING MODELS $\ldots \ldots \ldots \ldots \ldots \ldots \ldots \ldots \ldots \ldots$ E 1

E.1 EPRI COMMEND END USE FORECASTING MODEL $\ldots \ldots \ldots \ldots \ldots \ldots \ldots \ldots \mathrm{E}-1$

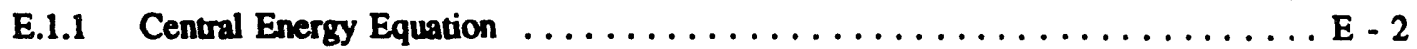

E.1.2 Load Shapes ........................... E 3

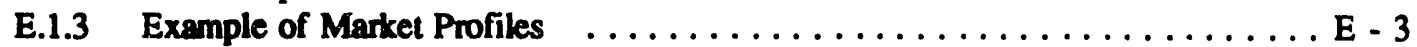

E.1.4 COMMEND Forecasting Framework $\ldots \ldots \ldots \ldots \ldots \ldots \ldots \ldots \ldots \ldots \ldots \ldots \ldots$

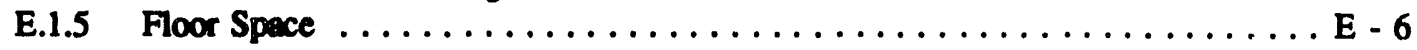

E.1.6 Modeling Share, EUI, and Usage Jecisions ................ E - 6

E.1.7 Future COMMEND Model Development .................. E - 11

E.2 LBL RESIDENTIAL ENERGY MODEL (LBL-REM) $\ldots \ldots \ldots \ldots \ldots \ldots \ldots \ldots$ E - 11

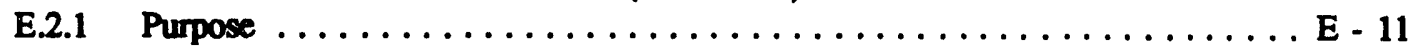

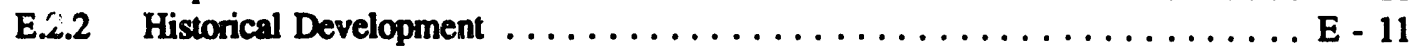

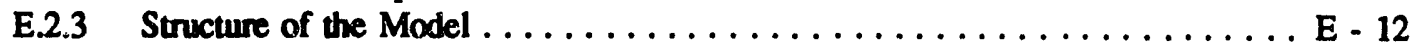

E.2.4 Housing Stock Submodel ....................... E - 12

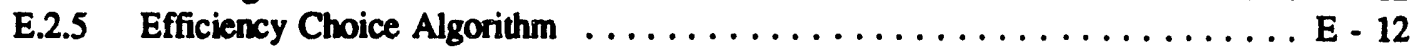

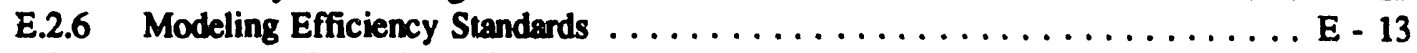

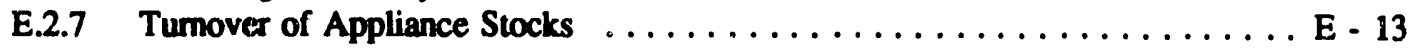

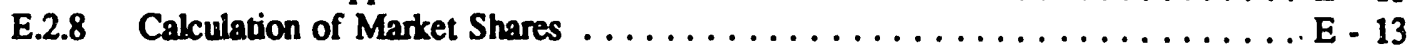

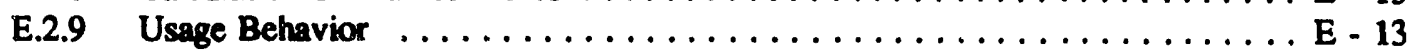

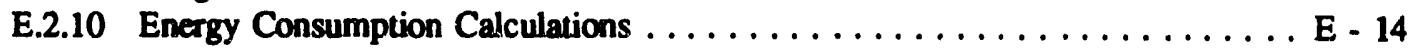

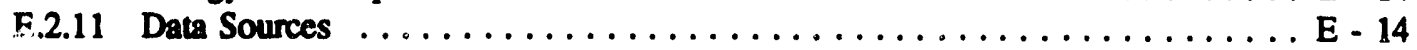

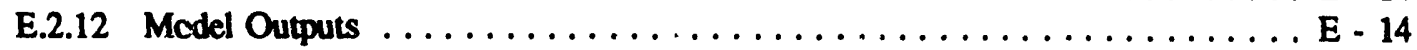

APPENDIX F COMMERCIAL SECTOR POLICY ANALYSIS RESULTS $\ldots \ldots \ldots \ldots \ldots \ldots$ F 1

APPENDIX G EXISTING ENERGY CODES ADDRESSING LIGHTING . . . . . . . . . G - 1

G.1 ENERGY CODES: LIGHTING PERFORMANCE AND EQUIPMENT STANDARDS . . G - 1

G.1.1 Energy Policy Act of 1992: Regulations on Lighting Equipment . . . . . . . G - 1

G.1.2 ASHRAE/IES 90.1 and DOE-1988 and -1993 Building Codes ......... G - 2

G.1.3 Performance and Component Standards at the State Level ............ G - 2

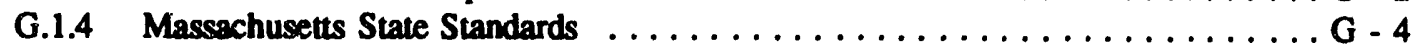

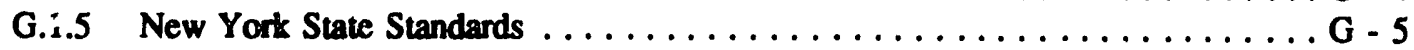

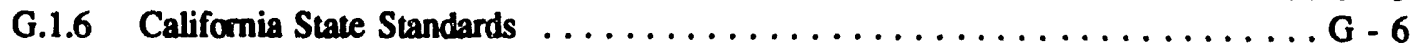

G.1.7 Minnesota State Standards ...................... G - 8

G.1.8 Northwest Power Planning Council Standards ................ G - 9

G.1.9 Washington State Standards $\ldots \ldots \ldots \ldots \ldots \ldots \ldots \ldots \ldots \ldots \ldots \ldots \ldots$ G -9

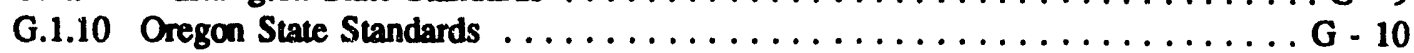

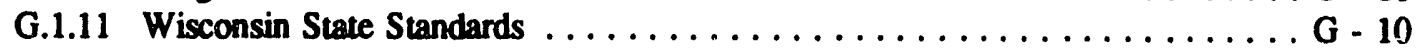

G.1.12 Florida State Standards $\ldots \ldots \ldots \ldots \ldots \ldots \ldots \ldots \ldots \ldots \ldots \ldots \ldots \ldots$, G -10

G.1.13 Georgia State Standards ......................... G - 10

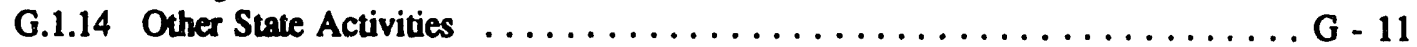

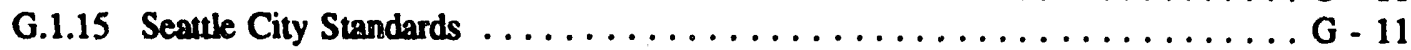

G.2 COMPLIANCE WITH BUILDING CODES $\ldots \ldots \ldots \ldots \ldots \ldots \ldots \ldots \ldots \ldots, 11$

APPENDIX H LIGHTING INTERACTIONS WITH HEATING, VENTILATING, AND

AIR-CONDITIONING ENERGY USE $\ldots \ldots \ldots \ldots \ldots \ldots \ldots \ldots \ldots \ldots \ldots$ H -1

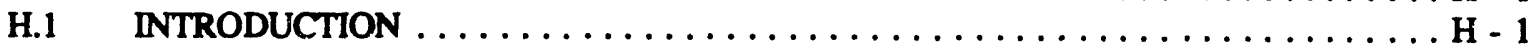

H.2 COMMERCIAL SECTOR RESULTS $\ldots \ldots \ldots \ldots \ldots \ldots \ldots \ldots \ldots \ldots \ldots \ldots \ldots \ldots \ldots$

H.2.1 COMMEND Results in Perspective $\ldots \ldots \ldots \ldots \ldots \ldots \ldots \ldots \ldots \ldots \ldots \ldots$ H -4

H.3 RESIDENTIAL SECTOR RESULTS $\ldots \ldots \ldots \ldots \ldots \ldots \ldots \ldots \ldots \ldots \ldots \ldots$ 


\section{LIST OF FIGURES}

Figure S-1 Figure S-2

Figure i Figure ii Figure iii Figure iv

Figure v

Figure vi

Figure vii Figure viii Figure ix

Figure $x$

Figure $x i$

Figure xii

Figure xiii

Figure 1.1

Figure 2.1 Figure 2.2 Figure 2.3 Figure 2.4 Figure 2.5 Figure 2.6 Figure 2.7 Figure 2.8 Figure 2.9

Figure 3.1

Figure 3.2 Figure 3.3 Figure 3.4 Figure 3.5 Figure 3.6

Figure 3.7

Figure 3.8
Annual Lighting Energy Use Intensities $\ldots \ldots \ldots \ldots \ldots \ldots \ldots \ldots \ldots \ldots \ldots$ s -5 Lighting Unit Energy Consumption in $2030 \ldots \ldots \ldots \ldots \ldots \ldots \ldots \ldots$. -5

U.S. Lighting Electricity $(515$ TWh), $1990 \ldots \ldots \ldots \ldots \ldots \ldots \ldots \ldots$. . . . . . . . . iii Policies and Technologies Included in Commencial Sector Analysis $\ldots \ldots \ldots \ldots \ldots \ldots$ vi Policies and Technologies Included in Residential Sector Analysis .............. vii Annual Lighting Energy Use Intensities, Baselines and Illustrative Policy Cases,

Commercial Sector ................................ xi Annual Lighting Energy Consumption, Baselines and Illustrative Policy Cases, Commercial Sector ............................... xi U.S. Commercial Lighting Energy Consumption in 2010, by Technology, Combination Equipment Standards, High-Efficiency Baseline . . . . . . . . . . . xiv Range of Cumulative Lighting Energy Savings by Policy, 1995 to 2030, Commercial Sector xv Range of Cumulative Net Present Values by Policy, 1995 to 2030, Commercial Sector . . . xv Range of Cumulative Lighting Energy Savings from Lamp Standards, 1995 to 2030,

Residential Sector . . . . . . . . . . . . . . . . . . . . . . . . . . . . xvii Range of Cumulative Net Present Values from Lamp Standards, 1995 to 2030,

Residential Sector . ............................... xvii Lighting Unit Energy Consumption in 2030, Baselines and Illustrative Policy Cases,

Residential Sector ............................... xviii Annual Lighting Energy Consumption, Baselines and Illustrative Policy Cases,

Residential Sector .............................. xviii U.S. Residential Lighting Energy Consumption in 2010, by Technology,

Component Standards, High-Efficiency Baseline $\ldots \ldots \ldots \ldots \ldots \ldots \ldots$ xix

U.S. Lighting Electricity $(515$ TWh), $1990 \ldots \ldots \ldots \ldots \ldots \ldots \ldots \ldots \ldots \ldots \ldots$

Methodology for Lighting Policy Energy and Economic Analysis .......... 2 - 2

Policies and Technologies Included in Commercial Sector Analysis $\ldots \ldots \ldots \ldots \ldots 2$ - 3

Policies and Technologies Included in Residential Sector Analysis ............. 2 - 4

Technology Tradeoff Curve $\ldots \ldots \ldots \ldots \ldots \ldots \ldots \ldots \ldots \ldots \ldots \ldots \ldots \ldots . \ldots \ldots$

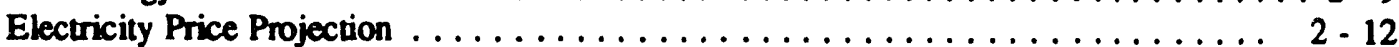

Commercial Sector Floor Space $\ldots \ldots \ldots \ldots \ldots \ldots \ldots \ldots \ldots \ldots \ldots \ldots \ldots \ldots$ 2 -12

COMMEND Calibration Technology Tradeoff Curve ................. 2-15

Baseline Forecast Comparison, Commercial Sector ..................... 2 - 16

COMMEND Policy Implementation Teshnology Tradeoff Curve ............ 2-18

Life Cycle Costs for 4 Foot Fluorescent Lamps with Electronic Ballast,

Commercial Sector ............................... 3 - 7

Fluorescent Luminaire Light Distribution Geometry . . . . . . . . . . . . . . . . . 3 - 19

Commercial Open Fixture Standards, by Fixture Type ................ 3- 22

Commercial Open Fixture Standards, by Number of Lamps .............. 3-22

Percent and Number of Fixtures Passing Standard Levels by Fixture Type ... . . . . . 3 - 23

Percent and Number of Open Fixtures (Narrow) Passing Standard Levels by

Number of Lamps .................................. . 3 24

Percent and Number of Open Fixtures (Wide) Passing Standard Levels by

Number of Lamps ................................. 3-24

Percent and Number of Wraparound Fixtures Passing Standard Levels by

Number of Lamps . . . . . . . . . . . . . . . . . . . . . . . . . 3 - 25 
Figure 3.9

Figure 3.10

Figure 4.1

Figure 4.2

Figure 4.3

Figure 4.4

Figure 4.5

Figure 4.6

Figure 4.7

Figure 4.8

Figure 4.9

Figure 4.10

Figure 4.11

Figure 5.1

Figure 5.2

Figure 5.3

Figure 5.4

Figure 5.5

Figure 6.1
Percent and Number of Lensed Troffer Fixtures Passing Standard Levels by

Number of Lamps ................................. 3 - 25

Relationship Between Luminaire Efficiency and Luminaire Efficacy Rating . . . . . . 3 - 28

Effect of Building Code on Average Lighting Power Density of New Buildings . . . . 4 - 7 Annual Lighting Energy Use Intensities, Baselines and Illustrative Policy Cases,

Commencial Sector ..................................... 4 - 9

Annual Lighting Energy Consumption, Baselines and Illustrative Policy Cases,

Commercial Sector ................................... . 4 - 9

Range of Cumulative Lighting Energy Savings, 1995 to 2030, Fluorescent Lamps,

Commercial sector ...................................4 4 - 16

Range of Cumulative Net Present Values, 1995 to 2030, Fluorescent Lamps,

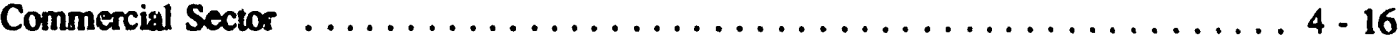

Range of Cumulacive Lighting Energy Savings, 1995 to 2030, Incandescent Lamps,

Commercial Sector . . . . . . . . . . . . . . . . . . . . . . . . . . . . . . 4 4 - 17

Range of Cumulative Net Present Values, 1995 to 2030, Incandescent Lamps,

Commercial Sector .................................. . 4 - 17

Range of Cumulative Lighting Energy Savings, 1995 to 2030, Fixtures and Controls,

Commencial Sector .............................. 4 - 18

Range of Cumulative Net Present Values, 1995 to 2030, Fixtures and Controls,

Commercial Sector .................................4 4 - 18

Range of Cumulative Lighting Energy Savings by Policy, 1995 to 2030,

Commencial Sector ................................... 4 4 . 21

Range of Cumulative Net Present Values by Policy, 1995 to 2030, Commercial Sector . 4 - 21

U.S. Residential Lighting Energy Consumption in 2010, by Technology Component

Standards, High-Efficiency Baseline $\ldots \ldots \ldots \ldots \ldots \ldots \ldots \ldots \ldots \ldots \ldots \ldots$

Lighting Unit Energy Consumption in 2030, Baselines and Illustrative Policy Cases,

Residential Sector ................................... 5 5 9

Annual Lighting Energy Consumption, Baselines and Illustrative Policy Cases,

Residential Sector ............................... 5 - 9

Range of Cumulative Lighting Energy Savings from Lamp Standards,

1995 to 2030, Residential Sector . . . . . . . . . . . . . . . . . . . . . . . . . . 5 . 10

Range of Cumulative Net Present Values from Lamp Standards,

1995 to 2030, Residential Sector .......................... 5 - 10

Lamp Manufacturer Market Shares $\ldots \ldots \ldots \ldots \ldots \ldots \ldots \ldots \ldots \ldots \ldots$. 2

\section{APPENDICES}

Figure A.1

Figure A.2

Figure A.3

Figure A.4

Figure A.5

Figure A.6

Figure A.7

Figure B.1N

Figure B.2

Figure B.3

Figure B.4

Figure B.5N
Typical Fluorescent Lamp $\ldots \ldots \ldots \ldots \ldots \ldots \ldots \ldots \ldots \ldots \ldots \ldots \ldots \ldots \ldots$

Magnetic and Electronic Ballasts $\ldots \ldots \ldots \ldots \ldots \ldots \ldots \ldots \ldots \ldots \ldots \ldots \ldots \ldots \ldots \ldots$

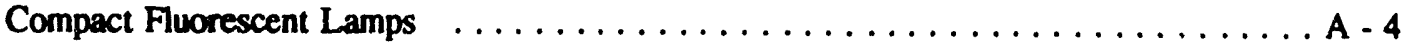

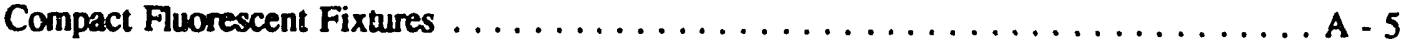

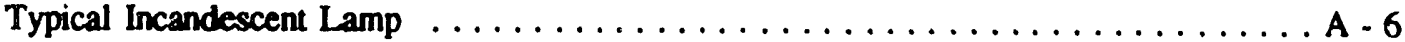

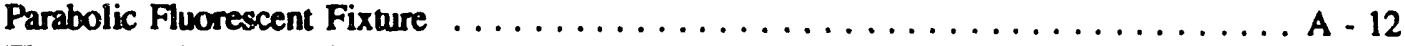

Fluorescent Fixture With and Without Specular Reflector . . . . . . . . . . . . . A - 12

Life Cycle Costs for Incandescent Lamps, General Service, Commercial Sector . . . . . . B - 7

Life Cycle Costs for Incandescent Lamps, General Service, Residential Sector . . . . . . . B - 8

Life Cycle Costs for Incandescent Lamps, Reflector, Commercial Sector . . . . . . . . . B - 9

Life Cycle Costs for Incandescent Lamps, Reflector, Residential Sector . . . . . . . . . B - 10

Life Cycle Costs for Compact Fluorescent Lamps, Commercial Sector ......... B - 11 
Figure B.6

Figure B.7N

Figure B.8N

Figure B.9N

Figure E.1

Figure E.2

Figure E.3

Figure E.4

Figure E.5

Figure F.1

Figure F.2

Figure F.3

Figure F.4

Figure F.5

Figure F.6

Figure F.7

Figure F.8

Figure F.9

Figure F.10

Figure F.11

Figure F.12

Figure F.15

Figure F.14

Figure F.15

Figure F.16

Figure F.17

Figure F.18

Figure F.19

Figure F.20

Figure F.21

Figure F.22

Figure F.23

Figure F.24

Figure F.25

Figure F.26

Figure F.27

Figure F.28

Figure F.29

Figure F.30

Figure F.31
Life Cycle Costs for Compact Fluorescent Lamps, Residential Sector . . . . . . . . . . . B - 12

Life Cycle Costs for 4 Foot Fluorescent Lamps with Energy-Efficient

Magnetic Ballast, Commercial Sector (Normalized) .................. B - 13

Life Cycle Costs for 4 Foot Fluorescent Lamps with Cathode Cutout Ballast,

Commercial Sector (Normalized) $\ldots \ldots \ldots \ldots \ldots \ldots \ldots \ldots \ldots \ldots$. . . 14

Life Cycle Costs for 4 Foot Fluorescent Lamps with Electronic Ballast,

Commencial Sector (Normalized) $\ldots \ldots \ldots \ldots \ldots \ldots \ldots \ldots \ldots \ldots$. . . . . . . . . . 15

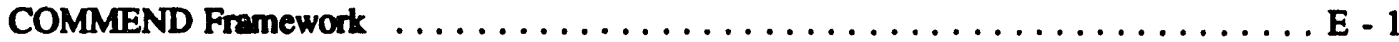

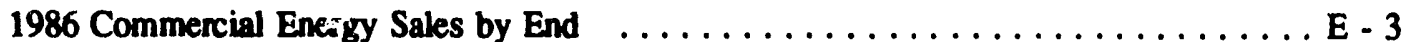

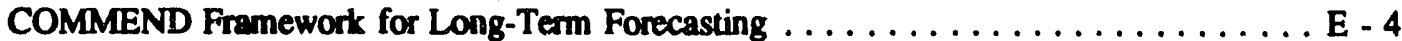

COMMEND Forecast Framework $\ldots \ldots \ldots \ldots \ldots \ldots \ldots \ldots \ldots \ldots \ldots \ldots \ldots \ldots \ldots$

Forecast of Electricity Sales by End $\ldots \ldots \ldots \ldots \ldots \ldots \ldots \ldots \ldots \ldots \ldots \ldots, E, 10$

Fluorescent Lamps, High-Efficiency Baseline, Average Commercial Indoor Lighting EUIs $F$ - 2 Fluorescent Lamps, High-Efficiency Baseline, Commercial Indoor Lighting Energy . . . . F - 2 Fluorescent Lamps, Low-Efficiency Baseline, Average Commercial Indoor Lighting EUIs F - 3 Fluorescent Lamps, Low-Efficiency Baseline, Commercial Indoor Lighting Energy . . . . F - 3 Incandescent Lamps, High-Efficiency Baseline, Average Commencial Indoor

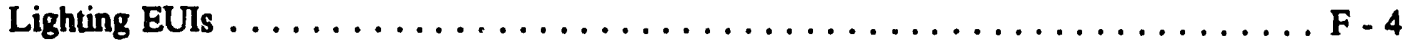
Incandescent Lamps, High-Efficiency Baseline, Commercial Indoor Lighting Energy . . . F - 4 Incandescent Lamps, Low-Efficiency Baseline, Average Commercial Indoor

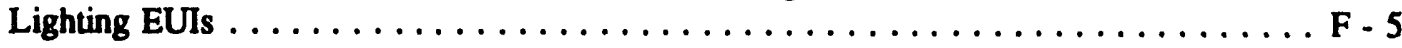
Incandescent Lamps, Low-Efficiency Baseline, Commercial Indoor Lighting Energy . . . . F - 5 Fixtures, High-Efficiency Baseline, Average Commercial Indoor Lighting EUIs . . . . . F - 6 Fixtures, High-Efficiency Baseline, Commercial Indoor Lighting Energy . . . . . . . . F - 6 Fixtures, Low-Efficiency Baseline, Average Commencial Indoor Lighting EUIs . . . . . F - 7 Fixcures, Low-Efficiency Baseline, Commercial Indoor Lighting Energy . . . . . . . . F - 7 Lighting Controls, Low-Efficiency Baseline, Average Commercial Indoor Lighting EUIs . F - 8 Lighting Controls, High-Efficiency Baseline, Commercial Indoor Lighting Energy . . . . F - 8 Lighting Controls, Low-Efficiency Baseline, Average Commercial Indoor Lighting EUIs . F - 9 Lighting Controls, Low-Efficiency Baseline, Commercial Indoor Lighting Energy . . . . . F - 9 Mandatory Combination Equipment Standards, High-Efficiency Baseline,

Average Commercial Indoor Lighting EUIs . . . . . . . . . . . . . . . . . . . . F - 10 Mandatory Combination Equipment Standards, High-Efficiency Baseline,

Commercial Indoor Lighting Energy . . . . . . . . . . . . . . . . . . . . . . . . F - 10

Mandatory Combination Equipment Standards, Low-Efficiency Baseline,

Average Commercial Indoor Lighting EUls $\ldots \ldots \ldots \ldots \ldots \ldots \ldots \ldots \ldots \ldots$ F - 11 Mandatory Combination Equipment Standards, Low-Efficiency Baseline,

Commercial Indoor Lighting Energy $\ldots \ldots \ldots \ldots \ldots \ldots \ldots \ldots \ldots \ldots \ldots \ldots$ F 11 Voluntary Combination Equipment Standards, High-Efficiency Baseline,

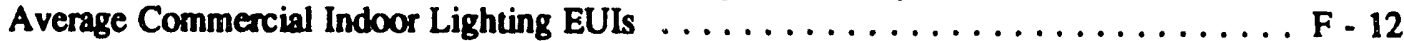

Voluntary Combination Equipment Standards, High-Efficiency Baseline,

Commencial Indoor Lighting Energy . . . . . . . . . . . . . . . . . . . . F - 12

Voluntary Combination Equipment Standards, Low-Efficiency Baseline,

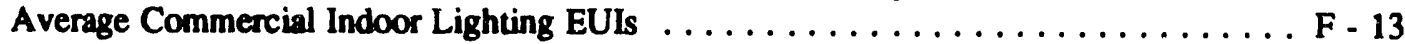

Voluntary Combination Equipment Standards, Low-Efficiency Baseline,

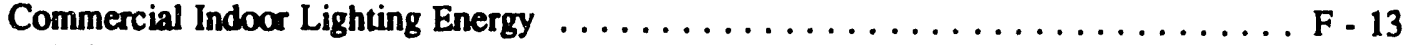

Building Codes, High-Efficiency Baseline, Average Commercial Indoor Lighting EUls . F - 14

Building Codes, High-Efficiency Baseline, Commercial Indoor Lighting Energy . . . . . . F - 14 Building Codes, Low-Efficiency Baseline, Average Commercial Indoor Lighting EUIs . F - 15 Building Codes, Low-Efficiency Baseline, Commercial Indoor Lighting Energy . . . . . . F - 15 Incentive Policies, High-Efficiency Baseline, Average Commercial Indoor Lighting EUIs F - 16 Incentive Policies, High-Efficiency Baseline, Commencial Indoor Lighting Energy . . . . F - 16 Incentive Policies, Low-Efficiency Baseline, Average Commercial Indoor Lighting EUIs F - 17 
Figure F.32 Incentive Policies, Low-Efficiency Baseline, Commencial Indoor Lighting Energy . . . . F - 17

Figure H.1 Range of HVAC-Lighting Interaction Effects (DOE-2 and COMMEND Results) $\ldots \ldots$. H - 5 


\section{LIST OF TABLES}

Table S-1 Summary of Cumulative Impacts of Selected Commercial Lighting Policies Measured with Respect to the High- (Low-) Efficiency Baseline ................ . S - 3

Table S-2 Summary of Cumulative Impacts of Selected Residential Lighting Policies Measured with Respect to the High- (Frozen-) Efficiency Baseline . . . . . . . . . S - 3

Table i

Table ii

Scope of Lighting Technology Options and Sectors Analyzed .............. iii Summary of Alternative Policies to Promote Greater Lighting Energy Efficiency,

Table iii Commercial Sector . . . . . . . . . . . . . . . . . . . . . . . . . . . xiii

Table iv Summary of Cumulative Impacts of Selected Commencial Lighting Policies Measured with Respect to the High- (Low-) Efficiency Baseline ............... xiv Summary of Cumulative Impacts of Selected Residential Lighting Policies Measured with Respect to the High- (Frozen-) Efficiency Baseline ................. xix

Table 1.1

Scope of Lighting Technology Options and Sectors Analyzed $\ldots \ldots \ldots \ldots \ldots \ldots \ldots$

Table 2.1

Table 2.2

Table 2.3

Commercial Floorspace (Billion $s q \mathrm{ft}) \ldots \ldots \ldots \ldots \ldots \ldots \ldots \ldots \ldots \ldots \ldots \ldots \ldots$

Baseline Lighting Energy Use Intensity (kWh/sq ft-yr) $\ldots \ldots \ldots \ldots \ldots \ldots \ldots \ldots 2.16$

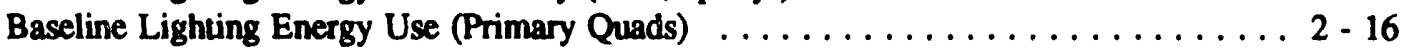

Table 3.1

Table 3.2

Table 3.3

Table 3.4

Table 3.5

Table 3.6

Table 3.7

Table 3.8

Table 3.9

Table 3.10

Table 3.11

Table 3.12

Table 3.13

Table 3.14

Table 3.15

Table 3.16

Table 3.17

Table 3.18

Product Classes for Lamps, Commercial Sector $\ldots \ldots \ldots \ldots \ldots \ldots \ldots \ldots \ldots \ldots$. 2

Technology Options for Fluorescent Lamps ................... 3 - 3

Technology Options for Incandescent Lamps (General Service and Reflector) . . . . . 3 - 3

Technology Options for Compact Fluorescent Lamps ................ 3 - 3

Product Classes for Lamps, Residential Sector . . . . . . . . . . . . . . . . . . . . . . 3 - 4

Fluorescent Lamp Technology Options Modeled (Commercial Sector) . . . . . . . . . . 3 3 - 10

Fluorescent Lamp Efficacies, Prices, and Service Lives (Commercial Sector) . . . . . . 3 - 10 Incandescent Lamp Technology Options Modeled (Commercial Sector) . . . . . . . . 3 - 11 Incandescent Lamp Prices, Efficacies, and Service Lives (Commercial Sector) . . . . . . 3 - 12

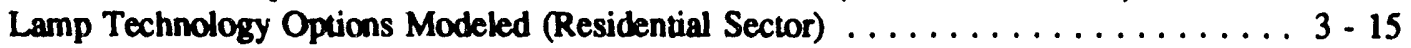

Lamp Efficacies, Prices, and Service Lives (Residential Sector) . . . . . . . . . 3 - 15

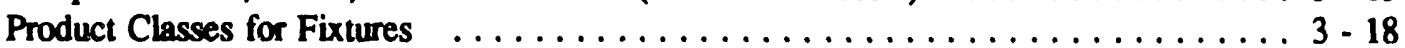

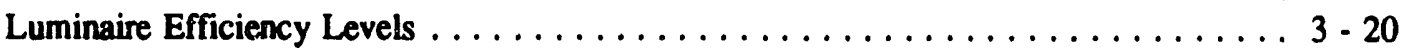

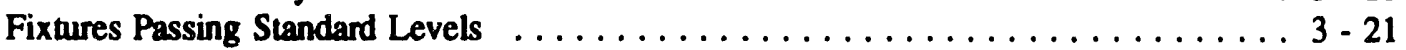

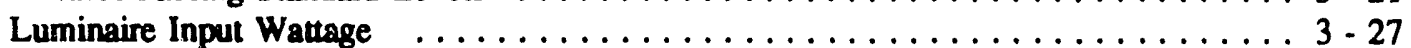

Technology Options for Controls .......................... 3- 29

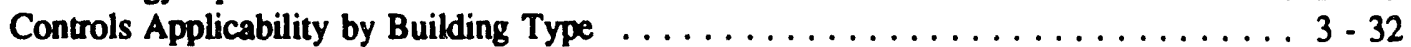

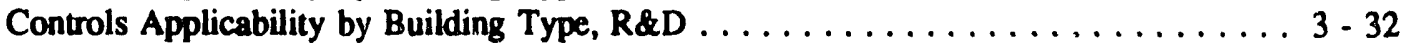

Controls Savings, Costs, and Applicability, Commercial Sector Indoor Lighting ... . . 3 3 33

Controls Savings, Costs, and Applicability, Commercial Sector Indoor Lighting, R\&D . 3 - 34

Table 4.1

Table 4.2

Table 4.3

Table 4.4

Fluorescent Market Shares (\%) and Technology Properties ............. 4 -5

Derivation of Lighting Power Densities for Use in Building Codes Analysis . . . . . . 4 - 7

Summary of Alternative Policies to Promote Greater Lighting Energy Efficiency,

Commercial Sector ................................ 4 - 10

Annual Commercial Lighting Energy Consumption, High-Efficiency Baseline,

1995 to 2030 . . . . . . . . . . . . . . . . . . . . . . . . . . . . . . 4 - 11

Table 4.5

Annual Commercial Lighting Energy Consumption, Low-Efficiency Baseline,

1995 to 2030 . . . . . . . . . . . . . . . . . . . . . . . . . . . . . . . 4 - 12

Table 4.6 Cumulative Commercial Lighting Energy Consumption and Savings, 1995 to $2030 \ldots 4-13$ 
Table 4.7

Table 4.8

Table 5.1

Table 5.2a

Table 5.2b

Table 5.3a

Table 5.3b

Table 5.4

Table 5.5

Table 7.1

Table 7.2

Table 7.3

Table 7.4

Table 8.1

Table 8.2

Table 8.3

Table 8.4

Table 8.5

Table 8.6

Table 8.7

Table 9.1

Table 9.2

Table 9.3

Table 9.4

Table 9.5

Table 9.6

Table B.1

Table B.1N

Table B.2

Table B. $2 \mathrm{~N}$

Table B.3

Economic Analysis of Commercial Lighting Policy Cases, High-Efficiency Baseline, 1995 to 2030 . . . . . . . . . . . . . . . . . . . . . . . . . . . . 4 414 Economic Aralysis of Commercial Lighting Policy Cases, Low-Efficiency Baseline, 1995 to 2030 . . . . . . . . . . . . . . . . . . . . . . . . . . . . . . 4 - 15

1995 Penetration Rates (\%) of Technologies for Residential Policies, High-Efficiency

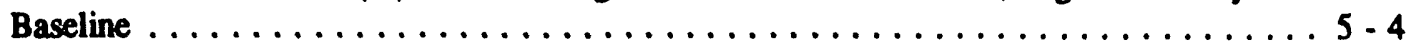
Residential Lighting Energy Consumption, High-Efficiency Baseline (Primary Quads) . . 5 - 5 Residential Lighting Energy Consumption, High-Efficiency Baseline (TWh) ... . . . 5 - 5 Residential Lighting Energy Consumption, Frozen-Efficiency Baseline (Primary Quads) . 5 - 6 Residential Lighting Energy Consumption, Frozen-Efficiency Baseline (TWh) . . . . . 5 - 6 Residential Unit Energy Consumption for Lighting, Frozen-Efficiency and HighEfficiency Baselines (Weighted Average $k W h / H o u s e h o l d-Y e a r) \ldots \ldots \ldots \ldots \ldots 57$ NPV of Policies for Residential Lighting (Billion $\$$ 1990) . . . . . . . . . . . 5 . 7

Commercial Lighting Peak Demand Reductions Relative to High-Efficiency Baseline . . 7 - 3 Commercial Lighting Peak Demand Reductions Relative to Low-Efficiency Baseline . . 7 - 4 Residential Lighting Peak Demand Reductions Relative to High-Efficiency Baseline . . 7 - 5 Residential Lighting Peak Demand Reductions Relative to Frozen-Efficiency Baseline . . 7 - 5

U.S. $\mathrm{CO}_{2}, \mathrm{SO}_{2}, \mathrm{NO}_{2}$ Electric Power Plant Emissions .............. 8 - 2 Electrical Generation and Emissions Data and Emission Rates for $\mathrm{SO}_{2}$ and $\mathrm{NO}_{\mathrm{x}}$ at

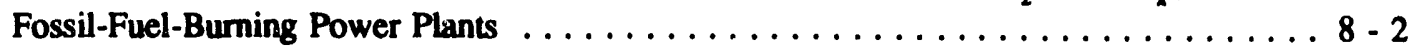
Electrical Generation Data, Emissions Data, and Emissions Rates for $\mathrm{CO}_{2}$ at

Fossil-Fuel-Burning Power Plants ..................... 8 - 4

Environmental Impacts of Selected Commercial Lighting Policy Cases, High-Efficiency

Baseline, 1995 to 2030 ... . . . . . . . . . . . . . . . . . . . . . . . 8 - 5

Environmental Impacts of Selected Commercial Lighting Policy Cases, Low- Efficiency

Baseline, 1995 to $2030 \ldots \ldots \ldots \ldots \ldots \ldots \ldots \ldots \ldots \ldots \ldots \ldots$. . . . . . . . \& - 6

Environmental Impacts of Residential Lighting Policy Cases, High-Efficiency

Baseline, 1995 to 2030 ... . . . . . . . . . . . . . . . . . . . . . . 8 - 7

Environmental Impacts of Residential Lighting Policy Cases, Frozen-Efficiency

Baseline, 1995 to $2030 \ldots \ldots \ldots \ldots \ldots \ldots \ldots \ldots \ldots \ldots \ldots$. . . . . . . . . . .

Comparison of Selected Lighting Studies and Savings Estimates $\ldots \ldots \ldots \ldots \ldots \ldots-3$ LBL Lighting Consumption and Savings, $2010 \ldots \ldots \ldots \ldots \ldots \ldots \ldots \ldots$. 6

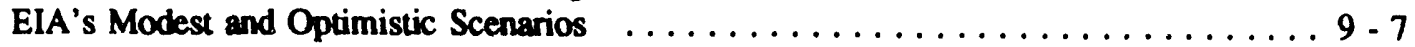
EIA's Equipment Replacement Schemes .................... 9 - 8 Comparison of LBL and EIA LPDs and EUIs, 1986 (total floorspace) . . . . . . . 9 - 9 LBL and ACEEE Lamp Standards Savings, $2010 \ldots \ldots \ldots \ldots \ldots \ldots \ldots \ldots$. . . . . 13

\section{APPENDICES}

Total Life Cycle Costs and Payback Periods of Incandescent Lamps, General Service, Commercial .............................. B - 16 Total Life Cycle Costs and Payback Periods of Incandescent Lamps, General Service, Commercial (Normalized) . . . . . . . . . . . . . . . . . . . B - 17 Total Life Cycle Costs and Payback Periods of Incandescent Lamps, General Service, Residential . ........................... B - 18 Total Life Cycle Costs and Payback Periods of Incandescent Lamps, General Service, Residential . . . . . . . . . . . . . . . . . . . . . . . . . . . . B - 19 Total Life Cycle Costs and Payback Periods of Incandescent Lamps, Reflector, Commercial B - 20 
Table B.4

Table B.5

Table B.5N

Table B.6

Table B.7

Table B.7N

Table B.8

Table B.8N

Table B.9

Table B.9N

Table B.10

Table B.10N

Table B.11

Table B.11N

Table B.12

Table B.12N

Table B.13

Table B.13N

Table B.14

Table B.14N

Table B.15

Table B.15N

Table B.16

Table B.16N

Table B.17

Table B.17N

Table B.18
Total Life Cycle Costs and Payback Periods of Incandescent Lamps, Reflector, Residential ................................... B - 21

Total Life Cycle Costs and Payback Periods of Compact Fluorescent Lamps, Commencial ................................. B - 22

Total Life Cycle Costs and Payback Periods of Compact Fluorescent Lamps, Commencial (Normalized) . . . . . . . . . . . . . . . . . . . . . . . . . . B - 23

Total Life Cycle Costs and Payback Periods of Compact Fluorescent Lamps,

Residential ...................................... B - 24

Total Life Cycle Costs and Payback Periods of 4-Foot Fluorescent Lamps with

Energy-Efficient Magnetic Ballast, Commercial ...................... B - 25

Total Life Cycle Costs and Payback Periods of 4-Foot Fluorescent Lamps with

Energy-Efficient Magnetic Ballast, Commencial (Normalized) ............... . B - 26

Total Life Cycle Costs and Payback Periods of 4-Foot Fluorescent Lamps with

Cathode Cutout Ballast, Commercial ......................... B - 27

Total Life Cycle Costs and Paybeck Periods of 4-Foot Fluorescent Lamps with

Cathode Cutout Ballast, Commercial (Normalized) .................. B - 28

Total Life Cycle Costs and Payback Periods of 4-Foot Fluorescent Lamps with

Electronic Ballast, Commercial ... . . . . . . . . . . . . . . . . . . . . . B - 29

Total Life Cycle Costs and Payback Periods of 4-Foot Fluorescent Lamps with

Electronic Ballast, Commencial (Normalized) ...................... B - 30

Total Life Cycle Costs and Payback Periods of 4-Foot U-Shaped Fluorescent

Lamps with Energy-Efficient Magnetic and Electronic Ballast, Commercial ....... B - 31

Total Life Cycle Costs and Payback Periods of 4-Foot U-Shaped Fluorescent

Lamps with Energy-Efficient Magnetic and Electronic Ballast, Commercial (Normalized) B - 32

Total Life Cycle Costs and Payback Periods of 8-Foot Fluorescent Lamps with

Energy-Efficient Magnetic Ballast, Commercial ..................... B - 33

Total Life Cycle Costs and Payback Periods of 8-Foot Fluorescent Lamps with

Energy-Efficient Magnetic Ballast, Commercial (Normalized) . . . . . . . . . . . . . . B - 34

Total Life Cycle Costs and Payback Periods of 8-Foot Fluorescent Lamps with

Electronic Ballast, Commercial ............................ B - 35

Total Life Cycle Costs and Payback Periods of 8-Foot Fluorescent Lamps with

Electronic Ballast, Commencial (Normalized) .................. B - 36

Total Life Cycle Costs and Payback Periods of 4-Foot Fluorescent Lamps with

Energy-Efficient Magnetic Ballast, Commercial .................... B - 37

Total Life Cycle Costs and Payback Periods of 4-Foot Fluorescent Lamps with

Energy-Efficient Magnetic Ballast, Commercial (Normalized) . . . . . . . . . . . . B - 38

Total Life Cycle Costs and Payback Periods of 4-Foot Fluorescent Lamps with

Cathode Cutout Ballast, Commercial .......................... . B - 39

Total Life Cycle Costs and Payback Periods of 4-Foot Fluorescent Lamps with

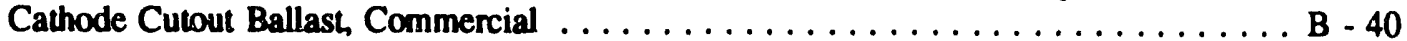

Total Life Cycle Costs and Payback Periods of 4-Foot Fluorescent Lamps with

Electronic Ballast, Commencial .......................... B - 41

Total Life Cycle Costs and Payback Periods of 4-Foot Fluorescent Lamps with

Electronic Ballast, Commercial (Normalized) ................... B - 42

Total Life Cycle Costs and Payback Periods of 8-Foot Fluorescent Lamps with

Energy-Efficient Magnetic Ballast, Commercial .................. B - 43

Total Life Cycle Costs and Payback Periods of 8-Foot Fluorescent Lamps with

Energy-Efficient Magnetic Ballast, Commercial (Normalized) . . . . . . . . . . . . . . B B 44

Total Life Cycle Costs and Payback Periods of 8-Foot Fluorescent High-Output

Lamps with Energy-Efficient Magnetic Ballast, Commercial . . . . . . . . . . . . . . . B - 45

Total Life Cycle Costs and Payback Periods of 8-Foot Fluorescent High-Output

Lamps with Energy-Efficient Magnetic Ballast, Commercial (Normalized) . . . . . . . . B - 46

Total Life Cycle Costs and Paybeck Periods of 8-Foot Fluorescent Lamps with

Electronic Magnetic Ballast, Commercial . . . . . . . . . . . . . . . . . . B . 47 
Total Life Cycle Costs and Payback Periods of 8-Foot Fluorescent Lamps with Electronic Ballast, Commercial (Normalized) ................... B - 48

Table B.19 Total Life Cycle Costs and Paybeck Periods of 8-Foot Fluorescent High-Output Lamps with Electronic Magnetic Ballast Commencial ... . . . . . . . . . . . . . . B - 49

Table B.19N Total Life Cycle Costs and Payback Periods of 8-Foot Fluorescent High-Output Lamps with Electronic Ballast, Commercial (Normalized) . . . . . . . . . . . B - 50

Table C.1

Table C.2

U.S. Commencial Lighting Codes and Floor Space, by Census Region and State . . . . . C - 3 1989 National Commercial Building Characteristics .................. C - 5 Average Change in IES Mluminance Values, by Building Type, 1972-1987 . . . . . . . . C - 6 Maximum Lighting Power Densities in State Building Codes $\ldots \ldots \ldots \ldots \ldots \ldots$ C - 8

Table C. 4

Table C.5 Adjustment of Low-Efficiency Baseline for Building Codes $\ldots \ldots \ldots \ldots \ldots \ldots$. . . 9

Table D.1 Table D.2 COMMEND Baseline and Policy EUls $\ldots \ldots \ldots \ldots \ldots \ldots \ldots \ldots \ldots \ldots \ldots \ldots \ldots$ Baseline Market Shares, Fluorescent Lamp/Ballast Combinations . . . . . . . . . . . D - 9 Baseline Market Shares, Incandescent and Compact Fluorescent Lamps . . . . . . . . D - 13 Baseline Market Shares, Fluorescent Fixtures . . . . . . . . . . . . . . . D - 15 Fluorescent Policy Case Market Shares, 1995 Sales . . . . . . . . . . . . . . . . . D - 17 Incandescent Policy Case Market Shares, 1995 Sales . . . . . . . . . . . . . . . D - 25

Table D.4

Table D.5

Table D.6

Table D.7

Fixture Policy Case Market Shares, 1995 Sales . . . . . . . . . . . . . . . . . D - 35

Table G.1

Table G.2

Table G.3

Lighting Power Density Allowance, Interior Lighting Prescriptive Approach,

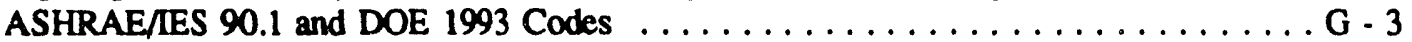

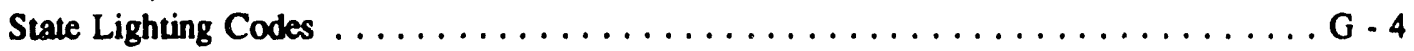

Complete Building Method Califomia Tite 24 Lighting Power Density Values . . . . . G - 7

Table H.1 Coincidence of Lighting Energy Use with Heating and Cooling Periods,

Residential Sector ............................... H 6 


\section{LIST OF ORGANIZATIONS}

$\begin{array}{ll}\text { ACEEE } & \text { American Council for an Energy Efficient Economy } \\ \text { ALPAC } & \text { Advanced Lighting Professional Advisory Committee (CEC) } \\ \text { ANSI } & \text { American National Standards Institute } \\ \text { ASHRAE } & \text { American Society of Heating, Refrigerating and Air-Conditioning Engineers } \\ \text { BPA } & \text { Bonneville Power Administration } \\ \text { CABO } & \text { Council of American Building Officials } \\ \text { CEC } & \text { California Energy Commission } \\ \text { CIE } & \text { International Commission on Illumination (Commission Internationale de } \\ & \text { Leclairage) } \\ \text { DOE } & \text { (U.S.) Department of Energy } \\ \text { EIA } & \text { (U.S.) Energy Information Administration } \\ \text { EPA } & \text { (U.S.) Environmental Protection Agency } \\ \text { EPRI } & \text { Electric Power Research Institute } \\ \text { FEMP } & \text { Federal Energy Management Program } \\ \text { FTC } & \text { Federal Trade Commission } \\ \text { IES } & \text { Illuminating Engineering Society } \\ \text { LBL } & \text { Lawrence Berkeley Laboratory } \\ \text { LRC } & \text { Lighting Research Center } \\ \text { LRI } & \text { Lighting Research Institute } \\ \text { MEOER } & \text { Massachusetts Executive Office of Energy Resources } \\ \text { NALMCO } & \text { interNational Association of Lighting Maintenance Companies } \\ \text { NCSBCS } & \text { National Conference of States on Building Codes and Standards } \\ \text { NEMA } & \text { National Electrical Manufacturers Association } \\ \text { NERC } & \text { North American Electric Reliability Council } \\ \text { NIST } & \text { National Institute of Standards and Technology } \\ \text { NPPC } & \text { Northwest Power Planning Council } \\ \text { NYSEO } & \text { New York State Energy Office } \\ \text { NYSERDA } & \text { New York State Energy Research and Development Authority } \\ \text { ORNL } & \text { Oak Ridge National Laboratory } \\ \text { PNL } & \text { Pacific Northwest Laboratory }\end{array}$




\section{LIST OF ABBREVIATIONS}

$\begin{array}{ll}\text { AEO } & \text { Annual Energy Outlook (EIA) } \\ \text { AF } & \text { Area Factor } \\ \text { Btu } & \text { British Thermal Unit } \\ \text { CBECS } & \text { Commercial Buildings Energy Consumption Survey (EIA) } \\ \text { CFL } & \text { Compact Fluorescent Lamp } \\ \text { CO } & \text { Carbon Dioxide } \\ \text { COP } & \text { Coefficient of Performance } \\ \text { CRI } & \text { Color Rendering Index } \\ \text { DSM } & \text { Demand-Side Management } \\ \text { ECPA } & \text { Energy Conservation Policy Act } \\ \text { ELPA } & \text { Exterior Lighting Power Allowance (watts/sq ft or watts/linear ft) } \\ \text { EUI } & \text { Energy Use Intensity (kWh/sq ft-year) } \\ \text { GNP } & \text { Gross National Product (\$) } \\ \text { GW } & \text { Gigawatt (109 watts) } \\ \text { HID } & \text { High Intensity Discharge (Lamp) } \\ \text { HIR } & \text { Halogen Infrared (Lamp) } \\ \text { HO } & \text { High Output (Lamp) } \\ \text { HVAC } & \text { Heating Ventilating and Air Conditioning } \\ \text { ILPA } & \text { Interior Lighting Power Allowance (watts/sq ft) } \\ \text { kWh } & \text { Kilowatt-hour (103 watt-hours) } \\ \text { LCC } & \text { Life-Cycle Cost (\$) } \\ \text { LER } & \text { Luminaire Efficacy Rating (lumens/watt) } \\ \text { LPG } & \text { Liquid Petroleum Gas } \\ \text { MCS } & \text { Model Conservation Standard } \\ \text { MEC } & \text { Model Energy Code } \\ \text { MER } & \text { Monthly Energy Review } \\ \text { MPR } & \text { Major Projects Rule } \\ \text { NBECS } & \text { Non-Residential Buildings Energy Consumption Surveyl (EIA) } \\ \text { NO } & \text { Nitrogen Oxide } \\ \text { NPV } & \text { Net Present Value (\$) } \\ \text { PAF } & \text { Power Adjustment Factor } \\ \text { PAR } & \text { Parabolic Aluminized Reflector } \\ \text { Quad } & \text { Quadrillion (10's) Btus } \\ \text { RASS } & \text { Residential Appliance Saturation Survey } \\ \text { RCR } & \text { Room Cavity Ratio } \\ \text { RECS } & \text { Residential Energy Consumption Survey (EIA) } \\ \text { REM } & \text { Residential Energy Model } \\ \text { SEDR } & \text { State Energy Data Report (EIA) } \\ \text { SO } & \text { Sulfur Dioxide } \\ \text { T\&D } & \text { Transmission and Distribution } \\ \text { TWh } & \text { Terawatt-Hour (1012 watt-hours = one billion kWh) } \\ \text { UEC } & \text { Unit Energy Consumption (kWh/household-year) } \\ \text { UV } & \text { Ultraviolet } \\ \text { VDT } & \text { Video Display Terminal } \\ \text { VLT } & \text { Visible Light Transmittance } \\ & \end{array}$

${ }^{1}$ Name changed to CBECS beginning in 1989 


\section{EXECUTIVE SUMMARY}

\section{INTRODUCTION: PURPOSE AND SCOPE}

The U.S. Department of Energy (DOE) has recognized the opportunity to achieve energy, economic, and environmental benefits by promoting energy-efficient lighting through federal policies, including lighting standards, financial incentives, and information programs. To assist in this process, the Office of Conservation and Renewable Energy's Office of Codes and Standards invited Lawrence Berkeley Laboratory to assess prospective national impacts for a variety of policy options.

Some progress has already been made in developing lighting policies at both the federal and state levels. The U.S. DOE's Office of Building Technologies has evaluated lighting efficiency incentives as part of its analysis for the National Energy Strategy. Fluorescent and incandescent lamp standards are included in the national Energy Policy Act of 1992 (P.L. 102-486, October 24, 1992). These policies' projected impacts are presented in Sections 4.2 and 5.2; other lighting-related elements of the Act are discussed below. A few states have analyzed or implemented lamp and luminaire standards. Both the national industry consensus (ASHRAE/IES) building energy code and DOE's voluntary code incorporate lighting regulations, and several states have adopted these model codes. Current national and state standards are described in Appendix G.

Many policy-related issues merit further investigation. For example, there is considerable debate over issues such as mandatory or voluntary standards versus component labeling and other education-oriented strategies. Regardless of the policy approach taken, it is important for policymakers to have the information necessary to assess and weigh the pros and cons of various new policies in the context of the projected impacts of existing market forces and non-regulatory programs such as utility DSM incentives for lighting, EPA's Green Lights, and FEMP's Federal Relighting Initiative.

Analysis and implementation of energy-efficient lighting systems is multifaceted. Several different technologies are involved that interact with each other-lamps (incandescent, compact fluorescent, and HID), ballasts (for fluorescent and HID lamps), and fixtures with reflectors and lenses. Control systems and operation patterns must also be considered (timers, automated dimming, or occupancy sensors). Lighting applications are diverse, ranging from offices, restaurants, hallways, hospital operating rooms, to exterior lights. Lighting energy use influences heating and cooling requirements in buildings. Successful lighting system design must also address interactions between architectural design elements and daylighting availability. Proper system installation and ongoing operation and maintenance are crucial to the performance of a lighting system over its lifetime. The economic aspects of the preceding points must also be considered for policy making. 
In 1990, lighting was responsible for 515 TWh or 5.9 primary Quads of energy use in the U.S. (worth $\$ 36$ billion to consumers) or 5.9 primary Quads, excluding interactions with heating and cooling energy use. ${ }^{1}$ The energy used for lighting is equivalent to 19 percent of total U.S. electricity use and 7 percent of total U.S. primary energy use. Of the 1990 total, lighting consumed $331 \mathrm{TWh}$ or 3.8 primary Quads of comme, cial electricity (including street lighting), $103 \mathrm{TWh}$ or 1.2 primary Quads of residential electricity ${ }^{2}$, and $81 \mathrm{TWh}$ or 0.9 primary Quads of industrial electricity. ${ }^{3}$ Figure i shows the end-use breakdown of lighting electricity consumption and Table i shows the technologies considered in this study by sector. Interior lighting is studied for the commercial sector, while both interior and exterior lighting are considered for the residential sector. The end uses included in this study represent 69 percent of U.S. lighting electricity and 74 percent of the associated cost. The industrial sector is not studied because data are scarce and no current tool adequately models industrial lighting energy demand.

\section{BOUNDING THE UNCERTAINTY}

Projecting the future, even without new national policies designed to reduce lighting energy demand, is difficult. Electric utility and other incentive programs could permanently change the set of available technologies as suppliers phase out older, less-efficient (unsubsidized) designs. As newer technologies increase market share, their prices are expected to decline from current levels. To the extent that incentive programs and other market forces lead to increased production and lower prices of more efficient lighting equipment, federal policies (e.g., those considered here) will have less impact because there will be fewer energy savings to pursue. Alternatively, if these forces are short-lived or ineffective, greater savings with greater certainty can be captured by federal policy. In either case, federal policy would ensure significant improvements in the efficiency of lighting systems and would indirectly support voluntary programs by stimulating market availability.

With these factors in mind, the following baselines have been created, from which energy, economic, and environmental benefits are measured.

\footnotetext{
${ }^{1}$ One TWh (terawatt-hour) equals 1012 watt-hours and one Quad equals 1015 Btus; 1 Quad of primary energy = 87 TWh of electricity, based on a typical heat rate of $11,500 \mathrm{Btus} / \mathrm{kWh}$, measured at the point of final end use. In converting between site electricity ("at the meter") and energy input at the power plant, a thermal efficiency of 32 percent and a transmission and distribution loss of 7.5 percent are assumed.

2US DOE Energy Information Administration (EIA). 1991. Annual Energy Outlook, Sectoral Electricity Consumption. DOE/EIA 0383 (91), Washington, DC.

${ }^{3}$ Electric Power Research Institute, uripublished data, 1991.
} 
Figure i U.S. Lighting Electricity (515 TWh), 1990

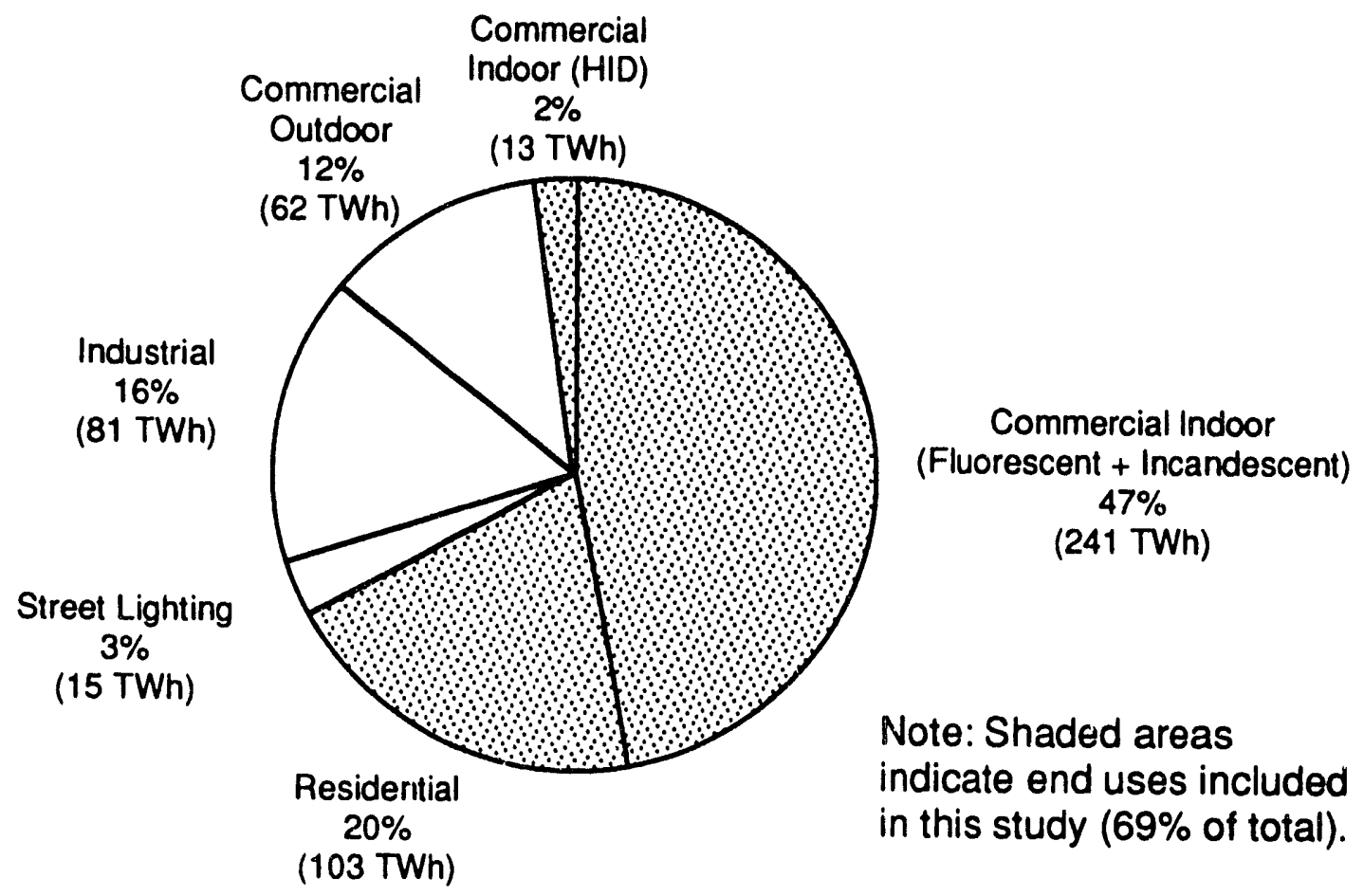

Table i Scope of Lighting Technology Options and Sectors Analyzed

\begin{tabular}{|c|c|c|c|c|c|}
\hline \multirow[b]{2}{*}{$\begin{array}{l}\text { Sector or } \\
\text { Application }\end{array}$} & \multicolumn{3}{|c|}{ LAMPS } & \multirow[b]{2}{*}{ Fixtures } & \multirow[b]{2}{*}{ Controls } \\
\hline & Fluorescent & Incandescent & $\begin{array}{l}\text { High Intensity } \\
\text { Discharge }\end{array}$ & & \\
\hline \multicolumn{6}{|l|}{ Residential } \\
\hline Interior & $\cdots$ & $\sqrt{ }$ & -- & $\ldots$ & --- \\
\hline Exterior & $\cdots$ & $\checkmark$ & -- & $-\cdots$ & --- \\
\hline \multicolumn{6}{|l|}{ Commercial } \\
\hline Interior & $\checkmark$ & $\checkmark$ & $\cdots$ & $\checkmark$ & $\sqrt{ }$ \\
\hline Exterior & --- & $\cdots$ & --- & -- & -.. \\
\hline Industrial & $\cdots$ & -- & --- & --- & --- \\
\hline Street Lighting & $\cdots$ & $\cdots$ & $\cdots$ & -- & -.- \\
\hline
\end{tabular}


1. No-Programs Baseline: This baseline assumes that consumer decisions on efficiency level are altered only by energy price changes. For perspective, it is important to note that the No-Programs Baseline results are virtually identical to a pure frozen-efficiency baseline (i.e., with no change in energy intensity, $\mathrm{kWh} / \mathrm{sq}$.ft.-year, for lighting) and to the current Annual Energy Outlook (AEO) forecast prepared by the Energy Information Administration of the U.S. DOE. This result occurs because projected electricity prices rise only slightly in real terms. In this baseline, increased floorspace becomes the primary determinant of lighting energ, demand.

2. Low-Eficiency Baseline: This baseiine assumes that significant lighting efficiency improvements are stimulated in the near-term by utility demand-side management (DSM) programs, the Environmental Protection Agency's (EPA) Green Lights Program, The Federal Energy Management Program (FEMP) Federal Relighting Initiative, and state building codes and standards. Assumptions on efficiency levels are primarily based on the Lighting Research Institute's supply/demand survey of manufacturers, utilities, and lighting maintenarce companies that provides projections through $1995 .^{4}$ Most of the incentive programs are present from 1990-1995, but are removed thereafter; only state building ccdes remain. This baseiine appioaches the Frozen-Efficiency and No-Programs Baselines in later years of the analysis. Efficiency improvements are modeled as a response to modest reductions in equipment costs as a result of incentive programs (see Section 2.1.2).

3. High-Efficiency Baseline: Savings from current programs and standards are assumed to persist throughout the analysis period to 2030. Equipment costs continue to fall after 1995 (more than in the Low-Efficiency Baseline). This baseline is considered the "most likely" scenario for lighting energy use given current programs and policies and near-term product supply constraints.

The High- and Low-Efficiency Baselines are not technical potential scenarios, nor are they achievable potentia! scenarios. Forecasts of policy impacts compared to these baselines reveal savings potential beyond existing progranns and therefore absolute as well as percentage savings are less than those from forecasts that compare with frozen-efficiency scenarios.

\section{POLICY OPTIONS}

The policy options selected for analysis have received considerable attention from many parts of the lighting community. Research organizations, manufacturers, lighting designers, equipment designers, lighting maintenance companies, energy conservation organizations, regulators, utility officials, and government agency representatives have provided extensive feedback. Existing

\footnotetext{
4Lighting Research Institute (LRI) and Plexus Research, Inc. 1991. Survey and Forecast of Mari -tplace Supply and Demand for Energy-Efficient Lighting Products. Phase I Report. Electric Power Research Instituth, Palo Alto, CA.
} 
experience within the U.S. is reviewed in Section 2.2 and the following categories of policy options are explicitly considered in the analysis (see Figures ii and iii for more detail):

- Mandatory component performance and prescriptive standards

- Mandatory system performance standards

- Voluntary component standards

- Federal incentive programs

- consumer rebates

- consumer tax credits

- Education/information programs

- consumer/designer education

- component labeling

Component performance standards studied for the commercial and residential sectors set minimum efficiency limits for specific technologies (e.g. lamps) while prescriptive standards require the use of specific equipment (e.g. programmable timer controls). Mandatory and voluntary component performance and prescriptive standards are analyzed for incandescent lamps, fluorescent lamps, fixtures, and controls. ${ }^{5}$ Ballasts are treated only as part of the lamp/ballast system for the lamp analysis; fluorescent ballasts have been studied in another report as part of ECPA-legislated updates.

System performance standards are typically implemented through building energy codes that impose limits on the installed Lighting Power Density (LPD), measured in watts/square foot. The impacts of the lighting provisions of two existing codes, ASHRAE/IES 90.1-1989 and DOE 1993, are studied as if the codes became mandatory nationwide. Because of limited evidence of compliance levels, voluntary standards for the commercial sector are modeled as delayed mandatory standards.

Federal incentive programs and education/information programs are analyzed for the commercial sector. Impacts are estimated using assumptions for participation rates and effects on consumer behavior based on the limited amount of research available on these types of policies. Labeling programs alone are assumed to have minimal effect given the absence of evidence that existing labeling programs, which target other end uses such as appliances, influence consumer behavior. However, labeling or rating programs can enhance the effectiveness of standards, incentives, consumer education, and other policies.

\footnotetext{
${ }^{5}$ Standards for HID lamps are not studied because they are responsible for a small fraction of commercial indoor and residential lighting and the market for lamps in this category already tends towarc more efficient sources. Also, several applications of HID lamps merit special consideration (such as roadway lighting). However, HID lamp standards will be considered in future analysis under the Energy Policy Act of 1992 legislation.
} 


\section{Figure ii}

\section{Policies and Technologies Included in Commercial Sector Analysis}

Polley

Mandatory Component Standards
Voluntary Component Standards

System Performance Standards (Building Codes)

Federal Incentives

Education/ Information
Product Class

Policy Case

Eliminate Highest Wattage
(Energy Policy Act, 1992 - FI Lamps)

Fluorescent Lamps $\quad$ Minimum LCC Lamp Research \& Development Minimum LCC Lamp/Ballast

\begin{tabular}{ll} 
& $\begin{array}{l}\text { Eliminate Highest Wattage } \\
\text { Incandescent Lamps }\end{array}$ \\
\cline { 2 - 2 } & Maximum LCC \\
Research \& Development \\
CFL Downlights \\
1991 Proposed Lamp Standards (Inc Lamps) \\
Energy Policy Act, 1992 (Inc Lamps)
\end{tabular}

Fixtures - Luminaire Efficiency Standard

Controls $\quad\left[\begin{array}{l}\text { Timers }(T) \\ T+\text { Lumen Maintenance (I ...:; } ; \\ T+L M+\text { Occupancy Sensors }\end{array}\right.$

Fluorescent \&
Incandescent Lamp
Combinations $\quad \begin{aligned} & 1991 \text { Proposed Standards (F\&I Lamps) } \\ & \text { Energy Policy Act, } 1992 \text { (F\&I Lamps) } \\ & \text { Minimum LCC FI \& Inc Lamps } \\ & - \text { Minimum LCC FI L/B \& Inc Lamps }\end{aligned}$

Lamp/Ballast/_ Minimum LCC Combination

Fixture/Controls Research \& Development Combination Combinations

FI \& Inc Lamp Combinations, $\mathrm{L} / \mathrm{B} / \mathrm{F} / \mathrm{C}$ Comb.

Minimum LCC FI \& Inc Lamp
- Minimum LCC FI Lamp/Ballast \& Inc Lamps
Minimum LCC Combination

N/A ASHRAE/IES 90.1 Partial Compliance DOE - 1993 Partial Compliance ASHRAE/IES 90.1 Full Compliance DOE - 1993 Full Compliance

N/A

Consumer Rebates

Consumer Tax Credits

N/A
- Consumer/Designer Education \& Component Labeling 


\section{Figure IiI}

Policies and Technologles Included in

Residential Sector Analysis

Policy

Mandatory Component Standards
Product Class

Policy Case

Fluorescent Lamps — Eliminate Highest Wattage

Incandescent Lamps/CFLs

Combinations Minimum LCC Combination Research \& Development Combination 
For the residential sector, policies such as requirement of dedicated fixtures or controls (within building codes), federal rebates or tax credits, and consumer education are not analyzed.

\section{Provisions of the Energy Policy Act of 1992}

During the preparation of this report, the U.S. Energy Policy Act of 1992 was signed into law. The energy-efficiency provisions contain standards and other regulations for lighting products, discussed below. The Act also requires that states adopt the ASHRAE/IES-90.1 building code (including the lighting provisions) (see Appendix G).

Component standards are established for four-foot, eight-foot and eight-foot high-output fluorescent lamps, and for incandescent reflector lamps, to take full effect in one-and-a-half to four years from enactment. Periodic updates are required by the law.

The energy-use baselines developed in this study do not reflect the impacts of the standards. Rather, the effects of the initial standards for commercial (indoor) and residential lamps are modeled as policy cases and summarized in Table $i$. The building code regulation is modeled by two "ASHRAE/IES" policy cases, one assuming full compliance and the other partial compliance (see Sections 2.2.3 and 4.4.). Note that modeled energy savings from the various aspects of the Energy Policy Act (component standards, building codes, and design centers) cannot be combined to determine the overall effect of the Act on energy consumption.

The Act also includes a labeling requirement for incandescent general service lamps, a call for regional lighting centers, and establishment of a luminaire rating and labeling procedure; there is no requirement for a luminaire standard. The Luminaire Efficacy Rating method proposed by the lighting industry, who would take part in devising the exact procedure, is discussed in Section 3.3. These features of the Act are not explicitly analyzed in this study.

\section{APPROACH}

The analysis begins with detailed characterizations of individual technologies, building up to projections of national lighting energy consumption. Engineering data on component energy consumption, performance, lumen output, lifetime, replacement cost, and price are gathered for standard and energy-efficient lighting technologies including lamps, their associated ballasts, ${ }^{6}$ fixtures, and controls. Eleven lamp product classes and four fixture product classes are examined for the commercial sector, and four lamp product classes are studied for the residential sector. This specific engineering information is then mapped onto the commercial and residential existing and future lighting equipment stock.

\footnotetext{
${ }^{6}$ Ballasts are considered in detail in a separate analysis in support of a forthcoming DOE rulemaking.
} 
An analysis of aggregate lighting energy consumption, equipment sales, and current and future saturations of technologies is undertaken to characterize the breakdown of new equipment sales according to equipment types (e.g., incandescent, fluorescent, HID lamps), and into sub-categories within those types (e.g., four-foot vs. eight-foot lamps, F40 vs. F32 lamps, etc.). To extrapolate from individual technologies to aggregate energy consumption for commercial lighting, the Commercial Buildings Energy Consumption Survey (CBECS) data on operating hours by technology are used, disaggregated by building types. In the residential sector, lighting equipment stock and operating hours are derived from a compilation of utility surveys and manufacturer estimates. No reductions in lighting levels are assumed.

The study uses state-of-the-art end-use forecasting models to project future U.S. energy consumption for lighting (and other end uses). For the commercial sector, the Electric Power Research Institute's COMMEND model is used. For the residential sector, Lawrence Berkeley Laboratory's Residential Energy Model (LBL-REM) is used. The national demand for lighting energy is modeled for eleven commercial building types and for three residential building types. The forecasting models do not contain detailed technology information but utilize weighted-average consumption in the form of EUIs (Energy Use Intensities), $\mathrm{kWh} / \mathrm{sq} . \mathrm{ft}$-year, or UECs (Unit Energy Consumption, expressed as $\mathrm{kWh} /$ household-year), for each building type. The base year is 1986 for the commercial sector and 1990 for the residential sector. The final forecast year is $\mathbf{2 0 3 0}$ for both sectors.

Because of modeling uncertainties and data limitations, interactions between lighting and space-conditioning energy use (HVAC), are not included in the results reported in Sections 4 and 5 and Appendix F. Appendix $\mathrm{H}$, however, provides some analysis and discussion.

Policies are modeled by altering the available mix and efficiencies of technologies used in buildings. For lamp component standards, for example, those lamp designs that are less efficient than the standard are eliminated, and more efficient designs must be chosen. Changes in equipment and operating costs caused by each policy are also analyzed. The report also investigates the prospective impacts on the lighting industry and on the peak electricity demand of electric utilities. Airborne emissions from electric power production are evaluated, using emissions factors (e.g. grams of $\mathrm{NO}_{\mathrm{x}}$ per $\mathrm{kWh}$ ) for the base year and for future years based on projected changes in the generation mix and effectiveness of emission-control technologies.

For the commercial sector, this analysis does not cover lighting retrofit measures (such as specular reflectors with delamping). These measures are not easily affected by standards, and COMMEND 3.2 cannot easily model them (see Section 2.1.2). Operationally, this has little importance for the 2030 results given the turnover of all existing equipment by that year. 


\section{RESULTS}

In this study, the scope of technical and economic savings potentials is defined as follows: ${ }^{7}$

- For the commercial sector, the difference between the Low-Efficiency Baseline and the R\&D Combination case represents the technical potential energy savings from the energy-efficient technologies considered, measured with respect to the most conservative estimate of market trends in the absence of new policies. This potential savings is $351 \mathrm{TWh}$ (71 percent) in the year 2030, with a net present value (NPV) of $\$ 126$ billion and represents technologies near commercialization and their projected costs. The difference between the Low-Efficiency Baseline and the Minimum Life Cycle Cost Combination case represents the maximum economic potential. This potential is $291 \mathrm{TWh}$ (59 percent) in the year 2030, with an NPV of $\$ 88$ billion and represents commercially available technologies at today's costs.

- For the residential secto:, the difference between the Frozen-Efficiency Baseline and the R\&D Combination case represents the technical potential energy savings from the energy-efficient technologies considered. This potential is $107 \mathrm{TWh}$ (64 percent) in the year 2030, with an NPV of $\$ 26$ billion. The difference between the Frozen-Efficiency Baseline and the Minimum Life Cycle Cost Combination case represents the maximum economic potential savings. This potential is $58 \mathrm{TWh}$ (35 percent) in the year 2030, with an NPV of $\$ 39$ billion.

Notably, the combined commercial and residential economic benefits exceed the projected combined benefits from existing federal NAECA standards on appliances, i.e. $\$ 34$ to $\$ 44$ billion NPV between the years 1990 and $2015 .^{8}$ More detailed discussion of sectoral results is provided below.

\section{Commercial Sector}

Figures iv and $v$ illustrate different projections for commercial indoor lighting energy intensity and consumption in the U.S.. The top three lines are the baselines used in this analysis. The next line shows the impact of the Energy Policy Act of 1992 fluorescent and incandescent lamp standards. The lowest two lines show that substantial additional energy savings are achievable from the economic- and technical-potential cases described above.

\footnotetext{
${ }^{7}$ These savings potentials could also be defined with respect to the No-Programs Baseline (as in Section 9). Quantitatively, the No-Programs and Low-Efficiency Baselines are almost identical.

${ }^{8}$ J.E. McMahon, et al. 1990. "Impacts of U.S. Appliance Energy Performance Standards on Consumers, Manufacturers, Electric Utilities, and the Environment." In Proceedings of the 1990 ACEEE Summer Stucty on Energy Efficiency in Buildings. American Council for an Energy-Efficient Economy, Washington, D.C., p. 7.107.
} 
Figure Iv

Annual Lighting Energy Use Intensity

kWh/sq.ft.-year

Baselines and Illustrative Policy Cases

Commercial Sector

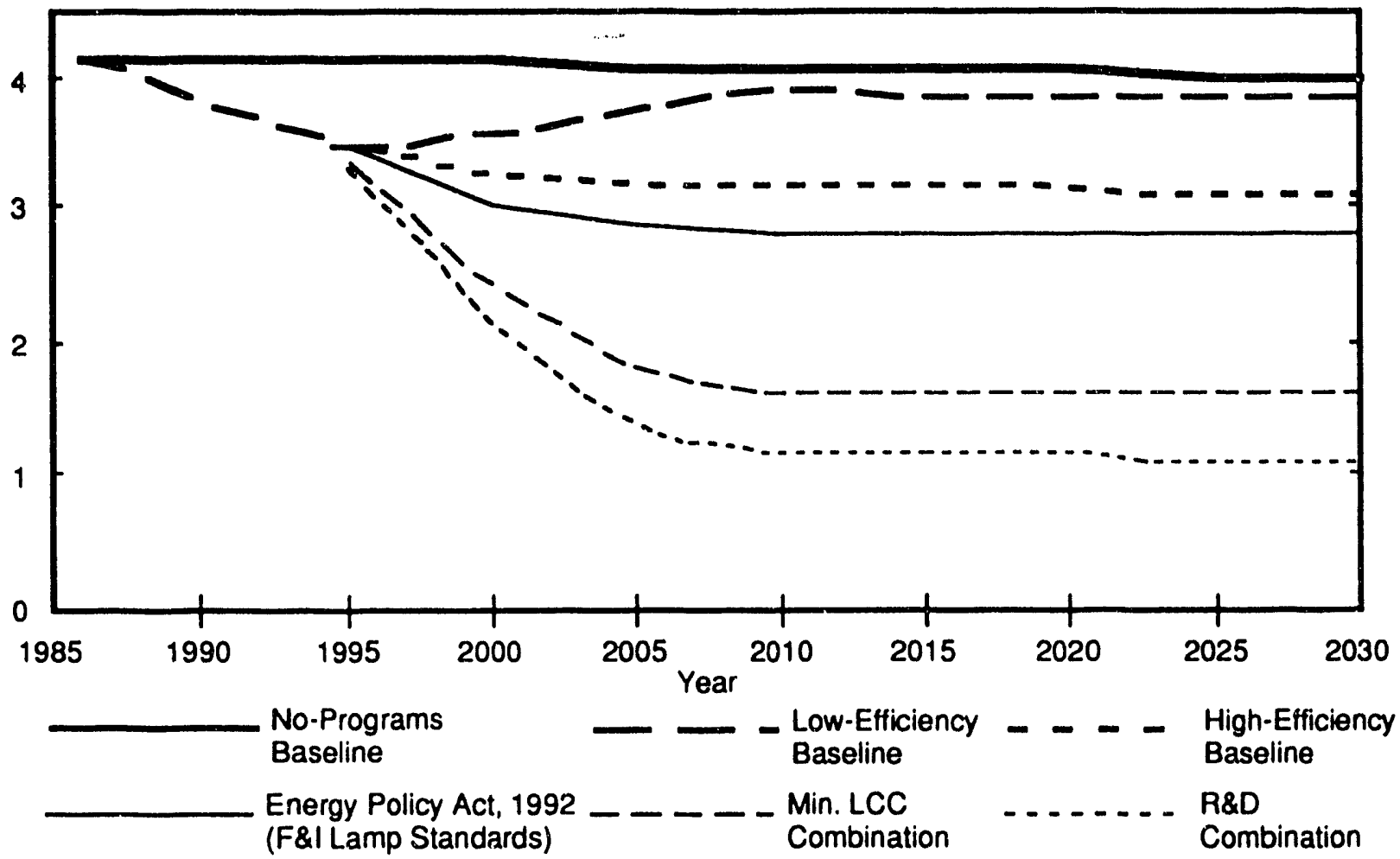

Figure $v$

Annual Lighting Energy Consumption

Primary Quads

Baselines and Illustrative Policy Cases

Commercial Sector

TWh

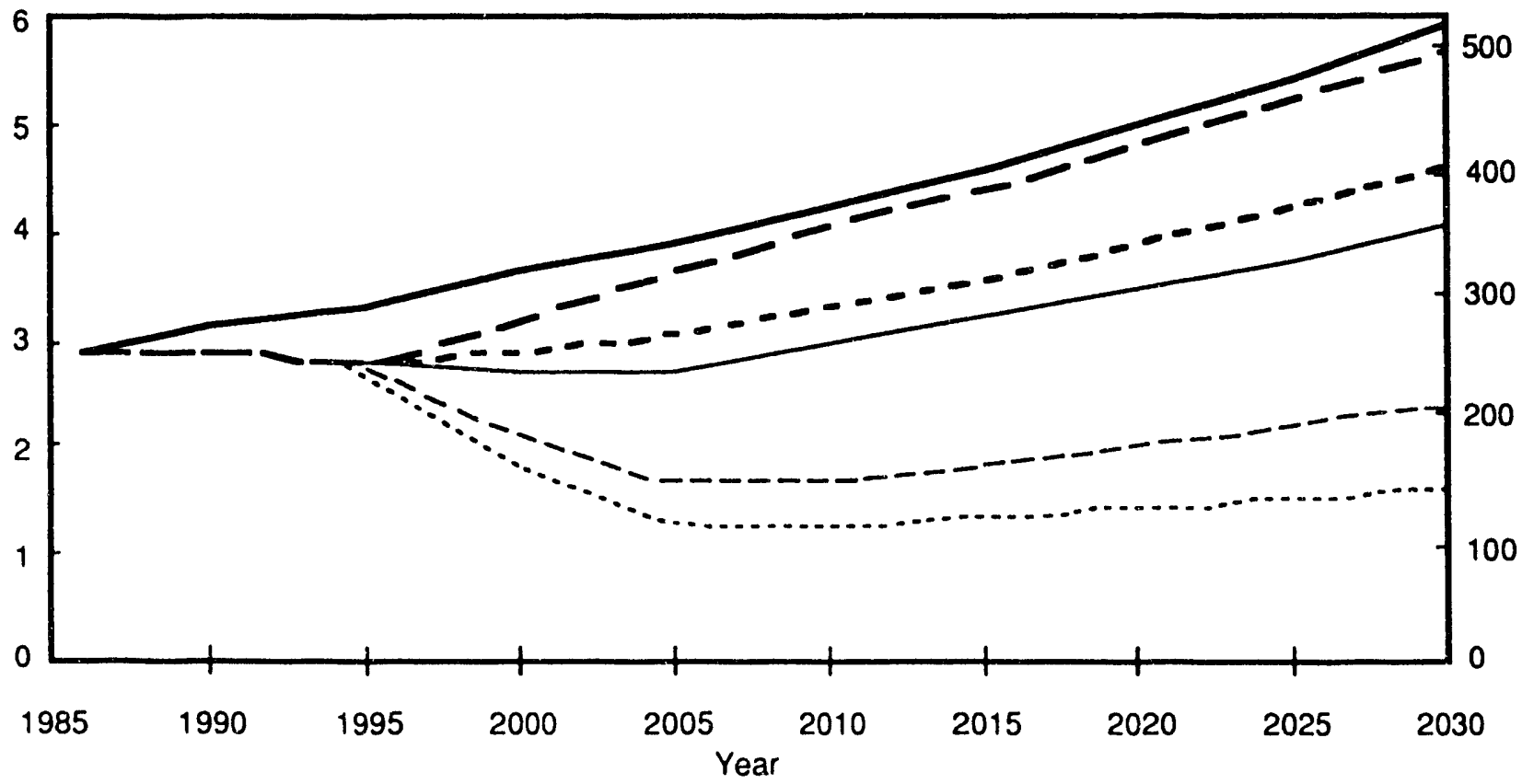

No.Programs

Baseline

_ - Low-Efficiency _ _ - High-Efficiency

Baseline

Baseline

Energy Policy ACt, 1992 _ _ - _ Min. LCC

R\&D

(F\&I Lamp Standards)

Combination

Combination 
Because of the nature of the COMMEND model, savings from individual policy cases may not be added together. To avoid double-counting, policies must be modeled together to accurately predict their combined effects. Nor can savings from policies that affect fixtures and controls be simply added to lamp results; net savings are less than the sum of the parts. Several combination cases account for interactions between fluorescent and incandescent lamp policies, or for lamp/ballast/fixture/controls interactions. Interactions among policies (such as consumer education with voluntary component standards) are not analyzed.

All federal commercial policies analyzed in this study save energy, peak power, and money, and reduce emissions beyond even the High-Efficiency Baseline. Table ii arrays a spectrum of results, along with comparative analysis of the qualitative differences among the policy approaches. Table iii presents a summary of ranges of cumulative savings measured with respect to the High- (Low-) Efficiency Baselines.

Figure vi illustrates the allocation of lighting electricity consumption in 2010 among fluorescent, incandescent, and compact fluorescent lamps for the baselines and several selected policies. Figure vii shows the commercial sector energy savings, expressed as a range over the two baselines, and Figure viii shows the corresponding net present values (NPV) of the policies. The net present value is the discounted difference between the baseline and policy case annual expenditures for lighting equipment and energy during the period 1995 to 2030. Net reductions in expenditures in the policy case relative to the baseline are reported as positive NPVs. Future expenditures are discounted at four-percent real for the commercial sector, and results are reported in billions of 1990 dollars.

System performance standards, or building codes, are applied only to new construction and substantial renovations. Savings from system performance standards are similar to those from single-component Eliminate Highest Wattage or Minimum LCC fluorescent or incandescent standards. The component combination case shows larger savings because fixtures and controls are included, whereas system performance standards specify maximum lighting power densities that do not embody all possible efficient technologies and do not achieve full compliance. The costs of system performance standards are not estimated because building codes allow substantial flexibility in choice of technologies.

For consumer rebates, tax credits, education, and labeling, the zero-percent savings estimates in Figures vii and viii are based on the assumption that federal programs beyond aggressive utility rebate programs in the High-Efficiency Baseline will save no marginal energy, whereas the high estimates (relative to the Low-Efficiency Baseline) assume additional savings from these policies. The NPVs include only the cost of the programs to the government, equal to 3.5 to $4 \mathrm{cents} / \mathrm{kWh}$, which in some cases may not equal the full incremental cost of the efficient technologies. These cases are represented by dotted lines in Figures vii and viii to reflect the relatively uncertainties of savings. 


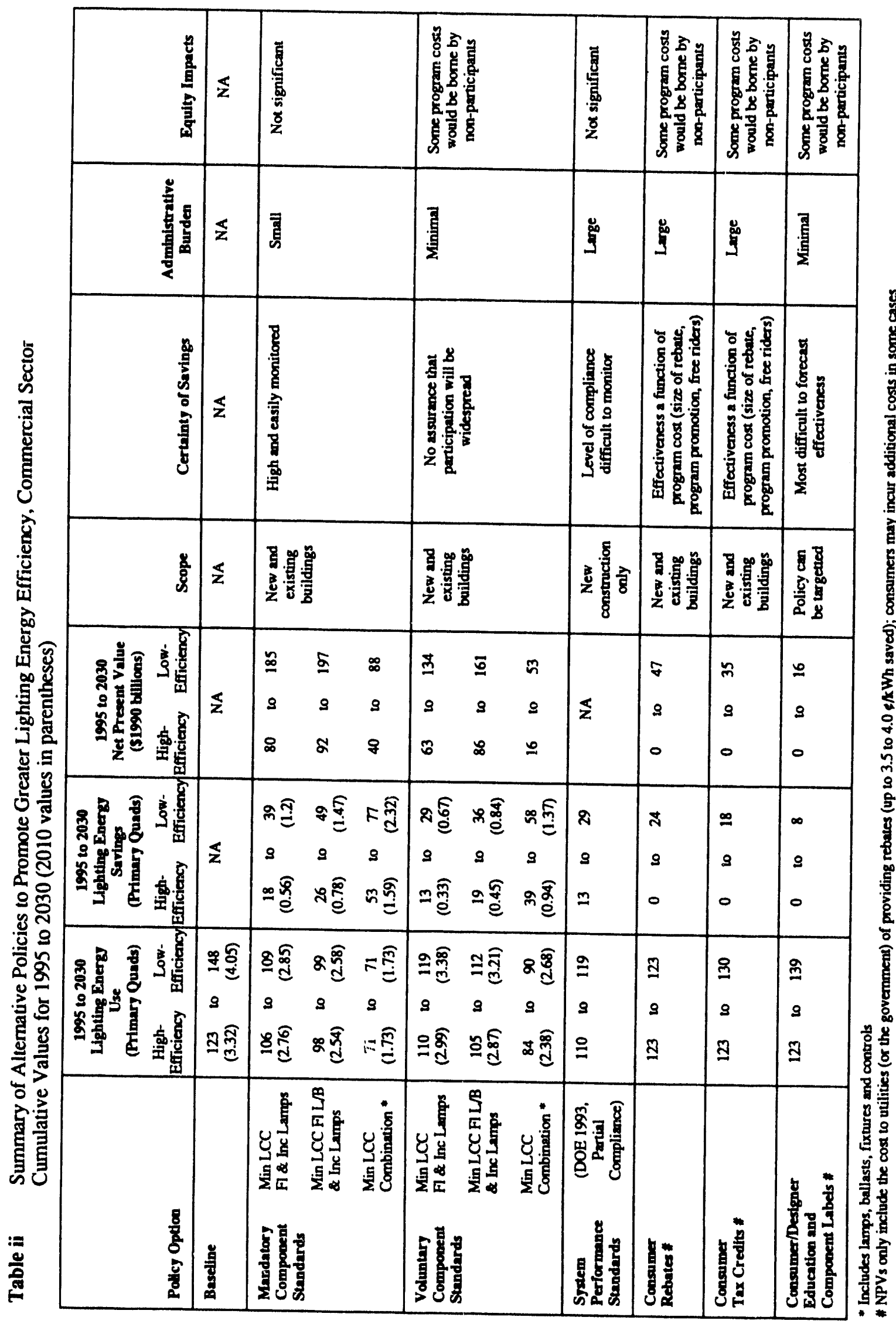


Table iii Summary of Cumulative Impacts of Selected Commercial Lighting Policies Measured with Respect o the High- (Low-) Efficiency Baseline*

\begin{tabular}{|c|c|c|c|}
\hline Type of Impact & $\begin{array}{l}\text { Energy Policy Act } \\
\text { of } 1992 \\
\text { Lamp Standards }\end{array}$ & $\begin{array}{l}\text { Minimum Life- } \\
\text { Cycle Cost } \\
\text { Combination } \\
\text { [Max. Econ. Pot'l] }\end{array}$ & $\begin{array}{l}\text { Research \& } \\
\text { Development } \\
\text { Combination } \\
\text { [Technical Potential] }\end{array}$ \\
\hline $\begin{array}{l}\text { Lighting Energy Intensity in } 2030: \\
\text { Energy Use Intensity, (kWh/ } \mathrm{ft}^{2} \text {-year) }\end{array}$ & $2.76(2.93)$ & $1.59(1.59)$ & $1.11(1.11)$ \\
\hline $\begin{array}{l}\text { Primary Energy Savings (Quads) } \\
(1995-2030)\end{array}$ & $13(31)$ & $53(77)$ & $69(93)$ \\
\hline $\begin{array}{l}\text { Electricity Savings in } 2030 \text { (TWh) } \\
\text { (Percent Savings) }\end{array}$ & $\begin{array}{c}45(117) \\
11 \%(24 \%)\end{array}$ & $\begin{array}{l}197(291) \\
49 \%(59 \%)\end{array}$ & $\begin{array}{l}258(351) \\
64 \%(71 \%)\end{array}$ \\
\hline Peak Power Savings by $2030\left(\mathrm{GW}, 10^{9} \mathrm{~W}\right)$ & $9(23)$ & $37(54)$ & $49(66)$ \\
\hline $\begin{array}{l}\text { Net Present Value }(\$ 1990 \text { billion })^{+} \\
\text {Avoided Emissions }(1995-2030)\end{array}$ & $23(55)$ & $40(88)$ & $76(126)$ \\
\hline - $\mathrm{CO}_{2}$ (Billion tons) & $1.1(2.7)$ & $4.3(7.2)$ & $5.0(8.4)$ \\
\hline - $\mathrm{SO}_{2}$ (Million tons) & $2.2(5.6)$ & $8.3(14.1)$ & $9.0(17.6)$ \\
\hline - $\mathrm{NO}_{\mathrm{x}}^{-}$(Million tons) & $2.0(5.1)$ & $7.8(13.1)$ & $8.7(16.0)$ \\
\hline
\end{tabular}

*Excludes interactions with heating, ventilating, and air conditioning (HVAC) energy use.

${ }^{+}$Real electricity prices increase only slightly between 1995 and 2030 . Real discount rate $=4$ percent.

\section{Figure vi \\ U.S. Commercial Lighting Energy Consumption in 2010, by Technology Combination Equipment Standards High-Etticiency Baseline}

Primary Quads

TWh

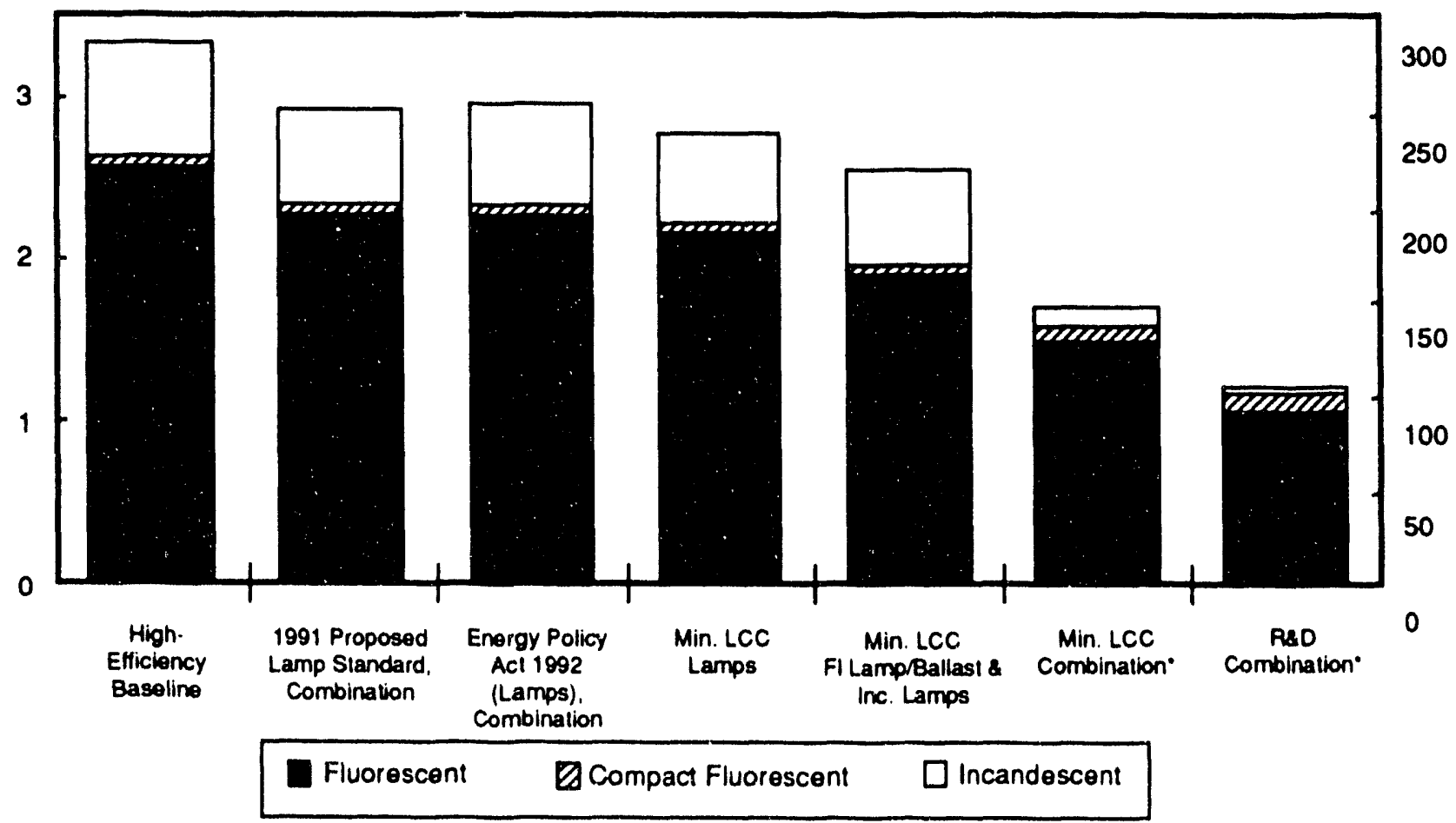

- Lamps/Ballasts with Fixtures and Controls 
Figure vil

Range of Cumulative Lighting Energy Savings by Policy

Primary Quads

1995-2030

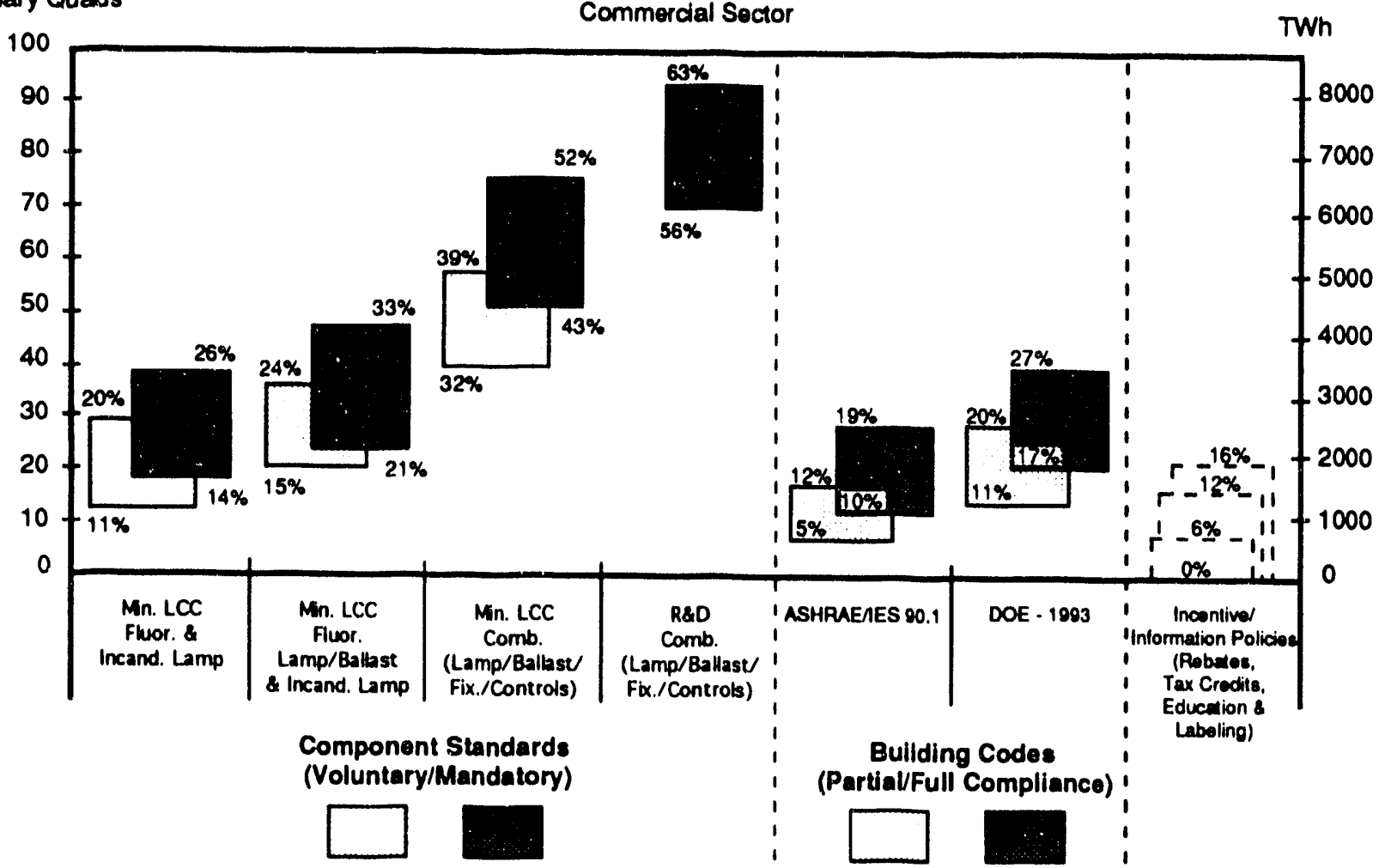

Note: Percentages are portion of respective baseline lighting energy.

Tops of bars represent savings under Low-Efficiency Baseline; bottoms of bars represent savings under High-Efliciency Baseline.

Figure vili

Range of Cumulative Net Present Vaiues by Policy

1995.2030

NPV

Commercial Sector

$\$ 1990$ Billions

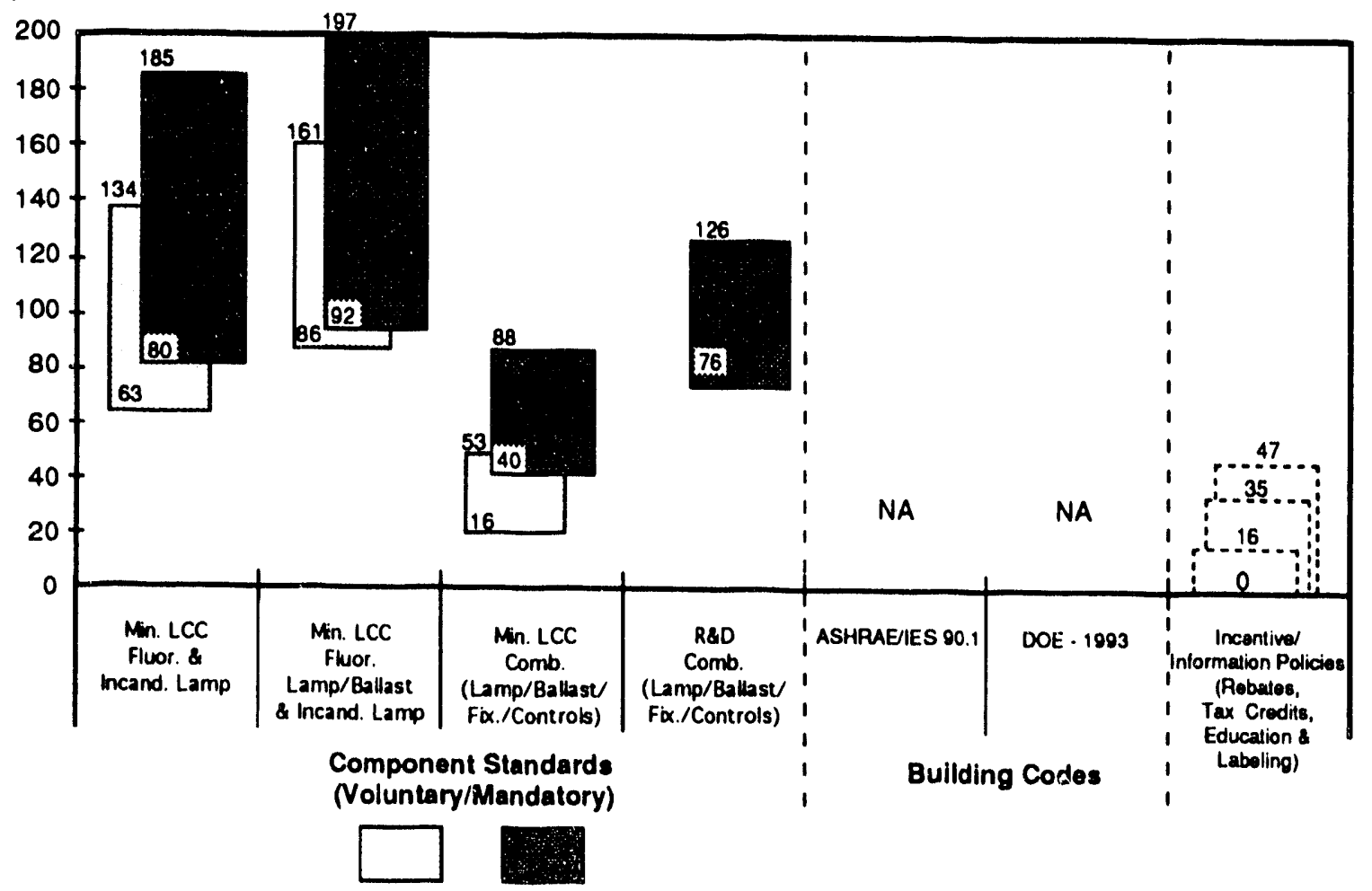

ToDs ol bars represent NPVs under Low-Efficiency Baseline; bothoms of bars represent NPVs under High-Efliciency Baseline. 


\section{Residential Sector}

Figures ix and $x$ show both energy savings and economic benefits (NPVs) for the residential sector from two baselines: Frozen-Efficiency and High-Efficiency. The policy cases modeled include incandescent lamp component standards, a fluorescent lamp component standard, a compact fluorescent prescriptive standard, Max Tech and R\&D lamp standards, a Minimum Life Cycle Cost Combination, an R\&D Combination, and an Energy Policy Act of 1992 lamp standards combination. The energy intensities (UEC, kWh/household-year) are shown in Figure $x i$ and the annual energy use for the baselines and policy cases are shown in Figure xii. A six-percent real discount rate is used in calculating the NPVs. Lastly, Figure xiii shows residential lighting use for the various cases disaggregated by light source.

In contrast to the commercial-sector results, the NPVs of the maximum technologically feasible (Max Tech) and R\&D lamp technologies are negative. This occurs primarily because some lower-usage lamps are included in the baseline, since these lamps would have to be replaced under a component standard as well as the higher-usage lamps. Other factors contributing to the negative NPV for these lamps in the residential sector, in contrast to positive NPVs for the same technologies in the commercial sector, include higher consumer equipment costs, lack of savings on replacement costs, and lower annual lighting hours.

Table iv presents a summary of ranges of residential energy, environmental, and economic impacts.

\section{Comparisons to Other Studies}

Comparisons among estimates of lighting savings potentials are complicated by differences in sectoral coverage, technologies included, operating hours, penetration rates, illumination levels, econometric assumptions, treatment of interactions among measures, time frame, and definition of baselines. Given the these variables, comparisons of absolute (e.g. terawatt-hour) savings can have little meaning. For five other studies examined, the most straight-forward comparison is among technical-potential estimates (see Section 9). For the commercial and residential sector, most other estimates are within about ten percentage points of this study. The two exceptions pertain to the residential sector.

\section{POLICY DISCUSSION}

This analysis identifies substantial potential energy, economic, and environmental benefits to the nation from policies that promote more efficient lighting. The magnitude of the savings depends upon the extent to which other forces (utility programs, other incentive programs, technological development, and pricing effects) operate. Nonetheless, in most policy approaches, a positive role for federal action is identified. 
Figure ix

Range of Cumulative Lighting Energy Savings from Lamp Standards

1995 to 2030

Residential Sector

Primary Quads

TWh

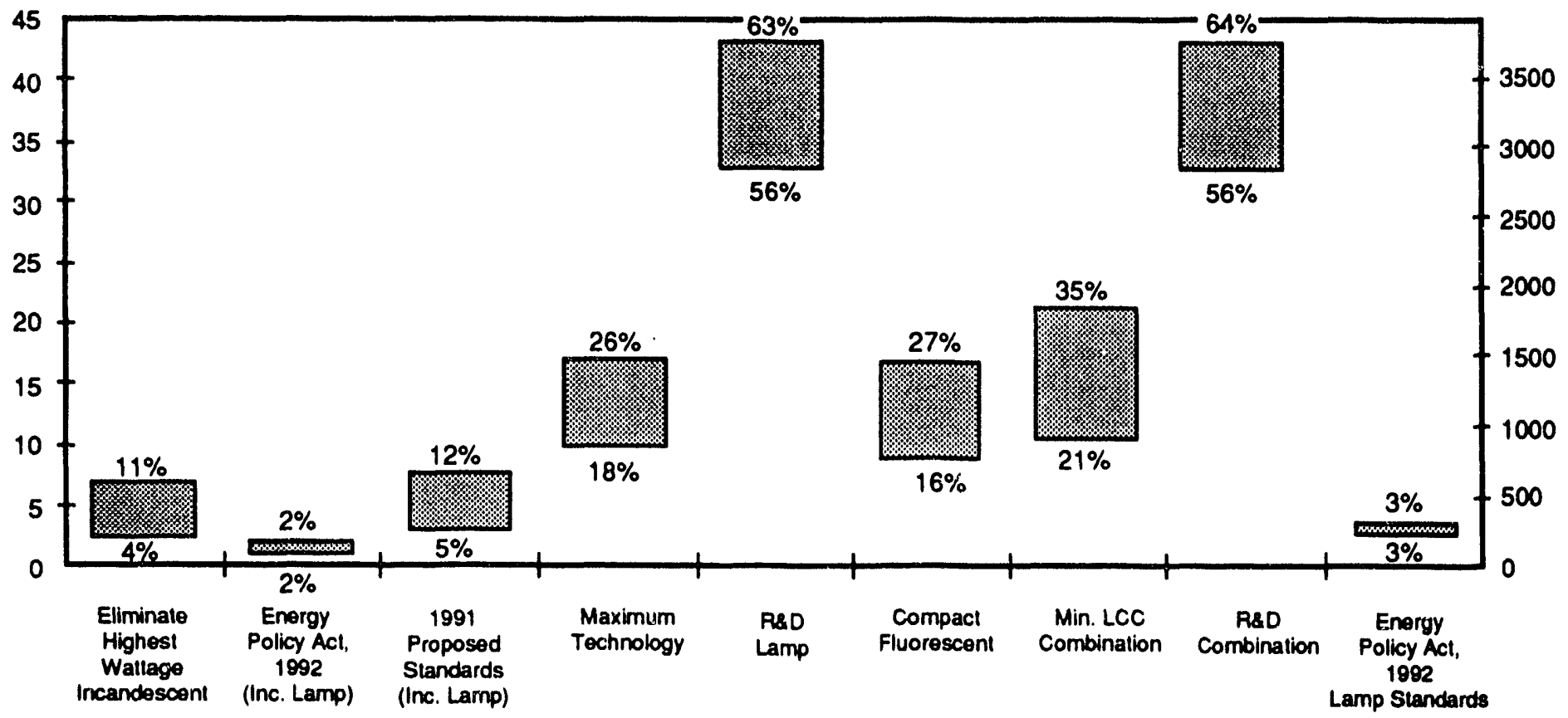

Nole: Percentages are portion of respective baseline lighting energy.

Tops of bars represert savings under Frozen-Efficiency Baseline; bottoms of bars represent savings under High-Efficiency Baseline.

Figure $x$

Range of Cumulative Net Present Values from Lamp Standards

1995 to 2030

NPV

Residential Sector

$\$ 1990$ Billions

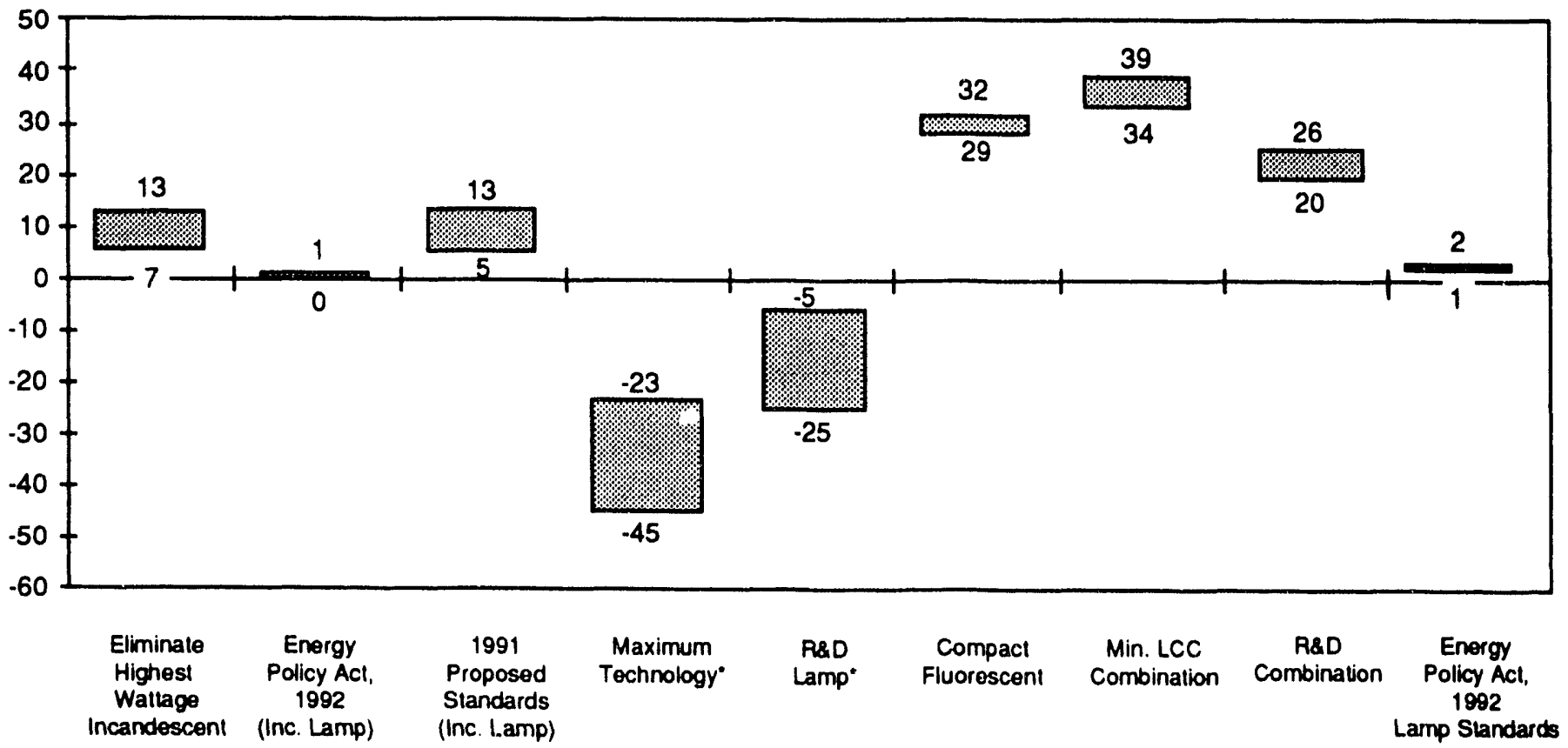

Tops of bars represent NPVs under Frozen-Efficiency Baseline, bolloms of bars represent NPVs under High-Efficiency Baseline; this relationship is reversed lor policy cases with and asterisk ("). 
Figure xI

Lighting Urit Energy Consumption in 2030

Baselines and Illustrative Policy Cases

$k W h$ / household-year Residential Sector

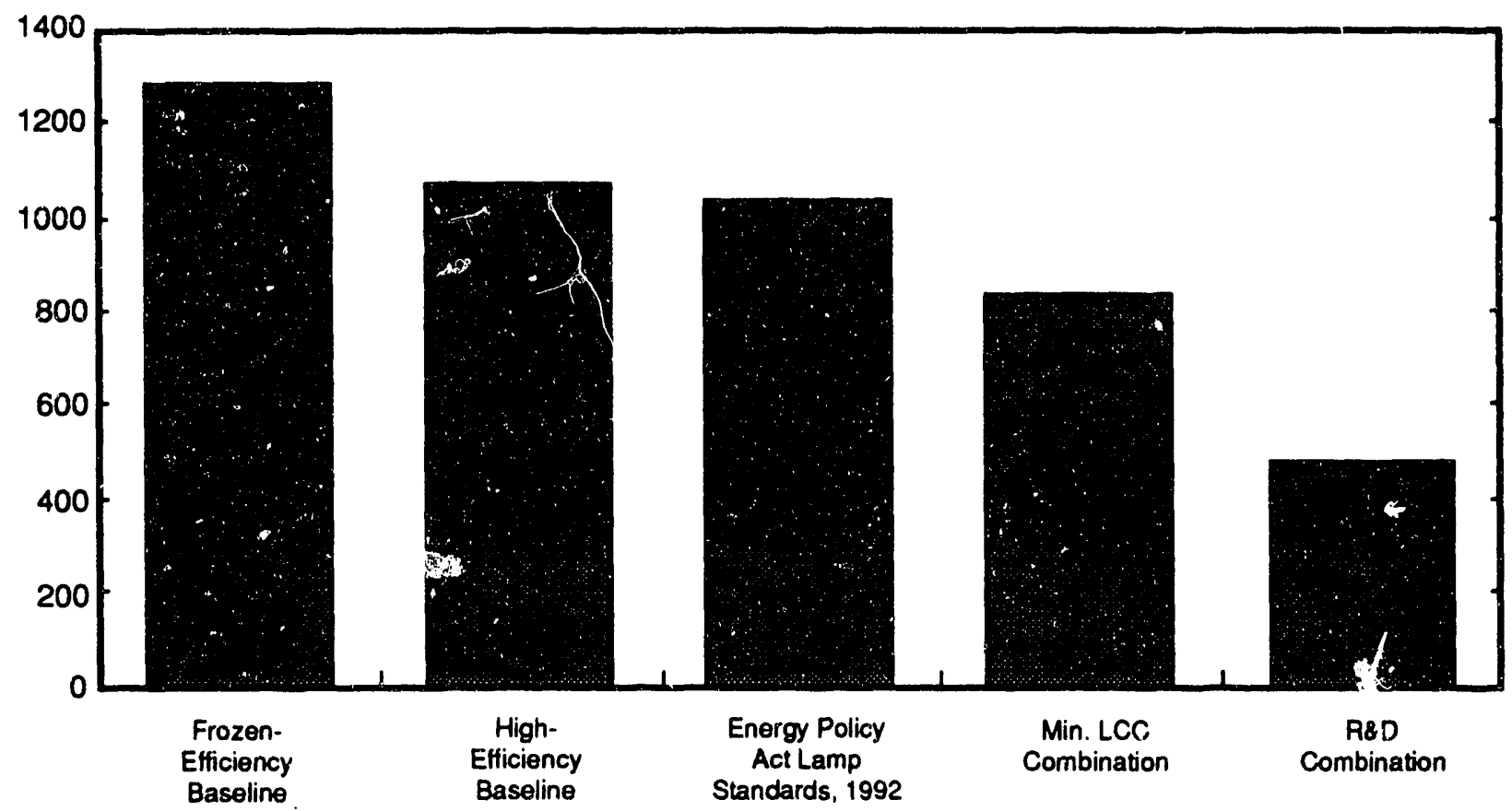

Figure xll

Annual Lighting Energy Consumption

Baselines and Illustrative Policy Cases

Primary Quads

Residential Sector

TWh
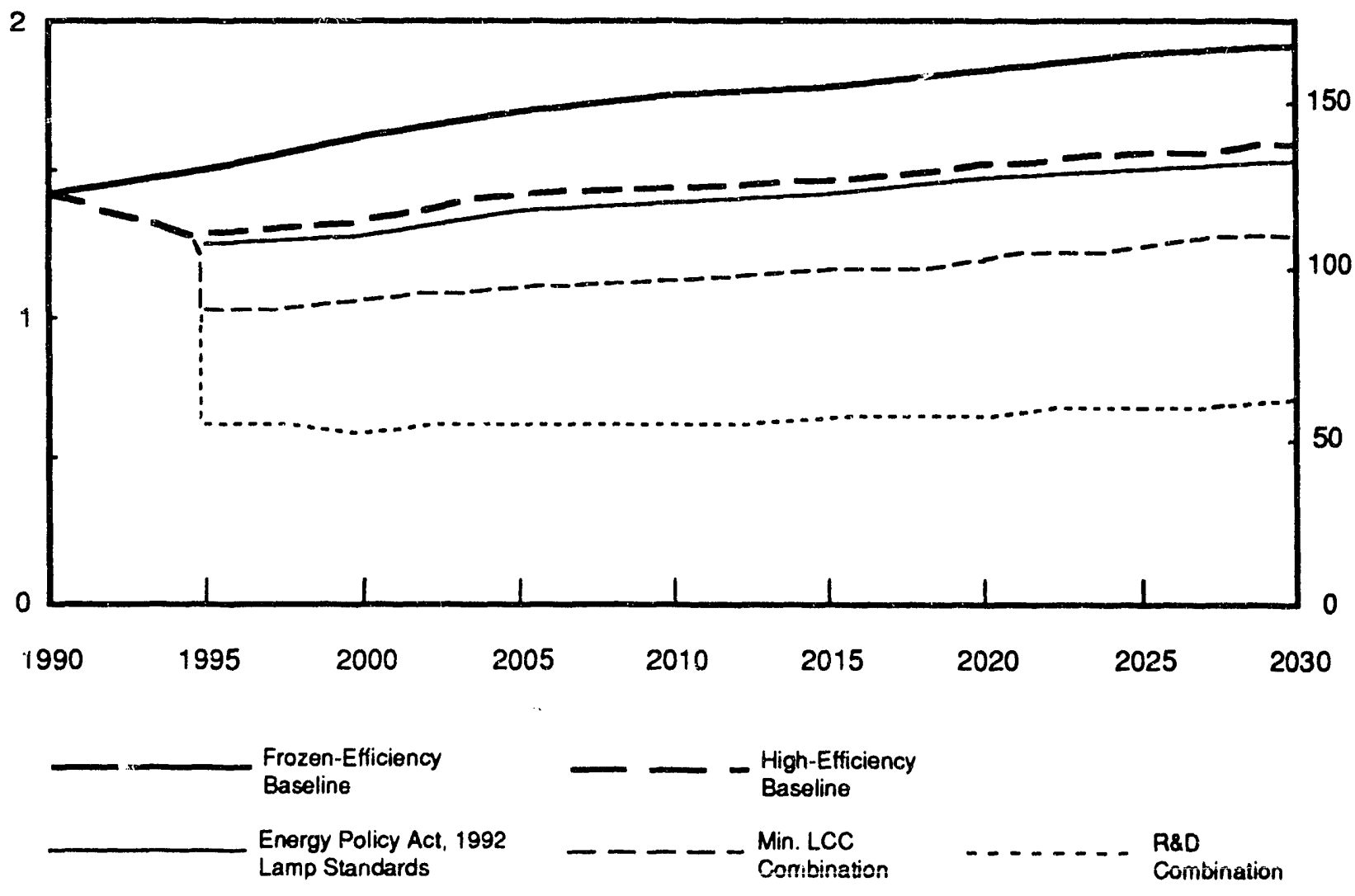


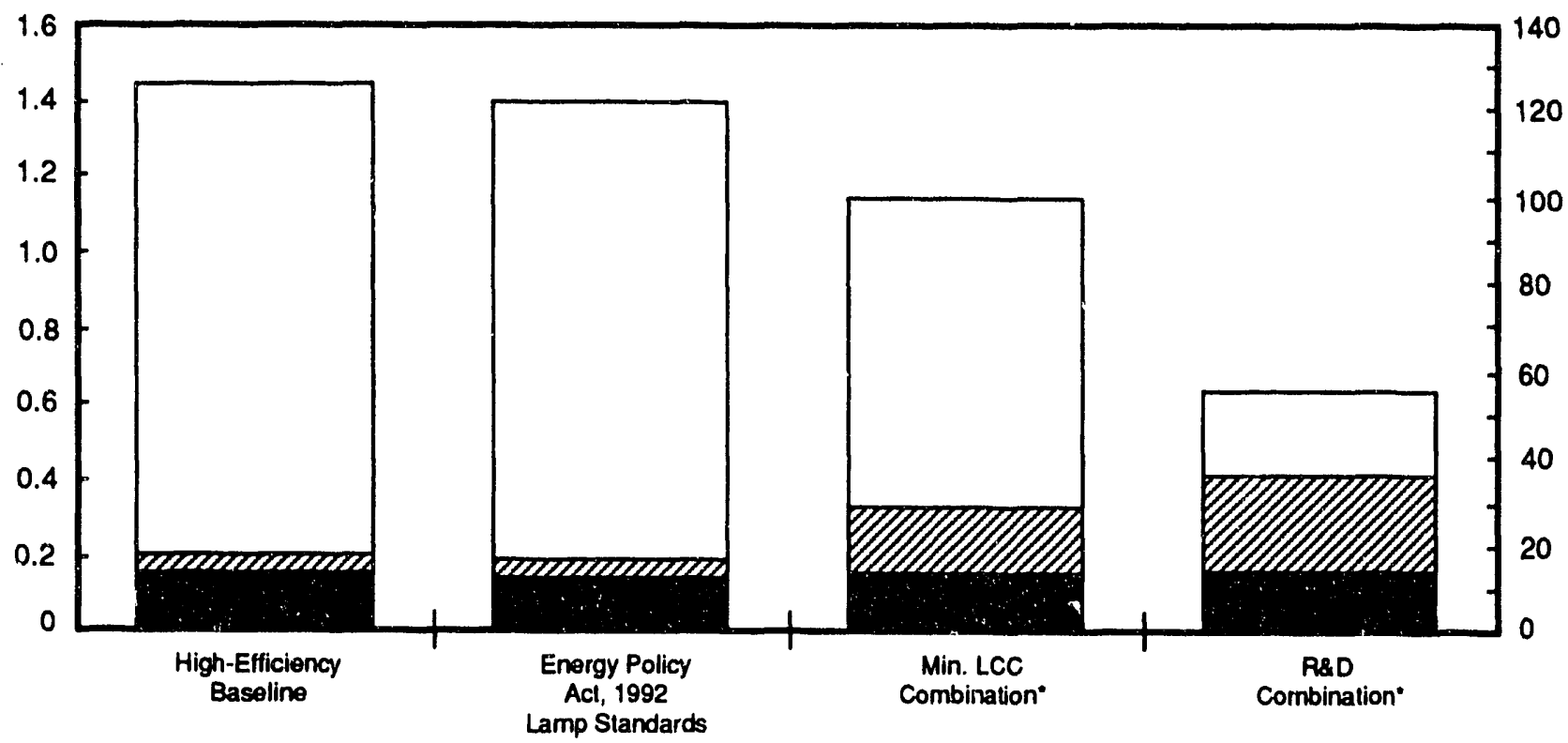

Fluorescent $\square$ Compact Fluorescent $\square$ Incandescent

- Including compact fluorescent substitution

Table iv

Summary of Cumulative Impacts of Selected Residential Lighting Policies Measured with Respect to the High- (Frozen-) Efficiency Baseline

\begin{tabular}{|c|c|c|c|}
\hline Type of Impact & $\begin{array}{l}\text { Energy Policy Act } \\
\text { of } 1992 \\
\text { Lamp Standards }\end{array}$ & $\begin{array}{l}\text { Minimum Life- } \\
\text { Cycle Cost } \\
\text { Combination } \\
\text { [Max. Econ. Pot'l] }\end{array}$ & $\begin{array}{l}\text { Research \& } \\
\text { Development } \\
\text { Combination } \\
\text { [Technical Potential] }\end{array}$ \\
\hline $\begin{array}{l}\text { Lighting Energy Intensity in 2030: } \\
\text { Unit Energy Consumption, UEC } \\
\text { (kWh/household-year) }\end{array}$ & $1,039(1,249)$ & $839(839)$ & $467(467)$ \\
\hline $\begin{array}{l}\text { Primary Energy Savings (Quads) } \\
\text { (1995-2030) }\end{array}$ & $1(2)$ & $11(22)$ & $29(40)$ \\
\hline $\begin{array}{l}\text { Electricity Savings in } 2030(\mathrm{TWh}) \\
\text { Percent Savings } \\
\text { Peak Power Savings by } 2030\left(\mathrm{GW}, 10^{\circ} \mathrm{W}\right) \\
\text { Net Present Value ( } \$ 1990 \text { billion) }\end{array}$ & $\begin{aligned} 4 & (6) \\
3 \% & (4 \%) \\
0.4 & (0.6) \\
1 & (2)\end{aligned}$ & $\begin{array}{l}29(58) \\
21 \%(35 \%) \\
3.2(6.4) \\
34(39)\end{array}$ & $\begin{array}{l}78(107) \\
56 \%(64 \%) \\
8.6(11.7) \\
20(26)\end{array}$ \\
\hline $\begin{array}{l}\text { Avoided Emissions (1995-2030) } \\
-\mathrm{CO}_{2} \text { (Billion tons) } \\
-\mathrm{SO}_{2} \text { (Million tons) } \\
-\mathrm{NO}_{\mathrm{x}} \text { (Million tons) }\end{array}$ & $\begin{array}{l}0.1(0.2) \\
0.3(0.4) \\
0.2(0.4)\end{array}$ & $\begin{array}{l}0.9(1.8) \\
2.3(4.3) \\
1.9(3.8)\end{array}$ & $\begin{array}{l}2.5(3.4) \\
6.1(8.4) \\
5.1(7.1)\end{array}$ \\
\hline
\end{tabular}

Excludes interactions with heating, ventlating, and air conditioning (HVAC) energy use.

${ }^{+}$Real electricity prices increase only slightly between 1995 and 2030. Real discount rate $=6$ percent. 


\section{Advantages and Disadvantages of Specific Policy Options}

Selecting the appropriate policy or mix of policies will involve considerations beyond the quantification of projected energy and economic savings (Table ii).

- Mandatory component performance standards have the advantages of relative certainty of energy savings per component, ease of monitoring, small administrative burden, and costs equitably borne by the participants. The disadvantages are restriction of the range of technologies that can be manufactured and of designer and consumer choices of lighting components, and enforcement.

- Voluntary component standards (or building codes) are less restrictive than mandatory standards, but energy savings are projected to be achieved more slowly and with much less certainty.

- Mandatory system performance standards have the potential to achieve significant energy savings with costs borne by participants, but disadvantages include less certainty of compliance, difficulty in enforcement, and a large administrative burden.

- Federal incentive programs (rebates or tax credits) have significant potential savings, but carry a large administrative burden, and are assumed in this study to be inconsequential if other incentives have already been offered on a large scale (as in the High-Efficiency Baseline).

- Education/information programs target the largest population, but the timing, magnitude, and reversibility of savings are uncertain. Nonetheless, education programs are important to ensure longer-term savings from better lighting design, higher participation rates in programs, and more rational economic decisions.

No one approach offers a panacea. Markets, market barriers, and technical factors suggest that a diversity of policy options applied collectively can achieve the greatest levels of cost-effective energy savings.

\section{Lighting Industry Implications}

Mandatory component regulations are generally not popular with lighting equipment manufacturers who prefer voluntary policies, market-based incentives, information programs, or system performance standards that allow more flexibility in component selection. However, manufacturers are projected to be able to adjust to the policies analyzed, given sufficient advance notice. For lamps, necessary time to retool to comply with a component performance standard is estimated at about eighteen months to five years, perhaps longer for new phosphor coatings. For compact fluorescent lamps, several firms are already planning additional production capacity in the next three to five years in response to increasing demand. The fixture industry appears to have excess capacity at present and has been consolidating. Continued consolidation is likely 
and could be accelerated by fixture standards. As excess production capacity is reduced, the financial health of the remaining firms may improve.

Standards have costs as well as benefits for the lighting industry. On the one hand, standards lead to increased requirements for capital investment and changes in product mix and, technology market shares. On the other hand, they create an environment in which manufacturers have much greater certainty about the level of demand for efficient products than would be the case where incentives and other optional inducements are operating in the marketplace.

\section{Implications for Policy Making}

Implementation of federal policy options can influence only some of the factors necessary to achieve comprehensive energy-efficient lighting. The inherently systems-based nature of lighting highlights the importance of proper system design and commissioning, ongoing operation and maintenance, thoroughly understanding of the interactions between lighting and space conditioning systems, and integrating artificial and daylighting technologies. These aspects of lighting are difficult to directly influence through formal policy mechanisms. Consumer and designer education, activities that can be supported by federal action, are essential in this respect; yet the resultant technical changes and associated savings are difficult to quantify.

Within the realm of policy options examined in this study, the following observations help place the results in context with the concerns, tools, and objectives of policy makers:

\section{Market trends may yield significant energy savings (but with considerable uncertainty) and new policies can cost-effectively achieve even more.}

- The price-driven No-Programs Baseline in the commercial sector results in a projection that is essentially synonymous with "frozen-efficiency," i.e., the energy intensity remains almost unchanged during the 1986 to 2030 forecast period. The 1992 Annual Energy Outlook (AEO) forecast arrives at a similar result. In the No-Programs Baseline, lighting energy consumption in 2030 for the end uses considered (indoor commercial lighting) would reach about 520 TWh per year, at a cost of approximately $\$ 42$ billion at projected real electricity prices (in 1990 dollars).

- The envelope of possibilities defined by the commercial sector Low- and High-Efficiency Baselines shows substantial cumulative energy savings even in the absence of new federal policies (4 percent to 22 percent, respectively) in comparison to the No-Programs Baseline. For the year 2030, the High-Efficiency case corresponds to a savings of 115 TWh ( $\$ 9$ billion). In the residential sector, the difference between the Frozen-Efficiency and High-Efficiency Baselines is 17 percent (for the 1995-2030 period, or 29 TWh ( $\$ 2$ billion) in the year 2030 . Where within these envelopes U.S. lighting energy use will actually fall without federal intervention is highly uncertain and depends on factors largely out of the control of federal policy makers, such as energy prices and utility actions. 
- New federal policies based on minimum life-cycle cost offer absolute savings exceeding even the maximum future savings likely from current programs and policies (i.e., the aforementioned 22-percent savings). The Minimum Life Cycle Cost Combination case achieves 49-percent cumulative savings beyond the High-Efficiency Baseline, and the net present value of these marginal savings is $\$ 40$ billion.

\section{A mixture of strategies promises to be the most sound approach for increasing lighting energy efficiency.}

- Important synergies can operate among policy options. For example, financial incentives such as rebates are likely to be more effective when complemented with strong education/information programs. Similarly, information (and perhaps other inducements) can lead to increased compliance with standards. Mandatory standards in turn serve as a potentially valuable "safety net" in the event that the other policies fail to attain the intended energy savings. In addition, financial incentive mechanisms can be used to reward manufacturers or consumers that exceed the standards.

- In come cases, policy approaches essentially must be combined For example, prescriptive residential standards (such as mandatory fluorescent lighting in kitchens and bathrooms as in California's Title 24 residential building code) have proven difficult to enforce. Regulations mandating CFLs or other fluorescent lighting for the residential sector must be accompanied by a vigorous campaign of consumer and designer education to acquaint users with the benefits of modern fluorescent lighting (especially better color rendition and the lack of hum and flicker from electronic ballasts) and dispel misconceptions about health hazards.

No single form of standards is universally applicable.

- System performance standards (e.g. building codes) may be more difficult to implement and enforce than component standards, requiring post-evaluation of individual buildings for compliance. A national system performance standard would avoid the inconsistency or cost of potential redundancies among individual state standards, but might be less stringent than the current standards in some states.

- Component and system performance standards can be used in combination to ensure both the availability of efficient technologies and a flexible design framework in which they can be applied. However, experience in state efforts shows that policies using both types of standards must be carefully designed from both the technical and political standpoint.

- Especially for the residential sector, a successful approach to increasing the penetration of compact fluorescent lamps in incandescent sockets may include "fleet averaging" to regulate the average efficacy of products offered/sold by manufacturers (discussed below). Another approach may involve mandating fixtures that accept only CFLs for new construction. 
Comprehensive standards offer a cost-effective savings potential well in excess of that anticipated from the Energy Policy Act of 1992 lamp standards.

-While federal efficiency standards for lamps have recently been legislated, they capture only a fraction of the full cost-effective savings potential from lighting component standards. As shown in Tables iii and iv with respect to the High-Efficiency Baseline in 2030, the Energy Policy Act of 1992 standards for incandescent and fluorescent lamps are projected to achieve one-fourth of the potential commercial energy savings and one-seventh of the potential residential energy savings in comparison to the Minimum Life Cycle Cost Combination case. The difference in net present values for the two sectors is $\$ 50$ billion and the peak-power difference is 34,000 megawatts.

Low program participation or incomplete standards compliance can have significant opportunity costs.

- The extent of realized energy savings from all policies considered depends on the success of implementation. For mandatory standards, this in turn depends on (a) acceptance by practitioners and designers and (b) the credibility and effectiveness of enforcement. Their likelihood can be increased in a consensus standard-setting process, involving collaboration among policymakers, the lighting industry, energy conservation advocates, designers, and other interested parties.

- Estimates derived in this study show approximately two-thirds as much energy savings for mandatory standards than would be the case for 100-percent compliance.

- Savings for voluntary standards cannot be determined with a reasonable degree of certainty. In response to this uncertainty, policies can stipulate that, if efficiency targets are not attained, voluntary standards become mandatory after a pre-agreed time period. In the case of a ten-year delay before full implementation of the Voluntary Minimum Life Cycle Cost Combination (as assumed in this analysis), the cumulative opportunity costs (i.e., the difference in electricity savings between the mandatory and voluntary cases) would be 14 Quads under the High-Efficiency Baseline and 19 Quads under the Low-Efficiency Baseline. This corresponds to $\$ 24$ billion and $\$ 35$ billion differences in NPV, respectively.

Considerable reductions in airborne emissions from electric power production can be achieved by utilizing energy-efficient lighting.

- As an illustration with respect to the High-Efficiency Baseline, the Research \& Development Combination case achieves combined commercial and residential $\mathrm{CO}_{2}$ emissions reductions of 7.5 billion tons during the period 1995 to 2010. Corresponding savings in $\mathrm{SO}_{2}$ are 15 million tons and in $\mathrm{NO}_{x}$ are 16 million tons. 
Research and development is essential for a continued supply of conservation resources.

- Significant past progress in lighting technology has made possible the large savings identified in this study. Ongoing R\&D can ensure a continued supply of conservation opportunities. Technologies just now approaching market readiness offer a savings potential of approximately one-third beyond currently minimum life-cycle cost options for the commercial sector (Table iii) and approximately one-half in the residential sector (Table iv). Additional technical advances are on the horizon (see Section 10).

\section{Policy Appraaches Not Examined in the Analysis}

Following is a brief discussion of additional policy approaches-applicable to both the commercial and residential sectors-not examined in this study. These policies are not included in the analysis because of modeling difficulties and/or lack of field experience upon which to estimate impacts. Similarly, aside from the "Combination" cases, synergistic benefits of groups of policies used jointly have not been quantified.

Increased Research and Development - The effort expended on R\&D by industry and by the public sector will strongly influence the rate of commercialization of new energy-efficient lighting products. The U.S. lighting industry today spends three to six percent of its revenues on research (approximately $\$ 270$ to $\$ 540$ million annually). Only a fraction of this is applied towards improving energy efficiency. Many potential improvements are not pursued vigorously by industry because of uncertain short-term benefits. In this instance, government-supported R\&D can make a critical difference. ${ }^{9}$ The electronic ballast, for example, was initially developed at Lawrence Berkeley Laboratory with $\$ 3$ million of government funding and has today reached a 10-percent market share (approximately 10 million ballasts/year), saving approximately $\$ 750$ million between 1985 and 1990. At 100-percent saturation, electronic ballasts will be saving approximately $\$ 6$ billion/year net. Further promising research avenues are described below.

Market Transformation - Large purchasers of lighting equipment have a powerful influence on the marketplace. The concentrated government and corporate purchasing power can increase the availability and penetration of efficient lighting technologies. Large buyers can also accelerate the commercialization of new technologies by creating the "market pull" necessary to give manufacturers a clear signal that demand indeed exists for a new product. Large-scale applications of efficient technologies also have great educational and confidence-building value. The U.S. EPA's Green Lights Program and FEMP's Federal Relighting Initiative offer examples of this approach and the possibilities for creative public-private interaction.

Utility Shareholder Incentives - Recent experience in California and New England has shown that electric utilities promote energy efficiency much more aggressively (and cost-effectively)

\footnotetext{
${ }^{9}$ H. Geller, et al. 1987. "The Role of Federal Research and Development in Advancing Energy Efficiency." Annual Review of Energy, vol. 12, page 357-95.
} 
when they are given a financial incentive for doing so. New policies introduced by regulatory agencies allow utilities to earn as much or more profit from their efficiency investments as from their competing supply-side investments. Conservation program plans have burgeoned as a result and some of the nation's largest lighting efficiency programs have been established by utilities receiving such incentives.

"Golden Carrots"- Rebates to manufacturers can accelerate the commercialization of new efficient products, or increase the marketing effort expended on existing efficient ones. For example, a $\$ 30$ million award from a consortium of U.S. utilities was recently offered to refrigerator manufacturers. The winning proposed design must achieve a performance level of at least 25-percent less (preferably 50-percent less) energy use than required by the federal appliance efficiency standard. A related approach has been implemented in Sweden for various end-use technologies, including lighting. ${ }^{10}$ Such incentives could also take the form of manufacturer tax credits.

Fleet-Averaging - the concept of fleet averaging is analogous to the Corporate Average Fuel Economy (CAFE) standards that have been in place for automobiles in the U.S. for nearly two decades. Rather than regulating the efficiency of each product, a standard (target) is set such that the sales-weighted average efficiency of all products of a certain type/class sold must meet or exceed the target. This approach gives manufacturers the flexibility to offer a wider variety of products, some of which need not meet the target. The CAFE standards have been raised gradually over a period of years, allowing manufacturers time to adjust. For lighting, a fleet average standard could be set by aggregating annual lumen hours of projected lighting use, divided by projected lighting electricity consumption. (The International Commission on Illumination (CIE) has compiled such data since 1960 for 16 member countries, including the U.S.) ${ }^{11}$ A fleet-averaging system can be implemented such that credits can be traded to encourage new entries and to avoid discrimination against small or specialized manufacturers. This approach could prove especially applicable to the "Edison socket" market, i.e., for efficient incandescent and compact fluorescent lamps. Even in the absence of a fleet-averaging standard, the reporting of such data would prove extremely useful in tracking national progress towards lighting efficiency goals.

Feebates - It is possible to complement a voluntary lighting component standard or mandatory fleet-average standard by establishing a mechanism by which buyers of products more efficient than the standard receive a rebate and buyers of products falling below the standard are assessed a fee at the point of sale. Fee and rebate levels can be proportional to efficiency and balanced

\footnotetext{
${ }^{10}$ S. Stillesjo. 1993. "Innovative Procurement Mechanisms for the Commercialization of Energy-Efficient Lighting and Ventilation Products," Energy-The International Journal (forthcoming).

${ }^{11}$ For example, average efficacy (lumens/watt) for the entire lighting equipment stock in 16 reporting countries increased from about $25 \mathrm{l} / \mathrm{W}$ in 1960 to $50 \mathrm{l} / \mathrm{W}$ in 1990. See E. Mills and M.A. Piette. 1993. "Advana d Energy-Efficient Lighting Systems: Progress and Potential," Energy-The Intemational Joumal (forthcoming).
} 
a fee at the point of sale. Fee and rebate levels can be proportional to efficiency and balanced such that the system is self-financing. The "revenue-neutral" point (i.e. where fee revenues equal rebate payments) can be gradually shifted towards increased efficiency levels as market shares move the more efficient products. This approach has the advantage of keeping money within the lighting industry and of not requiring outside operating funds. Such systems have already been proposed for buildings and legislated for automobiles (State of Maryland, 1992). Energy labeling or rating systems can assist in the implementation of feebate systems.

Mandatory Efficiency Renovation at Time of Resale - The lost opportunity represented by a building constructed with an inefficient lighting system can be partially addressed by requiring that lighting efficiency be improved at the time when a building is resold, renovated, or refinanced. Criteria can be set so that the required improvements will not pose a financial hardship to the concerned parties (e.g. limited to one percent of the building's cost). Such mechanisms have been implemented at the city scale as Residential Energy Conservation Ordinances (RECOs) in Berkeley, California and other cities. San Francisco, California has implemented a Commercial Energy Conservation Ordinance (CECO) for non-residential buildings and Berkeley is about to implement one. These existing ordinances address lighting along with other energy end uses.

Raising Electricity Prices - Price increases (via taxes of one form or another) would, in principle, encourage increased efficiency investment for lighting and other end uses. While prices are set at the state level, federal energy taxes could affect them. The prospective demand responses to this policy are complex and have not been analyzed in depth. Note that the No-Programs Baseline reflects an eleven-percent increase in real electricity prices, yet results in virtually no efficiency improvements.

\section{Analytic and Research Needs}

Following is a list of areas in which future analyses can play an important role in advancing the ability to achieve lighting energy savings and in designing and implementing relevant policies and programs:

- Analysis of potential savings from efficient industrial and outdoor commercial lighting

- Analysis of buildings standards exceeding ASHRAE/RES

- Clarification of the influence of commercial and residential HVAC interactions, especially the net effect across the entire building stock

- Understanding of the relationship between efficiency choice (by customer type) and electricity prices

- Prediction of future equipment prices as a function of sales levels 
- Development and continual update of supply curves of conserved energy for lighting

- Understanding of the extent and determinants of code compliance in locations where building standards (mandatory or voluntary) are already in place

- Parametric analyses of policies to identify sensitivity of savings estimates to penetration rates, time dynamics, equipment prices, etc.

- Identification of the effect of incentive type, size, and delivery mechanism on program participation/penetration rates

Technology and design-tool development (see Section 10) represents another opportunity for future lighting energy savings. New horizons in lamp technology include radio-frequency lamps, mercury-free HID lamps, longer-lived phosphors, and scotopically-enriched light sources for improved visual performance and energy efficiency. Improving the thermal efficiency of fluorescent fixtures (compact and full-size) offers further savings opportunities. Daylighting options and issues warranting further R\&D include new glazing and shading systems, new lighting control technologies and their associated sensors, integrated envelope and lighting technologies, and improved lighting design tools.

\section{CONCLUSIONS}

The major conclusions of this study are:

1. The transition from older technologies to more energy-efficient designs is already underway, spurred by electronics advances, market forces, state building codes, utility programs, and federal programs. The future rate of efficiency improvement in the marketplace is uncertain. The degree to which current trends will capture the technical potential depends upon the magnitude and duration of electric utilities' and governmental commitment to promote (and subsidize) efficient lighting systems and on the response of lighting equipment manufacturers.

2. Savings projections are critically dependent on forecasts of prices of efficient products. Two baselines are modeled to account for this uncertainty. In the short run, prices of more efficient lighting equipment are expected to decline, partly because of existing utility subsidies and increased production volume. The extent to which these price decreases will persist in the long run is unknown.

3. All federal policies analyzed save energy, reduce electric peak demand, and reduce emissions of $\mathrm{CO}_{2}, \mathrm{SO}_{2}$, and $\mathrm{NO}_{x}$ from electric power plants, and most save money. In some cases, these prospective benefits are substantially greater than those anticipated from current market forces and the standards contained within the Energy Policy Act of 1992. 
4. The federal policy alternatives are qualitatively different (Table ii) and not mutually exclusive. Important differences include issues of equity, certainty of savings, and relative administrative burden.

5. Many research and development needs exist. Concerted efforts in this area will help to commercialize improvements in existing technologies in the near term and to introduce fundamental innovations, with corresponding additional energy savings potential, in the longer term. Opportunities also exist for parallel efforts in modeling and analyzing lighting policies. 


\section{INTRODUCTION}

\subsection{WHY ENERGY-EFFICIENT LIGHTING?}

The electric utility industry was born with the light bulb. Lighting has become an important electricity end use in every sector and building type. In his day, Thomas Edison saw energy efficiency as a key to the competitiveness and profitability of electric utilities. Today economic, political, and environmental realities are prompting utilities and energy planners to revisit Edison's ideas.

There are many compelling reasons to pursue energy-efficient lighting. From economic and business perspectives, investments in efficient lighting offer fast payback times and opportunities to build markets for new products as well as avoid costly electric power plants. From an environmental standpoint, reduced electricity demand means fewer emissions of greenhouse gases and other pollutants. From a national security perspective, energy-efficient lighting can serve as a means for increasing energy independence and reducing various risks associated with electric power systems.

The world of energy-efficient lighting is broad and complex.' A unifying axiom is that illumination is a service that is essential to allow people to perform visual tasks, to create aesthetically pleasing visual environments, to provide safety, and to enhance productivity and many other aspects of daily life. From this perspective, it follows that the amount of electricity (and the cost) required to provide illumination is highly dependent on the efficiency of lighting system design and operation. Related to implementing energy-efficient lighting are architectural factors, cost considerations, occupant responses, effects on non-lighting building equipment and systems, effects on the power supply system and associated power plant emissions, and strategies for maximizing the penetration of market acceptance and efficient technologies.

The potential for lighting efficiency improvements is substantial. In many cases, more than twice as much electricity is used than is needed to provide sufficient illumination. Numerous field studies confirm that cost-effective energy savings can be achieved by applying a combination of efficient lighting technologies with more effective lighting controls, and by integrating lighting system efficiency considerations into the process of architectural design. However, the obstacles to achieving increased efficiency also are substantial, stemming mostly from market barriers such as inadequate information, lack of capital and financing, and scarcity of efficient products. Fortunately, these barriers can generally be addressed by policy responses.

\footnotetext{
' For a recent review of energy-efficient lighting technologies and implementation strategies, see the Special Issue of Energy-The International Journal devoted to the subject (E. Mills, ed.), Pergamon Press, forthcoming 1993.
} 


\subsection{PURPOSE AND SCOPE OF THIS STUDY}

The U.S. Department of Energy (DOE) requested that the Lawrence Berkeley Laboratory analyze the potential effects of promoting energy efficiency in lighting through new federal policies, including lighting standards, incentives, and information programs. The Department's Office of Codes and Standards (in the Office of Conservation and Renewable Energy) sponsored the study. An important aspect of the investigation has been to explore likely trends in lighting energy use in the absence of new policies. This exploration has been approached by identifying two likely levels of lighting efficiency promotion, and a "No Programs" Baseline in which only electricity prices drive the demand for efficient lighting.

In 1990, lighting was responsible for $515 \mathrm{TWh}^{2}$ (or 5.9 primary quads) of electricity use in the U.S. (\$36 billion), excluding interactions with heating and cooling energy use (Fig. 1.1). ${ }^{3}$ This study was limited to the commercial and residential sectors and to the end-use technologies and applications (indoor and/or outdoor) depicted in Table 1.1 (69 percent of total lighting energy use and 74 percent of the cost).

Figure 1.1 U.S. Lighting Electricity (515 TWh), 1990

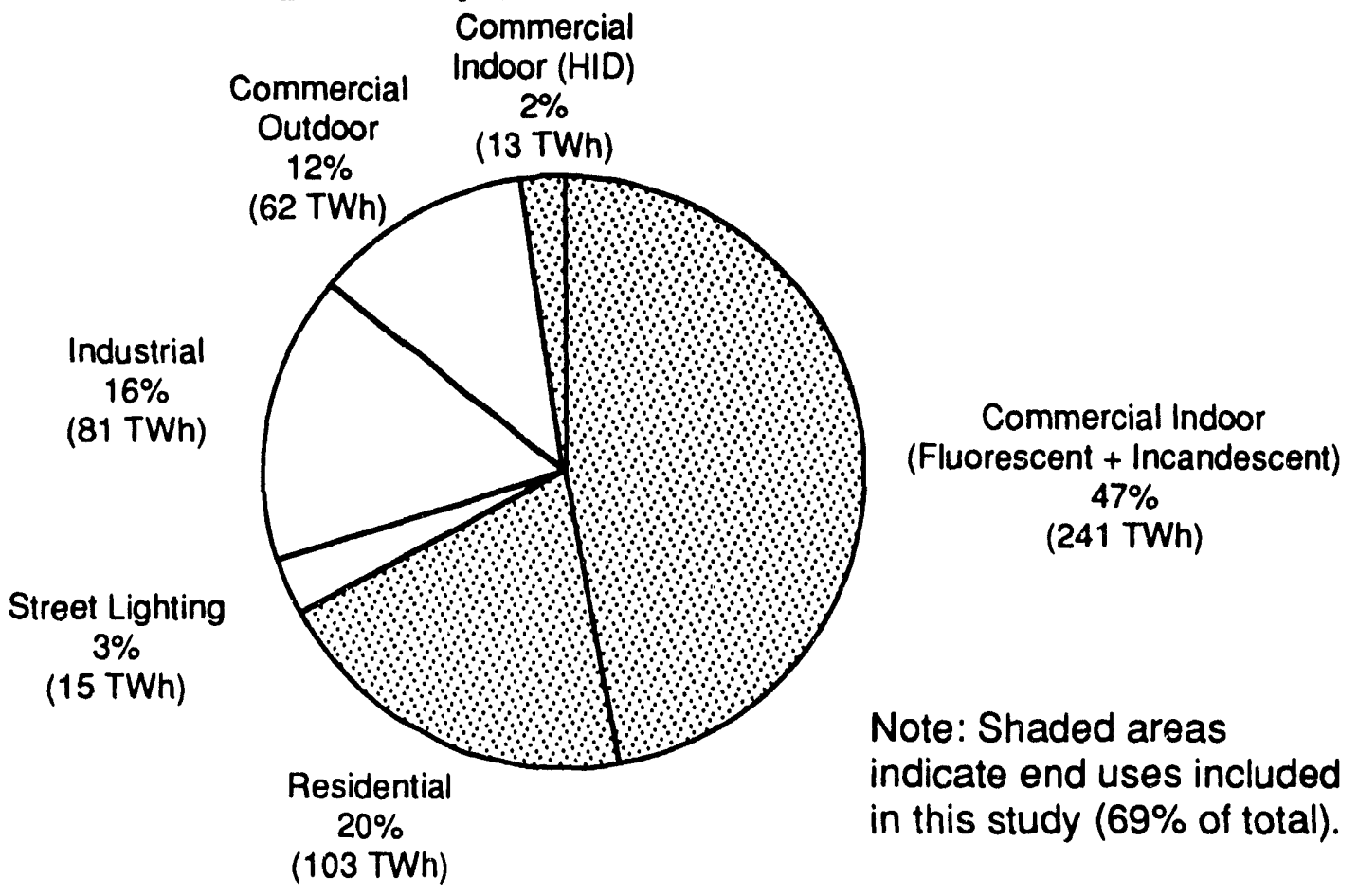

\footnotetext{
${ }^{2}$ One TWh (terawatt-hour) equals $10^{12}$ watt-hours and one Quad equals $10^{15}$ Btus; one Quad of primary energy = 87 TWh of electricity, based on a typical heat rate of $11,500 \mathrm{Btus} / \mathrm{KWh}$, measured at the point of final end use. In converting between site electricity ("at the meter") and primary energy input at the power plant, a thermal efficiency of 32 percent and a transmission and distribution loss of 7.5 percent are assumed.
}

${ }^{3}$ US DOE Energy Information Administration (EIA). 1991. Annual Energy Outlook Sectoral Electricity Consumption. DOE/EIA 0383(91), Washington, DC; EPRI, unpublished data, 1991. 
Table 1.1 Scope of Lighting Technology Options and Sectors Analyzed

\begin{tabular}{|c|c|c|c|c|c|}
\hline \multirow[b]{2}{*}{$\begin{array}{l}\text { Sector or } \\
\text { Application }\end{array}$} & \multicolumn{3}{|c|}{ LAMPS } & \multirow[b]{2}{*}{ Fixtures } & \multirow[b]{2}{*}{ Controls } \\
\hline & Fluorescent & Incandescent & $\begin{array}{l}\text { High Intensity } \\
\text { Discharge }\end{array}$ & & \\
\hline \multicolumn{6}{|l|}{ Residential } \\
\hline Interior & $\cdots$ & $r$ & -- & $\cdots$ & --. \\
\hline Exterior & $\cdots$ & $\sqrt{ }$ & $\cdots$ & $\cdots$ & $\cdots$ \\
\hline \multicolumn{6}{|l|}{ Commercial } \\
\hline Interior & $\checkmark$ & $\checkmark$ & -- & $\sqrt{ }$ & $\checkmark$ \\
\hline Exterior & $\cdots$ & $\cdots$ & -- & $--\cdot$ & $\cdots$ \\
\hline Industrial & $\cdots$ & $-\cdots$ & --- & $\cdots$ & $\cdots$ \\
\hline Street Lighting & $\cdots$ & -- & -- & $\cdots$ & $\cdots$ \\
\hline
\end{tabular}

\subsection{STRUCTURE OF THE REPORT}

This report consists of a synopsis, an executive summary, ten sections, and eight appendices covering the following topics:

\section{Section 1. Introduction}

Section 2. Analytic Approach presents LBL's overall approach to analyzing lighting efficiency policies, summarizes the methodology used in the engineering/economic analyses, and presents the method used to forecast lighting energy dernand. The section on Lighting Efficiency Policies describes the policies that are modeled, specific assumptions, and the U.S. experience in each area.

Section 3. Engineering Analysis discusses the details of the engineering analysis of fluorescent lamp standards, incandescent lamp standards, fixture standards, and controls.

Section 4. Commercial Sector Forecasts presents the development of input to the commercialsector model COMMEND for all commercial lighting policy options. Development of base-case forecasts is explained, and the methodology for determining EUIs (Energy Use Indices) for each policy is elaborated. Results of the COMMEND forecasting model of projected savings from all policies are summarized and discussed.

Section 5. Residential Sector Forecasts presents the method used to estimate the energy consumption, costs, and lifetimes for the base-case residential lighting forecast and the policy 
options; and results of the forecasting model (LBL-REM) for the residential policy options, including unit energy consumption, annual and cumulative energy consumption for lighting, and economic analysis.

Section 6. Impacts of Policies on Manufacture,'s discusses the market for lighting components and the likely impact of proposed design options on lighting equipment manufacturers.

Section 7. Impacts of Policies on Electric Peak Demand estimates peak-load savings from commercial and residential lighting policy options.

Section 8. Environmental Impacts calculates $\mathrm{SO}_{2}, \mathrm{NO}_{\mathbf{x}}$, and $\mathrm{CO}_{2}$ emissions associated with the various baselines and policy scenarios.

Section 9. Comparison with Other Estimates of Lighting Energy Savings compares the analysis with that of other forecasts, and describes analysis and features that may cause different results from other lighting savings potential estimates.

Section 10. Research and Development Needs briefly discusses emerging technologies for improving the effic:ency of lighting systems. New frontiers in lamp and fixture design are described along with daylighting technologies and design issues.

Appendix A. Lighting Technology describes the design and operating characteristics of energyefficient lamps and future components used in the policy analysis.

Appendix B. Engineering Analysis Tables presents the efficiencies, efficacies, and costs associated with lamp design options, payback periods, total life-cycle cost, cost of conserved energy calculations, and life-cycle costs curves for lamps.

Appendix C. Calculation of National Average Lighting Power Densities contains the methodology for adjusting the Baselines to include the persistent effects of existing state building codes.

Appendix D. Lighting Technology Spreadsheets for the Commercial Sector contains the spreadsheets used to develop the commercial end-use forecasts described in Section 4.

Appendix E. The Demand Furecasting Models has two sections. First is a general description of EPRI's COMMEND 3.2 forecasting model for the commercial sector. (Details on model calibration and use for this analysis are found in Section 2.1.2). The second section contains a general description of the LBL Residential Energy Model (LBL-REM).

Appendix F. Commercial Sector Policy Analysis Results contains detailed figures and tables presenting 5-year COMMEND forecast results.

Appendix G. Existing Building Energy Codes Addressing Lighting describes the lighting features 
of the major model building energy codes and detaiis the performance and component standards in effect in various U.S. states. The experience with code compliance is summarized in this Appendix.

Appendix H. Lighting Interactions Between Heating, Ventilating, and Air-Conditioning Energy Use discusses the analytical complexities of determining the net effect of lighting on annual HVAC energy use. Illustrative calculations are given for the commercial and residential sectors. 
This section briefly describes the approach used to analyze lighting efficiency policies. Section 2.1 presents an overview of the major components of the analysis: Engineering Analysis, Commercial Forecasting Models, and Residential Forecasting Models. The models predict consumer response to market economic trends, including those induced by the policies between a base year and the year 2030. Section 2.2 describes the policy cases that are modeled.

Figure 2.1 illustrates the energy and economic analysis methodology for the commercial sector. The analytical approaches to evaluating impacts of policies on lighting manufacturers, electric peak demand, and emissions are described in Sections 6, 7, and 8, respectively.

\subsection{IMPACT MODELS, DATA, AND ASSUMPTIONS}

\subsubsection{Engineering Analysis}

Figures 2.2 and 2.3 identify the broad categories of policies analyzed. These policies are linked to lighting product classes and to specific policy cases. The technology options (or groups of technologies) used in constructing the policy cases are detailed in Tables 3.6, 3.8, and 3.10.

The Engineering Analysis provides information on efficiencies or efficacies ${ }^{1}$ of lighting products, user or retail costs, and performance characteristics for input to the consumer impact models.

Product classes are subsets of general product types (such as fluorescent or incandescent lamps); each class is made up of products that provide similar utility to the user. For example, the product class of four-foot fluorescent lamps is a subset of fluorescent lamps. The Engineering Analysis develops cost and efficiency data for a set of design options within each product class. This analysis is performed in the following steps: (1) selection of product classes; (2) selection of baseline units; (3) selection of technology options within each product class; (4) determination of maximum-technologically-feasible and research and development technologies; (5) development of cost estimates; (6) development of price/efficiency relationships, e.g., simple payback, life-cycle cost, and cost-of-conserved energy calculations.

The baseline lighting technology is the starting point for analyzing technology options that improve energy efficiency. For lamps, the baseline represents the standard, generally least

\footnotetext{
'Efficiency is defined as the ratio of one performance level of a product to a base or reference performance level of that same product; it is expressed as a percentage and is dimensionless. Luminaire efficiency, for example, is the ratio of light output from a lamp/ballast combination in a particular fixture to that from the same equipment combination in open air without a fixture. Efficacy is expressed as a ratio of light output to input wattage, and is measured in lumens/watt. For simplicity, "efficiency" is used in this section, while in other sections the terms are used with their precise meaning.
} 


\section{Figure 2.1}

\section{Methodology for Lighting Policy Energy and Economic Analysis}

\section{Energy}

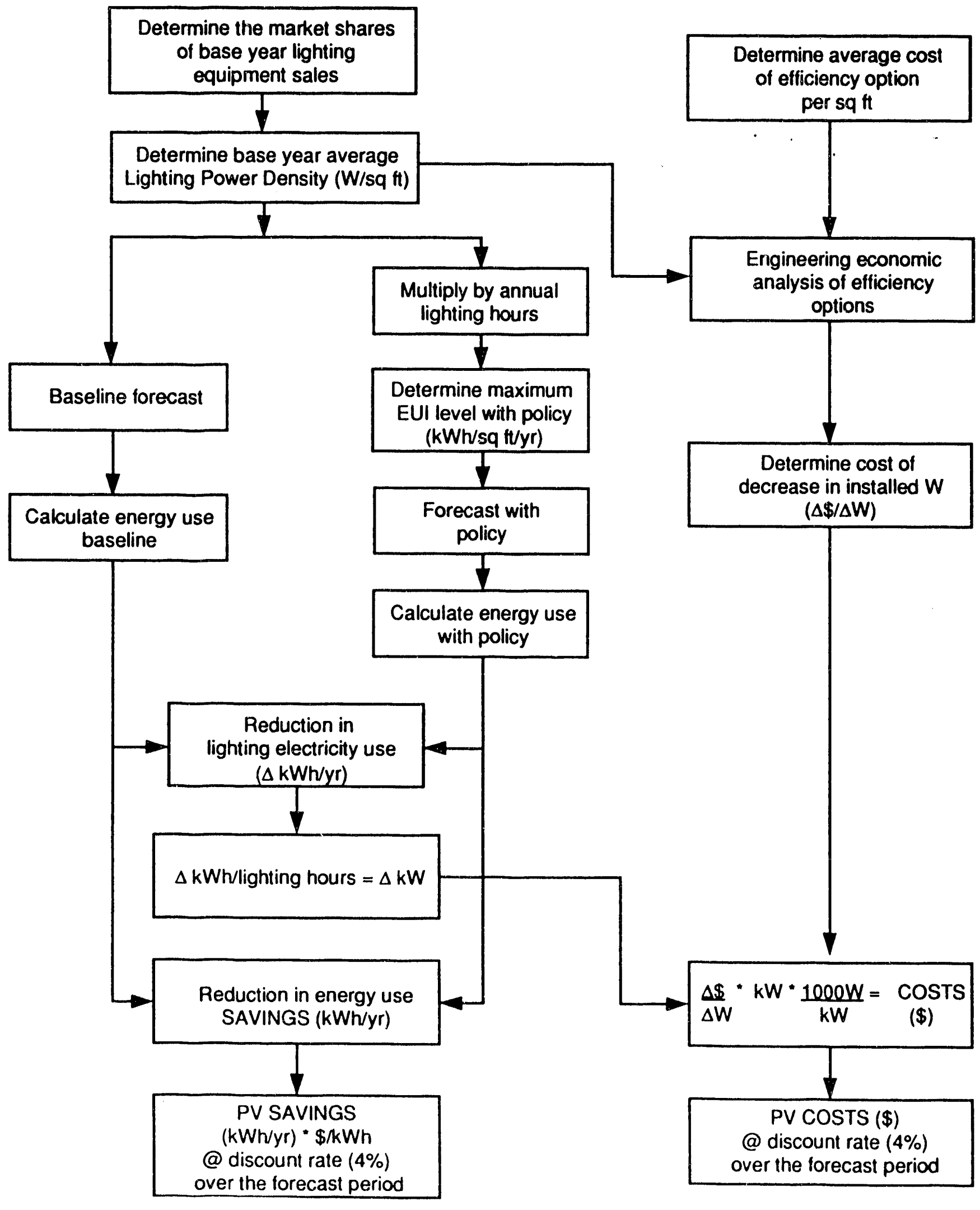

Economics

termine average cost

sq $\mathrm{ft}$

Engineering economic of efficiency

Determine cost of $\Delta \$ / \Delta W)$ 


\section{Policies and Technologies Included in Commercial Sector Analysis}

\begin{tabular}{l} 
Policy \\
$\begin{array}{l}\text { Mandatory Component } \\
\text { Standards }\end{array}$ \\
\hline
\end{tabular}

Voluntary Component Standards

System Performance
Standards
(Building Codes)

\section{Federal} Incentives

Education/ Information

\section{Product Class}

Fluorescent Lamps $\begin{aligned} & \text { Eliminate Highest Wattage } \\ & \text { (Energy Policy Act, 1992 - FI Lamps) } \\ & \text { Minimum LCC Lamp } \\ & \text { Maximum Technology } \\ & \text { Mesearch \& Development } \\ & \text { Minimum LCC Lamp/Ballast }\end{aligned}$
Eliminate Highest Wattage Minimum LCC
Incandescent Lamps $\quad$\begin{tabular}{l} 
Maximum Technology \\
\cline { 2 - 2 }
\end{tabular} CFL Downlights 1991 Proposed Lamp Standards (Inc Lamps) Energy Policy Act, 1992 (Inc Lamps)

Fixtures - Luminaire Efficiency Standard Controls $\quad\left[\begin{array}{l}\text { Timers }(T) \\ T+\text { Lumen Maintenance (LM) } \\ T+L M+\text { Occupancy Sensors }\end{array}\right.$ Fluorescent \&
Incandescent Lamp
Combinations $\quad \begin{aligned} & 1991 \text { Proposed Standards (F\&I Lamps) } \\ & \text { Energy Policy Act, } 1992 \text { (F\&I Lamps) } \\ & \text { Minimum LCC FI \& Inc Lamps } \\ & \text { Minimum LCC FI L/B \& Inc Lamps }\end{aligned}$ Lamp/Ballast/
Fixture/Controls
Combinations FI \& Inc Lamp Combinations, L/B/F/C Comb.

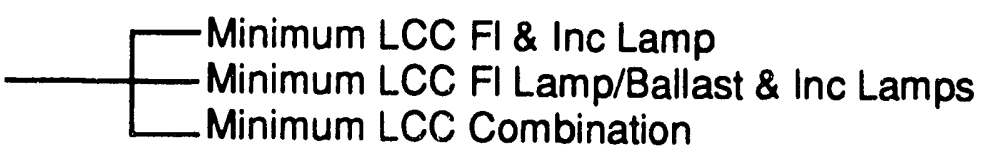

N/A ASHRAE/IES 90.1 Partial Compliance DOE - 1993 Partial Compliance ASHRAE/IES 90.1 Full Compliance DOE - 1993 Full Compliance

N/A Consumer Rebates Consumer Tax Credits

N/A
Consumer/Designer Education \& Component Labeling 


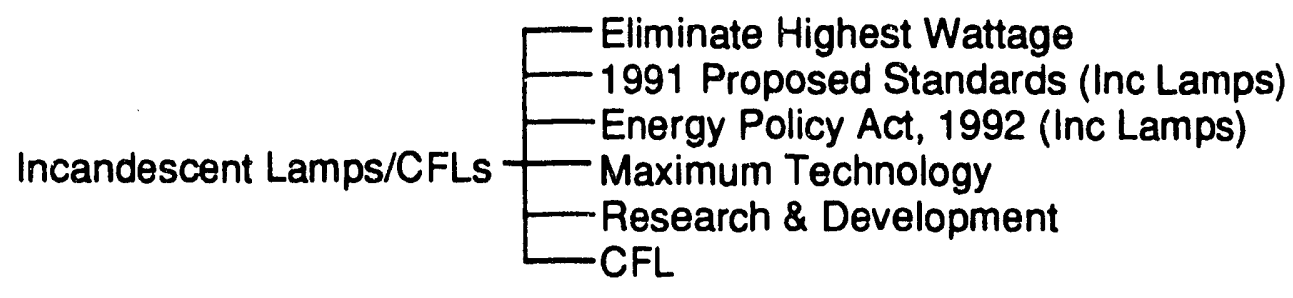

Fluorescent Lamps — Eliminate Highest Wattage.

Incandescent Lamps/CFLs Combinations 
efficient, and least-cost product on the market for each product class. For fixtures, the baseline represents the "average" technology within each fixture type or product class without special design features. The efficiency improvements and costs of technology options relative to the baseline are calculated. The Engineering Analysis uses information from manufacturer catalogs, consultants, and the Lighting Systems Research Group to select the baseline units.

Technology Options: The Engineering Analysis identifies technology options with the potential to improve energy efficiency. Alternative options analyzed include currently available technologies and more efficient prototypes. Energy consumption, efficiencies, and costs of alternative options are compared with those of the baseline technologies in each product class.

Maximum Technologically Feasible Designs: These are emerging technology options identified as the most efficient products in the prototype stage that can be commercialized by 1995 . In some cases, these are specified designs, and in others they simply represent an efficiency target that manufacturers expect to be able to meet within five years.

Research and Development: Another set of technology options now in the research and development stage are chosen as likely to enter the market by the year 2000 . These designs represent the next technologies to be commercialized after the maximum technologically feasible designs above.

Cost Estimates: Cost data represent prices and replacement labor costs of various technology options to the commercial or residential consumer. Cost estimates are developed based on manufacturers' suggested price lists, distributors' catalogs, and utility and consumer price surveys (see Appendix B).

Cost- and Price-Efficiency Relationships: In the engineering tables, designs are ordered according to simple payback period. Total life-cycle cost and cost of conserved energy are also calculated. LCC is used in selection of the minimum LCC technology option.

\section{Economic Perspective}

Economic analysis of energy-efficiency improvements can reflect several perspectives, e.g., those of the energy user, utility, or society as a whole. For policy making, it is important to consider a societal perspective in which the sum of costs to all parties is evaluated and compared to the costs of lighting systems used in the absence of the new policies.

To the extent possible, a societal perspective is used in this analysis. Total costs include energy costs, direct capital costs, and associated labor costs for installing lighting equipment. Societal costs exclude sales taxes (which are an income transfer rather than a true cost). The administrative costs of implementing the various policies are not estimated. Indirect costs for utility programs-generally more expensive per unit of energy saved than federal 
policies-represent up to 10 to 15 percent of direct costs. ${ }^{2}$ Indirect costs are not included in the policy cost estimates of this report.

For utility programs, the assumed "rebate" level averages the equivalent of 3.5 to 4 cents/kWh saved, which should approximate the total societal cost. In practice, this cost will be allocated in some fashion between the utility and the consumer. Financial impacts on utilities are the product of program costs and lost net revenues resulting from lower electricity sales. U.S. utilities do not currently account for such factors in a uniform way, but there is a general policy trend toward allowing such costs to be passed on to ratepayers through higher electricity rates. Ratepayers who install energy-efficient components generally recover these costs by reducing electricity consumption.

Societal economic assessments typically employ lower discount rates than those implicit in consumer decision-making. In the engineering and the economic analysis in this report, a real discount rate of 4 percent is used for the commercial sector. For the engineering analyses, sensitivity analyses are performed at 1 and 7 percent. A real discount rate of 6 percent is used for the residential sector with engineering sensitivity analyses at 2 and 10 percent. Commercial and residential sensitivity analyses are summarized in Tables B.1 through B.19 in Appendix B.

In the commercial sector forecasting model, higher "consumer" discount rates are used because the discount rate in this context represents actual consumer decision-making and efficiency choices in the absence of federal policies. For the residential sector end-use model, the consumer discount rate is zero. While this is surely inaccurate, there is not enough information on consumer behavior in purchasing lighting equipment to select an appropriate discount rate.

\section{Data Sources}

Lighting product shipment data are based on information from the Bureau of Census (1982-1989) and from a survey performed by the Lighting Research Institute. ${ }^{3}$ Equipment efficiencies are based on manufacturers' catalogs and CEC's Advanced Lighting Guidelines estimates of lamp/ballast performance in fixtures (see Section 3.23 for thermal effects of system performance). Installation times and costs are drawn from Means Electrical Cost Data, 1992 (Means); interNational Association of Lighting Management Companies (NALMCO)'; Lee Saylor, Inc. Current Construction Costs, 1990 (Lee Saylor); and Engineered Performance Standards, Public

\footnotetext{
${ }^{2}$ S. M. Nadel, B. A. Atkinson, J. E. McMahon. 1993. "A Review of US and Canadian Lighting Programs for the Residential, Commercial, and Industrial Sectors," Energy-The International Journal (forthooming).

'Lighting Research Institute (LRI) and Plexus Research, Inc. 1991. Survey and Forecast of Marketplace Supply and Demand for Energy-Efficient Lighting Products. Phase I Report. EPRI, Palo Alto, CA.

“California Energy Commission. 1992. 1992 Advanced Lighting Technologies Application Guidelines. Sacramento CA. October 1992 Draft.

'Charles Occhino, NALMCO. Personal communication, September 1992.
}

$$
2-6
$$


Works Maintenance, "Electric, Electronic" volume of the NAVDOCS series (NAVDOCS). Existing saturations of lighting equipment are taken from NBECS (1986) for the commercial sector and from utility residential appliance saturation surveys and compact fluorescent potential studies for the residential sector.

\section{Data Development}

In the commercial sector, data from the above sources are used to calculate payback periods, total life-cycle costs, and costs of conserved energy for three discount rates. Data for the commercial sector are presented in Appendix B in two forms. In the first, actual wattages and costs are used to calculate equipment and operating costs for each technology option. The second form "normalizes" these costs, by manufacturers' rated initial lumen output of a given lamp, to the equivalent lumen output of the baseline lamp. This normalization ensures that energy use, equipment, and installation costs are compared equally for equipment producing the same light output. It is thus assumed that, on average, the number of lamps/ballasts/fixtures installed in new construction or renovation would slightly increase or decrease to provide the same utility as the baseline lamp in the replaced system. This assumption is conservative because it implies that no overlighting is present in the existing buildings. The one exception is incandescent reflector lamps, whose options are not normalized because lumen output data are not available for many reflector lamps. Normalized data are used in this consumer analysis forecast in order to compare alternative lamp/ballast systems used in new or renovated buildings. (The one exceptional policy case is explained in Section 3.2.4, Normalization by Lumen Output.)

For the residential sector, data from the sources above are used in LBL's Residential Lighting Energy Use Spreadsheets to yield average unit energy consumption (UEC in $\mathrm{kWh}$ per householdyear), costs, and lifetimes for the various technology options. For this sector, actual costs rather than normalized costs are used. Here, the assumption is that slightly reduced or slightly increased light output from the baseline technology would on average not be compensated for by using more or fewer light sources.

\subsubsection{Commercial Sector and EPRI COMMEND Model}

COMMEND is a commercial end-use forecasting model supported by The Electric Power Research Institute (EPRI). COMMEND forecasts energy consumption by end use and building type. The model includes eleven building types, ten end uses and three fuel types. Model Version 3.2 is the most up-to-date edition currently available, and is used exclusively in this analysis. (Version 4.0 is currently in the development phase and will be available in 1993.) See Appendix $\mathrm{E}$ for a general description of COMMEND.

Forecast energy prices and floorspace are exogenous inputs to COMMEND, which models fuel switching and the selection of equipment based on life-cycle-cost criteria. Decision-makers fall into four groups with different discount rates. Short-run price elasticities for utilization of energy services are used. Interactions between lighting and space-conditioning energy use are also handled within the model but, because of uncertainties, results are reported only in Appendix $\mathbf{H}$. 


\section{Representation of Technologies}

In COMMEND, technology options are represented on a technology trade-off curve that graphs efficiency choice as a function of equipment cost (see Figure 2.4). Technology trade-off curves are defined for at least one equipment market for each energy end use. A trade-off curve for each particular building type is defined by the base year equipment cost level, average EUI (kWh/sq ft-year), and an elasticity representing the cost-efficiency relationship.

Several equipment components make up the lighting end use: lamps, ballasts, fixtures, and controls. With COMMEND's present structure, it is not possible to represent the actual technology options for lighting directly. Instead, technology options have to be mapped onto the technology trade-off curves for the single lighting end use by analysis performed outside COMMEND. In this study lighting component spreadsheets are used to derive lighting power densities (in watts/square foot) for each building type based on the energy characteristics and penetrations of the different technologies, and these LPDs are then converted to EUIs using annual lighting hours developed from EIA data (see Section 4.1 and Appendix D).

\section{Turnover of Lighting Equipment}

COMMEND defines only one tradeoff curve for the lighting end use. Note that individual component efficiencies and costs are not specified in the sample tradeoff curve in Figure 4.4. This single lifetime introduces complications, since lamps have to be replaced much more frequently than ballasts and fixtures. (Discrete lighting component representation will be a feature of Version 4.0).

A lighting equipment lifetime of 12 years is used in this analysis, with lamp costs increased to represent the actual lifetime of lamps for the economic analysis. Twelve years corresponds well with the rated lifetime of ballasts at average annual lighting hours. ${ }^{6}$ It also approximates the fixture tumover rate in renovated buildings, somewhat underestimating the average value of 15 years. Although the more rapid tumover of lamps is compensated for in equipment costs, energy savings occur over the 12-year lifetime, rather than over the shorter 3- to 4-year lamp service life.

\footnotetext{
'Actual ballast lifetimes in the field may be 7 to 8 years (personal communication, Charles Occhino, NALMCO, September 1992).

${ }^{7}$ Four-foot fluorescent lamps are replaced every 3.4 to 4.1 years $[20,000$ hours rated lifetime $\times 0.70$ or $0.75 / 4,103$ annual lighting hours], or 3.5 times during the 12-year ballast/fixture lifetime. Eight-foot fluorescent lamps have a 12,000 hour rated lifetime and are replaced every 2.1 years. In the case of modular lamps, CFLs ballasts are replaced 1.5 times during the 12 years $[9,000$ hours rated lifetime $\times 0.70 / 4,270$ anual lighting hours for incandescent sockets]. Fluorescent lamps are assumed to be replaced in "group relamping" when maintenance personnel replace all the lamps in an area at once before they are expected to fail. "Spot relamping," in which lamps are replaced one at a time after they fail, has higher labor costs and is less convenient for the building occupants. Lamps are generally replaced at 70 to 75 percent of their rated lifetimes.
} 
Figure 2.4 Technology Tradeoff Curve

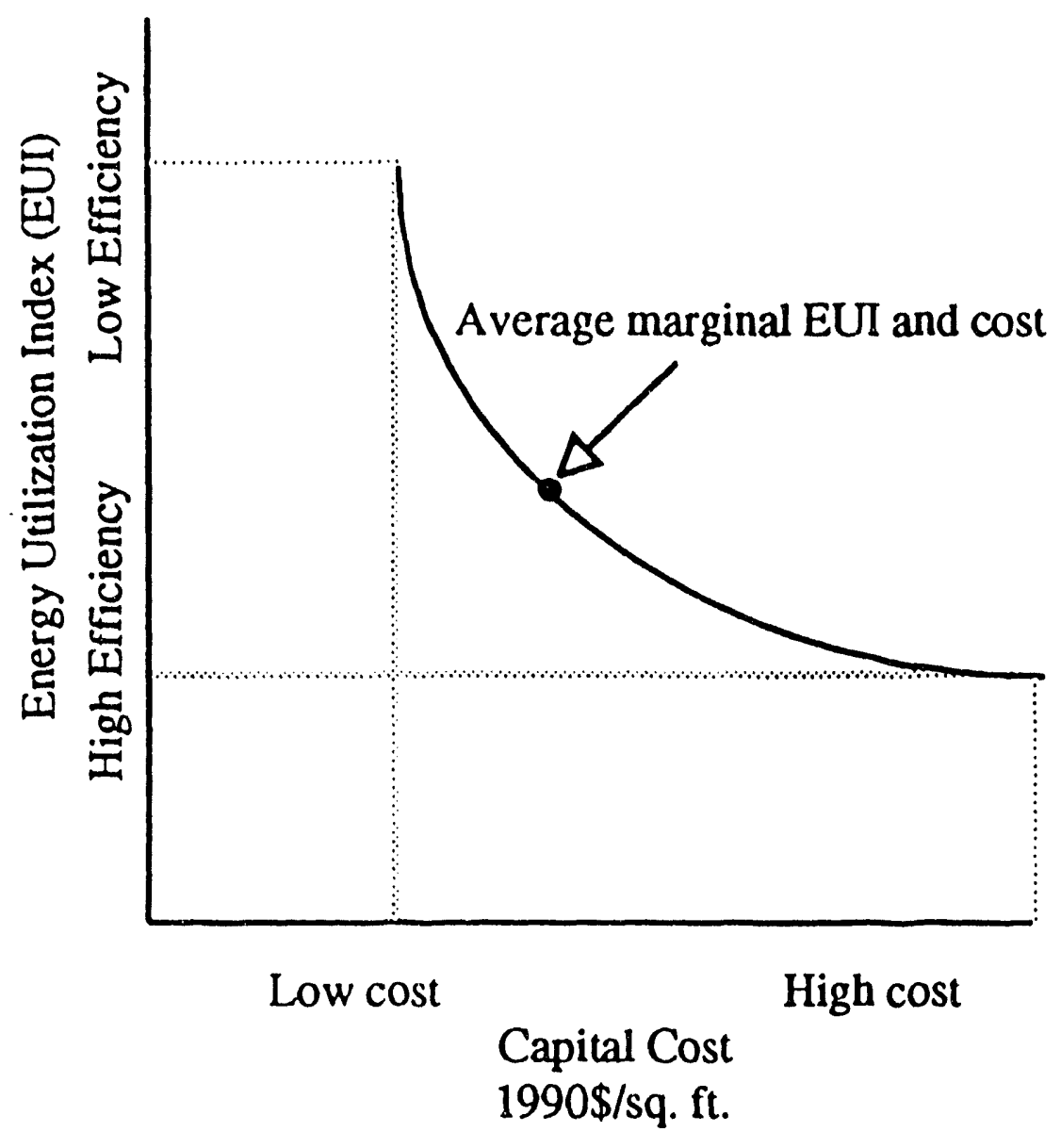




\section{Annual Operating Hours}

To represent hours per year that commercial sector lighting equipment is operating for each building type, EIA's "effective lighting hours" ${ }^{\text {"8 }}$ are used. Effective lighting hours are derived from NBECS 1986 and include hours the building is operating plus hours during which the floorspace is lit outside of normal operating hours. Effective lighting hours more accurately represent lighting operating schedules than do building operating hours. However, the NBECS survey questions do not provide supporting details and lighting hours may be overestimated. Calculation of effective lighting hours assumes lighting equipment is on during all building operating hours, while in reality some lights may be turned off during these hours. Also, floorspace classified as lit during off-hours is considered lit during all of those hours, while lights may be operating for less than the entire period. Also, the NBECS survey does not specify the reasons that lights are on during off-hours (e.g. people working, negligence, cleaning, security).

Despite these limitations, effective lighting hours are considered the most accurate national representation of lighting operating hours. Little possible error is introduced into the analysis. Commercial lighting energy consumption calculations are based on EUIs, which are derived from conditional end-use analyses by building type as described in Section 4.1. LPDs are derived from these EUIs using annual lighting operating hours for each building type, so that LPDs are lower than those derived using building operating hours. The analysis adjusts EUIs by applying the LPD percentage change resulting from a policy as described in Section 4.1. Thus the choice of operating hours introduces negligible differences in the final EUI inputs to COMMEND. Savings from controls are also calculated using percentage change in LPDs, so the sensitivity of this calculation to operating hours is also small. The most serious potential error is in the building codes cases, where absolute LPDs are important are important (see Sections 4.4 and 2.2).

8 DOE/EIA. 1992. Lighting in Commercial Buildings. Energy Information Administration, Washington, D.C. DOE/EIA-0555(92)/1. 


\section{Energy Prices}

Figure 2.5 shows the commercial and residential energy price forecasts used in this analysis. 9.10 Real commercial prices are in constant 1990 dollars. Prices prior to 1990 are taken from the MER." Price forecasts are taken from AEO 1991, ${ }^{12}$ extrapolated to 2030. The deflator values for the years 1973-1990 are taken from the MER. For the years 1991-2030 the deflators are calculated based on the trend given by the input files supplied with the COMMEND model. The commercial electricity price is $\$ 0.0813$ per $\mathbf{k W h}(\$ 1990)$ in the year 2030 . The projected residential electricity price is $\$ 0.0915$ per $\mathrm{kWh}(\$ 1990)$.

\section{Floorspace Data}

Table 2.1 and Figure 2.6 show the forecasted total U.S. commercial sector floorspace (including federal buildings) used in this analysis. This is based on data developed by Pacific Northwest Laboratory ${ }^{13}$ and is compared to other floorspace forecasts. Floorspace growth drives the overall growth in demand for energy services in the COMMEND model.

Table 2.1 Commercial Floorspace (Billion sq $\mathrm{ft}$ )

\begin{tabular}{lccccccccc}
\hline & 1990 & 1995 & 2000 & 2005 & 2010 & 2015 & 2020 & 2025 & 2030 \\
\cline { 2 - 8 } AEO '91 & 64.3 & 70.4 & 77.0 & 83.9 & 91.0 &.- & $\ldots$ &.. &.. \\
LBL-PNL & 64.0 & 69.3 & 75.3 & 82.1 & 89.6 & 98.0 & 107.1 & 117.1 & 128.0 \\
NES & 64.3 & 69.4 & 79.5 & 89.2 & 98.1 & 106.7 & 115.3 & 123.5 & 131.6 \\
\hline
\end{tabular}

\footnotetext{
Non-electric energy prices are important here because they affect the choice of heating energy in COMMEND forecasts, which ultimately influences the estimates of HVAC interactions reported in Appendix H.

${ }^{10}$ For natural gas prices beyond 2010, the price trajectory from the National Energy Strategy (NES) is used, scaled to the AEO 1992 price in 2010. This price path is based on output from the FOSSIL2 partial equilibrium model, and incorporates information about the supply/demand balance for natural gas not accounted for by a simple extrapolation. Growth in natural gas prices is expected to diminish after 2015, according to the NES prediction.
}

"EIA Monthly Energy Review (MER), May 1991.

${ }^{12}$ EIA Annual Energy Outlook (AEO) 1991.

${ }^{13}$ David Belzer, Pacific Northwest Laboratory, Richland, WA. Personal communication, July 1991. 
Figure 2.5

Electricity Price Projections

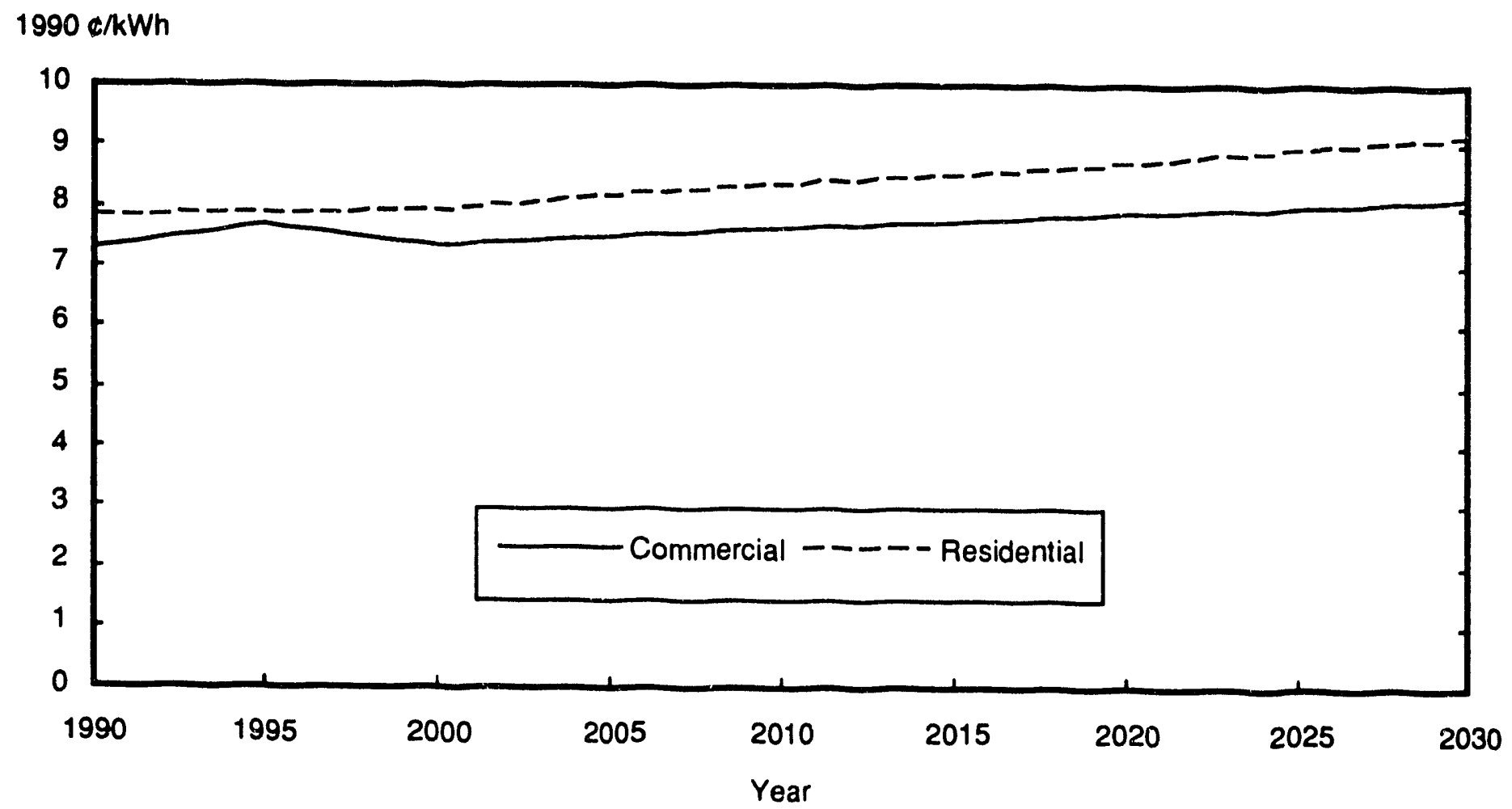

Figure 2.6

Billion sq.tt.

Commercial Sector Floor Space

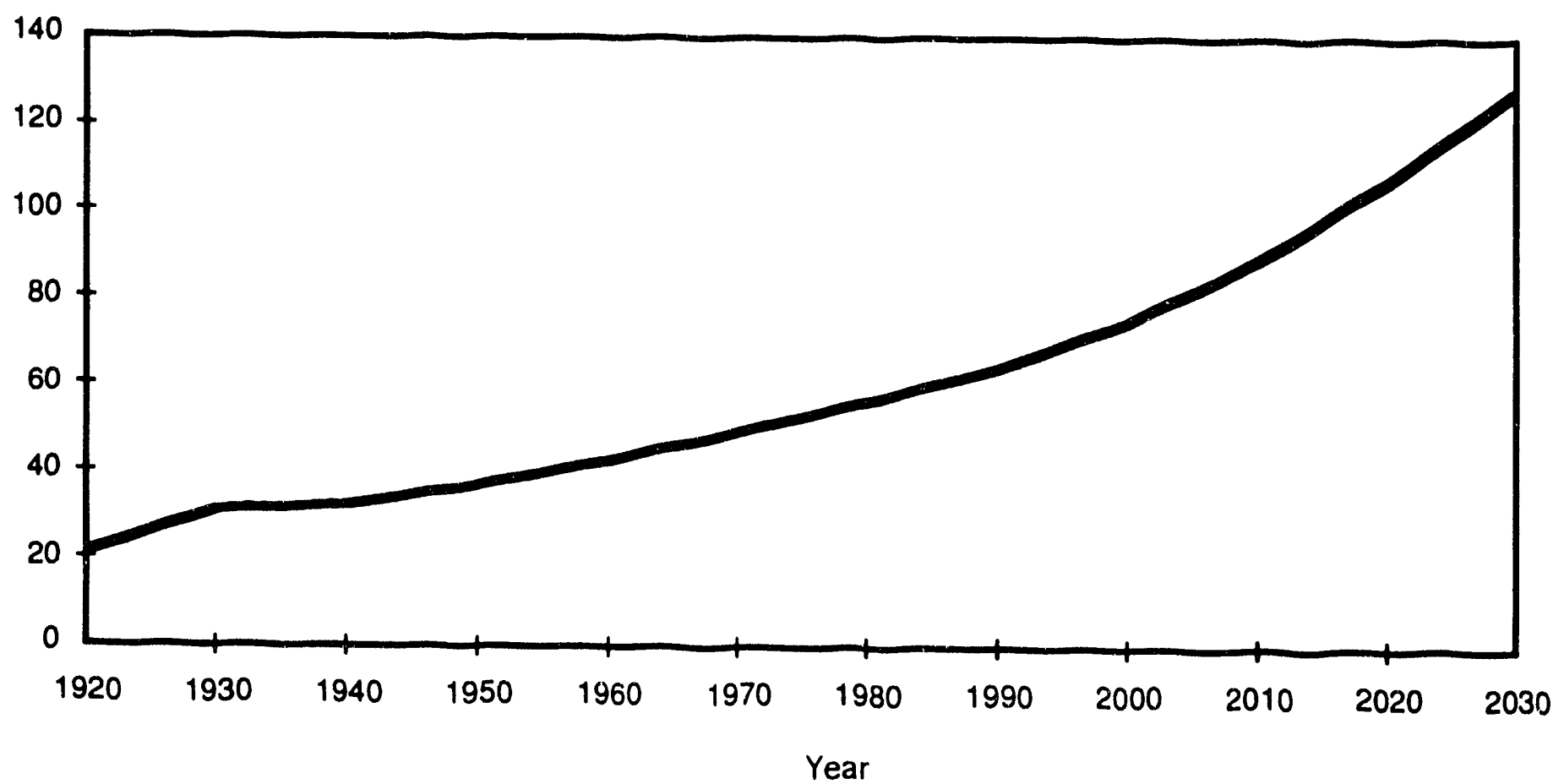


Floorspace values given by EPRI in the COMMEND default input files are slightly lower than the values published in the AEO 1991, the NES, and the values used by Pacific Northwest Laboratory (PNL). Because these other sources are in close agreement, the PNL floorspace data series has been chosen for this study, as it provides the most detail. PNL data give the vintages of existing commercial buildings. The survival functions specified in COMMEND characterize the retirement rate of buildings and are used to estimate annual cidditions from 1920 to 1989. For the future, the growth rate of total commercial floorspace is related to the Gross National Product (GNP) growth rate through the following regression equation calculated by PNL, which is based on data for 1963-1986.

$$
\Delta \ln \left(S_{1}\right)=0.117 \times x_{i} \Delta \ln (G N P)+0.863\left[\Delta \ln (S)_{(1-1)}\right]
$$

where $\Delta \ln (S) \quad=\quad$ a dimensionless growth rate relating the stock $S$ in the year $t$ to the stock in the previous year, $t-1$.

$$
\Delta \ln S_{t}=\ln S_{t}-\ln S_{(t-1)}=\ln \frac{S_{t}}{S_{(t-1)}}
$$

The GNP forecasting is based on DRI, Inc. numbers (to the year 2000) published in the AEO 1987 (Case A). After the year 2000, a GNP growth rate of 2.1 percent per year is assumed (based on AEO 1992 projections), which yields a 1.8 percent annual growth in floorspace. This total forecasted figure is distributed to building types base - on a fixed ratio (the average of the distribution of the last three years' additions for each building type), and is kept constant throughout the forecasting period.

Seventy-five percent ( 98 billion sq $\mathrm{ft}$ ) of the commercial floorspace in 2030 will have been built after 1986. All buildings, however, will have an opportunity for lighting system changes by 2030 (due to expected rates of renovationi).

\section{Calibration}

As a first step in the calihration process, comparisons between COMMEND inputs and NBECS (1986), AEO, and SEDR ${ }^{14}$ data are made in order to verify default assumptions in the model. Although there are definition discrepancies in the building types used by COMMEND and NBECS, as well as a ten percent disagreement over the commercial building stock total, EUIs for most building types and total consumption across segments correlate well.

The calibration for the lighting end use incorporates available data on the state of the market in 1986 and the predicted state in 1995. Trends in the characteristics of the lighting end-use tradeoff curves are defined to represent ongoing incentive programs, existing lighting regulations, and market equipment cost reductions that take the market from the known 1986 state to the predicted

\footnotetext{
14DOE/EIA. 1991. State Energy Data Report, Consumption Estimates, 1960-1989. DOE/EIA-0214(89).
} 
1995 state. $^{15}$ This predicted state represents the market effect of incentive and regulatory levels presently projected by lighting manufacturers, utility rebate programs, and lighting management companies. To achieve this transformation, existing programs and regulations are assumed to reduce the cost of high-efficiency technology options by 33 percent initially, and by an additional one percent per year, for a total of 42 percent from 1986 to 1995 . These assumptions are close to actual market behavior stimulated by utility rebate program cost reductions, which typically offer the equivalent of 3.5 to 4 cents/kWh saved to their participants. Figure 2.7 shows these cost shifts as they affect the lighting technology trade-off curve.

\section{Baseline Forecasts}

Three different baselines, No-Programs, High-Efficiency and Low-Efficiency, provide a spectrum of future market scenarios. In all three baselines, trade-off curves for all end uses other than lighting remain stationary. For the No-Programs case, the technology trade-off curve for the lighting end use is also held stationary, at its 1986 level, throughout the forecast period.

For the High-Efficiency Baseline, the 42-percent cost reduction (from incentive programs, etc.) at the efficient end of the lighting technology trade-off curve is left in place after 1995, and the trade-off curve remains in its 1995 state through 2030. For the Low-Efficiency Baseline, much of the price reduction at the efficient end of the trade-off curve ( 33 of the 42 percent) is removed after 1995 to model a case in which utilities and agencies no longer provide DSM incentives. The remaining cost reductions are left in place in order to simulate the permanent price effect that exiting DSM programs and other market forces would have on the market for efficient technologies. In addition, the Low-Efficiency Baseline includes small savings from state building codes introduced before 1995 and expected to persist. (See "Representation of Policies" below for a discussion of standards implementation in the model.)

These three baseline forecasts provide a framework for analyzing the impacts of policy actions. When the No-Programs baseline is compared to the other two baselines, the effect of incentive programs plus existing regulations and market forces can be estimated. The two other baselines represent two boundaries of the forecast range. The High-Efficiency Baseline represents a large number of incentives, but not a "maximum incentives" scenario. The Low-Efficiency Baseline accounts for current, widespread DSM activity but assumes that these programs do not persist at their current high level.

Figure 2.8 and Tables 2.2 to 2.3 compare the High- and Low-Efficiency Baseline consumption forecasts with other baselines. The comparison includes DOE's most recent Annual Energy Outlook (AEO 1992) forecast. The AEO forecast corresponds to frozen efficiency; i.e., lighting energy intensity remains at $5.1 \mathrm{kWh} / \mathrm{sq} \mathrm{ft}$ throughout a two-decade period. (The AEO values are higher than this report's Frozen-Efficiency Baseline because the AEO base-year values may

\footnotetext{
${ }^{15}$ This predicted state represents the market effect of incentive and regulatory levels presently projected by lighting manufacturers, utility rebate program managers, and lighting management companies.
}

$$
2-14
$$


Figure 2.7 COMMEND Calibration Technology Tradeoff Curve

\section{Calibration}

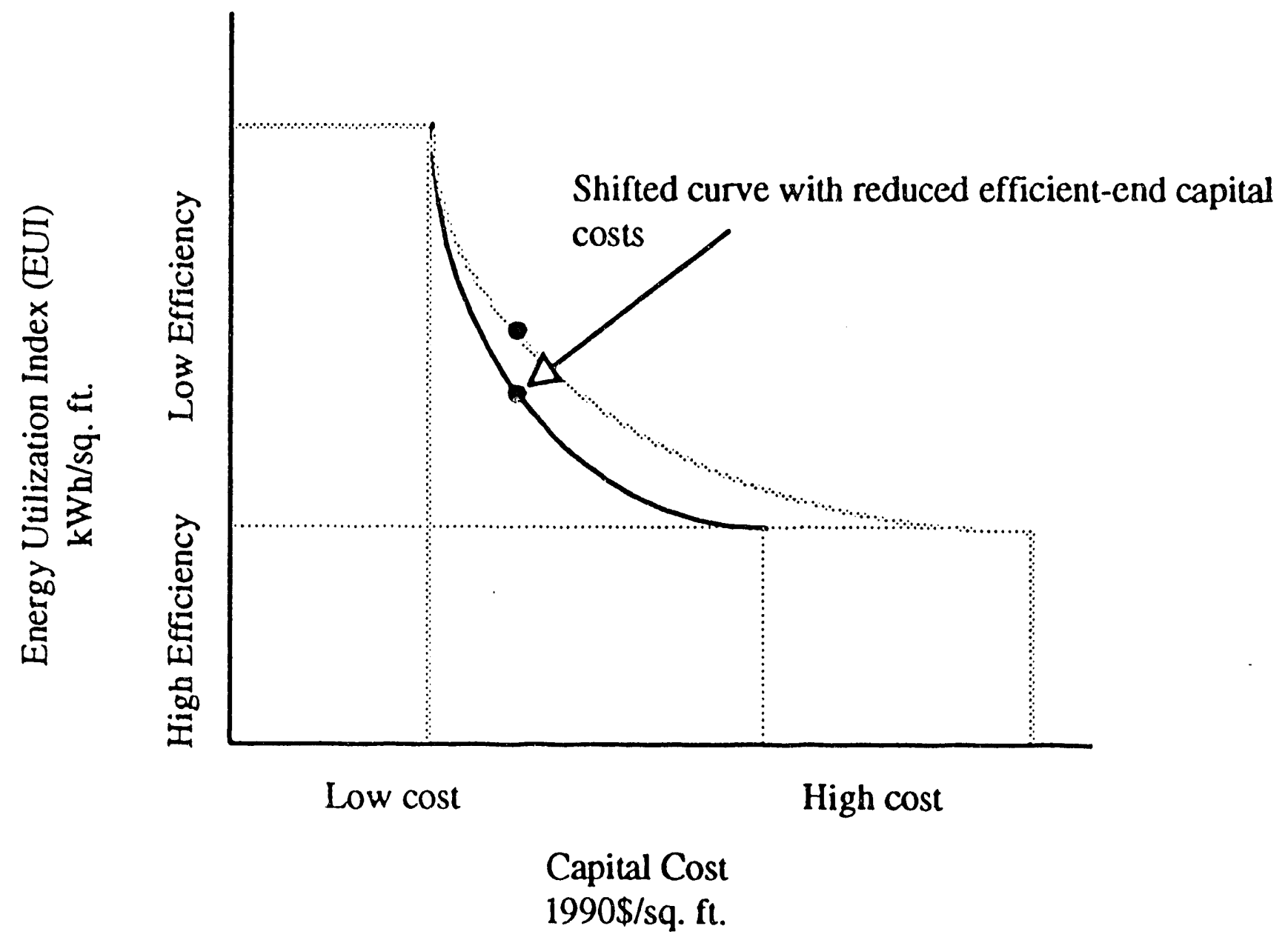


Figure 2.8

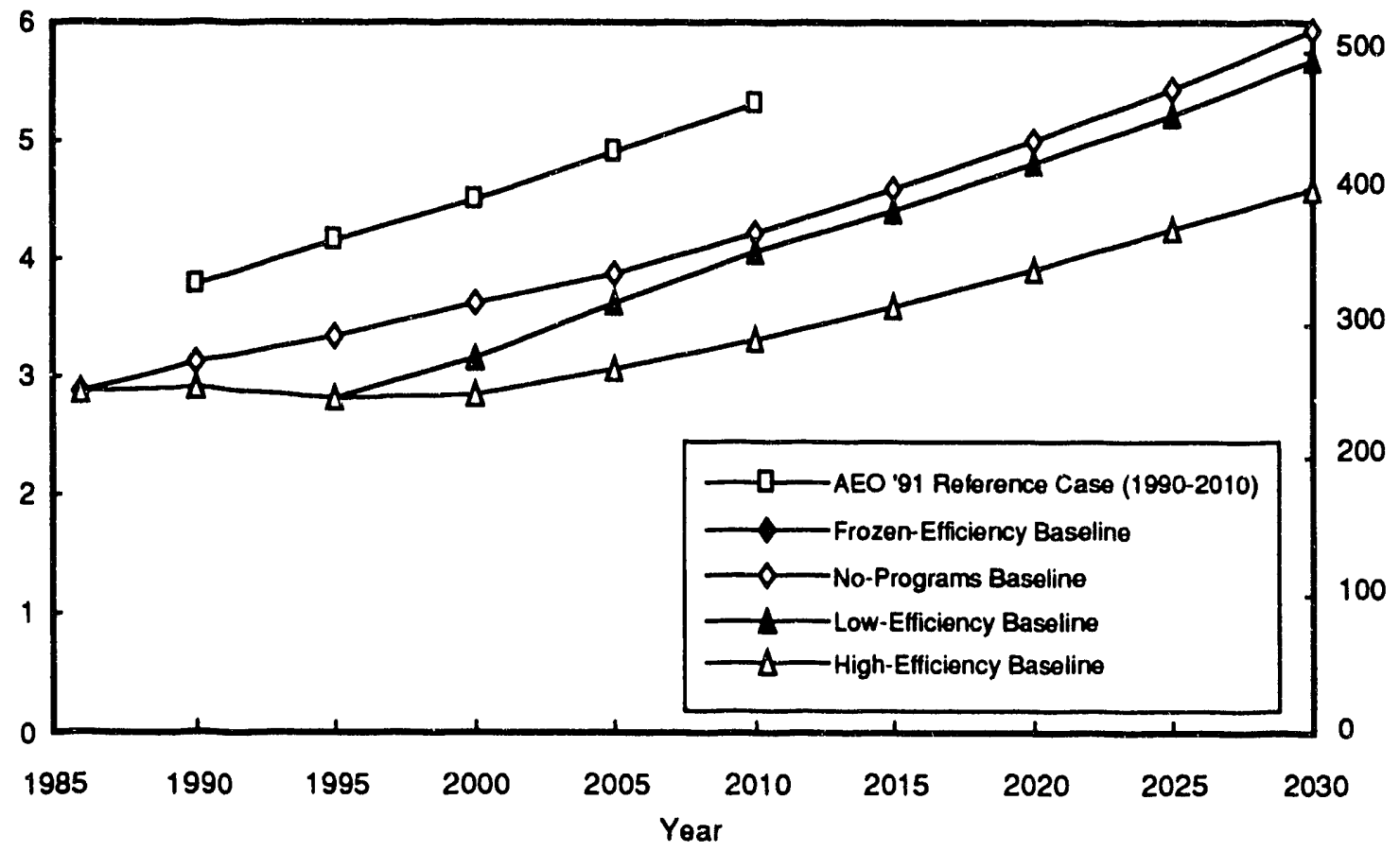

Notes: Frozen-Efficiency and the No-Programs Baseline are coincident. "AEO '91" includes outdoor lighting.

Table 2.2 Baseline Lighting Energy Use Intensity (kWh/sq ft-yr)*

\begin{tabular}{llllll}
\hline & 1990 & 1995 & 2000 & 2005 & 2010 \\
\cline { 2 - 6 } AEO '91 Reference Case & 5.10 & 5.12 & 5.10 & 5.10 & 5.09 \\
Frozen-Efficiency Baseline & 4.91 & 4.91 & 4.91 & 4.91 & 4.91 \\
No-Programs Baseline & 4.91 & 4.89 & 4.96 & 4.95 & 4.94 \\
Low-Efficiency Baseline & 4.55 & 4.08 & 4.21 & 4.47 & 4.57 \\
High-Efficiency Baseline & 4.55 & 4.08 & 3.82 & 3.75 & 3.73 \\
\hline
\end{tabular}

*total floorspace including lit and unlit areas; AEO includes outdoor lighting

Table 2.3 Baseline Lighting Energy Use (Primary Quads)

\begin{tabular}{llllll}
\hline & 1990 & 1995 & 2000 & 2005 & 2010 \\
\cline { 2 - 6 } AEO '91 Reference Case & 3.77 & 4.14 & 4.52 & 4.92 & 5.32 \\
Frozen-Efficiency Baseline & 3.61 & 3.91 & 4.28 & 4.68 & 5.09 \\
No-Programs Baseline & 3.61 & 3.91 & 4.28 & 4.68 & 5.09 \\
Low-Efficiency Baseline & 3.34 & 3.23 & 3.64 & 4.21 & 4.72 \\
High-Efficiency Baseline & 3.34 & 3.27 & 3.30 & 3.54 & 3.84 \\
\hline
\end{tabular}


reflect the inclusion of other lighting end uses, primarily outdoor lighting.) In the No-Programs Baseline, changes in lighting energy result only from the electricity price increases used in the COMMEND analysis (Figure 2.5). As may be seen in the figure, this baseline is almost synonymous with frozen efficiency. By the year 2030, the Low-Efficiency Baseline corresponds to a 4 percent reduction in lighting energy use compared to the No-Programs Baseline. The corresponding reduction with respect to the High-Efficiency Baseline is 22 percent.

COMMEND uses an average consumer discount rate of 28 percent to model commercial consumer decision-making. To test the sensitivity of this assumption, the No-Programs Baseline is estimated using average discount rates of 15 and 68 percent. Commercial sector primary energy consumption decreases in the year 2030 by 0.2 Quads ( 0.6 percent) and increases by 0.7 Quads ( 2 percent) respectively, for all end uses. This effect will be even smaller in the other baselines and policy cases because as programs and policies lead to price reductions for efficient lighting equipment, energy consumption levels become less sensitive to consumer discount rates.

\section{Representation of Policies}

Component and efficiency standards are modeled by limiting the choice of decision-makers at the low-efficiency end of the lighting technology trade-off curve (Figure 2.9). Incentive and information programs, on the other hand, do not limit the choices of decision-makers but facilitate the selection of high-efficiency options. These types of policies are modeled by making the efficient end of the technology curve less expensive while keeping the inefficient end fixed in cost.

\subsubsection{Residential Sector, LBL Residential Energy Model}

Residential lighting energy demand is forecast with the LBL Residential Energy Model, LBLREM (Section 5 and Appendix E). This section describes implementation of the REM model for the lighting end use. Interactions between lighting and space-conditioning energy use and peak load are reported only in Appendix $\mathbf{H}$.

Lighting is treated as a combination of five separate product classes. These classes are (1) general service incandescent lamps; (2) reflector incandescent lamps; (3) compact fluorescent lamps; (4) reflector compact fluorescent lamps; and (5) full-size fluorescent lamps. Total residential lighting energy consumption is calculated as the sum of the energy used by each of the classes.

Annual Unit Energy Consumption (UECs), prices, and equipment lifetimes from the engineering analysis for the technology options modeled are used as inputs to LBL-REM. Because the model performs calculations on a yearly basis, technologies with lifetimes less than a year are considered in multiple units so that total lifetimes are greater than a year. For example, standard incandescent lamps, each with a lifetime of 0.71 year, are grouped in twos with a composite lifetime of 1.42 years and a cost twice that of a single lamp. Seventy percent of the combination is then retired in the first year. 
The market shares of the product classes are assumed to be constant from 1995 to 2030 . (Retiring lamps are replaced with the same kinds of lamps to maintain the same saturation.) New houses are assumed to have the same mix of lamps as existing houses. When a CFL with a separable ballast is considered in a policy case, replacement of the lamp with a shorter lifetime is calculated separately from that of the ballast with a longer lifetime.

Because information is insufficient for a forecast of efficiency improvement, the UEC of each product class is assumed to be constant in the baselines. The hours of usage for the lamps are also assumed to be constant over the years. In policy cases other than the CFL case and the Min LCC and R\&D Combinations, the standard technology within a product class is replaced entirely by a more efficient technology option. After the policy takes effect, this efficiency choice remains constant. In the CFL case and the Min LCC Combination, approximately half of the standard designs are replaced by CFLs while the remainder are the standard design; thereafter, their market shares stay constant. For the R\&D Combination, 50 to 75 percent of lamps are replaced by CFLs, retaining a constant market share.

\subsection{LIGHTING EFFICIENCY POLICIES}

This section describes policies with the potential to improve national lighting efficiency. The relative benefits and drawbacks of each policy are discussed and the U.S. experience with each policy is summarized. Assumptions used in the forecasting models to replicate the effect of a policy on total energy consumption are provided. Some policies are not modeled in the study, for the reasons presented below.

\subsubsection{Component Performance/Prescriptive Standards (Commercial and Residential Sectors)}

\section{Description and Assessment}

A component performance standard requires that lighting components sold must have an efficiency above a specified level. Separate standards can be developed for individual lighting components, such as lamps, ballasts, or fixtures. Enforcement is relatively straightforward, by methods such as random product testing. A major benefit is that component performance standards are comprehensive: all products sold in the U.S. would be affected, regardless of whether they are used in the commercial, residential, or industrial sectors, or new construction or existing buildings. Because a standard requires that equipment meet performance levels, manufacturers would have some latitude in developing components to meet the standard. However, for some components (such as fixtures), there would need to be consensus in the lighting industry regarding a single measure for determining energy efficiency. ${ }^{16}$ In addition, a component performance standard would not guarantee by itself that an efficient component would

\footnotetext{
${ }^{16}$ See Section 3.3.5 on Luminaire Efficacy Rating (LER).
} 
be used correctly within a system to reduce energy consumption.

\section{U.S. Experience}

$\mathrm{EPCA}^{17}$ legislation requires that all fluorescent lamp ballasts meet a minimum ballast efficacy factor. These consensus standards are based on standards developed by California in 1978. The first update for the ballast standards is expected in 1996. Two states, New York and Massachusetts, have approved additional performance standards for other lighting components. New York's standards, which took effect in March 1991 as part of building code revisions, are for fluorescent lamps and fixtures designed for fluorescent, incandescent, and HID lamps. Massachusetts' standards are for fluorescent, general service, and reflector incandescent lamps. These standards have not taken effect because they have not been signed by the governor.

Although the two states' lamp standards are based on initial lumen output per watt input, they differ in one respect. The Massachusetts standards were developed to allow the use of reduced wattage ("energy-saving") fluorescent lamps with standard halophosphors, which require lower wattage input but produce less lumen output. The decision to include reduced wattage lamps was based on the assumption that most lamps purchased in Massachusetts would be used in existing fixtures rather than in new construction where these lamps are not appropriate. In contrast, under New York's standards, reduced-wattage lamps with halophosphors do not meet the required efficacy levels. See Section 3.3 for discussion of the New York fixture standards.

\section{Modeling Assumptions}

This policy is modeled for the commercial and residential sectors. The analysis assumes that a mandatory component standard takes effect in 1995 and applies to all equipment within a product class. The effects of a variety of different component standards, as well as several policies that combine efficiency standards for individual components, are examined.

Data used to analyze component performance standards are discussed in Sections 3.2 and 3.3, and modeling results are presented in Sections 4.2 and 5.2.

\subsubsection{Voluntary Component Performance Standards (Commercial Sector)}

\section{Description and Assessment}

In the past, the federal government has studied model component performance standards to be achieved voluntarily by component manufacturers. Such standards could be entirely voluntary or could become mandatory after a certain time period. The benefit of a voluntary standard is that it allows manufacturers sufficient lead time for developing the capability to produce more

\footnotetext{
${ }^{17}$ The Energy Policy and Conservation Act (P.L. 94-163), as amended by the National Appliance Energy Conservation Amendments of 1988 (P.L. 100-357).
} 
efficient components. The drawback of a voluntary standard that becomes mandatory is that it may not provide manufacturers sufficient incentive to actively develop new production capability before the standard is made mandatory, which delays the transition to new production techniques.

\section{U.S. Experience}

There is no U.S. experience with voluntary component standards for lighting.

\section{Modeling Assumptions}

This policy is only modeled for the commercial sector. The analysis assumes that the voluntary standard specifies the energy-efficiency levels of mandatory component performance standards, and that voluntary standards become mandatory after five years (in the year 2000). It is also assumed that no progress is made toward voluntary standards until those standards become mandatory. Once the standards become mandatory, it is assumed to take two years to establish the standards, and three years for full compliance. Thus, the voluntary standards result in a ten-year delay in contrast to the timeframe for mandatory component standards.

\subsubsection{System Performance Standards (Commercial Sector)}

\section{Description and Assessment}

A system performance standard allows more flexibility in designing energy-efficient lighting systems than a component performance standard. System performance can be regulated by imposing limits on a building's connected lighting load. System standards typically include lighting power density (LPD) limits, which are expressed in watts of connected lighting load per square foot of floorspace. The system performance standard encourages, but does not necessarily require, the use of higher-efficiency components. Because the standard applies to the entire lighting system, this policy allows a designer to develop a system that uses any combination of lamps, ballasts, fixtures, controls, and room surface characteristics, or a combination of relatively efficient and inefficient components, as long as the system performance standard is met.

Two major drawbacks of building codes are (1) the difficulty in enforcing compliance and (2) their limited application. Most states have devoted few resources to enforce compliance with local building codes. There is little information regarding the current level of compliance with energy building codes in the absence of strong enforcement. The establishment of a system to enforce code compliance at either the federal or state level would require significant resources. See Appendix $\mathbf{G}$ for a discussion of research on building code compliance.

Current building codes affect only new construction, or, in some states, major renovation of existing buildings. This means that system performance standards would have little effect in mature building markets where there is relatively little new development or renovation. Lighting performance standards similar to those for new construction could be imposed on existing buildings when they are sold. However, local governments have little experience with this type 
buildings when they are sold. However, local governments have little experience with this type of standard. In addition, the few standards that have been adopted for existing buildings are of a prescriptive, rather than performance, nature (i.e., they require the installation of specific products/technologies rather than allow building designers the flexibility of a performance standard)..$^{10,19}$

\section{U.S. Experience}

The DOE considered establishing a mandatory national building code for all new construction in 1981. However, opposition from the building and electricity industries resulted in the adoption of a voluntary rather than mandatory national building code (the code is currently mandatory only for new federal buildings). A revision of the current code is to become effective in 1993 (DOE-93). ${ }^{20}$ Updates to the lighting section of this code will create the strictest lighting standards in the country.

Thirty-nine states currently have building codes that include lighting system performance standards. Many of these codes are based on model (i.e., voluntary) energy efficiency codes, such as those developed by the American Society of Heating, Refrigerating and Air-Conditioning Engineers (ASHRAE) and the Illuminating Engineering Society (IES). In addition to requiring LPD limits for specific types of buildings and task areas, the ASHRAE/IES code calls for minimum number of controls (swiiches), and includes LPD adjustment credits for the installation of other lighting controls (occupancy sensors, dimmers, timers, and daylight sensors) that limit the actual use of the installed lighting load. Some states have developed codes that have more stringent lighting standards than those in the current version of the ASHRAE/IES code (ASHRAE-90.1-1989). For a detailed presentation of federal and state building codes, see Appendix G.

The Energy Policy Act of 1992 mandates that all states adopt commercial building codes that meet or exceed the ASHRAE/IES-90.1 code, including the lighting provisions, within two years after enactment (October 1992). If the ASHRAE/IES code is updated later, DOE must determine whether the revision improves energy-efficiency in buildings before requiring states to adopt the

\footnotetext{
"K. Egel, J. Cook, and B. Knox. 1990. "Mandating Energy Efficient Commercial Buildings: San Francisco's Commercial Energy Conservation Ordinance." Proceedings of the ACEEE 1990 Summer Study on Energy Efficiency in Buildings. ACEEE, Washington, DC, pp. $7.43-7.50$.

${ }^{19}$ Energy Office, Office of Economic Opportunity, City of Berkeley. 1992. Berkeley Commercial Energy Conservation Ordinance (CECO), draft ordinance to be incorporated into the Berkeley Municipal Code.

${ }^{20}$ Code of Federal Regulations 10CFR435. 1989 (July). Energy Conservation Volu iztary Performance Standards, Mandatory for New Federal Buildings.
} 
updated code. ${ }^{21}$ There is no mechanism to ensure that states adopt the codes, or that states enforce the codes they adopt. However, DOE is required to provide technical assistance and incentive funding to states to implement the requirements. For new federal commercial and residential buildings, DOE, in consultation with other federal and professional agencies, must establish new energy standards within two years after enactment.

The compliance and coverage limitations of building codes discussed above are not addressed by the Act. To increase compliance, the government could provide incentives for new buildings that have LPDs lower than required by code or meet a more stringent voluntary code. The coverage of the Act could be increased by including prescriptive energy-efficient lighting standards $^{2}$ in the CABO Model Energy Code for new residential buildings, and by extending the stricter requirements for federal buildings to all commercial buildings receiving federal funds for financing (such as federally-insured mortgages, construction loans, etc.). ${ }^{23}$

\section{Modeling Assumptions}

Implementation of the lighting section of two building codes is modeled: the ASHRAE/IES 90.1 code and the DOE-93 code. It is assumed that enactment of each code modifies the distribution of LPDs in new construction. Data based on lighting industry and utility DSM programs are used to calculate a 1986 distribution of LPDs for each building type. Adoption of a building code eliminates some higher-end LPDs for each building type. The mean LPD for each building type is then recalculated based on this truncated distribution. To account for less than 100 percent compliance with the building codes, a second forecast ("partial compliance") is performed for each code. In these forecasts, the portion of the LPD distribution removed is all LPDs in excess of the limit set by the building code plus one standard deviation from the original distribution. This methodology is described fully in Section 4.4.

The ASHRAE/IES 90.1 full and partial compliance policy cases approximate the range of energy savings from the building code provisions of the Energy Policy Act of 1992. The full compliance case assumes that all states adopt, and fully enforce compliance with, the ASHRAE/IES 90.1 code; the partial compliance case allows for less than 100 percent code adoption and compliance.

\footnotetext{
${ }^{21}$ Each state must also review its residential building code and determine whether revising it to meet or exceed the CABO (Council of American Building Officials) residential Model Energy Code is appropriate. However, there are no lighting provisions in this code.

${ }^{22}$ Such as requirement of fluorescent lighting in kitchens and bathrooms (as in California's Title 24), fixtures that accommodate compact fluorescent lamps, or lighting controls (e.g. timers or photocells for outdoor lighting).

${ }^{23}$ The Act already extends requirements for federal residential buildings to all residential buildings receiving federal financing assistance.
} 


\subsubsection{Consumer Rebates (Commercial Sector)}

\section{Description and Assessment}

Consumer rebates would directly encourage consumers to purchase energy-efficient lighting components, regardless of whether they are used in the commercial, residential, or industrial sector, or in new construction or existing buildings. However, the effectiveness of a consumer rebate program largely depends on three aspects of the program design: the size of the incentives, the methods of promoting the incentives, and the proportion of "free riders" who would have purchased the efficient equipment anyway and take advantage of the incentives. The degree to which these design aspects are addressed, in turn, depends on the level of resources devoted to such a program. Rebate program planners should send a clear signal to manufacturers that demand for efficient products will be higher than would have been the case without the program. Rebates should also be in place long enough to encolizage product redesign and allow the lead time necessary for manufacturers to adapt production processes and levels to respond to increased demand for more efficient products.

\section{U.S. Experience}

Approximately 50 utilities in 28 states have developed rebate programs for a range of energy-efficient lighting components that reduce electricity demand. ${ }^{24.25}$ Pilot utility programs have shown that rebate promotion may have as much of an impact on customer participation as rebate amount. Analysis of the relationship between rebate size and customer participation has been limited. However, some experimental programs have found that rebates below 50 percent of component cost have little impact on participation (although even a small incentive generates more response than no incentive). ${ }^{26}$

It is difficult to quantify the direct effectiveness of utility rebate programs. Some consumers would have purchased efficient components without the rebate incentive. Therefore, the number of "free riders" may mask the actual effectiveness of any particular rebate program. An analysis of eight programs found that between 10 and 65 percent of rebate recipients were free riders, depending on the program and the components purchased. ${ }^{27}$ The number of free riders can be minimized by allowing rebates only on components with low-market penetration and/or by requiring inspection to ensure that customers are not using energy-efficient components already.

\footnotetext{
${ }^{24}$ S.M. Nadel. 1990. Lessons Learned: A Review of Utility Experience with Conservation and Load Management Programs for Commercial and Industrial Customers. American Council for an Energy-Efficient Economy, Washington D.C.

25."Demand-Side Management Incentives at a Glance," Energy User News, July 1991.

${ }^{26}$ Nadel. 1990. Op. cil, Ref. 18 p. 57.

${ }^{27}$ Nadel. 1990. Op. cil, Ref. 18 p. 50.
} 
Another report estimated the energy savings and benefit-cost ratios for full adoption for a number of demand-side management (DSM) programs by three New York utilities. Among the programs analyzed were rebates for the purchase of compact fluorescent lamps by residential customers and rebates for a variety of commercial components (compact fluorescent lamps and fixtures, electronic ballasts, T8 lamps, reflectors, high-intensity discharge lamps, occupancy sensors, and daylighting controls). The study assumed rebates of nearly 80 percent of the purchase price and fairly low cumulative participation rates (12 to 36 percent, depending on the component) and proportion of free riders (5 to 15 percent, depending on the component). Using these assumptions, the study found that all of the rebate programs proved cost-effective from both the utility and societal perspectives (from the perspective of the non-participating ratepayer, the programs were not cost-effective).

Although many utilities currently provide consumer rebates, these rebates are available only in certain regions of the country. In order to promote wider use of rebate programs, the federal government could provide rebates directly to consumers. However, there is no existing administrative mechanism for such a nationwide rebate program. In addition, one reason utilities provide rebates to consumers is that it is more cost-effective to society and to the utilities, given proper regulatory incentives, to reduce electricity demand by promoting efficiency measures than to increase electricity supply by constructing new generation facilities. The federal government would incur most of the costs of a national rebate program while benefits would accrue to consumers, utilities, and society through the avoided cost of constructing additional power plants. An alternative to direct federal rebates to consumers would be to develop incentives (or requirements) for more utilities to pursue consumer rebate programs.

\section{Modeling Assumptions}

This policy is modeled for the commercial sector only. Consumer rebates are a large part of utility DSM programs. The High-Efficiency Baseline scenario is projected to be the probable future rebate level, given product supply constraints. Thus, the consumer rebate policy is equivalent to the High-Efficiency Baseline scenario. The associated reduction in the cost of energy-efficient lighting components under the High-Efficiency Baseline approximates a 3.5 to 4 cent rebate per kilowatt-hour saved for over a ten-year period. This cost is representative of the costs of the rebates offered under existing utility programs.

\subsubsection{Consumer Tax Credits}

\section{Description and Assessment}

The benefits and drawbacks of tax credits are similar to those of consumer rebates. Tax credits might more easily be administered than rebates because they can be implemented through an

\footnotetext{
${ }^{22}$ S. Nadel and H. Tress. 1990. The Achievable Conservation Potential in New York State from Utility Demand-Side Management Programs. New York State Energy Research and Development Authority (NYSERDA) and New York State Energy Office (NYSEO), Albany, NY.
} 
existing governmental structure, the Internal Revenue Service (IRS). However, the fact that consumers realize the credit months after product purchase (when income taxes are filed or a tax refund is provided by the IRS) would reduce consumer participation in a tax credit program. Middle- and low-income purchasers, who generally have little ready cash to purchase more expensive products, would be less likely to participate in a tax credit program than a rebate program. Small energy consumers would also probably not bother to file for tax credits, while building contractors, who make large purchases of lighting components, would be more likely to take advantage of the credits.

\section{U.S. Experience}

The Energy Tax Act of 1978 (P.L. 95-618) provided homeowners with a tax credit of up to 15 percent for the installation of energy-saving materials and equipment (not including lighting equipment). This tax credit was usable in one year or over a number of years, but it could not exceed $\$ 300$ for a given residence. Iti 1980 the credit was increased to 40 percent, and the credit could not exceed $\$ 4,000$. All federal tax credits for energy-efficient purchases were removed in 1985. Between 1981 and 1987 California awarded similar tax credits for the purchase of conservation materials (not including lighting equipment).

Nearly six percent of all U.S. households received the federal energy conservation credit in 1978, the first year of the program. Although participation steadily declined to three percent by 1982 , the cumulative participation in the program over five years was nearly 23 percent of U.S. households. Participation continued to decline in 1980 when the credit was raised from 15 to 40 percent, implying that the increased credit did not result in more purchases of conservation materials.

An analysis of the program found that the credits were less regressive than federal credits for solar water heaters. This is most likely because of the small investment required to qualify for the credit (the average investment in conservation improvements was $\$ 650$ in 1982, compared to much higher purchase prices of solar water heaters). ${ }^{29}$ Also, the federai government was providing funding to states to finance conservation purchases by low-income households during this period. ${ }^{30}$ The existence of these grants most likely made tax credits less appealing to lowincome households.

Because the federal government has not enacted similar credits for commercial users, no information regarding the commercial sector's response to tax credits for the purchase of energy-efficient equipment is available.

\footnotetext{
${ }^{29}$ J.M. Quigley, 1991. "Residential Energy Conservation: Standards, Subsidies and Public Programs." in Regulalory Choices: A Perspective on Developments in Energy Policy. RJ. Gilbert (ed.), University of California Press: Berkeley, CA.

${ }^{30}$ ibid. These funds were provided through the Weatherization Assistance Program and Low-Income Home Energy Assistance Program block grants.
} 


\section{Modeling Assumptions}

This policy is modeled for the commercial sector only. It is assumed that tax credits achieve 75 percent of the savings attributable to consumer rebates.

\subsubsection{Dealer Rebates}

\section{Description and Assessment}

Providing rebates to lighting dealers for each energy-efficient component sold is an alternative to consumer rebates. Although consumer rebates affect demand, dealer rebates give a portion of the monetary incentive to dealers to promote the sale of efficient lighting components. The portion of the incentive passed on to the consumer in the form of lower prices increases the number of efficient lighting components demanded. Dealer rebates may be more effective than consumer rebates or tax credits because the portion of the rebate passed on io consumers as reduced prices would be received at the time of purchase. However, unless dealer rebates are regulated, there will be no guarantee that any, or most, of the rebate will be passed on to the consumer. Utilities are beginning to gain experience with this type of program; this policy may be effective in promoting efficient lighting components, especially for residential uses.

\section{U.S. Experience}

One utility tested a dealer rebate program against four other rebate programs for fluorescent lamps in commercial businesses. The study found that dealers were already aggressively selling energy-efficient fluorescent lamps because of the higher profit earned from each lamp sold. The utility concluded that dealers did not need rebates to encourage them to stock or promote energy-efficient lamps. ${ }^{31}$

Another utility compared the relative effectiveness of consumer and dealer rebate programs for commercial customers. ${ }^{32}$ The dealer program achieved slightly higher participation, at a higher cost per $\mathrm{kWh}$ saved, than the consumer rebates, and with a higher percentage of free riders. Free riders in the dealer rebate program ranged from 5 percent for compact fluorescents to 65 percent for full-size fluorescent lamps. The program did not require dealers to pass on the rebates to customers. Dealers reported that 80 percent of the time they passed on 80 percent of the rebate to customers. The utility concluded that consumer pressure may be necessary to encourage dealers to pass rebates on to consumers. A consultant who is experienced with several compact fluorescent dealer rebate programs estimates that dealers pass on no more than 90 percent of the

\footnotetext{
${ }^{31}$ A. Goett and J. Dillon. 1990. "Niagara Mohawk Commercial Lighting Conservation Program." Proceedings of the ACEEE 1990 Summer Study. American Council for an Energy Efficient Economy, Washington, DC. p. 8.43.

${ }^{32}$ S. Nadel. 1988. "Utility Commercial/Industrial Lighting Incentive Programs: A Comparative Evaluation of Three Different Approaches Used by the New England Electric System." Proceedings from the ACEEE 1988 Summer Study. Washington, DC, p. 6.154.
} 
incentive to the consumer in the form of lower prices. ${ }^{33}$

\section{Modeling Assumptions}

This policy is not modeled because of the uncertainties involved.

\subsubsection{Manufacturer Tax Credits}

\section{Description and Assessinent}

This policy would take the form of a federal tax credit for a portion of the costs that marufacturers would incur in retooling to accommodate increased consumer demand for certain lighting components. The benefit of manufacturer tax credits is that they would increase the supply of energy-efficient lighting components available to consumers. However, because the degree of retooling required to produce each component varies, the size of the credit would have to vary by component. In addition, consumer demand for certain components may have led to retooling already, making tax incentives for this purpose unnecessary.

\section{U.S. Experience}

There currently is no experience with federal tax incentives for manufacturers who retool to produce energy-efficient products. Therefore, the effectiveness of such a policy on lighting component manufacturers is unknown. Utilities have begun an incentive program for refrigerator equipment manufacturers to develop models that are more efficient than those required by the DOE 1993 standards (the "Golden Carrot").

\section{Modeling Assumptions}

This policy is not analyzed because more information from manufacturers is required to model the impact of a manufacturer tax credit policy. However, lighting manufacturers claim that, even without retooling incentives, they already undertake research to develop more efficient lighting products.

\subsubsection{Consumer Education (Commercial Sector)}

\section{Description and Assessment}

A major barrier to the purchase of energy-efficient lighting products appears to be the general lack of consumer information regarding their economic benefits. A consumer education program in the form of media advertisements and informational mailings would increase consumer

\footnotetext{
${ }^{33}$ G. Schaeffer, consultant to Southem California Edison Company, Rosemead, CA. Personal communication, September 1991.
} 
awareness, and increase demand for these products. A drawback of a general education program is that the direct impact of education alone on consumer behavior is unknown. In addition, education alone would not have an impact on lighting equipment purchasers who do not pay electricity bills. Consumers, such as the purchasing departments of large corporations or tenants of master-metered buildings, are more concerned about reducing the initial purchase price of a lighting product than reducing the operating cost (energy and maintenance) over the product's lifetime.

\section{U.S. Experience}

Some utilities have tried to assess the impact of education-only programs on energy consumption. One utility ran an education-only program concurreritly with a rebate program to compare the relative effectiveness among its commercial customers. The participation rates after six months were 3.0 percent for those receiving information only and 5.6 percent for those offered a full or partial rebate. ${ }^{34}$ This and other utility experience suggest consumer education programs appear to be less effective in the short term than rebate programs.

\section{Modeling Assumptions}

Consumer education, designer education, and component labeling are modeled as a single policy. Based on the limited experience with the relative effectiveness of these programs, it is assumed that such a policy achieves 35 percent of the energy savings of the consumer rebate policy.

\subsubsection{Designer Education (Commercial Sector)}

\section{Description and Assessment}

The resources devoted to consumer education could be more effective if directed toward those making the initial decisions reganding the installation of lighting systems, i.e., lighting designers and building contractors. The drawback is that this approach would probably affect only new construction or major renovation.

\section{U.S. Experience}

Utilities have developed some programs intended to educate lighting designers about the energy-efficiency of lighting components. Seattle City Light, Southern California Edison, and Pacific Gas and Electric have opened lighting design laboratories for use by designers, architects, and the general public. ${ }^{35}$ The Lighting Research Center at Rensselaer Polytechnic Institute in

\footnotetext{
Nadel. 1990. Op. cit., Ref. 18 p. 41.

${ }^{33}$ D. Setuerfield. 1991. "The Lighting Design Lab: A Success Story from the Commercial Sector." Proceedings of the 1st European Conference on Energy-Efficient Lighting. E. Mills (ed.), Swedish National Board for Industrial and Technical Development, Department of Energy Efficiency, Stockholm, Sweden.
} 
A survey of the Seattle Lighting Design Lab users* found that about a third would not have used an energy-efficient lighting design without a consultation from the Lab. These users reported a reduction in the designed wattage of their lighting systems from an average of 2 watts per square foot (prior to consultation) to an average 1.59 watts per square foot (after consultation), a 20percent decrease.

The Energy Policy Act of 1992 directs DOE to provide grants to help establish or support 10 regional building energy efficiency centers, similar to the design laboratories discussed above, throughout the country. The centers will provide technical information to building professionals and assist in developing academic curricula stressing energy efficiency in building design.

\section{Modeling Assumptions}

The effect of a designer education program is estimated in conjunction with a consumer education program.

\subsubsection{Component Labeling (Commercial Sector)}

\section{Description and Assessment}

Labeling is intended to give purchasers information about the potential savings from installing energy-efficient lighting components. Lighting manufacturers and designers tend to support labels rather than mandatory component standards. However, after more than a decade of federal labeling programs, there is little evidence of their effect on the purchase of efficient appliances. Labels for certain lighting components, such as fixtures, would require a consensus among lighting professionals regarding a single measure of energy efficiency. Labeling of fixtures is complicated by the fact that system efficiency depends on the type of lamps and ballasts used. ${ }^{37}$

Labels may not be effective for purchasers who do not pay electric bills, such as purchasing departments in large businesses, or lighting designers or contractors who specify lighting equipment for new or renovated buildings. An alternative to labels would be to publish a directory of ratings of "approved" energy-efficient components for commercial purchasing departments.

\section{U.S. Experience}

Labels have been required on certain residential appliances since 1980 . The labels display the annual operating cost of each model and compare its cost with costs of other models. The Federal Trade Commission . FTC) published a study on the effectiveness of labels on the

\footnotetext{
Welson, J. 1991. "Evaluation of the Lighting Design Lab's Consultation Program." Evaluation Unit, Energy Maragement Services Division, Seaule City Light, Seatule WA.

${ }^{\text {T}}$ NEMA's proposed Luminaire Efficacy Rating (see Section 3.3.5) addresses these complications.
} 
departments.

\section{U.S. Experience}

Labels have been required on certain residential appliances since 1980 . The labels display the annual operating cost of each model and compare its cost with costs of other models. The Federal Trade Commission (FTC) published a study on the effectiveness of labels on the purchase of energy-efficient appliances in 1986. The study was based on consumer surveys before and after the introduction of labelling. Consumers' awareness of labels increased over the study period, but this awareness apparently did not change consumer purchase decisions. Energy efficiency still ranked below other factors (such as size, price, and brand names) in consumer decision-making. The FTC study did not evaluate market data on the number of appliances purchased, or the extent to which labels affected the purchases.

\section{Modeling Assumptions}

The effect of a component labeling program is estimated in conjunction with consumer and designer education programs.

3. McMahon. 1991. "Appliance Energy Labelling in the USA," Consumer Policy Review, April 1(2). 


\section{ENGINEERING ANALYSIS}

\subsection{INTRODUCTION}

The economic impacts of improving lighting efficiency depend on the relationships between: the incremental cost of an efficiency improvement, its effect on replacement costs, and the change in energy use. This section presents the engineering basis for cost-efficiency relationships for components. The subsequent sections apply the results to the U.S. as a whole.

The analysis covers fluorescent lamps, incandescent lamps, fluorescent fixtures, and controls. Fluorescent ballasts are not included in this report because they are being analyzed as part of the EPCA update analysis.' Full-sized fluorescent lamps are analyzed for the commercial sector, and compact fluorescents and incandescents are analyzed for both the commercial and residential sectors. Fluorescent fixtures and controls are analyzed only for the commercial sector. In practice, use of controls would be regulated by building energy codes, in the form of either prescriptive standards or credits allowing adjustment in LPD levels to reflect savings from controls. Besides being analyzed as separate policies, controls and fixtures are also modeled in combination with lamps and ballasts.

Lamps and fixtures are separated into discrete product classes, consisting of technology options with different efficiency levels. The Engineering Analysis is performed for fifteen lamp product classes and four fixture product classes (commercial and residential sectors). (See Section 2.1.1 for a description of terminology and the structure of the analysis.)

For lamps, identification of baseline units and design options with efficiency improvements is based on information from manufacturers' catalogs, CEC's Advanced Lighting Guidelines, ${ }^{2}$ and consultants' expertise. Selection of maximum technologically feasible options and research and development options is based on research by the LBL Lighting Systems Research Group.

For fluorescent fixtures/luminaires, identification of baseline units and technology options is based on extensive discussions with fixture and lighting designers. Luminaire efficiencies for subclasses within each product class are taken from manufacturers' published photometric reports. Wattages for lamp/ballast combinations in various fixture types are taken from the Advanced Lighting Guidelines (see Section 3.2.3).

\footnotetext{
'Technical Support Document: Energy Conservation Standards for Consumer Products. 1993. U.S. DOE (forthcoming).
}

\footnotetext{
${ }^{2}$ California Energy Commission. 1992. 1992 Advanced Lighting Technologies Application Guidelines. CEC, Sacramento, CA, October 1992 Draft.
} 


\subsection{LAMPS}

Tables 3.1 to 3.5 list the product classes and technology options analyzed. Fluorescent lamps are listed with several corresponding ballasts. All technology options listed in the tables are presently produced by major lamp manufacturers, with the exception of those labeled "Max Tech" and "Research and Development." Not all design options are available for each product class. Tables B.1 through B.19 in Appendix B give a listing of available lamps in each product class. Cathode cutout lamps (which are distinct from cathode cutout ballasts) are available only for four-foot tubes and are recommended for use only with energy-efficient magnetic ballasts. The T8 and the T10 lamps are not available in eight-foot lengths. Eight-foot, T8 lamps with electronic ballasts will come on the market in 1993; this is the maximum technologically feasible ("Max Tech") option for 8-foot lamps. Design options for incandescent and compact fluorescent lamps in the residential sector are the same as those for incandescent lamps in the commercial sector.

\subsubsection{Commercial Sector Product Classes and Design Options}

Table 3.1

Product Classes for Lamps, Commercial Sector

\begin{tabular}{ll}
\hline 1 & Fluorescent Four-Foot with Energy-Efficient Magnetic Ballast \\
2 & Fluorescent Four-Foot with Cathode Cutout Ballast \\
3 & Fluorescent Four-Foot with Electronic Ballast \\
4 & Fluorescent Four-Foot U-Shaped with Energy-Efficient Magnetic Ballast \\
5 & Fluorescent Eight-Foot with Energy-Efficient Magnetic Ballast \\
6 & Fluorescent Eight-Foot with Electronic Ballast \\
7 & Fluorescent Eight-Foot High-Output with Energy-Efficient Magnetic Ballast \\
8 & Fluorescent Eight-Foot High-Output with Electronic Ballast \\
9 & Compact Fluorescent \\
10 & Incandescent General Service \\
11 & Incandescent Reflector \\
\hline
\end{tabular}




$\begin{array}{ll}1 & \text { Standard Wattage with RE } 70 \text { rare-earth phosphor } \\ 2 & \text { Standard Wattage with RE } 80 \text { rare-earth phosphor } \\ 3 & \text { Reduced-Wattage with krypton-fill } \\ 4 & \text { Reduced-Watage with krypton-fill and RE } 70 \text { rare-earth phosphor } \\ 5 & \text { Reduced-Wattage with krypton-fill and RE } 80 \text { rare-earth phosphor } \\ 6 & \text { T10 11/4-inch diameter with rare-earth phosphor } \\ 7 & \text { T8 1-inch diameter with rare-earth phosphor } \\ 8 & \text { Cathode Cutout Lamp } \\ 9 & \text { Cathode Cutout Lamp with RE } 70 \text { rare-earth phosphor } \\ 10 & \text { Max Tech Lamp } \\ 11 & \text { Research and Development Lamp }\end{array}$

\begin{tabular}{ll} 
Table 3.3 & Technology Options for Incandescent Lamps (General Service and Reflector) \\
\hline 1 & Reduced-Wattage \\
2 & Halogen \\
3 & Halogen Infrared (HIR - Max Tech) \\
4 & Coated Filament (Research and Development) \\
\hline
\end{tabular}

Table 3.4 Technology Options for Compact Fluorescent Lamps

\begin{tabular}{ll}
\hline 1 & Twin Tube + Separable Magnetic Ballast \\
2 & Quad Tube + Separable Magnetic Ballast \\
3 & Quad Tube + Integral Electronic Ballast \\
\hline
\end{tabular}




\subsubsection{Residential Sector Product Classes}

Table $3.5 \quad$ Product Classes for Lamps, Residential Sector

\begin{tabular}{ll}
\hline 1 & Incandescent General Service \\
2 & Incandescent Reflector \\
3 & Compact Fluorescent \\
4 & Full-Size Fluorescent \\
\hline
\end{tabular}

\subsubsection{Energy Use, Efricacy, Equipment Costs, Replacement Costs and Operating Hours}

Energy consumption data for fluorescent lamps, or wattages drawn by various lamp/ballast combinations, are taken from CEC's Advanced Lighting Guidelines. ${ }^{3}$ Incandescent lamp wattage is assumed to be the nominal wattage from manufacturers' catalogs. Rated initial lumens from 1992 lamp manufacturers' catalogs are used. These catalogs reflect recent corrections made by manufacturers to rated lumen output data.

Lamp service life (years) is taken from average rated lamp lifetime (hours) from manufacturers' catalogs. This figure is divided by annual lighting hours (see Section 2.1.2). Ballast service life is assumed to be 12 years $(4,171$ hours/year fluorescent operation) for all ballast types.

ANSI wattages are based on manufacturer data for equipment tested under ANSI conditions, using a reference circuit and specific ambient temperature conditions. These wattages are referred to as ANSI wattages in the engineering tables in Appendix B.

Efficacy, expressed as lumens per watt, is calculated by dividing rated lamp lumens by ANSI wattage. This allows efficacies to be consistent with those used in other analyses and in the proposed lamp standards. Efficacy cannot be calculated for certain incandescent reflector lamps because their output is given as candlepower distribution rather than lumens in manufacturers' catalogs. Candlepower distribution, defined in Section 3.3.1, describes light distribution properties rather than light output; distribution is more important for typical reflector lamp types such as spot lights or flood lights.

The power drawn by each four-foot lamp/ballast combination is taken from the Advanced Lighting Guidelines. These values represent average input wattages for numerous lamp/ballast combinations in various fixture types. The wattages are accompanied by application factors that account for the effects on light output of ballast factor as well as thermal factor, which accounts for different operating temperatures inside different fixture types and can differ substantially from ANSI values. These wattages and application factors most accurately represent

\footnotetext{
${ }^{3}$ CEC, 1992. Op. cit, Ref. 2.
} 
lamp/ballast/fixture performance under actual operating conditions. They are referred to as Fixture Wattages in the engineering tables. These wattages are used to prepare input for fourfoot lamps the COMMEND model in the consumer analysis described in Section 4.

Since most eight-foot fixtures are generally open strip or industrial fixtures without lenses and operate at close to ANSI conditions, the Guidelines do not report wattages or application factors for eight-foot or eight-foot high output lamps. In this report, ANSI wattages are used for both types of eight-foot lamps to prepare COMMEND input.

Equipment prices for the commercial sector assume that the average customer purchases in large quantity. Average prices are derived from a comparison survey of various data sources, including an LBL Purchasing Department price survey for large quantity purchases, manufacturers' lamp price schedules, the Defense General Supply Center catalog for government prices, and several lighting analyses software data bases. Manufacturer factory cost data are not available. Equipment prices for the residential sector are those that would be paid by typical consumers buying small quantities and are derived from a survey of distributors' and manufacturers' price lists and utility surveys. Standard residential prices, especially for newer products, are more difficult to obtain, and further research on "average" national consumer prices for all design options is warranted. See Appendix B for further discussion on price assumptions.

Replacement times are based on information from the interNational Association of Lighting Maintenance Companies (NALMCO), Means, Lee Saylor, and NAVDOCS (see Section 2.2.1). The labor rates for commercial sector lamp and ballast replacement are taken from Means rate for an Electrician and an Electrician's Helper, including overhead and profit. Replacement times for lamps assume a group relamping situation, and for ballasts as individual replacements. It is assumed that homeowners install residential sector lamps, so installation costs are zero.

Annual lighting hours for the commercial sector are calculated from EIA's Lighting in Commercial Buildings, ${ }^{4}$ based on NBECS 1986 . A weighted average of building types and lamp types yields 4,103 hours per year for fluorescent lamps and 4,270 hours for incandescent lamps. Average residential hours of operation are derived from LBL's Residential Lighting Energy Usage spreadsheet model. These include a weighted average derived from usage of three to five hours per day (1,593 hours per year) for indoor lamps and four to nine hours per day $(2,228$ hours per year) for outdoor lamps.

These cost estimates are combined with the efficiency estimates to generate the cost-efficiency relationships found in the engineering tables in Appendix B. A more detailed description of the selection and sources of the above parameters is found in that appendix.

\footnotetext{
${ }^{4}$ DOE/EIA. 1992. Lighting in Commercial Buildings. Energy Information Administration, Washington, D.C., DOE/EIA-0555(92)/1.
} 


\subsubsection{Commercial Sector Analysis}

Results of the engineering analysis calculations are shown in Tables B.1 through B.19 in Appendix B. Annual electricity usage, annual energy cost, simple payback period, total life-cycle cost, and cost of conserved energy are presented. These LBL spreadsheets use standard engineering and economic analysis calculations. The spreadsheet life-cycle costs have been tested for consistency with those from National Institute of Standards and Technology's (NIST) Building Life-Cycle Cost Program, and found to be identical. LBL's spreadsheets are used in order to accommodate additions and special revisions.

The present value method of life-cycle cost (LCC) calculation is an economic indicator typically used in energy policy analyses. The LCC is the sum of first costs and discounted lifetime operating costs (i.e., energy and labor). Life-cycle cost typically varies widely over a range of efficiencies and available technology options. The LCC is thus a powerful tool for identifying least-cost policy options. LCC graphs are found for a range of lighting technology options in Figures B.1N-B.9N in Appendix B. As an example, Figure 3.1 shows the LCC for a baseline (0) and eight alternative designs of 4-foot fluorescent lamps.

\section{Normalization by Lumen Output}

Calculations for the commercial sector are presented in two forms. The first, in Tables B.1 through B.19 (Appendix B), uses actual wattage, equipment price, and replacement costs. This represents a simple retrofit situation, where new lamps are substituted for old lamps in existing fixtures on a one-for-one basis. Many technology options, however, have initial lumen output slightly different from the baseline standard lamp. Thus, users would experience slightly reduced or increased light output from the new system.

In most retrofit situations, users do not notice a light output reduction because the old lamps have undergone lumen depreciation and fixtures have become dirty; new lamps might even appear brighter after lenses are cleaned. However, in new construction or in major renovation, designers and specifiers have the opportunity to combine lamps and ballasts and fixtures to achieve desired light output. 
Figure 3.1

\section{Life Cycle Costs for 4 Foot Fluorescent Lamps with Electronic Ballast \\ Commercial Sector}

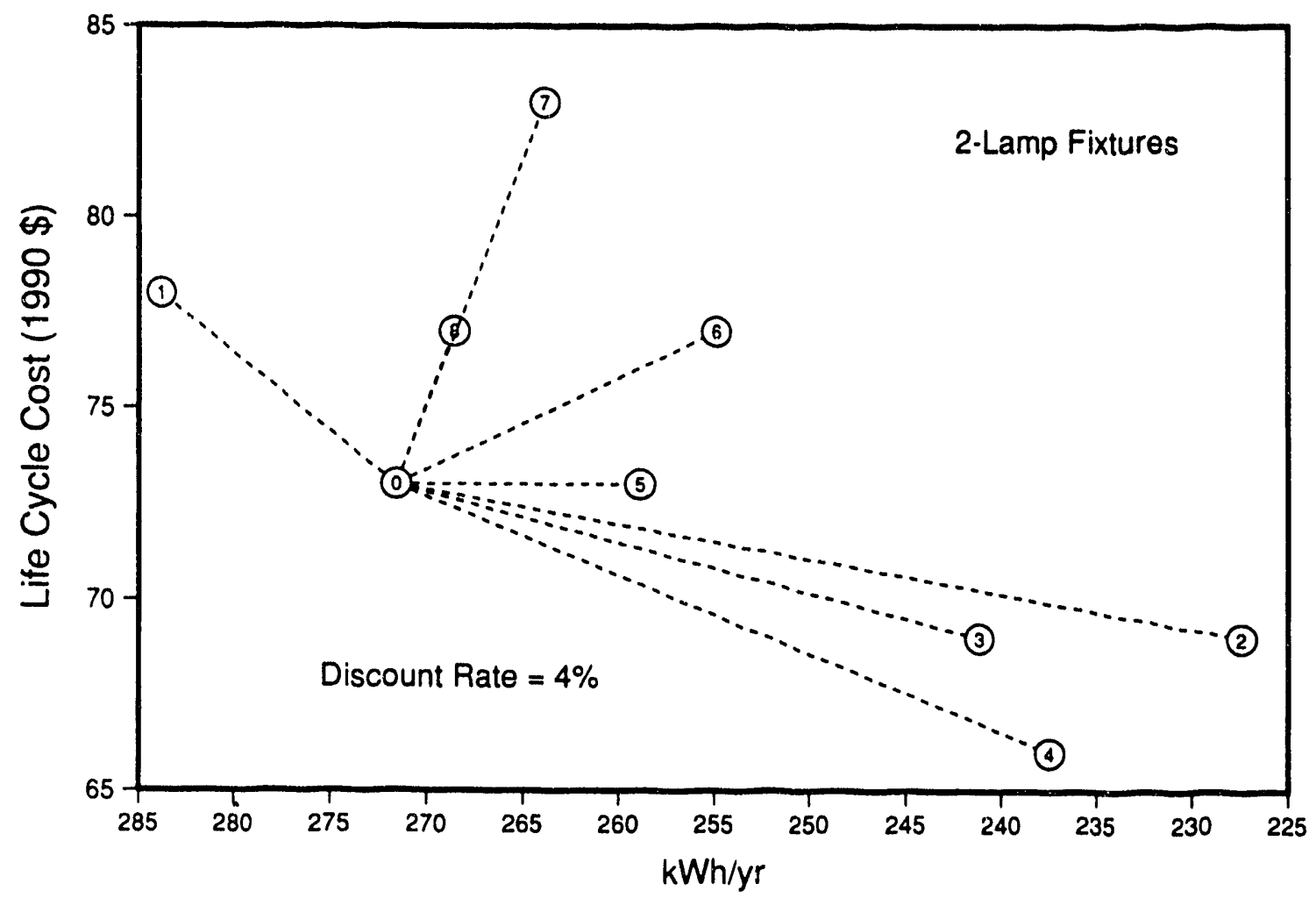

On average for a large planar area, it is assumed that the number of lamps used, multiplied by their rated initial lumen output, would be equivalent to the number of baseline lamps multiplied by their lumen output (see Light Output and Fixture Spacing below). In this way all lamps are treated equally based on their capacity to deliver light. "Normalization" by lumen output is accomplished by multiplying new lamp characteristics by the ratio of the new lamp lumen output to the baseline lumen output. The characteristics normalized in this manner are wattage, capital cost, and replacement cost. Normalized calculations are presented in Tables B.1N through B.19N. Fluorescent, incandescent general service, and compact fluorescent lamps are normalized for the commercial sector. Incandescent reflector lamps (Table B.3) are not normalized because lumen output data are not available for all technology options.

Normalization allows comparison of lighting systems with equivalent light output for new buildings. Normalization is inherently conservative because it assumes that there is no overlighting present in existing buildings. In reality, buildings undergoing renovation may have been designed to meet older IES recommended lighting levels. These levels were substantially revised (downwards) in 1987 from their previous 1972 values (see Table C.3 in Appendix C for historical comparison of IES levels.) IES recommended illuminance levels are actually a wide range of values for each task illuminance category. Actual installed lighting levels may be higher or lower than the middle value for that illuminance category. In overlit cases, replacement 
lighting equipment could be designed for lower light levels and still provide adequate illumination. In such cases, using normalized values underestimates encrgy savings. (For existing buildings, potential savings from delamping measures, e.g., with specular reflectors, are also excluded from this analysis because the limitations of the forecasting model prevent retrofits before the end of equipment lifetime [Section 4.2] and because delamping is not considered to be a measure easily influenced by federal policies).

For nearly all the policies modeled, normalized values are used, following the above assumptions. The single exceptions are the Eliminate Highest Wattage Fluorescent policy cases. In the 1991 Proposed Standards and the Energy Policy Act of 1992 cases for fluorescent lamps, the four-foot 34-watt T12 reduced-wattage lamp meets the standard. This lamp was designed as a retrofit product for installation in an existing lighting system where lighting levels are higher than the IES recommended levels, and where lamp lumen output has depreciated and fixtures need cleaning. In contrast, in new construction other lamp options are usually more appropriate (see Appendix A for a discussion of lamp characteristics). The intent and probable effect of lamp standards would be to replace the remaining standard F40 lamps with reduced-wattage lamps during a three- to five-year period; by the time new fixtures began to be installed, a next generation of lamp standards requiring a higher-efficiency product might take effect.

As discussed in Section 2.1.2, the present version of COMMEND, with its single lighting end use, does not allow energy consumption to be adjusted over the time horizon of the analysis (as would be the case with retrofitted lamps). Using normalized wattages to analyze the two fluorescent Lamp Standards cases would be overly conservative. In order to account for the special circumstances described above, energy savings and economic benefits for these cases are calculated using the actual (in-fixture) fluorescent wattages and costs; in other words, equivalent light output is not required for the replacement lamp/ballast/fixture system. In later years, savings from this case are probably too high.

\section{Light Output and Fixture Spacing}

Some members of the lighting community have argued that there are no practical energy savings benefits associated with fixtures/luminaires of slightly higher light output than standard ones. To provide a specific light level (e.g., 50 footcandles), 3-lamp fixtures on 8 by 8 -foot centers using standard lamps rated at 3,050 lumens would be used. When installed in a "typical space" with "typical reflectances," the result is 50 footcandles maintained. The argument is that there is no practical benefit to slightly more efficient equipment (specifically, with the same input power but more light output) because the fixture spacing remains the same; using the same spacing, no energy savings would result and light levels would be too high. Thus, there would be no benefit to more efficient equipment unless it produced enough additional lumens to allow the fixture spacing to increase to the next available standard spacing size (e.g., to 8 by 10 feet from 8 by 8 feet).

However, the light levels obtained in any installation reflect a combination of several factors, each with a considerable range: 
1. Ballast Factor (typically 0.7 to 1.0 )

2. Luminaire Efficiency (typically 60 to 75 percent)

3. Room Reflectances

4. Lamp Lumen Rating (typically 2650 to 3300 lumens)

If it were true that all ballasts had the same ballast factor, all fixtures the same efficiency, all rooms the same reflectance values, and all lamps the same lumen output, the above argument would be essentially correct. However, there is a wide range of values associated with each of the above variables. For example, electronic ballasts are now available with a large range of ballast factors; the conventional assumption of a 0.95 ballast factor is no longer realistic. Luminaire efficiencies even within a given product class also vary significantly. The so-called "standard" pattern 12 recessed troffer has luminaire efficiencies varying from 60 to 75 percent. Virtually no spaces have the 80/50/20 (ceiling, wall, and floor) percent reflectances assumed in the argument; typically, a range of reflectances is encountered depending on many factors. Finally, lumen ratings vary depending on phosphor composition, cathode type, etc.

When considered together, the multiplicative effect of all these factors allows considerable design flexibility with respect to providing the desired light level. For example, if an improved lamp puts out 5 percent more lumens, a ballast can be selected with a ballast factor that is 5 percent lower. The same is true for the other parameters. If the wall reflectance, for example, is actually 40 percent rather than 50 percent, the useful light at the task will be about 10-percent lower. While in the past construction practices have limited luminaire geometry, the variety of technologies available and flexible design practices should allow flexibility in luminaire location.

\section{Economics}

Economic calculations for incandescent lamps are presented in Tables B.1 - B.4, for compact fluorescent lamps (CFLs) in Tables B.5(N) and B.6, and for fluorescent lamps in Tables B.7(N) through B.19(N). Technology options are rank-ordered by simple payback according to the normalized tables (appearing to be out of order in the non-normalized tables). The fluorescent tables present the common two-lamp configuration, followed by one-, three-, and four-lamp configurations for four-foot lamps, and the one-lamp configuration for eight-foot lamps. The number of lamps generally does not alter the order of simple payback.

Note that the CFL tables are configured to reflect the different lifetimes of lamps and ballasts in the separable units. Economic calculations for fluorescent lamp/ballast combinations are presented in Tables B.13(N) through B.19(N), also configured for the different lamp ballast lifetimes. These tables allow comparison of life-cycle costs among ballast combinations while the lamp tables described above simply allow comparisons among different lamps using the same ballast. 


\section{Selection of Technology Options}

Tables 3.6 and 3.8 present the technology options and costs analyzed for lamps in the commercial sector. Tables 3.7 and 3.9 describe their efficacies, prices, and service lives.

Table 3.6 Fluorescent Lamp Technology Options Modeled (Commercial Sector)

\begin{tabular}{llll}
\hline $\begin{array}{l}\text { Technology } \\
\text { Optlon }\end{array}$ & \multicolumn{1}{c}{ 4-Foot } & 8-Foot & 8-Foot High-Output \\
\hline Baseline & Standard F40T12 & Standard F96T12 & Standard F96T12 HO \\
$\begin{array}{l}\text { Eliminate Highest } \\
\text { Wattage }\end{array}$ & 34 W T12 Reduced-Wattage & 60 W Reduced-Wattage & 95 W Reduced-Wattage \\
$\begin{array}{l}\text { Minimum LCC } \\
\text { Lamp }\end{array}$ & F32 T8 w/ Magnetic Ballast & 60 W Reduced-Watlage & 95 W Reduced-Wattage \\
$\begin{array}{l}\text { Max Tech } \\
\text { R \& D Lamp }\end{array}$ & Maximum Technology & T8 w/ Electronic Ballast & Maximum Technology \\
$\begin{array}{l}\text { Min LCC } \\
\text { Combination }\end{array}$ & $\begin{array}{l}\text { F32 T8 with Electronic } \\
\text { Ballast }\end{array}$ & $\begin{array}{l}60 \mathrm{~W} \text { Reduced-Wattage with } \\
\text { Electronic Ballast }\end{array}$ & $\begin{array}{l}\text { 95 W Reduced-Wattage with } \\
\text { Electronic Ballast }\end{array}$ \\
$\begin{array}{l}\text { R\&D Combination } \\
\text { Research and Development }\end{array}$ & Research and Development & Research and Development \\
\hline
\end{tabular}

Table 3.7 Fluorescent Lamp Efficacies, Prices, and Service Lives (Commencial Sector)

\begin{tabular}{lllccc}
\hline Product Class & \multicolumn{1}{c}{ Technology Option } & \multicolumn{2}{c}{$\begin{array}{c}\text { Emcacy } \\
\text { (Lumens/Watt) } \\
\text { 2-lamp, 1-ballast }\end{array}$} & $\begin{array}{c}\text { Lamp } \\
\text { Price } \\
\text { (\$1990) }\end{array}$ & $\begin{array}{c}\text { Service Life } \\
\text { (Years) }\end{array}$ \\
& & $\begin{array}{c}\text { Magnetic } \\
\text { Ballast }\end{array}$ & $\begin{array}{c}\text { Electronic } \\
\text { Ballast }\end{array}$ & & \\
\hline 4-Foot Lamps & F40 T12 & 65 & 75 & 1.12 & 3.41 \\
& 34 W Reduced Wattage T12 & 64 & 75 & 1.56 & 3.41 \\
& F32 T8 & 78 & 88 & 2.45 & 3.66 \\
& T8 (Max Tech) & 91 & 100 & 2.94 & 3.66 \\
& R\&D & 100 & 110 & 3.43 & 3.66 \\
8-Foot Lamps & F96 T12 & 70 & 84 & 2.60 & 2.05 \\
& 60 W Reduced-Watage & 73 & 90 & 3.27 & 2.05 \\
& T8 (Max Tech) & NA & 94 & 8.50 & 2.56 \\
8-Foot HO & F96 T12 HO & 68 & 84 & 3.52 & 2.05 \\
& 95 W Reduced-Wattage & 72 & 84 & 4.50 & 2.05 \\
\hline
\end{tabular}


Table 3.8 Incandescent Lamp Technology Options Modeled (Commercial Sector)

\begin{tabular}{|c|c|c|c|}
\hline $\begin{array}{l}\text { Technology Option } \\
\text { or Policy Case }\end{array}$ & $\begin{array}{l}\text { General Service } \\
\text { Incandescent }\end{array}$ & $\begin{array}{l}\text { Reflector } \\
\text { Incandescent }\end{array}$ & $\begin{array}{l}\text { Compact } \\
\text { Fluorescent }\end{array}$ \\
\hline Baseline & $\begin{array}{l}\text { Standard A-Lamp } \\
(75 \mathrm{~W})\end{array}$ & $\begin{array}{l}\text { Standard Reflector } \\
(150 \mathrm{~W})\end{array}$ & Standard Incandescent \\
\hline $\begin{array}{l}\text { Eliminate Highest } \\
\text { Wattage }\end{array}$ & $\begin{array}{l}\text { Reduced-Wattage } \\
(67 \mathrm{~W})\end{array}$ & $\begin{array}{l}\text { Reduced-Wattage } \\
(120 \mathrm{~W})\end{array}$ & \\
\hline Minimum LCC Lamp & $\begin{array}{l}\text { Halogen } \\
(72 \mathrm{~W})\end{array}$ & $\begin{array}{l}\text { Halogen Infrared } \\
(60 \mathrm{~W})\end{array}$ & \\
\hline Max Tech & Halogen Infrared & Halogen Infrared & \\
\hline R \& D Lamp & Coated Filament & Coated Filament & \\
\hline $\begin{array}{l}1991 \text { Proposed } \\
\text { Standards }\end{array}$ & Reduced-Wattage & Halogen & \\
\hline $\begin{array}{l}\text { Energy Policy Act, } \\
1992\end{array}$ & Standard & Halogen & \\
\hline CFL Downlights & Standard & Standard & $\begin{array}{l}\text { Twin Tube + } \\
\text { Magnetic Ballast }\end{array}$ \\
\hline $\begin{array}{l}\text { Min LCC } \\
\text { Combination }\end{array}$ & Halogen & Halogen Infrared & $\begin{array}{l}\text { Twin Tube + Magnetic } \\
\text { Ballast }\end{array}$ \\
\hline R\&D Combination & Coated Filament & Coated Filament & $\begin{array}{l}\text { Quad Tube with } \\
\text { Electronic Ballast }\end{array}$ \\
\hline
\end{tabular}


Table 3.9 Incandescent Lamp Prices, Efficacies, and Service Lives (Commercial Sector)

\begin{tabular}{llccc}
\hline Product Class & \multicolumn{1}{c}{ Technology Option } & $\begin{array}{c}\text { Emicacy } \\
\text { (Lumens/Watt) }\end{array}$ & $\begin{array}{c}\text { Lamp Price } \\
\mathbf{( \$ 1 9 9 0 )}\end{array}$ & $\begin{array}{c}\text { Service Life } \\
\text { (Years) }\end{array}$ \\
\hline General Service & Standard (75 W) & 16 & 0.34 & 0.18 \\
& Reduced-Watage (67 W) & 17 & 0.43 & 0.18 \\
& Halogen (72 W) & 18 & 1.87 & 0.82 \\
& Halogen Infrared & 21 & 3.43 & 0.47 \\
& Coated Filament & 50 & 5.35 & 0.82 \\
Reflector & Baseline (150 W) & & & \\
& Reduced-Wattage (120 W) & 13 & 3.66 & 0.47 \\
& Halogen (90W) & NA & 3.63 & 0.47 \\
& Halogen Infrared (60 W) & NA & 4.91 & 0.47 \\
& Coated Filament & 50 & 6.15 & 0.58 \\
Compact & Baseline Incandescent (60 W) & 15 & & 0.82 \\
Fluorescent & Twin Tube + Magnetic Ballast & 62 & 0.34 & 0.18 \\
& Quad Tube with Electronic & 69 & $($ lamp/ballast) & (lamp/ballast) \\
& Ballast & & 9.12 (unit) & 2.11 \\
& & & & \\
\hline
\end{tabular}

The selection rationale for technology options in the lamp policy cases is the following. Sections 3.3 and 3.4 describe the engineering analyses for fixtures and controls.

Eliminate Highest Wattage involves moving from the baseline to the next highest wattage lamps in the normalized tables, which are the "reduced-wattage" fluorescent and incandescent lamps. The 1991 version of the Congressional energy legislation included lamp standards met by these lamps. However, the final version of the legislation exempts incandescent general service lamps from mandatory standards. Both of these lamp standard versions are analyzed; see description of the 1991 Proposed Standards case and the Energy Policy Act of 1992 case below and Table 3.8 for details.

Minimum Life-Cycle Cost maximizes benefits to purchasers. This option is analyzed for fluorescent lamps, for a combination of incandescent general service and reflector lamps, for a fluorescent lamp/ballast combination, for controls, and for a Combination case described below.

The Maximum Technologically Feasible (Max Tech) option is a technology that could reach the commercial prototype stage by 1995 , which would result in the greatest energy savings possible for each product class achievable in the near term. Maximum technological feasibility is analyzed for fluorescent lamps, a combination of incandescent general service and reflector lamps, and fixtures. 
Research and Development determines the effects of lamp technologies now in the research and development stage that could be commercialized after 1995. This option is analyzed for fluorescent lamps, a fluorescent lamp/ballast combination, incandescent lamps, a combination of fluorescent and incandescent lamps, and for the R\&D Combination case described below.

Compact Fluorescent Downlights is a prescriptive policy assuming compact fluorescent lamp retrofits in all incandescent downlights (but not all incandescent fixtures); it was applied to new construction and renovation only. CFLs are treated differently in the Combination cases below.

1991 Proposed Standards represents the lamp standards incorporated into H.R. 776, passed by the Energy and Power Subcommittee of the House Energy and Commerce Committee, in the 1991 legislation discussed above.

Energy Policy Act of 1992 represents the consensus lamp standards developed jointly by industry representatives and conservation advocates. These standards are in the Energy Policy Act of 1992 (Public Law 102-486) mentioned above.

Minimum Life-Cycle Cost Combination models the effects of the minimum life-cycle cost technologies for each component (lamps, ballasts, fixtures, controls) used in combination with the others. The interactive effects of the lamps and ballast with the fixture are considered through use of the Fixture Watts described in Section 3.2.3. The minimum LCC fixture is called a "high-efficiency fixture" and represents a 10 percent improvement in average fixture efficiency from 1991 levels. The controls selected are those used in the individual controls policy cases (see Section 3.4), and their effects on reducing consumption are calculated assuming the efficient lamp/ballast/fixture technologies are in place.

Research and Development Combination is similar to the Minimum LCC Combination policy case. It models the effects of the R\&D technology for all components used interactively. The R\&D fixture is a "super-efficient" fixture using specular reflectors described in Section 3.3 and Appendix A. The controls selected are those from the R\&D controls tables (3.18 and 3.20) in Section 3.4.

\subsubsection{Residential Sector Analysis}

Results of the engineering analysis for the residential sector are presented in Tables B.2, B.4, and B.6. Only non-normalized tables are used for the residential sector because it is assumed that homeowners, builders, and interior designers will not compensate for slightly reduced light output from incandescent lamps by installing more fixtures or more lamps. No provision is made for the possibility that consumers might choose a higher wattage lamp, e.g. a 90-watt rather than a 67-watt to replace a 75-watt lamp, or install more task lighting. Because of first costs, fewer consumers would choose to upgrade, but the savings from some consumers switching to other options such as CFLs would be enough to offet the use of higher wattage lamps by other consumers. 
The technology options in Table 3.10 are analyzed for the residential sector. Table 3.11 describes their characteristics.

Ten lamp policy cases are modeled. One incandescent case models the combination of a reduced-wattage general service lamp (which is also the Min LCC lamp) and halogen reflector lamp, representing the 1991 Proposed Standards. Another case, which represents the Energy Policy Act of 1992 (EPA-92), models only the halogen reflector lamp. The compact fluorescent prescriptive policy case specifies CFLs in sockets used more than three hours per day, if the CFL can fit into the fixture. A Max Tech and an R\&D lamp case each models the impacts of a standard requiring those lamps. The Minimum Life-Cycle Cost Combination models the minimum LCC technologies together with CFL replacement. The R\&D Combination models the R\&D technologies with further CFL replacement. An "eliminate highest wattage" fluorescent case estimates the impacts of the EPA-92 on residential fluorescents, and a combination policy estimates the impacts of the EPA-92 fluorescent and incandescent lamp standards. See Section 5.1.2 for further description of the residential policy cases.

\subsubsection{Inputs to Consumer Analyses}

Commercial sector results of the Engineering Analysis are used to prepare inputs to the COMMEND model. In most cases, normalized wattage is used to develop Energy Use Intensities (EUIs). Normalized costs are used in economic net present value calculations. The exception is the Eliminate Highest Wattage fluorescent case, as discussed in Section 3.2.4. See Appendix $\mathrm{D}$ for the COMMEND input spreadsheets.

Wattages, lifetimes, and costs from the engineering tables are used in the Residential Lighting Energy Usage Spreadsheets. These calculate aggregated Unit Energy Consumption (UEC, $\mathrm{kWh}$ /household-year), costs, and lamp service lives separately for prototype single-family homes, mobile homes, and multifamily dwellings. These prototypes are developed from a number of utility Residential Appliance Saturation Surveys (RASSes), monitored lighting usage surveys, and other utility residential lighting estimates. Residential sector results from the spreadsheet model are used in the REM analysis. See Section 2.1.1 for a description of model data development, Appendix E for a general description of the LBL-REM model, and Section 5 for results of the residential analysis. 
Table 3.10

Lamp Technology Options Modeled (Residential Sector)

\begin{tabular}{|c|c|c|c|}
\hline Technology Option & $\begin{array}{l}\text { General Service } \\
\text { Incandescent }\end{array}$ & $\begin{array}{c}\text { Reflector } \\
\text { Incandescent }\end{array}$ & Compact Fluorescent \\
\hline Baseline & Standard (75 W) & Standard $(75 \mathrm{~W})$ & Standard Incandescent \\
\hline $\begin{array}{l}\text { Eliminate Highest } \\
\text { Wattage Inc. }\end{array}$ & Reduced-Wattage (67 W) & Reduced-Watuage & \\
\hline $\begin{array}{l}1991 \text { Proposed } \\
\text { Standards (Inc. Lamps) }\end{array}$ & Reduced-Wattage (65 W) & Halogen Reflector & \\
\hline $\begin{array}{l}\text { Energy Policy Act, } \\
\text { 1992, (Inc. Lamps) }\end{array}$ & Standard & Halogen Reflector & \\
\hline Max Tech & Halogen Infrared & Halogen Infrared & \\
\hline CFL & Standard & Standard & Twin Tube Lamp + Mag Ballast \\
\hline$R \& D$ & Coated Filament & Coated Filament & \\
\hline Min LCC Combination & Reduced-Wattage & Halogen Reflector & Twin Tube Lamp + Mag Ballast \\
\hline R\&D Combination & R\&D & R\&D & Quad Tube with Elect Ballast \\
\hline $\begin{array}{l}\text { Eliminate Highest } \\
\text { Wattage Fluor. }\end{array}$ & Reduced-Wattage Fluor & $\mathbf{N} / \mathbf{A}$ & N/A \\
\hline
\end{tabular}

Table 3.11 Lamp Efficacies, Prices and Service Lives (Residential Sector)

\begin{tabular}{llccc}
\hline Product Class & \multicolumn{1}{c}{ Technology Option } & $\begin{array}{c}\text { Enicacy } \\
\text { (Lumens/Watt) }\end{array}$ & $\begin{array}{c}\text { Lamp Price } \\
\text { (\$1990) }\end{array}$ & $\begin{array}{c}\text { Service Life } \\
\text { (Years) }\end{array}$ \\
\hline General Service & Standard (75 W) & 16 & 0.48 & 0.47 \\
& Reduced-Wattage (67 W) & 17 & 0.60 & 0.47 \\
& Halogen Infrared & 21 & 7.98 & 1.26 \\
& Coated Filament & 50 & 11.63 & 2.20 \\
Reflector & Standard (75 W) & & & \\
& Reduced-Wattage Reflector (65 W) & 10 & 5.19 & 0.90 \\
& Halogen Reflector & NA & 7.50 & 0.90 \\
& Halogen Infrared & NA & 10.79 & 0.90 \\
& Coated Filament & 50 & 12.02 & 1.12 \\
Compact & Baseline Incandescent & & & 1.57 \\
Fluorescent & Twin Tube + Magnetic Ballast & 62 & $4.02 / 9.68$ & $5.96 / 28.29$ \\
& & & $($ lamp/ballast) & $($ (lamp/ballast) \\
& Quad Tube with Electronic Ballast & 69 & 14.47 (unit) & 5.65 \\
Full-Size & Standard F40 T12 & & & 10.95 \\
Fluorescent & 34W T12 Reduced-Wattage & 65 & 1.00 & 10.95 \\
\hline
\end{tabular}




\subsection{FIXTURES/LUMINAIRES}

\subsubsection{Introduction}

This section discusses regulation of the efficiency of the fixture component of the luminaire system and presents a methodology for analyzing fluorescent fixture standards for the commercial sector. The goal is to develop a simple luminaire efficiency standard that would eliminate the least efficient fixtures on the market and encourage the commercialization and use of more efficient advanced technologies than are presently available.

This study does not examine incandescent fixtures, compact fluorescent fixtures, or high intensity discharge (HID) fixtures. Full-sized fluorescent fixtures are analyzed because they consume the majority of energy in the commercial sector and because of existing state and federal legislative interest in fluorescent fixture standards.

\section{Definitions}

A fixture is a housing for securing lamp(s) and ballast(s) and for controlling light distribution to a work plane or area. Light distribution is determined by reflector and/or lens material and geometry. Fixture performance is assessed by luminaire efficiency and the geometric distribution of light. Luminaire efficiency and many other fixture performance characteristics are presented in of photometric reports, which are performed by manufacturers or independent testing laboratories according to specified, procedures.

A luminaire is a lighting system consisting of the fixture, lamp(s), and ballast(s).

Luminaire efficiency is defined as the ratio of the total light output from the fixture containing the lamps to the total light output of the same (bare) lamps, both in a $25^{\circ} \mathrm{C}$ thermal environment. While the correct term is luminaire efficiency, this parameter is sometimes referred to as fixture efficiency.

Candlepower is the luminous intensity in the direction of view; units are lumens/unit solid angle.

The coefficient of utilization (CU) is a metric for evaluating the effectiveness of an entire lighting system (luminaire), incorporating luminaire efficiency, light distribution, room cavity ratio (RCR), and wall, floor, and ceiling reflectivities. It is defined as the ratio of lumens intercepting the work plane to total lamp lumens emitted from all the lamps in the ceiling lighting system.

Luminance is the luminous flux per unit solid angle (one steradian) emitted from a small area of a luminous surface in a given direction. Units are footlamberts (fL) Even though the use of fL has been deprecated by the IES, it is used in this analysis because of its presence in many photometric reports.

Room Cavity Ratio $(R C R)$ indicates room proportions by relating the area (length $\mathrm{x}$ width) of the 
room cavity to its height.

\section{Present Proposed Regulations and Classifications}

The New York State building energy code, adopted in March 1991, regulates luminaire efficiency. The code classifies fixtures by type: small-cell louver, large-cell louver, wraparound, flat diffuser lens, and other. Each fixture type is further classified into one of three categories of light distribution: narrow, medium, or wide. This classification is based on the percentage of flux within the range of 0 to $40^{\circ}$ from vertical (see Figure 3.2). There are 15 fixture categories.

The National Electrical Manufacturers Association (NEMA) has proposed a draft rating methodology based on luminaire efficacy, the Luminaire Efficacy Rating (LER) ${ }^{5}$. LER is defined as the ratio of the total fixture lumens (incorporating ballast factor) to the system input wattage (lumens/watt). It includes the effects of each system component: fixture, lamp, and ballast. This method has categories based on fixture type with sub-categories based on several parameters, for a large number of sub-categories. LER is described further in Section 3.3.5.

The Energy Policy Act of 1992 includes a provision for development of a voluntary national energy-efficiency rating and labeling program for luminaires. This program will be developed, within one year after enactment of the legislation (October 1992), by DOE in consultation with NEMA, industry representatives, and other appropriate organizations. If such a program is not established with two years of enactment, DOE in consultation with NIST will develop a luminaire rating program within one more year.

\subsubsection{Product Classes and Technology Options}

\section{Product Classes}

The first step in analyzing luminaire efficiency standards is to choose product classes. The number of classes is ideally kept to the minimum necessary to represent most fixture applications.

In this analysis, fixtures are first classified by fixture type: open/louvered, enclosed/lensed, wraparound, and other. Open/louvered fixtures include large-cell parabolics, small-cell parabolics, and shielded fixtures. Enclosed/lensed fixtures are also referred to as lensed troffers. Other fixture types include strip and industrial fixtures. See Figures A-6 and A-7, Appendix A for diagrams of fluorescent fixtures. Large-cell parabolic fixtures fall within both the narrow and wide open/louvered product classes. Small-cell parabolics have mostly narrow distribution. Luminaire efficiency for direct lighting systems generally depends on light distribution. For example, narrow distribution fixtures tend to have lower efficiency due to the increased control (more internal reflection) needed to limit the light emitted at high angles and thereby minimize

\footnotetext{
${ }^{5}$ National Electrical Manufacturers Association. 1992. "Procedure for Determining Luminaire Efficacy Ratings for Fluorescent Luminaires." Washington, DC. NEMA Standards Publication LE-5-1991.
} 
glare. This classification system allows fixtures designed for narrow light distribution to have less strict efficiency limits than fixtures designed for wider distribution applications.

Some fixtures of the same type, especially parabolic louvers, can have very different distribution characteristics. Alternatively, large-cell parabolic, small-cell parabolic, and lensed troffers can have the same light distribution and could each be used in the same application. However, the lighting designers' choice would then be governed by price, fixture appearance, and/or efficiency.

Strip and industrial fixtures fall into the other product class. They are typically 85 to 90 percent efficient, since they are closer to the bare lamp/ballast conditions that define one hundred percent efficiency. Most of these are 8-foot fixtures; luminaire efficiency standards are not considered for these fixture types in this analysis.

Classification based on light distribution properties is a desirable approach, since it is a primary basis on which designers choose fixtures. Figure 3.2 illustrates the geometry of light distribution. For example, narrow distribution fixtures, which concentrate light on a work area and reduce glare by minimizing the amount of light in the $60-90^{\circ}$ zone, are usually selected for offices that contain many video display terminals. Parabolic (open/louvered) fixtures are most often used for applications where minimizing glare is desired; luminance should not exceed certain levels at specific viewing angles. For the parabolic fixture type, light distribution is characterized for this analysis by luminance at $65^{\circ}$ from vertical, averaged over 3 azimuth planes $\left(0,45\right.$, and $\left.90^{\circ}\right)$. Luminance, measured in foot-lamberts (fL), combined with the viewing angle is related to direct glare and causes reflected glare in computer screens. Luminance at $65^{\circ}\left(\mathrm{L}\left[65^{\circ}\right]\right)$ is the mean value from the IES (Illuminating Engineering Society) Recommended Practice for Lighting Offices Containing Computer VDTs (RP-24).

Fixture product classes are listed in Table 3.12.

Table 3.12 Product Classes for Fixtures

\section{Luminaire Type}

1. Open/louvered" (narrow distribution)

$\left(\mathrm{L}[65]^{\circ}\right)^{\circ}<250 \mathrm{fL}$, Flux $90-180^{\circ}=0 \%$ )

2. Open/louvered" (wide distribution)

$\left(\mathrm{L}\left[65^{\circ}\right] \geq 250 \mathrm{R}\right.$ )

3. Wraparound

4. Enclosed/lensed

(Flux $90-180^{\circ}=0 \%$ or Flux $\left.0-90^{\circ}=0 \%\right)^{c}$

5. Other

- Subtract $5 \%$ for all air-handling luminaires

${ }^{b}$ Luminance at $65^{\circ}$ vertical angle averaged over the 0,45 , and $90^{\circ}$ azimuth planes

'Indirect fixtures with no downwards light flux 
Figure 3.2 Fluorescent Luminaire Light Distribution Geometry
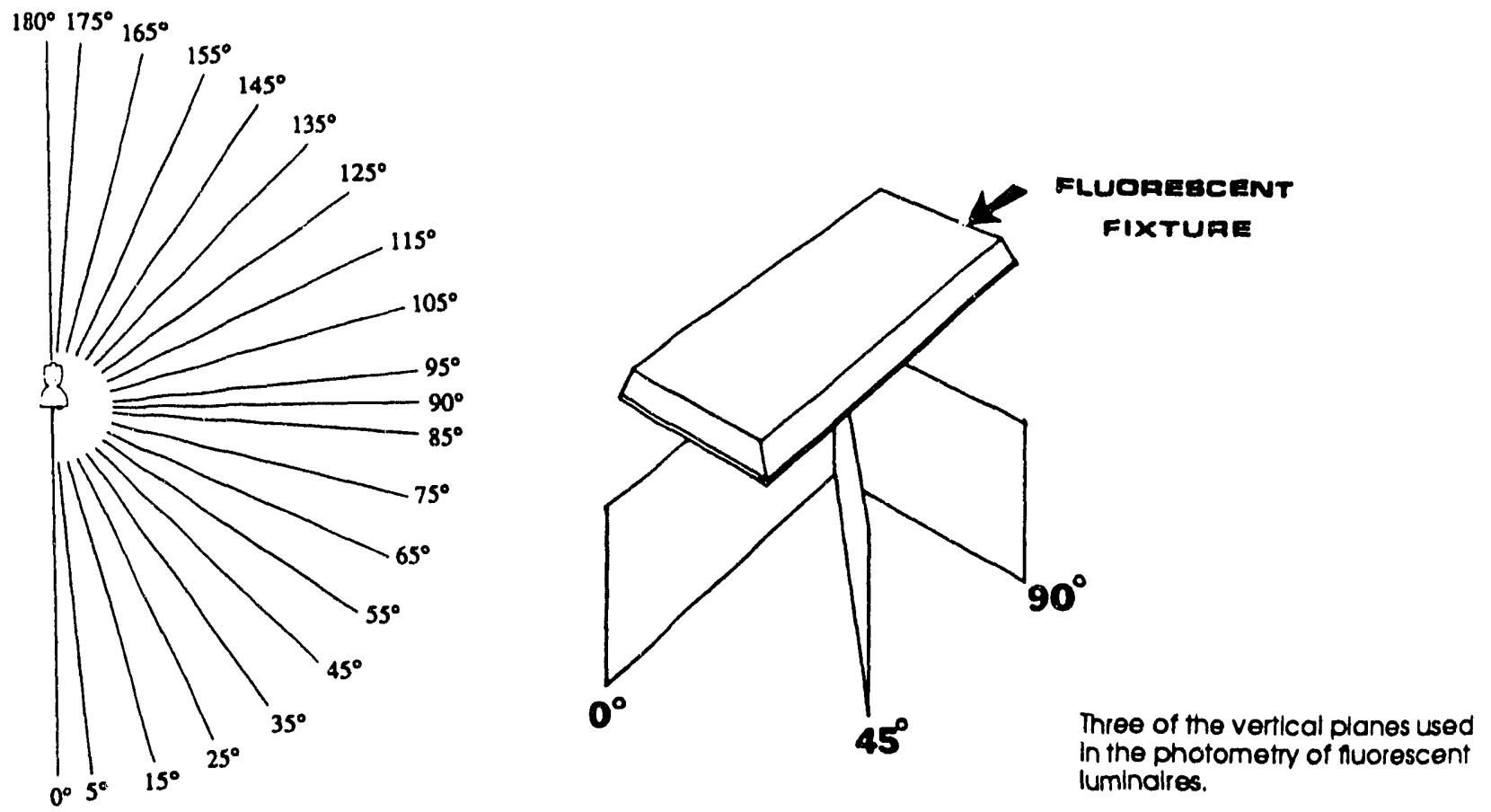

Vertical angles used in photometry.

Source: Applied Illumination Engineering by Jack Lindsey

Fairmont Press, 1991.

\section{Data Analysis for Technology Options}

Consultation with lighting and fixture designers yielded some consensus on which types of fixtures they believe to be least efficient. The approach has been tested to ensure that the greatest percentage of inefficient fixtures are eliminated by a trial standard level. The designers concur that four-lamp fixtures, which tend to be less efficient, could be replaced by three- and two-lamp fixtures. Also, typical four-lamp luminaires at typical spacings produce more light than is necessary to accommodate today's lower lighting levels. Alternatively, four-lamp fixtures could be made more efficient by using advanced ("max tech") technologies (see Appendix A for description). Similarly, the small-cell louvered fixture has relatively low efficiency and could be improved by advanced technologies.

A database has been created of a large number of fixtures (representing low-, medium-, and highcost ranges) from major manufacturers' 1991 catalogs. Data for open/louvered (large- and smallcell), wraparound, enclosed/lensed, strip, and industrial fixtures are listed. These include airhandling fixtures, specular reflectors, and improved small-cell parabolic fixtures. 
In the database, fixtures are assigned a product class based on their fixture type and luminance (if appropriate). Data include number of lamps, luminaire efficiency, luminance at $65^{\circ}$, and Coefficient of Utilization, entered by fixture type and distribution category. Within each fixture type, fixtures are sub-grouped by number of lamps (1-, 2-, 3-, and 4-lamp fixtures). Average luminaire efficiency is calculated for each sub-group.

Results of the data analysis are presented in Figures 3.3 through 3.9. The analysis also shows that, on average, efficiencies of four-lamp fixtures are the lowest.

\section{Technology Options}

Four draft luminaire efficiency levels are chosen for each product class (Table 3.13), and luminaire efficiency vs. luminance are plotted for both fixture type and number of lamps in Figures 3.3 and 3.4 .

Table 3.13 Luminaire Efficiency Levels

\begin{tabular}{lcccc}
\hline & \multicolumn{3}{c}{ Product Class } \\
\cline { 2 - 5 } Level & Open (Narrow) & Open (Wide) & Wraparound & Enclosed/Lensed \\
\hline 1 & $55 \%$ & $60 \%$ & $65 \%$ & $60 \%$ \\
2 (Technology Option 1) & $60 \%$ & $65 \%$ & $70 \%$ & $65 \%$ \\
3 & $65 \%$ & $70 \%$ & $75 \%$ & $70 \%$ \\
Max Tech (Technology Option 2) & $85 \%$ & $90 \%$ & $90 \%$ & $90 \%$ \\
\hline
\end{tabular}

The percentage of each product class meeting the three levels is presented in Table 3.14. This method selectively eliminates a higher percentage of four-lamp and small-cell parabolic fixtures because they tend to have the lowest efficiency in each class. 
Table 3.14 Fixtures Passing Standard Levels (1991 Models)

\begin{tabular}{|c|c|c|c|c|}
\hline Product Class & $\begin{array}{l}\text { Luminaire } \\
\text { Efriciency } \\
\text { Standard } \\
\text { Level }\end{array}$ & $\begin{array}{l}\text { Number } \\
\text { Passing } \\
\text { Standard }\end{array}$ & $\begin{array}{l}\text { Percent } \\
\text { Passing } \\
\text { Standard }\end{array}$ & $\begin{array}{l}\text { Average } \\
\text { Luminaire } \\
\text { Erriciency of } \\
\text { Passing } \\
\text { Fixtures }\end{array}$ \\
\hline \multicolumn{5}{|c|}{ Open, Wide Distribution (37 total) } \\
\hline Level 1 & $60 \%$ & 36 & $97 \%$ & $73 \%$ \\
\hline Level 2 & $65 \%$ & 32 & $86 \%$ & $74 \%$ \\
\hline Level 3 & $70 \%$ & 23 & $62 \%$ & $77 \%$ \\
\hline Max Tech & $90 \%$ & 2 & $5 \%$ & $90 \%$ \\
\hline \multicolumn{5}{|c|}{ Open, Narrow Distribution (93 total) } \\
\hline Level 1 & $55 \%$ & 72 & $77 \%$ & $65 \%$ \\
\hline Level 2 & $60 \%$ & 55 & $59 \%$ & $68 \%$ \\
\hline Level 3 & $65 \%$ & 36 & $39 \%$ & $71 \%$ \\
\hline Max Tech & $85 \%$ & 0 & $0 \%$ & NA \\
\hline \multicolumn{5}{|c|}{ Lensed Troffer (59 total) } \\
\hline Level 1 & $60 \%$ & 47 & $80 \%$ & $72 \%$ \\
\hline Level 2 & $65 \%$ & 40 & $68 \%$ & $74 \%$ \\
\hline Level 3 & $70 \%$ & 28 & $47 \%$ & $77 \%$ \\
\hline Max Tech & $90 \%$ & 0 & $0 \%$ & NA \\
\hline \multicolumn{5}{|c|}{ Wraparound (28 total) } \\
\hline Level 1 & $65 \%$ & 22 & $79 \%$ & $73 \%$ \\
\hline Level 2 & $70 \%$ & 16 & $57 \%$ & $76 \%$ \\
\hline Level 3 & $75 \%$ & 9 & $32 \%$ & $78 \%$ \\
\hline Max Tech & $90 \%$ & 0 & $0 \%$ & NA \\
\hline
\end{tabular}

Technology Option 1 is Level 2, the set of medium efficiency levels listed in Table 3.13. Level 2 achieves the goal of eliminating a large number of lower efficiency four-lamp fixtures and many small-cell parabolic louvers.

Technology Option 2, or Maximum Technologically Feasible, includes new fixtures that use advanced technologies to achieve higher efficiency levels. These technologies, specular reflectors in new fixtures and efficient small-cell parabolic designs, are described in Section A.5, Appendix A. Implementing these technologies in fixtures that do not meet Technology Option 1 standard levels would improve tieir efficiency, so that they could meet the standards. 
Commercial Open Fixture Standards, by Fixture Type

\section{Fixture Efficiency}

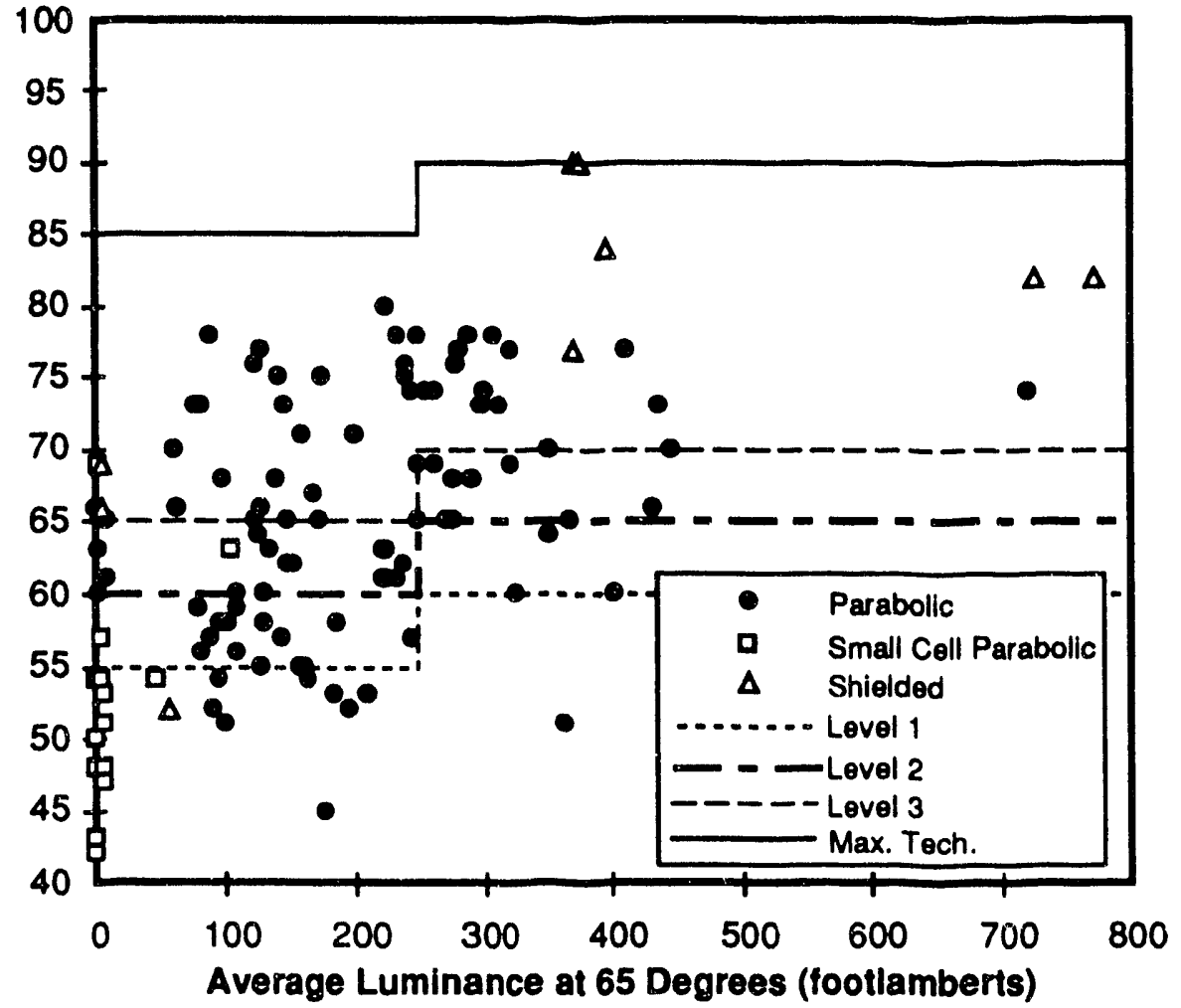

Figure 3.4

Commercial Open Fixture Standards, by Number of Lamps

Fixture Efticiency

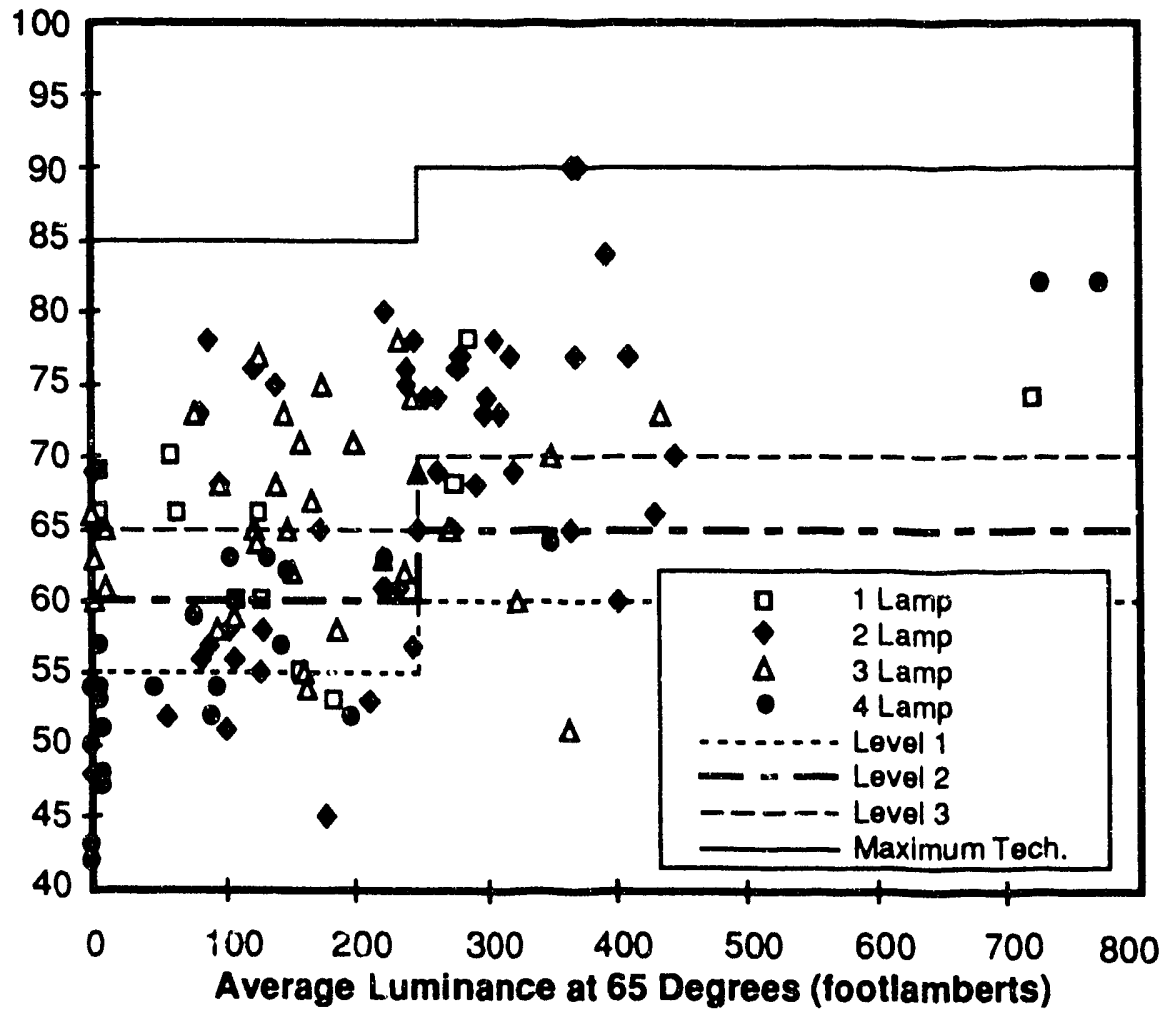

$3-22$ 


\section{Percont Paseing Standard}

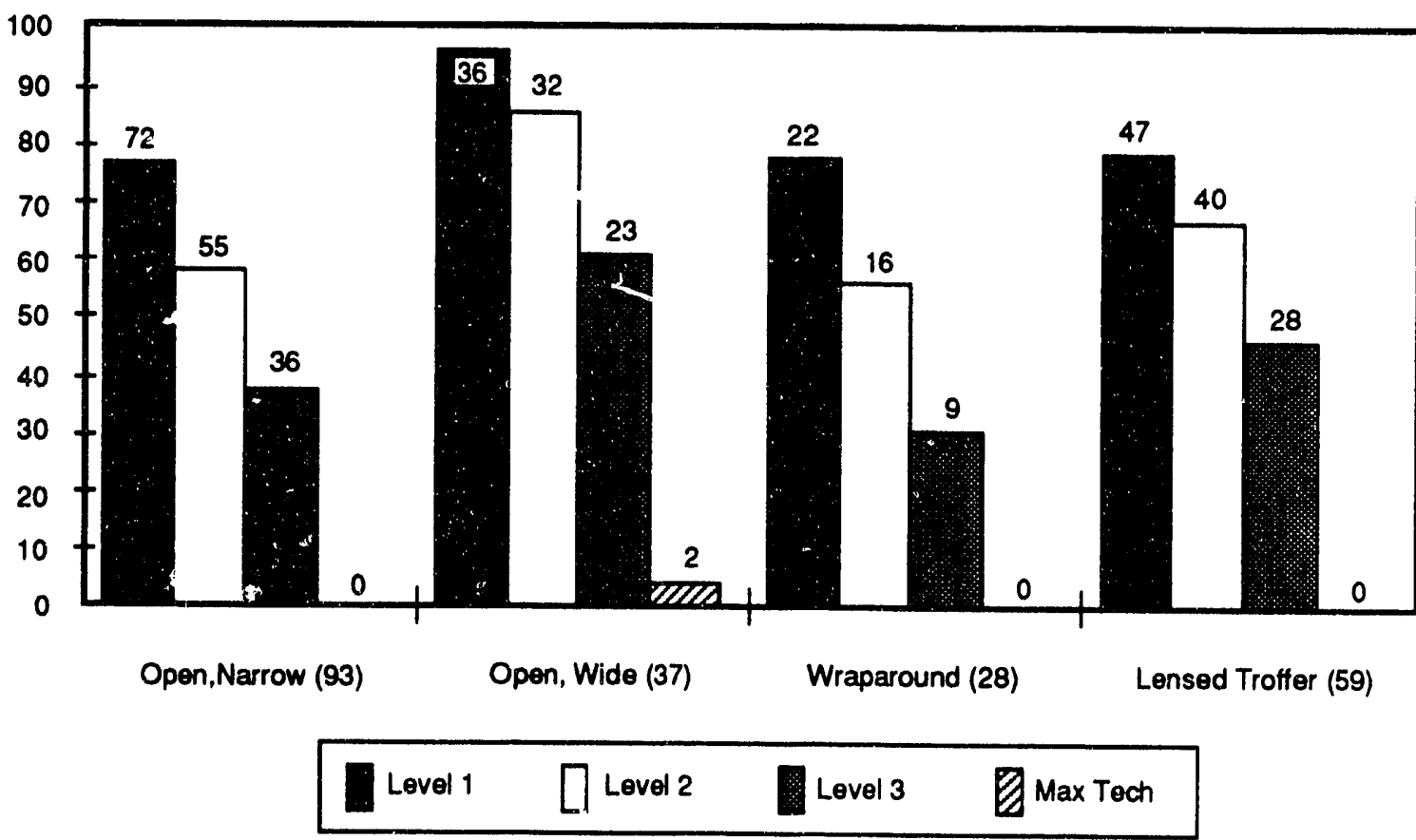

Notes: Numbers of passing fixtures shown above bars; total number of fixtures shown in parentheses. Standard levels different for each fixture type; see Table 3.13.

Specific design options are not analyzed because of the complexity of fixture shape and the relationship between the system components. Variations in luminaire efficiency exist among fixtures in the same category, even those with similar features such as specular reflective surfaces. Estimation of the effect of a small change in luminaire efficiency on system wattage is also difficult. In fact, two fixtures with the same rated luminaire efficiency and the same lamp/ballast combination can draw different wattages or produce different lumen outputs because of design complexities and differences in thermal operating environment. Thus, the analysis does not cover more discrete design improvements, but instead uses efficiency standards that can be met by a variety of techniques.

\subsubsection{Energy Use Data}

This section describes the method for translating data from the technology options analysis into COMMEND modeling input. The goal is to calculate the effect of efficiencies corresponding to Technology Option 1 or Technology Option 2.

Market shares for each fixture type by number of lamps are derived from data from the Bureau of Census and from the Lighting Research Institute. ${ }^{6}$

GRI and Plexus Research. 1991. Op. cil, Ref. 3, Section 2. 
Figure 3.6

Percent and Number of Open Fixtures (Narrow) Passing Standard Levels

by Number of Lamps

\section{Porcent Passing Standard}

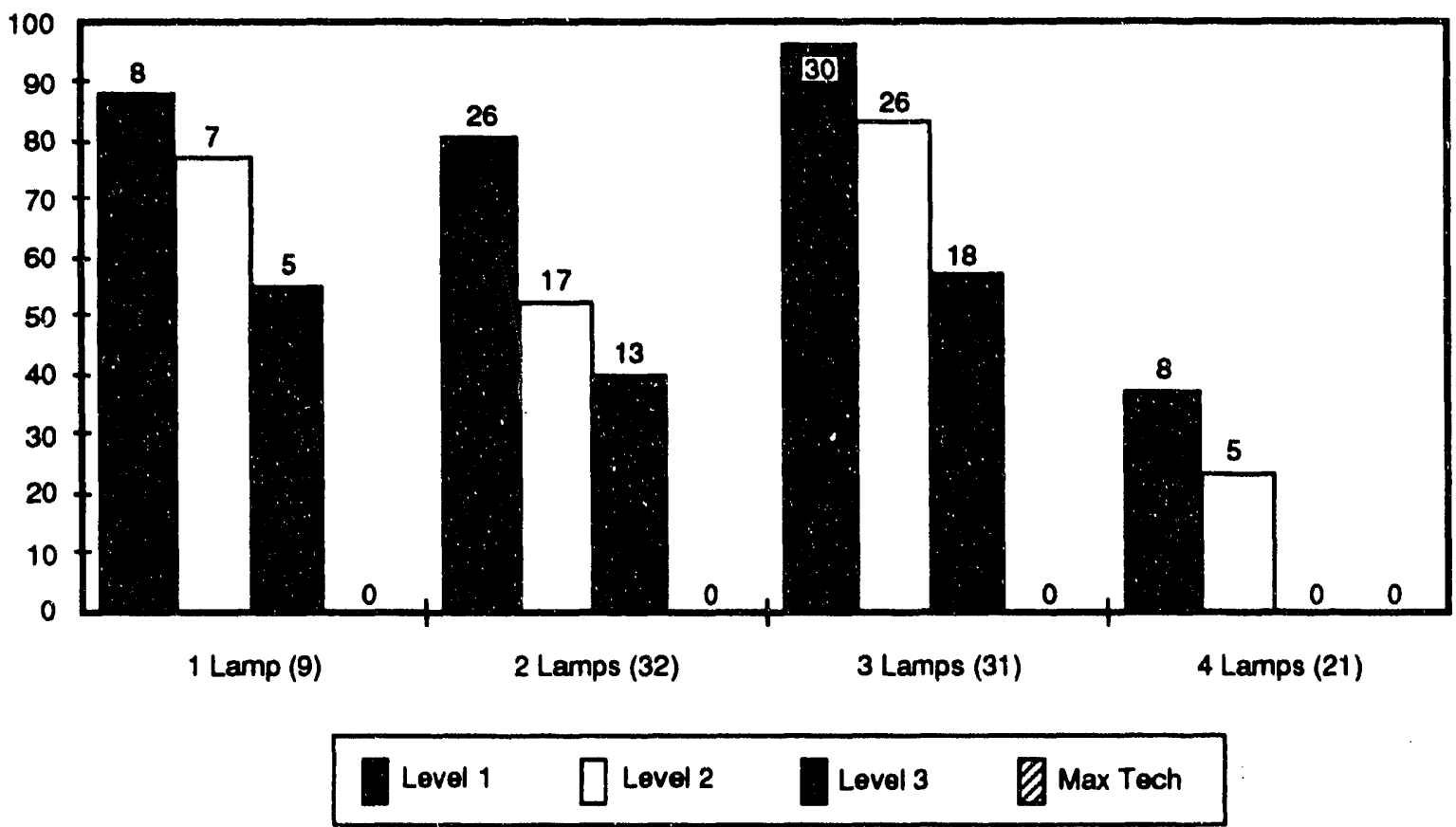

Notes: Numbers of passing fixtures shown above bars; total number of fixtures shown in parentheses. Standard levels different for each fixture type; see Table 3.13.

Figure 3.7

Percent and Number of Open Fixtures (Wide) Passing Standard Levels by Number of Lamps

\section{Porcent Paseing Standard}

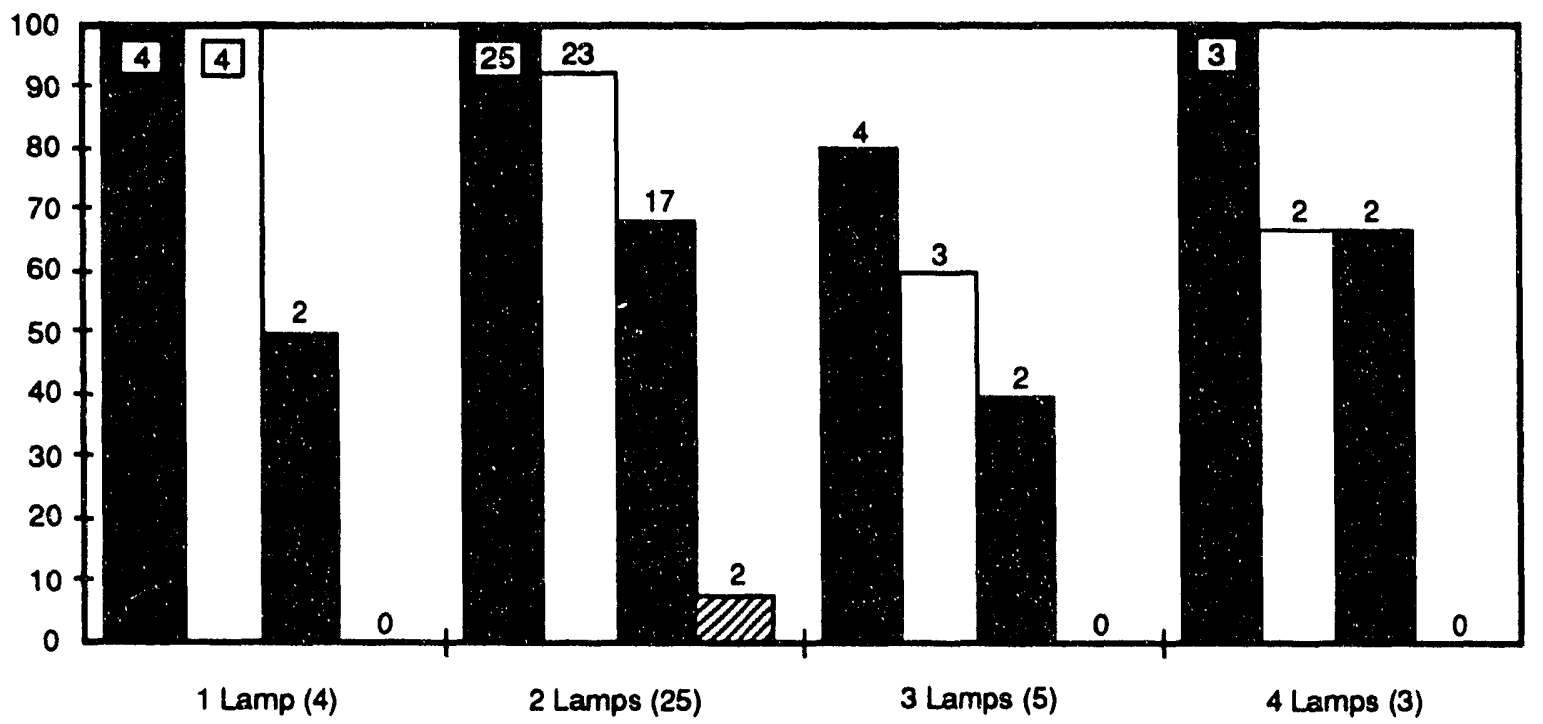

$$
\text { iavel } 1 \square \text { Level } 2 \quad \text { Level } 3 \text { Max Tech }
$$

Notes: Numbers of passing fixtures shown above bars; total number of fixtures shown in parentheses. Standard levels different for each fixture type; see Table 3.13 
Figure 3.8

Percent and Number of Wraparound Fixtures Passing Standard Levels

by Number of Lamps

Percent Paseing Standard

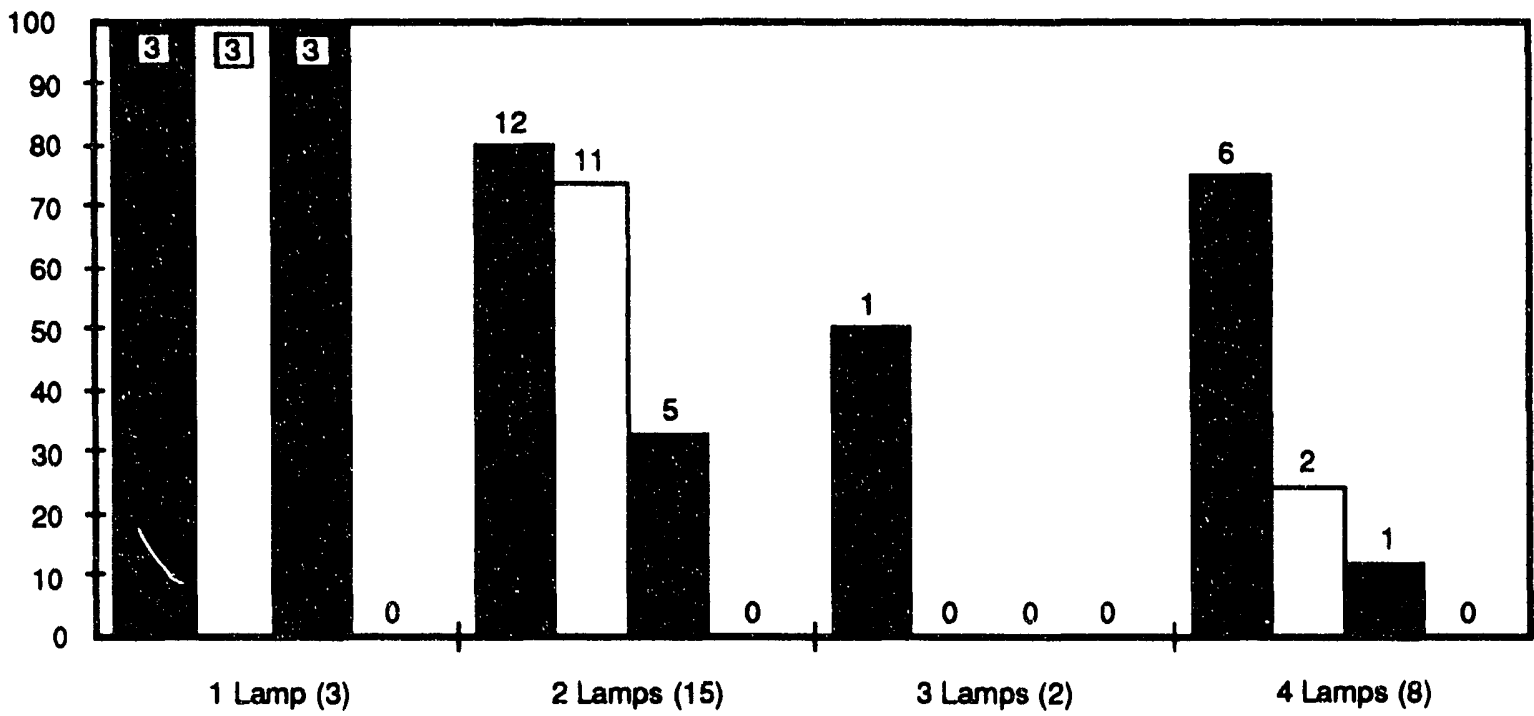

Level $1 \square$ Level $2 \square$ Level 3

Notes: Numbers of passing fixtures shown above bars; total number of fixtures shown in parentheses. Standard leveis different for each fixture type; see Table 3.13.

Figure 3.9

Percent and Number of Lensed Troffer Fixtures Passing Standard Levels by Number of Lamps

\section{Porcent Passing Standard}

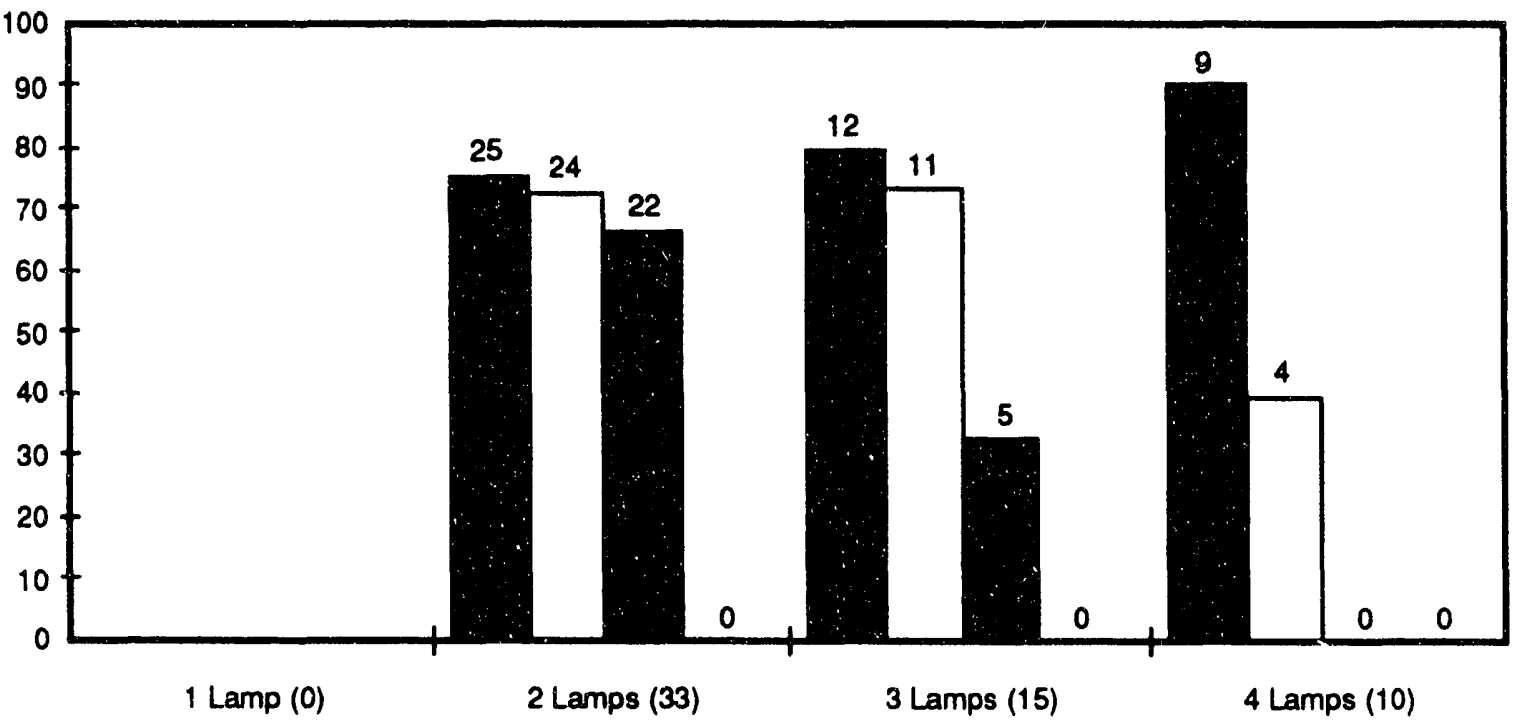
Level 1
$\square$ Level 2
Level 3
Max Tech

Notes: Numbers of passing fixtures shown above bars; total number of fixtures shown in parentheses. Standard levels different for each fixture type; see Table 3.13. 
For the fixture analysis, wattages for the standard F40 lamp with the energy-efficient magnetic ballast are used. Wattages for lamps/ballasts in fixtures are taken from the Advanced Lighting Guidelines (see Section 3.2.3). Wattages are normalized by application factor. Luminaire efficiencies are derived from the fixture database (Section 3.3.2), using average efficiency by fixture type and number of lamps. Weighted average wattages for each product class are calculated from existing and projected numbers of lamps in each class. An overall market average fixture wattage is calculated from existing and projected market shares by product class and by number of lamps. The market share of parabolic fixtures is expected to increase significantly by 1995 , and 2- and 3-lamp parabolic fixtures are projected to increase relative to 4-lamp fixtures, especially in office VDT (video display terminal) areas.

New wattages for Technology Option 1 are calculated assuming that the 4-lamp fixture is replaced by the 3-lamp fixture for enclosed lensed and wraparound fixtures, under the Level 2 fixture efficiencies. For open/louvered fixtures, the 4-lamp fixture is replaced by 2- and 3-lamp fixtures. Since more 2- and 3-lamp fixtures would be needed to provide the same light output as the 4-lamp fixture, despite their higher efficiencies, their wattage is recalculated from relative lumen output by number of lamps.

For Technology Option 2, a 20 percent improvement in luminaire efficiency (not an increase of 20 percentage points) from the average is assumed based on the improved technology.

\subsubsection{Cost-Efriciency Data}

The relationship between fixture price and luminaire efficiency is difficult to determine. Just as many design elements enter into luminaire efficiency, many more factors (e.g., quantity, aesthetics, shipping costs, marketing considerations) enter into fixture pricing than for other lighting components. A survey of lighting distributors for fixture prices representing the trial efficiency levels yields no direct relationship between price and efficiency for mid-efficiency fixtures. It would be necessary to survey distributors for every fixture in the database and to aggregate prices to determine whether a relationship exists. Thus, no cost data are presented and no economic analysis of fixtures is performed.

\subsubsection{NEMA's Luminaire Efficacy Rating}

NEMA has proposed a voluntary Luminaire Efficacy Rating scheme (LER) ${ }^{7}$ as a basis for rating fluorescent luminaires. LER is defined as follows:

$$
L E R=\frac{\text { Total Rated Lamp Lumens } \times \text { Ballast Factor } \times \text { Luminaire Efficiency }}{\text { Luminaire Input Watts }}
$$

\footnotetext{
${ }^{7}$ Op. cit, Ref. 5
} 
The major feature of LER that distinguishes it from a standard that limits luminaire efficiency (LE) is that LER takes into account the efficacy of the lamp/ballast system while luminaire efficiency, per se, does not. As a result LER has units of lumens/watt while luminaire efficiency is unitless.

However, as indicated above, LER explicitly contains luminaire efficiency in the numerator, Thus, a good relationship between LER and LE would be expected. LE vs. LER are plotted in Figure 3.9 for 192 fixtures (all 2-, 3-, and 4-lamp parabolic, wraparound and troffers) in the luminaire database of 288 fixtures. Luminaire input watts used from the CEC Advanced Lighting Guidelines ${ }^{8}$ are shown in Table 3.15. The table assumes that energy-efficient magnetic ballasts (ballast factor $=0.94$ ) and standard F40 lamps are used.

Table 3.15 Luminaire Input Wattage

\begin{tabular}{ll}
\hline Lumens per lamp & 3050 \\
Ballast factor & 0.94 \\
2-lamp (parabolic) & 81 watts \\
3-lamp (parabolic) & 118 watts \\
4-lamp (parabolic) & 161 watts \\
2-lamp (troffer) & 80 watts \\
3-lamp (troffer) & 117 watts \\
4-lamp (troffer) & 160 watts \\
2-lamp (wraparound) & 75 watts \\
3-lamp (wraparound) & 110 watts \\
4-lamp (wraparound) & 150 watts \\
\hline
\end{tabular}

Figure 3.9 shows that there is a very good correlation between LER and LE. This suggests that if the LER and LE limits were commensurate, then their overall impact on the fixture market and on energy savings would be essentially equivalent. However, the elaborate scheme used by NEMA to classify luminaires is more difficult to analyze than the scheme used to classify luminaires for the LE standard in this study. A future detailed analysis of the differences between the two standards could be developed.

The LER rating method has been approved by NEMA members. An appendix to the draft standards publication has proposed preliminary minimum LER values that may change; the appendix is under a different review process. As currently conceived by NEMA, under an LERbased standard, fixture manufacturers could take advantage of LER's sensitivity to lamp/ballast

\footnotetext{
${ }^{8}$ CEC, 1992. Op. cit, Ref. 2.
} 
system efficacy to sell fixtures that would not qualify with standard ballasts by shipping the fixtures with more efficient ballasts (such as electronic ballasts). Selection of an LER-type standard or of a luminaire efficiency standard depends on the interaction of such a standard with existing lamp and ballast component standards. Policy issues such as industry consensus are equally important.

\subsection{CONTROLS}

Lighting controls complement lighting equipment efficiency improvements by reducing lighting when it is not needed. Controls save energy if they eliminate unnecessary lighting operating hours when occupants are not present, or reduce light levels when they are higher than necessary to perform tasks. Controls range from simple mechanical timeclocks to sophisticated multi-level electronic devices that interface with a building's energy management system, which also controls other building systems such as heating, ventilation, and air conditioning (HVAC).

Figure 3.10

Relationship Between Luminaire Efficiency and Luminaire Efficacy Rating Assuming Efficient Magnetic Ballasts and Standard F40 Lamps

Luminaire Efficacy Rating

(lumens/watt)

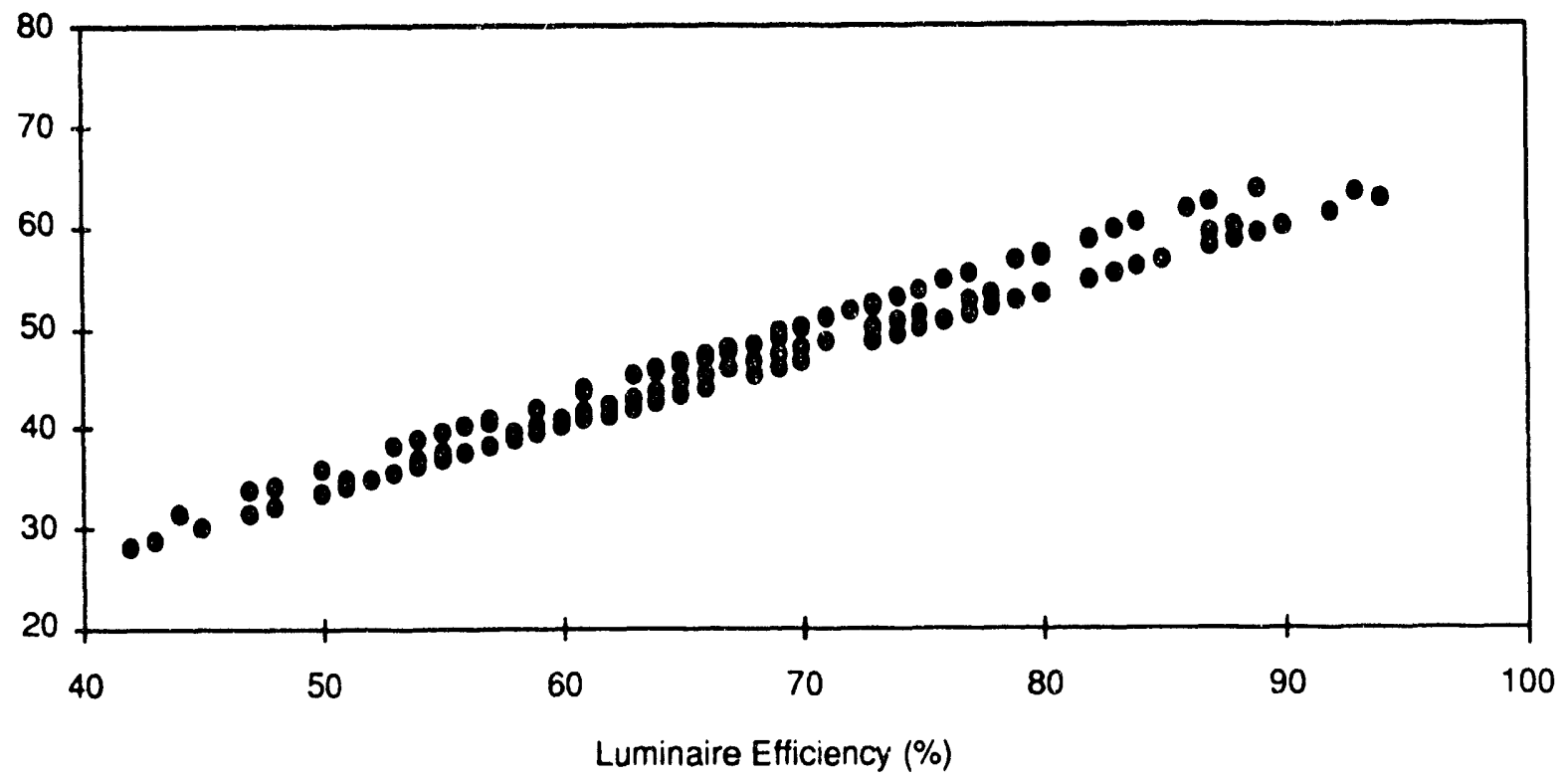

This study considers four technology options for controls listed in Table 3.16 and defined below.

Programmable Timers provide time-based control of lighting equipment. The usual method of implementation is a system of low-voltage relays controlled by a programmable timeclock. These systems are used primarily to schedule lighting equipment operation efficiently. To accommodate off-hours lighting needs, systems usually have overrides, so lights can be turned on by building occupants either by low-voltage switches or telephone-based override systems. Controls can provide simple on/off switching or multi-level control. In this analysis, timers are assumed to 
be multi-level and are applied to both fluorescent and incandescent lights.

Lumen Maintenance controls limit power and light output when fluorescent lamps are new and the fixtures are clean. Light output decreases as the lamps age and dirt accumulates on the fixture reflector and/or lens. With lumen maintenance dimming controls, power is gradually increased over time until full power is achieved when it is time to replace the lamps and clean the fixtures. Thus light output remains fairly consistent with rated output throughout the lamp lifetime. This option is applied to full-size fluorescent lamps only (not CFLs).

Table 3.16 Technology Options for Controls

1. Timers

2. Lumen Maintenance

3. Occupancy Sensors

4. Daylighting/Dimming

Occupancy Sensors are activated by the presence or absence of people in the field of view. The lights in a controlled zone are turned on automatically when a person enters the area, and turned off after the room is unoccupied for a set period of time. There are two basic types of sensing: passive infrared and ultrasonic. In this analysis, this option applies to fluorescent and incandescent lights.

Daylighting controls use a photocell with a dimming system to provide a fixed light level at the workplane by decreasing the amount of electric light as daylight levels increase and increasing it with reduced daylight. This option is applied to full-size fluorescent lamps only.

Other types of individual controls, such as two-level switching, incandescent or CFL dimmers, and stepped switching (varying light level by outdoor light level or time of day) are not analyzed.

Comprehensive automated building energy management systems may control equipment for several energy end uses including lighting, HVAC, etc. Lighting control equipment may be linked with the central energy management system or it may be separate. A well-designed energy management system may offer greater energy-savings potential than controls on individual end uses and a systems approach is becoming more common in both new construction and retrofit. However, analysis of savings and costs for the lighting portion of an energy management system is complex and is beyond the scope of this report.

\subsubsection{Analysis Method}

For the separate controls policy cases, controls are analyzed as they would be used with the baseline lamp/ballast and fixture technologies. Controls are assumed to be applied in a sequence 
to avoid double counting of energy savings.' In the Minimum LCC and R\&D Combination policy cases, controls are analyzed interactively with the appropriate minimum life-cycle cost or R\&D lamp/ballast/fixture combination. In these cases, controls are applied after the other efficient equipment savings have occurred, again to avoid double-counting.

Net present values (NPVs) of controls over a period of 12 years at a 4 percent real discount rate are analyzed. The analysis considers each building type and fluorescent/incandescent lighting technology stock separately, using the savings and costs presented in Section 3.4.2. If the NPV of a technology option is positive for a building type and technology, the option is applied in the analysis. Savings estimates are used in the COMMEND pre-processor spreadsheets described in Section 4.1. COMMEND energy savings projections are used along with estimated costs to determine NPVs as presented in Section 4.5.

Controls technology options analyzed are presented in Tables 3.17 and 3.18. If a technology option is not selected in these tables, it is either not applicable or not cost-effective for that building or technology type. Daylighting is cost-effective only in an R\&D scenario where equipment costs are substantially lower and expected savings are higher than they are today.

\subsubsection{Energy Savings}

Energy savings from timers and occupancy sensors accrue as annual lighting hours are reduced. Also, applicable areas for controls vary by building type. Finally, lumen maintenance and daylighting controls are applicable only to fluorescent lighting, but timers and occupancy sensors are assumed to apply to fluorescent, incandescent, and CFL stock in most building types. For timers and occupancy sensors, percentage savings, applicable percent floor area, and applicable building types are determined from manufacturer estimates ${ }^{10}$ and staff experience. Energy savings from lumen maintenance accrue in watts/sq $\mathrm{ft}$ during the early part of a lamp's lifetime. In California's Title 24 energy code, controls credits allow one watt per square $\mathrm{ft}$ (watt/sq $\mathrm{ft}$ ) savings for lumen maintenance. For this analysis, savings are assumed to be 10 percent, or 0.1 watt/sq $\mathrm{ft}$ where the fluorescent LPD is 1.0 and are adjusted proportionally for higher or lower LPDs. Energy savings from daylighting accrue in reduced lighting hours for on-off controls and in watts/sq $\mathrm{ft}$ for dimming. This is translated into percentage savings, estimated by the LBL Lighting Systems Research Group. Daylighting controls are applied to one-half of the building perimeter floor area taken from NBECS 1986 . For the R\&D Combination case, savings percentages increase for some technology options as estimated by the manufacturer and LBL sources referenced above.

\footnotetext{
'Double counting would result in savings estimates that are inaccurately high. For example, if the first controls option ( e.g., timers) reduces lighting energy use by 20 percent and the second (e.g., lumen maintenance) also reduces consumption by 20 percent, the total reduction is not 40 percent. Because the first option would reduce energy use to 80 percent of its original total, the second option applied sequentially would reduce consumption by 20 percent of 80 percent or 16 percent, for a total of 36 percent for the combined options.

${ }^{10}$ Timers: Dave Peterson, GE Wiring Devices, Rhode Island and LBL's Lighting Systems Research Group. Occupancy sensors: Jerry Mix, The Watt-Stopper, Santa Clara, California, and LBL's Lighting Systems Research Group.
} 
Percentage savings, applicable fractions, applicable technologies, and costs for the four technology options are presented in Tables 3.19 and 3.20. These tables also show the NPV calculations used to determine for which building types controls are cost effective. In the tables, fluorescent and incandescent LPDs are shown as well as total LPDs for each building type. Annual Lighting Hours are derived from NBECS 1986 as described in Section 3.2.3. Savings Fraction is the percentage savings for this technology and applicable fraction. Applicable Fraction refers to the portion of the floorspace to which the technology option applies. (For Daylighting, this represents half of the perimeter floorspace derived from NBECS 1986.) Applicable Tech refers to the technology $(\mathrm{F}=$ fluorescent, $\mathrm{I}=$ incandescent $)$ to which the technology option applies. The product of LPD (fluorescent, incandescent, or total) $x$ Annual Lighting Hours $\times$ Savings Fraction $\times$ Applicable Fraction / 1000 is Savings $(k W h)$. Savings $(\$ / s f-$ yr) equals Savings (kWh) x 1995 electricity price in 1990 dollars $(\$ 0.0729 / \mathrm{kWh}$, projected by AEO 1992).

Benefit is the present value of the energy savings per applicable square foot at 4 percent real over 12 years (the discount factor is 9.39). Cost is the capital cost of the technology option per applicable square foot. If a technology option's Benefit is greater than its Cost (i.e. its net present value is positive) in Table 3.19 then the option is selected for analysis for the separate controls policy cases and for the Min LCC Combination case.

Table 3.20 shows the future percentage savings, applicable fractions and technologies, and costs anticipated through research and development by the year 2000 . Note that for some technology options, percentage savings increases while for others, cost decreases. If a technology option's Benefit exceeds its Cost in this table, it is selected for analysis in the R\&D Combination case.

\subsubsection{Controls Costs}

Current and R\&D controls costs are estimated by the same sources listed above and include engineering/design costs. For lumen maintenance, costs are proportional to fluorescent LPD. Costs are assumed to persist throughout the period of the analysis.

As discussed in Section 3.4.1, controls technology options are assumed to be applied incrementally to avoid double-counting. In other words, the first option is assumed to have already been applied before savings from the next option are calculated. For some buildings, lumen maintenance (the second technology option) is cost-effective while timers are not; this may be observed in Tables 3.17 and 3.18. In some other building types, timers are not cost-effective while the combination of timers plus lumen maintenance is cost-effective. This is because the installation of equipment for lumen maintenance controls reduces the cost per square foot of timers. Thus the second option in Tables 3.19 and 3.20 is "Timers + Lumen Maintenance," unless the notes indicate "No Timers." 
Table 3.17 Controls Applicability by Building Type

\begin{tabular}{|c|c|c|c|c|c|c|c|}
\hline & & Timers & $\begin{array}{l}\text { Timers with } \\
\text { Lumen } \\
\text { Malntenance }\end{array}$ & $\begin{array}{l}\text { Timers with } \\
\text { Lumen } \\
\text { Malntenance }\end{array}$ & $\begin{array}{c}\text { Lumen } \\
\text { Maintenance } \\
\text { Only }\end{array}$ & $\begin{array}{l}\text { Occupancy } \\
\text { Sensors }\end{array}$ & Daylighting \\
\hline $\begin{array}{l}\text { Bullding } \\
\text { Type }\end{array}$ & $\begin{array}{l}\text { Llghting } \\
\text { Type }\end{array}$ & F,I & $\mathbf{F}$ & I & $\mathbf{F}$ & F,I & $F$ \\
\hline Small office & & $\mathbf{x}$ & $\mathbf{x}$ & $\mathbf{x}$ & $\mathrm{x}$ & $x$ & \\
\hline Large office & & $\mathbf{x}$ & $\mathbf{x}$ & $\mathbf{X}$ & $\mathrm{x}$ & $x$ & \\
\hline Restaurant & & & & & $x$ & $\mathbf{X}$ & \\
\hline Retail & & $\mathbf{X}$ & $\mathbf{x}$ & $\mathbf{X}$ & $\mathrm{x}$ & $X$ & \\
\hline Grocery & & $\mathbf{X}$ & $\mathbf{x}$ & $\mathbf{X}$ & $\mathrm{x}$ & $\mathbf{X}$ & \\
\hline Warehouse & & $\mathbf{X}$ & $\mathbf{x}$ & $\mathbf{X}$ & $x$ & $X$ & \\
\hline \multicolumn{8}{|l|}{ School } \\
\hline College & & & & & & $\mathrm{X}$ & \\
\hline Health & & & & & $\mathrm{x}$ & $x$ & \\
\hline Lodging & & & & & $\mathrm{x}$ & $\mathrm{X}$ & \\
\hline Miscellaneous & & & & & & & \\
\hline
\end{tabular}

Table 3.18 Controls Applicability by Building Type, R\&D

\begin{tabular}{|c|c|c|c|c|c|c|c|}
\hline & & Timers & $\begin{array}{l}\text { Timers with } \\
\text { Lumen } \\
\text { Maintenance }\end{array}$ & $\begin{array}{l}\text { Timers with } \\
\text { Lumen } \\
\text { Malntenance }\end{array}$ & $\begin{array}{c}\text { Lumen } \\
\text { Maintenance } \\
\text { Only }\end{array}$ & $\begin{array}{c}\text { Occupancy } \\
\text { Sensors }\end{array}$ & Daylighting \\
\hline $\begin{array}{l}\text { Bulkding } \\
\text { Type }\end{array}$ & $\begin{array}{l}\text { Llghting } \\
\text { Type }\end{array}$ & F,I & F & I & $\mathrm{F}$ & F,I & $\mathrm{F}$ \\
\hline Small of fice & & $\mathbf{X}$ & $\mathbf{X}$ & $\mathrm{X}$ & $\mathrm{x}$ & $\mathrm{X}$ & $\mathbf{X}$ \\
\hline Large office & & $x$ & $\mathbf{X}$ & $x$ & $\mathrm{X}$ & $X$ & $\mathbf{X}$ \\
\hline Restaurant & & & & & $\mathrm{x}$ & $x$ & $\mathbf{x}$ \\
\hline Retail & & $\mathbf{x}$ & $\mathbf{X}$ & $\mathbf{x}$ & $\mathbf{X}$ & $X$ & $\mathbf{X}$ \\
\hline Grocery & & $x$ & $\mathbf{X}$ & $x$ & $\mathrm{x}$ & $\mathrm{X}$ & $\mathbf{x}$ \\
\hline Warehouse & & $\mathrm{x}$ & $\mathbf{x}$ & $\mathrm{x}$ & $\mathrm{x}$ & $x$ & \\
\hline School & & & & & & & $x$ \\
\hline College & & $x$ & $\mathbf{x}$ & & & $x$ & $\mathbf{x}$ \\
\hline Health & & & & & $\mathrm{x}$ & $\mathrm{X}$ & $\mathrm{X}$ \\
\hline Lodging & & & & & $\mathrm{x}$ & $x$ & \\
\hline Miscellaneous & & $\mathbf{x}$ & $\mathbf{X}$ & & & $\mathrm{X}$ & \\
\hline
\end{tabular}


Table 3.19 Controls Savings, Costs, and Applicability, Commercial Soctor Indoor Lighting

\begin{tabular}{|c|c|c|c|c|c|c|c|c|c|c|c|c|}
\hline & Fluor & D (W/ & Th) & $\begin{array}{l}\text { Annual } \\
\text { Lighting } \\
\text { Hows }\end{array}$ & $\begin{array}{l}\text { Savings } \\
\text { Praction }\end{array}$ & $\begin{array}{l}\text { Appli- } \\
\text { cable } \\
\text { Frection }\end{array}$ & $\begin{array}{l}\text { Appli- } \\
\text { cable } \\
\text { Toch }\end{array}$ & $\begin{array}{l}\text { Savings } \\
\text { (kWh) }\end{array}$ & $\begin{array}{c}\text { Savings } \\
\text { S/sf-yr } \\
\text { (2) }\end{array}$ & $\begin{array}{c}\text { Benefit } \\
\$ / s f-y r \\
(2)\end{array}$ & $\begin{array}{l}\text { Cost } \\
\text { S/sf-yr } \\
(2)\end{array}$ & Notes (3) \\
\hline $\begin{array}{l}\text { TIMERS } \\
\text { Small Office } \\
\text { Lerge Office } \\
\text { Restaurant } \\
\text { Retnil } \\
\text { Grocery } \\
\text { Warchouse } \\
\text { School } \\
\text { College } \\
\text { Health } \\
\text { Lodging } \\
\text { Miec. }\end{array}$ & $\begin{array}{l}1.22 \\
0.95 \\
0.53 \\
0.79 \\
1.46 \\
0.52 \\
0.55 \\
1.16 \\
0.52 \\
0.06 \\
0.59\end{array}$ & $\begin{array}{l}0.16 \\
0.13 \\
0.51 \\
0.28 \\
0.13 \\
0.11 \\
0.13 \\
0.10 \\
0.10 \\
0.33 \\
0.18\end{array}$ & $\begin{array}{l}1.39 \\
1.07 \\
1.04 \\
1.06 \\
1.58 \\
0.69 \\
0.67 \\
1.24 \\
0.61 \\
0.38 \\
0.77\end{array}$ & $\begin{array}{l}3,603 \\
3,603 \\
5,146 \\
4,062 \\
6,126 \\
3,853 \\
3,196 \\
3,192 \\
7,993 \\
8,421 \\
3,561\end{array}$ & $\begin{array}{l}0.23 \\
0.23 \\
0.00 \\
0.10 \\
0.10 \\
0.30 \\
0.15 \\
0.15 \\
0.00 \\
0.00 \\
0.15\end{array}$ & $\begin{array}{l}1.00 \\
1.00 \\
1.00 \\
1.00 \\
1.00 \\
1.00 \\
1.00 \\
1.00 \\
1.00 \\
1.00 \\
1.00\end{array}$ & $\begin{array}{l}\mathbf{F}+\mathbf{I} \\
\mathbf{F}+\mathbf{I} \\
\mathbf{F}+\mathbf{I} \\
\mathbf{F}+\mathbf{I} \\
\mathbf{F}+\mathbf{I} \\
\mathbf{F}+\mathbf{I} \\
\mathbf{F}+\mathbf{I} \\
\mathbf{F}+\mathbf{I} \\
\mathbf{F}+\mathbf{I} \\
\mathbf{F}+\mathbf{I} \\
\mathbf{F}+\mathbf{I}\end{array}$ & $\begin{array}{l}1.15 \\
0.89 \\
0.00 \\
0.43 \\
0.97 \\
0.80 \\
0.32 \\
0.59 \\
0.00 \\
0.00 \\
0.41\end{array}$ & $\begin{array}{l}0.084 \\
0.065 \\
0.000 \\
0.031 \\
0.071 \\
0.058 \\
0.023 \\
0.043 \\
0.000 \\
0.000 \\
0.030\end{array}$ & $\begin{array}{l}0.79 \\
0.61 \\
0.00 \\
0.29 \\
0.66 \\
0.55 \\
0.22 \\
0.41 \\
0.00 \\
0.00 \\
0.28\end{array}$ & $\begin{array}{l}0.30 \\
0.30 \\
0.00 \\
0.25 \\
0.25 \\
0.25 \\
0.45 \\
0.45 \\
0.00 \\
0.00 \\
0.30\end{array}$ & \\
\hline $\begin{array}{l}\text { TIMERS + L } \\
\text { Small Office } \\
\text { Lorge Office } \\
\text { Reatnurant } \\
\text { Retnil } \\
\text { Grocery } \\
\text { Warehouse } \\
\text { School } \\
\text { College } \\
\text { Health } \\
\text { Lodging } \\
\text { Misc. }\end{array}$ & $\begin{array}{l}\text { UMIEN } \\
1.22 \\
0.95 \\
0.53 \\
0.79 \\
1.46 \\
0.52 \\
0.55 \\
1.16 \\
0.52 \\
0.06 \\
0.59\end{array}$ & $\begin{array}{l}\text { IAINTI } \\
0.16 \\
0.13 \\
0.51 \\
0.28 \\
0.13 \\
0.11 \\
0.13 \\
0.10 \\
0.10 \\
0.33 \\
0.18\end{array}$ & $\begin{array}{l}\text { NANCE ( } \\
1.39 \\
1.07 \\
1.04 \\
1.06 \\
1.58 \\
0.69 \\
0.67 \\
1.24 \\
0.61 \\
0.38 \\
0.77\end{array}$ & $\begin{array}{l}\text { (4) } \\
3,603 \\
3,603 \\
5,146 \\
4,062 \\
6,126 \\
3,853 \\
3,196 \\
3,192 \\
7,993 \\
8,421 \\
3,561\end{array}$ & $\begin{array}{l}0.10 \\
0.10 \\
0.10 \\
0.10 \\
0.10 \\
0.10 \\
0.10 \\
0.10 \\
0.10 \\
0.10 \\
0.10\end{array}$ & $\begin{array}{l}1.00 \\
1.00 \\
1.00 \\
1.00 \\
1.00 \\
1.00 \\
1.00 \\
1.00 \\
1.00 \\
1.00 \\
1.00\end{array}$ & $\begin{array}{l}\mathbf{F} \\
\mathbf{F} \\
\mathbf{F} \\
\mathbf{F} \\
\mathbf{F} \\
\mathbf{F} \\
\mathbf{F} \\
\mathbf{F} \\
\mathbf{F} \\
\mathbf{F} \\
\mathbf{F}\end{array}$ & $\begin{array}{l}0.34 \\
0.26 \\
0.27 \\
0.29 \\
0.80 \\
0.14 \\
0.15 \\
0.31 \\
0.42 \\
0.05 \\
0.18\end{array}$ & $\begin{array}{l}0.025 \\
0.019 \\
0.020 \\
0.021 \\
0.059 \\
0.010 \\
0.011 \\
0.023 \\
0.030 \\
0.004 \\
0.013\end{array}$ & $\begin{array}{l}0.92 \\
0.72 \\
0.19 \\
0.42 \\
1.16 \\
0.51 \\
0.28 \\
0.60 \\
0.28 \\
0.03 \\
0.34\end{array}$ & $\begin{array}{l}0.57 \\
0.49 \\
0.16 \\
0.39 \\
0.59 \\
0.31 \\
0.52 \\
0.70 \\
0.16 \\
0.02 \\
0.38\end{array}$ & $\begin{array}{l}\text { No Timers } \\
\text { No Timers }\end{array}$ \\
\hline $\begin{array}{l}\text { OCCUPANC } \\
\text { Small Office } \\
\text { Large Office } \\
\text { Restaurant } \\
\text { Retnil } \\
\text { Grocery } \\
\text { Warehouse } \\
\text { School } \\
\text { College } \\
\text { Health } \\
\text { Lodging } \\
\text { Miec. }\end{array}$ & $\begin{array}{l}\text { Y SENS } \\
1.22 \\
0.95 \\
0.53 \\
0.79 \\
1.46 \\
0.52 \\
0.55 \\
1.16 \\
0.52 \\
0.06 \\
0.59\end{array}$ & $\begin{array}{l}\text { ORS } \\
0.16 \\
0.13 \\
0.51 \\
0.28 \\
0.13 \\
0.11 \\
0.13 \\
0.10 \\
0.10 \\
0.33 \\
0.18\end{array}$ & $\begin{array}{l}1.39 \\
1.07 \\
1.04 \\
1.06 \\
1.58 \\
0.69 \\
0.67 \\
1.24 \\
0.61 \\
0.38 \\
0.77\end{array}$ & $\begin{array}{l}3,603 \\
3,603 \\
5,146 \\
4,062 \\
6,126 \\
3,853 \\
3,196 \\
3,192 \\
7,993 \\
8,421 \\
3,561\end{array}$ & $\begin{array}{l}0.30 \\
0.30 \\
0.40 \\
0.40 \\
0.40 \\
0.50 \\
0.20 \\
0.30 \\
0.30 \\
0.40 \\
0.30\end{array}$ & $\begin{array}{l}0.35 \\
0.50 \\
0.10 \\
0.10 \\
0.10 \\
0.60 \\
0.80 \\
0.80 \\
0.15 \\
0.20 \\
0.60\end{array}$ & $\begin{array}{c}F+1 \\
F+1 \\
F \\
F \\
F \\
F+1 \\
F+1 \\
F+1 \\
F+1 \\
F+1 \\
F+1\end{array}$ & $\begin{array}{l}1.05 \\
0.82 \\
0.98 \\
1.04 \\
2.90 \\
0.78 \\
0.43 \\
1.19 \\
1.36 \\
1.29 \\
0.65\end{array}$ & $\begin{array}{l}0.076 \\
0.060 \\
0.072 \\
0.076 \\
0.211 \\
0.057 \\
0.031 \\
0.087 \\
0.099 \\
0.094 \\
0.047\end{array}$ & $\begin{array}{l}0.72 \\
0.56 \\
0.67 \\
0.71 \\
1.98 \\
0.53 \\
0.29 \\
0.81 \\
0.93 \\
0.89 \\
0.44\end{array}$ & $\begin{array}{l}0.46 \\
0.46 \\
0.70 \\
0.70 \\
0.70 \\
0.40 \\
0.36 \\
0.36 \\
0.70 \\
0.50 \\
0.50\end{array}$ & $\begin{array}{l}\text { No Timers } \\
\text { No T, LM } \\
\text { No T, LM } \\
\text { No Timers } \\
\text { No Timers } \\
\text { No T, LM }\end{array}$ \\
\hline $\begin{array}{l}\text { DAYLIGHTI } \\
\text { Small Office } \\
\text { Large Office } \\
\text { Reatnurant } \\
\text { Retail } \\
\text { Grocery } \\
\text { Wurehouse } \\
\text { School } \\
\text { College } \\
\text { Health } \\
\text { Lodging } \\
\text { Misc. }\end{array}$ & $\begin{array}{l}\text { NG (5) } \\
1.22 \\
0.95 \\
0.53 \\
0.79 \\
1.46 \\
0.52 \\
0.55 \\
1.16 \\
0.52 \\
0.06 \\
0.59\end{array}$ & $\begin{array}{l}0.16 \\
0.13 \\
0.51 \\
0.28 \\
0.13 \\
0.11 \\
0.13 \\
0.10 \\
0.10 \\
0.33 \\
0.18\end{array}$ & $\begin{array}{l}1.39 \\
1.07 \\
1.04 \\
1.06 \\
1.58 \\
0.69 \\
0.67 \\
1.24 \\
0.61 \\
0.38 \\
0.77\end{array}$ & $\begin{array}{l}3,603 \\
3,603 \\
5,146 \\
4,062 \\
6,126 \\
3,853 \\
3,196 \\
3,192 \\
7,993 \\
8,421 \\
3,561\end{array}$ & $\begin{array}{l}0.35 \\
0.35 \\
0.35 \\
0.35 \\
0.35 \\
0.35 \\
0.35 \\
0.35 \\
0.35 \\
0.35 \\
0.35\end{array}$ & $\begin{array}{l}(6) \\
0.28 \\
0.28 \\
0.00 \\
0.00 \\
0.00 \\
0.00 \\
0.20 \\
0.20 \\
0.25 \\
0.00 \\
0.20\end{array}$ & $\begin{array}{l}\mathbf{F} \\
\mathbf{F} \\
\mathbf{F} \\
\mathbf{F} \\
\mathbf{F} \\
\mathbf{F} \\
\mathbf{F} \\
\mathbf{F} \\
\mathbf{F} \\
\mathbf{F} \\
\mathbf{F}\end{array}$ & $\begin{array}{l}0.95 \\
0.71 \\
0.86 \\
0.87 \\
2.43 \\
0.31 \\
0.62 \\
0.98 \\
1.25 \\
0.15 \\
0.56\end{array}$ & $\begin{array}{l}0.070 \\
0.051 \\
0.063 \\
0.064 \\
0.177 \\
0.023 \\
0.045 \\
0.072 \\
0.091 \\
0.011 \\
0.041\end{array}$ & $\begin{array}{l}0.65 \\
0.48 \\
0.59 \\
0.60 \\
1.67 \\
0.21 \\
0.42 \\
0.67 \\
0.86 \\
0.10 \\
0.39\end{array}$ & $\begin{array}{l}1.10 \\
1.10 \\
1.10 \\
1.10 \\
1.10 \\
1.10 \\
1.10 \\
1.10 \\
1.10 \\
1.10 \\
1.10\end{array}$ & $\begin{array}{c}\text { No T, LM, OS } \\
\text { No T, LM } \\
\text { No Timers } \\
\text { No Timers } \\
\text { No T, LM, OS }\end{array}$ \\
\hline
\end{tabular}


Table 3.20 Controls Savings, Costs, and Applicability, Commencial Sector Indoor Lighting, R \& D

\begin{tabular}{|c|c|c|c|c|c|c|c|c|c|c|c|c|}
\hline & Fluor & $\begin{array}{l}\mathrm{D}(\mathrm{W} / \mathrm{e} \\
\text { Inc }\end{array}$ & $\begin{array}{l}\text { n n) } \\
\text { Total (1) }\end{array}$ & $\begin{array}{l}\text { Annual } \\
\text { Lighting } \\
\text { Hours }\end{array}$ & $\begin{array}{l}\text { Savings } \\
\text { Fruction }\end{array}$ & $\begin{array}{l}\text { Appli- } \\
\text { cable } \\
\text { Fraction }\end{array}$ & $\begin{array}{l}\text { Appli- } \\
\text { cable } \\
\text { Tech }\end{array}$ & $\begin{array}{c}\text { Savings } \\
\text { (kWh) }\end{array}$ & $\begin{array}{c}\text { Sevings } \\
\text { S/sf-yr } \\
\text { (2) }\end{array}$ & $\begin{array}{c}\text { Benefit } \\
\text { S/af-yr } \\
\text { (2) }\end{array}$ & $\begin{array}{l}\text { Cout } \\
\text { S/sf-yt } \\
(2)\end{array}$ & Notes (3) \\
\hline $\begin{array}{l}\text { TIMERS (4) } \\
\text { Small Office } \\
\text { Lerge Office } \\
\text { Restnurant } \\
\text { Resnil } \\
\text { Grocery } \\
\text { Warehouse } \\
\text { School } \\
\text { College } \\
\text { Health } \\
\text { Lodging } \\
\text { Misc }\end{array}$ & $\begin{array}{l}1.22 \\
0.95 \\
0.53 \\
0.79 \\
1.46 \\
0.52 \\
0.55 \\
1.16 \\
0.52 \\
0.06 \\
0.59\end{array}$ & $\begin{array}{c}0.16 \\
0.13 \\
0.51 \\
0.28 \\
0.13 \\
0.11 \\
0.13 \\
0.1 \\
0.1 \\
0.33 \\
0.18\end{array}$ & $\begin{array}{l}1.39 \\
1.07 \\
1.04 \\
1.06 \\
1.58 \\
0.69 \\
0.67 \\
1.24 \\
0.61 \\
0.38 \\
0.77\end{array}$ & $\begin{array}{l}3603 \\
3603 \\
5146 \\
4062 \\
6126 \\
3853 \\
3196 \\
3192 \\
7993 \\
8421 \\
3561\end{array}$ & $\begin{array}{l}0.29 \\
0.29 \\
0.00 \\
0.13 \\
0.13 \\
0.38 \\
0.19 \\
0.19 \\
0.00 \\
0.00 \\
0.19\end{array}$ & $\begin{array}{l}1.00 \\
1.00 \\
1.00 \\
1.00 \\
1.00 \\
1.00 \\
1.00 \\
1.00 \\
1.00 \\
1.00 \\
1.00\end{array}$ & $\begin{array}{l}\mathbf{F}+\mathbf{I} \\
\mathbf{F}+\mathbf{I} \\
\mathbf{F}+\mathbf{I} \\
\mathbf{F}+\mathbf{I} \\
\mathbf{F}+\mathbf{I} \\
\mathbf{F}+\mathbf{I} \\
\mathbf{F}+\mathbf{I} \\
\mathbf{F}+\mathbf{I} \\
\mathbf{F}+\mathbf{I} \\
\mathbf{F}+\mathbf{I} \\
\mathbf{F}+\mathbf{I}\end{array}$ & $\begin{array}{l}1.44 \\
1.11 \\
0.00 \\
0.54 \\
1.21 \\
1.00 \\
0.40 \\
0.74 \\
0.00 \\
0.00 \\
0.51\end{array}$ & $\begin{array}{l}0.105 \\
0.081 \\
0.000 \\
0.039 \\
0.088 \\
0.073 \\
0.029 \\
0.054 \\
0.000 \\
0.000 \\
0.037\end{array}$ & $\begin{array}{l}0.99 \\
0.76 \\
0.00 \\
0.37 \\
0.83 \\
0.68 \\
0.27 \\
0.51 \\
0.00 \\
0.00 \\
0.35\end{array}$ & $\begin{array}{l}0.30 \\
0.30 \\
0.00 \\
0.25 \\
0.25 \\
0.25 \\
0.45 \\
0.45 \\
0.00 \\
0.00 \\
0.30\end{array}$ & \\
\hline $\begin{array}{l}\text { TIMERS + LI } \\
\text { Small Office } \\
\text { Large Office } \\
\text { Restaurant } \\
\text { Retail } \\
\text { Grocery } \\
\text { Warehouse } \\
\text { School } \\
\text { College } \\
\text { Health } \\
\text { Lodging } \\
\text { Misc }\end{array}$ & $\begin{array}{l}\text { UMEN } \\
1.22 \\
0.95 \\
0.53 \\
0.79 \\
1.46 \\
0.52 \\
0.55 \\
1.16 \\
0.52 \\
0.06 \\
0.59\end{array}$ & $\begin{array}{l}\text { LAINTE } \\
0.16 \\
0.13 \\
0.51 \\
0.28 \\
0.13 \\
0.11 \\
0.13 \\
0.1 \\
0.1 \\
0.33 \\
0.18\end{array}$ & $\begin{array}{l}1.39 \\
1.07 \\
1.04 \\
1.06 \\
1.58 \\
0.69 \\
0.67 \\
1.24 \\
0.61 \\
0.38 \\
0.77\end{array}$ & $\begin{array}{l}3603 \\
3603 \\
5146 \\
4062 \\
6126 \\
3853 \\
3196 \\
3192 \\
7993 \\
8421 \\
3561\end{array}$ & $\begin{array}{l}0.10 \\
0.10 \\
0.10 \\
0.10 \\
0.10 \\
0.10 \\
0.10 \\
0.10 \\
0.10 \\
0.10 \\
0.10\end{array}$ & $\begin{array}{l}1.00 \\
1.00 \\
1.00 \\
1.00 \\
1.00 \\
1.00 \\
1.00 \\
1.00 \\
1.00 \\
1.00 \\
1.00\end{array}$ & $\begin{array}{l}\mathbf{F} \\
\mathbf{F} \\
\mathbf{F} \\
\mathbf{F} \\
\mathbf{F} \\
\mathbf{F} \\
\mathbf{F} \\
\mathbf{F} \\
\mathbf{F} \\
\mathbf{F} \\
\mathbf{F}\end{array}$ & $\begin{array}{l}0.31 \\
0.24 \\
0.27 \\
0.28 \\
0.78 \\
0.13 \\
0.14 \\
0.30 \\
0.42 \\
0.05 \\
0.17\end{array}$ & $\begin{array}{l}0.029 \\
0.017 \\
0.020 \\
0.008 \\
0.064 \\
0.007 \\
0.003 \\
0.015 \\
0.030 \\
0.004 \\
0.005\end{array}$ & $\begin{array}{l}1.08 \\
0.84 \\
0.19 \\
0.47 \\
1.30 \\
0.60 \\
0.32 \\
0.68 \\
0.28 \\
0.03 \\
0.39\end{array}$ & $\begin{array}{l}0.44 \\
0.39 \\
0.11 \\
0.31 \\
0.44 \\
0.25 \\
0.46 \\
0.58 \\
0.10 \\
0.01 \\
0.32\end{array}$ & $\begin{array}{l}\text { No Timers } \\
\text { No Timers }\end{array}$ \\
\hline $\begin{array}{l}\text { OCCUPANC } \\
\text { Small Office } \\
\text { Large Office } \\
\text { Restaurant } \\
\text { Retail } \\
\text { Grocery } \\
\text { Warehouse } \\
\text { School } \\
\text { College } \\
\text { Health } \\
\text { Lodging } \\
\text { Misc }\end{array}$ & $\begin{array}{l}Y \text { SENS } \\
1.22 \\
0.95 \\
0.53 \\
0.79 \\
1.46 \\
0.52 \\
0.55 \\
1.16 \\
0.52 \\
0.06 \\
0.59\end{array}$ & $\begin{array}{l}\mathrm{RS}(6) \\
0.16 \\
0.13 \\
0.51 \\
0.28 \\
0.13 \\
0.11 \\
0.13 \\
0.1 \\
0.1 \\
0.33 \\
0.18\end{array}$ & $\begin{array}{l}1.39 \\
1.07 \\
1.04 \\
1.06 \\
1.58 \\
0.69 \\
0.67 \\
1.24 \\
0.61 \\
0.38 \\
0.77\end{array}$ & $\begin{array}{l}3603 \\
3603 \\
5146 \\
4062 \\
6126 \\
3853 \\
3196 \\
3192 \\
7993 \\
8421 \\
3561\end{array}$ & $\begin{array}{l}0.30 \\
0.30 \\
0.40 \\
0.40 \\
0.40 \\
0.50 \\
0.20 \\
0.30 \\
0.30 \\
0.40 \\
0.30\end{array}$ & $\begin{array}{l}0.35 \\
0.50 \\
0.10 \\
0.10 \\
0.10 \\
0.60 \\
0.80 \\
0.80 \\
0.15 \\
0.20 \\
0.60\end{array}$ & $\begin{array}{c}\mathbf{F}+\mathbf{I} \\
\mathbf{F}+\mathbf{I} \\
\mathbf{F} \\
\mathbf{F} \\
\mathbf{F} \\
\mathbf{F}+\mathbf{I} \\
\mathbf{F}+\mathbf{I} \\
\mathbf{F}+\mathbf{I} \\
\mathbf{F}+\mathbf{I} \\
\mathbf{F}+\mathbf{I} \\
\mathbf{F}+\mathbf{I}\end{array}$ & $\begin{array}{l}0.97 \\
0.76 \\
0.98 \\
1.01 \\
2.82 \\
0.70 \\
0.43 \\
0.89 \\
1.36 \\
1.29 \\
0.62\end{array}$ & $\begin{array}{l}0.071 \\
0.055 \\
0.072 \\
0.074 \\
0.205 \\
0.051 \\
0.031 \\
0.065 \\
0.099 \\
0.094 \\
0.045\end{array}$ & $\begin{array}{l}0.66 \\
0.52 \\
0.67 \\
0.69 \\
1.93 \\
0.48 \\
0.29 \\
0.61 \\
0.93 \\
0.89 \\
0.42\end{array}$ & $\begin{array}{l}0.35 \\
0.35 \\
0.53 \\
0.53 \\
0.53 \\
0.30 \\
0.27 \\
0.27 \\
0.53 \\
0.38 \\
0.38\end{array}$ & $\begin{array}{l}\text { No T, LM } \\
\text { No Timers } \\
\text { No Timers }\end{array}$ \\
\hline $\begin{array}{l}\text { DAYLIGHTI } \\
\text { Small Office } \\
\text { Large Office } \\
\text { Reatuurant } \\
\text { Retail } \\
\text { Grocery } \\
\text { Warehouse } \\
\text { School } \\
\text { College } \\
\text { Health } \\
\text { Lodging } \\
\text { Misc }\end{array}$ & $\begin{array}{l}\text { NG (7) } \\
1.22 \\
0.95 \\
0.53 \\
0.79 \\
1.46 \\
0.52 \\
0.55 \\
1.16 \\
0.52 \\
0.06 \\
0.59\end{array}$ & $\begin{array}{c}0.16 \\
0.13 \\
0.51 \\
0.28 \\
0.13 \\
0.11 \\
0.13 \\
0.1 \\
0.1 \\
0.33 \\
0.18\end{array}$ & $\begin{array}{l}1.39 \\
1.07 \\
1.04 \\
1.06 \\
1.58 \\
0.69 \\
0.67 \\
1.24 \\
0.61 \\
0.38 \\
0.77\end{array}$ & $\begin{array}{l}3603 \\
3603 \\
5146 \\
4062 \\
6126 \\
3853 \\
3196 \\
3192 \\
7993 \\
8421 \\
3561\end{array}$ & $\begin{array}{l}0.50 \\
0.50 \\
0.50 \\
0.50 \\
0.50 \\
0.50 \\
0.50 \\
0.50 \\
0.50 \\
0.50 \\
0.50\end{array}$ & $\begin{array}{l}(8) \\
0.28 \\
0.28 \\
0.00 \\
0.00 \\
0.00 \\
0.00 \\
0.20 \\
0.20 \\
0.25 \\
0.00 \\
0.20\end{array}$ & $\begin{array}{l}\mathbf{F} \\
\mathbf{F} \\
\mathbf{F} \\
\mathbf{F} \\
\mathbf{F} \\
\mathbf{F} \\
\mathbf{F} \\
\mathbf{F} \\
\mathbf{F} \\
\mathbf{F} \\
\mathbf{F}\end{array}$ & $\begin{array}{l}1.26 \\
0.93 \\
1.18 \\
1.21 \\
3.38 \\
0.39 \\
0.74 \\
1.03 \\
1.79 \\
0.21 \\
0.63\end{array}$ & $\begin{array}{l}0.092 \\
0.068 \\
0.086 \\
0.088 \\
0.246 \\
0.029 \\
0.054 \\
0.075 \\
0.130 \\
0.015 \\
0.046\end{array}$ & $\begin{array}{l}0.86 \\
0.64 \\
0.81 \\
0.83 \\
2.31 \\
0.27 \\
0.51 \\
0.70 \\
1.22 \\
0.14 \\
0.43\end{array}$ & $\begin{array}{l}0.45 \\
0.45 \\
0.45 \\
0.45 \\
0.45 \\
0.45 \\
0.45 \\
0.45 \\
0.45 \\
0.45 \\
0.45\end{array}$ & $\begin{array}{l}\text { No T, LM } \\
\text { No Timers } \\
\text { No Timers }\end{array}$ \\
\hline
\end{tabular}

(1) Minus 0.1 or $0.2 \mathrm{LPD}$ (W/sq $\mathrm{ft}$ ) for controls in baseline

(2) Assumes discount factor of 9.39 (4 percent discount rate over 12 years); assumes electricity price of $\$ 0.0729 / \mathrm{kWh}$

(3) T = Timers, LM = Lumen Mainienance, OS = Occupancy Sensor

(4) Savings fractions increase by 25 percent, costs same

(5) Savings fractions sume, costs of $\$ 0.20$ per sq. ft. where Fluorescent LPD $=1.0$

(6) Savings fractions same, costs fall by 25 percent

(7) Savings and costs are per applicable aquare foot; savings fractions increase, costs fall

(8) Applicable fraction is one-half of the perimeter area of total building floorspace 


\section{COMMERCIAL SECTOR FORECASTS}

\subsection{BACKGROUND}

The Engineering Analysis (Section 3 and Appendix B) presents energy use and cost information for standard and energy-efficient lighting products. The cost effectiveness and efficacies of these products are the major basis for identifying specific lighting design options. To estimate the net impact of policies based on these design options for indoor lighting in the commercial buildings sector, the EPRI commercial forecasting model, COMMEND 3.2, is used. Further detail on the model is presented in Section 2.1.2 and Appendix E.

The basic relation modeled by COMMEND is that lighting energy use is the product of floor area (in square feet) and energy use per unit area (in kilowatt-hours per square foot per year; referred to as Energy Use Intensity, or EUI) for that end use, summed over all building types. This section describes how changes produced by lighting component standards and building code policies are translated into lighting EUIs that are input into COMMEND. It also describes how the net economic impacts of these policies are estimated.

The analysis integrates a variety of data: current equipment market shares, recent usage trends for various lighting products, and the wattages, costs, and service lives derived from the LBL engineering analysis. The results of this integration are used first to develop a baseline set of lighting EUIs. These EUIs are then used to calibrate COMMEND and develop baseline forecasts from which the net impacts of the policies are estimated. Finally, the baseline lighting EUIs are modified to reflect the impact of lighting component standards, building codes, and consumer incentive policies on energy consumption. The difference between the baseline and each policy forecast is the net energy savings.

\subsection{OVERVIEW OF THE COMMERCIAL SECTOR ANALYSIS}

There are three stages in the analysis. Stage 1 (Section 4.3) is the development of a baseline set of four lighting EUIs for each building type: for the lighting equipment stock in 1986 and in 1995, and for new and renovated buildings in 1986 and in 1995. Each EUI corresponds to a weighed average of the four lighting technologies (fluorescent, incandescent, HID', and other). The 1995 EUIs are referred to as the sales (or marginal) EUIs. Stage 2 (Section 4.4) is the development of the sales (marginal) 1995 EUIs for each policy analyzed. Stage 3 (Section 4.5) is the estimation of the costs of each policy. Section 4.6 presents the energy and economic

\footnotetext{
'Although efficiency improvements (technology options) for HID lamps are not analyzed, HID lamps are included in the lamp stock and sales market shares. In the High- and Low-Efficiency Baselines, metal halide and high-pressure sodium lamps replace the mercury vapor stock at the end of its useful lifetime. This penetration is assumed to be driven by market forces.
} 
results of the policies modeled with COMMEND.

\subsection{DEVELOPMENT OF BASELINE LIGHTING EUIS (STAGE 1)}

Baseline lighting EUIs are used to calibrate other parameters in the COMMEND model and to develop a baseline forecast against which the effects of the policies can be measured. The purpose of the calibration is to account for all influences on lighting energy use before the policies are applied. These influences include: (1) the operation of existing market forces on lighting energy use, such as the effects of energy prices and the availability and cost of energyefficient lighting products; (2) the impacts of electric utility demand-side management (DSM) activities to stimulate the market for efficient lighting technologies and practices; (3) the impacts of state and federal system and component performance standards for buildings; (4) the Environmental Protection Agency's Green Lights Program; and (5) the Federal Energy Management Program's Federal Relighting Initiative for federal buildings. These influences are accounted for simultaneously since they are not disaggregated in the sources listed in Step 4 below.

Four baseline lighting EUIs are developed for each of the 11 commercial building types modeled by COMMEND. Both a stock and a marginal EUI are developed for the years 1986 and 1995. The benchmark year for the calibration is 1986. The policies examined are assumed to take effect in 1995. The stock EUI refers to the average EUI for the entire floorspace of lit buildings in a given year. Marginal EUI refers to the EUI of new buildings or of existing buildings with renovated lighting systems in a given year.

The method used to estimate EUIs for the baseline consists of six steps:

(1) A stock 1986 EUI, by building type, is developed from the average of seven different utility studies. $^{2}$

(2) The implied lighting power density (LPD, in watts per square foot) is calculated by dividing the EUI (kWh/sq ft-year) by annual lighting hours. Annual Lighting Hours, by building type, are taken from EIA data on effective lighting hours, as described in Section 2.1.1 and Section 9.3.1.

(3) LPDs by lighting technology (fluorescent, incandescent, high-intensity discharge, and other) are estimated by applying lighting technology shares developed from a large and detailed set of audit data collected in $1986 .^{3}$

\footnotetext{
${ }^{2}$ H. Akbari, et al. 1990 "A Review of Existing Commercial Energy Use Intensity and Load-Shape Studies." ACEEE 1990 Summer Study on Energy Efficiency in Buildings. Washington D.C., vol. 3, pp 3.7-3.18.

${ }^{3}$ ADM Associates Inc. 1986. CEC Commercial On-Site Survey Database, PG\&E Selected Sample of Commercial Premises. Sacramento, CA.
} 
(4) LPDs for fluorescent and incandescent lamps are further disaggregated into a number of technology types (e.g., standard fluorescent lamp, electronic ballast, etc.), using a combination of survey data collected by the Lighting Research Institute, the Energy Information Administration, ${ }^{3}$ and the Bureau of the Census. For fluorescent lamps, the categories of standard, reduced-wattage, T-8, "maximum technologically feasible" (max tech), and "research and developritent" (R\&D) are considered separately for 4-foot lamps; standard, reduced-wattage, max tech, and R\&D for 8-font lamps; and standard and reduced-wattage for 8-foot, high-output (HO) lamps. Also separate । are standard magnetic, energy-efficient magnetic, cathode cut-out, and electronic ballests for 4-foot lamps, and all but the cathode cut-out ballast for the 8-foot and 8foot HO fluorescent lamps. Lensed troffer, wraparound, parabolic, and other fixture types are separated for the fluorescent lamps. Five classes of general service and six classes of reflector lamps are disaggregated for incandescent lamps, in addition to compact fluorescent lamps. The market share of each lighting component is then multiplied by its wattage; this is done for each component, summed, and divided ove : total units to obtain a weighted-average watt for the 1986 stock.

(5) Daia on sales of lighting components are used to adjust the distribution of components sold in 1986 and 1995, as weil as the total stock of components in 1995. These changes are estimated primarily through analysis of the projections contained in the LRI report, as well as:

- the elimination of standard magnetic ballasts in 1990, as required by the existing ECPA standard; and

- the substitution of metal halide and high-pressure sodium lamps, in equal proportion, for mercury vapor lamp stock beginning in 1995.

Weighted-average watts (WAWs) are then calculated for 1986 sales, 1995 sales, and 1995 stock. Finally, the ratio of each WAW to the 1986 stock WAW is multiplied by the $1986 \mathrm{LPD}$ in obtain 1986 sales, 1995 sales, and 1995 LPDs for each building type. Calculation of the baseline WAW is shown in Tables D.2, D.3, and D.4 in Appendix D.

(6) All LPDs are converted back to EUIs using Annual Lighting Hours.

The impacts of changes in the stock and sales of lighting control components are estimated separately (see Section 4.4).

LRI and Plexus Research. 1991. Op. cit., Ref. 3, Section 2. The repon contains projected supply and demand of lighting products from surveys of lamp and ballast manufacturers, utility DSM program planners, and lighting maintenance companies.

'1986 Non-Residential Buildings Fnergy Consumption Survey (NBECS). 1988. Commercial Buildings Consumption and Expenditures 1986. U.S. Department of Energy, Energy Information Agency, D. NE/EIA-0318(86).

'U.S. Department of Commerce, Bureau of Census. 1982 to 1989. Census of Manufacturers, Electric Lighting and Wiring Equipment; these are annual reports derived from surveys of inanufacturers of lamps, ballasts, and fixtures.

$$
4-3
$$




\subsection{DEVELOPMENT OF POLICY CASE LIGHTING EUIS (STAGE 2)}

The adoption of component standards, building codes, or incentive policies changes the 1995 sales EUIs. New 1995 sales EUIs are developed for each policy using a methodology similar to that of Stage 1. The 1995 sales EUIs for each policy are presented in Table D.1 in Appendix D. The calculation of weighted-average watts is shown for fluorescent, incandescent, and fixture policy cases in Tables D.5, D.6, and D.7, respectively.

The modeling approach for component standards other than controls cases is identical. For each standard, particular lighting components below a certain efficiency become unavailable. As a result, the distribution of component sales is shifted to the remaining available products. The fluorescent lighting technology market share assumptions used to develop new fluorescent weighted-average watts for illustrative policy cases are shown in Table 4.1.

As seen in Table D.5, the incandescent stock is calculated together with the CFL stock to yield an "incandescent socket" weighted-average watt. The fraction of CFLs is 20 percent for baseline 1995 sales and is increased for the CFL Downlights and the Min LCC and R\&D Combination policy cases. For all policy cases where incandescent lamps are affected, the incandescent stock market shares are adjusted separately and the effects added to those from the CFL stock.

For controls policies, 1995 sales LPDs are directly adjusted for each controls technology based on savings fractions and applicable floorspace for each building type (weighted-average watts are not used). The controls analysis is discussed in more detail in Section 3.4.1.

For system performance standards (building codes), 1995 sales LPDs are also directly adjusted, based on the maximum LPDs allowed in the two building codes analyzed (ASHRAE/IES-90.1 and DOE-93). Installed LPDs can vary greatly, even within the same building type. Distributions of LPDs are developed for each building type from a large sample of detailed commercial building audits collected in northern California.? In principle, building codes prohibit LPDs in new or renovated buildings higher than a specified standard level. If all new buildings comply with the standard, the average LPD for new buildings will be below the standard level, since some buildings will beat the standard. This is taken into account by calculating the new average LPD for each building type after adoption of a national building code. Under the full compliance building code policies, all LPDs higher than the maximum LPD in the code are eliminated. The average LPD of the new, truncated distribution of LPDs is then calculated for each building type.

However, non-conıpliance with LPD standards in building codes may be a significant issue (see Appendix G). In practice, the maximum standard levels set in building codes are sometimes exceeded in particular buildings. To account for this effect, a second case assuming only partial compliance is developed for each of the two building code policies. Under the partial compliance

\footnotetext{
'ADM Associates, Inc. 1986. Op. cit., Ref. 3.
} 
Table 4.1 Fluorescent Market Shares (\%) and Technology Properties

\begin{tabular}{|c|c|c|c|}
\hline \multirow[b]{2}{*}{ Technology } & \multicolumn{3}{|c|}{ Market Share (\% of Projected 1995 Sales) } \\
\hline & $\begin{array}{l}\text { No-Programs } \\
\text { Baseline }\end{array}$ & $\begin{array}{c}\text { Minimum LCC } \\
\text { Combination }\end{array}$ & $\begin{array}{c}\text { R \& D } \\
\text { Combination }\end{array}$ \\
\hline 4-Foot Lamps & & & \\
\hline \multicolumn{4}{|l|}{ Energy-Eff :ient Magnetic Ballast } \\
\hline Standard F40 T12 & $8.6 \%$ & -- & -- \\
\hline Reduced Wattage $34 \mathrm{~W}$ T12 & $25.7 \%$ & -- & -. \\
\hline T 8 & $8.8 \%$ & -- & -. \\
\hline \multicolumn{4}{|l|}{ Cathode Cutout Ballast } \\
\hline Standard F40 T12 & $1.5 \%$ & -- & -- \\
\hline Reduced Wattage $34 \mathrm{~W}$ T12 & $4.4 \%$ & -- & -- \\
\hline T 8 & $1.5 \%$ & -- & -- \\
\hline \multicolumn{4}{|l|}{ Electronic Ballast } \\
\hline Standard F40 T12 & $5.9 \%$ & -. & -- \\
\hline Reduced Wattage $34 \mathrm{~W}$ T12 & $17.8 \%$ & -. & -- \\
\hline T 8 & $6.1 \%$ & -- & $-\cdots$ \\
\hline T 8 w/Electronic Ballast with High-Efficiency Fixture & -- & $80.3 \%$ & $-\cdot$ \\
\hline VHF Electrodeless with Super- Efficient Fixture & -- & -- & $80.3 \%$ \\
\hline \multicolumn{4}{|l|}{ 8-Foot Lamps } \\
\hline \multicolumn{4}{|l|}{ Energy-Efficient Magnetic Ballast } \\
\hline Standard $75 \mathrm{~W}$ & $0.8 \%$ & -. & .- \\
\hline Reduced Wattage $60 \mathrm{~W}$ & $7.2 \%$ & -. & -. \\
\hline \multicolumn{4}{|l|}{ Electronic Ballast } \\
\hline Standard $75 \mathrm{~W}$ & $0.2 \%$ & -. & -- \\
\hline Reduced Watage $60 \mathrm{~W}$ & $2.3 \%$ & $10.5 \%$ & -. \\
\hline T 8 & -- & -. & $10.5 \%$ \\
\hline \multicolumn{4}{|l|}{ 8-Foot High Output Lamps } \\
\hline \multicolumn{4}{|l|}{ Energy-Efficient Magnetic Ballast } \\
\hline Standard HO $110 \mathrm{~W}$ & $0.4 \%$ & -- & -- \\
\hline Reduced Watage 95W HO & $3.3 \%$ & -. & -- \\
\hline \multicolumn{4}{|l|}{ Electronic Ballast } \\
\hline Standard HO 110W & $0.1 \%$ & .- & -. \\
\hline Reduced Wattage $95 \mathrm{~W}$ HO & $0.7 \%$ & $4.4 \%$ & $4.4 \%$ \\
\hline Other & $4.8 \%$ & $4.8 \%$ & $4.8 \%$ \\
\hline Total Market Share & $100.0 \%$ & $100.0 \%$ & $100.0 \%$ \\
\hline
\end{tabular}


policies, the cut-off point is moved one standard deviation higher than the actual standard. LPDs beyond this point are removed, and the average LPD of the new distribution is calculated. Figure 4.1 and Table 4.2 illustrate how LPDs are removed, and new average LPDs calculated, for the building code policies.

\subsection{ESTIMATION OF THE NET PRESENT VALUES OF POLICY CASES}

The procedure for estimating the net present values (NPVs) of component standards consists of six steps:

(1) The distribution of component sales and the cost of individual components are used to calculate a weighted-average cost, similar to the weighted-average watt (WAW) described in Section 4.3.

(2) The change in weighted-average cost and weighted-average watt between the baseline and the policy case is calculated. The change in cost is then divided by the change in watts to obtain the net change in cost per watt for each policy.

(3) The energy savings, in $\mathrm{kWh} / \mathrm{sq} \mathrm{ft}-\mathrm{yr}$ (change in EUI), is divided by annual lighting hours to yield the reduction in total lighting equipment wattage (change in LPD, watts/sq $\mathrm{ft}$ ).

(4) The change in wattage (step 3) times the change in cost per watt (step 2) in each year gives the annual cost of the policy. Annual costs are discounted to 1990 dollars and summed over the analysis period to obtain total costs.

(5) Annual economic savings are calculated by multiplying annual energy savings times the real annual electricity prices shown in Figure 2.5. Annual savings over the analysis period are summed to obtain total savings.

(6) Total costs are subtracted from total savings to obtain the NPV of each policy.

Investments in energy-efficient components lasting beyond the forecast period are annualized; only annual costs up to 2030 are included in the economic analysis.

NPVs are not calculated for the fixture policy cases or the building code cases because of the lack of data on how these policies would change the average cost of installed lighting components. The costs of the consumer incentive policies used to calculate NPVs are based on an average rebate level of 3.5 to 4 cents per kilowatt-hour saved paid by the agency offering the programs, which may or may not equal 100 percent of the incremental cost of the efficient lighting measures (see Appendix B for cost of conserved energy calculations for efficient lighting components). Thus, comparison of the NPVs or benefit/cost ratios of incentive policies with those of the other policies is not appropriate. 
Figure 4.1:

Effect of Building Code on Average Lighting Power Density of New Buildings (Illustration for Large Office Buildings)

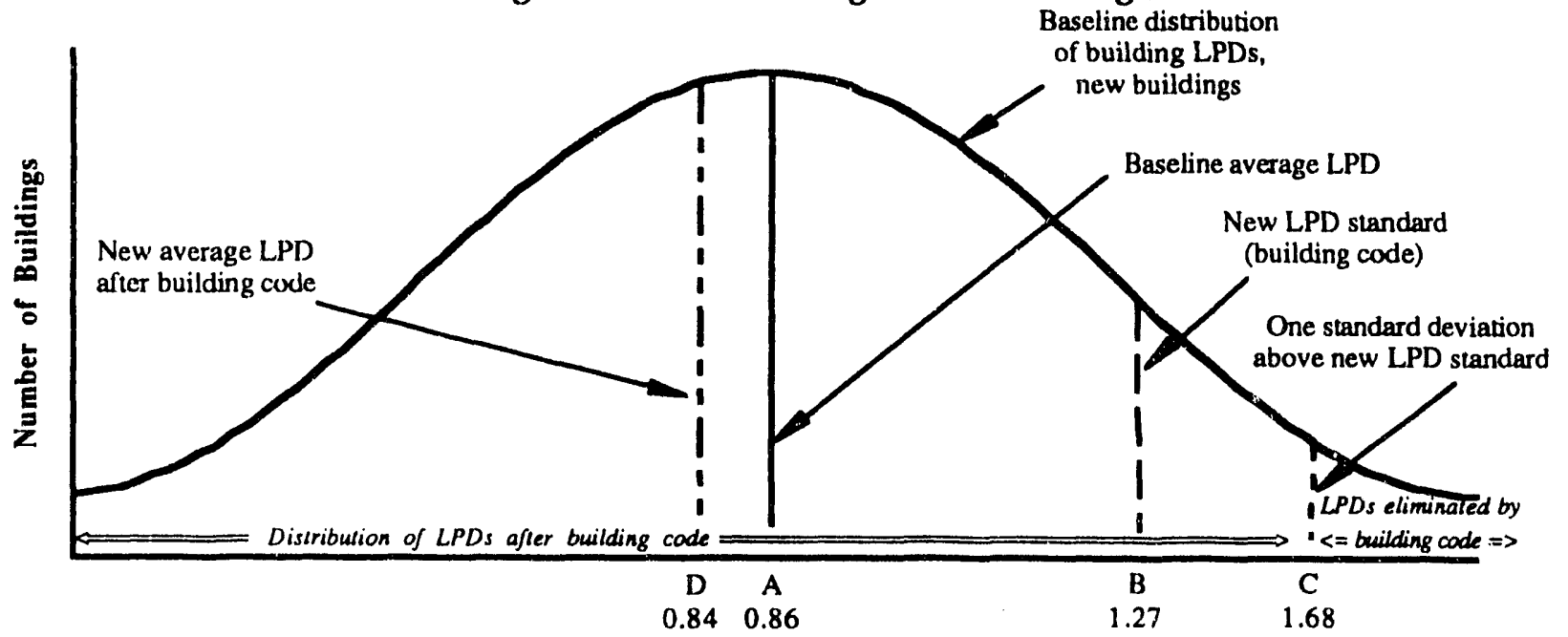

Lighting Power Density (Watts per square foot)

Table 4.2 Derivation of Lighting Power Densities for use in Building Codes Analyais: ASHRAE 90.1 (volunary) and DOE-1993 (proposed), Partial and Full Compliance

\begin{tabular}{|c|c|c|c|c|c|c|c|c|c|c|c|c|c|}
\hline \multirow[b]{4}{*}{$\begin{array}{l}\text { Building } \\
\text { Type }\end{array}$} & \multirow[b]{2}{*}{$\mathbf{A}$} & \multicolumn{6}{|c|}{ ASHRAE 90.1} & \multicolumn{6}{|c|}{ DOE - 1993} \\
\hline & & \multirow[b]{3}{*}{$\begin{array}{l}\text { Sundard } \\
\text { IPD } \\
\text { (W/sq. fi.) }\end{array}$} & C & D & $\mathbf{D}^{\prime}$ & D & $\mathbf{D}^{\prime}$ & B & C & D & $\mathbf{D}^{\prime}$ & D & $\mathbf{D}^{\prime}$ \\
\hline & \multirow[b]{2}{*}{$\begin{array}{l}\text { Pre- } \\
\text { Standard } \\
\text { Average } \\
\text { LPD } \\
\text { (W/sq. ft.) }\end{array}$} & & \multirow[b]{2}{*}{$\begin{array}{c}\text { Standard } \\
\text { LPD plus } \\
\text { Sud. Dev. } \\
\text { (1) } \\
\text { (W/sq. fl.) }\end{array}$} & \multicolumn{2}{|c|}{ Partial Compliance } & \multicolumn{2}{|c|}{ Full Compliance } & \multirow[b]{2}{*}{$\begin{array}{l}\text { Standard } \\
\text { IPD } \\
\text { (W/sq. f.) }\end{array}$} & \multirow[b]{2}{*}{$\begin{array}{l}\text { Standard } \\
\text { LPD plus } \\
\text { Std. Dev. } \\
\text { (1) } \\
\text { (w/sq. ft) }\end{array}$} & \multicolumn{2}{|c|}{ Partial Compliance } & \multicolumn{2}{|c|}{ Full Complinnce } \\
\hline & & & & $\begin{array}{l}\text { Post- } \\
\text { Standard } \\
\text { Average } \\
\text { LPD } \\
\text { (W/sq. f.) }\end{array}$ & $\begin{array}{c}\text { Post. } \\
\text { Standard } \\
\text { Average } \\
\text { EdI } \\
\text { (xWh/sq. f.) }\end{array}$ & $\begin{array}{l}\text { Post. } \\
\text { Standard } \\
\text { Average } \\
\text { LPD } \\
\text { (w/rq. f.) }\end{array}$ & $\begin{array}{l}\text { Pon- } \\
\text { Standard } \\
\text { Average } \\
\text { Edl } \\
\text { (kWh/sq. fl.) }\end{array}$ & & & $\begin{array}{l}\text { Post- } \\
\text { Sundard } \\
\text { Average } \\
\text { LPD } \\
\text { (W/sq. f.) }\end{array}$ & $\begin{array}{l}\text { Post- } \\
\text { Standard } \\
\text { Average } \\
\text { EII } \\
\text { (kWh/sq. f.) }\end{array}$ & $\begin{array}{l}\text { Post- } \\
\text { Sianderd } \\
\text { Average } \\
\text { LPD } \\
\text { (W/sg. f.) }\end{array}$ & $\begin{array}{l}\text { Post- } \\
\text { Standard } \\
\text { Average } \\
\text { Eul } \\
\text { (kWh/sq. fr) }\end{array}$ \\
\hline Small office & 1.15 & 1.72 & 2.19 & 1.14 & 4.11 & 1.06 & 3.67 & 1.27 & 1.62 & 1.02 & 3.83 & 0.75 & 2.72 \\
\hline Large office & 0.86 & 1.72 & 2.27 & 0.86 & 3.10 & 0.85 & 3.04 & 1.27 & 1.68 & 0.84 & 3.05 & 0.75 & 269 \\
\hline Restaurant & 0.87 & 1.38 & 2.02 & 0.83 & 4.29 & 0.67 & 3.08 & 0.85 & 1.25 & 0.60 & 3.45 & 0.32 & 1.64 \\
\hline Retail & 0.96 & 3.08 & 3.62 & 0.96 & 3.90 & 0.96 & 3.90 & 252 & 2.96 & 0.96 & 3.90 & 0.96 & 3.90 \\
\hline Grocery & 1.38 & 2.37 & 3.43 & 1.35 & 8.27 & 1.16 & 7.98 & 2.03 & 2.94 & 1.30 & 7.13 & 1.01 & 6.18 \\
\hline Warchouse (2) & 0.59 & 0.56 & -. & 0.58 & 2.23 & 0.54 & 2.07 & 0.42 &.. & 0.52 & 1.99 & 0.42 & 1.63 \\
\hline School & 0.57 & 1.83 & 3.54 & 0.56 & 1.79 & 0.48 & 1.72 & 1.35 & 2.61 & 0.54 & 1.52 & 0.39 & 1.23 \\
\hline College & 1.18 & 2.01 & 2.88 & 1.16 & 3.69 & 1.01 & 3.34 & 1.49 & 2.13 & 1.05 & 3.21 & 0.72 & 231 \\
\hline Health & 0.57 & 2.20 & 4.81 & 0.56 & 4.45 & 0.45 & 4.38 & 1.90 & 4.15 & 0.55 & 3.62 & 0.41 & 3.31 \\
\hline Lodging (2) & 0.34 & 1.90 & .. & 0.33 & 2.81 & 0.68 & 2.61 & 1.10 & .. & 0.65 & 2.51 & 0.53 & 205 \\
\hline Miscellancous (3) & 061 & .. & .. & 0.61 & 2.17 & 0.61 & 2.17 & -. & .. & 0.61 & 2.17 & 0.61 & 217 \\
\hline Weighted Average & 0.77 & & & 0.77 & 3.08 & 0.75 & 2.94 & & & 0.75 & 2.88 & 0.65 & 2.53 \\
\hline
\end{tabular}

(1) Partial compliance assumed to eliminate all l.PDs one Aandard deviation above adopted standard

(2) Values for case "D" are hased on the average cstimaled change in LPDs for all other buikding types

(3) No standurd 


\subsection{RESULTS OF THE COMMERCIAL ENERGY MODEL}

The analysis is separated into five groups of policy cases, which are modeled within the COMMEND structure: fluorescent lamp standards, incandescent lamp standards, fixture standards, lighting controls standards and national building codes. Several combination policies are also modeled, since results from two or more policy cases may not be added to determine their combined effect. Additionally, incentive policies are analyzed outside the COMMEND framework, with the best available information about the effects of these types of policies. The results of these forecasts are expressed in terms of EUIs and total U.S. lighting energy use and are presented in policy groups in Appendix F (Figures F.1-F.32). HVAC interactions are treated separately in Appendix H.

Each policy is modeled under the conditions of both the High- and Low-Efficiency Baselines to demonstrate the range of potential energy savings. Although the High-Efficiency Baseline captures much of the efficiency potential in the market (see Section 2.1.2), substantial additional savings are possible with implementation of individual policies. Even more savings are possible under the Low-Efficiency Baseline.

Figures 4.2 and 4.3 illustrate energy consumption relative to the three baselines, as well as three illustrative policy cases. Note that there is no difference between the savings for each baseline with the two combination policies. This is because the policy EUIs under both baselines fall near the bottom of the technology tradeoff curve defined by COMMEND (see Figure 2.9). Therefore, consumers select from a single point rather than a curve of lighting technologies. As a result, all consumers purchase at the EUI standard level, and overall lighting consumption is identical under the Low-Efficiency and High-Efficiency Baselines.

Table 4.3 summarizes the quantitative and qualitative aspects of various policies. The annual energy consumption of each policy analyzed is shown in Table 4.4 (under the High-Efficiency Baseline) and Table 4.5 (under the Low-Efficiency Baseline). Cumulative consumption and savings over the 36-year analysis period (1995 to 2030) from both Baselines are presented in Table 4.6.

Figures 4.4, 4.6 and 4.8 compare the range of cumulative lighting energy savings for each component standard for the period 1995 to 2030. The bottom of each bar represents savings from the High-Efficiency Baseline, while the top represents savings from the Low-Efficiency Baseline.

The results of the economic analysis for each policy are presented in Tables 4.7 and 4.8. The tables show the present values of savings and costs, NPVs, and benefit/cost ratios for each policy. Figures 4.5, 4.7 and 4.9 present the NPVs u.Ider the High- and Low-Efficiency Baselines for each policy analyzed. 


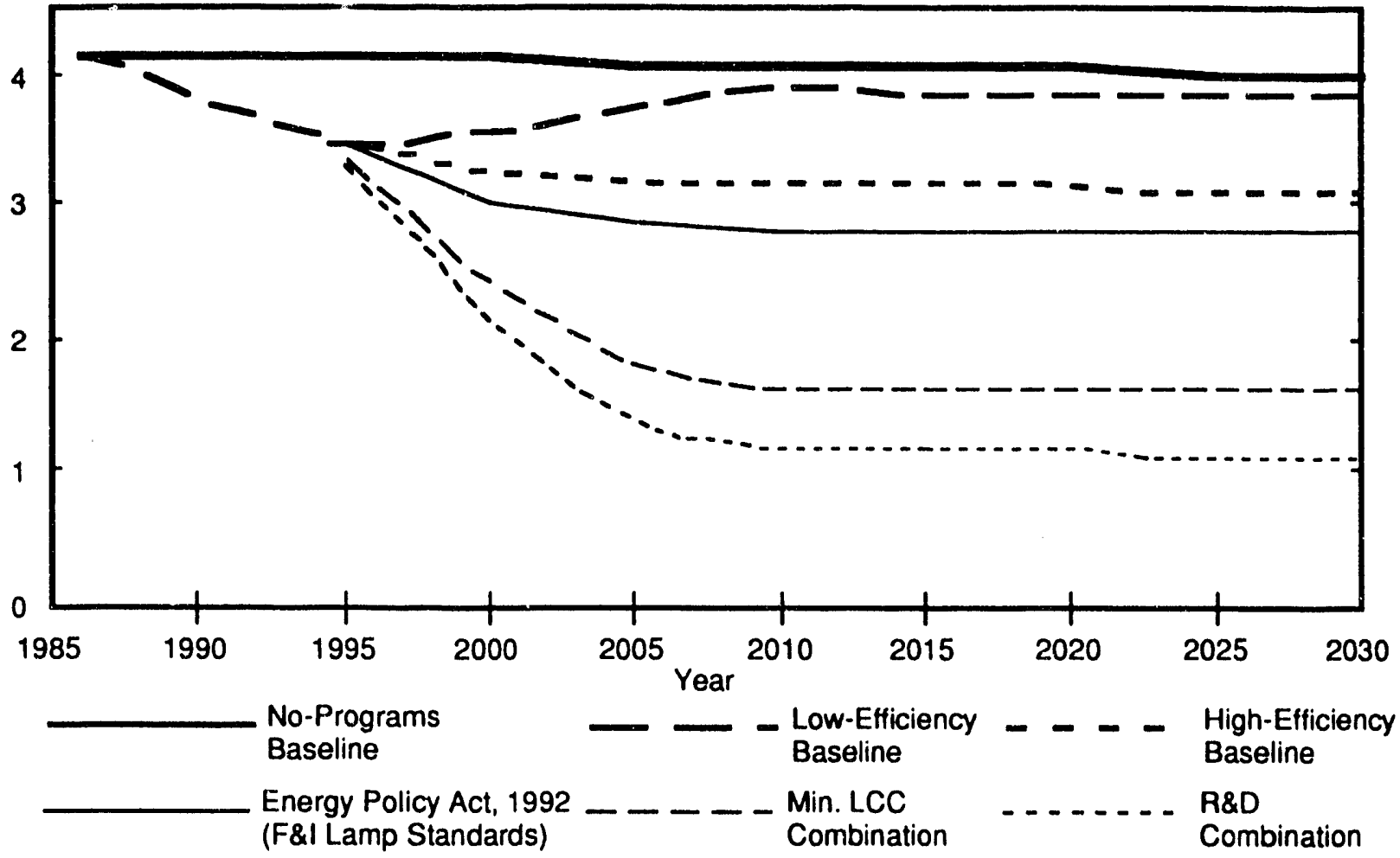

Figure 4.3

\section{Annual Lighting Energy Consumption}

Primary Quads

Baselines and Illustrative Policy Cases

Commercial Sector

TWh

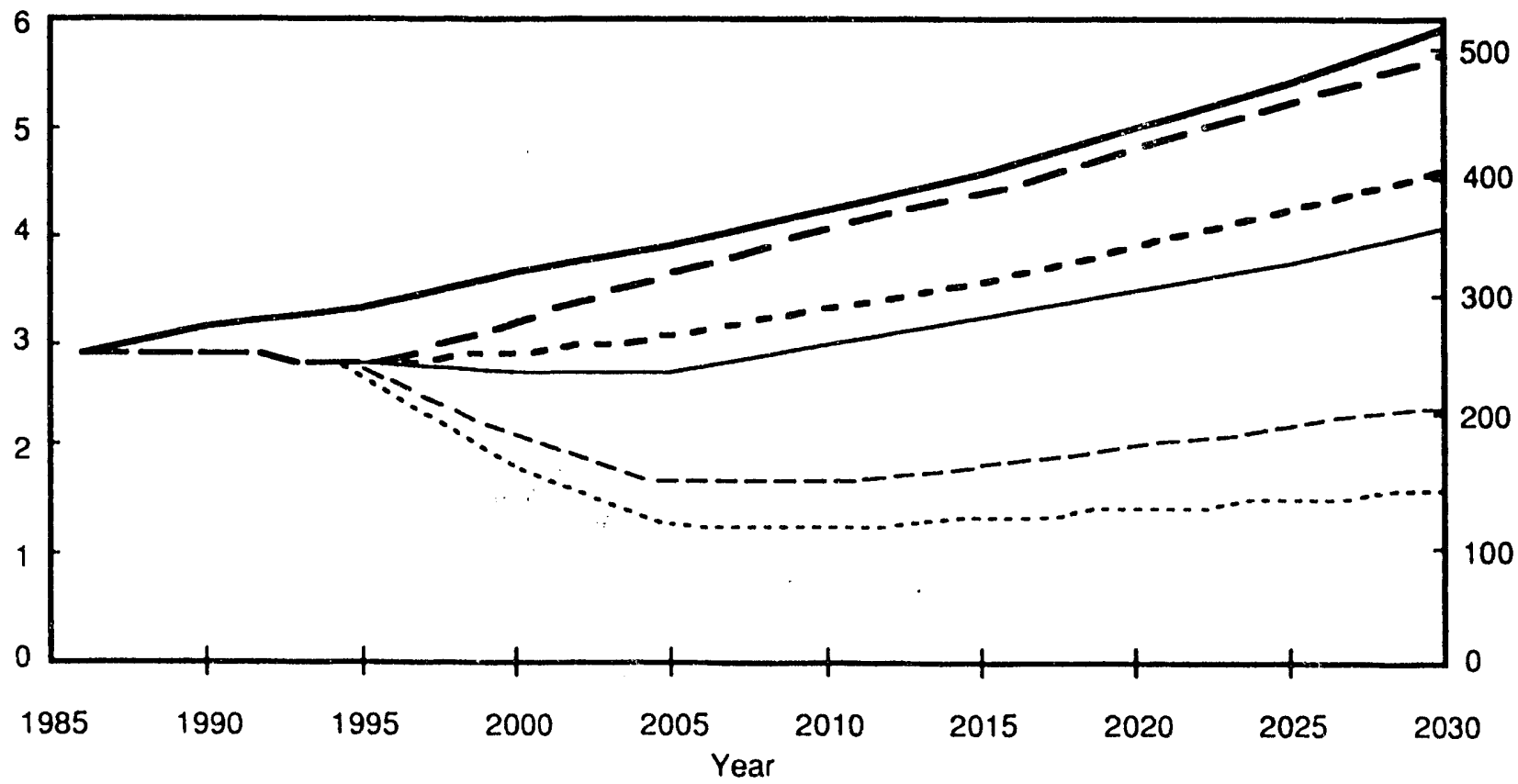

No-Programs

Baseline

$--\underset{\text { Low-Efficiency }}{\text { Baseline }}-\ldots$

High-Efficiency

Energy Policy Act, 1992 _ $\ldots$ - - Min. LCC

Baseline

(F\&I Lamp Standards)

Combination

R\&D

Combination 


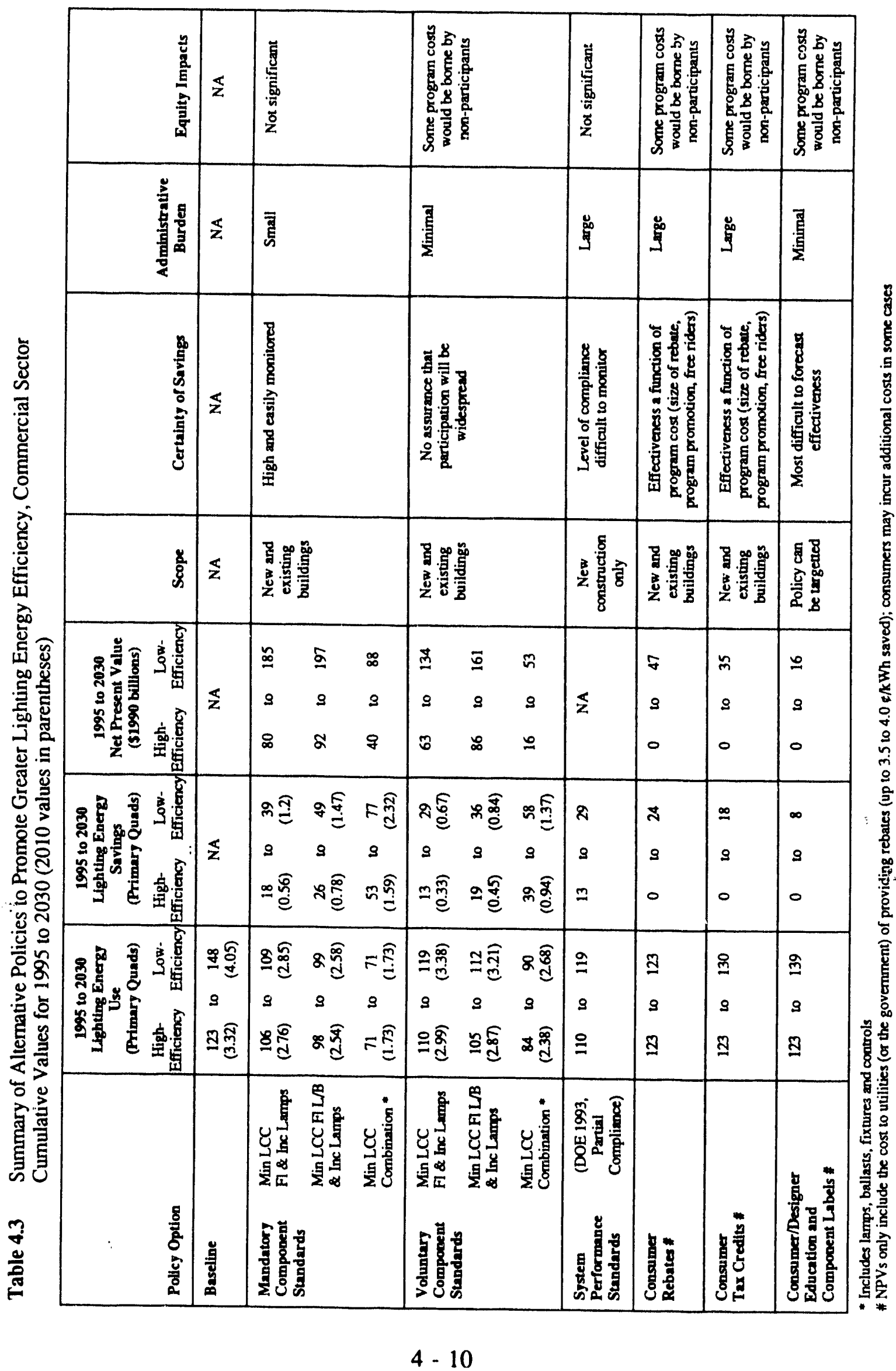


Table 4.4 Annual Commencial Lighting Energy Consumption, High-Efficiency Baseline, 1995 to 2030 (Quadrillion Btu primary energy; $11,500 \mathrm{Btu}=1 \mathrm{kWh}$ )

\begin{tabular}{|c|c|c|c|c|c|c|c|c|c|}
\hline Policy & 1990 & 1995 & 2000 & 2005 & 2010 & 2015 & 2020 & 2025 & 2030 \\
\hline No-Programs Baseline & 3.12 & 3.35 & 3.63 & 3.89 & 4.22 & 4.60 & 5.01 & 5.45 & 5.93 \\
\hline High-Enclency Baseline & 2.90 & 2.81 & 2.86 & 3.05 & 3.32 & 3.60 & 3.91 & 4.24 & $4.61^{\circ}$ \\
\hline \multicolumn{10}{|l|}{ Indivldual Component Standards } \\
\hline \multicolumn{10}{|l|}{ Fluorescent Lamps } \\
\hline $\begin{array}{l}\text { Eliminate Highest Wattage* } \\
\text { Minimum Life Cycle Cost } \\
\text { Maximum Technology } \\
\text { R \& D } \\
\text { Min. LCC Lamp/Ballast }\end{array}$ & & $\begin{array}{l}2.79 \\
2.78 \\
2.76 \\
2.76 \\
2.76\end{array}$ & $\begin{array}{l}2.71 \\
2.63 \\
2.55 \\
2.50 \\
2.54\end{array}$ & $\begin{array}{l}2.78 \\
2.63 \\
2.48 \\
2.38 \\
2.46\end{array}$ & $\begin{array}{l}2.99 \\
2.82 \\
2.64 \\
2.52 \\
2.61\end{array}$ & $\begin{array}{l}3.25 \\
3.06 \\
2.86 \\
2.73 \\
2.83\end{array}$ & $\begin{array}{l}3.53 \\
3.32 \\
3.10 \\
2.96 \\
3.07\end{array}$ & $\begin{array}{l}3.84 \\
3.61 \\
3.37 \\
3.22 \\
3.34\end{array}$ & $\begin{array}{l}4.18 \\
3.93 \\
3.67 \\
3.50 \\
3.63\end{array}$ \\
\hline \multicolumn{10}{|l|}{ Incandescent Lamps } \\
\hline $\begin{array}{l}\text { Eliminate Highest Wattage } \\
\text { Minimum Life Cycle Cost } \\
\text { Maximum Technology } \\
\text { R \& D } \\
\text { CFL Downlights } \\
1991 \text { Proposed Standards (Inc. Lamps) } \\
\text { Energy Policy Act, } 1992 \text { (Inc. Lamps) }\end{array}$ & & $\begin{array}{l}2.79 \\
2.78 \\
2.78 \\
2.77 \\
2.79 \\
2.79 \\
2.79\end{array}$ & $\begin{array}{l}2.69 \\
2.67 \\
2.65 \\
2.58 \\
2.69 \\
2.69 \\
2.69\end{array}$ & $\begin{array}{l}2.74 \\
2.71 \\
2.68 \\
2.54 \\
2.74 \\
2.73 \\
2.74\end{array}$ & $\begin{array}{l}2.94 \\
2.86 \\
2.87 \\
2.71 \\
2.94 \\
2.93 \\
2.94\end{array}$ & $\begin{array}{l}3.19 \\
3.15 \\
3.11 \\
2.94 \\
3.19 \\
3.19 \\
3.19\end{array}$ & $\begin{array}{l}3.47 \\
3.43 \\
3.38 \\
3.19 \\
3.47 \\
3.46 \\
3.47\end{array}$ & $\begin{array}{l}3.77 \\
3.72 \\
3.68 \\
3.47 \\
3.77 \\
3.76 \\
3.77\end{array}$ & $\begin{array}{l}4.10 \\
4.05 \\
4.00 \\
3.78 \\
4.10 \\
4.09 \\
4.10\end{array}$ \\
\hline \multicolumn{10}{|l|}{ Fixtures } \\
\hline $\begin{array}{l}\text { Luminaire Efficiency Standard } \\
\text { Maximum Technology }\end{array}$ & & $\begin{array}{l}2.78 \\
2.76\end{array}$ & $\begin{array}{l}2.64 \\
2.55\end{array}$ & $\begin{array}{l}2.65 \\
2.49\end{array}$ & $\begin{array}{l}2.83 \\
2.65\end{array}$ & $\begin{array}{l}3.08 \\
2.87\end{array}$ & $\begin{array}{l}3.34 \\
3.11\end{array}$ & $\begin{array}{l}3.63 \\
3.38\end{array}$ & $\begin{array}{l}3.95 \\
3.68\end{array}$ \\
\hline \multicolumn{10}{|l|}{ Controls } \\
\hline $\begin{array}{l}\text { Timers } \\
\text { T+Lumen Maintenance } \\
\text { T+LM+Occupancy Sensors }\end{array}$ & & $\begin{array}{l}2.77 \\
2.76 \\
2.75\end{array}$ & $\begin{array}{l}2.60 \\
2.54 \\
2.47\end{array}$ & $\begin{array}{l}2.57 \\
2.47 \\
2.33\end{array}$ & $\begin{array}{l}2.75 \\
2.62 \\
2.46\end{array}$ & $\begin{array}{l}2.98 \\
2.84 \\
2.67\end{array}$ & $\begin{array}{l}3.23 \\
3.08 \\
2.89\end{array}$ & $\begin{array}{l}3.52 \\
3.35 \\
3.14\end{array}$ & $\begin{array}{l}3.82 \\
3.64 \\
3.42\end{array}$ \\
\hline
\end{tabular}

\section{Combination Standards and Polkcies}

\begin{tabular}{|c|c|c|c|c|c|c|c|c|}
\hline \multicolumn{9}{|l|}{ Mandatory Component Standards } \\
\hline 1991 Proposed Standards (F \& I Lamps) & 2.78 & 2.67 & 2.71 & 2.91 & 3.16 & 3.43 & 3.73 & 4.06 \\
\hline Energy Policy Act, 1992 (F \& I Lamps) & 2.79 & 2.68 & 2.73 & 2.93 & 3.18 & 3.46 & 3.76 & 4.09 \\
\hline Min. LCC Fl. \& Inc. Lamps & 2.77 & 2.61 & 2.59 & 2.76 & 3.00 & 3.31 & 3.54 & 3.85 \\
\hline Min. LCC Fl. L/B \& Inc. Lamps & 2.76 & 2.51 & 2.40 & 2.54 & 2.76 & 2.99 & 3.25 & 3.53 \\
\hline Min. LCC Combination & 2.70 & 2.13 & 1.71 & 1.73 & 1.86 & 2.00 & 2.17 & 2.35 \\
\hline R\&D Combination & 2.66 & 1.91 & 1.30 & 1.24 & 1.32 & 1.42 & 1.53 & 1.65 \\
\hline \multicolumn{9}{|l|}{ Voluntary Component Standards } \\
\hline Min. LCC Fl. \& Inc. Lamps & 2.81 & 2.86 & 2.98 & 2.99 & 3.03 & 3.27 & 3.55 & 3.86 \\
\hline Min. LCC Fl. L/B \& Inc. Lamps & 2.81 & 2.86 & 2.96 & 2.87 & 2.81 & 3.00 & 3.26 & 3.54 \\
\hline Min. LCC Combination & 2.81 & 2.86 & 2.85 & 2.38 & 1.95 & 2.03 & 2.19 & 2.37 \\
\hline \multicolumn{9}{|l|}{ Building Codes } \\
\hline ASHRAE/IES 90.1 (Partial Compliance) & 2.80 & 2.77 & 2.89 & 3.12 & 3.39 & 3.68 & 4.00 & 4.34 \\
\hline DOE - 1993 (Partial Compliance) & 2.78 & 2.67 & 2.71 & 2.91 & 3.16 & 3.43 & 3.72 & 4.05 \\
\hline ASHRAE/IES 90.1 (Full Compliance) & 2.79 & 2.69 & 2.75 & 2.95 & 3.20 & 3.48 & 3.78 & 4.11 \\
\hline DOE - 1993 (Full Compliance) & 2.77 & 2.58 & 2.53 & 2.70 & 2.92 & 3.17 & 3.45 & 3.74 \\
\hline \multicolumn{9}{|l|}{ Incentive/Information Policies } \\
\hline Consumer Rebates & 2.81 & 2.86 & 3.05 & 3.32 & 3.60 & 3.91 & 4.24 & 4.61 \\
\hline Consumer Tax Credils & 2.81 & 2.86 & 3.05 & 3.32 & 3.60 & 3.91 & 4.24 & 4.61 \\
\hline Consumer/Designer Education \& Labeling & 2.81 & 2.86 & 3.05 & 3.32 & 3.60 & 3.91 & 4.24 & 4.61 \\
\hline
\end{tabular}

\footnotetext{
* Energy Policy Act, 1992 (Fluorescent Lamps)
} 
Table 4.5 Annual Commercial Lighting Energy Consumption, Low-Efficiency Baseline, 1995 to 2030 (Quadrillion Btu primary cnergy; $11,500 \mathrm{Btu}=1 \mathrm{kWh}$ )

\begin{tabular}{|c|c|c|c|c|c|c|c|c|c|}
\hline Policy & 1990 & 1995 & 2000 & 2005 & 2010 & 2015 & 2020 & 2025 & 2030 \\
\hline No-Programs Baseline & 3.12 & 3.35 & 3.63 & 3.89 & 4.22 & 4.60 & 5.01 & 5.45 & 5.93 \\
\hline Low-Emciency Basellne & 2.90 & 2.81 & 3.15 & 3.63 & 4.05 & 4.42 & 4.81 & 5.23 & 5.69 \\
\hline \multicolumn{10}{|l|}{ Individual Component Standards } \\
\hline $\begin{array}{l}\text { Fluorescent Lamps } \\
\text { Eliminate Highest Wattage } \\
\text { Minimum Life Cycle Cost } \\
\text { Maximum Technology } \\
\text { R \& D } \\
\text { Min. LCC Lamp/Ballast }\end{array}$ & & $\begin{array}{l}2.79 \\
2.78 \\
2.76 \\
2.76 \\
2.76\end{array}$ & $\begin{array}{l}2.80 \\
2.68 \\
2.57 \\
2.51 \\
2.56\end{array}$ & $\begin{array}{l}2.95 \\
2.73 \\
2.53 \\
2.41 \\
2.50\end{array}$ & $\begin{array}{l}3.21 \\
2.93 \\
2.70 \\
2.56 \\
2.66\end{array}$ & $\begin{array}{l}3.49 \\
3.19 \\
2.93 \\
2.77 \\
2.89\end{array}$ & $\begin{array}{l}3.80 \\
3.46 \\
3.18 \\
3.01 \\
3.14\end{array}$ & $\begin{array}{l}4.14 \\
3.77 \\
3.46 \\
3.27 \\
3.41\end{array}$ & $\begin{array}{l}4.50 \\
4.10 \\
3.76 \\
3.56 \\
3.71\end{array}$ \\
\hline $\begin{array}{l}\text { Incandescent Lamps } \\
\text { Eliminate Highest Wattage } \\
\text { Minimum Life Cycle Cost } \\
\text { Maximum Technology } \\
\text { R \& D } \\
\text { CFL. Downlights } \\
1991 \text { Proposed Standards (Inc. Lamps) } \\
\text { Energy Policy Act, } 1992 \text { (Inc. Lamps) }\end{array}$ & & $\begin{array}{l}2.79 \\
2.78 \\
2.78 \\
2.77 \\
2.79 \\
2.79 \\
2.79\end{array}$ & $\begin{array}{l}2.76 \\
2.73 \\
2.71 \\
2.62 \\
2.76 \\
2.75 \\
2.76\end{array}$ & $\begin{array}{l}2.88 \\
2.83 \\
2.79 \\
2.61 \\
2.88 \\
2.87 \\
2.88\end{array}$ & $\begin{array}{l}3.12 \\
3.01 \\
3.01 \\
2.80 \\
3.12 \\
3.11 \\
3.12\end{array}$ & $\begin{array}{l}3.40 \\
3.33 \\
3.27 \\
3.04 \\
3.39 \\
3.38 \\
3.39\end{array}$ & $\begin{array}{l}3.69 \\
3.62 \\
3.55 \\
3.30 \\
3.69 \\
3.68 \\
3.69\end{array}$ & $\begin{array}{l}4.02 \\
3.94 \\
3.87 \\
3.59 \\
4.02 \\
4.00 \\
4.01\end{array}$ & $\begin{array}{l}4.37 \\
4.29 \\
4.21 \\
3.91 \\
4.37 \\
4.36 \\
4.37\end{array}$ \\
\hline $\begin{array}{l}\text { Fixtures } \\
\text { Luminaire Efficiency Standard } \\
\text { Maximum Technology }\end{array}$ & & $\begin{array}{l}2.78 \\
2.76\end{array}$ & $\begin{array}{l}2.69 \\
2.58\end{array}$ & $\begin{array}{l}2.74 \\
2.54\end{array}$ & $\begin{array}{l}2.95 \\
2.71\end{array}$ & $\begin{array}{l}3.21 \\
2.94\end{array}$ & $\begin{array}{l}3.49 \\
3.19\end{array}$ & $\begin{array}{l}3.80 \\
3.47\end{array}$ & $\begin{array}{l}4.13 \\
3.78\end{array}$ \\
\hline $\begin{array}{l}\text { Controls } \\
\text { Timers } \\
T+\text { Lumen Maintenance } \\
T+L M+O c c u p a n c y \text { Sensors }\end{array}$ & & $\begin{array}{l}2.77 \\
2.76 \\
2.75\end{array}$ & $\begin{array}{l}2.64 \\
2.57 \\
2.50\end{array}$ & $\begin{array}{l}2.65 \\
2.53 \\
2.39\end{array}$ & $\begin{array}{l}2.85 \\
2.71 \\
2.53\end{array}$ & $\begin{array}{l}3.09 \\
2.94 \\
2.74\end{array}$ & $\begin{array}{l}3.36 \\
3.19 \\
2.98\end{array}$ & $\begin{array}{l}3.65 \\
3.47 \\
3.23\end{array}$ & $\begin{array}{l}3.97 \\
3.77 \\
3.52\end{array}$ \\
\hline
\end{tabular}

Combination Standards and Polkies

\begin{tabular}{|c|c|c|c|c|c|c|c|c|}
\hline \multicolumn{9}{|l|}{ Mandatory Component Standards } \\
\hline 1991 Proposed Standards (F \& I Lamps) & 2.78 & 2.74 & 2.84 & 3.07 & 3.34 & 3.63 & 3.95 & 4.30 \\
\hline Energy Policy Act, 1992 (F \& I Lamps) & 2.79 & 2.75 & 2.87 & 3.11 & 3.38 & 3.67 & 4.00 & 4.35 \\
\hline Min. LCC FI. \& Inc. Lamps & 2.77 & 2.64 & 2.66 & 2.85 & 3.10 & 3.42 & 3.66 & 3.99 \\
\hline Min. LCC Fl. L/B \& Inc. Lamps & 2.76 & 2.52 & 2.43 & 2.58 & 2.80 & 3.03 & 3.30 & 3.59 \\
\hline Min. LCC Combination & 2.70 & 2.13 & 1.71 & 1.73 & 1.86 & 2.00 & 2.17 & 2.35 \\
\hline R\&D Combination & 2.66 & 1.91 & 1.30 & 1.24 & 1.32 & 1.42 & 1.53 & 1.65 \\
\hline \multicolumn{9}{|l|}{ Voluntary Component Standards } \\
\hline Min. LCC Fl. \& Inc. Lamps & 2.81 & 3.20 & 3.53 & 3.38 & 3.17 & 3.39 & 3.68 & 4.00 \\
\hline Min. LCC Fl. L/B \& Inc. Lamps & 2.81 & 3.20 & 3.49 & 3.21 & 2.88 & 3.06 & 3.32 & 3.60 \\
\hline Min. LCC Combination & 2.81 & 3.20 & 3.35 & 2.68 & 1.97 & 2.04 & 2.20 & 2.38 \\
\hline \multicolumn{9}{|l|}{ Building Codes } \\
\hline ASHRAE/IES 90.1 (Partial Compliance) & 2.80 & 2.93 & 3.21 & 3.53 & 3.84 & 4.18 & 4.55 & 4.95 \\
\hline DOE - 1993 (Partial Compliance) & 2.78 & 2.78 & 2.92 & 3.17 & 3.44 & 3.74 & 4.07 & 4.43 \\
\hline ASHRAE/IES 90.1 (Full Compliance) & 2.79 & 2.78 & 2.92 & 3.18 & 3.45 & 3.75 & 4.08 & 4.44 \\
\hline DOE - 1993 (Full Compliance) & 2.77 & 2.64 & 2.65 & 2.85 & 3.09 & 3.36 & 3.65 & 3.97 \\
\hline \multicolumn{9}{|l|}{ Incentive/Information Policies } \\
\hline Consumer Rebates & 2.81 & 2.86 & 3.05 & 3.32 & 3.60 & 3.91 & 4.24 & 4.61 \\
\hline Consumer Tax Credits & 2.81 & 2.93 & 3.20 & 3.50 & 3.81 & 4.13 & 4.49 & 4.88 \\
\hline Consumer/Designer Education \& Labeling & 2.81 & 3.04 & 3.43 & 3.80 & 4.13 & 4.49 & 4.89 & 5.31 \\
\hline
\end{tabular}

- Energy Policy Act, 1992 (Fluorescent Lamps) 
Table 4.6 Cumulative Commercial Lighting Energy Consumption and Savings, 1995 to 2030 (Quadrillion Biu primary energy; $11,500 \mathrm{Btu}=1 \mathrm{kWh}$ )

\begin{tabular}{|c|c|c|c|c|c|c|c|c|}
\hline \multirow[b]{2}{*}{ Policy } & \multicolumn{3}{|c|}{ High-Efficiency Baseline } & \multicolumn{3}{|c|}{ Low-Efficiency Baseline } & \multicolumn{2}{|c|}{ No-Programs Baseline " } \\
\hline & $\begin{array}{r}\text { Energy } \\
\text { Use } \\
\text { (Quads) }\end{array}$ & $\begin{array}{l}\text { Savings } \\
\text { (Quads) }\end{array}$ & $\begin{array}{l}\text { Percent } \\
\text { Savings }\end{array}$ & $\begin{array}{r}\text { Energy } \\
\text { Use } \\
\text { (Quads) }\end{array}$ & $\begin{array}{l}\text { Savings } \\
\text { (Quads) }\end{array}$ & $\begin{array}{l}\text { Percent } \\
\text { Savings }\end{array}$ & $\begin{array}{l}\text { Savings } \\
\text { (Quads) }\end{array}$ & $\begin{array}{l}\text { Percent } \\
\text { Savings }\end{array}$ \\
\hline Baselline & 123 & & & 148 & & & & \\
\hline \multicolumn{9}{|l|}{ Indlvldual Component Standards } \\
\hline $\begin{array}{l}\text { Fluorescent Lamps } \\
\text { Elininate Highest Wastage * } \\
\text { Minimum Life Cycle Cost } \\
\text { Maximum Technology } \\
\text { R \& D } \\
\text { Min. LCC Lamp/Ballast }\end{array}$ & $\begin{array}{r}113 \\
107 \\
101 \\
97 \\
100\end{array}$ & $\begin{array}{l}10 \\
16 \\
22 \\
26 \\
23\end{array}$ & $\begin{array}{l}8 \% \\
13 \% \\
18 \% \\
21 \% \\
19 \%\end{array}$ & $\begin{array}{r}120 \\
111 \\
103 \\
98 \\
102\end{array}$ & $\begin{array}{l}28 \\
37 \\
45 \\
49 \\
46\end{array}$ & $\begin{array}{l}19 \% \\
25 \% \\
30 \% \\
33 \% \\
31 \%\end{array}$ & $\begin{array}{l}37 \\
46 \\
54 \\
59 \\
55\end{array}$ & $\begin{array}{l}24 \% \\
29 \% \\
34 \% \\
37 \% \\
35 \%\end{array}$ \\
\hline $\begin{array}{l}\text { Incandescent Lamps } \\
\text { Eliminate Highest Wattage } \\
\text { Minimum Life Cycle Cost } \\
\text { Maximum Technology } \\
\text { R \& D } \\
\text { CFL Downlights } \\
1991 \text { Proposed Stundards (Inc. Lamps) } \\
\text { Energy Policy Act, } 1992 \text { (Inc. Lamps) }\end{array}$ & $\begin{array}{l}111 \\
110 \\
109 \\
104 \\
111 \\
111 \\
111\end{array}$ & $\begin{array}{l}12 \\
14 \\
15 \\
20 \\
12 \\
12 \\
12\end{array}$ & $\begin{array}{l}10 \% \\
11 \% \\
12 \% \\
16 \% \\
10 \% \\
10 \% \\
10 \%\end{array}$ & $\begin{array}{l}117 \\
115 \\
113 \\
106 \\
117 \\
117 \\
117\end{array}$ & $\begin{array}{l}30 \\
33 \\
34 \\
41 \\
30 \\
31 \\
31\end{array}$ & $\begin{array}{l}21 \% \\
22 \% \\
23 \% \\
28 \% \\
21 \% \\
21 \% \\
21 \%\end{array}$ & $\begin{array}{l}40 \\
42 \\
44 \\
51 \\
40 \\
40 \\
40\end{array}$ & $\begin{array}{l}25 \% \\
27 \% \\
28 \% \\
32 \% \\
25 \% \\
26 \% \\
25 \%\end{array}$ \\
\hline $\begin{array}{l}\text { Fixtures } \\
\text { Luminaire Efficiency Standard } \\
\text { Maximum Technology }\end{array}$ & $\begin{array}{l}108 \\
101\end{array}$ & $\begin{array}{l}16 \\
22\end{array}$ & $\begin{array}{l}13 \% \\
18 \%\end{array}$ & $\begin{array}{l}112 \\
104\end{array}$ & $\begin{array}{l}36 \\
44\end{array}$ & $\begin{array}{l}24 \% \\
30 \%\end{array}$ & $\begin{array}{l}46 \\
54\end{array}$ & $\begin{array}{l}29 \% \\
34 \%\end{array}$ \\
\hline $\begin{array}{l}\text { Controls } \\
\text { Timers } \\
T+L u m e n \text { Maintenance } \\
T+L M+O \text { ccupancy Sensors }\end{array}$ & $\begin{array}{r}105 \\
101 \\
95\end{array}$ & $\begin{array}{l}19 \\
23 \\
28\end{array}$ & $\begin{array}{l}15 \% \\
19 \% \\
23 \%\end{array}$ & $\begin{array}{r}108 \\
103 \\
98\end{array}$ & $\begin{array}{l}40 \\
44 \\
50\end{array}$ & $\begin{array}{l}27 \% \\
30 \% \\
34 \%\end{array}$ & $\begin{array}{l}49 \\
54 \\
60\end{array}$ & $\begin{array}{l}31 \% \\
34 \% \\
38 \%\end{array}$ \\
\hline \multicolumn{9}{|l|}{ Comblnation Standards and Pollcles } \\
\hline $\begin{array}{l}\text { Mandatory Component Standards } \\
\text { 1991 Proposed Standards (F \& I Lamps) } \\
\text { Energy Policy Act, } 1992 \text { (F \& I Lamps) } \\
\text { Min. LCC Fl. \& Inc. Lamps } \\
\text { Min. LCC Fl. L/B \& Inc. Lamps } \\
\text { Min. LCC Combination } \\
\text { R\&D Combination }\end{array}$ & $\begin{array}{r}110 \\
111 \\
106 \\
98 \\
71 \\
54\end{array}$ & $\begin{array}{l}13 \\
13 \\
18 \\
26 \\
53 \\
69\end{array}$ & $\begin{array}{l}11 \% \\
10 \% \\
14 \% \\
21 \% \\
43 \% \\
56 \%\end{array}$ & $\begin{array}{r}115 \\
117 \\
109 \\
99 \\
71 \\
54\end{array}$ & $\begin{array}{l}32 \\
31 \\
39 \\
49 \\
77 \\
93\end{array}$ & $\begin{array}{l}22 \% \\
21 \% \\
26 \% \\
33 \% \\
52 \% \\
63 \%\end{array}$ & $\begin{array}{r}42 \\
40 \\
49 \\
58 \\
87 \\
103\end{array}$ & $\begin{array}{l}27 \% \\
26 \% \\
31 \% \\
37 \% \\
55 \% \\
65 \%\end{array}$ \\
\hline $\begin{array}{l}\text { Voluntary Component Standards } \\
\text { Min. LCC FI. \& Inc. Lamps } \\
\text { Min. LCC FI. L/B \& Inc. Lamps } \\
\text { Min. LCC Combination }\end{array}$ & $\begin{array}{r}110 \\
105 \\
84\end{array}$ & $\begin{array}{l}13 \\
19 \\
39\end{array}$ & $\begin{array}{l}11 \% \\
15 \% \\
32 \%\end{array}$ & $\begin{array}{r}119 \\
112 \\
90\end{array}$ & $\begin{array}{l}29 \\
36 \\
58\end{array}$ & $\begin{array}{l}20 \% \\
24 \% \\
39 \%\end{array}$ & $\begin{array}{l}38 \\
45 \\
67\end{array}$ & $\begin{array}{l}24 \% \\
29 \% \\
43 \%\end{array}$ \\
\hline $\begin{array}{l}\text { Building Codes } \\
\text { ASHRAE/LES 90.1 (Partial Compliance) } \\
\text { DOE - 1993 (Partial Compliance) } \\
\text { ASHRAE/1ES 90.1 (Full Compliance) } \\
\text { DOE - } 1993 \text { (Full Compliance) }\end{array}$ & $\begin{array}{l}117 \\
110 \\
111 \\
103\end{array}$ & $\begin{array}{r}6 \\
13 \\
12 \\
20\end{array}$ & $\begin{array}{l}5 \% \\
11 \% \\
10 \% \\
17 \%\end{array}$ & $\begin{array}{l}131 \\
119 \\
119 \\
108\end{array}$ & $\begin{array}{l}17 \\
29 \\
29 \\
40\end{array}$ & $\begin{array}{l}12 \% \\
20 \% \\
19 \% \\
27 \%\end{array}$ & $\begin{array}{l}27 \\
39 \\
38 \\
49\end{array}$ & $\begin{array}{l}17 \% \\
25 \% \\
24 \% \\
31 \%\end{array}$ \\
\hline $\begin{array}{l}\text { Incentive/lnformation Policies } \\
\text { Consumer Rebales } \\
\text { Consumer Tax Credits } \\
\text { Consumer/Designer Education \& Lubeling }\end{array}$ & $\begin{array}{l}123 \\
123 \\
123\end{array}$ & $\begin{array}{l}0 \\
0 \\
0\end{array}$ & $\begin{array}{l}0 \% \\
0 \% \\
0 \%\end{array}$ & $\begin{array}{l}123 \\
130 \\
139\end{array}$ & $\begin{array}{r}24 \\
18 \\
8\end{array}$ & $\begin{array}{r}16 \% \\
12 \% \\
6 \%\end{array}$ & $\begin{array}{l}34 \\
28 \\
18\end{array}$ & $\begin{array}{l}21 \% \\
18 \% \\
11 \%\end{array}$ \\
\hline
\end{tabular}

* Energy Policy Aa, 1992 (Flworescent Lamps)

* Consurnption of No-Programs Bascline (157 quads) minus consumption of policies run under Low-Efficiency Baseline 
Table 4.7 Economic Analysis of Commercial Lighting Policy Cases, High-Efficiency Bascline, 1995 to 2030 (Present values discounted to $\$ 1990$ at 4 percent real)

\begin{tabular}{|c|c|c|c|c|}
\hline Policy & $\begin{array}{l}\text { Savings from } \\
\text { High-Efficiency } \\
\text { Baseline } \\
\text { ( } \$ 1990 \text { billions) }\end{array}$ & $\begin{array}{c}\text { Cost from } \\
\text { High-Efficiency } \\
\text { Baseline } \\
\text { ( } \$ 1990 \text { billions) }\end{array}$ & $\begin{array}{c}\text { Net Present } \\
\text { Value } \\
\text { (Savings-Cost) } \\
\text { ( } \$ 1990 \text { billions) }\end{array}$ & $\begin{array}{c}\text { BenefivCos! } \\
\text { Ratio }\end{array}$ \\
\hline \multicolumn{5}{|l|}{ Individual Component Standards } \\
\hline \multicolumn{5}{|l|}{ Fluorescent Lamp Standards } \\
\hline Eliminate Highest Wattage * & 25 & 2 & 23 & 15.6 \\
\hline Minimum Life Cycle Cost & 39 & 4 & 35 & 10.4 \\
\hline Maximum Technology & 53 & 12 & 41 & 4.3 \\
\hline R \& D & 62 & -9 & 72 & N/A \\
\hline Min. LCC Lamp/Ballast & 55 & 9 & 46 & 6.0 \\
\hline \multicolumn{5}{|l|}{ Incandescent Lamp Standards } \\
\hline Eliminate Highest Wattage & 29 & 12 & 17 & 2.4 \\
\hline Minimum Life Cycle Cost & 33 & -41 & 73 & N/A \\
\hline Maximum Technology & 35 & -8 & 43 & N/A \\
\hline$R \& D$ & 47 & -2 & 50 & N/A \\
\hline Compact Fluorescent Downlights & 29 & -8 & 37 & N/A \\
\hline 1991 Proposed Standards (Inc. Lamps) & 30 & 9 & 20 & 3.1 \\
\hline Energy Policy Act, 1992 (Inc. Lamps) & 29 & 5 & 24 & 5.5 \\
\hline \multicolumn{5}{|l|}{ Controls } \\
\hline Timers & 45 & 25 & 19 & 1.8 \\
\hline $\mathrm{T}+$ Lumen Maintenance & 55 & 39 & 16 & 1.4 \\
\hline$T+L M+$ Occupancy Sensors & 67 & 65 & 2 & 1.0 \\
\hline \multicolumn{5}{|l|}{ Combination Standards } \\
\hline \multicolumn{5}{|l|}{ Mandatory Component Standards } \\
\hline 1991 Proposed Standards (FI. \& Inc. Lamps) & 32 & 11 & 20 & 2.8 \\
\hline Energy Policy Act, 1992 (Fl. \& Inc. Lamps) & 30 & 7 & 23 & 4.3 \\
\hline Min. LCC Fl. \& Inc. Lamps & 42 & -37 & 80 & N/A \\
\hline Min. LCC FI. L/B \& Inc. Lamps & 61 & -32 & 92 & N/A \\
\hline Min. LCC Combination & 125 & 85 & 40 & 1.5 \\
\hline R \& D Combination & 164 & 88 & 76 & 1.9 \\
\hline \multicolumn{5}{|l|}{ Voluntary Component Standards } \\
\hline Min. LCC Fl. \& Inc. Lamps & 28 & -36 & 63 & N/A \\
\hline Min. LCC Fl. L/B \& Inc. Lamps & 39 & -47 & 86 & N/A \\
\hline Min. LCC Combination & 30 & 14 & 16 & 2.2 \\
\hline \multicolumn{5}{|l|}{ Incentive/Information Policies } \\
\hline Consumer Rebates & 0 & 0 & 0 & 0.0 \\
\hline Consumer Tax Credits & 0 & 0 & 0 & 0.0 \\
\hline Consumer/Designer Education \& Labeling & 0 & 0 & 0 & 0.0 \\
\hline
\end{tabular}

* Energy Policy Act, 1992 (Fluorescent Lamps) 
Table 4.8 Economic Analysis of Commercial Lighting Policy Cases, Low-Efficiency Baseline, 1995 to 2030 (Present values discounted to $\$ 1990$ at 4 percent real)

\begin{tabular}{lcccc}
\hline & Savings from & Cost from & Net Present \\
& Low-Efficiency & Low-Efficiency & Value & \\
Baseline & Baseline & (Savings-Cost) & BenefilCost \\
Policy & $(\$ 1990$ billions $)$ & $(\$ 1990$ billions $)$ & $(\$ 1990$ billions $)$ & Ratio \\
\hline
\end{tabular}

\section{Individual Component Standards}

Fluorescent Lamp Standards Eliminate Highest Wattage *

Minimum Life Cycle Cost

Maximum Technology

R \& D

Min. LCC Lamp/Ballast

65

87

105

116

108

Incandescent Lamp Standards

Eliminate Highest Wattage

Minimum Life Cycle Cost

Maximum Technology

R \& D

Compact Fluorescent Downlights 1991 Proposed Standards (Inc. Lamps)

Energy Policy Act, 1992 (Inc. Lamps)

Contro!s

Timers

$T+$ Lumen Maintenance

$T+L M+$ Occupancy Sensors

\section{Combination Standards}

Mandatory Component Standards 1991 Proposed Standards (Fl. \& Inc. Lamps)

Energy Policy Act, 1992 (Fl. \& Inc. Lamps)

Min. LCC FI. \& Inc. Lamps

Min. LCC F1. L/B \& Inc. Lamps

Min. LCC Combination

$R$ \& D Combination

Voluntary Component Standards

Min. LCC Fl. \& Inc. Lamps

Min. LCC Fl. L/B \& Inc. Lamps

Min. LCC Combination

Incentive/Information Policies

Consumer Rebates

Consumer Tax Credits

Consumer/Designer Education \& Labeling
76

73

20

4
9
26
-18
18

61

78

79

134

90

15.2

10.1

4.0

N/A

5.9

2.3

N/A

N/A

N/A

N/A

3.0

5.3

14

49

59

3.7

2.7

1.8

* Energy Policy Act, 1992 (Fluorescent Lamps) 
$33 \%$

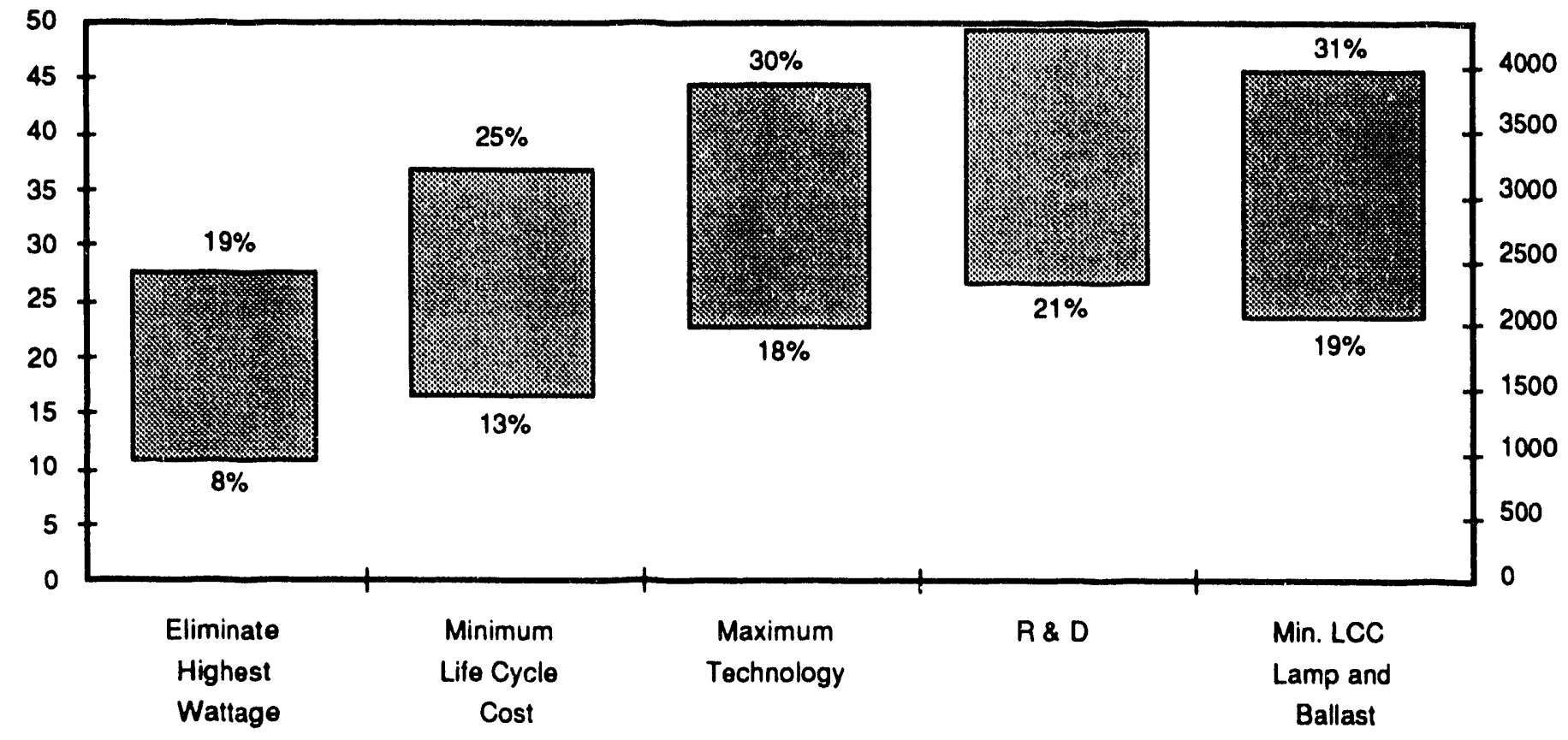

Note: Percentages are portions of relevant baseline lighting energy.

Tops of bars represent savings under Low-Etticiency Baseline; bottoms represent savings under High-Efficiency Baseline.

Figure 4.5

Range of Cumulative Net Present Values, 1995 to 2030

$\$ 1990$ Billions

Fluorescent Lamps, Commercial Sector

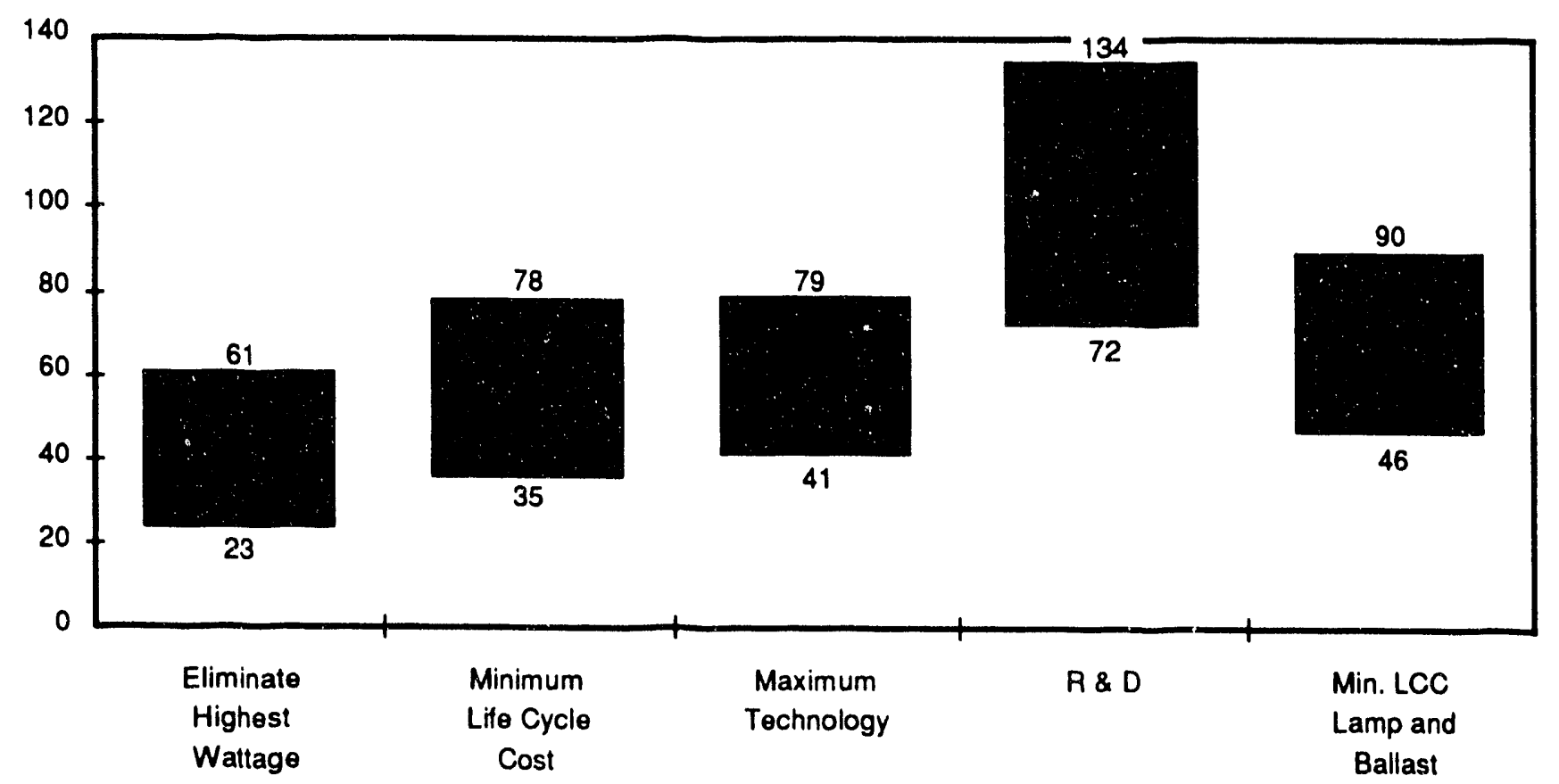

Note: Tops of bars represent NPVs under Low-Efficiency Baseline; bottoms represent NPVs under High-Efficiency Baseline. 
Figure 4.6

Range of Cumulative Lighting Energy/ Savings, 1995 to 2030

incandescent Lamps, Commercial Sector

Primary Quads

TWh

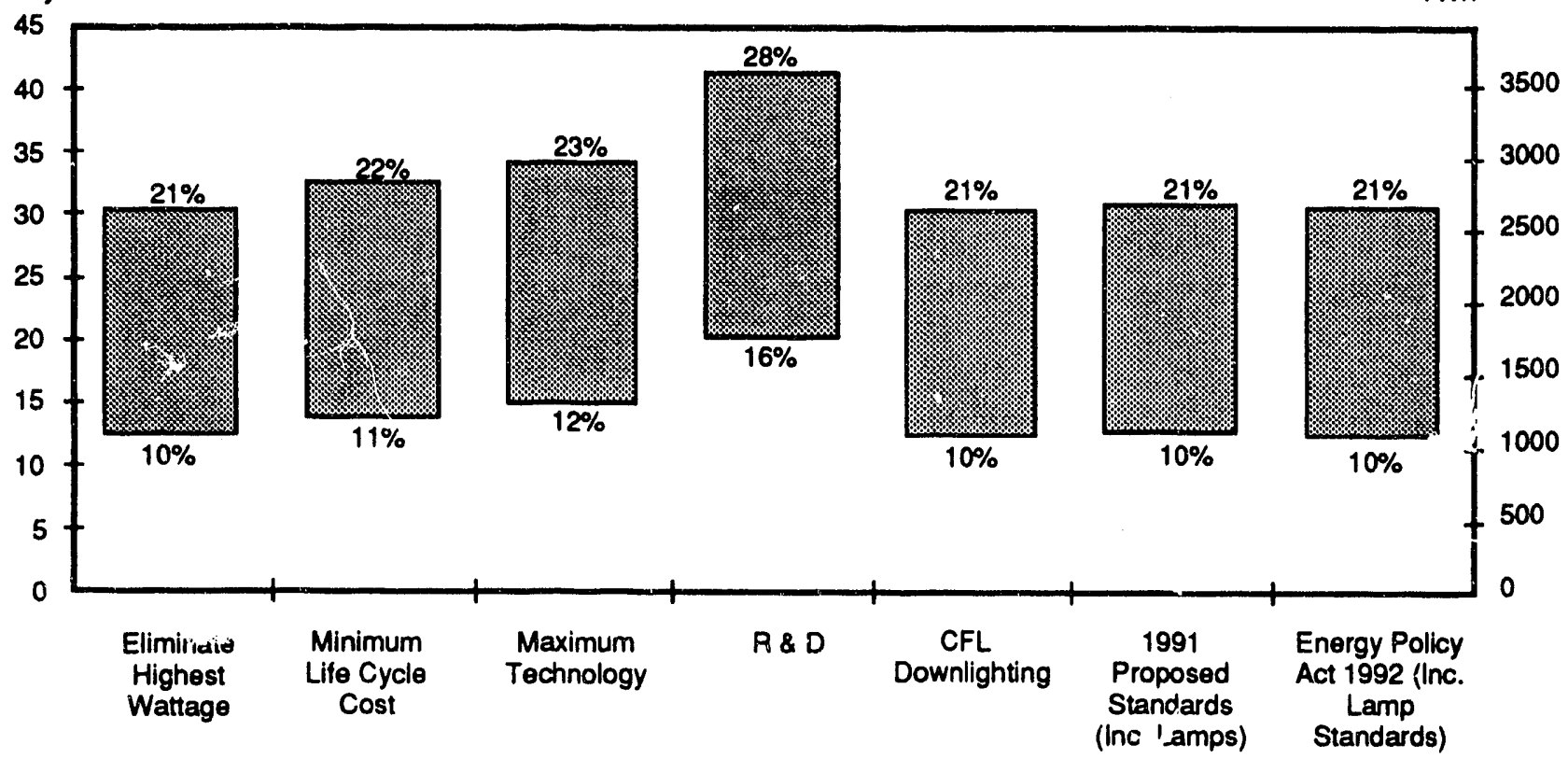

Note: Percentages are portions of respective baseline lighting energy.

Tops of bars represent savings under Low-Efficiency Baseline; bottoms iepresent savinge under High-Efficiency Baseline.

Figure 4.7

Range of Cumulative Net Present Values, 1995 to 2030

NPY Incandescent Lamps, Commercial Sector

$\$ 1990$ Billions

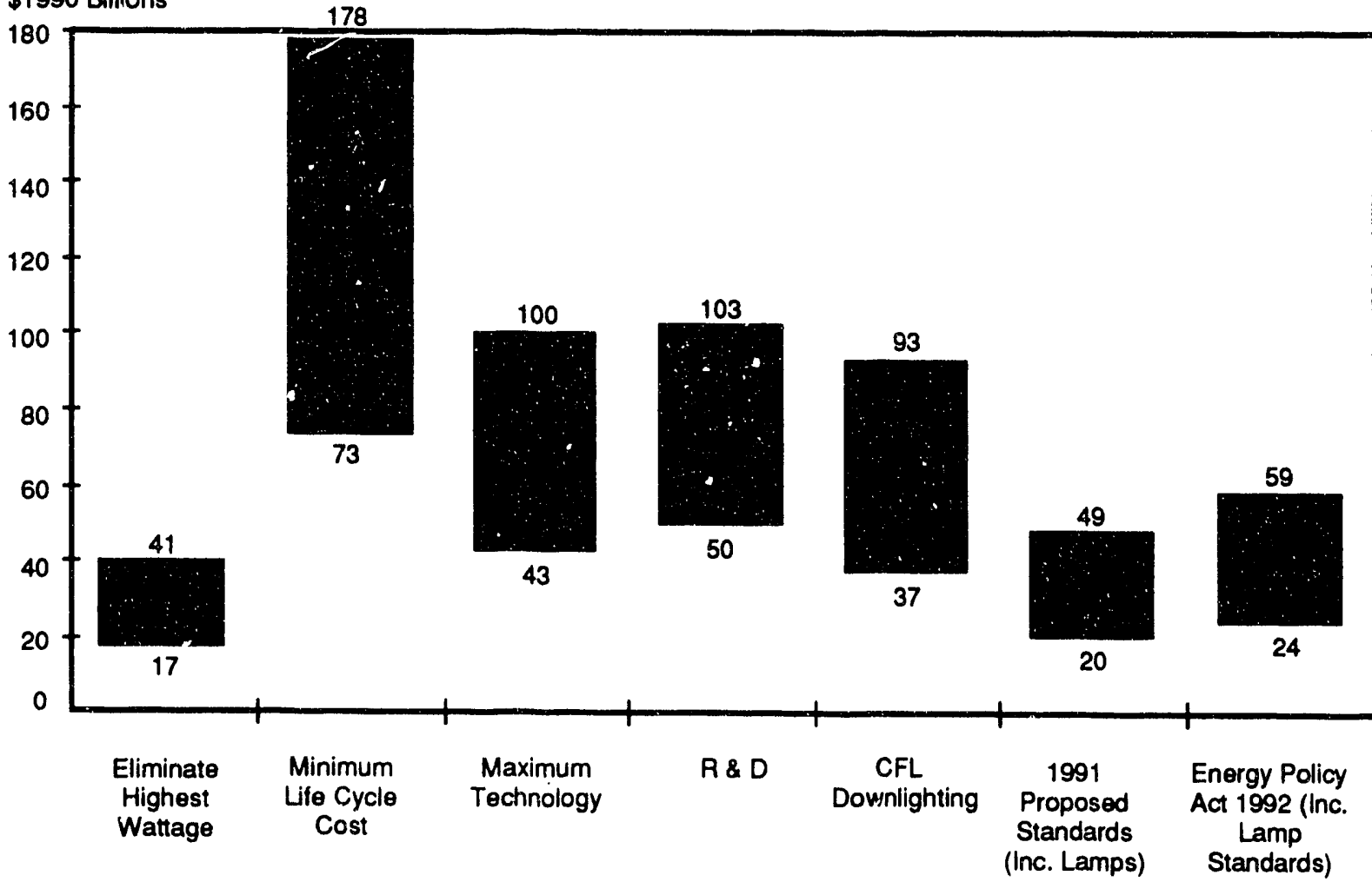

Note: Tops of bars represent NPVs under Low-Efficiency Baseline; bottoms represent NPVs under High-Efficiency Baseline.

$$
4-17
$$




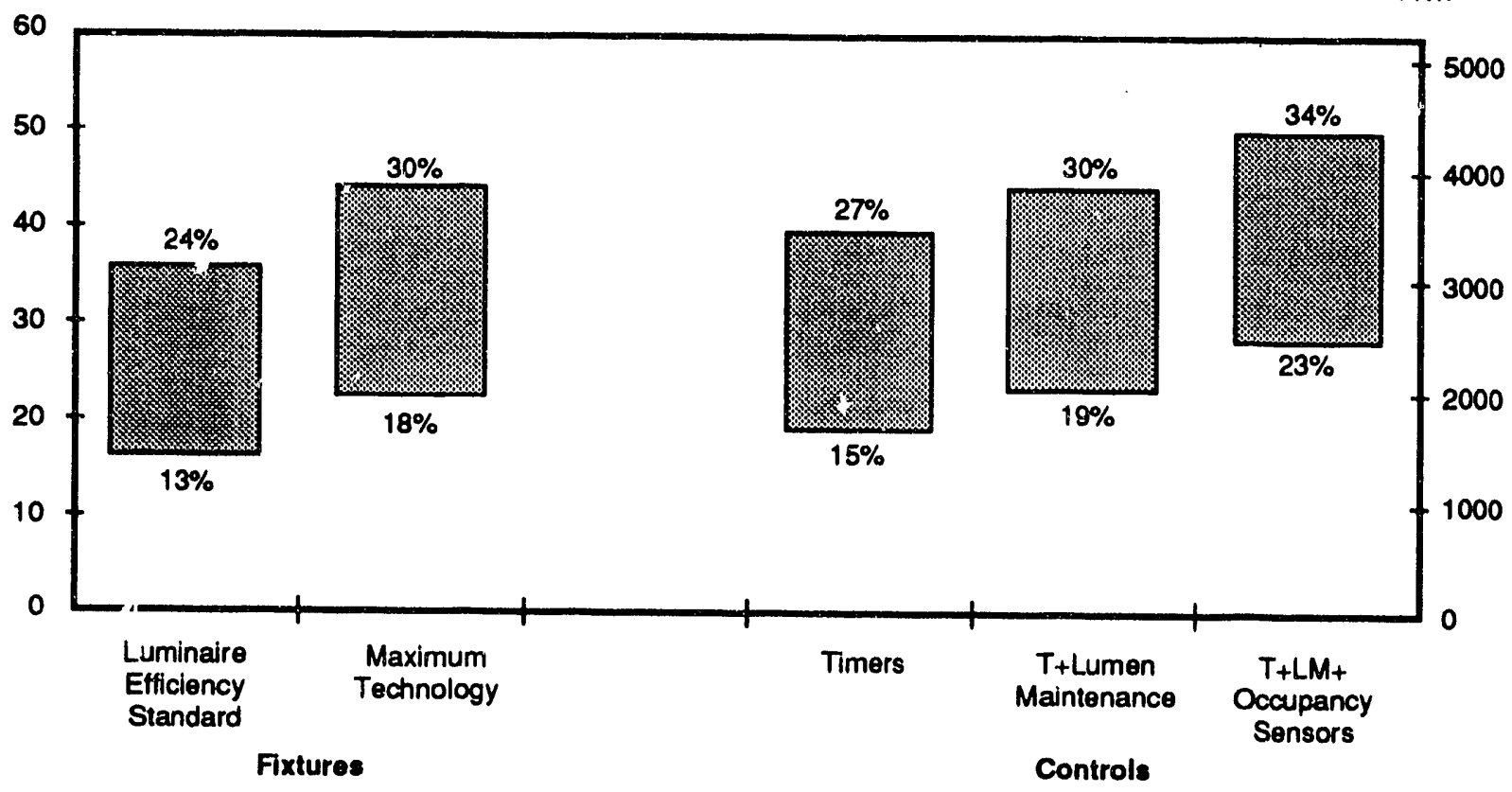

Note: Percentages are portion of respective baseline lighting energy.

Tops of bars represent savings under Low-Efficiency Baseline; bottoms of bars represent savings under High-Efficiency Baseline.

NPV $\$ 1990$ Billions

Fixtures

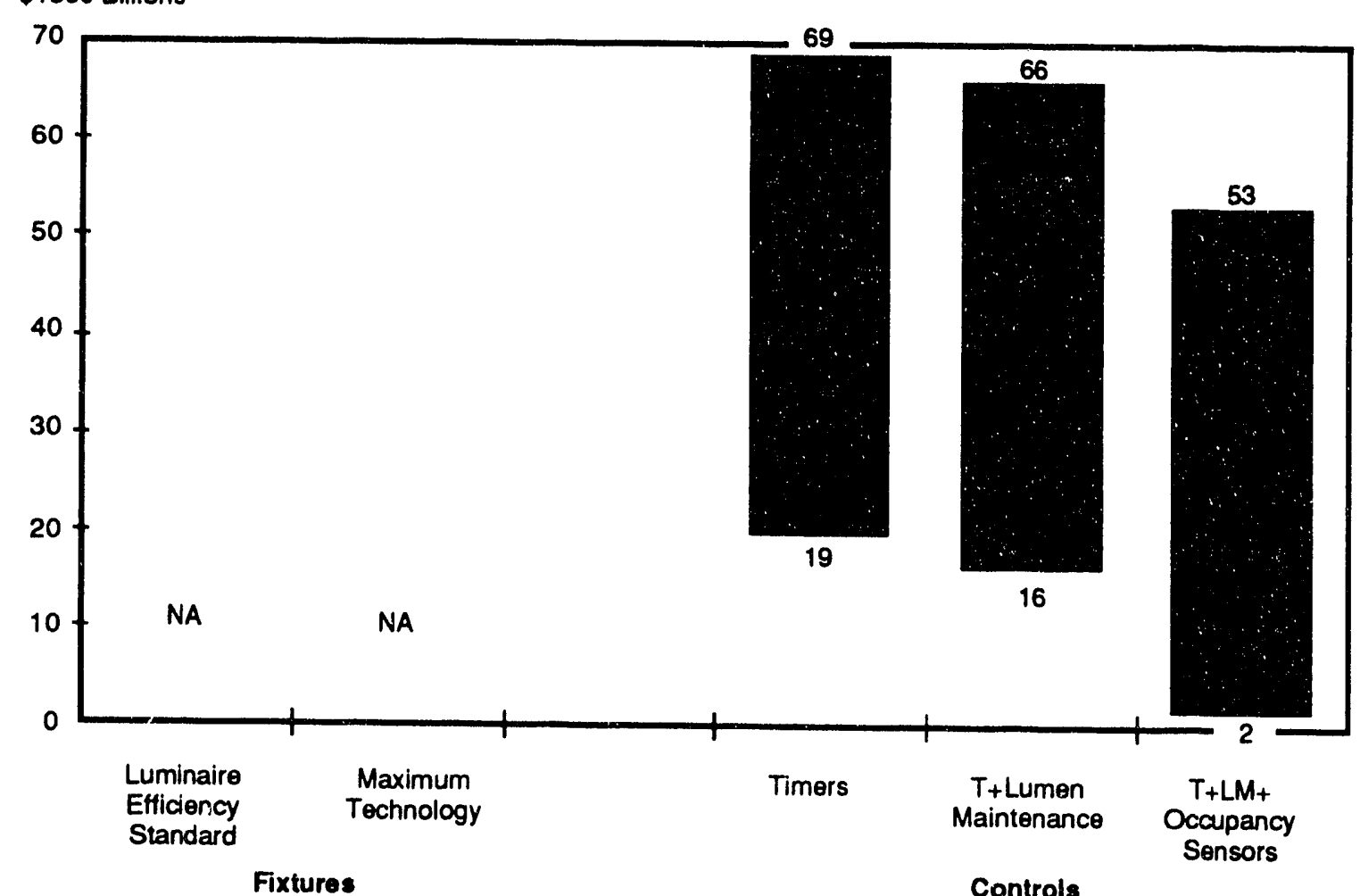

Figure 4.9

Range of Cumulative Net Present Values, 1995 to 2030 Fixtures and Controls, Commercial Sector

Note: Tops of bars represent NPVs under Low-Efficiency Baseline; bottoms of bars represent NPVs under High-Efficiencr Baseline. 


\subsubsection{Fluorescent Lamp Policies}

Figure 4.4 shows that the R\&D fluorescent lamp policy results in savings of between 21 percent (under the High-Efficiency Baseline) and 33 percent (under the Low-Efficiency Baseline). These savings are greater than those forecast from the two existing fluorescent lamp technologies (eight to 19 percent and 13 to 25 percent), the maximum technology case (18 to 30 percent), and the Min LCC lamp/ballast case (19 to 31 percent). The R\&D standard also results in the greatest net present value of the fluorescent lamp standards analyzed, ranging from $\$ 72$ to $\$ 134$ billion, as shown in Figure 4.5.

\subsubsection{Incandescent Lamp Policies}

Figure 4.6 shows that the R\&D incandescent lamp standard generates greater energy savings ( 16 to 28 percent) than the other incandescent or CFL lamp standards studied (10 to 23 percent). As shown in Figure 4.7, the Minimum LCC standard results in the greatest NPVs for incandescent lamps, ranging from $\$ 73$ to $\$ 178$ billion.

\subsubsection{Fixture Policies}

Energy savings from fixture standards are presented in Figure 4.8. The luminaire efficiency standard achieves energy savings of 13 to 24 percent, while the Maximum Technology fixture policy reduces energy consumption by 18 to 30 percent. Economic analyses are not performed for the fixture standards.

\subsubsection{Controls Policies}

Lighting controls standards, unlike the component standards, are incremental, with each standard incorporating the measures before it. As shown in Figure 4.8, the savings from the controls policies range from 15 to 23 percent from the High-Efficiency Baseline and from 27 to 34 percent from the Low-Efficiency Baseline, suggesting that there is at least as much conservation potential in controls as in most commercially-available lamp technologies. However, net economic savings from controls decrease as more controls are added due to diminishing percentage savings available as well as increasing costs, as shown in Figure 4.9. The NPVs of controls standards range from $\$ 19$ to $\$ 69$ billion for timers alone to $\$ 2$ to $\$ 53$ billion for timers + lumen maintenance + occupancy sensors.

\subsubsection{Comparison of Policies}

This section discusses the energy and economic savings from combination component standards, national building codes, and consumer incentive policies. COMMEND analyses for three mandatory combination standards are performed, as described in Section 2.2.3. These same combinations are modeled as a voluntary standard using the EUI levels of the mandatory component standard policies but with a delay in compliance (to simulate the slower manufacturer and consumer reaction to voluntary rather than mandatory standards). 
The national adoption of the ASHRAE/IES 90.1 and DOE-93 building codes, assuming either full or partial compliance, is also modeled, as described in Section 4.4. Finally, three types of consumer incentives are estimated. The High-Efficiency Baseline is regarded as synonymous with the consumer rebate policy. Consumer tax credits and consumer information policies are calculated as percentages of the High-Efficiency Baseline.

Figures 4.10 and 4.11 compare the energy savings and cost-effectiveness of the lighting policies mentioned above. As in Figures 4.4 through 4.9, the bottom of each bar represents energy or economic savings measured with respect to the High-Efficiency Baseline, while the top represents savings measured with respect to the Low-Efficiency Baseline. In Figure 4.10, voluntary component standards and partial code compliance are represented by lightly shaded bars, while mandatory component standards and full code compliance are shown by the dark bars. The dark bars in Figure 4.11 represent the net economic savings of the mandatory component standards; NPVs for voluntary component standards are shown by lightly shaded bars.

As shown in Figure 4.10, a combination Minimum LCC fluorescent and incandescent lamp standard would reduce consumption between 11 and 26 percent from baseline consumption. A Minimum LCC fluorescent lamp/ballast plus incandescent lamp combination produces 15 to 33 percent energy savings. The Minimum LCC Combination case, which includes fluorescent lamps and ballasts with fixture interactions, incandescent lamps with CFL substitution, and controls interactions, has projected savings of 32 to 52 percent. The R \& D Combination case, which substitutes R \& D components for the Minimum LCC components above, generates the greatest savings, 56 to 63 percent from baseline consumption. The ASHRAE/IES 90.1 standard yields savings of between 5 and 19 percent. Mandating the DOE-93 standard saves between 11 and 27 percent, depending on the baseline and the degree of compliance. Consumer rebates generate 16 percent savings, consumer tax credits 12 percent savings, and consumer education 6 percent savings from the Low-Efficiency Baseline. The dotted lines used for Incentive/Information policies indicate the relative uncertainty of the results compared to the other cases.

Figure 4.11 shows that net economic savings are greatest under the Minimum LCC fluorescent and incandescent lamp and the Minimum LCC fluorescent lamp/ballast plus incandescent lamp policies, ranging from $\$ 63$ to $\$ 185$ billion for the lamp combination, and from $\$ 86$ to $\$ 197$ billion for the lamp/ballast combination. The Minimum LCC and R \& D Combination policies are also cost-effective, resulting in NPVs of $\$ 16$ to $\$ 88$ billion and $\$ 76$ to $\$ 126$ billion, respectively. 
Figure 4.10

Range of Cumulative Lighting Energy Savings by Policy

Primary Quads

$1995-2030$

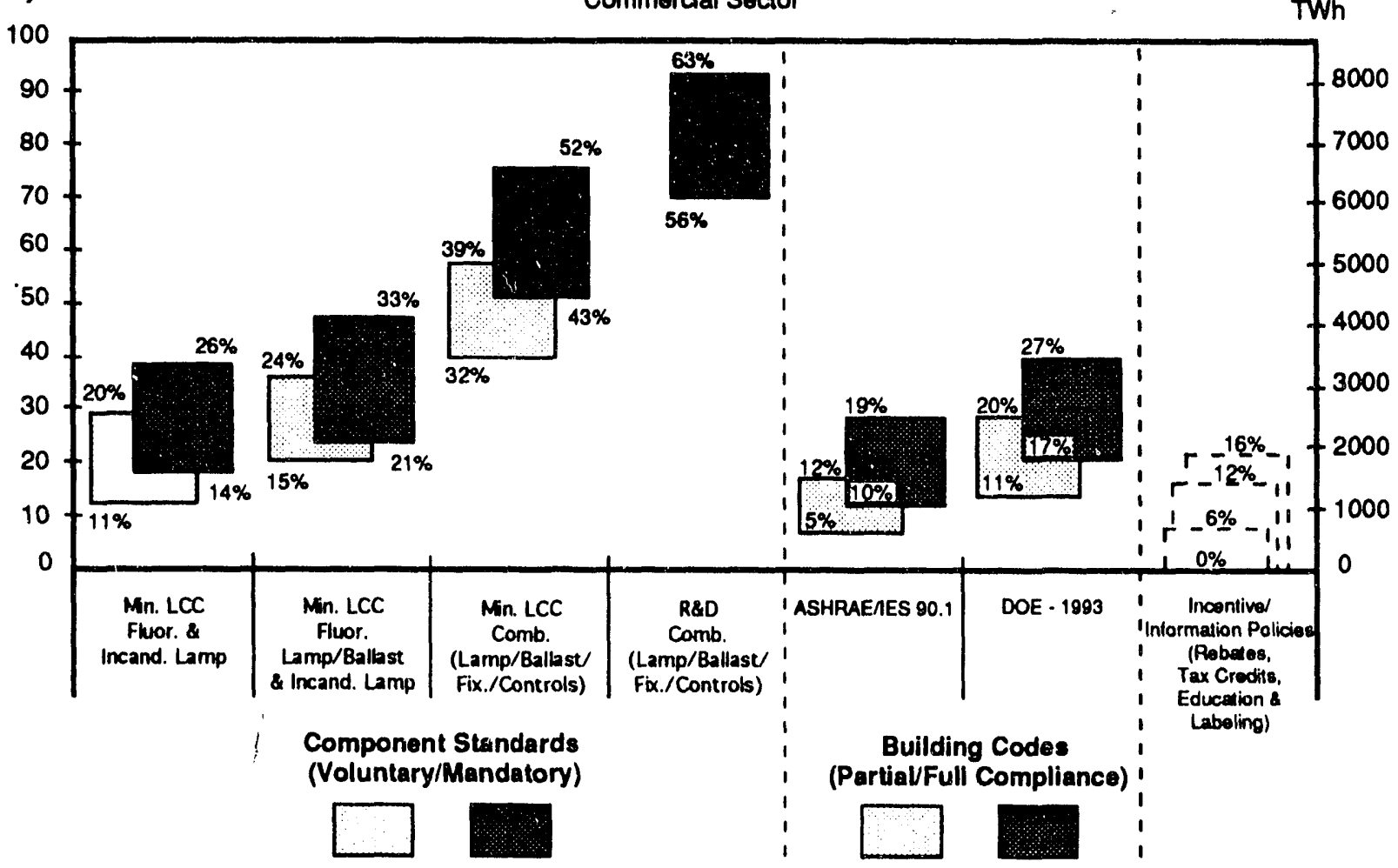

Nole: Percentages are portion of respective baseline lighting energy.

Tops of bars represent savings under Low-Efficiency Baseline; bottoms of bars represent savings under High-Efficiency Baseline.

Figure 4.11

Range of Cumulative Net Present Values by Policy $1995-2030$

NPV

Commercial Sector

$\$ 1990$ Billions

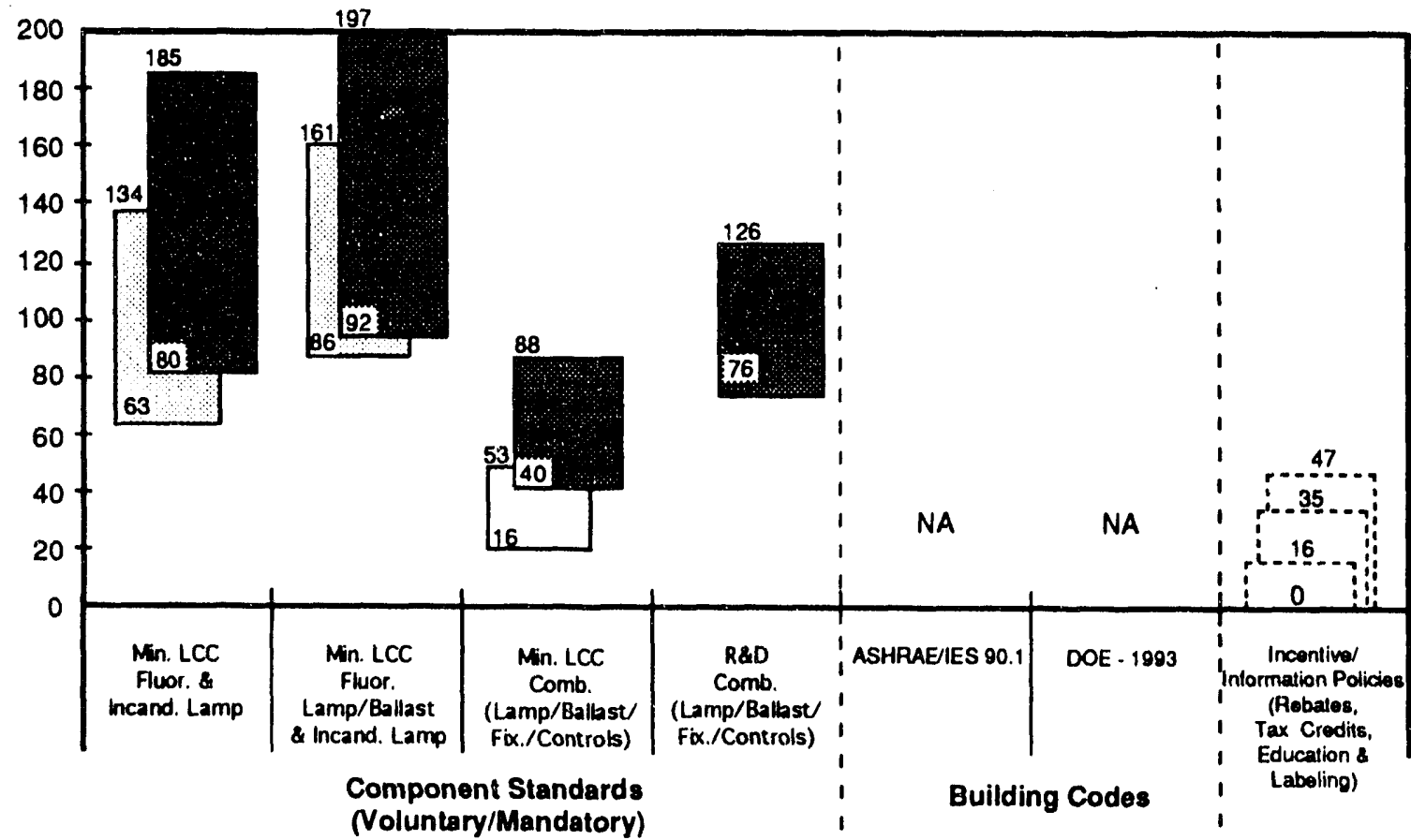

Voluntary/Mandatory)

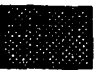

Tops of bars represent NPVs under Low-Elficiency Baseline; bottoms of bars represent NPVs under High-Efficiency Baseline.

$$
4-21
$$




\subsubsection{Discussion}

Mandatory component standards on all four components combined (the Minimum LCC and R \& D Combination policies) generally result in the greatest energy savings. Energy savings from component standards that include lamps and ballasts only are comparable to full compliance with the DOE-93 building code. The ASHRAE/IES 90.1 code, or less than full compliance with the DOE code, achieves savings within the range of incentive policy savings. However, the building codes cases include LPD limits only and do not cover controls savings that may also result from building codes (some existing state codes have mandatory switching requirements and/or controls credits toward LPD limits).

See the Executive Summary for a thorough discussion of policy results and their implications. 


\section{RESIDENTIAL SECTOR FORECASTS}

\subsection{BASELINE AND POLICY FORECASTS}

\subsubsection{Baseline and Policy Development}

Residential lighting analysis for this study is based on the Residential Lighting Energy Use Spreadsheets developed at LBL for use in producing supply curves of conserved energy. ${ }^{1}$ The spreadsheets estimate residential lighting consumption using a set of five house prototypes: large single-family, medium single-family, small single-family, mobile home, and multi-family. Large, medium, and small single-family are weight-averaged into "single family" for the residential model (LBL-REM) input. Percentages of each house type in the housing stock are derived from the 1987 Residential Energy Consumption Survey (RECS). ${ }^{2}$

Each house type is assigned a certain number of indoor and outdoor lamps with estimated wattages, hours of operation, and fraction of year used, based on aggregation of data from utility Residential Appliance Saturation Surveys (RASSes). The most comprehensive of those has been conducted by Pacific Gas and Electric in Northern California. ${ }^{3}$ Although data on residential lighting are sparse in most of these surveys, utility interest in promoting efficient outdoor lighting, and more recently compact fluorescent lighting, has led to an increase in the number and specificity of survey questions regarding lighting. Also, a few utilities have begun actual monitoring of residential lighting use. These sources provide up-to-date estimates of overall "lighting electricity consumption, which are used to calibrate spreadsheet results.

Lamp prices for baseline as well as efficient technologies assume small quantity purchases by a residential consumer. See Appendix B for the source of prices used in the analysis.

Weighted averages of lamp prices, lamp service lives, and annual unit energy consumption (UECs) are calculated in the spreadsheet and used as REM inputs. For a description of the LBLREM model and its application to the lighting end use, see Section 2.1.3 and Appendix E.

\footnotetext{
'J.G. Koomey, C. Atkinson, A. Meier, J.E. McMahon, S. Boghosian, B. Atkinson, I. Turiel, M.D. Levine, B. Nordman, P. Chan. 1991. "The Potential for Electricity Efficiency Improvements in the Residential Sector," Lawrence Berkeley Laboratory, Berkeley, CA, LBL-30477.

${ }^{2}$ DOE/EIA. 1989. Household Energy Consumption and Expenditures 1987, Part I: National Data. Energy Information Administration, Washington, D.C., DOE/EIA-0321/1 (87).

${ }^{3}$ Pacific Gas \& Electric. 1991. 1990 Residential Appliance Saturation Survey. PG\&E, San Francisco, CA.
} 


\section{Frozen-Efficiency Baseline}

Available data do not permit the development of a "No-Programs" baseline, driven by electricity prices. Instead, a simple Frozen-Efficiency Baseline is used. RASSes indicate that most household lamps are incandescent, mainly general service and a few reflector lamps (see Appendix A for description of lamp technologies). For the Frozen-Efficiency Baseline, standard wattage lamps are assumed throughout the period of the analysis. General service lamps are used indoors, and a combination of general service and reflector lamps are used outdoors. The lighting stock also has a small amount of standard F40 lamps, which are affected by one policy case (Eliminate Highest Wattage Fluorescent).

Most indoor lamps in the input spreadsheets operate five hours per day. Outdoor lights operate four to six hours per day, except in multi-family buildings where they operate nine hours per day (reflecting common areas). Most residential lighting analyses consider only lamps that are in operation for three hours or more per day so that retrofits to these sockets are cost effective. However, to model component standards policies, lamps in operation for fewer hours are included, because they would also have to be replaced by the more efficient technology when they burn out. A portion of the indoor general service incanciescents are assumed on for 1.5 hours per day. (Lamps with less usage than 1.5 hours are not included, because they are replaced very infrequently.) The spreadsheet calculates a weighted-average lamp service life that includes the lower-usage lamps.

\section{High-Efriciency Baseline}

For the High-Efficiency Baseline, 20 percent of both general service and reflector lamps are reduced-wattage lamps in 1990. In 1995 and later years, 40 percent of general service lamps are reduced-wattage, 10 percent halogen infrared, and 15 percent compact fluorescent. Of reflector lamps, 60 percent are reduced-wattage, 15 percent halogen infrared, and 10 percent compact fluorescent. These penetrations are based on utility RASSes, Bureau of Census data, the LRI supply/demand survey, and manufacturer market estimates. The saturations remain constant under this baseline throughout the analysis period (see Table 5.1).

Since the residential service lives of most incandescent lamps are less than one year, the lighting characteristics of stock and new homes are very similar.

\subsubsection{Policy Case UECs, Costs, and Lifetimes}

Table 3.5 in Section 3 lists the residential sector product classes, and Tables 3.3 and 3.4 list the technology options. Table 3.10 lists the technology options used in the residential sector policy cases. Appendix A describes these technology options in detail. Following is a description of each policy case.

Eliminate Highest Wattage Incandescent assumes replacement of the baseline lamps (standardwattage incandescent general service and reflector) with reduced-wattage lamps. 
1991 Proposed Standards (Incandescent Lamps) replaces baseline incandescent general service lamps with reduced-wattage lamps, and reflector lamps with halogen lamps. (These are also the minimum LCC lamps for each category.)

Energy Policy Act of 1992 (Incandescent Lamps) replaces baseline reflector lamps with halogen lamps; general service lamps remain standard-wattage.

Maximum Technologically Feasible replaces the baseline lamps with halogen infrared lamps.

Research and Development replaces the baseline lamps with coated filament lamps.

Compact Fluorescent (CFL) replaces approximately 50 percent of the baseline lamps with CFLs (see Table 5.1 for percentages in each category). Other lamps remain baseline lamps.

Minimum Life Cycle Cost Combination assumes the same percentage of CFL replacement as the $\mathrm{CFL}$ case, and the rest of the lamps are replaced by reduced-wattage general service or halogen reflector lamps.

Research and Development Combination assumes a greater percentage of CFL replacement (see Table 5.1), and the rest of the lamps are replaced by coated filament lamps.

Eliminate Highest Wattage Fluorescent replaces the full-size fluorescent baseline lamps with reduced-wattage lamps.

Energy Policy Act of 1992, Incandescent and Fluorescent Lamp Standards calculates savings and NPVs for the Energy Policy Act of 1992 lamp standards for the residential sector by combining the Energy Policy Act of 1992 (Incandescent Lamps) and the Eliminate Highest Wattage Fluorescent cases.

All of the policy cases analyzed are component performance or prescriptive standards. Some policies with potential energy savings are not studied for the residential sector. Lighting controls, such as timers, photocells, and occupancy sensors for indoor or outdoor lights are not included, since mandating such controls is difficult to enforce. Incentive and information policies such as rebates, tax credits, and consumer education are not studied due to lack of information and difficulty of quantifying potential savings. System performance standards, or lighting features in building codes, are also not analyzed. See Section 2.2.3 for further discussion of residential building codes.

Most policy cases assume the complete retrofit of the incandescent general service and reflector lamp categories addressed by each policy. In the CFL, Min LCC Combination, and R\&D Combination, only a fraction of the lamps are retrofitted with CFLs, since CFLs would not fit in all sockets. CFL fixture retrofit in existing buildings is estimated not to be cost-effective in the residential sector, and is not specifically analyzed in new construction. However, in the R\&D Combination case, a higher fraction of sockets are assumed to use CFLs than in the other two 
cases, reflecting future conditions in which CFLs fit in more sockets (including new fixtures) and can be used with dimmer switches. Table 5.1 shows the penetration rates assumed in each policy case, with the exception of Eliminate Highest Wattage Fluorescent. In this last case, all full-size fluorescent lamps are replaced with reduced-wattage lamps.

Hours of operation do not change for the policy cases. Some lamp service lives change with the longer lifetimes of more efficient technologies. Service lives, efficacies, and costs of residential technology options are shown in Table 3.11 .

Table 5.1

1995 Penetration Rates (\%) of Technologies for Residential Policies, High-Efficiency Baseline

\begin{tabular}{|c|c|c|c|c|c|c|c|c|c|}
\hline Pollcy & Baseline & $\begin{array}{l}\text { Elim. High } \\
\text { Waltage } \\
\text { Inc. }\end{array}$ & $\begin{array}{c}1991 \\
\text { Prop.Std. } \\
\text { Inc. }\end{array}$ & $\begin{array}{c}\text { EPA-92 } \\
\text { Inc. }\end{array}$ & Max Tech & R\&D & CFL & $\begin{array}{c}\text { Min LCC } \\
\text { Comb. }\end{array}$ & $\begin{array}{l}R \& D \\
\text { Comb. }\end{array}$ \\
\hline \multicolumn{10}{|c|}{ Incandescent General Servke } \\
\hline Standard & 30 & 0 & 0 & 30 & 0 & 0 & 21 & 0 & 0 \\
\hline Reduced-Wattage & 40 & 70 & 70 & 40 & 0 & 0 & 29 & 50 & 0 \\
\hline Halogen & 0 & 0 & 0 & 0 & 0 & 0 & 0 & 0 & 0 \\
\hline Halogen Infrared & 15 & 15 & 15 & 15 & 85 & 0 & 0 & 0 & $\mathbf{0}$ \\
\hline Coated Filament & 0 & 0 & 0 & 0 & 0 & 85 & 0 & 0 & 25.50 \\
\hline CFL & 15 & 15 & 15 & 15 & 15 & 15 & 50 & 50 & 50.75 \\
\hline \multicolumn{10}{|c|}{ Incandescent Reflector } \\
\hline Standard & 15 & 0 & 0 & 0 & 0 & 0 & 8 & 0 & 0 \\
\hline Reduced-Wattage & 60 & 75 & 0 & 0 & 0 & 0 & 34 & 0 & $\mathbf{0}$ \\
\hline Halogen & 0 & 0 & 75 & 75 & 0 & 0 & 0 & 50 & 0 \\
\hline Halogen Infrared & 15 & 15 & 15 & 15 & 90 & 0 & 8 & 0 & 0 \\
\hline Coated Filament & 0 & 0 & 0 & 0 & 0 & 90 & 0 & 0 & 25 \\
\hline CFL Reflector & 10 & 10 & 10 & 10 & 10 & 10 & 50 & 50 & 75 \\
\hline
\end{tabular}

\subsection{RESULTS OF THE LBL RESIDENTIAL ENERGY MODEL}

Table 3.10 in Section 3.2.5 lists the policy options for incandescent lamps in the residential sector. Tables 5.2a-b present lighting consumption results of the LBL-REM analysis for the High-Efficiency Baseline, and Tables 5.3a-b present results for the Frozen-Efficiency Baseline. Annual and cumulative residential lighting energy consumption are given for the period 19952030. Annual UEC per household of lighting equipment is given for 1990, and for the two baselines for the period 1995-2030, in Table 5.4. Note that by assumption UEC does not vary during the period. This is because the residential discount rate for efficiency choice and price utilization elasticity are not known. 
Real electricity prices used in determining the net present values for each case (shown in Figure 2.10 ) rise from $\$ 0.0784 / \mathrm{kWh}$ in 1990 to $\$ 0.0915 / \mathrm{kWh}$ in 2030.

Table 5.2a Residential Lighting Energy Consumption, High-Efficiency Baseline (Primary Quads) ${ }^{4}$

\begin{tabular}{|c|c|c|c|c|c|c|c|c|c|c|c|}
\hline Year & Beseline & $\begin{array}{l}\text { Elim. High } \\
\text { Waunge } \\
\text { Inc. }\end{array}$ & $\begin{array}{c}1991 \\
\text { Prop.Sud. } \\
\text { Inc. }\end{array}$ & $\begin{array}{l}\text { EPA.92 } \\
\text { Inc. }\end{array}$ & Max Toch & $R \& D$ & CFL. & $\begin{array}{l}\text { Min LCC } \\
\text { Comb. }\end{array}$ & $\begin{array}{l}R \text { \& D } \\
\text { Comb. }\end{array}$ & $\begin{array}{l}\text { Elim. High } \\
\text { Waunge } \\
\text { Fluor. }\end{array}$ & $\begin{array}{c}\text { EPA.92 } \\
\text { Inc. + } \\
\text { Fluor. }\end{array}$ \\
\hline 1990 & 1.4 & 1.4 & 1.4 & 1.4 & 1.4 & 1.4 & 1.4 & 1.4 & 1.4 & 1.4 & 1.4 \\
\hline 1995 & 1.3 & 1.2 & 1.2 & 1.2 & 1.0 & 0.6 & 1.1 & 1.0 & 0.6 & 1.3 & 1.2 \\
\hline 2000 & 1.3 & 1.3 & 1.3 & 1.3 & 1.1 & 0.6 & 1.1 & 1.1 & 0.6 & 1.3 & 1.3 \\
\hline 2005 & 1.4 & 1.3 & 1.3 & 1.4 & 1.2 & 0.6 & 1.2 & 1.1 & 0.6 & 1.4 & 1.4 \\
\hline 2010 & 1.4 & 1.4 & 1.4 & 1.4 & 1.2 & 0.6 & 1.2 & 1.1 & 0.6 & 1.4 & 1.4 \\
\hline 2015 & 1.5 & 1.4 & 1.4 & 1.5 & 1.2 & 0.7 & 1.2 & 1.2 & 0.6 & 1.5 & 1.4 \\
\hline 2020 & 1.5 & 1.5 & 1.4 & 1.5 & 1.2 & 0.7 & 1.3 & 1.2 & 0.7 & 1.5 & 1.5 \\
\hline 2025 & 1.6 & 1.5 & 1.5 & 1.5 & 1.3 & 0.7 & 1.3 & 1.2 & 0.7 & 1.5 & 1.5 \\
\hline 2030 & 1.6 & 1.5 & 1.5 & 1.6 & 1.3 & 0.7 & 1.3 & 1.3 & 0.7 & 1.6 & 1.6 \\
\hline 1995.2030 & 52.2 & 50.0 & 49.4 & 51.4 & 42.9 & 23.0 & 43.6 & 41.3 & 22.9 & 51.6 & 50.8 \\
\hline $\begin{array}{c}\text { Change from } \\
\text { Baseline }\end{array}$ & - & -2.2 & -2.8 & .0 .8 & -9.3 & -29.2 & -8.5 & -10.9 & -29.3 & -0.6 & -1.4 \\
\hline $\begin{array}{l}\text { Cumulative } \\
\text { Savings (\%) }\end{array}$ & - & 49 & $5 \%$ & $2 \%$ & $18 \%$ & $56 \%$ & $16 \%$ & $21 \%$ & $56 \%$ & $1 \%$ & $3 \%$ \\
\hline
\end{tabular}

Table 5.2b Residential Lighting Energy Consumption, High-Efficiency Baseline (TWh)

\begin{tabular}{cccccccccccc}
\hline & \multicolumn{1}{c}{$\begin{array}{c}\text { Elim. High } \\
\text { Waunge } \\
\text { Inc. }\end{array}$} & $\begin{array}{c}\text { Prop.Sid. } \\
\text { Inc. }\end{array}$ & $\begin{array}{c}\text { EPA.92 } \\
\text { Inc. }\end{array}$ & Max Tech & R\&D & CFL & $\begin{array}{c}\text { Min LCC } \\
\text { Comb. }\end{array}$ & $\begin{array}{c}\text { R \& D D } \\
\text { Comb. }\end{array}$ & $\begin{array}{c}\text { Elim. Hight } \\
\text { Waluge } \\
\text { Fluor. }\end{array}$ & $\begin{array}{c}\text { EPA-92 } \\
\text { Inc. }+ \\
\text { Fluor. }\end{array}$ \\
\hline 1990 & 122 & 122 & 122 & 122 & 122 & 122 & 122 & 122 & 122 & 122 & 122 \\
1995 & 110 & 105 & 104 & 108 & 91 & 53 & 93 & 89 & 54 & 110 & 108 \\
2000 & 116 & 111 & 110 & 114 & 95 & 51 & 97 & 92 & 51 & 115 & 113 \\
2005 & 123 & 117 & 116 & 121 & 101 & 54 & 102 & 97 & 54 & 121 & 119 \\
2010 & 125 & 120 & 119 & 124 & 103 & 55 & 105 & 99 & 55 & 124 & 122 \\
2015 & 129 & 123 & 122 & 127 & 106 & 57 & 108 & 102 & 56 & 127 & 125 \\
2020 & 132 & 126 & 125 & 130 & 108 & 58 & 110 & 104 & 58 & 131 & 129 \\
2025 & 136 & 130 & 128 & 133 & 111 & 60 & 113 & 107 & 59 & 134 & 131 \\
2030 & 139 & 133 & 131 & 137 & 114 & 61 & 116 & 110 & 61 & 137 & 135 \\
$1995-2030$ & 4541 & 4348 & 4297 & 4471 & 3732 & 2002 & 3796 & 3591 & 1992 & 4493 & 4422 \\
\hline
\end{tabular}

${ }^{4}$ Excludes HVAC interactions; includes T\&D losses.

${ }^{5}$ Excludes HVAC interactions; includes T\&D losses. 
Table 5.3a Residential Lighting Energy Consumption, Frozen-Efficiency Baseline (Primary Quads)

\begin{tabular}{|c|c|c|c|c|c|c|c|c|c|c|c|}
\hline Year & Baseline & $\begin{array}{l}\text { Elim. High } \\
\text { Waugec } \\
\text { Inc. }\end{array}$ & $\begin{array}{c}1991 \\
\text { Prop.Sid. } \\
\text { Inc. }\end{array}$ & $\begin{array}{c}\text { EPA.92 } \\
\text { Inc. }\end{array}$ & Max Tech & R\&D & CFL & $\begin{array}{c}\text { Min LCC } \\
\text { Comb. }\end{array}$ & $\begin{array}{l}R \& D \\
\text { Comb. }\end{array}$ & $\begin{array}{l}\text { Elim. High } \\
\text { Wauge } \\
\text { Fluor. }\end{array}$ & $\begin{array}{l}\text { EPA.92 } \\
\text { Inc. + } \\
\text { Fluor. }\end{array}$ \\
\hline 1990 & 1.4 & 1.4 & 1.4 & 1.4 & 1.4 & 1.4 & 1.4 & 1.4 & 1.4 & 1.4 & 1.4 \\
\hline 1995 & 1.5 & 1.4 & 1.3 & 1.5 & 1.1 & 0.6 & 1.1 & 1.0 & 0.6 & 1.5 & 1.5 \\
\hline 2000 & 1.6 & 1.4 & 1.4 & 1.6 & 1.2 & 0.6 & 1.2 & 1.1 & 0.6 & 1.6 & 1.6 \\
\hline 2005 & 1.7 & 1.5 & 1.5 & 1.7 & 1.3 & 0.6 & 1.2 & 1.1 & 0.6 & 1.7 & 1.6 \\
\hline 2010 & 1.7 & 1.6 & 1.5 & 1.7 & 1.3 & 0.6 & 1.3 & 1.1 & 0.6 & 1.7 & 1.7 \\
\hline 2015 & 1.8 & 1.6 & 1.6 & 1.7 & 1.3 & 0.7 & 1.3 & 1.2 & 0.6 & 1.8 & 1.7 \\
\hline 2020 & 1.8 & 1.6 & 1.6 & 1.8 & 1.4 & 0.7 & 1.3 & 1.2 & 0.7 & 1.8 & 1.8 \\
\hline 2025 & 1.9 & 1.7 & 1.7 & 1.8 & 1.4 & 0.7 & 1.4 & 1.2 & 0.7 & 1.9 & 1.8 \\
\hline 2030 & 1.9 & 1.7 & 1.7 & 1.9 & 1.4 & 0.7 & 1.4 & 1.3 & 0.7 & 1.9 & 1.9 \\
\hline $1995-2030$ & 63.0 & 56.2 & 55.4 & 61.5 & 46.7 & 23.2 & 46.3 & 41.3 & 22.9 & 62.5 & 60.9 \\
\hline $\begin{array}{c}\text { Change from } \\
\text { Baseline }\end{array}$ & - & -6.8 & -7.6 & -1.5 & -16.3 & -39.8 & -16.7 & -21.8 & .40 .1 & -0.6 & -2.1 \\
\hline $\begin{array}{l}\text { Cumulative } \\
\text { Savings (x) }\end{array}$ & - & $11 \%$ & $12 \%$ & $2 \%$ & $26 \%$ & $63 \%$ & $27 \%$ & $35 \%$ & $64 \%$ & $1 \%$ & $3 \%$ \\
\hline
\end{tabular}

Table 5.3b Residential Lighting Energy Consumption, Frozen-Efficiency Baseline (TWh) ${ }^{7}$

\begin{tabular}{|c|c|c|c|c|c|c|c|c|c|c|c|}
\hline Year & Baseline & $\begin{array}{l}\text { Elim. High } \\
\text { Waluge } \\
\text { Inc. }\end{array}$ & $\begin{array}{c}1991 \\
\text { Prop. Sid. } \\
\text { Inc. }\end{array}$ & $\begin{array}{l}\text { EPA-92 } \\
\text { Inc. }\end{array}$ & Max Tech & R\&D & CFL. & $\begin{array}{c}\text { Min LCC } \\
\text { Comb. }\end{array}$ & $\begin{array}{l}R \& D \\
\text { Comb. }\end{array}$ & $\begin{array}{l}\text { Elim. High } \\
\text { Wruage } \\
\text { Fluor. }\end{array}$ & $\begin{array}{c}\text { EPA.92 } \\
\text { Inc. + } \\
\text { Fluor. }\end{array}$ \\
\hline 1990 & 122 & 122 & 122 & 122 & 122 & 122 & 122 & 122 & 122 & 122 & 122 \\
\hline 1995 & 131 & 118 & 116 & 128 & 99 & 53 & 99 & 89 & 54 & 131 & 128 \\
\hline 2000 & 140 & 124 & 123 & 137 & 104 & 51 & 103 & 92 & 51 & 139 & 135 \\
\hline 2005 & 148 & 132 & 130 & 144 & 110 & 54 & 109 & 97 & 54 & 147 & 143 \\
\hline 2010 & 152 & 135 & 133 & 148 & 112 & 56 & 111 & 99 & 55 & 150 & 147 \\
\hline 2015 & 156 & 139 & 137 & 151 & 115 & 57 & 114 & 102 & 56 & 154 & 151 \\
\hline 2020 & 159 & 142 & 140 & 156 & 118 & 59 & 117 & 104 & 58 & 158 & 154 \\
\hline 2025 & 163 & 146 & 144 & 159 & 121 & 60 & 120 & 107 & 59 & 162 & 158 \\
\hline 2030 & 168 & 149 & 147 & 164 & 124 & 62 & 123 & 110 & 61 & 166 & 162 \\
\hline 1995.2030 & 5485 & 4890 & 4817 & 5350 & 4067 & 2020 & 4031 & 3591 & 1992 & 5436 & 5302 \\
\hline
\end{tabular}

${ }^{6}$ Excludes HVAC interactions; includes T\&D losses.

${ }^{7}$ Excludes HVAC interactions; includes T\&D losses.

$$
5-6
$$


Table 5.4 Residential Unit Energy Consumption for Lighting, Frozen-Efficiency and High-Efficiency Baselines (Weighted Average kWh/Household-Year)

\begin{tabular}{|c|c|c|c|c|c|c|c|c|c|c|c|}
\hline Year & Baseline & $\begin{array}{c}\text { Elim. High } \\
\text { Waunge } \\
\text { Inc. }\end{array}$ & $\begin{array}{l}1991 \\
\text { Prop.Sed. } \\
\text { Inc. }\end{array}$ & $\begin{array}{l}\text { EPA.92 } \\
\text { Inc. }\end{array}$ & Max Tech & R\&D & CFL & $\begin{array}{l}\text { Min LCC } \\
\text { Comb. }\end{array}$ & $\begin{array}{l}R \& D \\
\text { Comb. }\end{array}$ & $\begin{array}{l}\text { Elim. High } \\
\text { Watuge } \\
\text { Fluor. }\end{array}$ & $\begin{array}{c}\text { EPA-92 } \\
\text { Inc. + } \\
\text { Fluor. }\end{array}$ \\
\hline Historical 1990 & 1294 & & & & & & & & & & \\
\hline $\begin{array}{l}\text { Frozen-Efficiency } \\
\text { Baseline } 1995-2030\end{array}$ & 1294 & 1152 & 1134 & 1262 & 955 & 472 & 944 & 839 & 467 & 1282 & 1249 \\
\hline $\begin{array}{l}\text { High-Efficiency } \\
\text { Baseline 1995-2030 }\end{array}$ & 1068 & 1022 & 1009 & 1051 & 874 & 468 & 888 & 839 & 467 & 1055 & 1039 \\
\hline
\end{tabular}

\subsection{ECONOMIC ANAL YSIS FOR THE RESIDENTIAL SECTOR}

Table 5.5 presents the net present value to consumers of lighting policy cases for the period 1995-2030. The NPV is calculated using lighting electricity savings only. Heating and cooling effects on energy consumption and peak load are treated separately in Appendix $\mathrm{H}$.

Table 5.5 presents the results of the economic analysis for both baselines. Most policy cases have positive NPVs, with the exception of the Maximum Technology and the R \& D lamp cases. The primary reason for the negative NPV is the use of the efficient technologies in the lowerusage sockets; when these lamps are eliminated from the analyses the NPVs are positive. (These lamps have favorable economic parameters in the Engineering Tables B.2 and B.4 in Appendix B.) Policies requiring these two options have positive NPVs in the commercial sector, in residential applications they also have the disadvantages of higher prices, lower operating hours, and no replacement cost savings.

Table 5.5 NPV of Policies for Residential Lighting (Billion \$ 1990) Using Projected Electricity Prices Discounted to 1990 at 6\% Real

\begin{tabular}{lcccccccccc}
\hline \multicolumn{1}{c}{} & $\begin{array}{c}\text { Elim. High } \\
\text { Waluge } \\
\text { Year }\end{array}$ & $\begin{array}{c}\text { Inc. } \\
\text { Prop.Sid. } \\
\text { Inc. }\end{array}$ & $\begin{array}{c}\text { EPA.92 } \\
\text { Inc. }\end{array}$ & Max Tech & R\&D & CFL & $\begin{array}{c}\text { Min LCC } \\
\text { Comb. }\end{array}$ & $\begin{array}{c}\text { R \& D } \\
\text { Comb. }\end{array}$ & $\begin{array}{c}\text { Elim. High } \\
\text { Waunge } \\
\text { Fluor. }\end{array}$ & $\begin{array}{c}\text { EPA-92 } \\
\text { Inc. }+ \\
\text { Fluor. }\end{array}$ \\
\hline $\begin{array}{l}\text { Frozen-Efficiency } \\
\text { Baseline }\end{array}$ & 12.9 & 13.0 & 1.4 & -44.9 & -25.0 & 32.1 & 39.2 & 26.0 & 1.0 & 2.4 \\
$\begin{array}{l}\text { High-Efficiency } \\
\text { Baseline }\end{array}$ & 6.6 & 5.0 & 0.4 & -23.2 & -4.7 & 29.3 & 33.9 & 20.4 & 1.0 & 1.4 \\
\hline
\end{tabular}

Figure 5.1 shows the allocation of lighting energy use among incandescent, fluorescent, and compact fluorescent lamps in the year 2010 for selected cases. Figures 5.2 and 5.3 present the UECs for various policy cases and annual national electricity demand for the period 1990 to 2030. Figures 5.4 and 5.5 illustrate lighting energy savings and net present value, respectively, of the residential lighting policies analyzed. 
Figure 5.1

U.S. Residential Lighting Energy Consumption in 2010, by Technology

Primary Quads

Component Standards

High-Efficiency Baseline

TWh

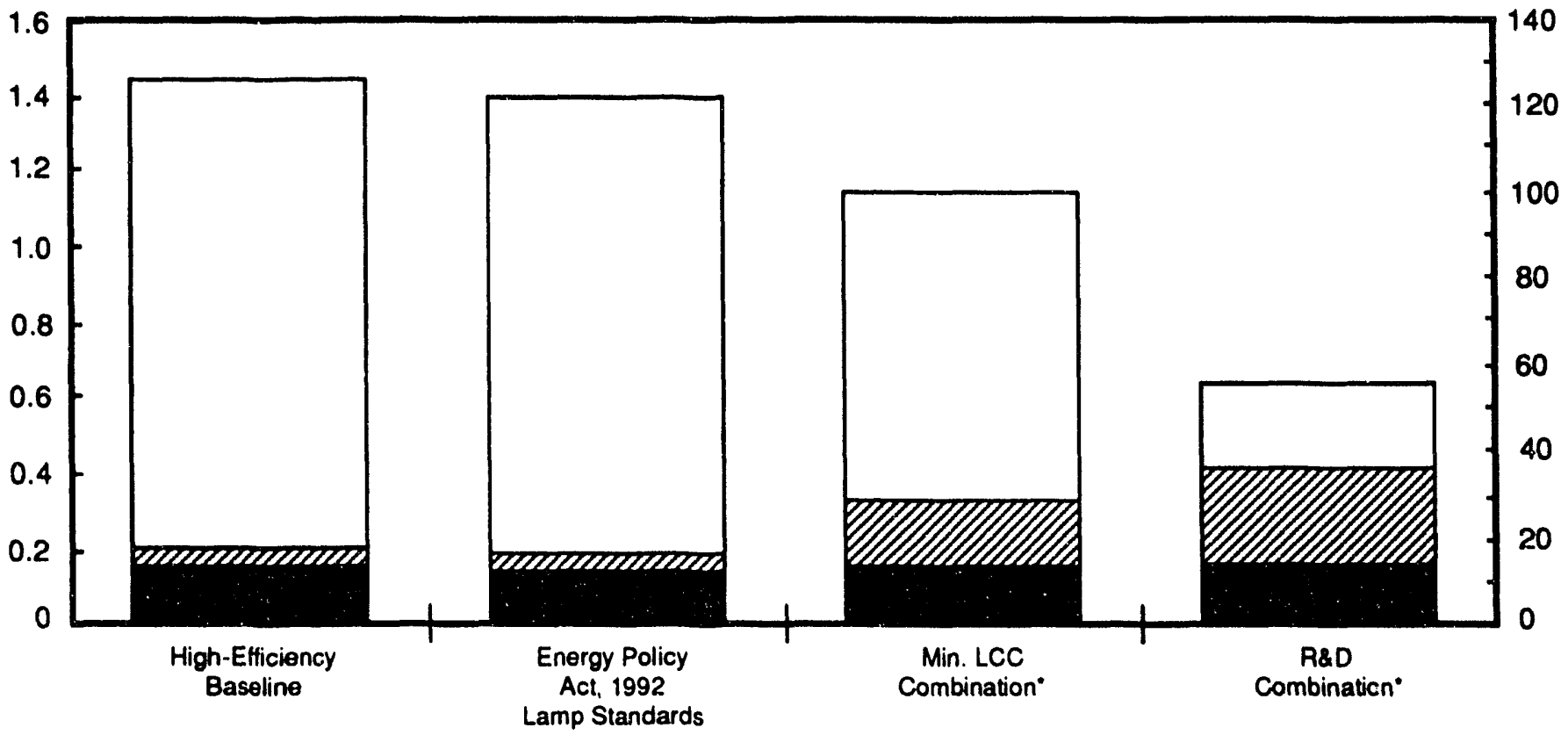

Fluorescent $\square$ Compact Fluorescent $\square$ Incandescent

- Including compact fluorescent substitution

$5-8$ 
Figure 5.2

Lighting Unit Energy Consumption in 2030

Baselines and lilustrative Policy Cases

kWh / househoid-year Residential Sector

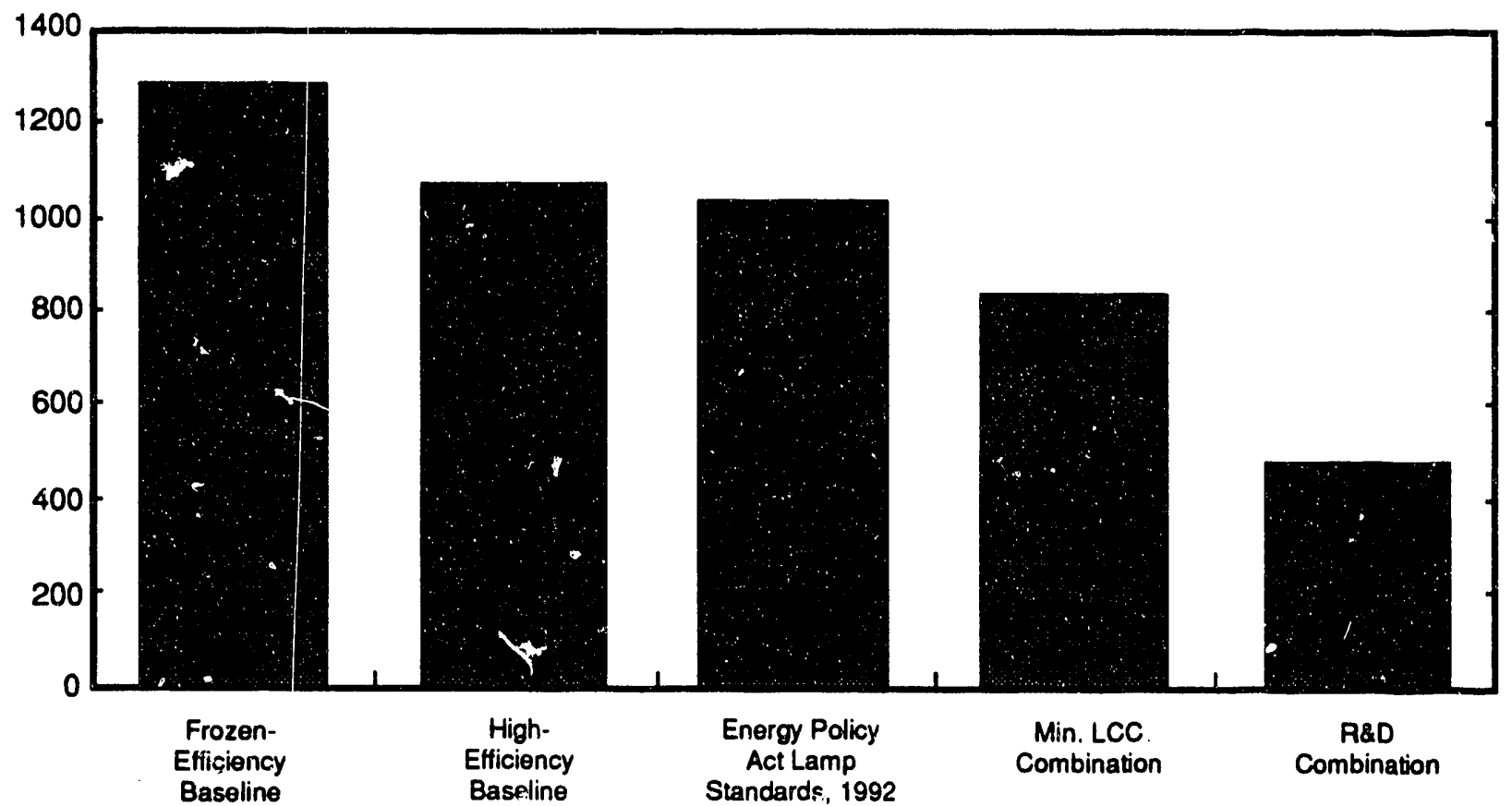

Figure 5.3

Annual Lighting Energy Consumption

Baselines and Illustrative Policy Cases

Primary Quads Residential Sector

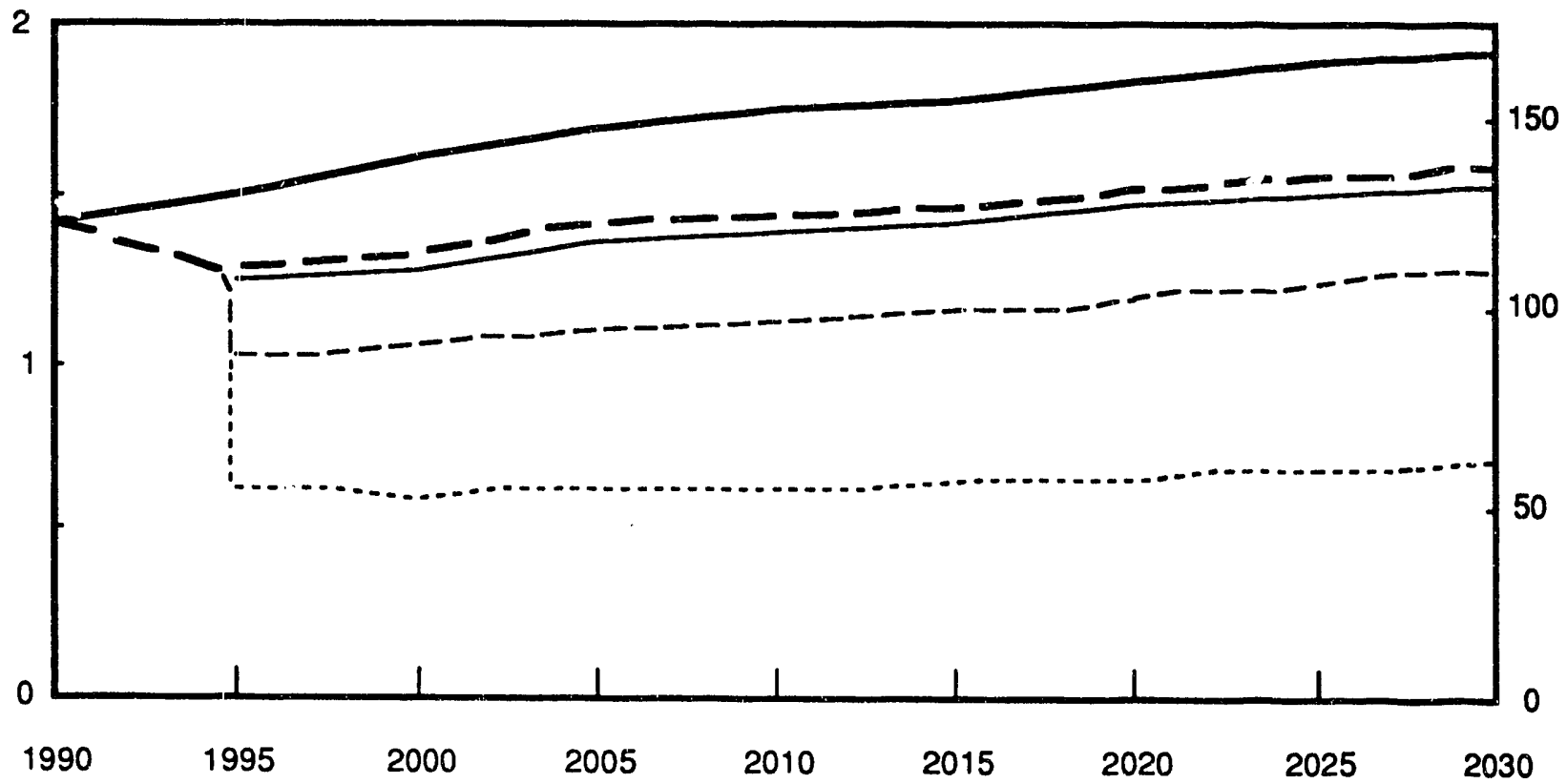

Frozen-Efficiency

Baseline

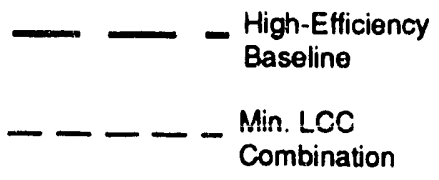

High-Efficiency

Energy Policy Act, 1992

Lamp Standards 


\section{Flgure 5.4}

Range of Cumulative Lighting Energy Savings from Lamp Standards

1995 to 2030

Residential Sector

Primary Quads

TWh

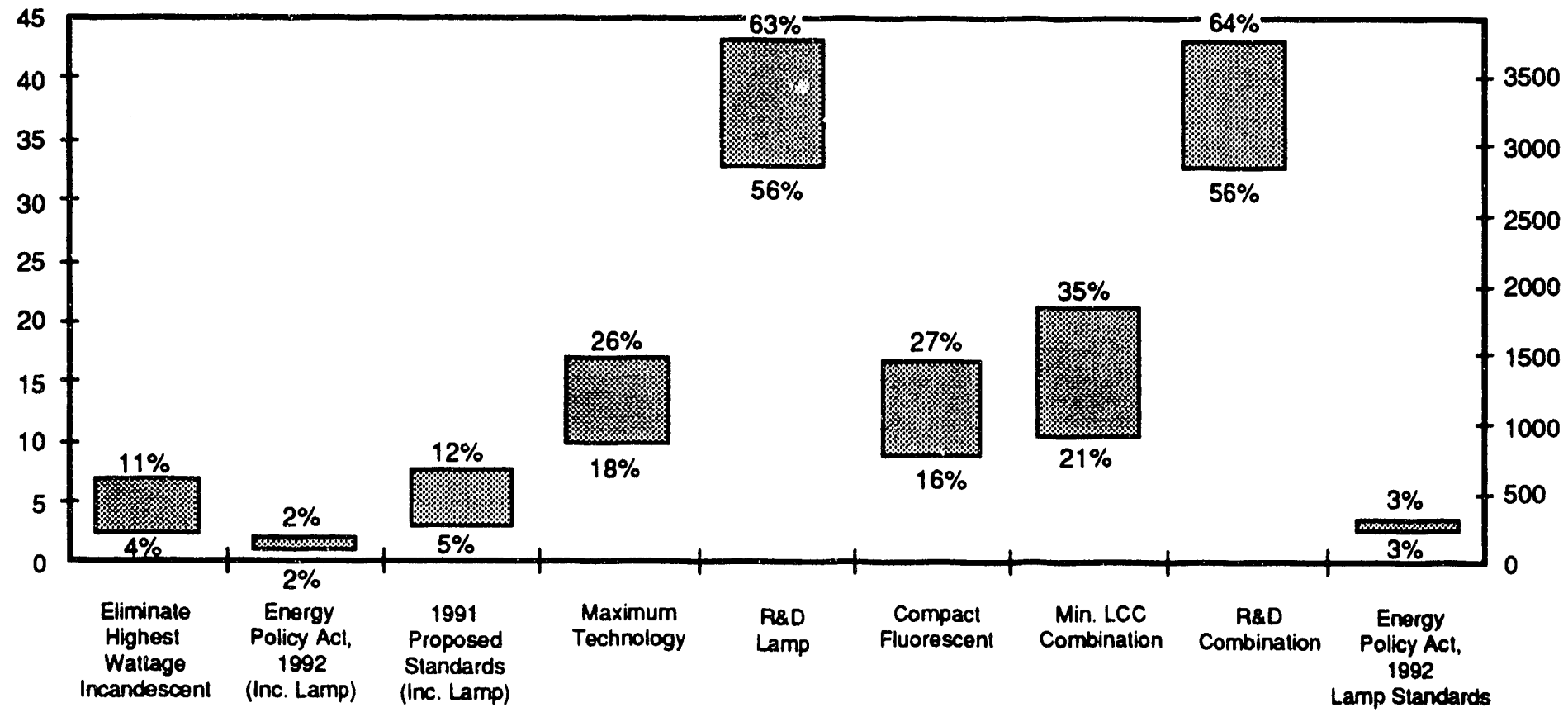

Nole: Percentages are portion of respective baseline lighting energy.

Tops of bars represent savings under Frozen-Efficiency Baseline; bottoms of bars represent savings under High-Efficiency Baseline.

Flgure 5.5

Range of Cumulative Net Present Values from Lamp Standards

1995 to 2030

NPV

Residential Sector

$\$ 1990$ Billions

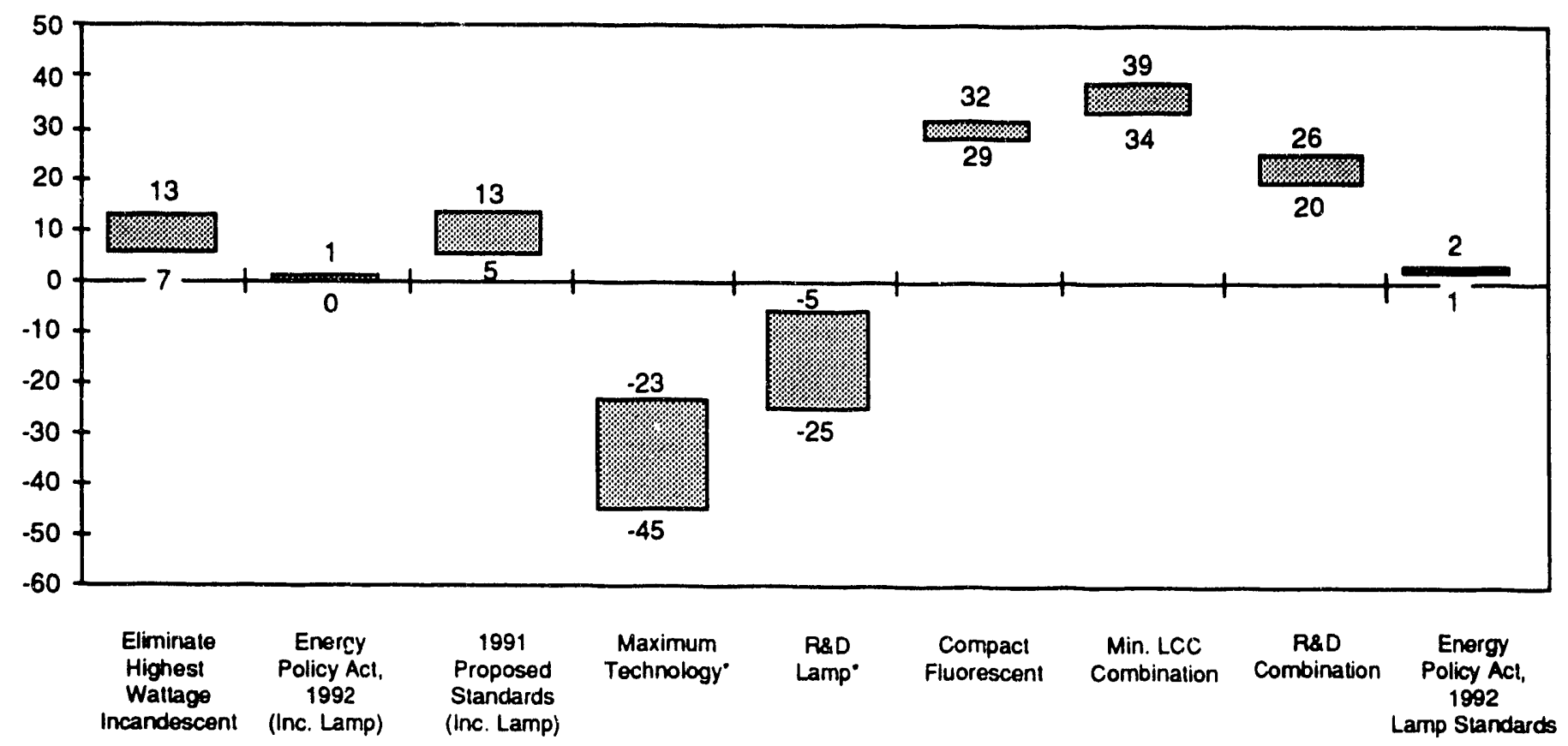

Tops of bars represent NPVs under Frozen-Efficiency Baseline, botloms of bars represent NPVs under High-Efficiency Baseline; this relationship is reversed for policy cases with and asterisk ( $\%$ ). 


\section{IMPACTS OF POLICIES ON MANUFACTURERS}

In the analysis of the impact of potential standards on lighting products, the following variables are examined: market concentration (particularly for lamps and fixtures), the impacts of technology options on manufacturers, the ability of manufacturers to retool for producing products with the new technology options, and the effects of the newer technologies on consumer prices and product lifetimes. A variety of industry sources have been consulted in the process of preparing this section.'

\subsection{MARKET CONCENTRATION}

Market concentration is the extent to which market share is controlled by the larger firms in an industry. Market share is significant because it may indicate market power; generally, market power positively affects the markups over cost that firms may pass on to consumers. Because standards usually lead to an increase in costs to firms, and because market power directly affects their ability to markup costs, an understanding of market power can give some indication as to how firms and product prices may be affected by standards.

\subsubsection{Lamps}

The U.S. market for lamps is more than $\$ 3$ billion annually (Figure 6.1). The major firms in the market are General Electric Co. (GE), GTE Corp. (Sylvania), and Philips Lighting Co. GE is a U.S. firm. GTE has just been bought by Siemens, and Philips's parent corporation is Dutch. All three firms have large international operations. ${ }^{2}$ They are also large players in smaller specialty markets (e.g., medical lamps, studio lamps), but there are many other firms in those markets. Other important lamp companies include Osram, Duro-Test, Iwasaki, Venture Lighting International, Ushio, Toshiba, and Matsushita. As a whole, the lamp industry is heavily concentrated.

\footnotetext{
${ }^{1}$ Lighting Research Institute (LRI) and Plexus Research, Inc. 1991. Survey and Forecast of Marketplace Supply and Demand for Energy-Efficient Lighting Products. Phase I Report, Project Number 2418-9, EPRI, Palo Alto CA, October 1991; A.B. Gough. 1990. "Meeting the Challenge for Lighting Leadership in the 1990's." Keynote Speech IES/NA 1990 Annual Meeting, Baltimore MD, July 30, 1990; R.K. Miller and M.E. Rupnow; Survey on Commercial Lighting. Future Technology Surveys Inc., Survey Report 107; U.S. Department of Commerce, Bureau of the Census. 1990. Current Industrial Reports, Electric Lamps. 1990. Washington DC, MQ36B(89)-4; U.S. Department of Commerce, Bureau of the Census. 1990. Current Industrial Reports, Electric Lighting Fixtures. Washington DC, MA36L(89)-1.

${ }^{2}$ Philips bought the ITT Lamp Division and several smaller companies in the early 1970 s and was in the US market under its Norelco brand, and more recently purchased the lamp division of Westinghouse. GTE sold its electrical products group (including lighting products) to Siemens in 1992.
}

$$
6-1
$$




\section{Figure 6-1 \\ Lamp Manufacturer Market Shares \\ ( \$3 Billion/year)}

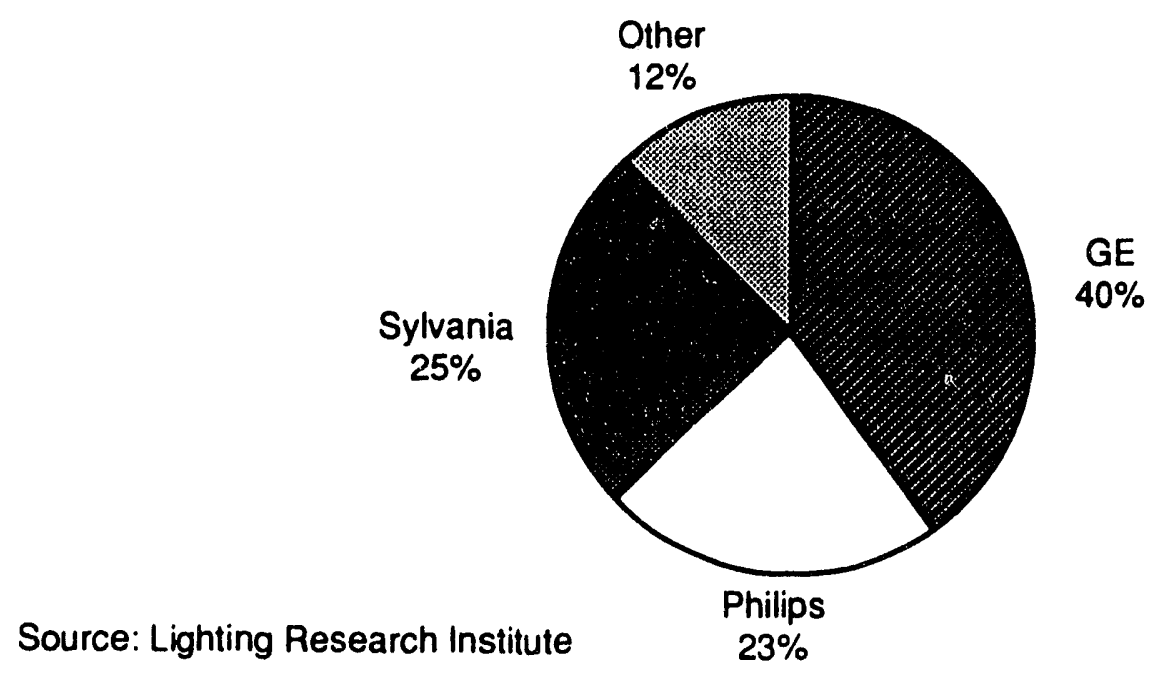

One submarket where GE, GTE, and Philips do not dominate as strongly is compact fluorescent lamps. Osram (a subsidiary of the German firm Siemens) started a compact fluorescent plant in the United States when demand began to rise and has up to 45 percent of the current U.S. market. Two Japanese firms, Matsushita (under the Panasonic label) and Toshiba, are large global manufacturers of compact fluorescent lamps (both supply up to 40 percent of the Japanese market). Panasonic and most of the above-mentioned firms have begun to make inroads in the U.S. market.

\subsubsection{Fixtures/Luminaires}

The U.S. market for fixtures/luminaires is approximately $\$ 5.3$ billion annually. This industry has seen a series of acquisitions during the past thirty years, and many firms are now subsidiaries of larger firms. The fixture industry may be broken down into four tiers by sales. The first tier consists of firms whose sales are in the $\$ 250$ million to $\$ 600$-million-plus category. The five major firms in this tier are Lithonia, Hanson Plc. (an English firm), Cooper Industries Inc., Genlyte Group Inc., and Thomas Industries Inc. The combined market share of these five firms is estimated at 50 to 57 percent of the fixture market. The second tier consists of eight to ten firms with sales in the $\$ 100$ to 250 million range. The market share of the second tier is estimated to range from 20 percent to 24 percent. The third tier consists of approximately ten to thirty firms with sales in the $\$ 10$ to $\$ 100$ million range with a combined market share of 17 to 20 percent.

Given that the five largest firms have such a large share of the market, this industry has a fair degree of market concentration. 
Foreign firms have not played a significant role in the U.S. luminaire market because they do not import assembled units. Assembled luminaires, when shipped, take up a large amount of air space, which results in high shipping costs per unit. Some offshore firms (e.g.. European and Far Eastern) have begun U.S. operations by shipping nested parts and adding some components with manufactured U.S. content. This establishment of a local presence has also been required to foster their marketing and sales impact in the U.S.

\subsubsection{Controls}

There are numerous (50 to 100) players in the lighting controls market. These include Honeywell, General Electric, Johnson Controls, Robertshaw Controls Co., Allen-Bradley Co. (a Rockwell International Corp. subsidiary), Cutler-Hammer Products (an Eaton Corp. subsidiary), Conservolite, Hubbell Inc., Lightolier (a Genlyte subsidiary) and Lutron. This market covers systems from simple timers to whole building controls (i.e., "intelligent buildings"). Many large firms are targeting the potentially very profitable whole-building-control-systems submarket. In addition to lighting, these systems control security, fire, HVAC, etc. This analysis considers more specifically the submarkets of programmable timers, occupancy sensors, and dimming equipment, where lighting controls firms and a number of others offer a variety of products.

\subsection{IMPACT OF PROPOSED DESIGN OPTIONS ON MANUFACTURERS}

Evaluating the impact of proposed design options on manufacturers includes considering whether or not the affected industries are able to convert or install adequate capacity to manufacture appropriate products. The evaluation also involves determining whether or not there are any barriers such as patents to the dissemination of technologies necessary to the manufacture of the selected technology options.

\subsubsection{Fluorescent Lamps}

Table 3.6 shows fluorescent lamp technology options. The 34-watt T12 (reduced wattage fourfoot lamp) is an option currently being manufactured by most firms in the industry. There are technical application barriers when the process for standard lamps is used to produce 34-watt lamps; lamps manufactured using the same process may have problems such as flicker or erratic starting. Hence, a major requirement is the addition of equipment for applying conductive coating. Projections for retooling range from three to five years. There are no other significant obstacles to industry conversion from the manufacture of the standard F-40 lamp to the 34-watt lamp. (See Appendix A for discussion of technical problem with some applications of the reduced-wattage lamp.)

All three large firms in the industry are currently converting existing equipment from T12 to T8 production in anticipation of growing demand. There is an estimated two- to three-year lag before this retooling will be complete. Changes need to be made to existing machinery to accommodate smaller diameter bulbs and to add tri-phosphor coatings, but these should be well within the capability of the industry. 
If there are mandated restrictions on phosphor coatings that can be used, then firms may have initial difficulty while they develop new formulae. Similar considerations apply for the eight-foot lamp.

Compact fluorescent lamps have become more common on the market, particularly because of utility and other conservation incentive programs. Hence, CFL manufacturers would not be adversely affected by the policy cases studied, although demand would likely increase, aggravating the current shortage in capacity. However the planned additional capacity by several firms is expected to alleviate shortages in three to five years.

\subsubsection{Incandescent Lamps}

The selected design options for incandescent lamps are detailed in Table 3.8. For both general service and reflector incandescents, reduced-wattage reflectors are well within industrial retooling capability. Capacity is not an obstacle to increases in production, nor are there other obstacles. The halogen and halogen infrared (HIR) general secvice and reflector technology options are also commercially feasible. In fact, lighting industry representatives and analysts estimate the HIR lamp may have as much as 15 to 20 percent of the market by the year 2000 . Hence capacity and tooling for new design options are not likely to be problematic issues for the lamp industry.

\subsubsection{Fixtures/Luminaires}

As noted in Section 3.3, a luminaire efficiency standard would not mandate specific technology options but rather would specify an increase in efficiency from the baseline. The industry currently has much excess capacity (estimates as high as 45 to 65 percent), further aggravated by a recent slowdown in construction; one result of this is industry consolidation over time. The imposition of a fixture standard might force some firms from the market. However, firms would be expected to either leave the market or merge with others to rectify the current excess capacity problem even if standards were not imposed. The departure (or consolidation) of firms would probably improve the financial health of the industry as a whole by reducing excess capacity. All other considerations being equal, smaller firms would more likely be affected adversely because of their relatively low capacity to weather financial or other adjustments. On the other hand, there is some indication that medium and smaller firms tend to produce innovative and energy-efficient products; thus, they would not be as adversely affected by (or might even benefit from) lighting efficiency policies. ${ }^{3}$ Medium to large firms (Tiers 1 and 2) could continue to develop, retool, and introduce energy-efficient lighting products when the marketplace demanded them.

Fixture technology does not have any preemptory patents or other barriers to its dissemination.

\footnotetext{
${ }^{3}$ F. Davis. 1991. "Engines of Energy Innovation: The Role of Smaller Manufacturers of Efficient Lighting Products." Proceedings of the 1st European Conference on Energy-Efficient Lighting. E. Mills ed. Swedish National Board for Industrial and Technical Development, Department of Energy Efficiency, Stockholm Sweden.
} 
Most designs in the industry date back 10 to 20 years, and a new fixture introduced in the market can generally be copied, tooled, and introduced within six months to a year by any other firm in the industry. Newer technologies include precision optics, highly-controlled light distribution for general and task lighting applications, and incorporation of advanced control systems for thermal and energy management, among other innovations. Indoor lighting systems are tending to combine these developments. Thus, patents issued in this area are often of the "combination" type and generally have not prevented competition from adopting these new technologies.

A luminaire efficiency standard would probably tend to move the market from four-lamp fixtures to three- and two-lamp fixtures.

\subsubsection{Lighting Controls}

No adverse impacts are expected in the lighting controls market because a component standard that prohibits existing models or limits future choices of technology is not analyzed. The selected options-timers, occupancy sensors, dimmers, and daylight controls-are all products currently offered by many firms in the industry. Because all firms produce a broad variety of controls, specific legislation is not expected to harm any particular size of firm. Although some patented and innovative control chips and communications systems are becoming available, it is expected that these offerings will improve and expand the use of energy-saving controls for lighting rather than inhibit technology expansion. Care must be taken in designing controls features in building codes, or imposing mandatory switching requirements, to avoid adverse impacts on controls manufacturers. 4

\subsection{IMPACT ON PRICES AND PRODUCT LIFE}

In this section, the impact of selected technology options on prices and product life is examined because these two variables influence sales and firm profitability. If an option has a significantly shorter lifetime than currently-available choices, consumers will tend to react negatively, which will affect the sales and payback of that option. An extreme shift in prices could also negatively affect sales. Tables 3.7, 3.9, and 3.11 present the costs and service lives for fluorescent and incandescent lamps, respectively, for the baseline and for each technology option. In no instance is the lifetime of the product adversely affected by any of the proposed options. In fact, in certain cases, such as the halogen and halogen infrared reflector lamp, lifetimes are longer than those of the baseline.

For incandescent lamps, marginal changes are projected in lamp prices to consumers for the reduced-wattage option, medium changes for halogen lamps, and larger changes for the halogen reflector and coated filament lamps. Larger variations from the baseline for fluorescent lamps

\footnotetext{
${ }^{4}$ Switching requirements are not present in the two national codes modeled in this study. Occupancy sensor manufacturers objected to California's Title 24 two-level switching requirement and an exemption was added for lighting controlled by occupancy sensors.
} 
are observed. In any case, lighting equipment is believed to be a relatively inelastic market (with the exception of controls) and the projected policy-induced price increases would probably not have a significant impact on shipments.

\subsection{CONCLUSIONS}

Overall, the technology options being considered for incandescent and fluorescent lamps and lighting fixtures are not expected to have any long-term adverse impact on the industries involved. For lamps, this evaluation is based on the relatively high market concentration, lack of patents or other significant barriers on technology distribution, efforts already underway in converting existing plants to produce the technology options under consideration (except for Tax Tech or R\&D options), the likely low elasticity of demand in the lamp market, and the lack of adverse impact on product lifetimes. Although the fixture market is not as concentrated as the lamp market, excess capacity in the industry will likely lead to further industry consolidation. Aside from market concentration, the other market factors present in the lamp industry are also common to the fixture industry.

In any industry, all other factors being equal, the adoption of a policy that would require retooling of existing plants and equipment is likely to affect smaller firms more adversely than larger firms. This is because smaller firms are at a disadvantage in resources (e.g., financial, engineering, managerial, etc.) in contrast to larger firms. In the lamp industry, this effect is mitigated by the fact that the industry is already converting existing plants and equipment. In addition, the three largest firms have such a large market share that any impact on competition or pricing as a result of smaller firms leaving the industry would probably be negligible.

In the fixture/luminaire industry, there are a greater number of small firms, but the lingering excess capacity would probably cause firms to leave the industry in the future anyway. The adoption of fixture standards may hasten this process slightly. There is also the possibility that smaller firms might be more innovative in developing energy efficient products. If this is the case, they would not be as adversely affected by standards and might even benefit.

Controls manufacturers would not be adversely affected by lighting efficiency policies. They may benefit because the incentives for use of controls would likely increase sales in certain segments of the market. 


\section{IMPACTS OF POLICIES ON ELECTRIC PEAK DEMAND}

\subsection{COMMERCIAL SECTOR}

\subsubsection{Lighting}

Peak demand reductions for commercial lighting are calculated using the concept of conservation load factor (CLF). ${ }^{1}$ The CLF is equal to the annual average load savings from a conservation measure, divided by the reduction in electricity demand at the time of utility system peak demand. The CLF is calculated using appropriate lighting load curves as described below. Approximations are developed to account for imperfect coincidence between lighting demand and utility system peak demand.

To calculate the CLF requires two components: the annual energy savings $(\mathrm{kWh})$ and the peak load savings (kW) as the numerator and denominator of the ratio. Peak demand is the average of electricity demand during the defined peak hours.

The quantity CLF $\times 8,760$ is equal to the amount of energy savings required to reduce a unit of peak demand. For example, a CLF of 0.5 implies $4,380 \mathrm{kWh}(0.5 \times 8,760)$ of energy savings results in $1 \mathrm{~kW}$ of peak demand savings. As CLF increases, peak demand becomes less sensitive to energy savings. In other words, a high CLF renders even significant energy savings ineffective in reducing peak demand.

To account for coincidence with utility system peak demand, the peak demand savings are averaged over the hours 9:00 a.m to 5:00 pm on the peak summer day (as defined by COMMEND). The summer peak day is chosen because for all North American Electric Reliability Council (NERC) regions of the U.S., the adjusted reserve margin is projected to be lower in the summer than in the winter for the next ten years. ${ }^{2}$

Results of lighting impacts on peak demand are shown in Tables 7.1 and 7.2. To simplify the calculations, the CLFs are determined for the savings from three different policy cases relative to the Low-Efficiency or High-Efficiency Baselines, ranging from small to large savings; these CLFs are nearly identical. The average CLFs are then applied to all other cases. For in the LowEfficiency policy cases, the CLF for lighting is $\mathbf{0 . 6 1}$, and for the High-Efficiency policy cases, the CLF is 0.60 .

\footnotetext{
${ }^{1}$ Koomey, Jonathan G., Arthur H. Rosenfeld, and Ashok K. Gadgil. 1990. "Conservation Screening Curves to Compare Efficiency Investments to Power Plants." Energy Policy, vol. 18, no. 8. p. 774.

${ }^{2}$ U.S. DOE. 1990. Staff Report: Electric Power Supply and Demand for the Contiguous United States 1989. 1998. DOE/IE-0018.
} 


\subsubsection{Cooling}

The CLF for cooling is 0.28 for both the High-Efficiency and Low-Efficiency Baselines, calculated using the same policies and technique as for the lighting CLFs.

Effects of lighting savings in the commercial sector are more complicated than in the residential sector because of the interactions between lighting and cooling energy use. See Appendix $\mathrm{H}$ for discussion of uncertainties regarding lighting/HVAC interactions, and for impacts of the cooling interactions on peak load.

\subsection{RESIDENTIAL SECTOR}

\subsubsection{Lighting}

Peak demand reductions for residential lighting are also calculated using the CLF and a conservation load factor of 1.04, which is determined using LBL's Hourly and Peak Demand Model. ${ }^{3}$ This calculation assumes national average lighting load shapes. It also assumes that averaging peak demand over the 250 hours with the highest residential loads yields a reasonable approximation to the demand reductions at the time of utility system peak demand. Note that the CLF is higher than that of the commercial sector, because most residential lighting occurs during off-peak hours in the U.S. Results of lighting impacts on peak demand are shown in Tables 7.3 and 7.4 .

\subsubsection{Cooling}

Peak demand reduction calculations for lighting/cooling interactions use a CLF of 0.15 .

As with the commercial sector, heating and cooling interactions are uncertain. See Appendix $H$ for further discussion of residential HVAC interactions and impacts of the cooling interactions on peak load.

\footnotetext{
${ }^{3}$ Ruderman, Henry and Mark D. Levine. 1984. "The Residential Hourly and Peak Demand Model: Description and Validation." Lawrence Berkeley Laboratory. LBL-18698.
} 
Table 7.1 Commercial Lighting Peak Demand Reductions Relative to High-Efficiency Baseline, as of Year Shown (Gigawatts)

\begin{tabular}{|c|c|c|c|c|c|c|c|}
\hline Policy & 2000 & 2005 & 2010 & 2015 & 2020 & 2025 & 2030 \\
\hline High-Emciency Baseline Peak Demand & 47 & 51 & 55 & 60 & 65 & 70 & 76 \\
\hline \multicolumn{8}{|l|}{ Individual Component Standards } \\
\hline \multicolumn{8}{|l|}{ Fluorescent Lamp Standards } \\
\hline Eliminate Highest Wattage * & 2 & 4 & 5 & 6 & 6 & 7 & 7 \\
\hline Minimum Life Cycle Cost & 4 & 7 & 8 & 9 & 10 & 10 & 11 \\
\hline Maximum Technology & 5 & 10 & 11 & 12 & 13 & 14 & 16 \\
\hline$R \& D$ & 6 & 11 & 13 & 14 & 16 & 17 & 18 \\
\hline Min. LCC Lamp/Ballast & 5 & 10 & 12 & 13 & 14 & 15 & 16 \\
\hline \multicolumn{8}{|l|}{ Incandescent Lamp Standards } \\
\hline Eliminate Highest Wattage & 3 & 5 & 6 & 7 & 7 & 8 & 8 \\
\hline Minimum Life Cycle Cost & 3 & 6 & 8 & 7 & 8 & 9 & 9 \\
\hline Maximum Technology & 3 & 6 & 7 & 8 & 9 & 9 & 10 \\
\hline R \& D & 5 & 8 & 10 & 11 & 12 & 13 & 14 \\
\hline Compact Fluorescent Downlights & 3 & 5 & 6 & 7 & 7 & 8 & 8 \\
\hline 1991 Proposed Standards (Inc. Lamps) & 3 & 5 & 6 & 7 & 7 & 8 & 9 \\
\hline Energy Policy Act, 1992 (Inc. Lamps) & 3 & 5 & 6 & 7 & 7 & 8 & 8 \\
\hline \multicolumn{8}{|l|}{ Fixtures } \\
\hline Luminaire Efficiency Standard & 4 & 7 & 8 & 9 & 9 & 10 & 11 \\
\hline Maximum Technology & 5 & 9 & 11 & 12 & 13 & 14 & 15 \\
\hline \multicolumn{8}{|l|}{ Controls } \\
\hline Timers & 4 & 8 & 9 & 10 & 11 & 12 & 13 \\
\hline $\mathrm{T}+$ Lumen Maintenance & 5 & 10 & 12 & 13 & 14 & 15 & 16 \\
\hline$T+L M+$ Occupancy Sensors & 6 & 12 & 14 & 15 & 17 & 18 & 20 \\
\hline \multicolumn{8}{|l|}{ Combination Standards and Policies } \\
\hline \multicolumn{8}{|l|}{ Mandatory Component Standards } \\
\hline 1991 Proposed Standards (Fl. \& Inc. Lamps) & 3 & 6 & 7 & 7 & 8 & 9 & 9 \\
\hline Energy Policy Act, 1992 (Fl. \& Inc. Lamps) & 3 & 5 & 6 & 7 & 8 & 8 & 9 \\
\hline Min. LCC Fl. \& Inc. Lamps & 4 & 8 & 9 & 10 & 10 & 12 & 13 \\
\hline Min. LCC Fl. L/B \& Inc. Lamps & 6 & 11 & 13 & 14 & 15 & 16 & 18 \\
\hline Min. LCC Combination & 12 & 22 & 26 & 29 & 32 & 34 & 37 \\
\hline R\&D Combination & 16 & 29 & 34 & 38 & 41 & 45 & 49 \\
\hline \multicolumn{8}{|l|}{ Voluntary Component Standards } \\
\hline Min. LCC Fl. \& Inc. Lamps & 0 & 1 & 5 & 9 & 11 & 12 & 12 \\
\hline Min. LCC Fl. L/B \& Inc. Lamps & 0 & 2 & 8 & 13 & 15 & 16 & 18 \\
\hline Min. LCC Combination & 0 & 4 & 16 & 27 & 31 & 34 & 37 \\
\hline \multicolumn{8}{|l|}{ Building Codes } \\
\hline ASHRAE/IES 90.1 (Partial Compliance) & 3 & 5 & 6 & 7 & 7 & 8 & 8 \\
\hline DOE-1993 (Partial Compliance) & 4 & 7 & 8 & 9 & 10 & 10 & 11 \\
\hline ASHRAE/IES 90.1 (Full Compliance) & 3 & 6 & 7 & 8 & 8 & 9 & 10 \\
\hline DOE-1993 (Full Compliance) & 6 & 11 & 13 & 14 & 15 & 17 & 18 \\
\hline
\end{tabular}

* Energy Policy Act, 1992 (Fluorescent Lamps) 
Table 7.2 Commercial Lighting Peak Demand Reductions Relative to Low-Efficiency Baseline, as of Year Shown (Gigawatts)

\begin{tabular}{lrrrrrrr}
\hline Policy & 2000 & 2005 & 2010 & 2015 & 2020 & 2025 & 2030 \\
\hline Low-Emciency Baseline Peak Demand & 51 & 59 & 66 & 72 & 78 & 85 & 93 \\
Individual Component Standards & & & & & & &
\end{tabular}

Fluorescent Lamp Standards

Eliminate Highest Wattage *

Minimum Life Cycle Cost

Maximum Technology

R \& D

Min. LCC Lamp/Ballast

$\begin{array}{rllllll}6 & 11 & 14 & 15 & 16 & 18 & 19 \\ 8 & 15 & 18 & 20 & 22 & 24 & 26 \\ 9 & 18 & 22 & 24 & 26 & 29 & 31 \\ 10 & 20 & 24 & 27 & 29 & 32 & 35 \\ 10 & 18 & 23 & 25 & 27 & 30 & 32\end{array}$

Incandescent Lamp Standards

Eliminate Highest Wattage

Minimum Life Cycle Cost

Maximum Technology

$R$ \& D

Compact Fluorescent Downlights

1991 Proposed Standards (Inc. Lamps)

Energy Policy Act, 1992 (Inc. Lamps)

$\begin{array}{lllllll}6 & 12 & 15 & 17 & 18 & 20 & 21\end{array}$

$\begin{array}{lllllll}7 & 13 & 17 & 18 & 19 & 21 & 23\end{array}$

$\begin{array}{lllllll}7 & 14 & 17 & 19 & 20 & 22 & 24\end{array}$

$\begin{array}{lllllll}9 & 17 & 20 & 22 & 25 & 27 & 29\end{array}$

$\begin{array}{lllllll}6 & 12 & 15 & 17 & 18 & 20 & 21\end{array}$

$\begin{array}{lllllll}6 & 12 & 15 & 17 & 18 & 20 & 22\end{array}$

Fixtures

Luminaire Efficiency Standard

Maximum Technology

$\begin{array}{lllllll}9 & 14 & 18 & 20 & 21 & 23 & 25\end{array}$

Controls

Timers

$T+$ Lumen Maintenance

$T+L M+$ Occupancy Sensors

$\begin{array}{lllllll}6 & 12 & 15 & 17 & 18 & 20 & 22\end{array}$

Combination Standards and Policies

Mandatory Component Standards

1991 Proposed Standards (Fl. \& Inc. Lamps)

Energy Policy Act, 1992 (Fl. \& Inc. Lamps)

Min. LCC Fl. \& Inc. Lamps

Min. LCC Fl. L/B \& Inc. Lamps

Min. LCC Combination

$R \& D$ Combination

$\begin{array}{rllllll}7 & 13 & 17 & 18 & 20 & 22 & 24 \\ 7 & 13 & 16 & 18 & 19 & 21 & 23 \\ 9 & 16 & 20 & 22 & 23 & 26 & 29 \\ 11 & 20 & 25 & 27 & 30 & 33 & 35 \\ 17 & 31 & 38 & 42 & 46 & 50 & 54 \\ 20 & 38 & 46 & 50 & 55 & 60 & 66\end{array}$

Voluntary Component Standards

Min. LCC Fl. \& Inc. Lamps

Min. LCC Fl. L/B \& Inc. Lamps

Min. LCC Combination

$\begin{array}{lllllll}0 & 2 & 11 & 21 & 24 & 26 & 29 \\ 0 & 2 & 14 & 26 & 29 & 32 & 35 \\ 0 & 5 & 23 & 41 & 47 & 51 & 56\end{array}$

Building Codes

$\begin{array}{llllllllll}\text { ASHRAE/IES } 90.1 \text { (Partial Compliance) } & & 6 & 12 & 15 & 16 & 18 & 19 & 21\end{array}$

DOE-1993 (Partial Compliance)

ASHRAE/ES 90.1 (Full Compliance)

$\begin{array}{ll}7 & 15\end{array}$

18

20

$\begin{array}{lll}22 & 23 & 26\end{array}$

DOE-1993 (Full Compliance)

$\begin{array}{lll}7 & 14 & 17\end{array}$

$\begin{array}{llll}18 & 20 & 22 & 24\end{array}$

$\begin{array}{lllllll}10 & 19 & 23 & 26 & 28 & 31 & 33\end{array}$

* Energy Policy Act, 1992 (Fluorescent Lamps) 
Table 7.3 Residential Lighting Peak Demand Reductions Relative to High-Efficiency Baseline, As of Year Shown (Gigawatts)

\begin{tabular}{llllllll}
\hline Policy & 2000 & 2005 & 2010 & 2015 & 2020 & 2025 & 2030 \\
\hline High-Emciency Baseline Peak Demand & 12.7 & 13.4 & 13.8 & 14.1 & 14.5 & 14.9 & 15.2 \\
& & & & & & & \\
Component Standards & & & & & & & \\
& & & & & & & \\
Eliminate Highest Wattage Incandescent & 0.5 & 0.6 & 0.6 & 0.6 & 0.6 & 0.6 & 0.7 \\
1991 Proposed Standards (Inc. Lamps) & 0.7 & 0.7 & 0.7 & 0.8 & 0.8 & 0.8 & 0.8 \\
Energy Policy Act, 1992 (Inc. Lamps) & 0.2 & 0.2 & 0.2 & 0.2 & 0.2 & 0.2 & 0.2 \\
Maximum Technology & 2.3 & 2.4 & 2.5 & 2.5 & 2.6 & 2.7 & 2.7 \\
R \& D & 7.1 & 7.5 & 7.7 & 7.9 & 8.1 & 8.3 & 8.5 \\
Compact Fluorescent & 2.1 & 2.2 & 2.3 & 2.3 & 2.4 & 2.4 & 2.5 \\
Min LCC Combination & 2.6 & 2.8 & 2.9 & 3.0 & 3.0 & 3.1 & 3.2 \\
R \& D Combination & 7.1 & 7.6 & 7.8 & 8.0 & 8.2 & 8.4 & 8.6 \\
Eliminate Highest Wattage Fluorescent & 0.1 & 0.2 & 0.2 & 0.2 & 0.2 & 0.2 & 0.2 \\
Energy Policy Act, 1992 (Inc. + Fluor.) & 0.3 & 0.4 & 0.4 & 0.4 & 0.4 & 0.4 & 0.4 \\
& & & & & & & \\
\hline
\end{tabular}

Table 7.4 Residential Lighting Peak Demand Reductions Relative to Frozen-Efficiency Baseline, As of Year Shown (Gigawatts)

\begin{tabular}{lrrrrrrr}
\hline Policy & 2000 & 2005 & 2010 & 2015 & 2020 & 2025 & 2030 \\
\hline Frozen-Emiency Baseline Peak Demand & 15.3 & 16.2 & 16.6 & 17.1 & 17.5 & 17.9 & 18.4 \\
& & & & & & & \\
Component Standards & & & & & & & \\
& & & & & & & \\
Eliminate Highest Watlage Incandescent & 1.7 & 1.8 & 1.8 & 1.9 & 1.9 & 1.9 & 2.0 \\
1991 Proposed Standards (Inc. Lamps) & 1.9 & 2.0 & 2.0 & 2.1 & 2.1 & 2.2 & 2.2 \\
Energy Policy Act, 1992 (Inc. Lamps) & 0.4 & 0.4 & 0.4 & 0.4 & 0.4 & 0.4 & 0.5 \\
Maximum Technology & 4.0 & 4.2 & 4.3 & 4.4 & 4.5 & 4.6 & 4.8 \\
R \& D & 9.7 & 10.3 & 10.5 & 10.8 & 11.1 & 11.3 & 11.6 \\
Compact Fluorescent & 4.0 & 4.3 & 4.4 & 4.5 & 4.6 & 4.8 & 4.9 \\
Min LCC Combination & 5.3 & 5.6 & 5.8 & 5.9 & 6.1 & 6.2 & 6.4 \\
R \& D Combination & 9.8 & 10.4 & 10.6 & 10.9 & 11.2 & 11.5 & 11.7 \\
Eliminate Highest Watlage Fluorescent & 0.1 & 0.2 & 0.2 & 0.2 & 0.2 & 0.2 & 0.2 \\
Energy Policy Act, 1992 (Inc. + Fluor.) & 0.5 & 0.6 & 0.6 & 0.6 & 0.6 & 0.6 & 0.6 \\
& & & & & & & \\
\hline
\end{tabular}




\section{ENVIRONMENTAL IMPACTS}

\subsection{INTRODUCTION}

This section describes the environmental impacts resulting from the lighting policies studied in this report. Reductions in sulfur oxides (listed in equivalent weight of sulfur dioxide, $\mathrm{SO}_{2}$ ), nitrogen oxides $\left(\mathrm{NO}_{\mathrm{x}}\right)$, and carbon dioxide $\left(\mathrm{CO}_{2}\right)$ are presented.

The lighting efficiency policies studied will generally decrease air pollution by decreasing future energy demand. Carbon dioxide $\left(\mathrm{CO}_{2}\right)$ emissions from fossil-fuel burning are considered an environmental hazard because they contribute to the "greenhouse effect" by trapping heat energy from the earth that is emitted as infrared radiation. The greenhouse effect is expected to gradually raise the mean global temperature.

The effects on particulate emissions related to a standard-induced decrease in electricity generation would be minor compared to effects on decreases in $\mathrm{SO}_{2}, \mathrm{NO}_{\mathrm{u}}$, and $\mathrm{CO}_{2}$. For example, in 1984, power plants contributed only 7 percent of U.S. total particulate emissions; however, they contributed 83 percent of total $\mathrm{SO}_{2}$ emissions and 34 percent of $\mathrm{NO}_{2}$ emissions. Although the reduction in particulate emissions would be relatively small, any reduction would probably reduce acid deposition and thus be beneficial to improving the quality of groundwater.

Reductions in particulate emissions accompanied by decreases in $\mathrm{SO}_{2}$ and $\mathrm{NO}_{\mathrm{x}}$ would have other beneficial effects on the environment. The resultant improvement to air quality and the decreased potential of acid rain formation would help improve the quality of woodlands, reduce harm to fish and wildlife and aid in the preservation of historical and archaeological sites.

\subsection{METHODS OF ESTIMATING ENVIRONMENTAL IMPACTS}

Projected emissions reductions for $\mathrm{SO}_{2}, \mathrm{NO}_{\mathrm{x}}$, and $\mathrm{CO}_{2}$ can be compared to U.S. power piant emissions for the year under consideration. In a report that accompanies the 1991 National Energy Strategy (NE), the impact on power plant emissions as a result of revisions to Title $\mathrm{V}$ of the 1990 Clean Air Act Amendments (i.e., H.R. 3030) is estimated.' In Title V of the Clean Air Act Amendments (P.L. 101-549), electric utilities are expected to employ several strategies to accelerate the reduction of $\mathrm{SO}_{2}$ and $\mathrm{NO}_{x}$ emissions. To reduce $\mathrm{NO}_{x}$ emissions, utilities are expected to add low $\mathrm{NO}_{\mathrm{x}}$ burners to many coal plants. The legislation requires that $\mathrm{NO}_{\mathrm{x}}$ emissions be reduced by two million tons by the year 2000 , but no emissions cap exists for $\mathrm{NO}_{\mathrm{x}}$. Therefore, as new units are added after $2000, \mathrm{NO}_{x}$ emissions will likely increase. To reduce $\mathrm{SO}_{2}$ emissions, utilities will modify their use of existing fossil-fuel plants, switch from high- to lowsulfur coal in coal plants that emit at a high rate, add flue-gas desulfurization units (scrubbers)

\footnotetext{
'Energy Information Administration. 1991. Improving Technology: Modeling Energy Futures for National Energy Straiegy. Service Report to the 1991 National Energy Strategy, DOE/EIA. S/NE/90-01.
} 
low-sulfur coal in coal plants that emit at a high rate, add flue-gas desulfurization units (scrubbers) to other plants, and buy emission rights from other utilities. As required by legislation, total $\mathrm{SO}_{2}$ emissions by utilities cannot exceed 8.9 million tons after December 31 , 2000. In the NES report, two possible outcomes are presented, a flexible case and a restricted case, to evaluate the effect of different degrees of emission nermit trading. The results presented for the two cases are virtually identical. Table 8.1 summarizes the U.S. power plant emission projections for the three pollutants under the assumptions made in the flexible case.

Table 8.1 U.S. $\mathrm{CO}_{2}, \mathrm{SO}_{2}$, $\mathrm{NO}_{\mathrm{x}}$ Electric Power Plant Emissions

\begin{tabular}{cccc}
\hline & $\mathrm{CO}_{2}$ & $\mathrm{SO}_{2}$ & $\mathrm{NO}_{\mathrm{x}}$ \\
Year & $10^{6}$ tons & $10^{6}$ tons & $10^{6}$ tons \\
\hline 1995 & 2,233 & 13.8 & 8.4 \\
2000 & 2,506 & 9.0 & 6.7 \\
2010 & 3,219 & 8.4 & 7.3 \\
2020 & 3,964 & 6.7 & 6.7 \\
2030 & 4,804 &. .4 & 4.8 \\
\hline
\end{tabular}

\subsubsection{Sulfur and Nitrogen Oxide Emissions}

To capture the effects of cleaner-burning power plants in future years, emission rates (tons/Quad) from fuel burned in power plants are calculated from projected emissions and electrical generation data (Table 8.2). The source of projec ${ }^{*} \mathrm{~d}$ emissions and electrical generation data is the report that accompanies the 1991 National Energy Strategy (data for Table 8.1 were extracted from the same report).

Table 8.2 Electrical Generation and Emissions Data and Emission Rates for $\mathrm{SO}_{2}$ and $\mathrm{NO}_{x}$ at FossilFuel-Burning Power Plants

\begin{tabular}{|c|c|c|c|c|c|c|}
\hline \multirow[b]{3}{*}{ Year } & \multicolumn{3}{|c|}{ Electrical Gelic ation } & \multirow{2}{*}{$\begin{array}{c}\text { Energy Use } \\
\text { Total }\end{array}$} & \multicolumn{2}{|c|}{ Emissions Rates } \\
\hline & Coal & Oil & Gas & & $\mathrm{SO}_{2}$ & $\mathrm{NO}_{x}$ \\
\hline & $10^{9} \mathrm{kWh}$ & $10^{9} \mathrm{kWh}$ & $10^{9} k W h$ & Quads & $10^{3}$ tons/Quad & $10^{3}$ tons/Quad \\
\hline 1995 & 1,602 & 194 & 442 & 26 & 553 & 336 \\
\hline 2000 & 1,814 & 180 & 605 & 30 & 310 & 231 \\
\hline 2010 & 2,661 & 150 & 483 & 38 & 229 & 199 \\
\hline 2020 & 3,728 & 67 & 292 & 47 & 147 & 147 \\
\hline 2030 & 4,837 & 29 & 179 & 58 & 85 & 105 \\
\hline
\end{tabular}


Calculated emissions rate data listed in Table 8.2 represent the average $\mathrm{SO}_{2}$ and $\mathrm{NO}_{\mathrm{x}}$ emissions rates for all fossil-fuel-burning power plants in the United States. To obtain emission rate values, emissions are divided by the total energy use of fossil-fuel-burning power plants. The total energy use of fossil-fuel-burning power plants is calculated from the electrical generation data supplied by the report accompanying the $1991 \mathrm{NE}$. To obtain total energy use (input), the electrical generation data from each fossil fuel are summed and then divided by the assumed efficiency of fossil-fuel-burning power plants ( 32 percent).

The $\mathrm{SO}_{2}$ and $\mathrm{NO}_{\mathrm{x}}$ emissions abated for any particular year are determined by multiplying the estimates of energy saved through reduced electricity generation in that year by the emission rate for that particular year. For years not covered in the 1991 report, linear interpolation is used to derive emission rates and the corresponding abated emissions.

Because of provisions in the Clean Air Act Amendments (Pub. L. 101-549, November 15, 1990), the possible reductions of $\mathrm{SO}_{2}$ reported here can be earned as credits by the utility realizing the reductions. Those credits can be banked or traded to another utility. To the extent $\mathrm{SO}_{2}$ credits are used for future emissions, the net effect on $\mathrm{SO}_{2}$ emissions would be only a postponement of those $\mathrm{SO}_{2}$ emissions.

\subsubsection{Carbon Dioxide Emissions}

Emission rates for carbon dioxide are derived using the same method as that used to derive emissions of $\mathrm{SO}_{2}$ and $\mathrm{NO}_{\mathbf{x}}$. As presented in Table 8.1, the report accompanying the 1991 National Energy Strategy (NE) also provides emissions data with regard to $\mathrm{CO}_{2}{ }^{2}{ }^{2}$ Table 8.3 presents the $\mathrm{CO}_{2}$ emission rate data as derived from the electrical generation data and emissions data supplied by the $1991 \mathrm{NE}$ report.

\footnotetext{
2In personal communication with David Streets at Argonne National Laboratory (February 1992), it was determined that the carbon emissions data provided in the report accompanying the $1991 \mathrm{NE}$ were mistakenly reported as tons of carbon emitted. David Streets was one of authors at Argonne who contributed to the 1991 NE report.
} 
Table 8.3 Electrical Generation Data, Emissions Data, and Emissions Rates for $\mathrm{CO}_{2}$ at Fossil-Fuel-Burning Power Plants

\begin{tabular}{ccccc|c|cc} 
& \multicolumn{3}{c|}{ Electrical Generation } & \multirow{2}{*}{ Energy Use Total } & Emission $\mathrm{CO}_{2}$ & Emission Rate $\mathrm{CO}_{2}$ \\
\cline { 2 - 4 } Year & $10^{\circ} \mathrm{kWh}$ & $10^{\circ} \mathrm{kWh}$ & $10^{\circ} \mathrm{kWh}$ & Quads & $10^{\circ}$ tons & $10^{\circ}$ tons/Quad \\
\hline 1995 & 1,602 & 194 & 442 & 26 & 2,233 & 89 \\
2000 & 1,814 & 180 & 605 & 30 & 2,506 & 86 \\
2010 & 2,661 & 150 & 483 & 38 & 3,219 & 88 \\
2020 & 3,728 & 67 & 292 & 47 & 3,964 & 87 \\
2030 & 4,837 & 29 & 179 & 58 & 4,804 & 85 \\
\hline
\end{tabular}

As with the $\mathrm{SO}_{2}$ and $\mathrm{NO}_{\mathrm{x}}$ emissions, the $\mathrm{CO}_{2}$ emissions abated in any particular year are determined by multiplying the estimates of energy saved through reduced electricity generation by the emission rate for that particular year. For years not covered in the 1991 report, linear interpolation is used to derive emission rates and the corresponding abated emissions.

\subsection{RESULTS}

Tables 8.4 to 8.7 indicate the extent to which various lighting policy cases reduce the amounts of $\mathrm{SO}_{2}, \mathrm{NO}_{x}$, and $\mathrm{CO}_{2}$ emitted by electric power plants. 
Table 8.4 Environmental Impacts of Selected Commercial Lighting Policy Cases,

High-Efficiency Baseline, 1995 to 2030

\begin{tabular}{|c|c|c|c|c|c|c|c|c|c|}
\hline Policy & 1995 & 2000 & 2005 & 2010 & 2015 & 2020 & 2025 & 2030 & $\begin{array}{r}\text { Cumulative } \\
1995-2030\end{array}$ \\
\hline \multicolumn{10}{|l|}{ Baseline Emissions } \\
\hline \multicolumn{10}{|l|}{ No Programs Baseline } \\
\hline SO2 (thousand tons) & 1,795 & 1,092 & 998 & 937 & 819 & 714 & 597 & 491 & 32,573 \\
\hline NOx (thousand tons) & 1,093 & 813 & 803 & 814 & 759 & 714 & 654 & 603 & 27,842 \\
\hline $\mathrm{CO} 2$ (million tons) & 290 & 304 & 329 & 359 & 389 & 422 & 455 & 491 & 13,638 \\
\hline \multicolumn{10}{|l|}{ High-Efficiency Baseline } \\
\hline SO2 (thousand tons) & 1,509 & 860 & 784 & 736 & 641 & 557 & 465 & 381 & 25,791 \\
\hline NOx (thousand tons) & 918 & 640 & 631 & 639 & 594 & 557 & 509 & 468 & 21,973 \\
\hline $\mathrm{CO} 2$ (million tons) & 244 & 240 & 258 & 282 & 305 & 330 & 354 & 381 & 10,717 \\
\hline \multicolumn{10}{|l|}{ Low-Efficiency Baseline } \\
\hline SO2 (thousand tons) & 1,507 & 947 & 567 & 899 & 786 & 685 & 573 & 471 & 28,185 \\
\hline NOx (thousand tons) & 917 & 705 & 456 & 781 & 729 & 685 & 628 & 579 & 24,392 \\
\hline $\mathrm{CO} 2$ (million tons) & 244 & 264 & 187 & 345 & 374 & 405 & 437 & 471 & 12,201 \\
\hline \multicolumn{10}{|c|}{ Emission Reductions from High-Efriciency Baseline } \\
\hline \multicolumn{10}{|c|}{ Energy Policy Act, 1992 (Fl. \& Inc. Lamps) } \\
\hline SO2 (thousand tons) & 15 & 51 & 81 & 84 & 73 & 63 & 52 & 42 & 2,203 \\
\hline NOx (thousand tons) & 9 & 38 & 66 & 73 & 68 & 63 & 57 & 51 & 2,002 \\
\hline $\mathrm{CO} 2$ (million tons) & 2 & 14 & 27 & 32 & 35 & 37 & 40 & 42 & 1,053 \\
\hline \multicolumn{10}{|c|}{ Minimum LCC Combination } \\
\hline SO2 (thousand tons) & 62 & 219 & 92 & 263 & 337 & 311 & 261 & 215 & 8,299 \\
\hline NOx (thousand tons) & 38 & 163 & 74 & 229 & 312 & 311 & 286 & 264 & 7,790 \\
\hline $\mathrm{CO} 2$ (million tons) & 10 & 61 & 30 & 101 & 160 & 184 & 199 & 215 & 4,338 \\
\hline \multicolumn{10}{|l|}{ R \& D Combination } \\
\hline SO2 (thousand tons) & 81 & 59 & 101 & 312 & 410 & 380 & 320 & 263 & 9,001 \\
\hline NOx (thousand tons) & 50 & 44 & 81 & 272 & 380 & 380 & 350 & 324 & 8,682 \\
\hline $\mathrm{CO} 2$ (million tons) & 13 & 16 & 33 & 120 & 195 & 225 & 244 & 264 & 4,995 \\
\hline
\end{tabular}


Table 8.5 Environmental Impacts of Selected Commercial Lighting Policy Cases, Low-Efficiency Baseline, 1995 to 2030

\begin{tabular}{|c|c|c|c|c|c|c|c|c|c|}
\hline Policy & 1995 & 2000 & 2005 & 2010 & 2015 & 2020 & 2025 & 2030 & $\begin{array}{r}\text { Cumulative } \\
1995-2030\end{array}$ \\
\hline \multicolumn{10}{|l|}{ Baseline Emissions } \\
\hline \multicolumn{10}{|l|}{ No Programs Baseline } \\
\hline SO2 (thousand tons) & 1,795 & 1,092 & 998 & 937 & 819 & 714 & 597 & 491 & 32,573 \\
\hline NOx (thousand tons) & 1,093 & 813 & 803 & 814 & 759 & 714 & 654 & 603 & 27,842 \\
\hline $\mathrm{CO} 2$ (million tons) & 290 & 304 & 329 & 359 & 389 & 422 & 455 & 491 & 13,638 \\
\hline \multicolumn{10}{|l|}{ High-Efficiency Baseline } \\
\hline SO2 (thousand tons) & 1,509 & 860 & 784 & 736 & 641 & 557 & 465 & 381 & 25,791 \\
\hline NOx (thousand tons) & 918 & 640 & 631 & 639 & 594 & 557 & 509 & 468 & 21,973 \\
\hline $\mathrm{CO} 2$ (million tons) & 244 & 240 & 258 & 282 & 305 & 330 & 354 & 381 & 10,717 \\
\hline \multicolumn{10}{|l|}{ Low-Efficiency Baseline } \\
\hline SO2 (thousand tons) & 1,507 & 947 & 567 & 899 & 786 & 685 & 573 & 471 & 28,185 \\
\hline NOx (thousand tons) & 917 & 705 & 456 & 781 & 729 & 685 & 628 & 579 & 24,392 \\
\hline $\mathrm{CO} 2$ (million tons) & 244 & 264 & 187 & 345 & 374 & 405 & 437 & 471 & 12,201 \\
\hline \multicolumn{10}{|c|}{ Emission Reductions from Low-Efficiency Baseline } \\
\hline \multicolumn{10}{|c|}{ Energy Policy Act, 1992 (Fl. \& Inc. Lamps) } \\
\hline SO2 (thousand tons) & 14 & 116 & 194 & 207 & 219 & 159 & 133 & 109 & 5,585 \\
\hline NOx (thousand tons) & 8 & 87 & 156 & 180 & 203 & 159 & 146 & 135 & 5,113 \\
\hline $\mathrm{CO} 2$ (million tons) & 2 & 32 & 64 & 79 & 104 & 94 & 102 & 110 & 2,714 \\
\hline \multicolumn{10}{|c|}{ Minimum LCC Combination } \\
\hline SO2 (thousand tons) & 61 & 306 & 249 & 427 & 786 & 439 & 370 & 305 & 14,099 \\
\hline NOx (thousand tons) & 37 & 228 & 201 & 371 & 729 & 439 & 405 & 375 & 13,132 \\
\hline $\mathrm{CO} 2$ (million tons) & 10 & 85 & 82 & 164 & 374 & 260 & 282 & 305 & 7,162 \\
\hline \multicolumn{10}{|l|}{ R \& D Combination } \\
\hline SO2 (thousand tons) & 80 & 373 & 933 & 476 & 521 & 508 & 428 & 353 & 17,625 \\
\hline NOx (thousand tons) & 49 & 277 & 751 & 414 & 483 & 508 & 469 & 434 & 15,994 \\
\hline $\mathrm{CO} 2$ (million tons) & 13 & 104 & 307 & 182 & 248 & 301 & 326 & 354 & 8,419 \\
\hline
\end{tabular}




\section{COMPARISON WITH OTHER ESTIMATES OF POTENTIAL LIGHTING ENERGY SA VINGS}

\subsection{ACHIEVING MEANINGFUL COMPARISONS}

This section compares the results of this study with five other estimates of potential lighting energy savings. These examples include analyses by the DOE's Energy Information Administration, the American Council for an Energy-Efficient Economy, E-Source, the Electric Power Research Institute, and the position statement of the U.S. government (U.S. State Department) in the international negotiations prior to the UNCED conference.

A myriad of factors influence these savings estimates, and variations from study to study (and sometimes inadequate documentation) confound attempts at comparisons. Relevant factors include the sectoral coverage, technologies considered, operating hours, penetration rates, illumination levels, econometric assumptions, and treatment of interactions among measures.

Equally important is the chosen baseline (plus base year and ending year). Valid comparisons depend, in part, on the selection of cases with analogous baselines. Furthermore, although baselines' qualitative specification (e.g. technical potential) may be comparable, they can differ markedly as a result of underlying assumptions such as floorspace growth. Studies estimating a static "overnight" conversion to efficient technologies circumvent these concerns (EIA, E-Source), but fail to yield absolute energy-use numbers that are relevant to future years.

Valid comparisons also require similarities in the qualitative nature of the efficiency scenarios in question. This study includes two widely used scenario types. A technical potential scenario reflects full penetration of the most efficient technologies. This is represented by the "Research \& Development Combination" case, which includes technologies approaching commercialization. A maximum economic potential scenario reflects full penetration of technologies that are today commercially available and cost-effective. This is represented by the "Minimum Life-Cycle Cost Combination" case. In both cases, these potentials should be measured from a baseline in which no efficiency improvements are included. In Table 9.2 savings are calculated from the NoPrograms Baseline (and are also found in the right-hand columns of Table 4.6). ${ }^{1}$

In addition to the sources of differences cited above, the opportunities for comparisons between this study and other studies are very limited because:

\footnotetext{
${ }^{1}$ In Tables S-1 and (iii), the Low-Efficiency Baseline is used for technical potential and maximum economic potential, since NPVs are available for this baseline as well as savings. The savings are very close to those from the NoPrograms Baseline.
} 
- Although this study includes policy-related savings estimates compared to baselines with no efficiency improvements (see Sections 4 and 5), savings are also presented with respect to "market" baselines that are driven by energy price changes and existing lighting efficiency incentive programs. In most instances the other studies do not attempt to isolate policy-related savings from market trends.

- This study considers a far broader set of policy cases than previous analyses (e.g. the Energy Policy Act of 1992 and incentive and education/information programs). Most of these cases have no parallel for comparison in the other studies.

- This study extends farther into the future (2030) than other analyses.

Most other studies do not estimate savings in peak electrical power.

Given the aforementioned variables, comparisons of absolute (e.g. terawatt-hour) savings can have little meaning. In light of this, Table 9.1 expresses savings in percentage terms, while eliminating as many other confounding variables as possible. The most straight-forward comparison is among technical potential estimates. With two exceptions (both in the residential sector) the results of this study (64 percent residential, 71 percent commercial) are within about ten percentage points of the other studies.

\subsection{CRITICAL ASSUMPTIONS}

This section reviews sources of differences between this analysis and other projections.

Coverage. The LBL analysis covers interior lighting for the commercial sector, and interior and exterior lighting for the residential sector. (Data for commercial exterior lighting and industrial lighting are scarce, and a forecasting model for industrial lighting is not yet available.) Some other studies include all commercial, residential, and industrial lighting sectors. Table (i) provides a matrix of lighting technologies and sectors covered by this report.

Savings from HID lamps are not included in this analysis. (HID consumption for commercial indoor or residential lighting is relatively small, and the market is assumed to be moving towards more efficient sources.) Some other analyses include potential HID lamp policies for interior as well as exterior applications.

Technologies/Measures. For the commercial sector, a few efficient lighting measures are not included in this analysis because they would be hard to mandate either by component standards or building codes. Examples are: specular reflectors as retrofits in existing buildings, tandem wiring of fluorescent ballasts, dual-switching of fluorescent luminaires, and reduction of light levels. System design approaches, advanced daylighting design techniques, and future technology improvements from long-range $R \& D$ are also not included. For the residential sector, this analysis covers incandescent lamp standards, including CFL. substitution. It also covers the fluorescent lamp standards included in the Energy Policy Act of 1992. Timers, photocells, and other controls

$$
9-2
$$


Table 9.1 Comparison of Selected Lighting Studies and Savings Estimates (1)

\begin{tabular}{|c|c|c|c|c|c|c|}
\hline & This Study & EIA & State Dept. & ACEEE & E-Source & EPRI \\
\hline Year of study & 1992 & 1992 & 1992 & 1992 & 1988 & 1990 \\
\hline \multicolumn{7}{|l|}{ Timeframe } \\
\hline - Base Year & 1986 & 1986 & 1991 & 1991 & 1986 & 1987 \\
\hline - Ending Year & 2030 & $\begin{array}{r}\text { "overnight" } \\
\text { analysis }\end{array}$ & 2000 & 2010 & $\begin{array}{l}\text { "overnight" } \\
\text { analysis }\end{array}$ & 2000 \\
\hline \multirow[t]{2}{*}{ Type of Baseline } & Frozen & Not & & & Not & Frozen \\
\hline & Efficiency & Applicable & AEO '91 & AEO '91 & Applicable & Efficiency \\
\hline - Policy/Program Potential & $\mathrm{Y}$ & $\mathbf{N}$ & $\mathbf{Y}$ & $Y$ & $\mathrm{~N}$ & $\mathrm{~N}$ \\
\hline - Technical Potential & $\mathrm{Y}$ & $\mathbf{Y}$ & $\mathbf{Y}$ & $\mathrm{Y}$ & $\mathbf{Y}$ & $Y$ \\
\hline \multicolumn{7}{|l|}{ Technologies/Measures } \\
\hline \multicolumn{7}{|l|}{ - Lamps } \\
\hline Incandescent & $\mathrm{Y}$ & $\mathrm{Y}$ & $\mathbf{Y}$ & $Y$ & $Y$ & $Y$ \\
\hline Fluorescent & $\mathrm{Y}$ & $\mathrm{Y}$ & Y & $Y$ & Y & $\mathrm{Y}$ \\
\hline HID & $\mathrm{N}$ & $\mathrm{Y}$ & $\mathbf{Y}$ & $Y$ & $Y$ & $\mathrm{Y}$ \\
\hline - Ballasts & $\mathrm{Y}$ & Y & $\mathbf{Y}$ & $\mathbf{Y}$ & $Y$ & $\mathrm{Y}$ \\
\hline - Fixtures & $\mathrm{Y}$ & $\mathrm{N}$ & $\mathbf{Y}$ & Y & $\mathrm{Y}$ & $\mathrm{Y}$ \\
\hline - Reflectors & $\mathrm{N}$ & Y & $\mathbf{Y}$ & $\mathrm{Y}$ & Y & $\mathrm{Y}$ \\
\hline - Controls & $\mathrm{Y}$ & Y & Y & $\mathrm{Y}$ & Y & $\mathrm{Y}$ \\
\hline - Reduced Light Levels & $\mathrm{N}$ & $\mathbf{N}$ & $\mathrm{N}$ & $\mathbf{N}$ & $\mathbf{N}$ & Y \\
\hline \multicolumn{7}{|l|}{ Other Distinguishing Factors } \\
\hline \multicolumn{7}{|l|}{ - Separate Estimate of Savings } \\
\hline from "Market Trends" & $\mathrm{Y}$ & $\mathrm{N}$ & $\mathrm{N}$ & $\mathbf{N}$ & $\mathbf{N}$ & $Y$ \\
\hline - HVAC Interations Analyzed & $\mathrm{Y}$ & $\mathrm{N}$ & $\mathrm{N}$ & $\mathbf{N}$ & $\mathrm{Y}$ & ? \\
\hline - Fixture/Lamp/Ballast Thermal Factors & $\mathrm{Y}$ & $\mathrm{N}$ & $\mathrm{N}$ & $\mathbf{N}$ & $\mathbf{N}$ & $\mathbf{N}$ \\
\hline - Peak Electric Power Savings & $\mathrm{Y}$ & $\mathrm{N}$ & $\mathrm{N}$ & Y & $\mathrm{Y}$ & $\mathbf{N}$ \\
\hline - Economic Assessment & $\mathrm{Y}$ & $\mathbf{N}$ & $\mathbf{Y}$ & $\mathrm{Y}$ & $\mathrm{Y}$ & $\mathrm{N}$ \\
\hline \multicolumn{7}{|l|}{ Technical Potential Savings } \\
\hline in year shown (excl HVAC) & 2010 & 1986 & 2000 & 2010 & 1986 & 2000 \\
\hline - Total & & & & & $79 \%$ & \\
\hline - Residential & $64 \%$ & & $75 \%$ & $47 \%$ & & $40 \%$ \\
\hline - Commercial & $71 \%$ & $72 \%$ & $65 \%$ & $66 \%$ & & $60 \%$ \\
\hline - Industrial & & & incl. in com'l & $38 \%$ & & $49 \%$ \\
\hline
\end{tabular}

Note: $(\mathrm{Y})$ es and $(\mathrm{N}) \mathrm{o}$ entries correspond to the savings estimates that appear in this table and not necessarily to all cases presented in the given study. The Research \& Development Combination case run under the No-Programs Baseline is used to represent "This Study" in 2010. 
are not included due to difficulty of implementing a standard requiring them. Other studies, including an LBL residential sector supply curve analysis, use timer/photocell or occupancy sensor controls on exterior lights. ${ }^{2}$

Penetration Rates. For commercial sector component standards policy cases (including combinations), the efficient lamp or lamp/ballast technology is generally assumed to substitute for 100 percent of the standard technology in new or renovated buildings. (All lighting equipment stock is turned over in 12 years.) The major exception is the Compact Fluorescent Downlight policy, which assumes CFL retrofit in downlight fixtures, which represent 23 percent of the incandescent sockets in new construction and major renovation. This estimate assumes that higher wattage lamps (greater than 150 watts), specialty lamps, sockets controlled by dimmer switches, and lamps whose fixtures must be changed to efficiently accommodate CFLs would probably not be quickly retrofit. Other studies may assume higher penetration rates for compact fluorescents in an individual component case.

In contrast to the CFL Downlight case, the Minimum LCC Combination case retrofits 67 percent of incandescent sockets, representing downlights plus fixture retrofits (found to be cost-effective in the commercial sector); dimmer-controlled sockets are not retrofit. For the R\&D Combination case, dimmable CFLs are assumed to be used in sockets with dimmers, for a total CFL penetration rate of 90 percent.

For controls policy cases, the applicable floor area fractions and savings fractions may vary among analyses. In the LBL study, these fractions are calculated from manufacturer and LBL Lighting Systems Research Group estimates. Controls economics are analyzed and those options with positive NPVs are chosen for each building type. See Tables 3.19 and 3.20 for a summary of controls penetrations.

For the Luminaire Efficiency Standard policy case, the four-foot fluorescent fixture stock is replaced so that the weighted-average luminaire efficiency increases to meet the standard levels. For the Max Tech fixture case and the Min LCC and R\&D Combination cases, the efficient technology is assumed to penetrate 100 percent of the four-foot fluorescent fixture stock. See Tables 3.6, 3.8, 3.10, 3.13, 3.19, and 3.20 for details on the specific technologies assumed in each component standards policy case.

For the system performance standards and the incentive and information policies, penetration rates are difficult to determine. Under system performance standards, LPD limits can be met by a flexible variety of technology combinations. Savings estimates for incentive and information policies are also not technology-specific but assume overall efficiency improvements in the lighting equipment stock as a whole.

For the residential sector, CFLs are substituted only where screw-in retrofits are possible. For

\footnotetext{
${ }^{2}$ J.G. Koomey et al. 1991. "The Potential for Electricity Efficiency Improvements in the Residential Sector," Lawrence Berkeley Laboratory, Berkeley CA, LBL-30477.
} 
the CFL and the Minimum LCC Combination cases, the penetration rate of CFLs averages 50 percent. In the R\&D Combination case, 50 to 75 pencent CFL penetration is assumed, depending on the incandescent lamp type replaced. Fixture replacement is found not to be cost-effective in the residential sector, since no maintenance savings are assumed, residential CFL prices are higher than commercial prices, and annual lighting hours are lower than those for the commercial sector. Dedicated residential CFL fixtures are not considered in this analysis.

Prices. The engineering and economic analyses use current equipment prices. Other studies may assume that future prices for present state-of-the-art technologies will fall to levels at or below those of standard technologies. As explained in Appendix B, efficient technologies receive the same quantity discounts as do conventional technologies, while in practice these discounts are probably smaller for new products. This somewhat compensates for the possibility of significant future price drops, and is done since prices used represent costs for the 1995 to 2030 period.

HVAC Interactions. As elaborated in Appendix $\mathrm{H}$, heating and air-conditioning impacts are not included in the commercial and residential lighting electricity savings estimates presented in the main report. As discussed in Appendix H, the HVAC results from the forecasting models are considered less robust than the lighting energy estimates. Other studies may assume larger net cooling savings (offsetting the heating penalty) in addition to the lighting savings.

Time Period. For each sector, this study forecasts to the year 2030; other scenarios may project to 2010 or other end years. Savings are presented for five-year intervals and cumulatively for the period 1995 to 2030.

\section{Defining Economic Potential}

- Discount Rates. This report assumes a real discount rate of 4 percent for the commercial sector. This represents a social discount rate, and is used in the engineering analysis for selection of design options and in the economic analysis of NPVs of policy cases. For the residential sector, the real discount rate used in the engineering and economic analyses is 6 percent. Use of substantially different discount rates may result in the selection of different technologies in a minimum life-cycle-cost analysis.

- Cost of Conserved Energy. Some analyses, including supply-curve studies, use the cost of conserved energy (CCE) as a criteria for selection of technologies and the order in which they are implemented. In this study, CCE is calculated in the engineering tables (Appendix B), but is not used explicitly as a technology selection criterion.

\subsection{COMPARISONS WITH OTHER PROJECTIONS}

Topics described above are discussed in this section, while other factors, such as minor discrepancies between assumed wattages or efficiencies of some technologies, are not detailed.

Table 9.2 presents LBL's commercial sector consumption estimates under three baselines and 
savings estimates using Low-Efficiency Baseline projections compared with the No-Programs baseline as described in Section 9.1. Residential sector consumption from two baselines and savings measured from the Frozen-Efficiency Baseline are also presented.

Table 9.2 LBL Lighting Consumption and Savings, 2010

\begin{tabular}{|c|c|c|c|}
\hline & $\begin{array}{l}\text { Energy Savings, } \\
\text { Primary Quads }\end{array}$ & $\begin{array}{l}\text { Electricity Savings, } \\
\text { TWh }\end{array}$ & Percent Savings \\
\hline \multicolumn{4}{|l|}{ Commerclal Sector } \\
\hline $\begin{array}{l}\text { Technical Potential, } 2010 \\
\text { (R\&D Combination) }\end{array}$ & 3.0 & 259 & 71 \\
\hline $\begin{array}{l}\text { Maximum Economic Potential, } 2010 \\
\text { (Min LCC Combination) }\end{array}$ & 2.5 & 217 & 59 \\
\hline $\begin{array}{l}\text { Total Consumption } \\
\text { No-Programs Baseline } \\
\text { Low-Efficiency Baseline } \\
\text { High-Efficiency Baseline }\end{array}$ & $\begin{array}{l}4.2 \\
4.1 \\
3.3\end{array}$ & $\begin{array}{l}367 \\
352 \\
287\end{array}$ & \\
\hline \multicolumn{4}{|l|}{ Residential Sector } \\
\hline $\begin{array}{l}\text { Technical Potential, } 2010 \\
\text { (R\&D Combination) }\end{array}$ & 1.1 & 97 & 64 \\
\hline $\begin{array}{l}\text { Maximum Economic Potential, } 2010 \\
\text { (Min LCC Combination) } \\
\text { Total Consumption }\end{array}$ & 0.6 & 52 & 35 \\
\hline $\begin{array}{l}\text { Frozen-Efficiency Baseline } \\
\text { Low-Efficiency Baseline }\end{array}$ & $\begin{array}{l}1.1 \\
1.4\end{array}$ & $\begin{array}{l}152 \\
125\end{array}$ & \\
\hline
\end{tabular}

\subsubsection{EIA's Lighting in Commercial Buildings}

The Energy Information Administration report projects 28 to 79 percent lighting electricity savings from 1986 commercial indoor lighting consumption of $321 \mathrm{TWh}$. This assumes immediate ("overnight") replacement of existing stock with more efficient, commercially-available technologies. Savings from converting all incandescent lamps to CFLs equal 27 to 28 percent (90 to $93 \mathrm{TWh}$ ) of commercial lighting electricity, and a combination of lamp and ballast replacement, reflectors and delamping, and lighting controls saves 57 to 72 percent (183 to 231 TWh). Seventy-nine percent savings (254 TWh) results if in addition lighting levels are reduced by 25 percent. HVAC impacts are not included in these estimates.

The savings ranges above represent two scenarios, "modest" and "optimistic," which vary by type of technology and/or degree of application. Table 9.3 summarizes these scenarios. The two scenarios are applied to three equipment replacement schemes. The technologies applied in those schemes are presented in Table 9.4.

'DOE/EIA. 1992. Lighting in Commercial Buildings. Energy Information Administration, Washington DC, DOE/EIA-0555(92)/1. 
Table 9.3 ElA's Modest and Optimintic Scensrios

Modent

Ballars - Energy-efficient magnetic

Reflectors - 17-percent savings

Delamping -- 10-percent savings

Controls -- 10-percent savings

Optimistic

Ballasts - Eloctronic

Reflectors - 23-percent savings

Delamping -- 25-percent savings

Controls -- 30-percent savings

Note: Lamp replacement depends on the replacement scheme rather than the modest or optimistic scenario; see Table 9.4.

LBL's policy cases cover all schemes for lamps (with 90 percent CFL conversion instead of 100 percent). For ballasts, the baselines assume all new ballasts are energy-efficient magnetic (EIA modest scenario) beginning in 1991 when the federal standard takes effect; the Min LCC Lamp/Ballast case represents 100 percent conversion to electronic ballasts (EIA optimistic scenario) with $T-8$ lamps. For controls, savings fractions are specific to building types, ranging from to 23 to 69 percent in the Min LCC Combination and from 19 to 75 percent in the R\&D Combination case. LBL's analysis does not include reflectors and delamping.

LBL's technical potential savings of 71 percent in 2010 are similar to those from EIA's optimistic scenario. The LBL study does not model reduced lighting levels. 
Equipment Replacement Scheme

(3)

Comprehensive

(2) Improvement Without

(1) Compact Fluorescent Compact Fluorescent

\begin{tabular}{|c|c|c|c|c|}
\hline Lamp Type & Conservation Features & Comprehensive & Conversion Only & Conversions \\
\hline \multicolumn{5}{|l|}{ Incandescent } \\
\hline & Controls & $\mathbf{X}$ & & $x$ \\
\hline & Compect Fluorescent & $\mathbf{x}$ & $\mathbf{X}$ & \\
\hline & Reflector & $\mathbf{x}$ & $\mathbf{x}$ & \\
\hline & Energy-Efficient Bulb & & & $\mathbf{x}$ \\
\hline \multicolumn{5}{|l|}{ Fluorescent } \\
\hline & Controls & $\mathbf{X}$ & & $\mathbf{X}$ \\
\hline & High-Efficiency Ballast & $\mathbf{x}$ & & $\mathbf{x}$ \\
\hline & $\begin{array}{l}\text { Very-High Efficiency } \\
\text { Lamp }\end{array}$ & $\mathbf{X}$ & & $\mathbf{x}$ \\
\hline & Reflector & $\mathbf{x}$ & & $\mathbf{x}$ \\
\hline \multicolumn{5}{|l|}{$\begin{array}{l}\text { High-Intensity } \\
\text { Discharge (HID) }\end{array}$} \\
\hline & Controls & $\mathbf{x}$ & & $\mathbf{x}$ \\
\hline & High-Pressure Sodium & $\mathbf{x}$ & & $\mathbf{x}$ \\
\hline
\end{tabular}

$\mathrm{X}=$ Addition of or conversion to this feature is assumed under the indicated scheme, for all floorspace lighted by the indicated lamp type.

\section{EUIs and LPDS}

Lighting electricity consumption estimates begin from the assumption that 1986 buildings (NBECS survey) were lit to IES 1987 recommended lighting levels (see Table C.3 in Appendix

${ }^{4}$ Op. cit, Ref. 3, Figure 13, p. 29.

$9-8$ 
C). The highest footcandle values from the three-level range for various illuminance categories are chosen. From these lighting levels, LPDs (watts/sq $\mathrm{ft}$ ) are derived and mapped onto the NBECS building types. LPDs are multiplied by Effective Lighting Hours, the annual lighting operating hours calculated from the NBECS survey (see Section 2.1.2), to produce EUIs (kWh/sq ft/year) for each building type:

$$
\text { EUI }(\mathrm{kWh} / \mathrm{sq} \mathrm{ft} / \mathrm{yr})=\mathrm{LPD}(\mathrm{W} / \mathrm{sq} \mathrm{ft}) \times \text { Hours } / \text { Year } / 1000
$$

LBL's approach uses the same simple equation relating LPDs and EUIs. However, the LBL study is based on EUIs for indoor lighting estimated from conditional demand studies from several utility service territories. These EUIs are divided by Effective Lighting Hours (the same as EIA's) to yield LPDs by building type. (See Section 4.1 for detailed description of this process, and Appendix D tables for the results.)

Table 9.5 shows the resulting 1986 EUIs and LPDs for the LBL and the EIA study.

Table 9.5 Comparison of LBL and EIA LPDs and EUIs, 1986 (total floorspace)

\begin{tabular}{lcccc}
\hline Building Type & LPD (W/sq ft) & \multicolumn{2}{c}{ EU (kWh/sq ft-yr) } \\
\hline Small Office & LBL & EIA & LBL & EIA \\
Large Office & 1.53 & 1.8 & 5.51 & 6.1 \\
Restaurant & 1.15 & 1.8 & 4.16 & 6.1 \\
Retail & 1.13 & 0.7 & 5.81 & 3.2 \\
Grocery & 1.26 & 1.0 & 5.11 & 3.8 \\
Warehouse & 1.81 & 1.1 & 11.1 & 6.3 \\
School & 0.80 & 0.4 & 3.10 & 1.2 \\
College & 0.75 & 1.9 & 2.41 & 6.2 \\
Health & 1.56 & 1.9 & 4.98 & 6.2 \\
Lodging & 0.75 & 3.6 & 6.03 & 28.6 \\
\hline
\end{tabular}

Note that LPD differences vary considerably by building type; no consistent pattern emerges. LBL's EUIs differ from those built up from recommended lighting design levels. While conditional demand analyses are based on measured whole-building energy consumption data, the equations used to derive end-use (e.g. lighting) consumption are theoretical and difficult to validate. Likewise, EIA's assumption that IES lighting levels are representative of actual practice

\footnotetext{
'Kaufman, J.E. (ed.) 1987. IES Lighting Handbook, 1987 Application Volume, llluminating Engineering Society of North America, New York NY.
}

$$
\text { 9- } 9
$$


is difficult to validate with field data. Estimates of lighting levels in existing buildings are scarce, especially on the national level. Anecdotal evidence ranges from observations of overlighting to underlighting ${ }^{\prime}$ in commercial buildings.

Even though the highest of the three IES recommended levels for each building type are chosen, EIA's LPDs may be low. Some of the ASHRAE-90.1 and DOE-93 building code LPDs are higher than EIA's (or LBL's). EIA's LPDs assume that lighting systems are designed to IES lighting levels without providing extra initial light output to compensate for future lamp lumen depreciation. LBL's lodging and health LPDs appear especially low. EIA's EUIs for these building types are high; the assumption is that all their floorspace is lit all of the time, and that hospitals have high lighting levels. As discussed in Section 2.1, EIA's effective lighting hours, used in LBL's study, may be high. A limited amount of field audit data has been compared with both sets of LFDs and shows that both may be low.

\section{Penetrations}

EIA's study gives technical potential savings for the 1986 market share distribution of lighting equipment. Penetrations of efficient lighting technologies for each efficiency scenario, including CFLs, are 100 percent. LBL's baselines begin from 1986 technology market shares, partially based on NBECS 1986, and are calibrated to projected 1995 market shares (see Section 2.1.2). Penetrations of efficient technologies under most policies in the LBL study are 100 percent, but even in the R\&D Combination case CFL penetration is only 90 percent.

\section{Economics}

EIA's study does not perform economic analysis of the applied measures in either the modest or the optimistic scenario. However, technologies must be available commercially. The LBL study considers economics in the Min LCC policy cases, including the Combination case. The LBL Max Tech and R\&D policy cases use current prices for the economic analysis; the R\&D Combination case assumes future penetrations and prices for controls.

\subsubsection{U.S. Views on Global Climate Change}

"U.S. Views on Global Climate Change"7 was prepared as the position statement of the U.S. government in the international negotiations prior to the United Nations Conference on Environment and Development in Brazil in June 1992. This analysis represents a U.S. interagency consensus between various government agencies, $\mathrm{i}$ ssluding DOE and EPA, on the

\footnotetext{
'Personal communication, Hayden McKay, Hayden McKay Lighting Design, New York, NY, August 1992 (regarding lighting levels in federal buildings).

${ }^{7}$ U.S. Department of State, Bureau of Oceans and International Environmental and Scientific Affairs. 1992. "U.S. Views on Global Climate Change, April 1992."
} 
energy savings and greenhouse-gas emissions mitigation potential from several federal and utility programs. Programs related to lighting include utility DSM programs, EPA's Green Lights, the lighting provisions in the Energy Policy Act of 1992, and FEMP's Federal Relighting Initiative.

U.S. lighting electricity consumption baseline estimates are 508 TWh for the commercial plus industrial sectors, and 117 TWh for the residential sector year 2000 (from the Frozen-Efficiency Baseline in the National Energy Strategy.) In the U.S. residential sector Views study, technical potential improvement for all lighting is 65 percent for the commercial and industrial sectors and 75 percent for the residential sector. Of this technical potential, market penetration anticipated from the efficient technologies is projected at 25 to 62 percent for commercial/industrial and 27 percent for residential. The resulting commercialindustrial lighting electricity savings in the year 2000 are projected as 81 to $203 \mathrm{TWh}$ and residential savings as $23 \mathrm{TWh}$.

\subsubsection{ACEEE}

\section{Overall Lighting Savings Achievable Potential}

ACEEE' etimates achievable potential lighting electricity savings of $345 \mathrm{TWh}$ in the year 2010, including $186 \mathrm{TWh}$ from utility prograins, $87 \mathrm{TWh}$ from equipment standards, and $72 \mathrm{TWh}$ from commercial building codes. These savings represent 46 percent of total predicted lighting electricity use for all sectors (utility programs and equipment standards apply to all three sectors).

ACEEE's analysis first estimates savings from codes and standards, and then accounts for further savings from aggressive utility programs. The assumptions include adoption of ASHRAE-90.1 by all states by 1993 followed by a stricter building code in 1998, federal ballast standards mandating electronic ballasts in 1995, and federal lamp standards on fluorescent, incandescent, and HID lamps phasing in from 1993 to 1995 . (Note that following 1998 the commercial building code in effect is stricter than the DOE-93 code modeled by LBL.) In addition to savings from these codes and standards, further savings are achieved by comprehensive utility DSM programs that reach 70 percent participation rates in twenty years.

In contrast, LBL's High-Efficiency Baseline (most comparable to the 46-percent ACEEE estimate) assumes that presently-projected levels of utility DSM and other federal and state programs continue. Savings from building codes and lamp standards are calculated in addition to these programs. In LBL's study, existing commercial federal, state, and utility programs save 78 TWh, the DOE-93 standard with full compliance saves 54 TWh, and lamp standards save 44 TWh in the year 2010.

\footnotetext{
'S.M. Nadel, B.A. Atkinson, J.E. McMahon. 1993. "A Review of U.S. and Canadian Lighting Programmes for the Residential, Commencial, and Industrial Sectors," Energy--The International Journal (forthcoming).

${ }^{9}$ Achievable potential refers to that portion of technical potential savings that can be actually achieved through various market mechanisms and incentive programs.
} 
Differences between the two estimates arise from differences in savings from lamp standards (discussed below) as well as stricter building codes, more aggressive utility programs, and the inclusion of more measures (i.e. reflector retrofits and wiring and switching improvements) in ACEEE's estimates.

Note: In this source ACEEE and LBL also estimate technical potential for three sectors as reported in Table 9.1 under "ACEEE."

\section{Lamp Standards Analysis}

The American Council for an Energy-Efficient Economy (ACEEE) estimates savings for the lamp standards proposed for the original congressional energy legislation (1991 Proposed Standards, Incandescent and Fluorescent Lamps policy cases). ACEEE's 2010 commercial (interior and exterior) lighting electricity consumption is $466 \mathrm{TWh}$, residential is $128 \mathrm{TWh}$, and industrial is 149 TWh (from AEO 1992). HVAC interactions are not included in ACEEE's estimates. ${ }^{10}$

LBL's estimates are for the commercial indoor and residential sectors only, while ACEEE's also include commercial outdoor plus industrial lighting. In Table 9.6, LBL's savings are presented from the commercial and residential High-Efficiency Baselines, and represent the commercial 1991 Proposed Standards (F \& I Lamps) case added to the residential 1991 Proposed Standards (F \& I lamps) case." Note that savings in Table 9.6 are from totals covering different sectors.

Comparison between the two estimates is complicated. ACEEE provides electricity savings for efficient lamp retrofits in the years 2000 and 2010. As discussed in Section 2.1.2, the LBL analysis does not model fluorescent lamp retrofits on the actual schedule with which they occur due to limitations of COMMEND Version 3.2. In effect, LBL's analysis models lighting replacements in new construction and substantial renovation. In contrast, the primary effect of the fluorescent lamp standards is to retrofit the 34-watt lamp into existing buildings (with possibility of a future stricter standard that mandates more efficient sources replacing the first generation standard). As discussed in Section 3.2.4, the LBL study approximates this retrofit situation by using actual wattages rather than normalized wattages. While such an adjustment increases the magnitude of the savings, it cannot reduce the time period within which they occur. The lamp replacements occur fully by 2007 when the entire lighting equipment stock has turned over, rather than by 1998 when they would occur through lamp replacement under their estimated service life. Thus results are reported for the year 2010.

\footnotetext{
${ }^{10}$ Geller, H. and Nadel, S.M. 1992. "Consensus National Efficiency Standards for Lamps, Motors, Showerheads and Faucets, and Commercial HVAC Equipment." Proceedings of the ACEEE 1992 Summer Study on Energy Efficiency in Buldings, Washington DC, p. 6.71 .

"These savings are greater than those from the Energy Policy Act of 1992 F \& I Lamps Standards policy c ses; those standards do not cover incandescent general service lamps.
}

$9-12$ 
ACEEE's estimates are based on 1988 lamp shipments from the Bureau of Census (BOC). Their present and future baseline market shares are fairly consistent with those used by LBL (which are based in part on $1986 \mathrm{BOC}$ data). Efficient lamp technologies are assumed to replace the baseline technologies The fraction of lamps already complying or projected to comply without the standards are taken into account. This method roughly approximates the LBL baseline projections that estimate effects of existing programs. However, LBL's model further estimates consumer behavior based on energy prices, equipment prices, and the lamp standards using consumer discount rates and elasticities not considered in ACEEE's analysis.

Table 9.6 LBL and ACERE Lamp Standards Savinge, 2010

\begin{tabular}{lcc}
\hline Lamp Technology & ACEEE Savings, TWh & LBL Savings, TWh (C,R) \\
\hline Fluorescent & 24.6 & \\
Incandescent, GS & 4.6 & \\
Incandescent, Ref* & 3.3 & \\
Total Savings & $32.5 \quad(4 \%)$ & 35 \\
Total Consumption & 743 & 7.0 \\
1991 Proposed Lamp Standards, Commercial & & $42.7(10 \%)$ \\
1991 Proposed Lamp Standards, Residential & & 414 \\
Total Savings & & \\
Total Consumption & & \\
\hline
\end{tabular}

* ACEEE's incandescent reflector savings have been adjusted downwards from those in the published source, since a loophole has been found in the standards allowing one reduced-wattage reflector lamp model to be sold (the standards are intended to require the use of lamps with efficacies of halogen reflector lamps or better). ${ }^{12}$ LBL's analysis does not reflect this savings reduction.

\subsubsection{E-Source}

E-Source (formerly Competitek) estimates 91 percent lighting savings potential from commercial and industrial fluorescent lighting, and 81 percent from commercial incandescent lighting. ${ }^{13}$ For the residential sector, the incandescent savings potential is 74 percent. When HID savings (60 percent) are included, the total U.S. lighting savings potential is 79 percent (299 to $481 \mathrm{TWh}$ ). These savings represent an "overnight" equipment substitution consumption and do not include HVAC interactions. Total savings increase to nearly 93 percent by including HVAC interactions,

\footnotetext{
${ }^{12}$ Steve Nadel, ACEEE. Personal communication, December 1992.

${ }^{13}$ A. Lovins, and R. Sardinsky. 1988. The State of the Art: Lighting, E-Source, Boulder, CO.
} 
reduced ambient overlighting, wider use of task lighting, advanced fixture technologies, increased use of daylighting, and other lighting design and maintenance strategies. In contrast, LBL's commercial sector technical potential savings are 71 percent $(259 \mathrm{TWh})$ and residential potential are 64 percent (97 TWh) in the year 2010.

E-Source estimates sectoral lighting electricity consumption in 1986 of 214 to 315 TWh for commercial, ${ }^{14} 82$ to 131 TWh for residential, and 82 to 163 TWh for industrial. These ranges bracket the values assumed in this report, except for the industrial sector which is slightly below the lower bound estimated by E-Source (see Figure 1.1).

The commercial/industrial fluorescent savings include specular reflector retrofits, high-efficiency lamps, electronic tunable ballasts, timers, occupancy sensors, and daylighting/dimming controls. Of these measures, LBL's commercial R\&D Combination case includes all but the specular reflector retrofits and the tunable feature for electronic ballasts.

In the E-Source analysis, all commercial sector incandescents are replaced with CFLs, with the exception of high-wattage lamps (replaced by HIDs), exit signs (replaced by fluorescents), decorative lamps (replaced by krypton incandescents or CFLs) and specialty lamps (replaced by miniature halogen lamps). In LBL's R\&D Combination, 90 percent of commercial sector incandescents are replaced by CFLs. The remaining 10 percent includes high-wattage, decorative, and specialty lamps. Exit signs are not separately considered from other lamps.

E-Source's residential incandescent savings include replacement of general service incandescents with integral CFLs, reflector lamps with separable CFLs, and decorative lamps with krypton incandescents. LBL's residential R\&D Combination case includes partial replacement of general service and reflector lamps with CFLs, and replacement of the remainder with coated-filament (R\&D) lamps. Consumption of decorative lamps is not included in the LBL study.

In the E-Source analysis, improvements in controls (especially for non-fluorescent lights), room surface colors and furnishings, task lighting, fixtures, daylighting design, lighting levels, and maintenance practices can save up to 67 percent of the lighting energy remaining after the savings reported above. Most of these features are beyond the scope of LBL's analysis (see Executive Summary). The exception is controls, where programmable timers and occupancy sensor controls apply to incandescent as well as fluorescent lights.

\footnotetext{
${ }^{14}$ Does not include street lighting.
} 


\subsubsection{Electric Power Research Institute}

The Eiectric Power Research Institute has developed what they refer to as a "realistic" estimate of maximum energy savings potential for several end uses including lighting for each sector by the year 2000.15 Savings are measured with respect to a baseline that includes naturally occurring improvements in efficiency and the effects of mandated standards. The conservation scenarios are bracketed by an "optimistic" case in which a wide range of efficient commercially-available technologies are used universally and a "conservative" case that attempts to incorporate constraints such as restricted product applicability and equipment manufacturer infrastructure. To maintain comparability with the other savings estimates presented in this section, the values shown in Table 9.1 reflect potential improvement from EPRI's optimistic scenario measured with respect to 1987 efficiencies, i.e. including those savings embodied in EPRI's baselines.

\footnotetext{
${ }^{15}$ Electric Power Research Institute. 1990. "Efficient Electricity Use: Estimates of Maximum Energy Savings." EPRI Report CU-6746.
} 


\section{RESEARCH AND DEVELOPMENT NEEDS}

This section briefly discusses specific emerging technologies for improving the efficiency of lighting systems. New frontiers in lamp and fixture design are described along with daylighting technologies and design issues.

\subsection{ELECTRIC LIGHTING}

Prospects for future R\&D in the electric lighting area exist for both lamps and fixtures (some of which are discussed in Appendix A). For example:

1. Gas-discharge lamps operated at radio frequencies allow the elimination of electrodes and thereby offer improved efficiency and extended lifetime. In addition, elimination of the electrodes allows use of gases that would otherwise rapidly corrode electrodes.

2. Prototypes of a mercury-free HID lamp have been developed that attain high efficacies and good color rendition as well as environmental benefits from reduced waste-disposal problems. The "cluster lamp" is one such promising new lamp technology. Essentially a hybrid of gas-discharge and tungsten-halogen technology (with the tungsten atoms clustered in supersaturated vapor form), cluster lamps are several-times more efficient (50 to 60 lumens/watt) than traditional incandescent lamps and have the added desirable feature of small size.

3. New research on visual efficiency suggests that optimal use of scotopically-rich light sources may result in significant energy savings. This technology is based on the concept that spectral distribution can affect pupil size in similar illuminance levels. By tuning the light spectrum, it may be possible to improve visual acuity and depth of field at lower illumiance levels. Scotopically-rich lamps have not been developeed (aside from research prototypes), but some lamps with high color temperatures are relatively scotopically-rich. For example, based on a recently-developed model for estimating "pupil lumens", a 5,000 K tri-phosphor lamp uses 24 percent less energy to maintain equivalent pupil size as a standard cool-white fluorescent lamp.

4. Phosphor efficiency diminishes during lamp life and, as a result, so does light output. The mechanisms of reduced performance of both rare-earth phosphors and halophosphates are not yet well established. Development of advanced phosphors could result in lamps for which future lumen depreciation need not be accounted for in initial design light levels, thereby savings energy over the first part of the lamp's service life.

For fluorescent lamps, efficiency is influenced by the thermal environment surrounding the lamp. Fluorescent fixture manufacturers are beginning to address the thermal heat loads within the fixture that cause lamps to operate 10 to 15 percent below optimal efficacy for standard enclosed (full-size fluorescent) fixtures and as high as $\mathbf{2 0}$ percent for compact fluorescent fixtures. 


\subsection{DAYLIGHTING}

Daylighting design strategies can reduce electric lighting needs in perimeter spaces by 50 to 80 percent by using light from the sun and sky, admitted through windows or skylights, to offset electric lighting needs. If the luminous flux in a single square foot of sunlight could be evenly distributed inside a building, it could provide adequate daylight over an area of 200 square feet.

The technical challenge in developing daylighting designs that enhance energy efficiency is two-fold: (1) to intercept, redirect and control the available daylight, which is intrinsically a powerful but highly variable source of light, in a manner that meets lighting task needs in terms of quantity and quality, and (2) to use lighting controls in a manner that operates electric lighting systems to provide light when daylight is inadequate, thus reducing electric energy use and electric demand.

Despite the large energy and demand savings potentials of daylighting, few buildings today effectively utilize this resource. The primary reason is that designing and implementing a successful daylighting design requires the integration of several different building components and systems, e.g. glazing, shading, lighting controls, which must function effectively over a range of dynamic operating conditions. This represents a challenge not only to product manufacturers but to designers and builders who must successfully integrate heating, cooling and lighting systems into a design that is aesthetically acceptable as well as functional. To meet the challenge delineated above, research and innovation are needed in four areas:

1. New glazing and shading systems that manage and control light more effectively than existing products. These would include products that reject near-infrared energy in daylight boosting the efficacy of light to 200 lumens/watt; products that control the direction of light transmission so that daylight can be more evenly spread over a room rather than pooling near the windows; and products that modulate the intensity of transmitted light to control the variation between sunny and overcast conditions.

2. New lighting control products with improved sensors that effectively manage the electric lighting system output over a wide range of sun and sky conditions and for a changing set of interior task conditions.

3. Integrated envelope and lighting technologies where the components described above have been integrated into a complete functional system, reducing the effort needed by a designer to select and integrate currently disparate elements. These would also link HVAC systems, comfort sensors, and lighting sensors with smart controllers to "optimize" the overall building system operation to meet user-defined criteria.

4. Improved design tools that allow architects, lighting designers and engineers to quickly and effectively generate design solutions that meet all appropriate design and operational criteria. 


\section{APPENDIX A LIGHTING TECHNOLOGY OPTIONS}

\section{A.1 INTRODUCTION}

This appendix provides supplemental information on the lamp and fixture technologies considered in the policy analyses presented in this report.'

A fluorescent lamp consists of a glass tube wi.h a phosphor material coating the inside walls (Figure A-1). The sealed tube is filled with inert gases and a small amount of mercury. A heated cathode produces electrons, and when high voltage is applied between the electrodes, an electrical arc is struck between the cathode and anode at opposite ends of the tube. This causes the gas to ionize, and an electric current flows through the tube. This current excites the vaporized mercury, and UV (ultraviolet) radiation is emitted as the mercury atoms return to their ground state. This UV radiation is absorbed by the phosphor coating and re-emitted as visible light.

The most common lamp is the 40-watt F40 T12. The most common phosphor coating is halophosphate. This four-foot-long lamp is one-and-a-half inches in diameter and is generally operated in rapid-start mode (see below). The 40-watt lamp is also available in a bent U-shape, or U-tube, so the tube can fit in a shorter fixture. The U-shaped lamp has a slightly lower efficacy. The "standard" four-foot lamp is filled with argon. The eight-foot standard lamp is also argon-filled; it uses halophosphate coatings and is operated in the "instant-start" mode. The eight-foot-high output lamp is longer and operated with a higher current to achieve higher lumen output; it is operated in the instant-start mode. Very high output lamps, operated at still higher currents, are used in the industrial sector.

The four-foot lamp can be operated with an old "standard" ballast, an "energy-efficient" magnetic ballast (the standard ballast since the January 1990 EPCA regulations), a cathode cutout or hybrid ballast (see below), or an electronic high-frequency ballast (Figure A-2). Energy-efficient magnetic ballasts may be of the rapid-start variety, in which cathodes are energized before the lamps are started and during normal operation, or instant-start, in which cathodes are not energized before starting or during operation.

Compact fluorescent lamps (CFLs) are fluorescent lamps configured to fit into small spaces and designed as screw-in or hardwire replacements for incandescent lamps (Figure A.3). They use either a double or "twin" tube shape, or two double or "quad" tubes. Compact fluorescent lamps use tri-phosphor coatings and many models have good color rendition. They may be operated

\footnotetext{
'For a more comprehensive review of efficient lighting technologies, see E. Mills and M.A. Piette, "Advanced EnergyEfficient Lighting Systems: Progress and Potential", Energy-The International Journal (forthcoming) 1993.
} 
lamps and ballasts (so that the lamps, which have shorter lifetimes than ballasts, can be replaced as they burn out) or as integral units (so the ballast must be disposed of with the lamp). Almost all electronic-ballast compact fluorescent versions are produced as integral units to keep their length as short as possible. 
Figure A-1. Typical Fluorescent Lamp

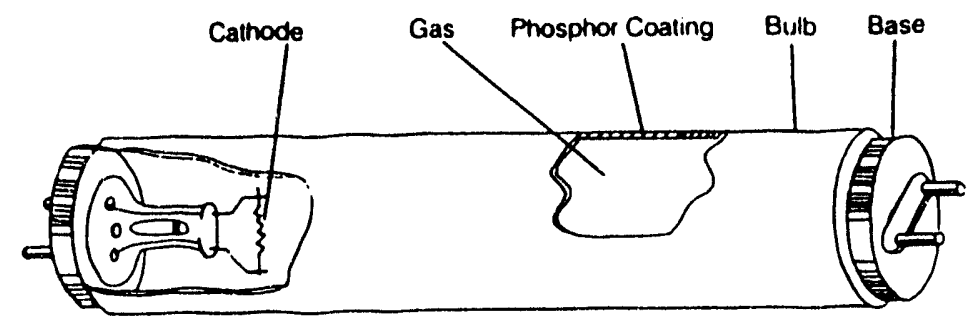

Figure A-2. Magnetic and Electronic Ballasts
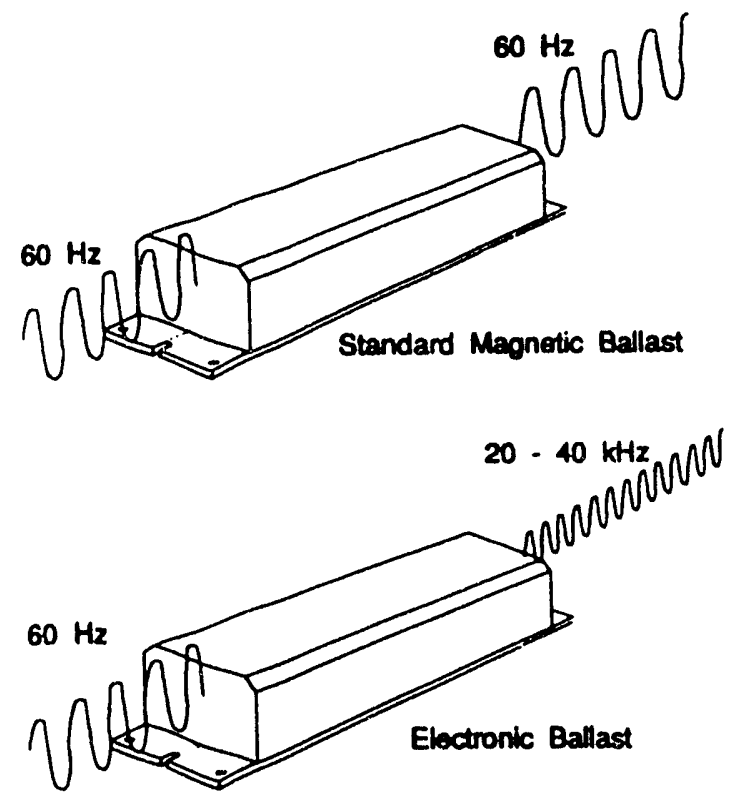

A - 3 
Figure A-3. Compact Fluorescent Lamps

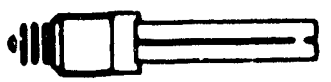

Tube Lamp \& Adapler

Assembly

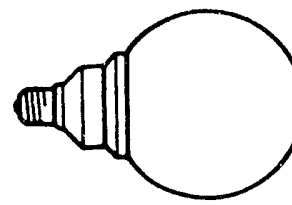

Compact

Fluorescent

Lamp

Globe

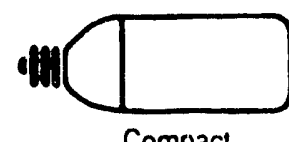

Compact

Fluorescent

Lamp

Capsule

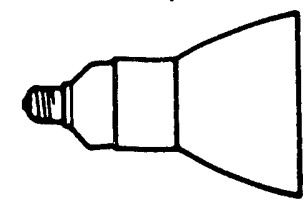

Compact Fluorescent

Lamp

(Reflector)

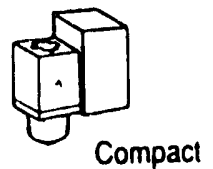

Lamp Adapter
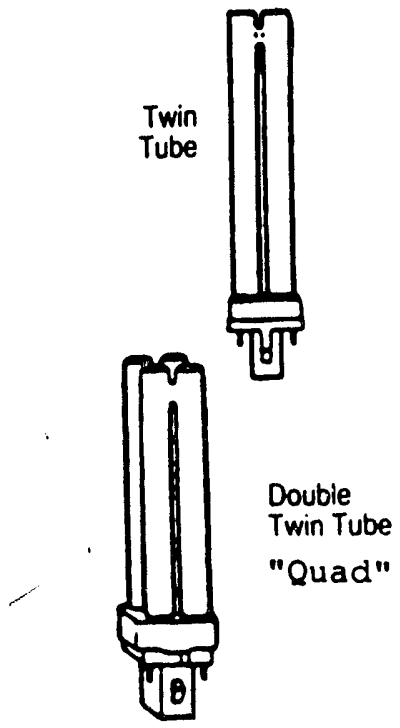

A -4 
Figure A-4. Compact Fluorescent Fixtures

Typical Compact Fluorescent Task Light

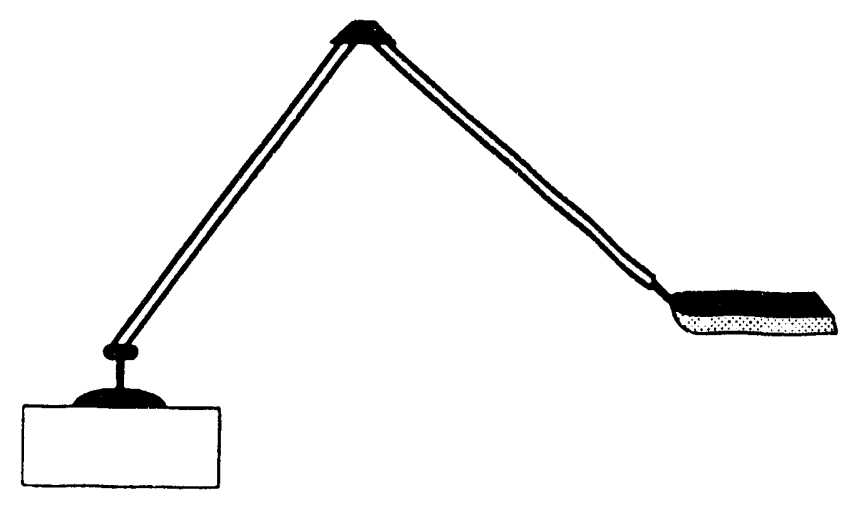

Compact Fluorescent Wall Sconce

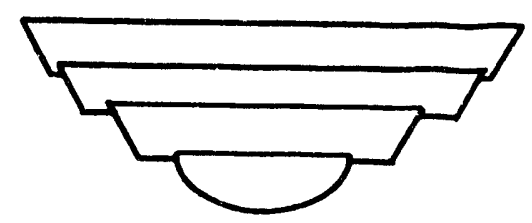

Decorative Pendant Luminaire

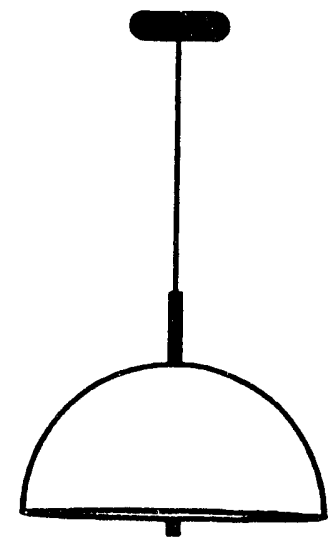

\section{Compact Fluorescent Track Light}

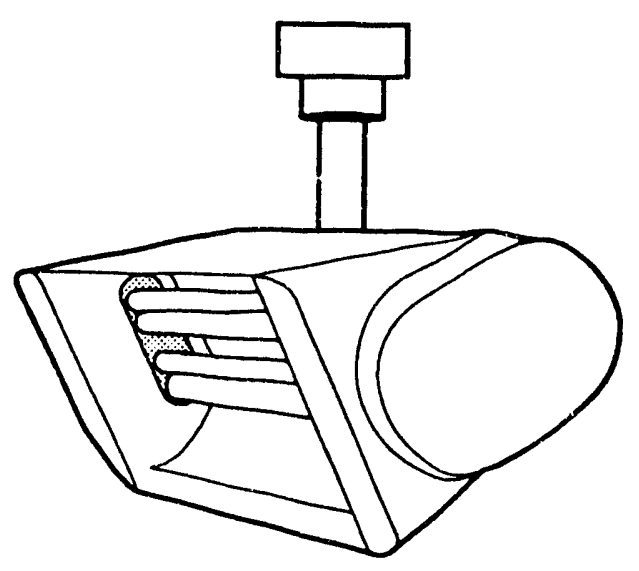

Screw-in Compact Fluorescent Luminaire

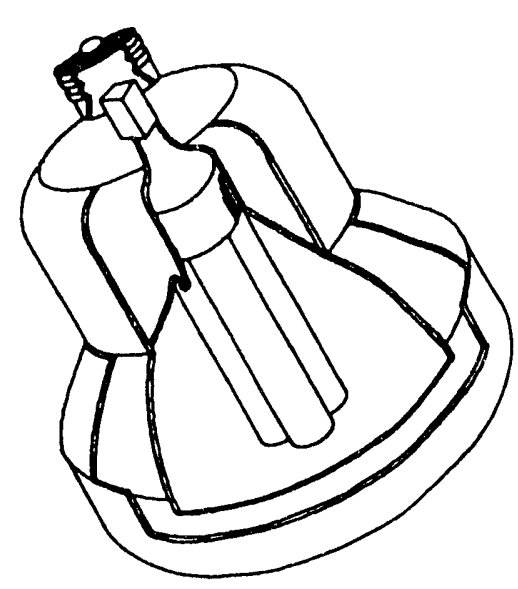


CFL's larger size compared with their incandescent equivalents currently limits the use of this technology - especially for retrofit applications in existing fixtures - because CFLs cannot fit into some fixtures as replacements for incandescent lamps. Electronic ballasts have the advantages of higher efficacy, lighter weight, instant startup, no 60-cycle flicker, and no hum. As the technology advances, more manufacturers are expected to produce separable lamps for use with electronic ballasts and fixtures designed for CFLs (Figure A-4).

An incandescent lamp heats a tungsten metal filament enclosed in a glass capsule filled with argon and a small amount of nitrogen (Figure A-5). An applied voltage causes the filament to incandesce, producing visible light. However, much of the incandescent's emissions are in the infrared, (thermal) range of the electromagnetic spectrum; this heat provides no light and is the reason for the relatively low efficacy of the incandescent lamp.

Figure A-5. Typical Incandescent Lamp

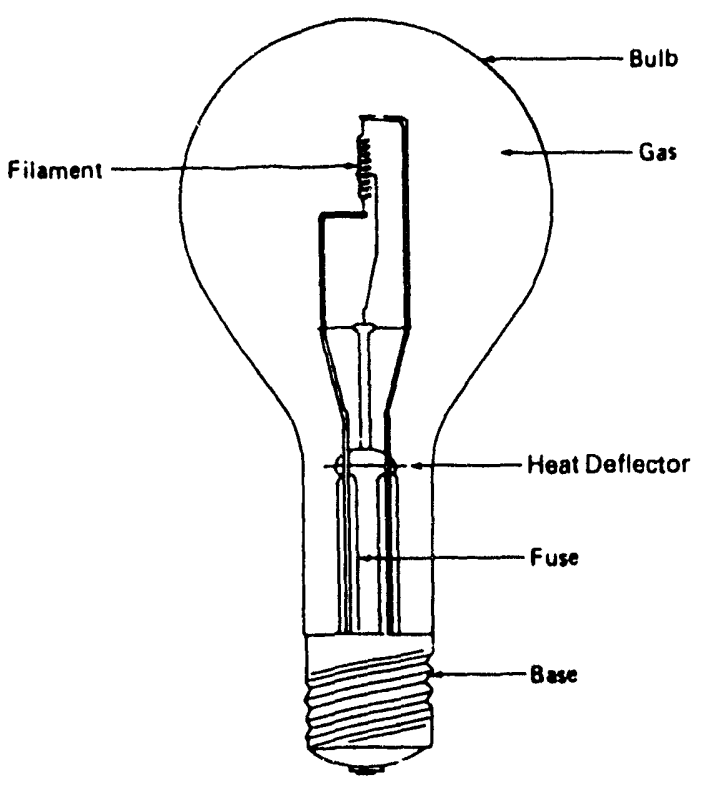


The two major categories of incandescent lamps are general service and reflector lamps. General service are pear-shaped "A-lamps" designed for general usage. Reflector lamps, such as flood or spot lights, are used for special applications to light selected areas. They use specular reflective interior surfaces and lenses to control light distribution. "PAR" (parabolic aluminized reflector) lamps are cone-shaped and have heavy pressed-glass covers for protection against outdoor exposure. "R" lamps are longer and have a cylindrical section near the screw base; their cover is lighter glass. PAR lamps tend to give better directional control and tend to be more efficacious than $R$ lamps. As an exception, the elliptical reflector ("ER") lamp focuses light more efficiently than the standard $R$ lamp when properly used in an enclosed fixture such as a downlight.

\section{A.2 FLUORESCENT LAMPS}

\section{Rare-Earth Phosphor Lamps (RE 70 and 80)}

Rare-earth phosphor lamps (sometimes referred to as tri-phosphor or tri-stimulus phosphor lamps) use several different rare-earth phosphors that emit visible light in the primary color spectra. These phosphors have high color rendering without a loss in efficacy. Rare-earth phosphor lamps may use a "thin-coat" phosphor or a "thick-coat" phosphor; in the latter, the ratio of the thickness of the tri-phosphor layer to the halophosphate layer is increased, with a corresponding increase in light output. In this report, rare-earth phosphor lamps are classified as RE 70 or RE 80 rather than as thin- or thick- coat. The RE 70 lamps have a Color Rendering Index (CRI) of 70-79 while the RE 80 lamps have a CRI of 80-89.

\section{Reduced-Wattage Lamp}

In response to the energy crises of the 1970s, the reduced-wattage (or "energy saver") lamp was developed for retrofit applications. The lamp may be used with an energy-efficient magnetic or electronic ballast. In this configuration the lamp draws less power but also gives lower light output. However, since many retrofit spaces are over lit according to newer IES recommended lighting levels, the lower light output may be desirable in these situations. (See Section 3.2.3 for further discussion).

Reduced-wattage lamps use an argon/krypton gas mixture and have a conductive coating to lower starting voltage. These lamps are not as easily dimmed as standard wattage lamps, and are rated to start at $60^{\circ} \mathrm{F}$ rather than $50^{\circ} \mathrm{F}$. Because of these limitations and their lower light output, reduced-wattage lamps are not recommended for use in new construction.

\section{T10 Lamp}

This one-and-one-quarter-inch diameter lamp offers higher light output and greater efficacy than standard lamps. It was designed to replace standard lamps when increased light output is necessary, such as in a delamping retrofit. A T10 lamp may be used with the same ballasts as a standard T12 lamp. The T10 lamp draws more power than the standard T12 lamp. 


\section{T8 Lamp}

This lamp is one-inch in diameter and uses tri-phosphor coatings. It fits in the same sockets as T12 lamps, but operates at 265 milliamps and requires a different ballast than the T12 ballast that operates at 430 milliamps. The lamp can also be operated with an electronic ballast in either the rapid-start or instant-start mode, forming the most efficacious combination presently on the market. In the "instant start" mode, 90 lumens/watt are attained at the expense of reduced lamp life. The improved phosphors allow for slightly longer lamp replacement time.

The T8 lamp is presently available in 2-, 3-, 4-, and 6-foot lengths. Eight-foot T8 lamps with electronic ballasts are expected to be available in 1993.

\section{Cathode Cutout Lamp}

This lamp is a reduced-wattage lamp with a heater cutout feature in which a thermal switch is used to disconnect filament power during operation after the lamp has started. This eliminates the cathode heater, about 2.5 watts per lamp, with no decrease in light output. If the lamp is turned off and then immediately restarted, a one- to two-minute restrike time is required.

The cathode cutout feature is also available in the ballast (cathode cutout or hybrid ballast) rather than the lamp. When operated with a standard lamp, the cathode cutout ballast also draws less wattage, but no restrike time is necessary. This ballast is generally designed with a lower ballasi factor than the standard ballast, and light output is decreased. The cathode cutout lamp is not used with the cathode cutout ballast (this would be redundant).

\section{Maximum Technology Lamp}

For the 4-foot and the 8-foot high-output product classes, the "Max Tech" option is a hypothetical lamp whose characteristics are based on an efficacy of 100 lumens/watt when used with an electronic ballast, as estimated by manufacturers to be achievable within the next five years. ${ }^{2}$ For the 8-foot product class, the T8 lamp with electronic ballast is the "max tech" design option.

\section{Research and Development}

This lamp technology option is a hypothetical lamp whose characteristics are based on an efficacy of 110 lumens/watt with an electronic ballast, as estimated by manufacturers as likely to be achievable within the next six to ten years.

\footnotetext{
${ }^{2}$ Lighting Research Institute (LRI) and Plexus Research, Inc. 1991. Survey and Forecast of Marketplace Supply and Demand for Energy-Efficient Lighting Products. Phase I Report, Project Number 2418-9, EPRI, Palo Alto, CA.
}

$$
\text { A }-8
$$




\section{Scotopically-Improved Lamp}

This technology is based on the concept of improving the light spectrum to allow human vision response that produces greater visual acuity and depth of field at lower light levels. Eye pupil size appears to be determined by the scotopic response of the rods in the human eye (previously assumed to be responsible only for night vision). Currently, photometric brightness (e.g. lumen measurement) is determined using only the photopic response curve of the cones of the eye. Lamps with scotopically-rich phosphors are best suited for achromatic visual tasks such as reading. Performance characteristics and costs have been estimated by LBL's Lighting Systems Research Group. Because the efficacy of the four-foot version is not as high as that projected for the Max Tech and R\&D options, this lamp is not analyzed in the policy cases. However, research results have important implications for both fluorescent and HID lamp applications (See Section 10 ).

\section{A.3 INCANDESCENT LAMPS}

\section{Reduced-Wattage Lamp}

This lamp is designed at a slightly lower wattage than the standard lamp it replaces. It also has reduced light output but is slightly more efficacious ( 3 to 6 percent). Several design features are available to reduce wattage.

For general service lamps, some major manufacturers have eliminated the molybdenum filament supports. Some have changed the composition and reduced the diameter of the lead-in wires. These techniques reduce conduction heat loss from the lamp.

For reflector lamps, improved optics from better reflector shape allow wattage reduction with a corresponding drop in light output but higher efficacy than the standard reflector lamp.

\section{Tungsten Halogen Capsule Lamp}

This lamp contains a quartz capsule surrounding the filament filled with a halogen gas (usually iodine or bromine), which slows down the evaporation of tungsten by redepositing the tungsten on the filament via the "halogen regenerative cycle". This redeposition of tungsten allows the filament to operate at a higher temperature, increasing efficacy and/or lamp life. This technology is used in both general service and reflector lamps.

\section{Halogen Infrared Lamp (HIR)}

Because nearly 90 percent of energy radiated by incandescent lamps is in the form of heat (infrared radiation), efficacy can be improved by reflecting the infrared portion of the spectrum back onto the lamp filament. Halogen "IR" lamps use a selective, reflective, thin film coating on the halogen capsule or on the reflector surface. The coating transmits visible light but reflects infrared back onto the filament to further heat it, increasing efficacy. This technology was

$$
\text { A }-9
$$


developed in recent years and is presently commercialized for reflector PAR lamps and for higher wattage double-ended quartz halogen lamps. It has also been developed for general service lamps, and it will be introduced to the market as the economics become more favorable (e.g., lower lamp prices, higher electricity prices).

\section{Coated Filament Lamp}

Still in the research and development stage, lamps with a filament coated with a selective coating of transition metal-oxide have low emissivity in the infrared and high emissivity in the visible portion of the electromagnetic spectrum. Efficacies and costs (Appendix B) are estimated by LBL's Lighting Systems Research Group.

\section{A.4 E-LAMP (INDUCTION LAMP)}

The E-Lamp, or "electronic light bulb," works much like a fluorescent lamp, but it uses no filaments. The lamp is filled with mercury vapor and has an inside phosphor coating. In the lamp a power supply modifies the incoming power to match the requirements of the radio wave generator. An oscillator generates the radio wave signal, which is fed through an amplifier that drives a radio frequency antenna. When these waves are produced through the antenna, the mercury vapor is excited and emits photons that are converted to visible light by the phosphor coating, as in a fluorescent lamp.

The system efficacy of the E-lamp is $\mathbf{5 0}$ lumens per watt. The lamp is intended to compete with the compact fluorescent, although the efficacy of an electronically-ballasted CFL can be as high as 70 lumens per watt. The manufacturer plans to market the product in 1993. Initially E-lamps will replace 75-watt reflector lamps and a replacement for the 75-watt general service incandescents will follow. Substitutes for higher-wattage incandescents are under development. The manufacturer aims to reduce the length and base width to fit into more fixtures than the compact fluorescent. The first generation E-lamps will not be dimmable, but the following ones will.

The lack of filaments means that the lamp itself could last almost indefinitely and the power supply components could last over 40,000 hours. However, depreciation of the phosphors would reduce light output by 30 percent within 15 to 20,000 hours, when people would replace the lamp. This reduces the useful life of the E-lamp to a range closer to that of a CFL.

The E-lamp's operating frequency (13.5 megahertz) and its first two harmonics fall into the Industrial/Medical/Scientific band, in which the Federal Communication Commission (FCC) allows unlimited electromagnetic signals. However, the lamp must be shielded to prevent interference from the third through fifth harmonics. The reflector lamp version of the E-lamp uses a cast magnesium housing for shielding (similar in shape to the housing of a compact fluorescent reflector lamp), limiting its use in smaller recessed fixtures. The shielding for the standard Alamp version is designed into the lamp wall itself. 
This lamp's globe has two layers, an inner layer with phosphor coating, and an outer layer with metal screening for shielding purposes. At the end of June 1992 an independent testing laboratory certified the standard model's compliance with FCC standards.

Other major lamp manufacturers have done research on the induction lamp technology, though none has pioneered it for the residential market. Philips Lighting makes the "QL-Lamp," an induction lamp with similar technology aimed at the European commercial and industrial market. This product features higher system efficacy, wattage, lifetime, and price than the E-lamp.

The E-lamp design has not been finalized and prototypes are yet not available for testing. Since the efficacy, size, and price of the product when it reaches the market are uncertain, the E-lamp has not been analyzed in this report.

\section{A.5 ADVANCED FLUORESCENT FIXTURE TECHNOLOGIES}

Figure A-6 shows a parabolic fixture that uses shaped louvers for optical control. Specular reflectors have improved reflectivity and reduced internal reflections, which results in a 15 to 20 percent efficiency improvement ${ }^{3}$ over those using standard white enamel surfaces (Figure A-7). Specular surfaces have a near-zero dispersion of reflected light rays, while white painted reflectors have a large dispersion. Light distribution tends to be more focused with specular reflecting surfaces, and the distribution is narrower. This is advantageous in situations where glare control is desired, but it may produce dark areas between fixtures and lower wall brightness in areas where uniform lighting is preferable. Three types of reflective materials are used: anodized aluminum, silver, and a multiple dielectric coating. Higher optical efficiency with the reflector may allow fewer lamps in the fixture, or for fewer fixtures in a light system to produce the same light output as a standard luminaire.

Efficient small-cell parabolic louvers eliminate the re-entrant surfaces that decrease their efficiency. In standard scale louvers, the ratio of exit area to fixture area is small, and light is reflected from the flat top or the "re-entrant" surface (on the upper side of the louvers) up into the fixture. Redesigning the louver to eliminate re-entrant surfaces can increase fixture efficiency by up to 20 percent.

Thermal improvements. Lamps in most full-size or compact fluorescent fixtures are operated below their optimum efficacy because their operating temperature is too high. Various conductive and convective cooling methods can improve fixture efficiency by 15 to 20 percent. These techniques are under development and are not considered in this analysis.

\footnotetext{
${ }^{3}$ This represents a percent efficiency improvement, not an increase in percentage-point efficiency.
}

A -11 

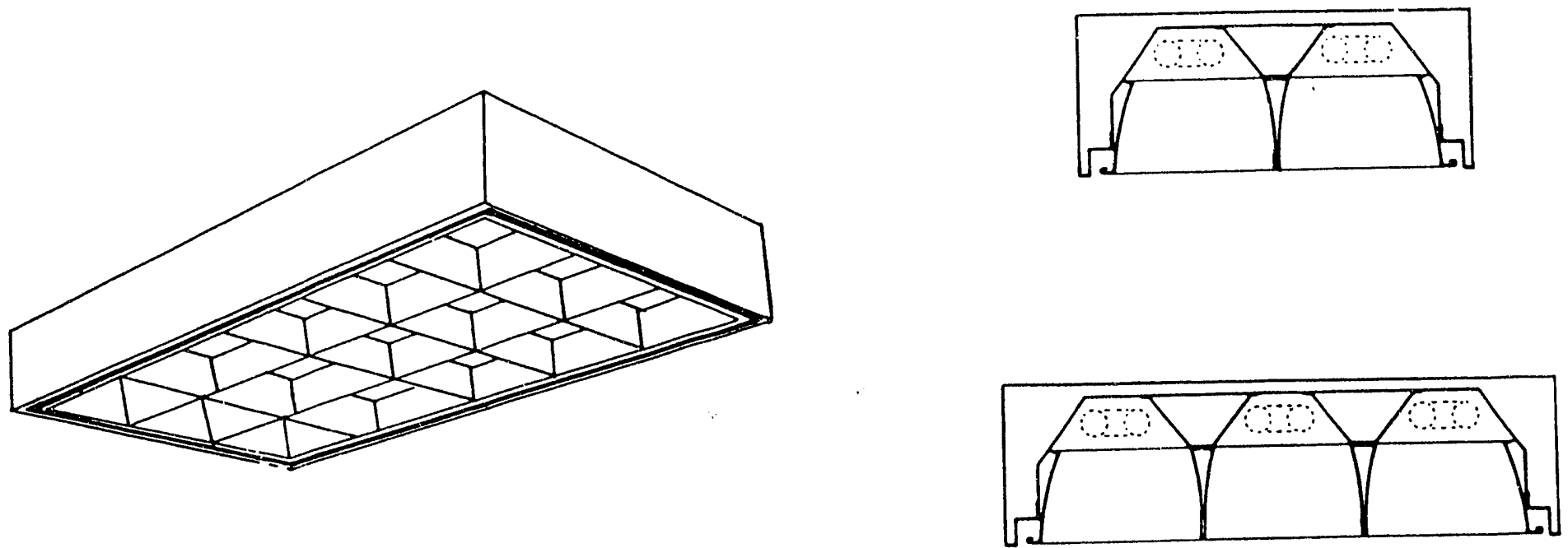

Figure A-7. Fluorescent Fixture with and without Specular Reflector.

- Before installation of the reflector

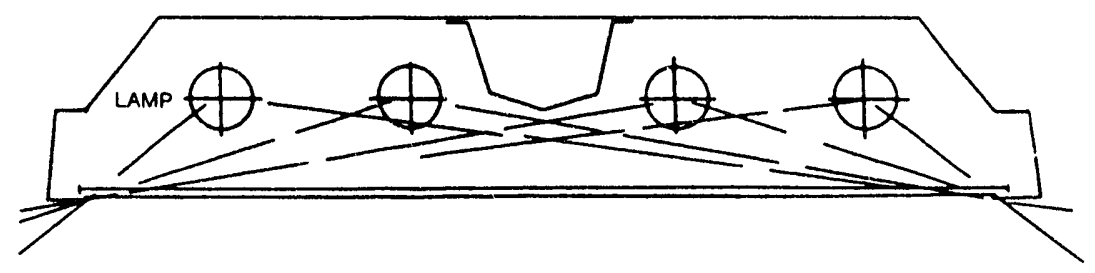

- After installation of the reflector

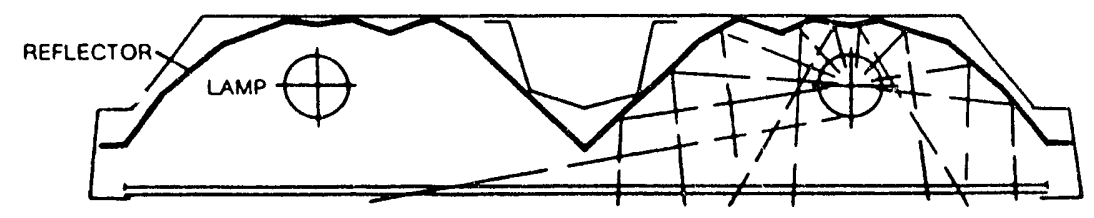

$$
\text { A }-12
$$




\section{APPENDIX B ENGINEERING ANALYSIS TABLES}

\section{B.1 INTRODUCTION}

Four types of tables and figures are presented in this appendix representing these groups of technologies:

Incandescent General Service and Reflector (Tables and Figures B.1 to B.4)

Compact Fluorescent (Tables and Figures B.5 and B.6)

Fluorescent Lamp (Tables B.7 to B.12, Figures B.7 to B.9)

Fluorescent Lamp/Ballast (Tables B.13 to B.19)

The tables contain all of the lamp technology options presented in Section 3.2. Incandescent and compact fluorescent tables include commercial and residential versions. Fluorescent lamp tables compare lamp costs only, while fluorescent lamp/ballast tables include ballast equipment and replacement costs. Fluorescent tables include four-foot, eight-foot (slimline) and eight-foot high output (HO) versions. The baseline fluorescent lamps are standard wattage lamps (e.g. F40T12).

For fluorescent lamps, the 2-lamp/1-ballast configuration is presented first, followed by the 1-, 3-, and 4-lamp combinations. The 3-lamp wattage is the average of that of a 3-lamp/2-ballast and a 3-lamp/tandem-wired-ballast configuration. For fluorescent/lamp ballast combinations, the 2-lamp/1-ballast combination is presented.

Incandescent general service tables compare lamp technology options with a 75-watt baseline lamp. The incandescent reflector baseline is a 150-watt PAR lamp for the commercial sector and a 75-watt PAR lamp for the residential sector.

The maximum technologically feasible (Max Tech) option is a technology that can be commercialized by 1995 . The research and development $(R \& D)$ option is a technology that can be commercialized by 2000 . Max Tech and R\&D technology options are presented for the 2 lamp versions only. Efficacy data for these options are estimates from LRI's supply and demand survey $^{1}$ and cost estimates are projected by LBL.

\section{B.2 NORMALIZED VALUES}

The tables are presented in two versions: one showing actual values (eg. Table B.1) and the other showing normalized values (eg. Table B.1N). In the normalized version, lamp and ballast costs, replacement costs, and wattages are normalized by the lamp technology option's rated

\footnotetext{
${ }^{1}$ LRI and Plexus Research. 1991. Op. cit, Sec. 2, Ref. 3.
} 
initial lumen output to the rated lumen output of the baseline lamp (technology option number 0 ). For lamps with more or less lumen output than the baseline, it is assumed that more or fewer fixtures will be installed (in new construction or renovation) to produce equivalent light output. See Section 3.2.4 for further description of this assumption and its implications.

Incandescent reflector tables do not include normalized versions because rated lumen output data are not available for some reflector lamps. Residential tables do not have a normalized version because it is assumed that residential customers will not, on average, compensate for reduced light output.

To review the actual input values, use the actual tables. On the normalized tables, normalized values are indicated with an asterisk $(*)$.

\section{B.3 WATTAGE}

For four-foot fluorescent lamps, wattage is presented in two forms. ANSI watts represent input power drawn by the lamp/ballast under ANSI test conditions in open air. The wattages are manufacturer data. Fixture watts are from the California Energy Commission's Advanced Lighting Guidelines, October 1992 Draft. $^{2}$ Fixture watts represent actual wattage drawn by the lamp/ballast combination in the fixture. Because the in-fixture system does not operate under optimal temperature conditions, the actual operating wattage as well as the light output is reduced. Using the CEC wattages thus accounts for thermal factor. Other CEC data used represents actual light output, accounting for the ballast factor.

Note that in the normalized version of Table B.7 and succeeding tables, the 34-watt lamp uses more energy than the standard baseline lamp. When thermal effects are included, and when normalized by lumen output, the lamp's fixture wattage is higher than that of the standard lamp. For incandescents and compact fluorescents, wattages listed do not include fixture thermal effects. For the energy and economic analysis of this lamp (Eliminate Highest Watiage policy case), ANSI wattage is used. See Section 2.4 for discussion of the assumptions for modeling this policy.

For eight-foot fluorescents, only ANSI watts are presented (since thermal effects in typical 8-foot fixtures are small). For incandescents and compact fluorescents, wattages listed do not include fixture thermal effects.

\section{B.4 ECONOMIC CALCULATIONS}

Results of economic calculations are given in terms of simple payback, total life-cycle cost, and cost of conserved energy. In the normalized tables, design options are sorted by simple payback, except for the Max Tech and the R\&D options. (They remain in the same order in the actual

${ }^{2}$ CEC. 1992. Op. cil, Sec. 3, Ref. 2.

B - 2 
tables.) Total life-cycle cost (LCC) is calculated over the service life of the longest-lived design option, except Max Tech and R\&D. LCC is presented for three real discount rates; four percent chosen by DOE as the social discount rate, and one percent and seven percent as sensitivity cases. The cost of conserved energy is capital costs are presented for the same three discount rates.

Payback represents the capital cost plus labor cost divided by the annual energy cost. Capital costs are calculated as the replacement cost plus lamp price in Tables B.1-B.12, and total cost (representing ballast cost plus ballast and lamp replacement costs) in Tables B.13-B.19.

\section{B.5 SERVICE LIVES}

Lamp service life is the rated lifetime of the lamp, divided by the annual lighting hours of operation, and multiplied by 0.7 (for most lamps) to represent lamp replacement at the 70 percent of rated lifetime typical of group relamping. Since the T8 lamp has less lumen depreciation than the $\mathrm{T} 12$, it is replaced at 75 percent of rated lifetime, giving it a slightly longer service life. Assumed ballast service life is 12 years, approximating rated lifetime divided by annual lighting hours. For the commercial sector, annual lighting hours are from EIA's NBECS 1986 survey and are estimated separately for fluorescent and incandescent lamps. For the residential sector, annual lighting hours are estimated from utility residential appliance saturation surveys. These hours represent usage of 3 to 5 hours per day; they do not include the lower-usage lamps $(1 / 2$ hours per day) used in the Residential Lighting Energy Usage Spreadsheets described in Sections 2.1.1 and 5.1.1.

\section{B.6 REPLACEMENT COSTS}

Replacement costs are calculated by multiplying replacement times by labor rate(s). Installation times are estimated from interNational Association of Lighting Maintenance Companies (NALMCO), Means, ${ }^{3}$ and other sources (see Section 2.1.1). Lamp replacement times are for group relamping of a large area (rather than the longer time for spot relamping when an individual lamp burns out). Labor rates are from the Means Catalog. The electrician's helper labor rate (\$25.63) is used for lamp replacement. An average of this rate and the electrician's rate $(\$ 35.69)$ is used for ballast replacement.

Replacement times for commercial lamps are also based on information from a variety of sources: major construction cost estimating guides such as Means, NALMCO, and estimates from energy consulting services, and sources of lighting design and analysis software. In general NALMCO estimates are assumed to best represent lamp replacement times, and Means estimates are used for ballast installation times.

Replacement costs are not considered for the residential sector. It is assumed that the homeowner

\footnotetext{
${ }^{3}$ R.S. Means Company, Inc. 1991. Means Electrical Cost Data 1992, 15th Annual Edition.
} 
replaces lamps rather than paying someone else to replace them.

\section{B.7 MONETARY UNITS}

All equipment prices and labor costs have been converted to $\$ 1990$ using Consumer Price Indices from EIA's Monthly Energy Review, August 1992. The deflation factor from 1990 to 1992 is 0.942 .

\section{B.8 EQUIPMENT PRICE SELECTION, COMMERCIAL SECTOR}

Many of the energy-efficient lamp technologies considered in this document are relatively new to the marketplace. In order to arrive at initial prices that are representative of the price a typical large commercial purchaser would pay for energy-efficient lamps, standard lamps, and ballasts for compact fluorescent lamps, prices have been collected from a wide variety of sources: wholesalers, manufacturers, distributors, local outlets, and sources of lighting design and analysis software. There is no single accepted consensus on prices for these products. Nevertheless, input from all of the above sources contributes to the decision to use the following relatively simple weighted-average price:

Price $=[(1-0.227) \times(0.6) \times(G)+(0.227) \times(D)] \times 0.942$

where $\mathrm{G}=$ Lamp price from the General Electric Commercial and Industrial Lamp Price List, March 1992

$\mathrm{D}=$ Lamp price from the Defense General Supply Center (DGSC) Energy Efficient Lighting ca:alog, May 1992.

This reflects 60 percent of list price paid by non-government buildings, and DGSC prices paid by government buildings. Percentages of total U.S. building stock falling in each category are from CBECS 1989. The equation includes a deflation factor of 0.942 to reflect 1990 dollars.

Exceptions to the price thus calculated occur whenever either primary source cannot supply a price for a particular lamp. Where DGSC has no price available, $0.45 \times \mathrm{G}$ is used in place of $D$ in the above equation. Where G.E. has no price available, either Sylvania ${ }^{4}$ or Philips prices are used in place of $G$ in the above equation. These cases are listed below (using LBL lamp designations as listed in the engineering tables):

\footnotetext{
${ }^{4}$ Sylvania 92-1-U Large Lamp Price Schedule, effective 1 April, 1992.

${ }^{5}$ Philips Lighting PS-101-U Large Price Schedule, effective 1 April, 1992.
}

B - 4 


\begin{tabular}{lll} 
Lamp (or ballast) & in place of D: & in place of G: \\
\hline F40SP41 (40 watt) & $0.45 \times$ G.E. list & $0.6 \times$ Philips F40AX41list \\
F40AXT10 & & \\
F40CW/ $/ 6$ ( 40 watt) & $0.45 \times$ G.E. list & \\
F40SP41/U (40 watt) & $0.45 \times$ G.E. list & \\
F96T12/SP41 (75 watt) & $0.45 \times$ G.E. list & \\
F96T12/SPX41 (75 watt) & $0.45 \times$ G.E. list & \\
F96T12/SP41/HO (110 watt) & $0.45 \times$ G.E. list & $0.6 \times$ Sylvania 72MB/CAP list \\
72 watt halogen & & \\
60 PAR/HIR & $0.45 \times$ G.E. list & \\
Twin Tube Mag. Ballast & $0.6 \times$ Sylvania list & \\
Quad Tube Mag. Ballast & $0.6 \times$ Sylvania list
\end{tabular}

The prices reflect costs of equipment in 1995 (when policies take effect). The same formula is used for newer energy-efficient products. While the discounts on list prices may be lower for a new product, it is assumed that by 1995 the full discounts will have taken effect.

\section{B.9 EQUIPMENT PRICE SELECTION, RESIDENTIAL SECTOR}

Residential lamp prices are determined in a similar manner to commercial prices. The following equation is used where possible, including the adjustment to 1990 dollars by a factor of 0.942 :

Residential Price $=0.8 \times G \times 0.942$

where $\mathbf{G}=$ Lamp price from the General Electric Commercial and Industrial Lamp Price List, March 1992.

Exceptions to the residential price equation for compact fluorescents and halogen lamps are:

Lamp:

Modified Equation:

Twin tube compact fluorescent

$\frac{(0.8 \times G)+E}{2} \times 0.942$

Quad tube compact fluorescent

$$
\frac{(0.8 \times G)+E}{2} \times 0.942
$$

Quad integral compact fluorescent

$$
\frac{(0.8 \times G)+E}{2} \times 0.942
$$

72-wall halogen

Replace $\mathrm{G}$ by Sylvania 72MB/CAP list in

where: $E=$ Energy Federation, Inc. ${ }^{6}$ retail prices.

Residential Price Equation

\footnotetext{
${ }^{6}$ Energy Federation, Irc. retail prices are obtained by multiplying EFI wholesale prices by 1.15 . The wholesale prices come from the EFI Wholesale Price List - August 1992, from Energy Federation Inc., Natick, MA.

B - 5
} 
Note that the twin tube and quad tube lamp prices used are for 13-watt lamps, and the quad integral price is for an 18-watt lamp. Prices are harder to obtain for 15-watt lamps of either type. The price difference between a 13-watt and an 18-watt lamp of the same type is comparatively small. Also, the 18-watt lamp is assumed in the commercial CFL analysis and is a major component of the residential analysis. In the compact fluorescent tables (B.5 and B.6), 13.5-watt (electronic ballast) and 15-watt (magnetic ballast) lamps are listed, because more energy data are available for 60-watt-equivalent replacements, but the 13- and 18-watt prices are used. 


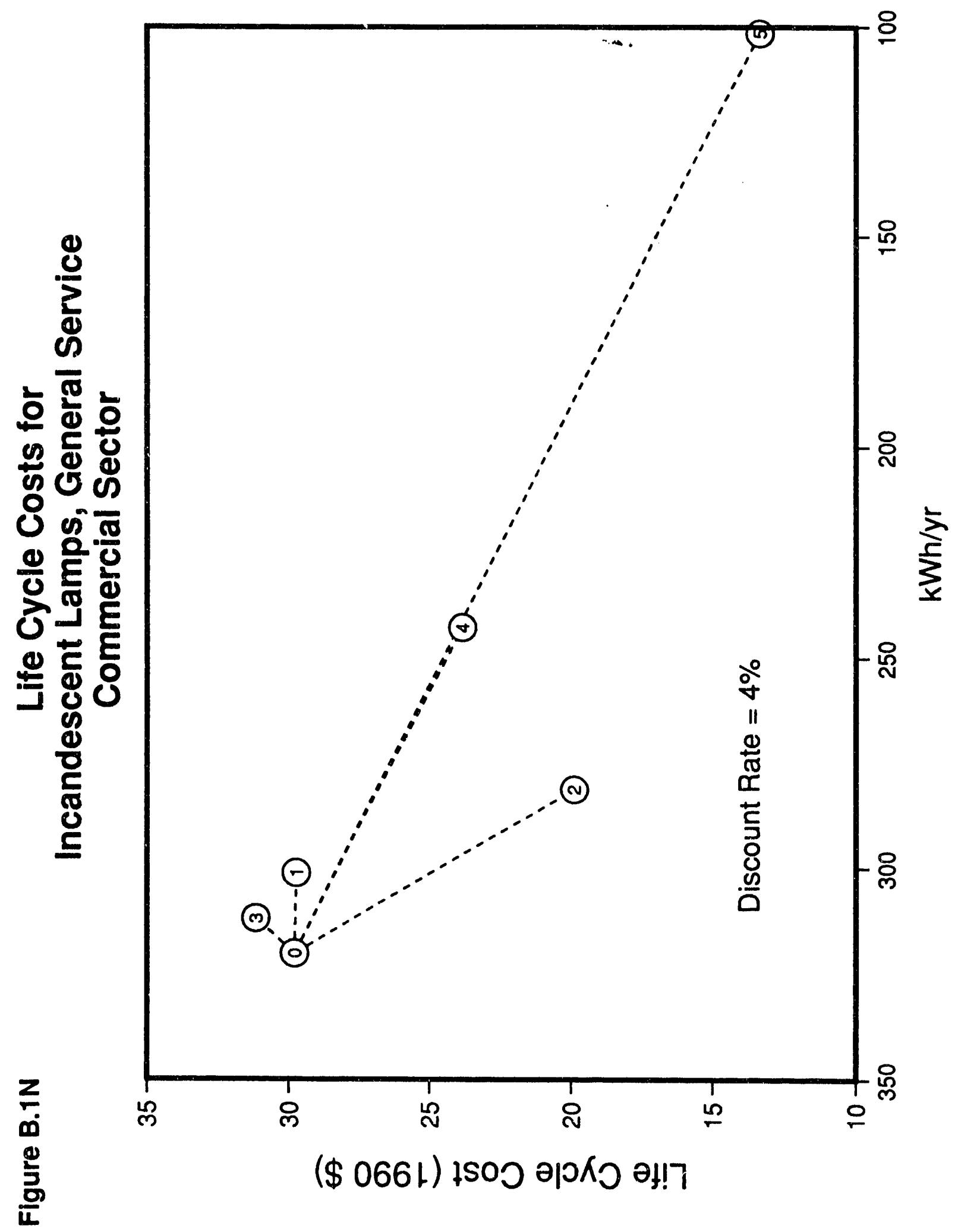

B - 7 


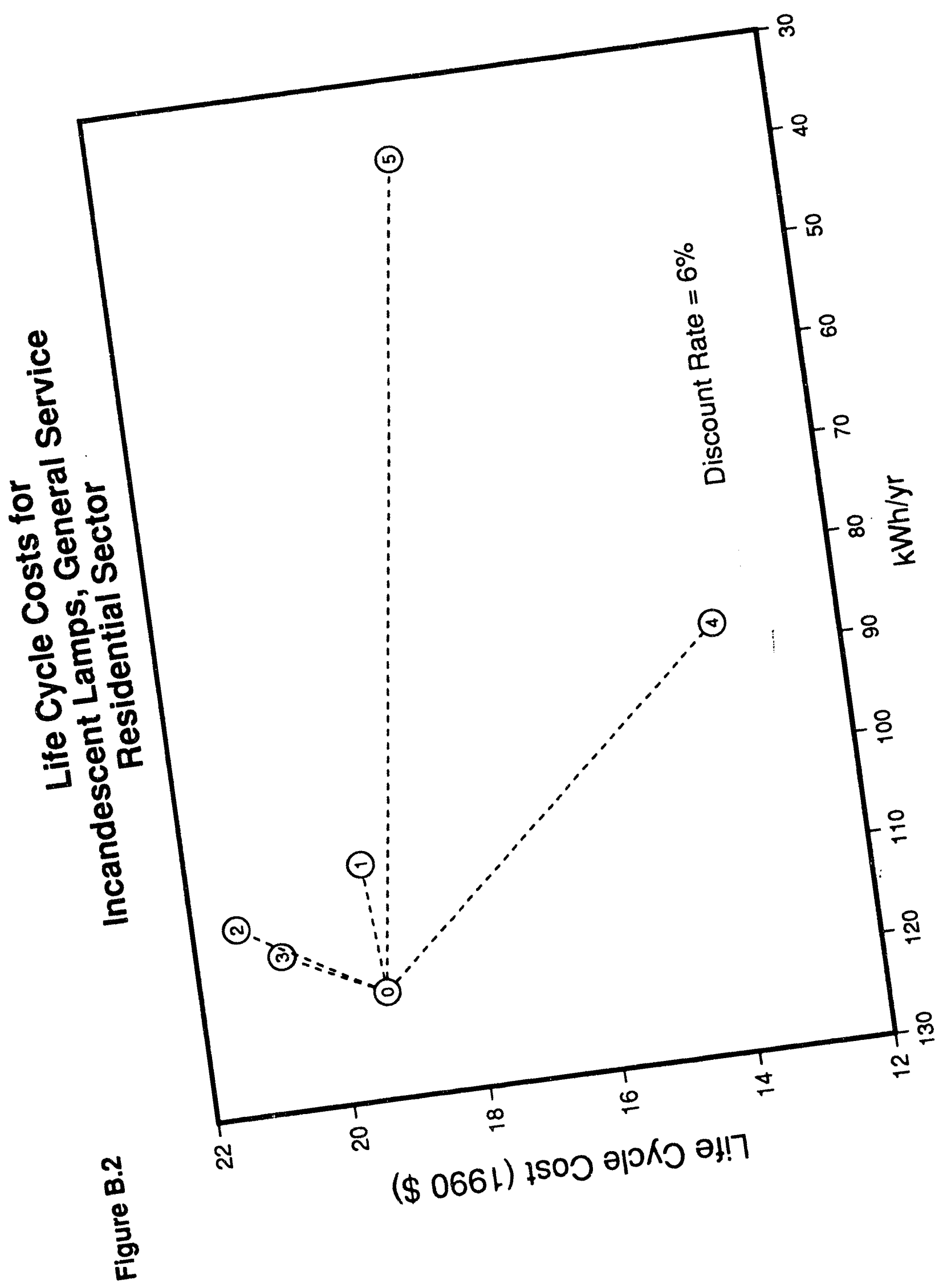

B -8 


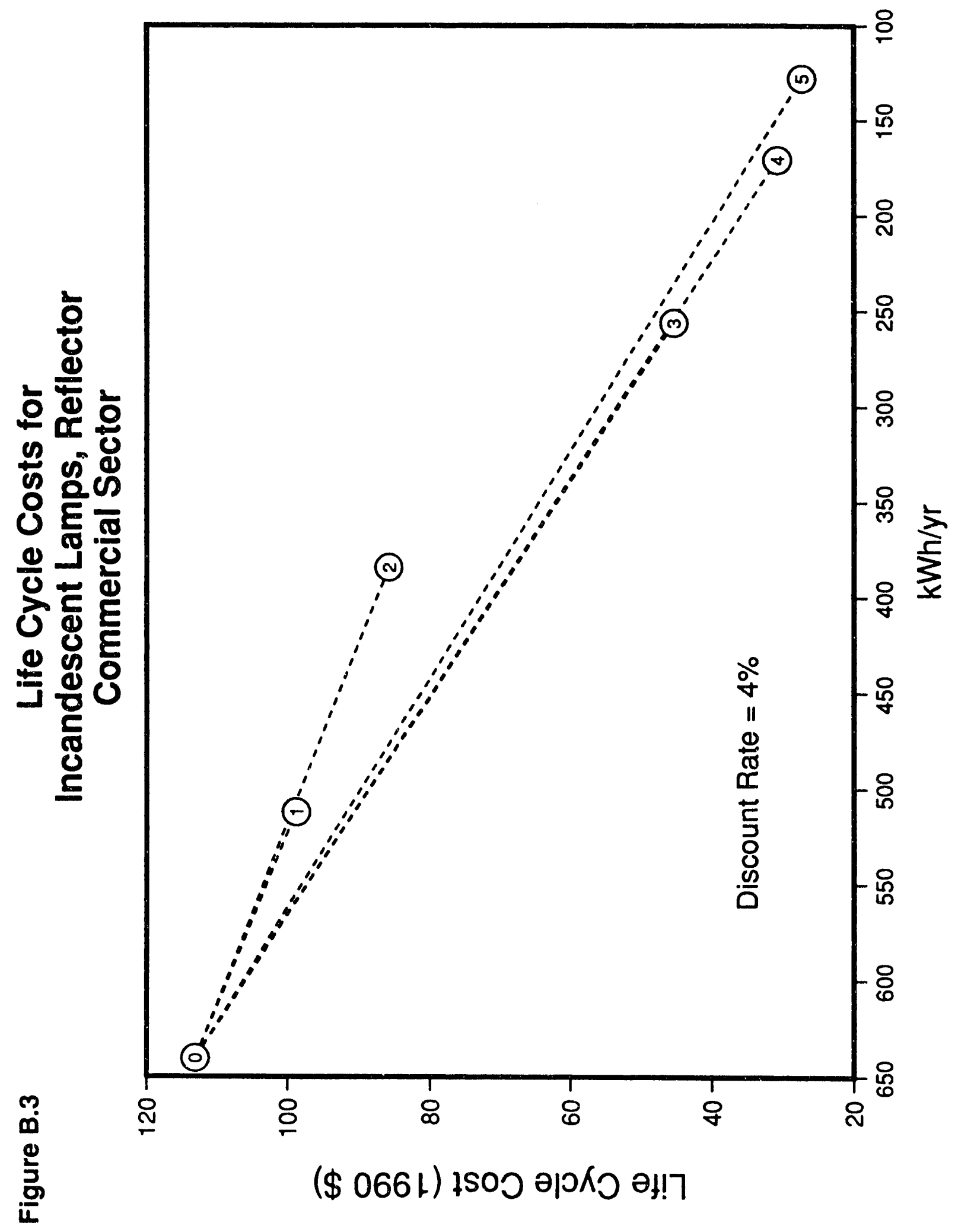

B - 9 


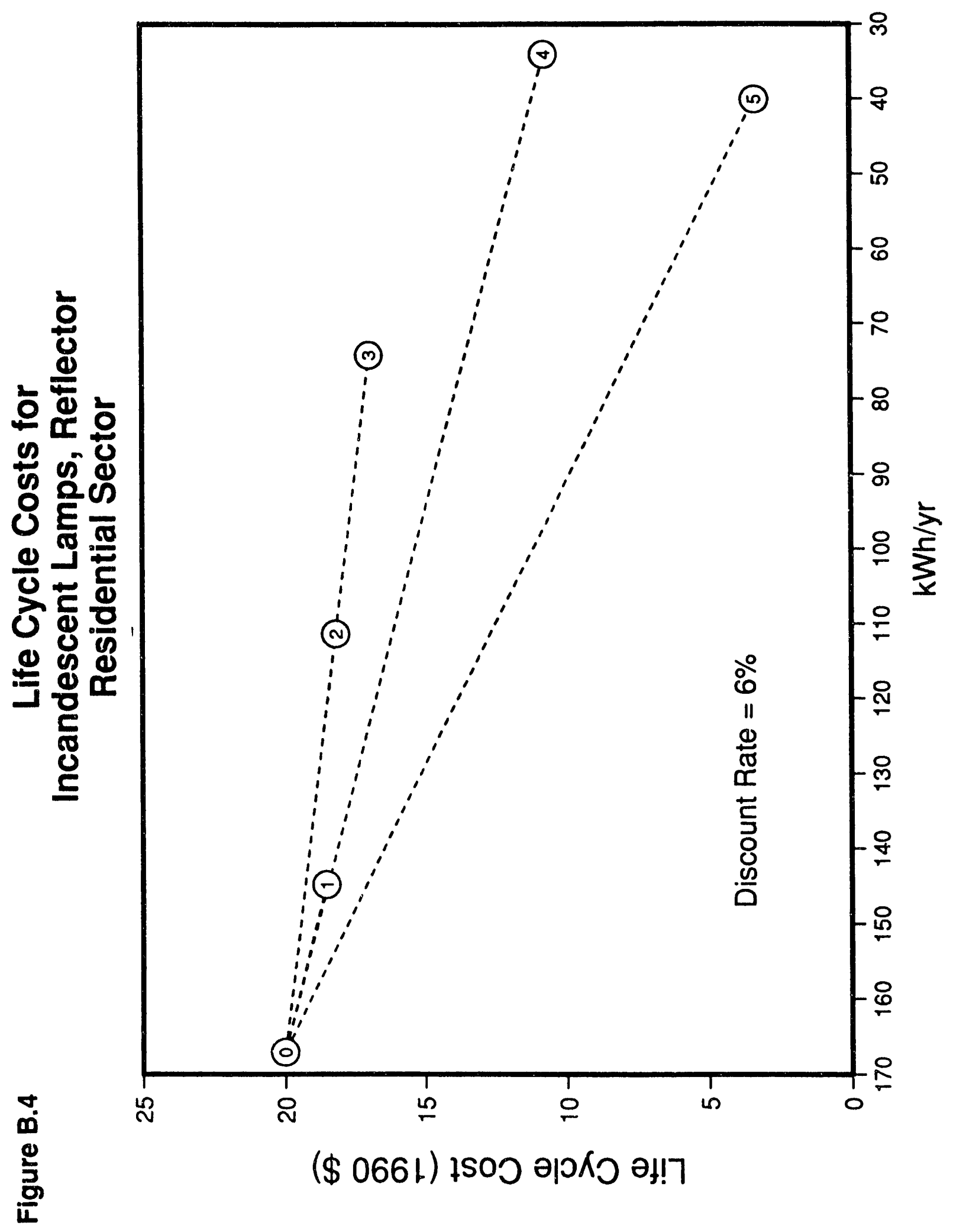

B- 10 


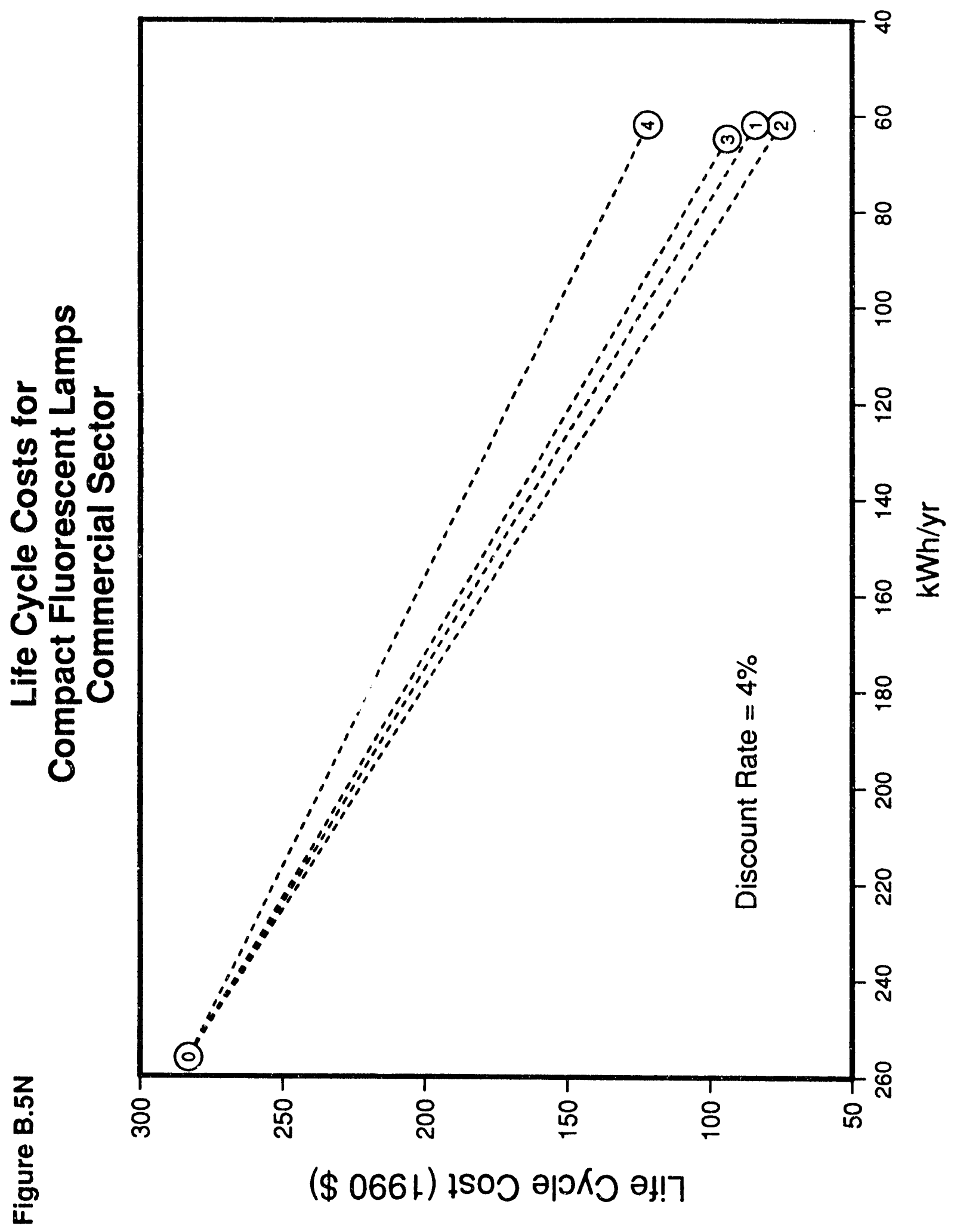

B - 11 


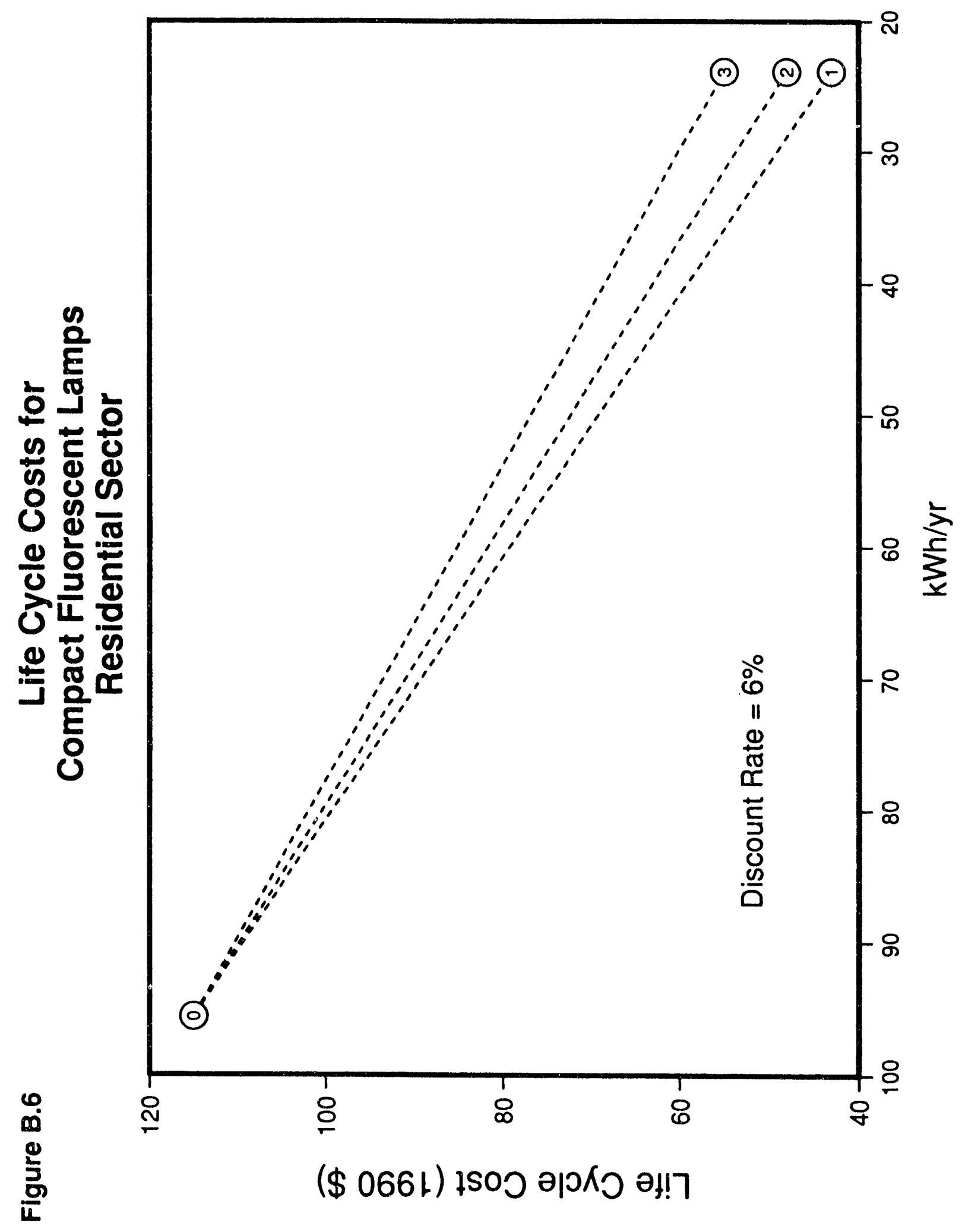

B -12 


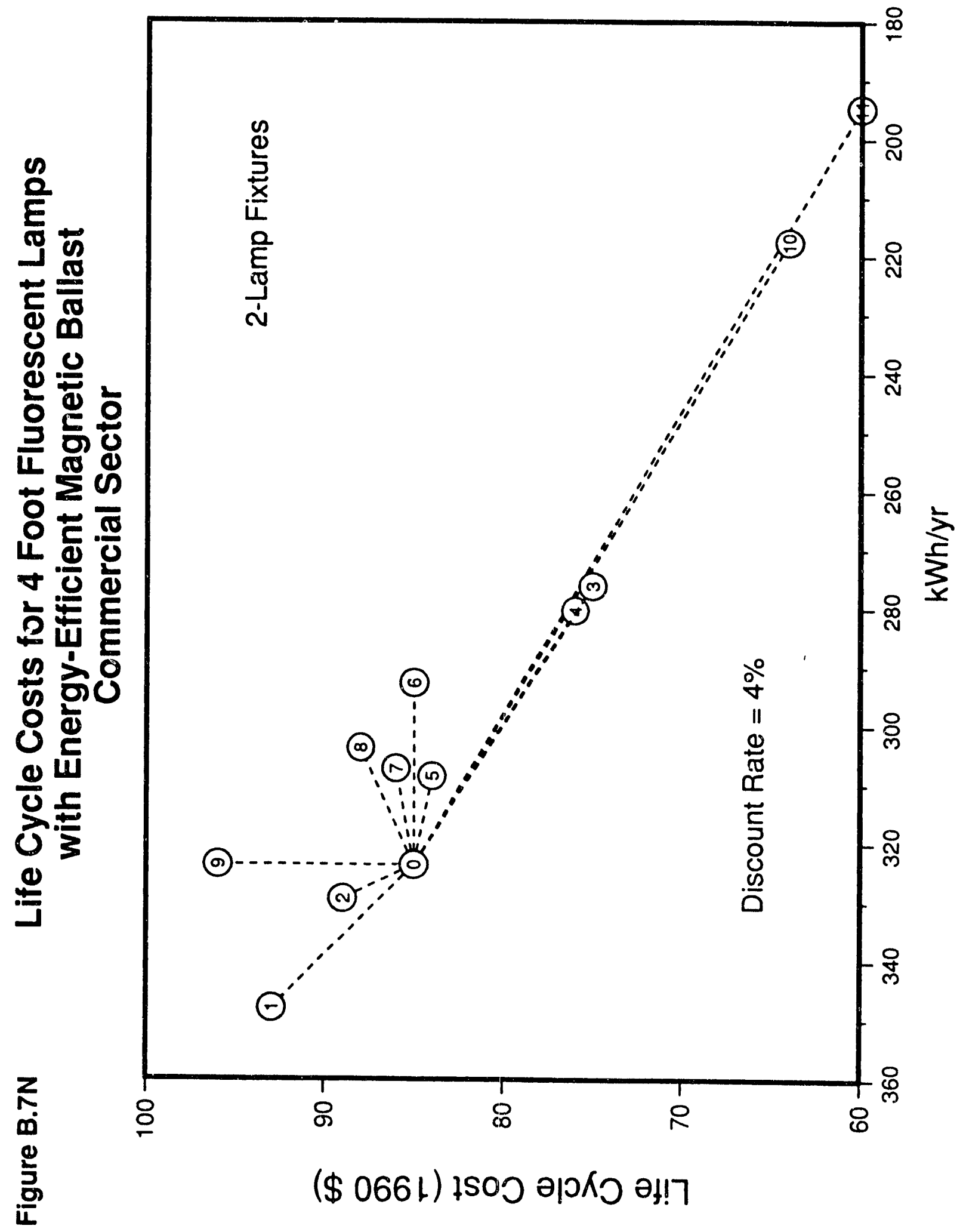

B -13 


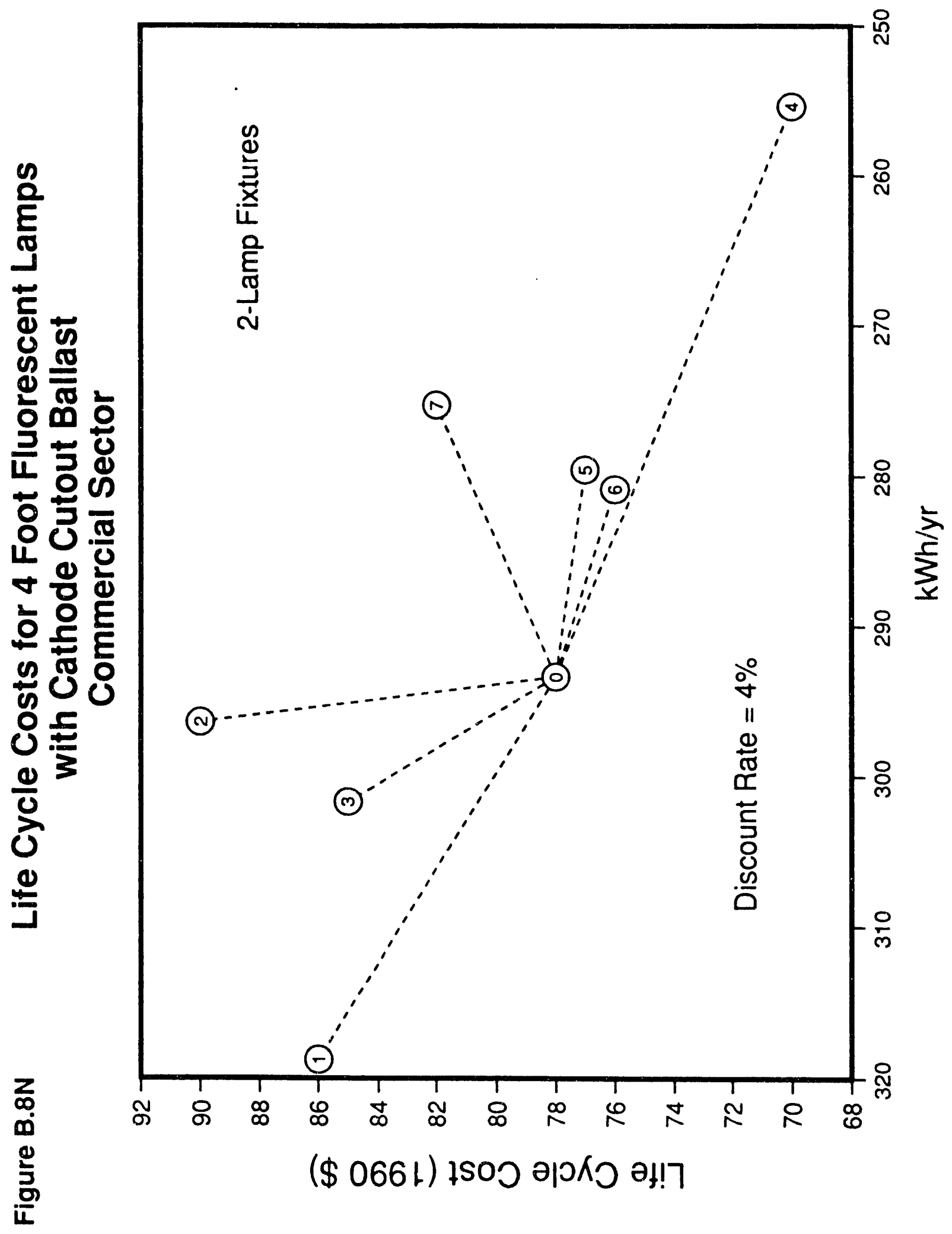

B - 14 


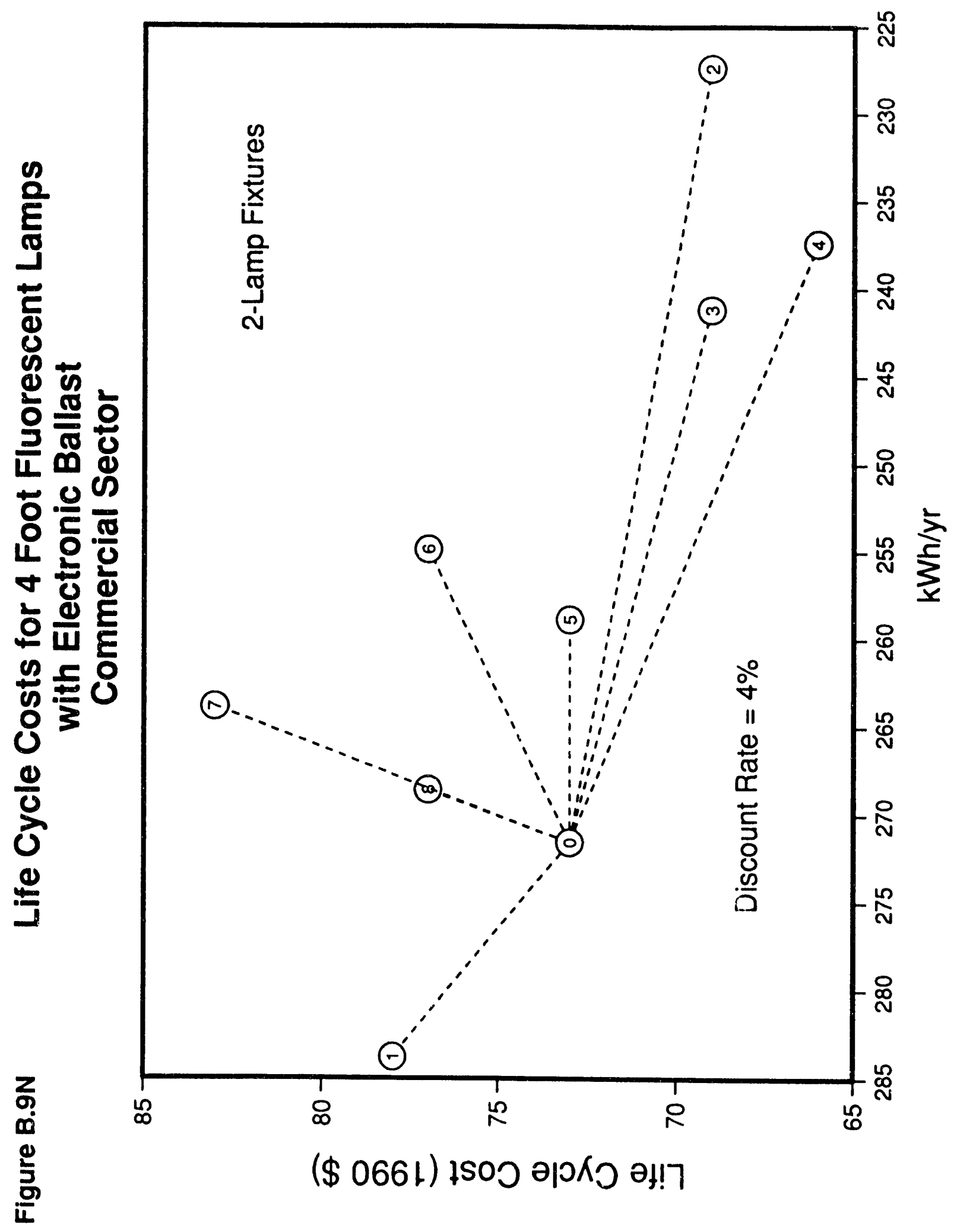

B -15 

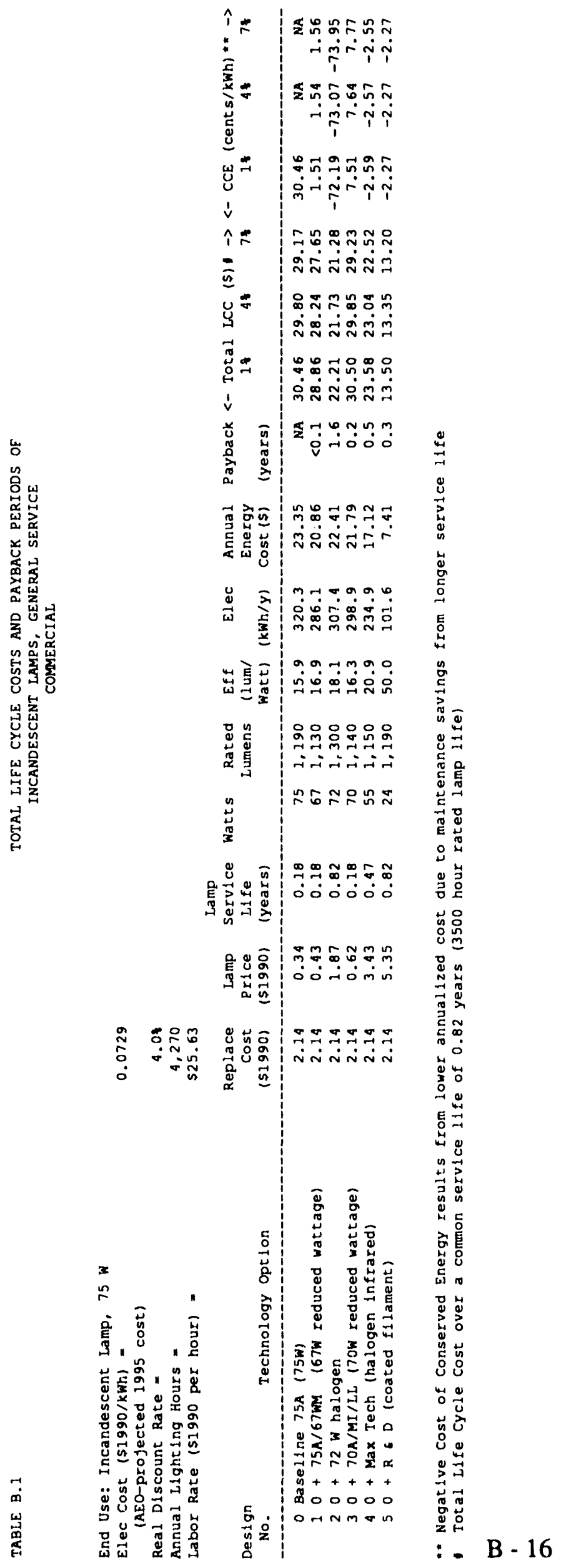

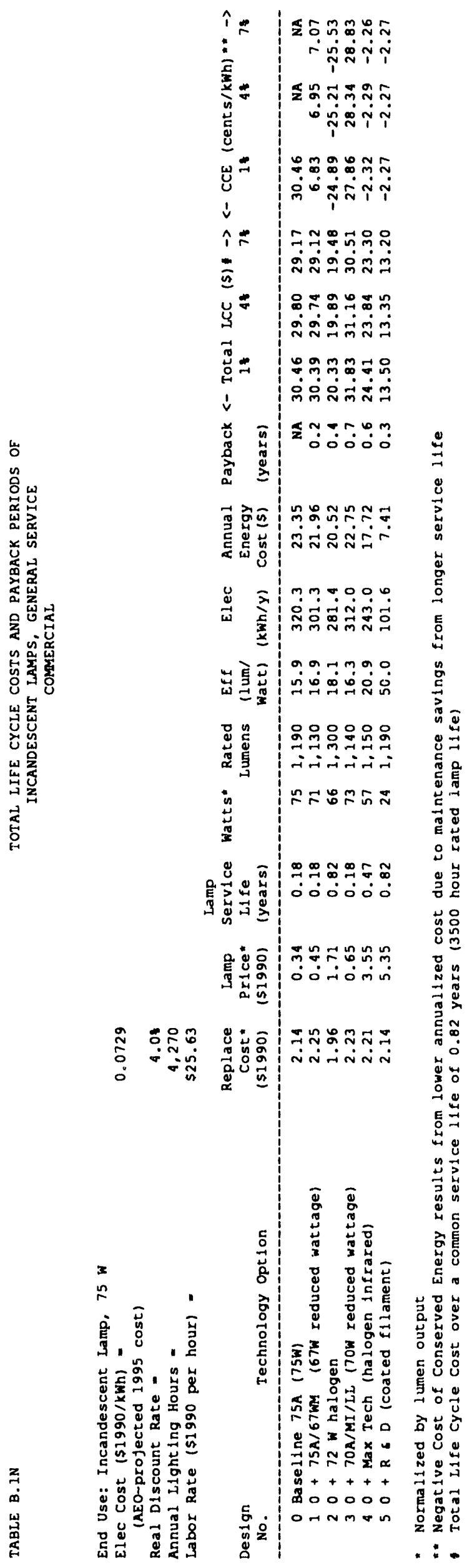

B -17 

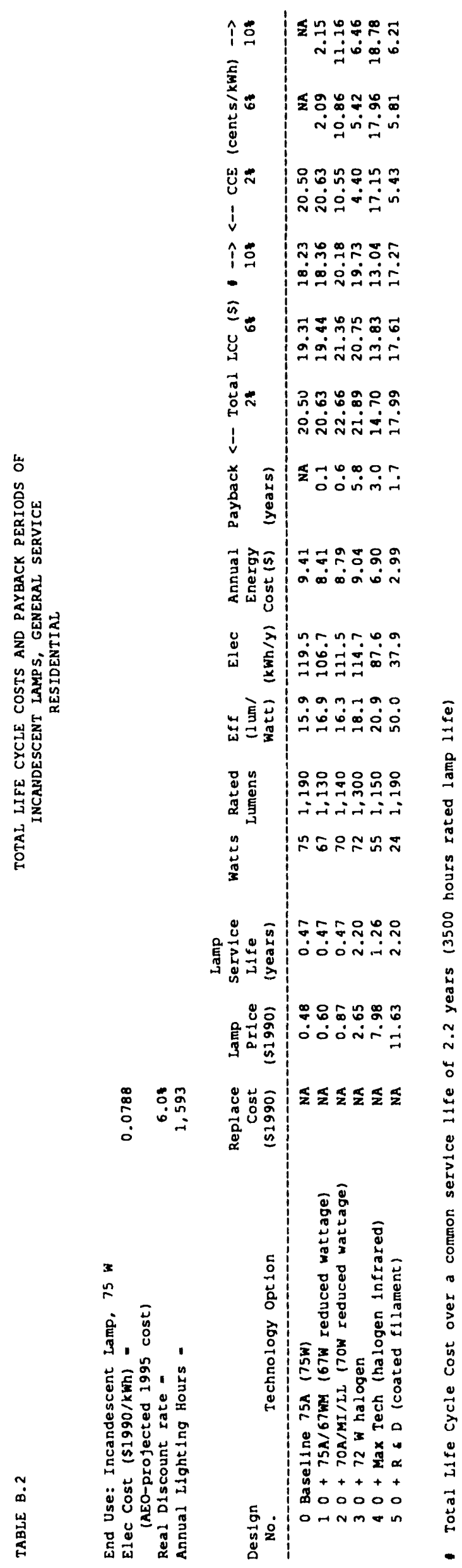

B -18 



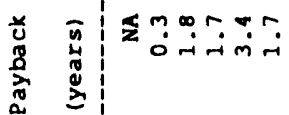

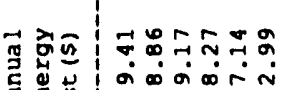
起藏

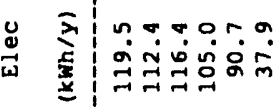

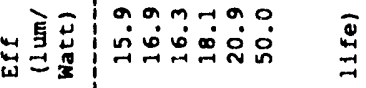

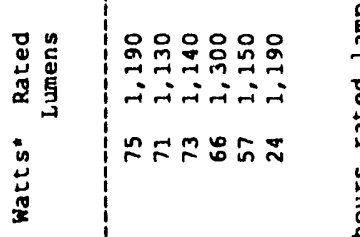

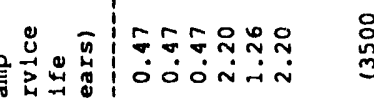

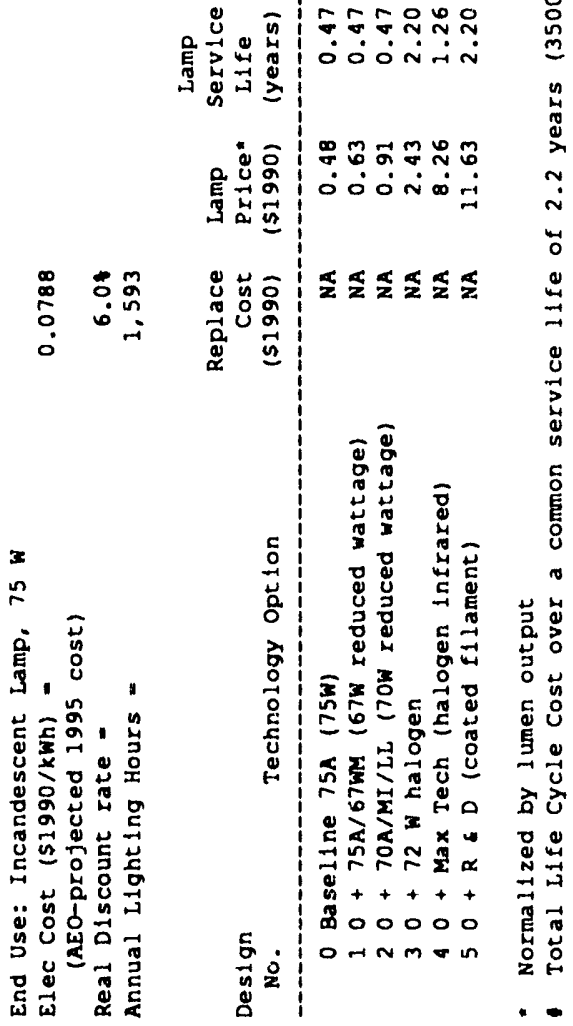

B -19 

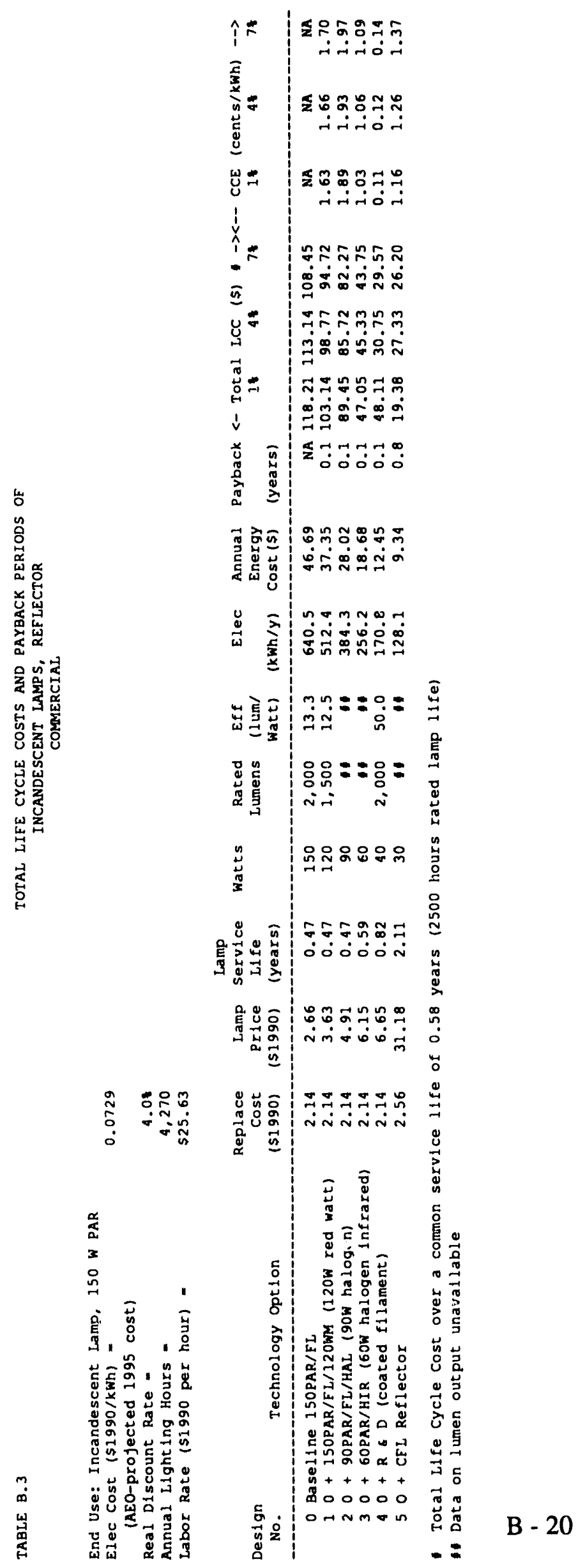


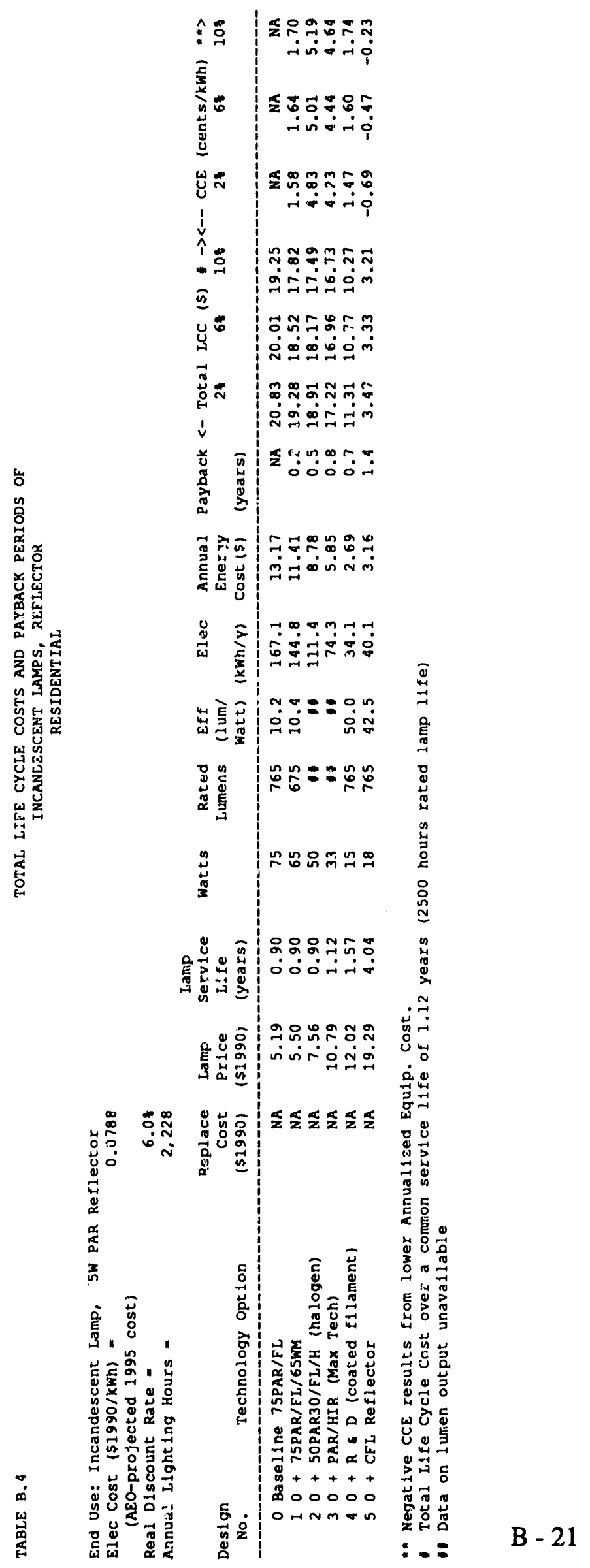



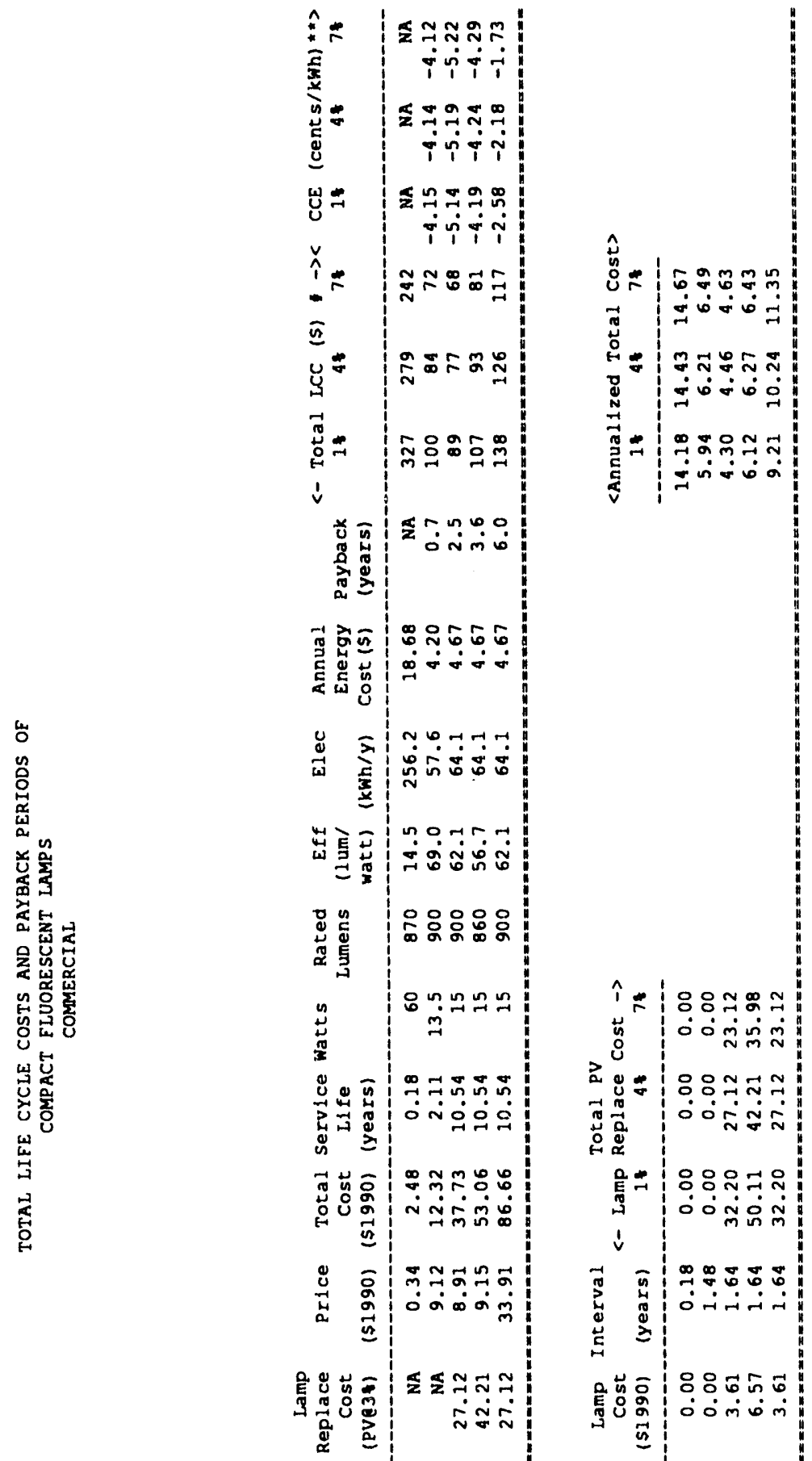

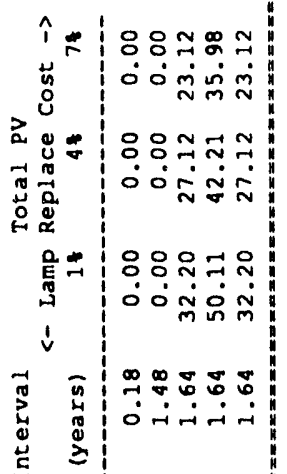

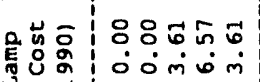

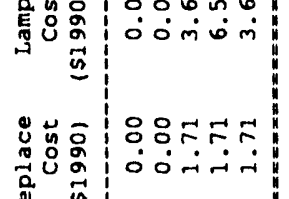

$\overbrace{0}^{n}$

遍 总

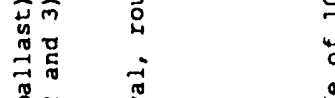

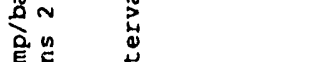

ते है

虫

年

莙点

至

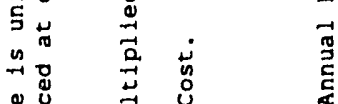

芒

$\therefore$ 峁

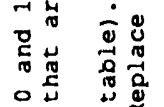

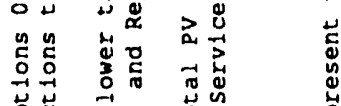

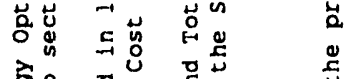

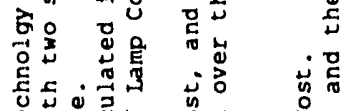

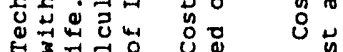

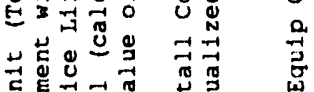

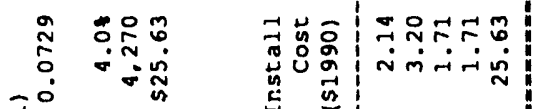

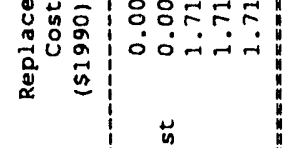

过

局起落

d

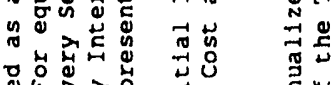

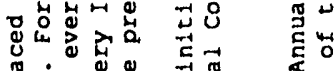

Tंग

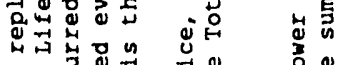

魚

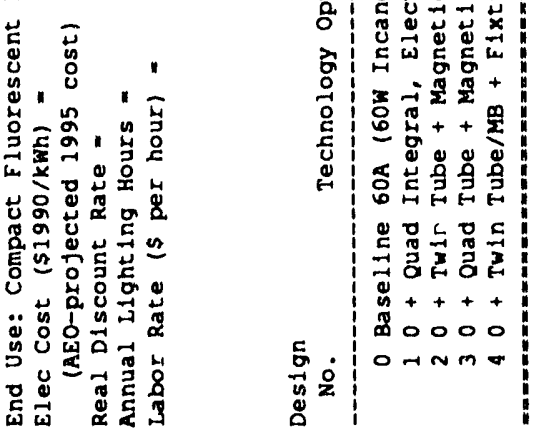

E

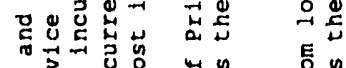

o

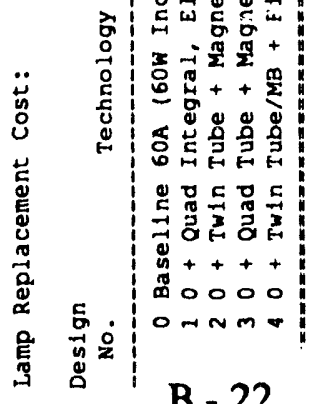

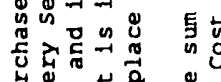

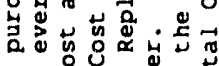

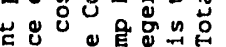

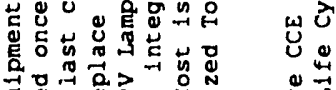

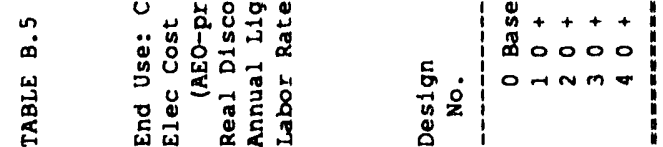

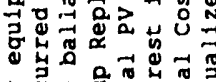

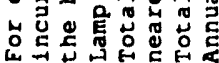

B - 22 


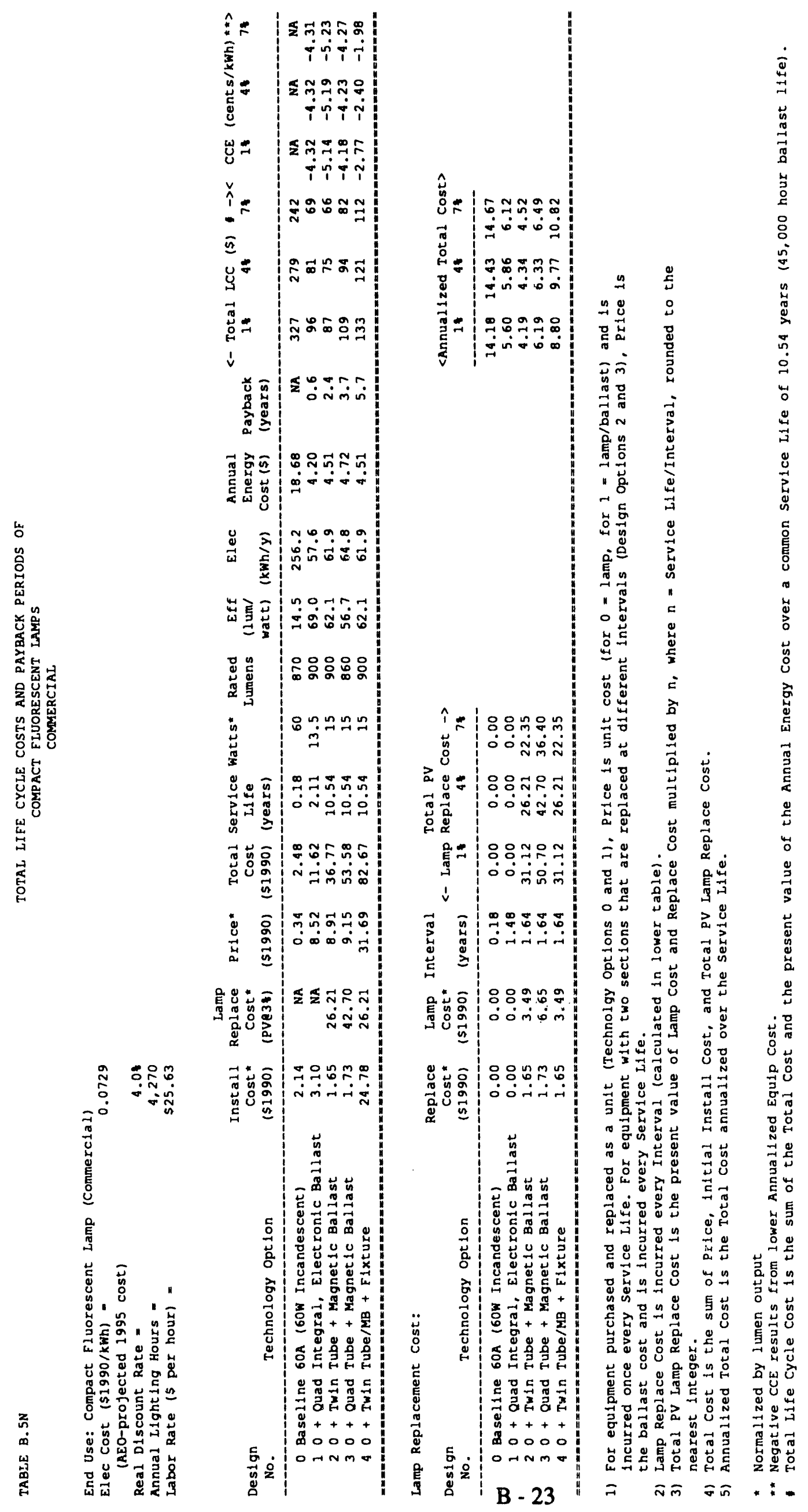



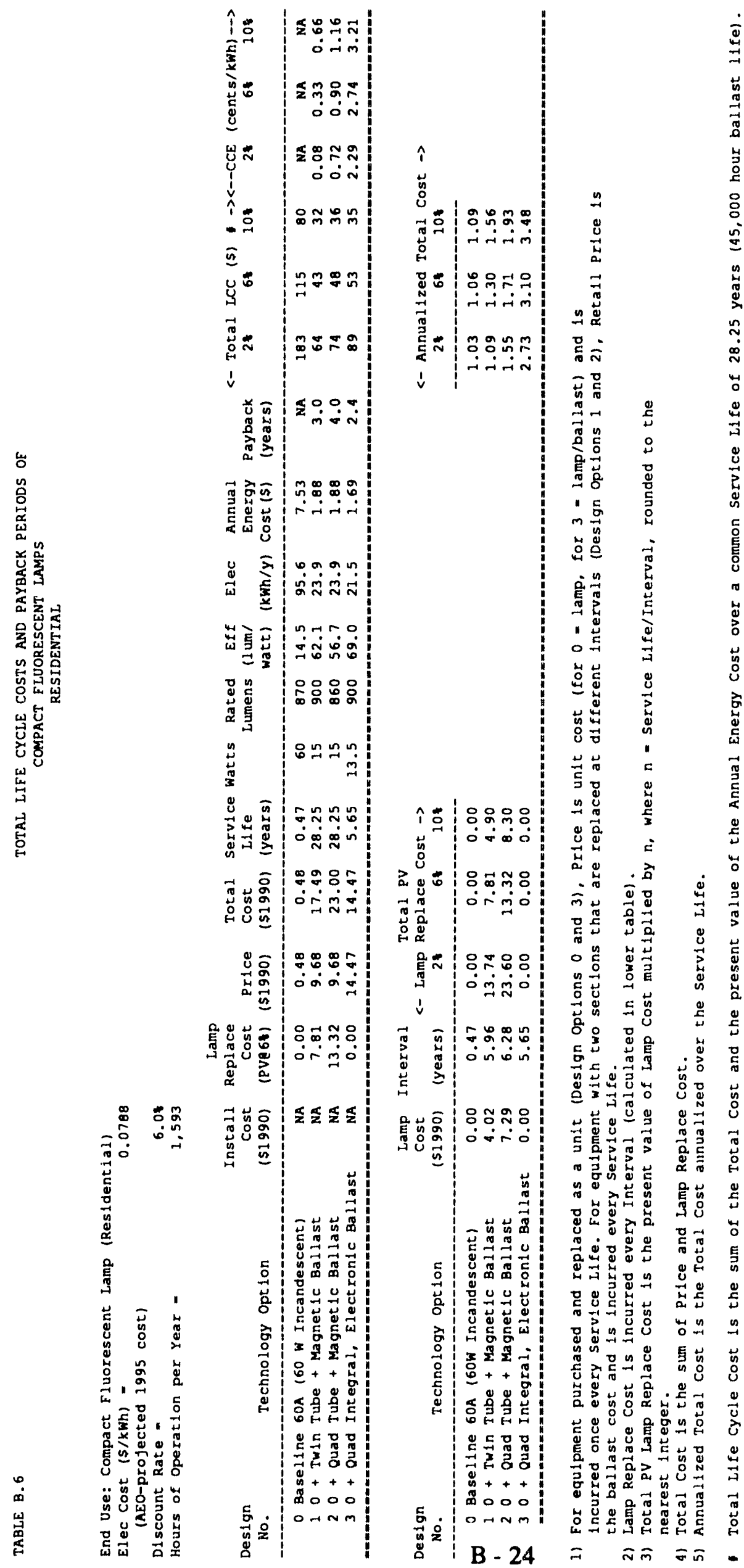
号

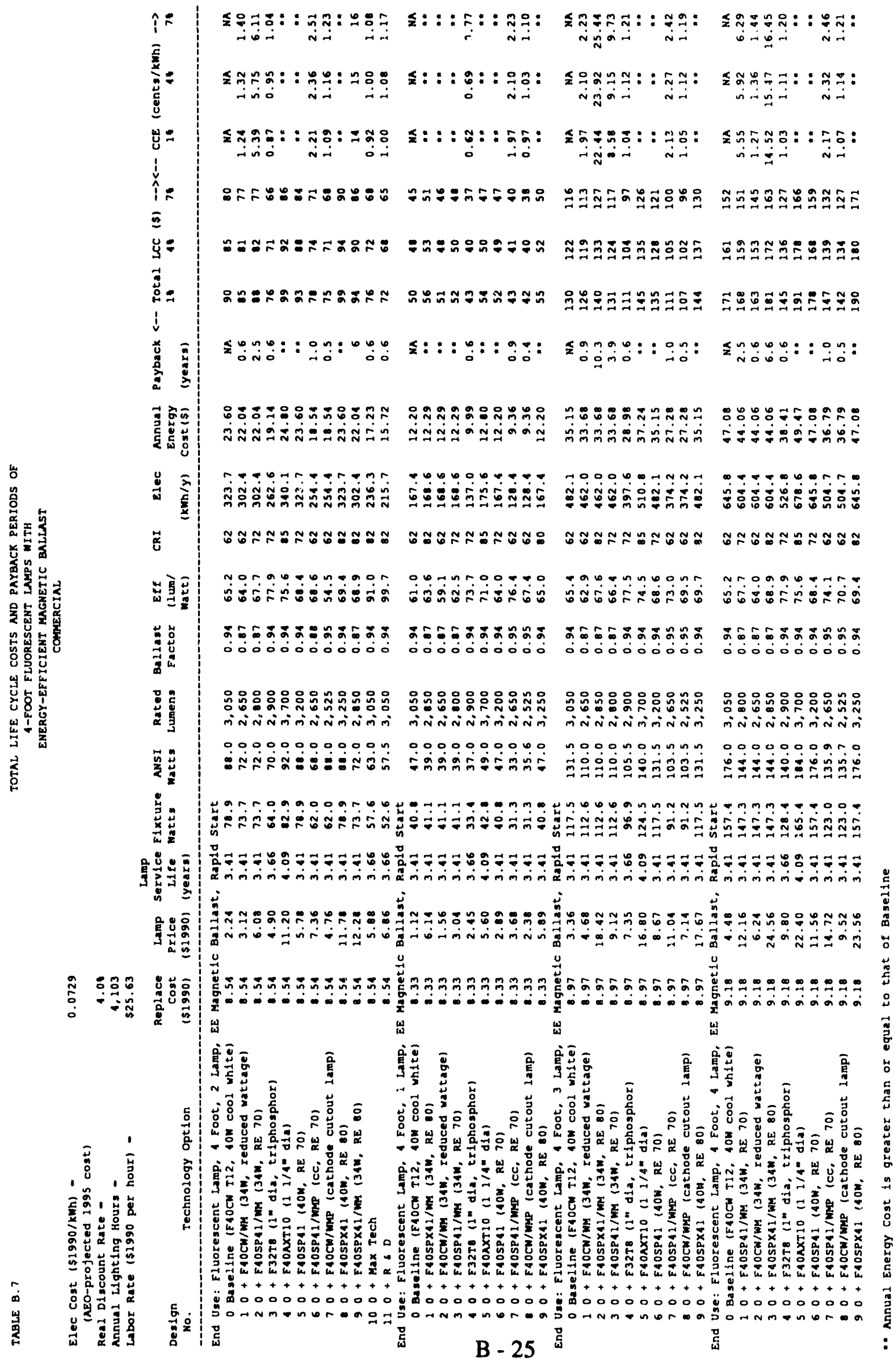


政

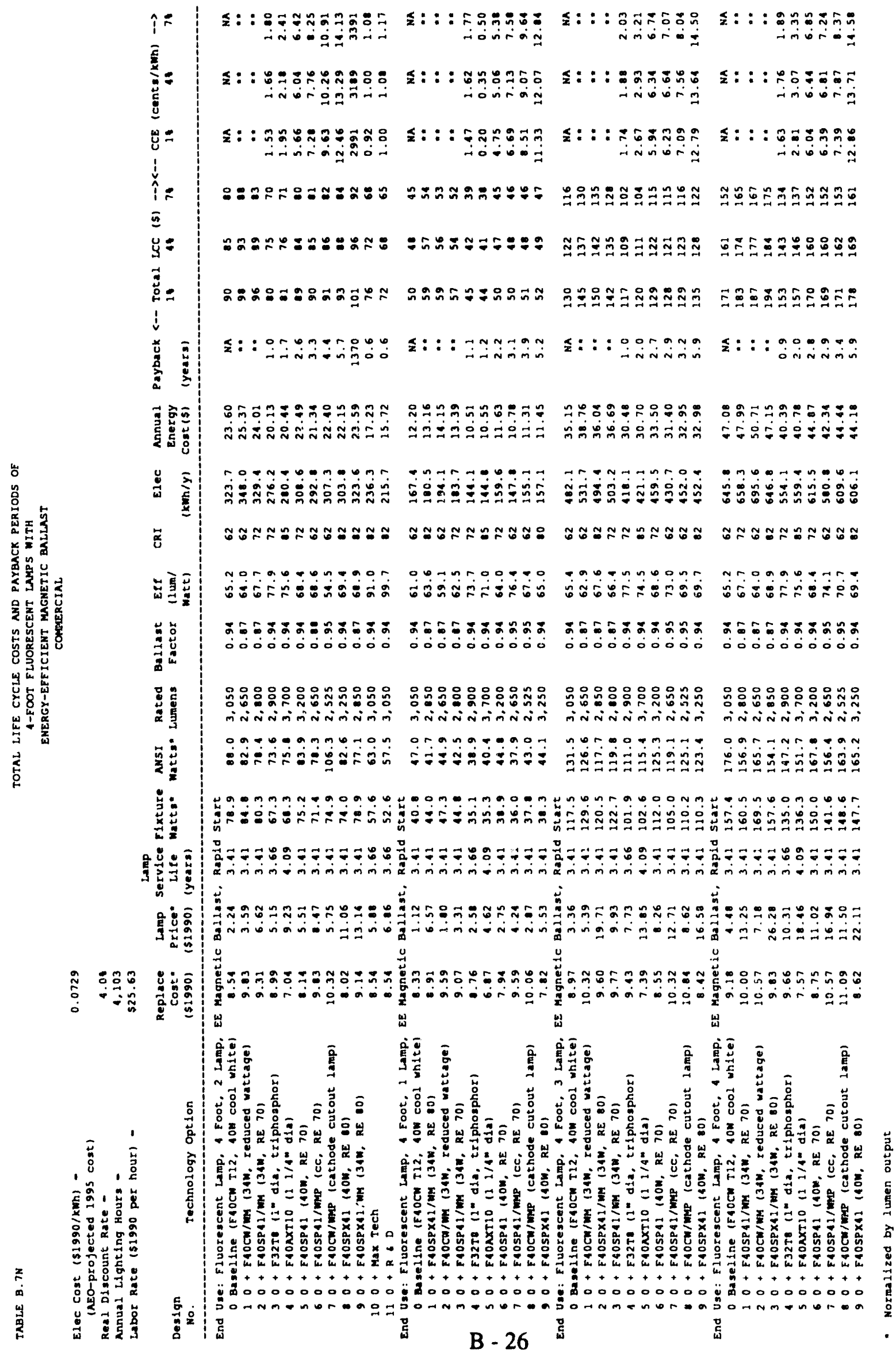




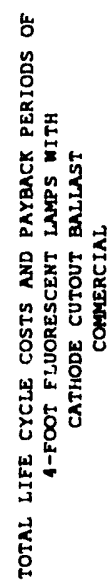

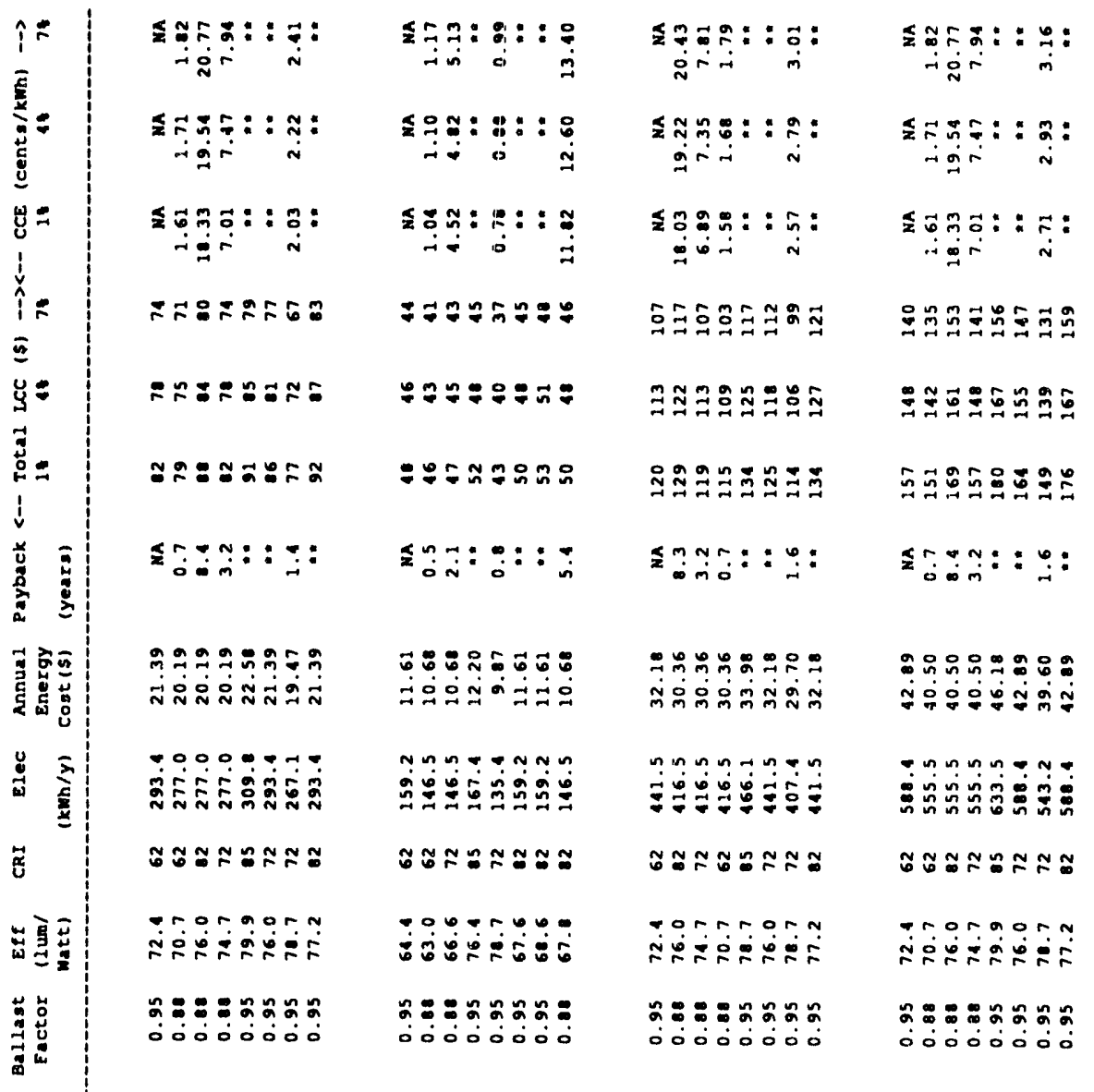
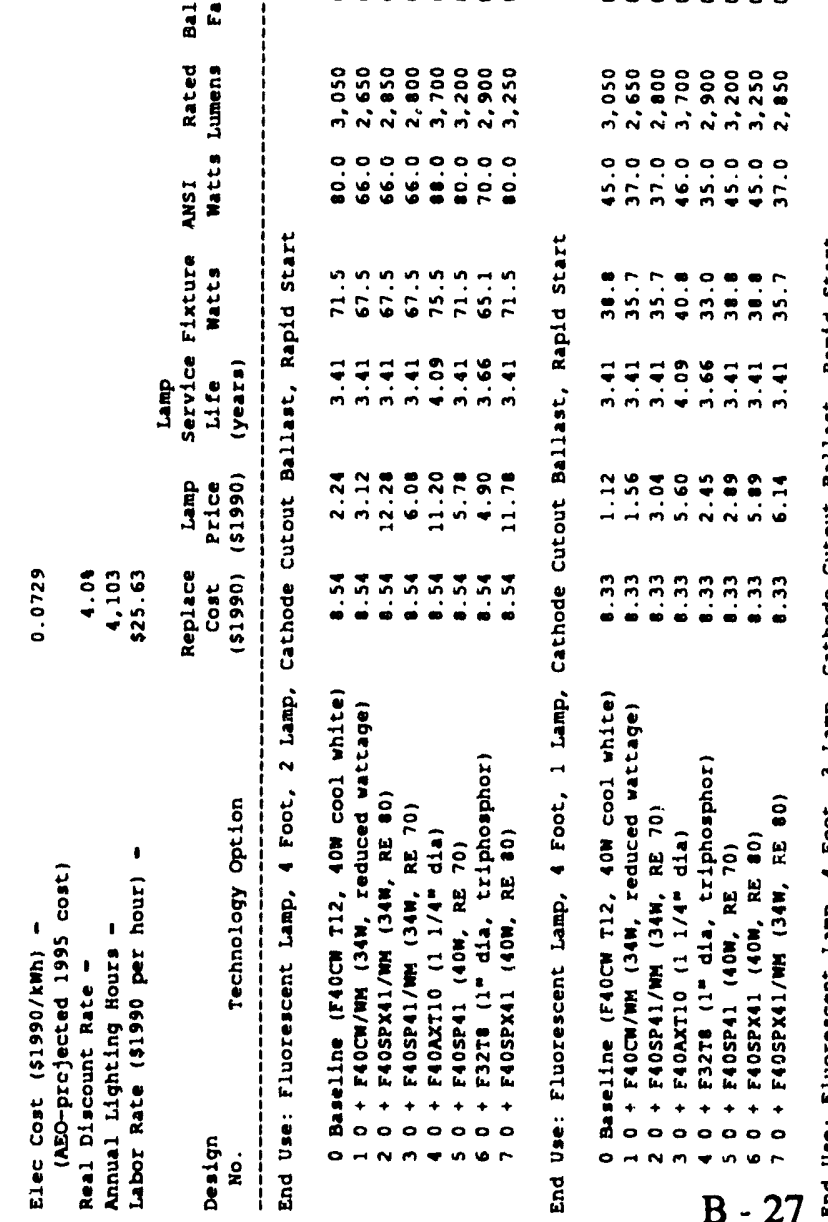

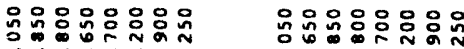

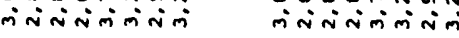

$00000000 \quad 00000000$

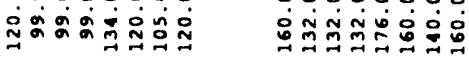
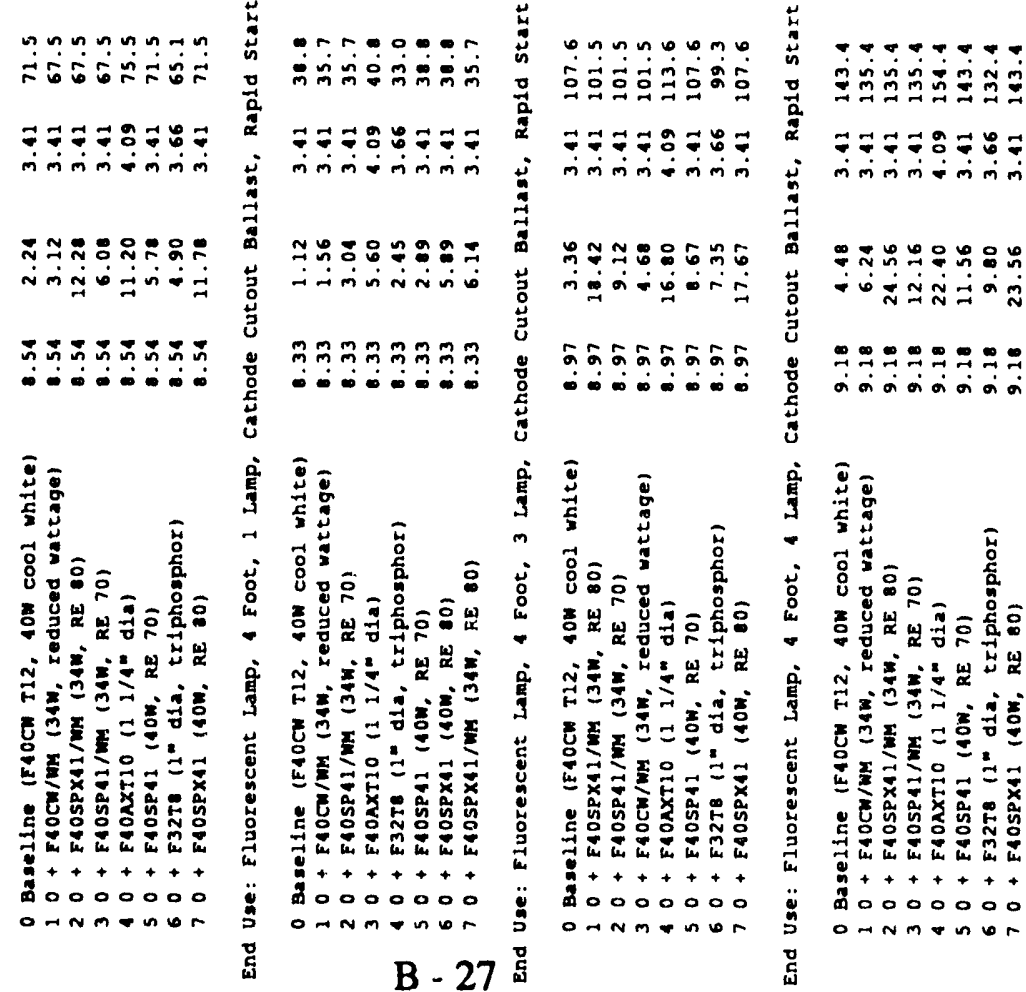


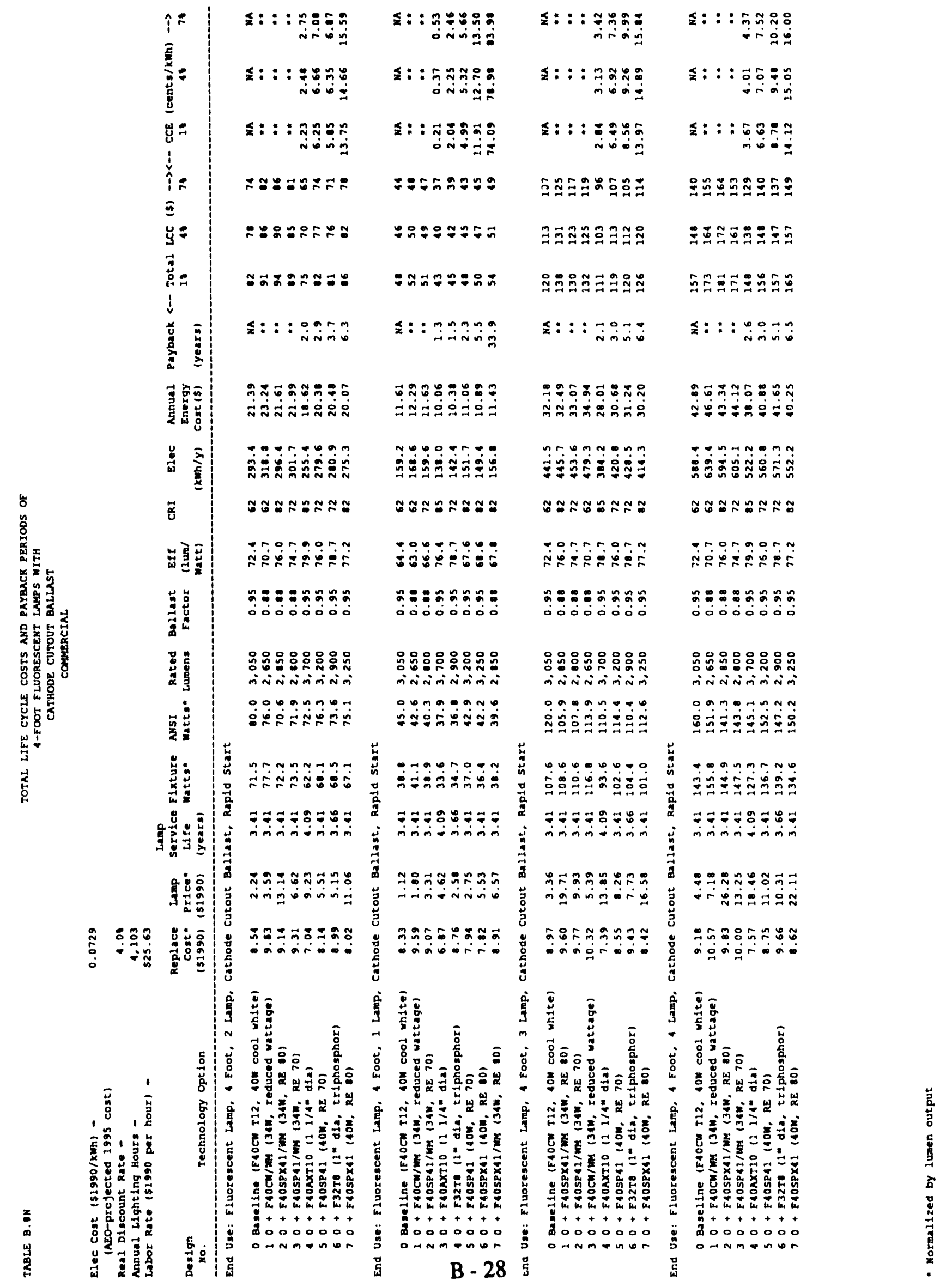



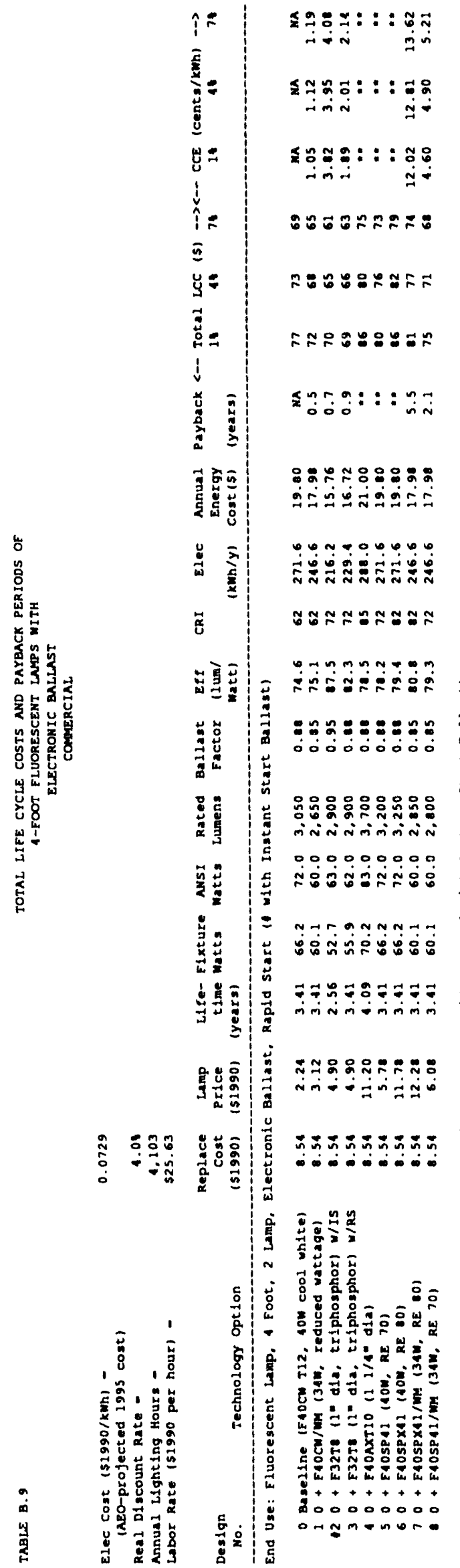

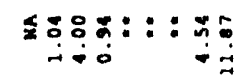

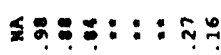

omi

\ู้โฺ: : :

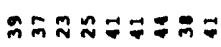

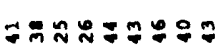

คะัะะะะะท

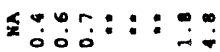

ะํำกะะก ơriogón

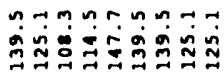

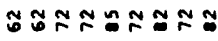

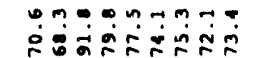

ะะละะะะะะะ

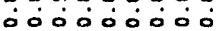

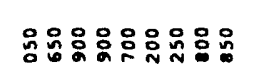

ininiminin

000000000

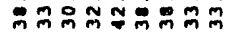

0n 00000 n

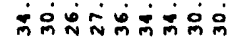

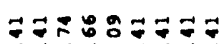

ininiminim

ำกะะด ะัะ

inivinisino

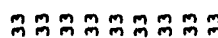

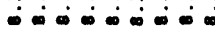

จำ

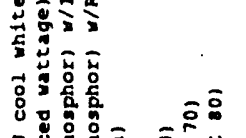

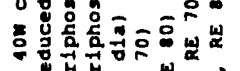

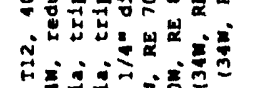

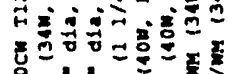

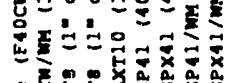

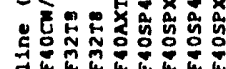

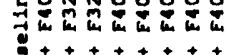

कि0000000

arnmonson

B - 29

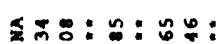

i⿻

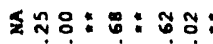

in

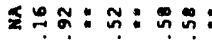

तं

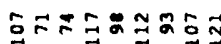

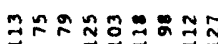

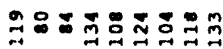

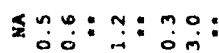

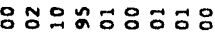

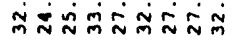

等

แกะ

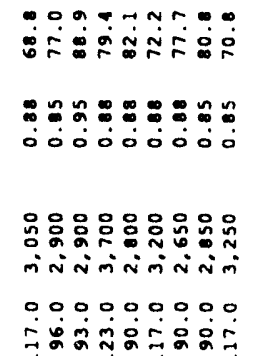

omanmommo

อั

Fะ゚ロ

minitiming

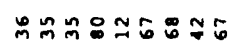
miñson

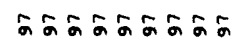

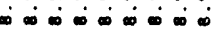

牙是

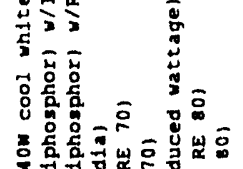

울

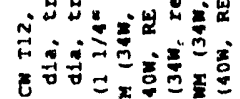

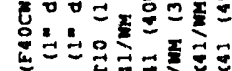

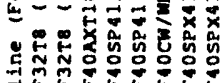

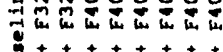

Dotot+t+a

onnmonor
รกำำ: : :

ระดำ:

तN

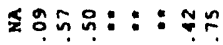
त成

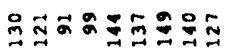

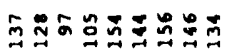

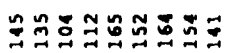

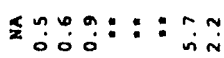

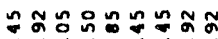

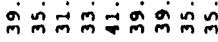

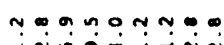

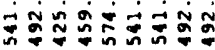

กับะกักับ

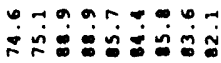

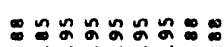
ó0ं0000

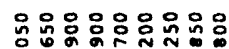
iniNininini

000000000

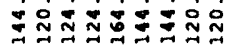

at ooganar

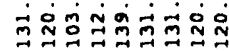

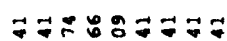

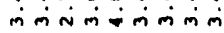

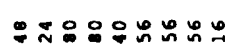
- oo

$\stackrel{\infty}{\infty} \pm \infty \pm \infty$

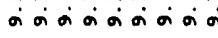

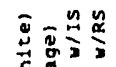

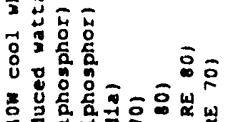

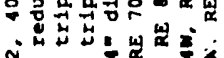

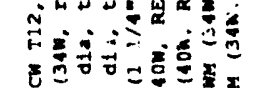

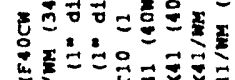

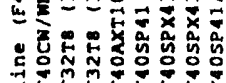

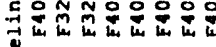

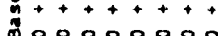
o-Nmonoro 


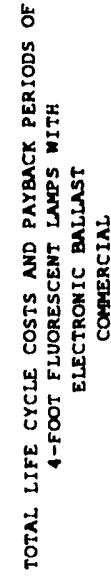

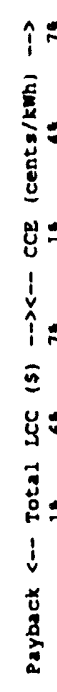

$\leq: 8 \div \div 8: 50$

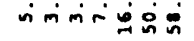

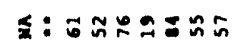
vinivis

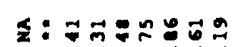

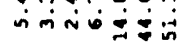

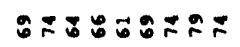

a

y.

总:

i

葛

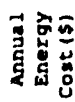

苔

$\tilde{\mathrm{B}}$

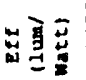

蓄

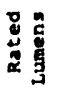

蒙蓄

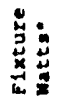

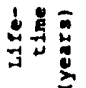

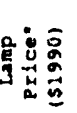

产

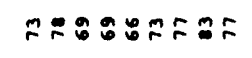

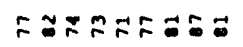

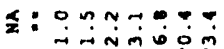

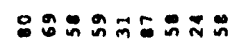

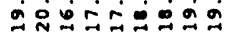

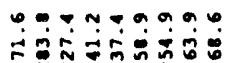

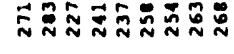

ธะกะบะ ะะก

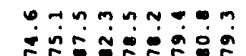

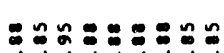

óo000000

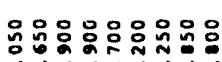

inivisinimivis

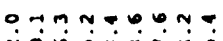

กิด

n $T-9-7 m n$

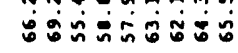

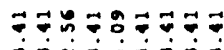

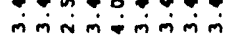

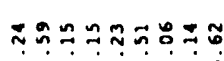

vinution

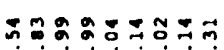

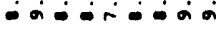

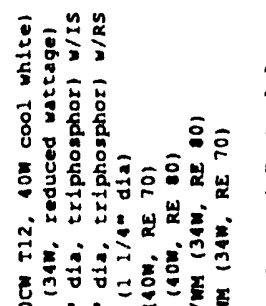

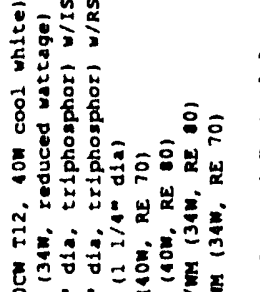

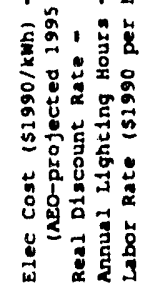

ธ: :

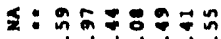

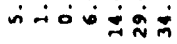

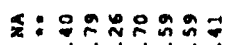

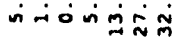

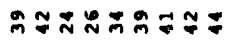

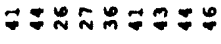

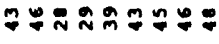

$\Sigma:$ :

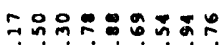

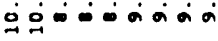

noarooma

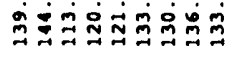

ธะกะะกะะะ

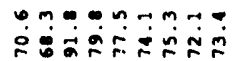

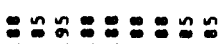

o00000000

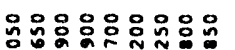

invisiviminivi

oourunram

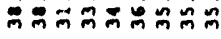

o-amr-ano

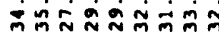

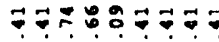

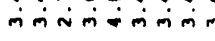

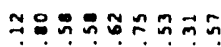

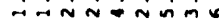

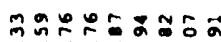

ondotorias

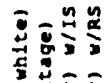

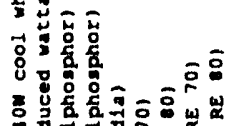

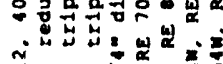

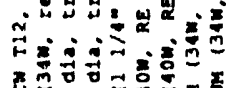

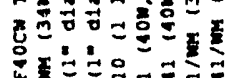
重政

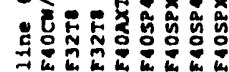

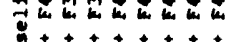

1 0000000

o-nm-nor.

B - 30

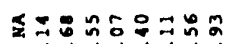

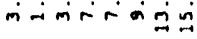

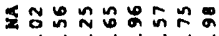

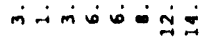

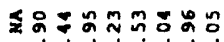

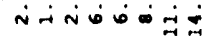

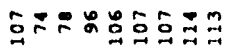

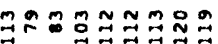

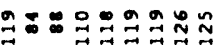

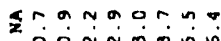

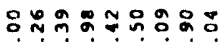

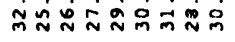

onogor mo

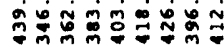

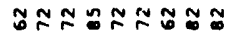

modo.

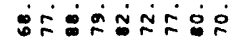

\$ะ

000000000

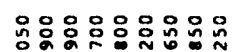

ivinimivinition

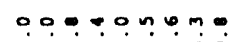

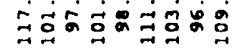

onnoroabr

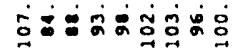

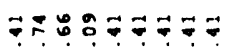

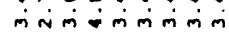

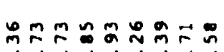

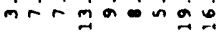

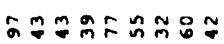

कorariono

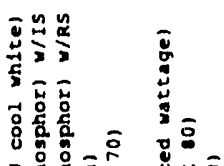

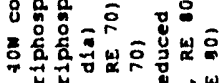

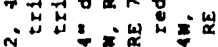

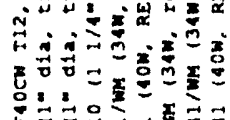

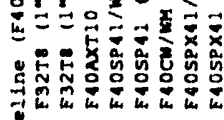

....+...

ondonoo

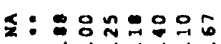

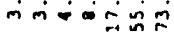

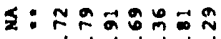
inimring

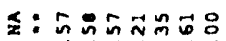
कितिए

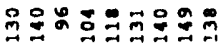

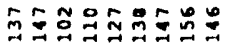

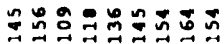

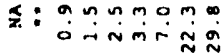

ษนกำ

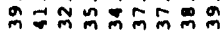

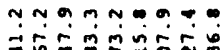
ชธะกะะะฐก

$07 a, r-0.7$

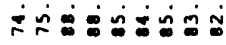

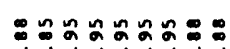
ó0.0.0.0

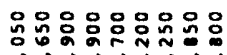
minisiminis

문?

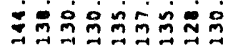

oñ⿻m-on

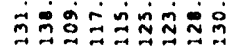

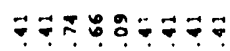

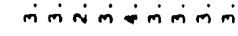

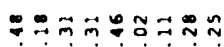
-

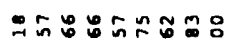
कóarióso

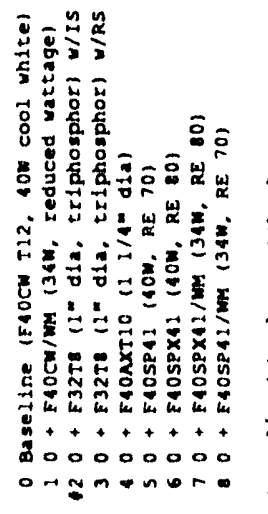




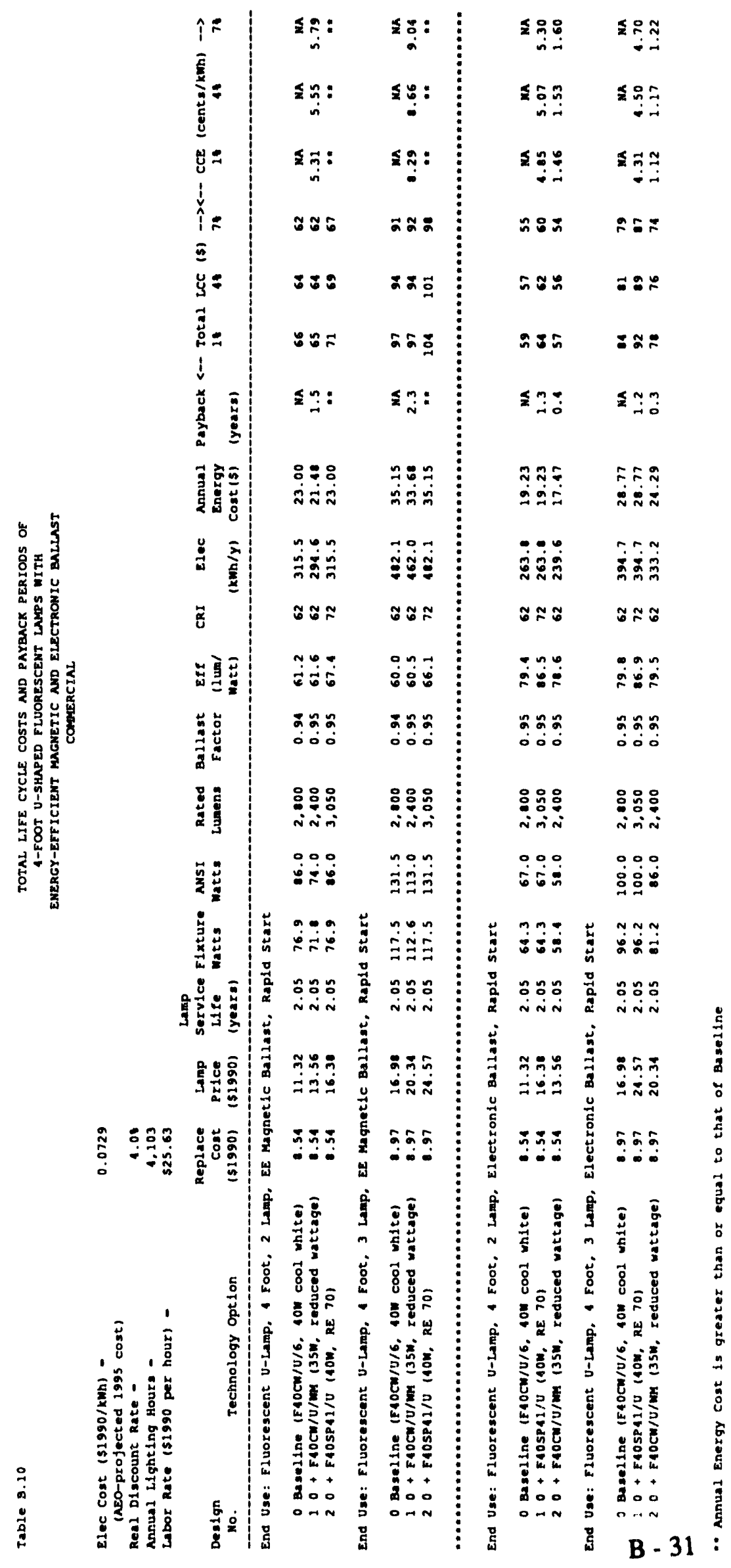




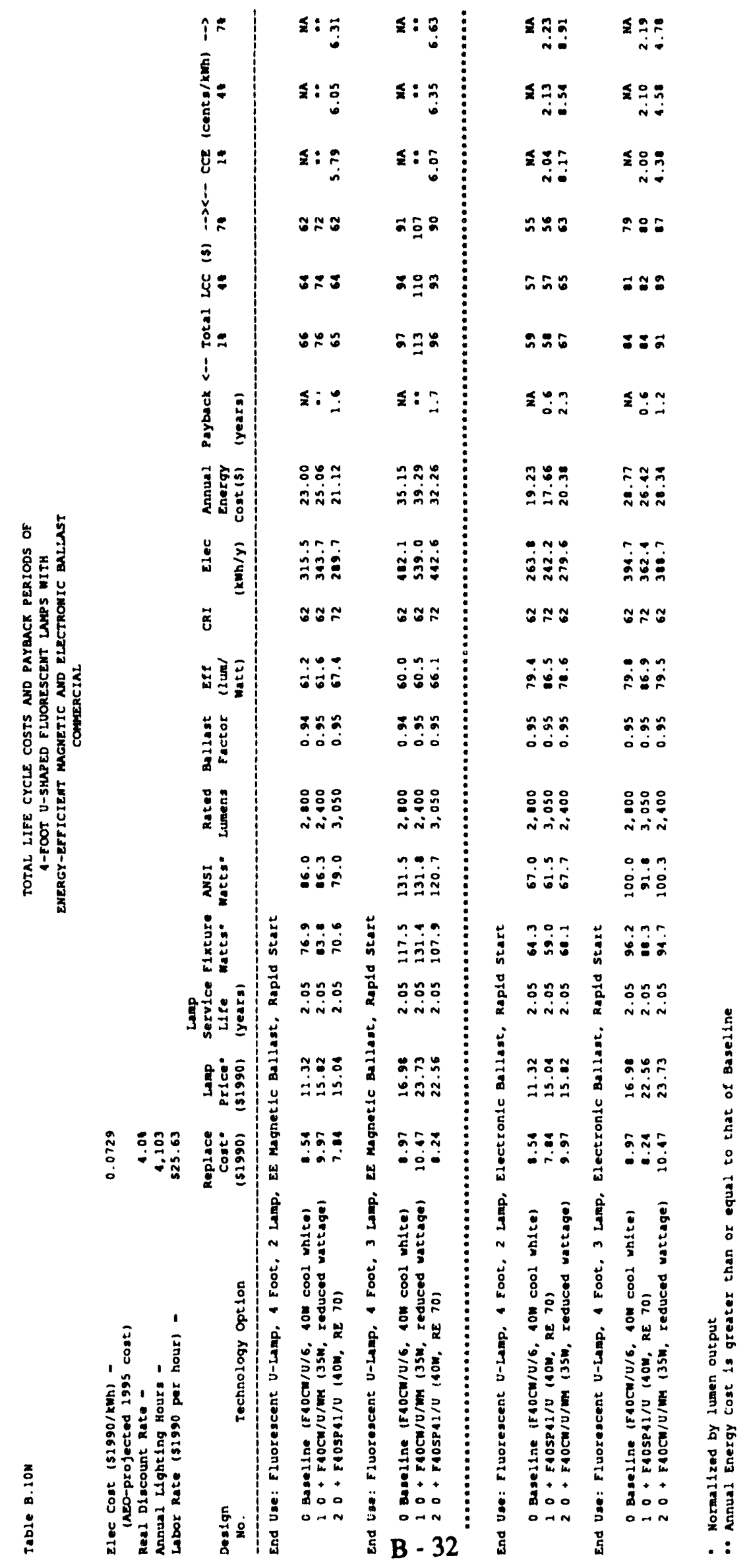




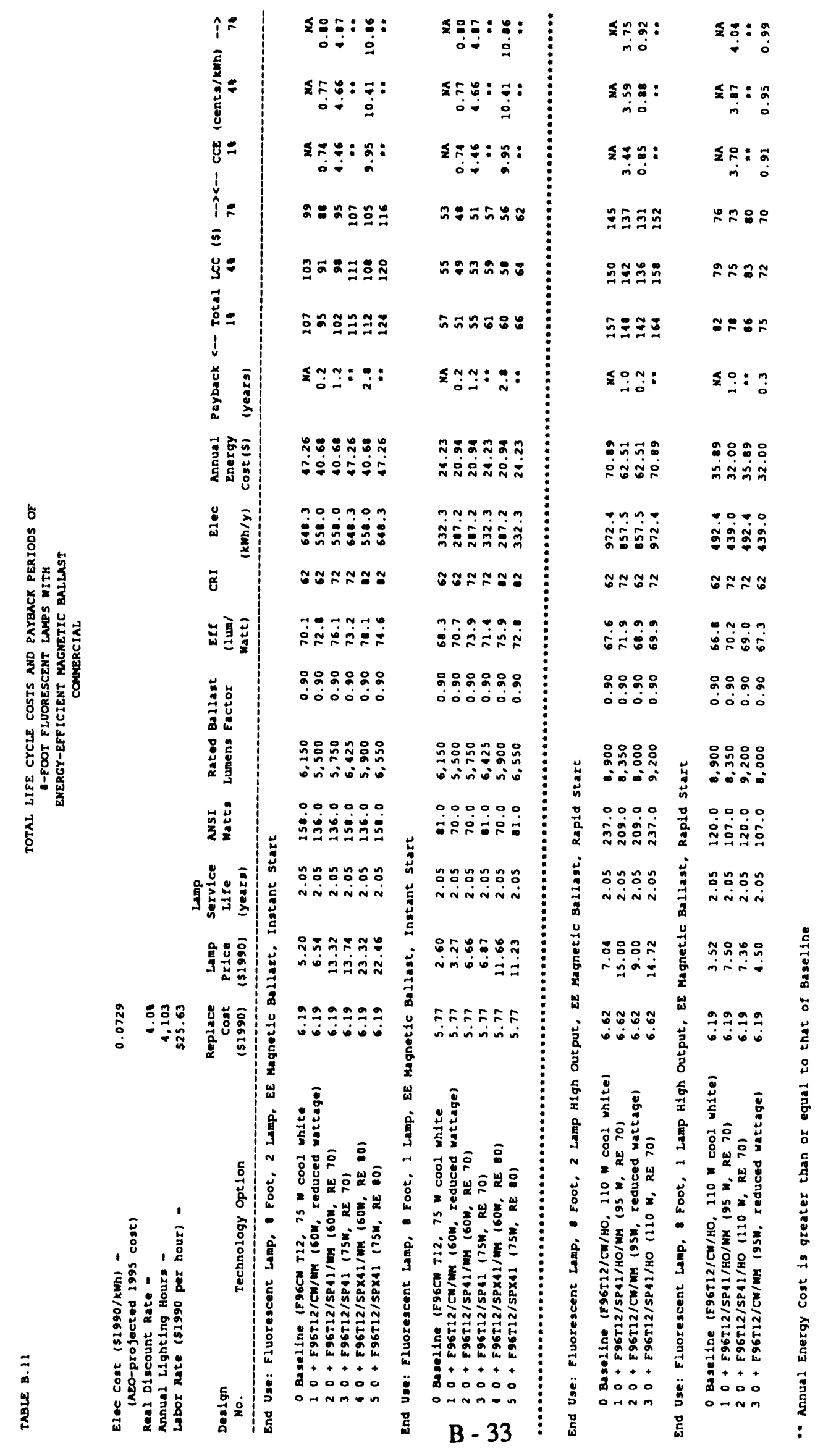




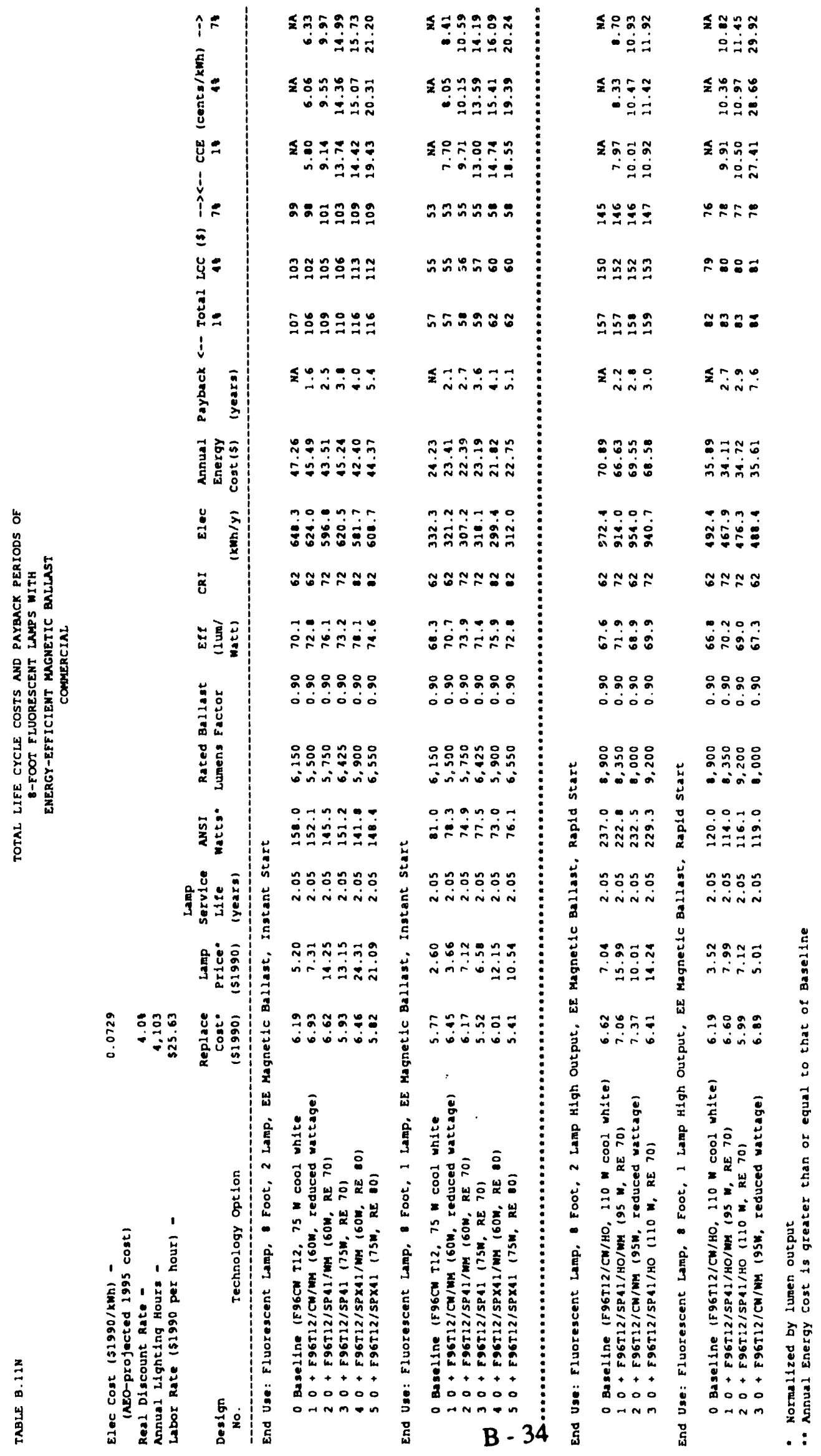




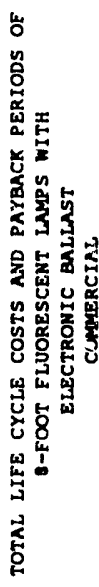

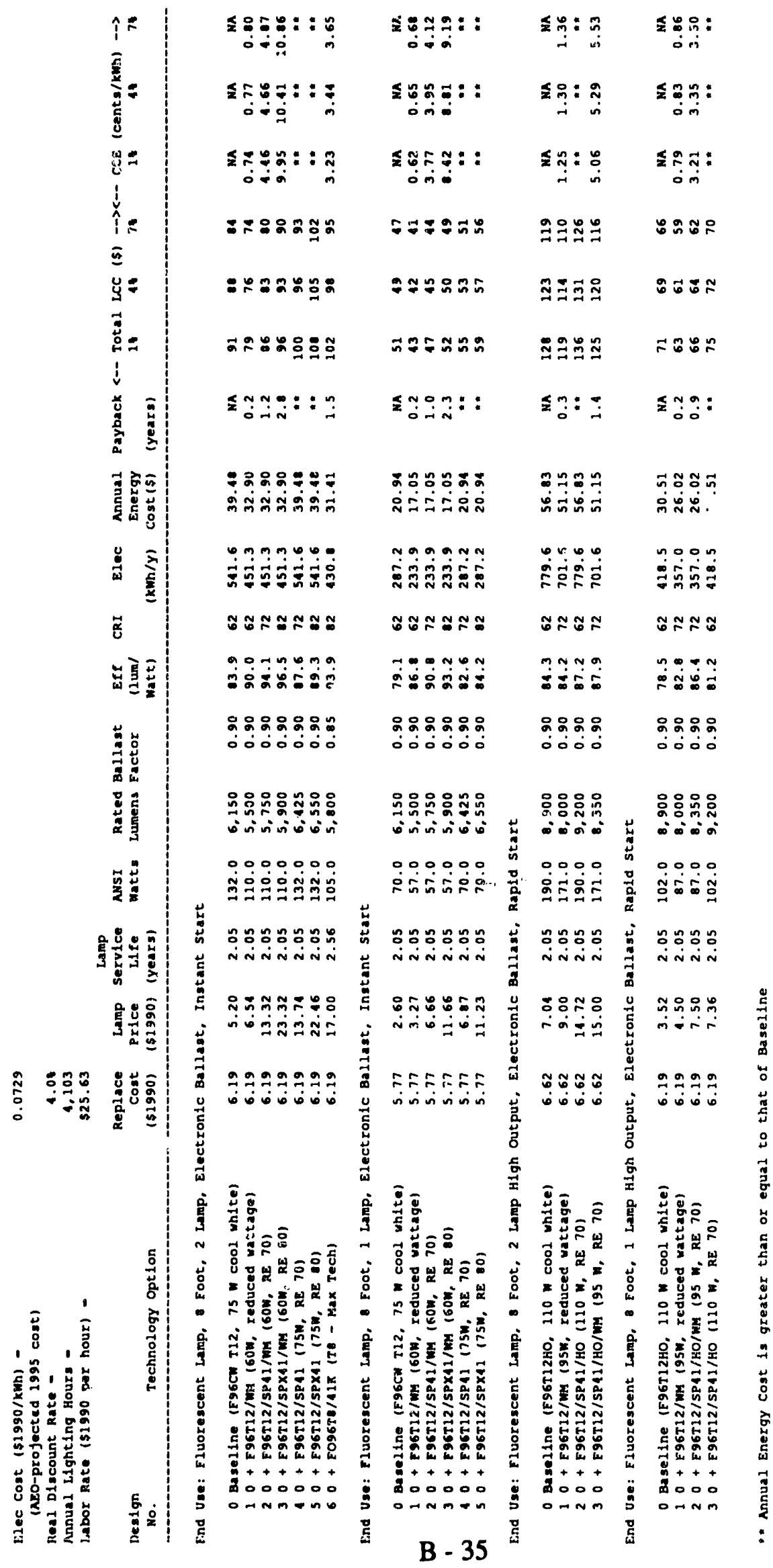




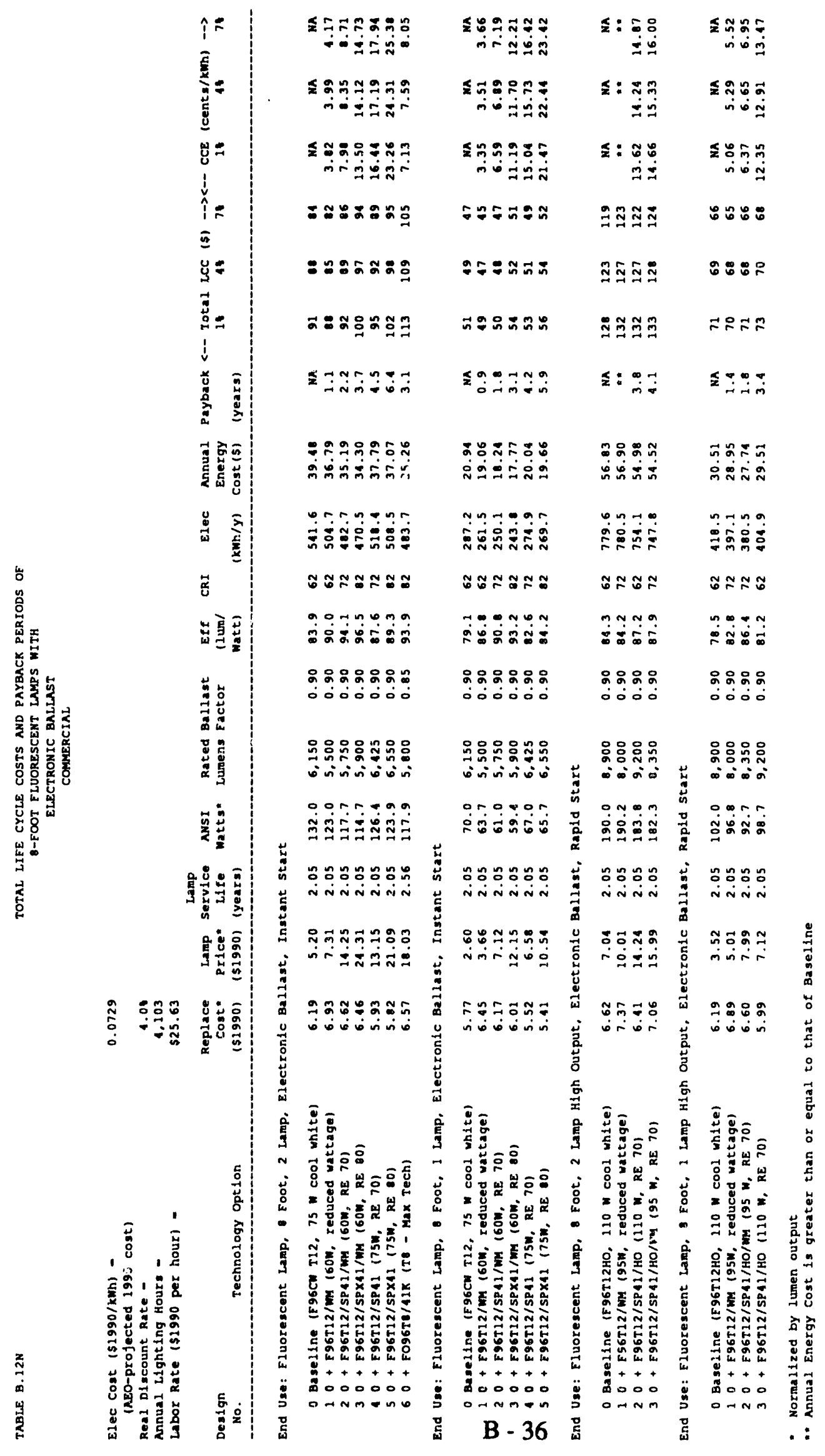



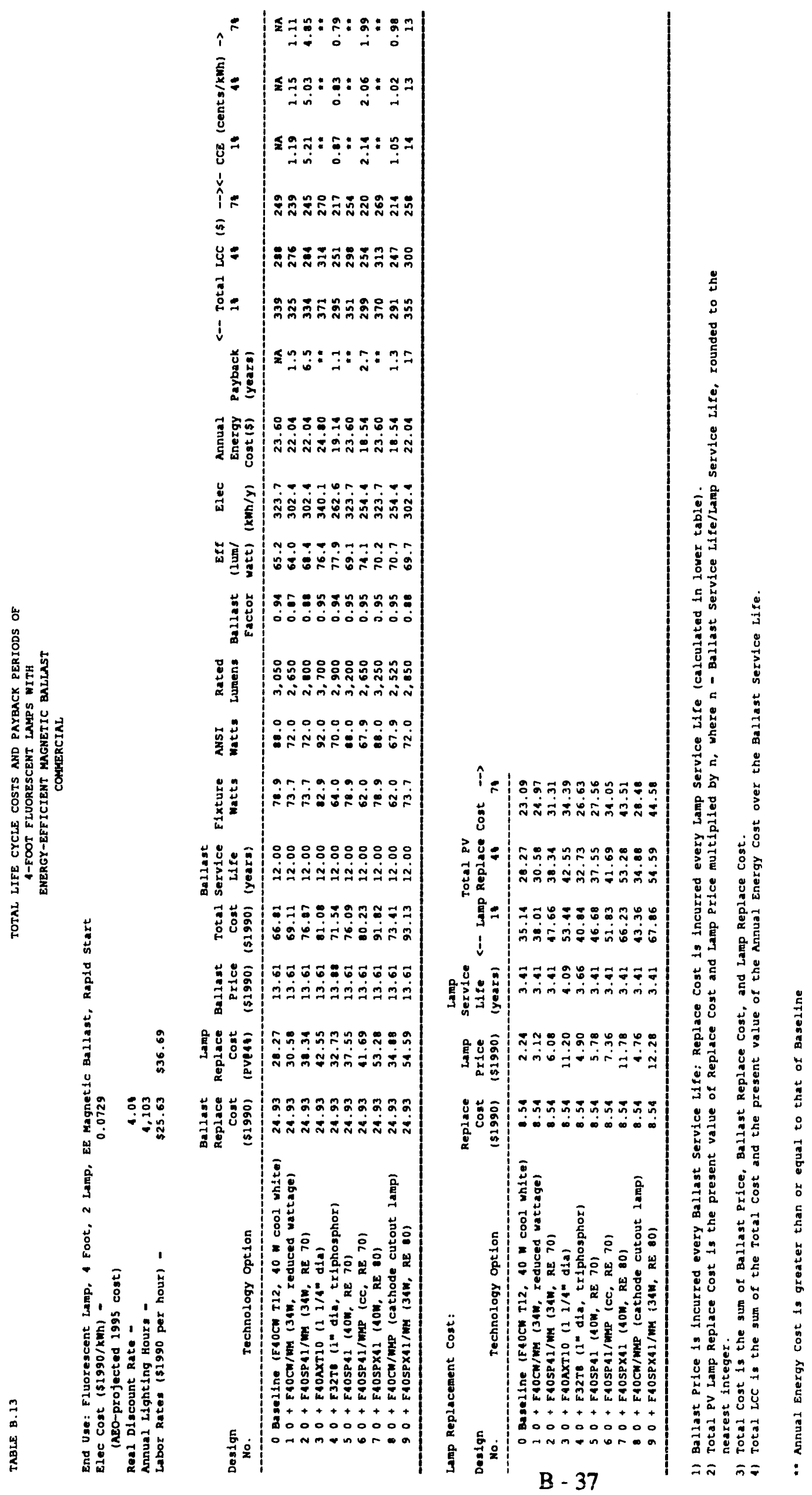


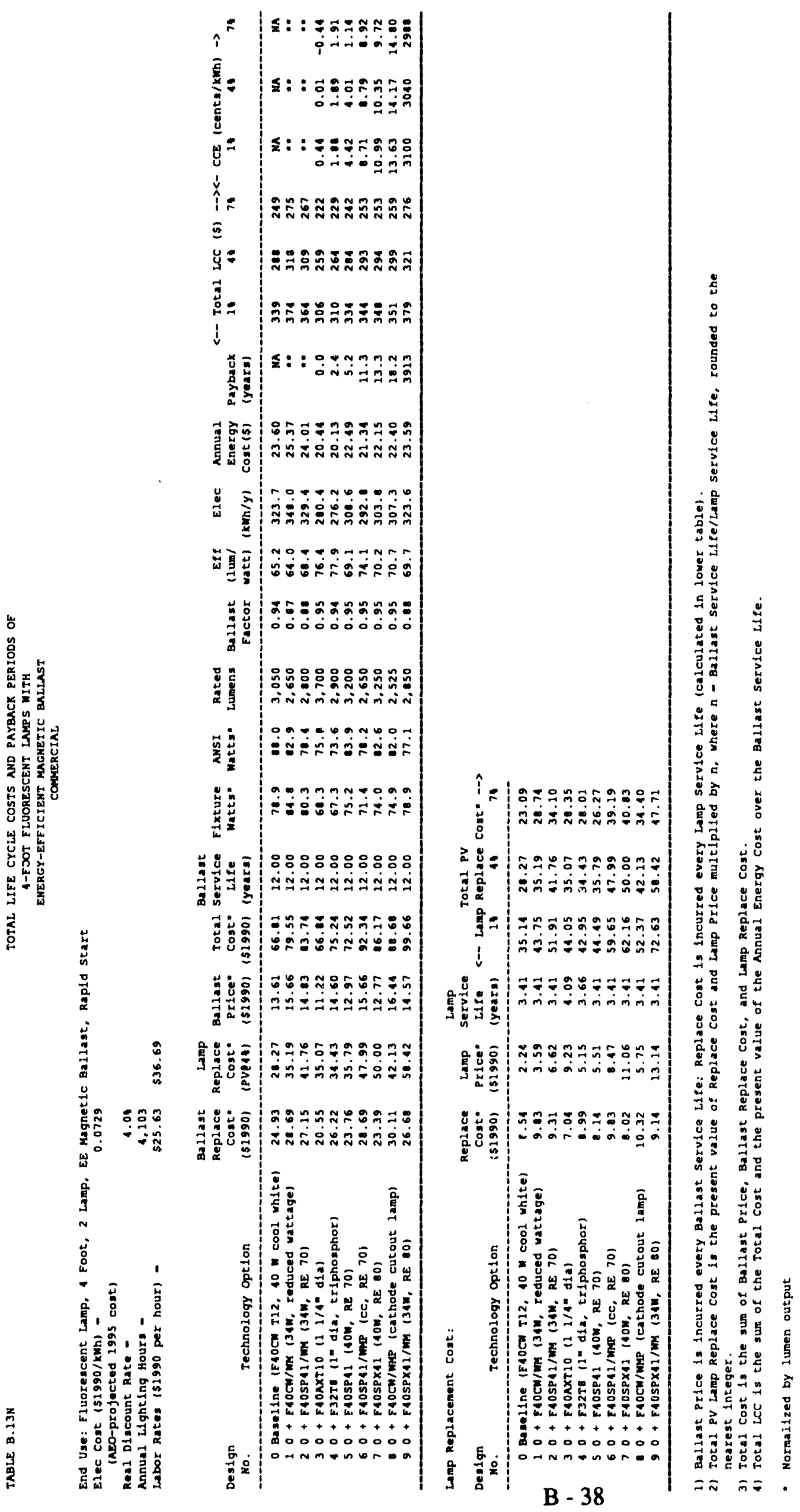




\section{年}

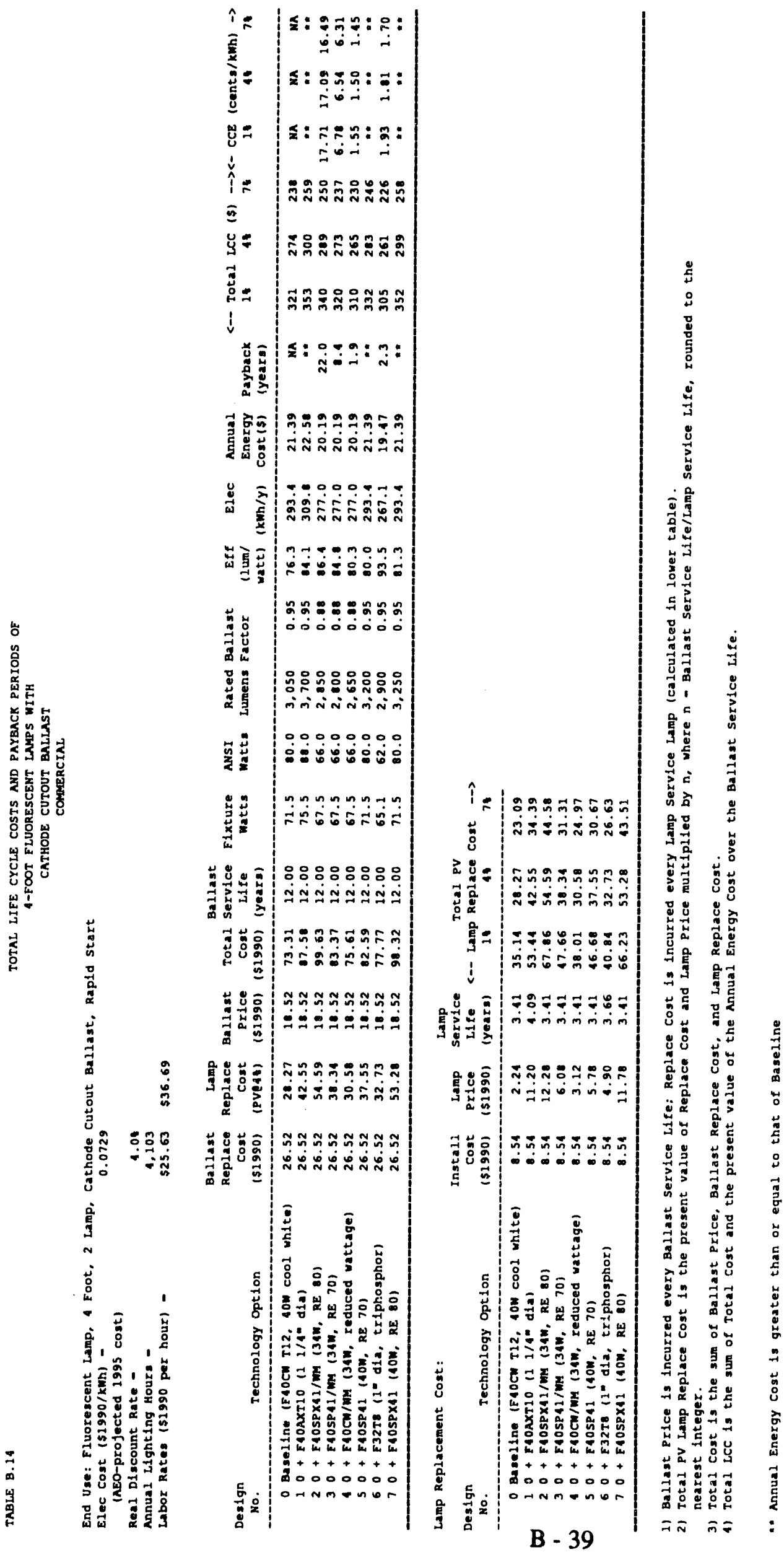




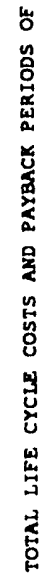

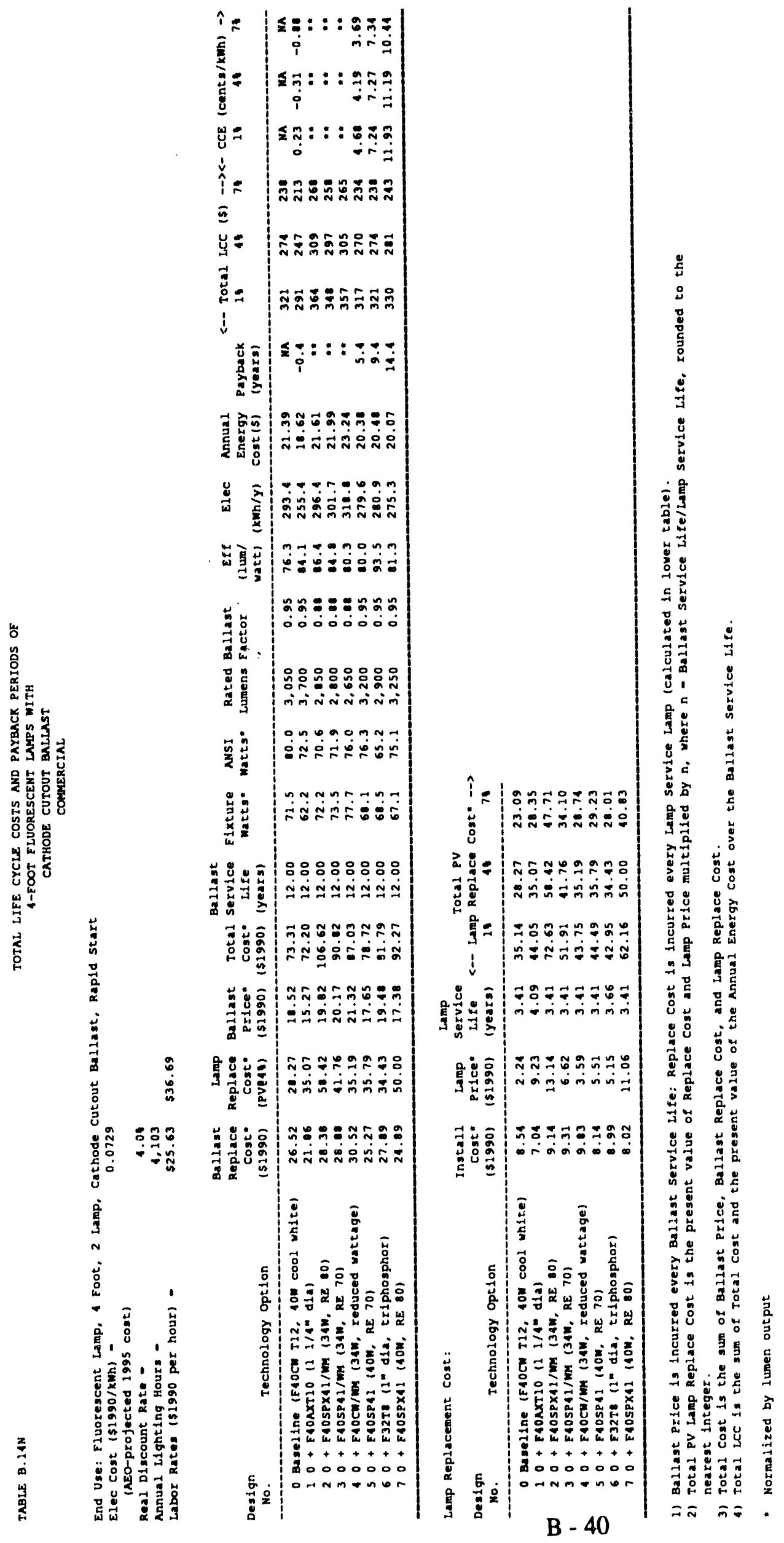




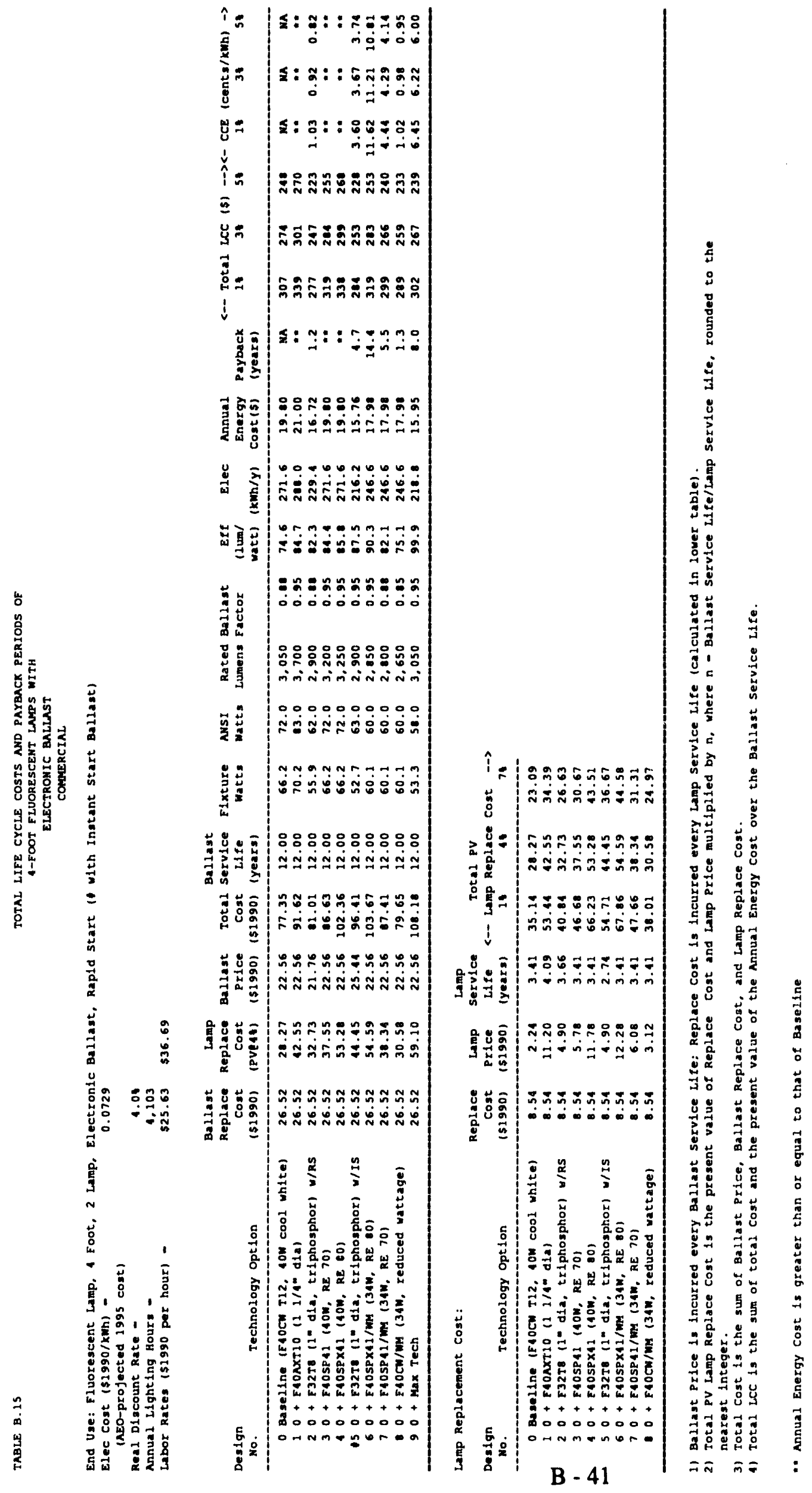




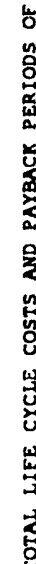

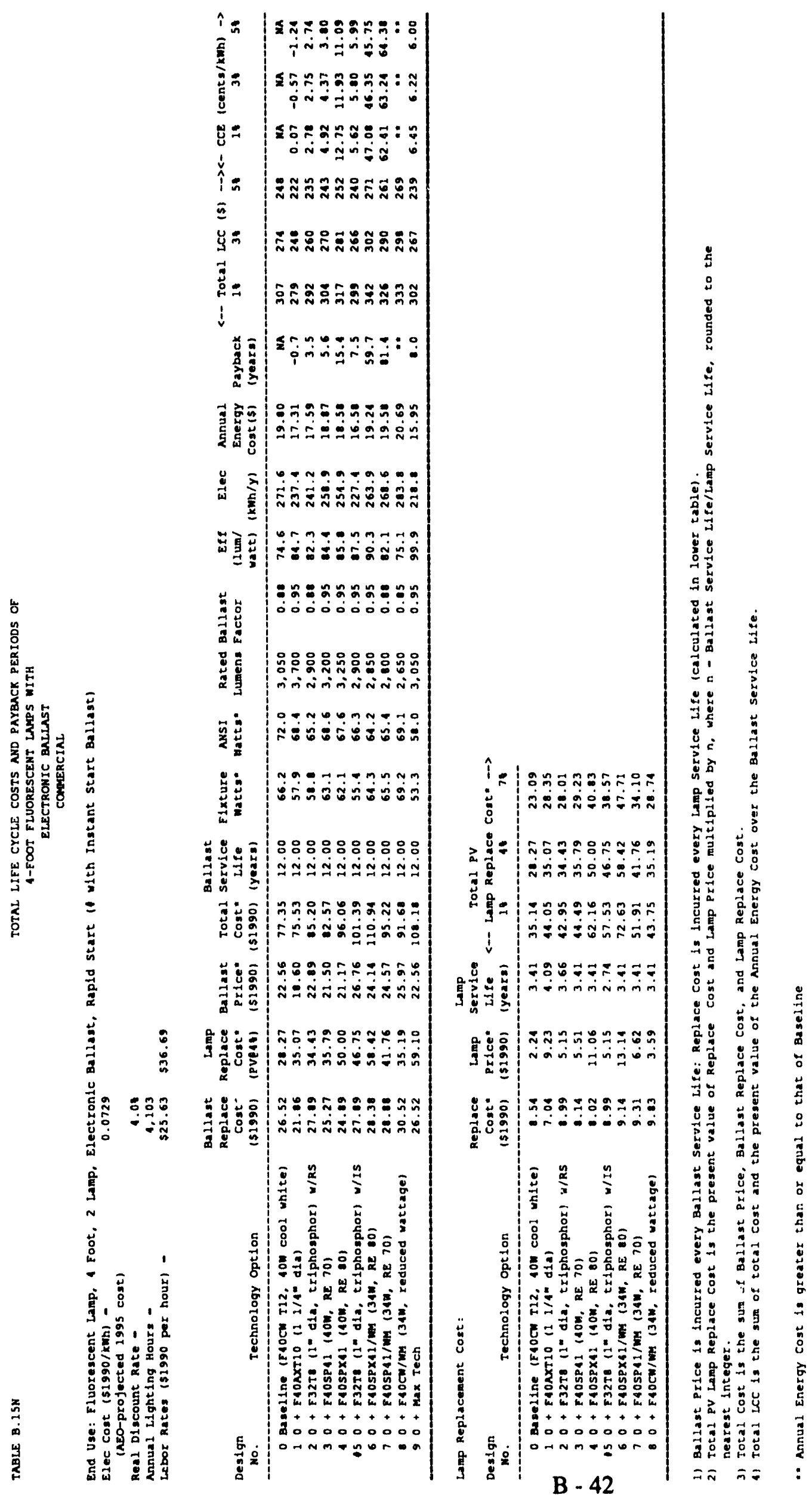




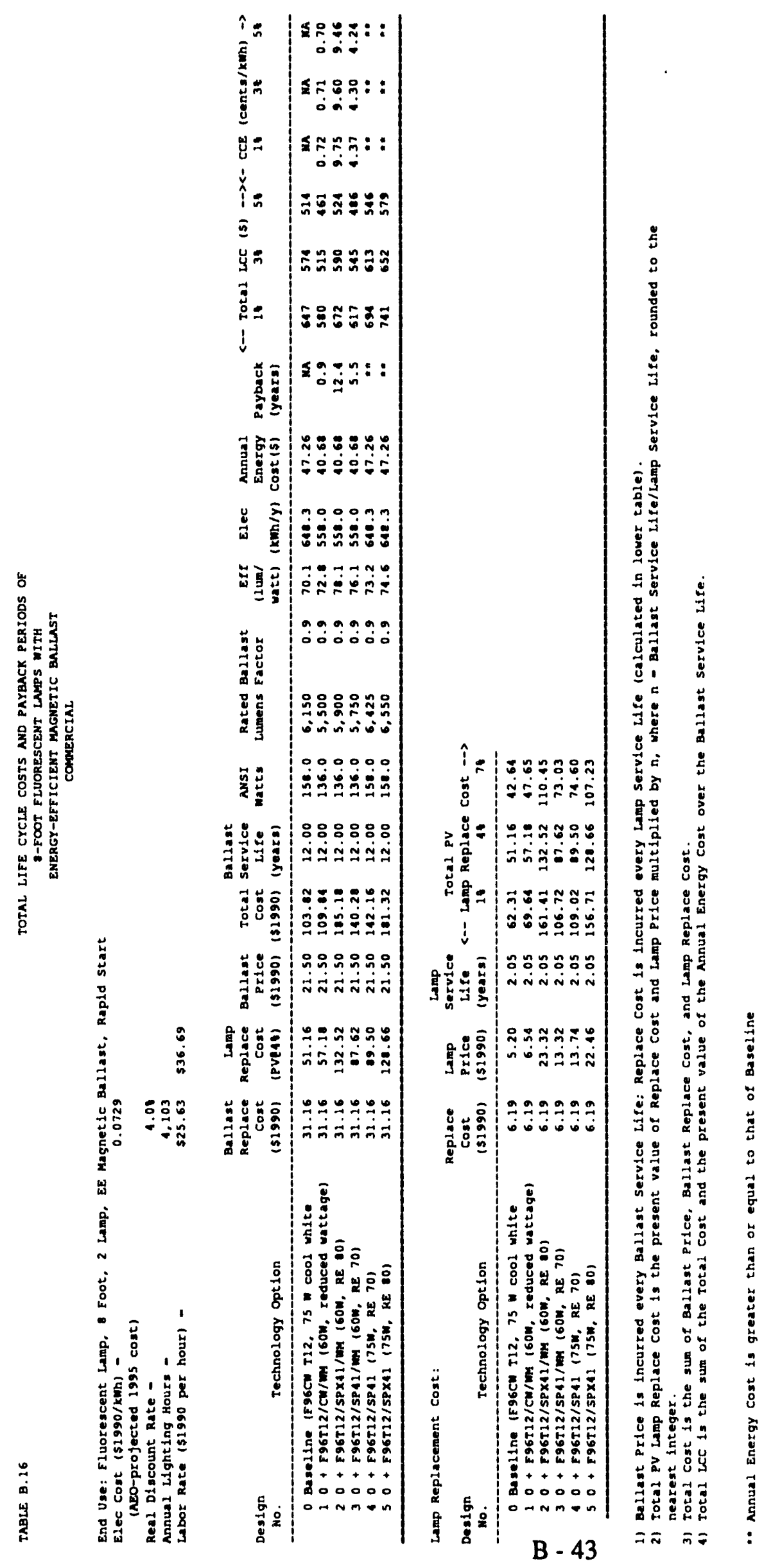




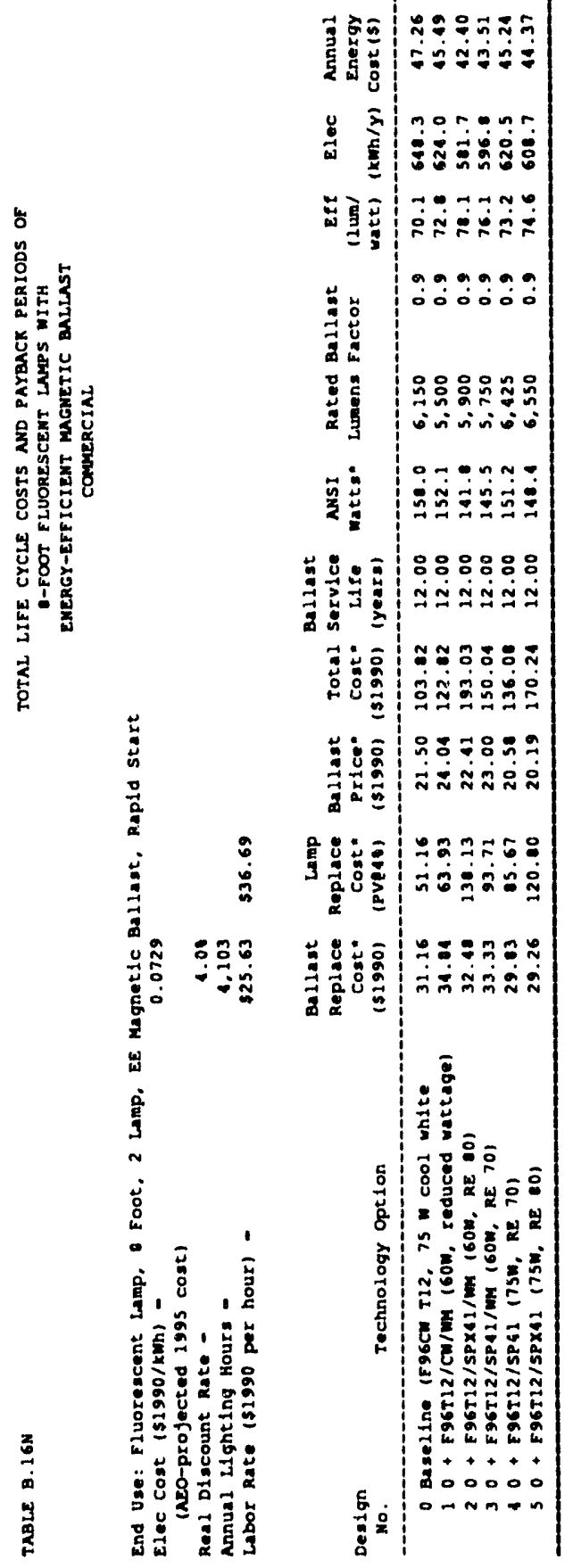

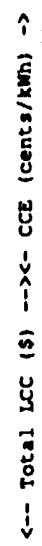
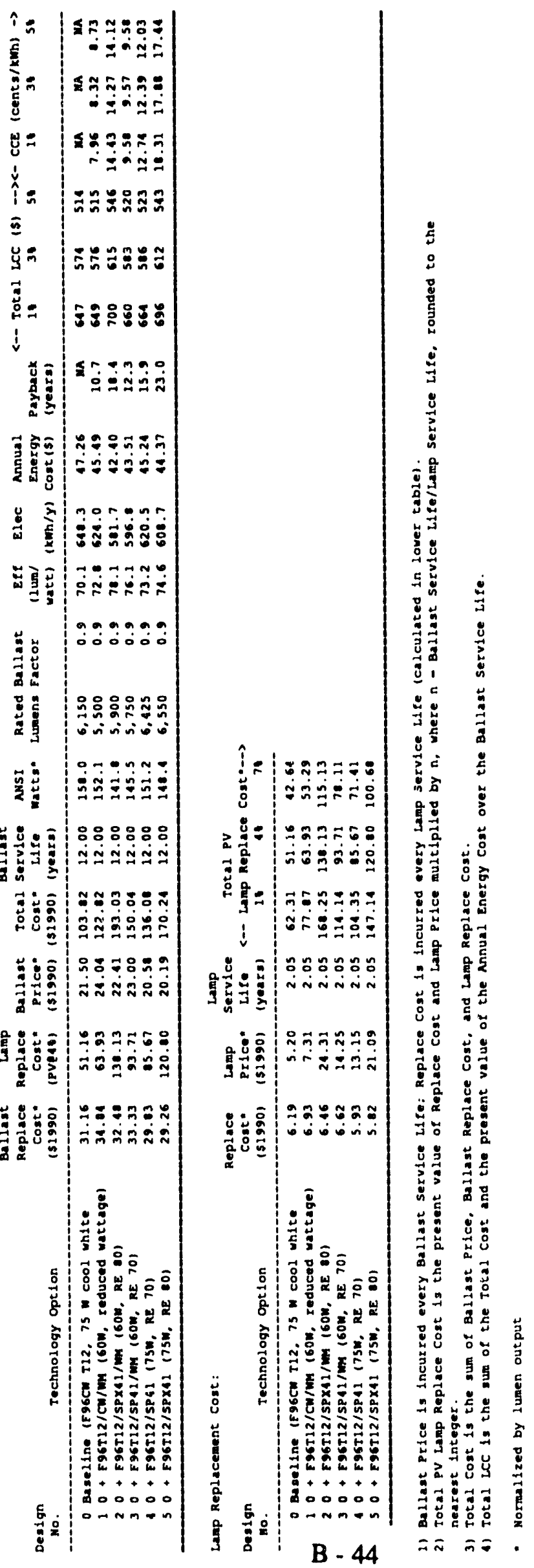


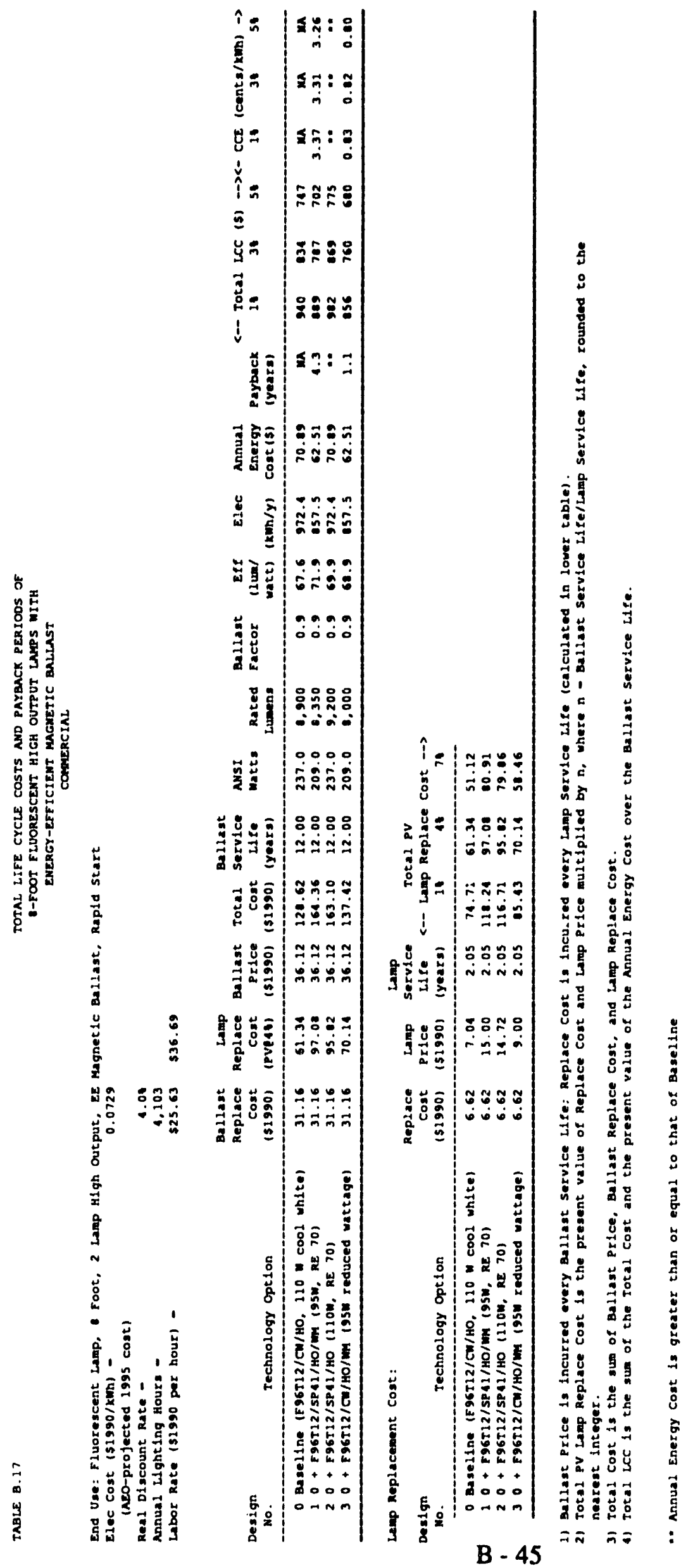



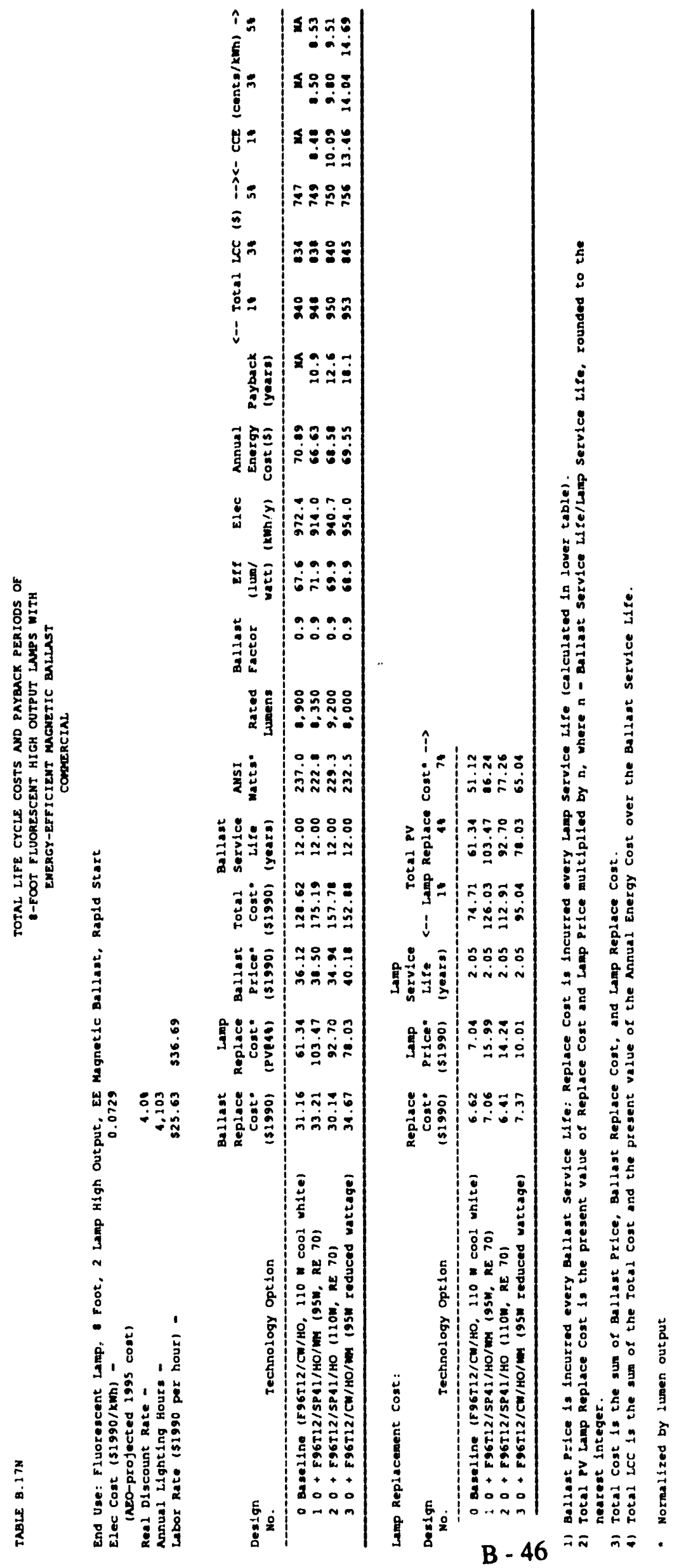


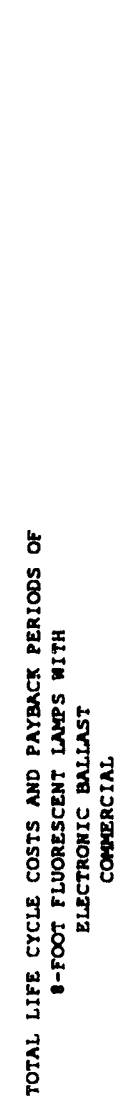

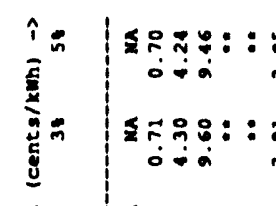$$
\text { Uू }
$$$$
\text { î. }
$$

ถำำำำ

픈

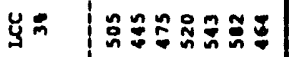

递.

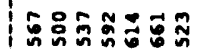

i

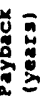

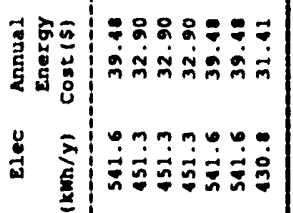

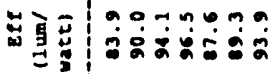

:

âạana

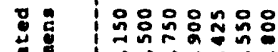

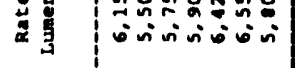

范

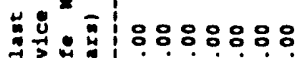

골

ำ

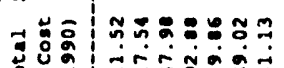

三ड

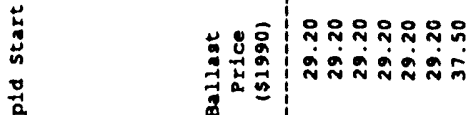

$\hat{\imath}$

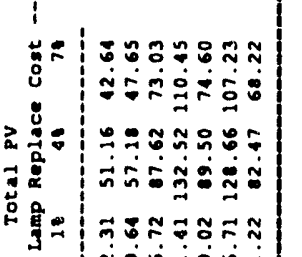

$\stackrel{5}{5}$

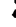

:

$\stackrel{5}{3}$

这

量

पू

s

范

$\stackrel{1}{3}$

$$
\text { 通 }
$$

范

范

㱐

造吕

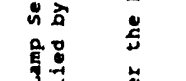

至

运

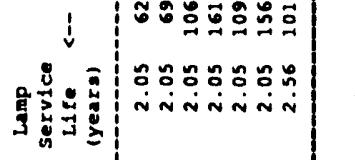

要要

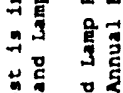

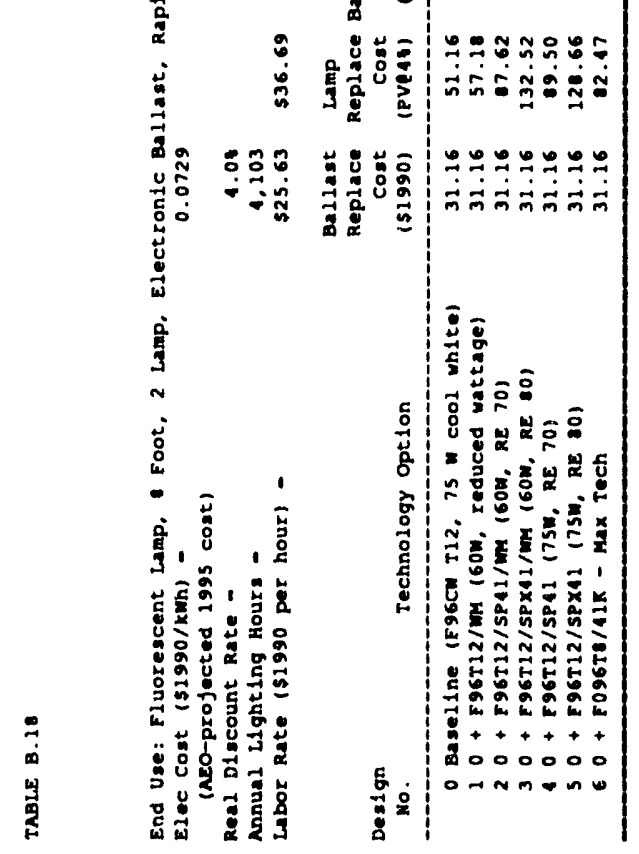

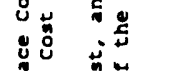

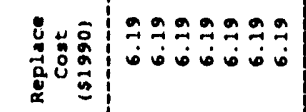

ํํำ

牙㟔这宸

过范

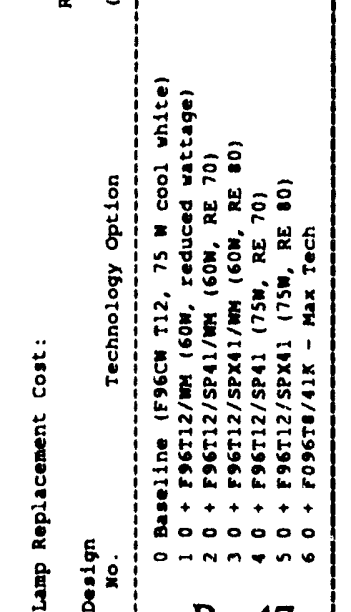

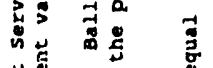

过

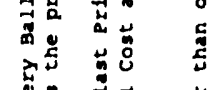

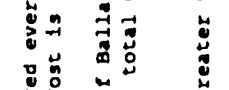

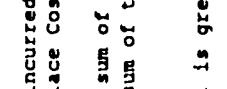

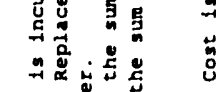

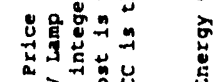

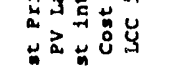

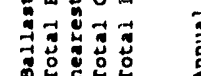


北

$\hat{\imath}$

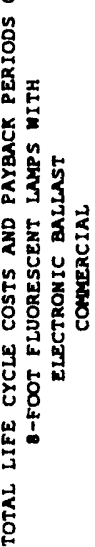

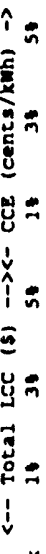

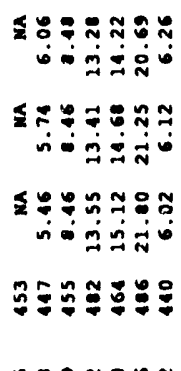

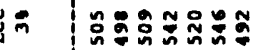

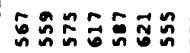

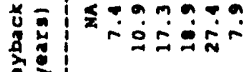

热

ำำำ

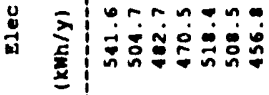

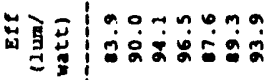

若

要

문

ovinisious

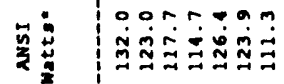

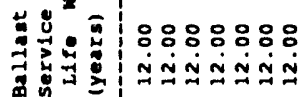

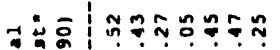

品造

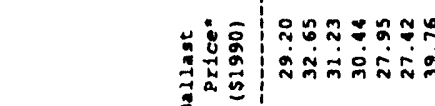

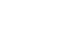

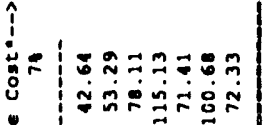

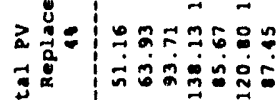

过

100

政

S

¿ั0

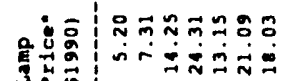

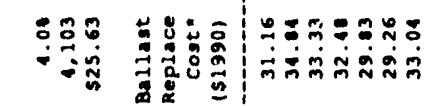

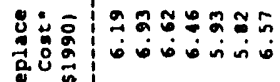

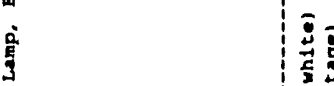

通

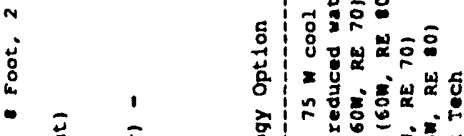

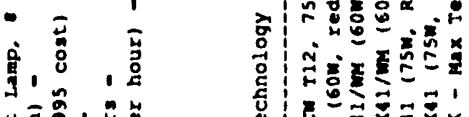

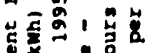

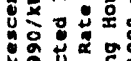

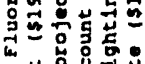

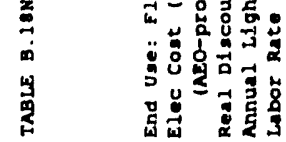

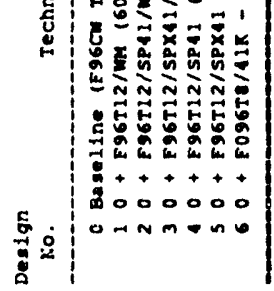



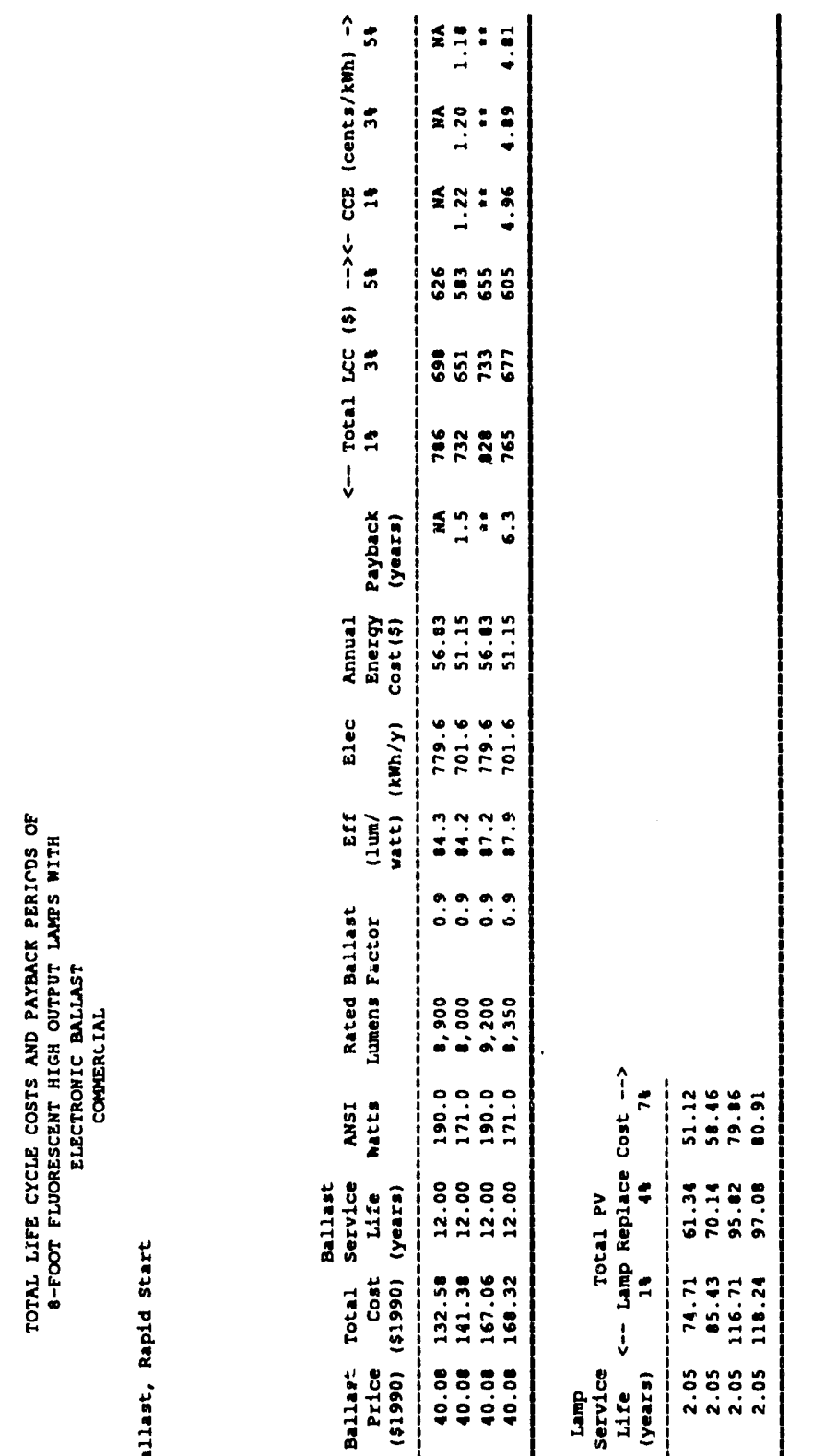

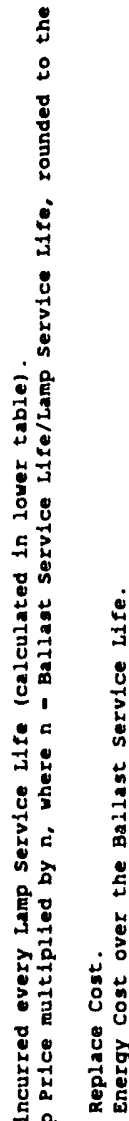

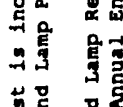

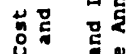

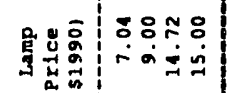

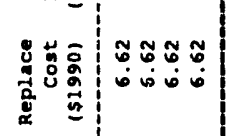

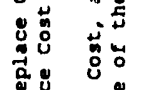

岕

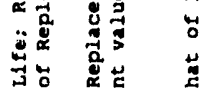

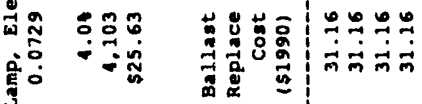

N

蕰
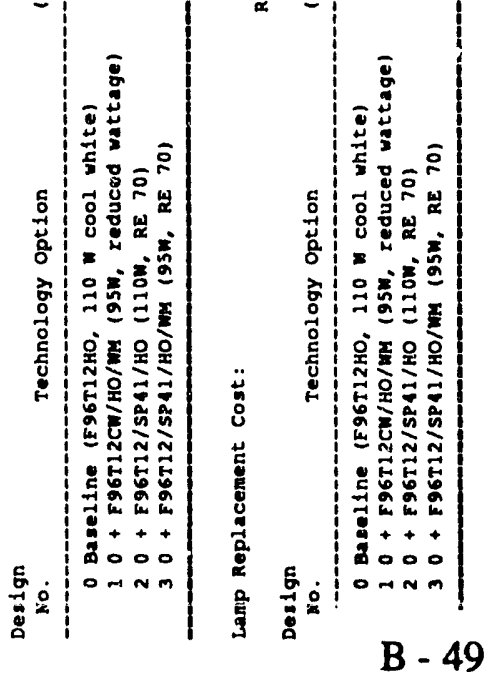

แै

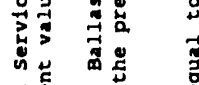

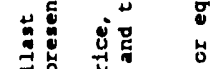

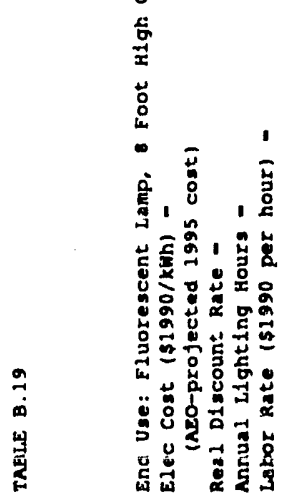

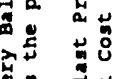

हैं

造通落

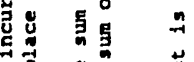

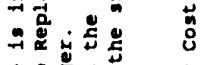

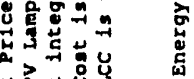

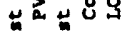

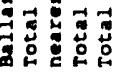
泣 $\bar{m}=$ 


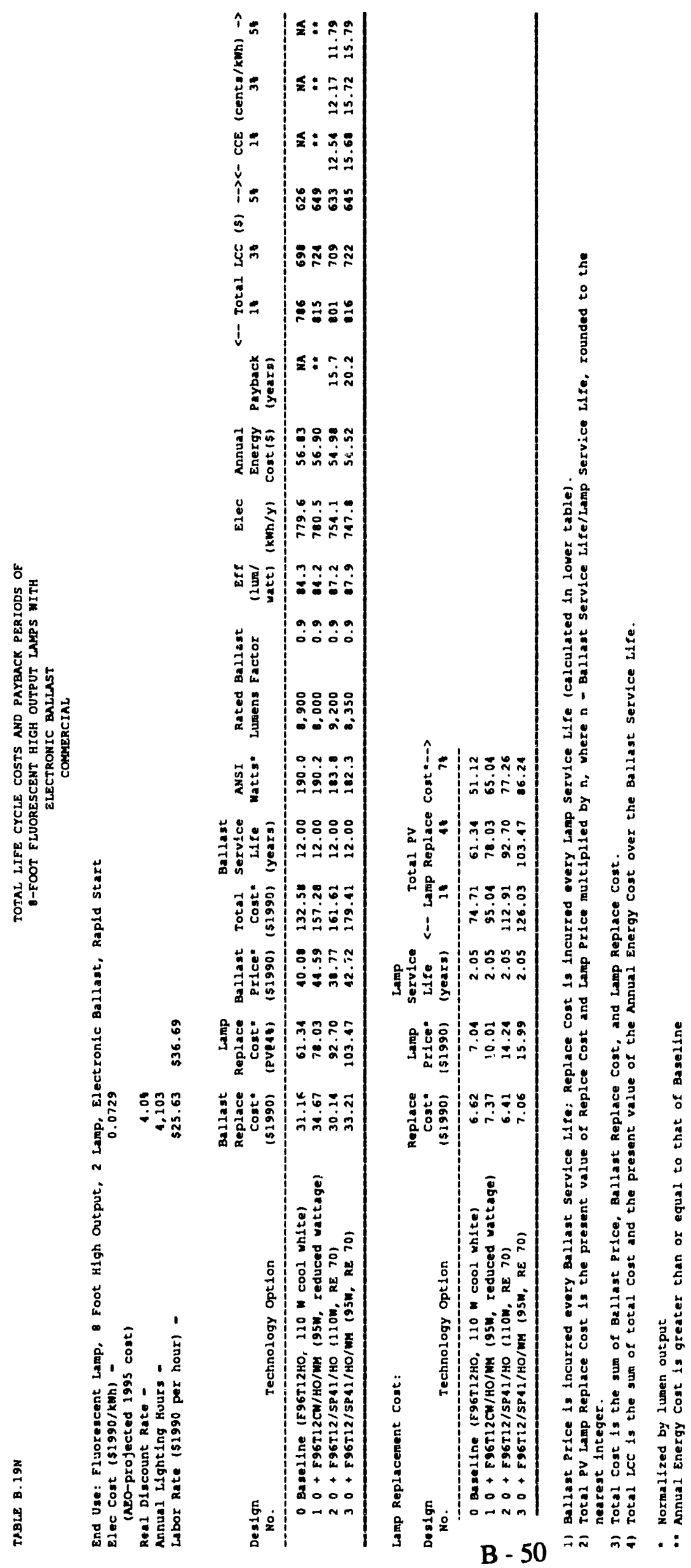




\section{APPENDIX C CALCULATION OF NATIONAL AVERAGE LIGHTING POWER DENSITIES}

This appendix shows the calculations of national average LPDs used to adjust the Low-Efficiency Baseline to reflect the continuing effects of state lighting standards.

Table C.1. Regional commercial floorspace, taken from 1989 CBECS, is allocated to individual states by 1989 population (U.S. Statistical Abstracts). ${ }^{1}$ Lighting regulations included in state lighting codes are taken from NCSBCS 1991 Energy Directory. ${ }^{2}$

Table C.2. Floorspace from CBECS 89; vacant floorspace is allocated to building types based on portion of total occupied floorspace. Average building size is rounded to the nearest thousand square feet.

Table C.3. Estimates of the change in IES illuminance values for tasks by building type between 1972 and 1989. ${ }^{3}$ Averages are not weighted. The college average includes tasks under the school category (reading and labs).

Table C.4. The change in illuminance values for building types calculated in Table C.3 is applied to 1989 ASHRAE 90.1 LPDs to estimate comparable 1972 LPDs. The 1989 ASHRAE code designates LPDs for specific building types. The LPDs for appropriate task areas are used for building types for which ASHRAE does not specify a single LPD. ${ }^{4}$ The estimated 1972 IES LPDs are used as "base case" national average LPDs prior to states' adoption of lighting regulations in their building codes. Thirty-seven states currently have codes that do not require stricter LPDs than those implied in the estimated IES LPDs. Four states have adopted the 1989 ASHRAE code. Ten states have specific LPD standards in their building codes; LPDs were selected that apply to each building type. Where LPDs are determined by building size (ASHRAE 1989, Massachusetts), the average U.S. building size is used (Table C.2). Where a state code does not identify a specific LPD for a building type, the appropriate 1972 IES LPD is used. The national average LPD in 1989 is weighted by each state's portion of total

\footnotetext{
${ }^{1}$ U.S. Bureau of the Census. 1991. Statistical Abstract of the United States: 1991 (111 th edition). Washington, D.C.

${ }^{2}$ The National Conference of States on Building Codes and Standards (NCSBCS). 1991. 1991 Energy Directory.

${ }^{3}$ Illuminating Engineering Society of North America (John Kaufman ed.). 1981, 1987. IES Lighting Handbook (1981 and 1987 Reference Volumes). New York.

4 For example, the average LPD for fast food (1.38) and dining (1.91) was used for restaurants, the average LPD of dorm room (1.4) and classroom (2.0) was used for colleges, the average of all health LPDs was used for hospitals, and the LPD for a hotel guest room (1.4) was used for lodging.
} 
commercial floor space. The final column in Table C.4 shows the percent change from the calculated 1972 IES LPDs to the 1989 national weighted average LPDs.

Table C.5. The Low-Efficiency Baseline assumes that all current DSM programs are to be eliminated after 1995. The portion of energy savings attributable to building codes between 1972 and 1989 is calculated based on the change in the maximum lighting power densities (LPDs) included in individual state building codes. The effect of state building codes is incorporated into the Low-Efficiency Baseline, because it is unlikely that the LPDs in states' building codes will be increased after 1995. 


\begin{tabular}{|c|c|c|c|c|c|c|}
\hline & $\begin{array}{l}\text { Region \& } \\
\text { State }\end{array}$ & $\begin{array}{r}\text { Population } \\
\text { (1989) }\end{array}$ & $\begin{array}{r}\text { Population } \\
\text { Dintribution } \\
\text { within } \\
\text { Retion }\end{array}$ & $\begin{array}{l}\text { Commercin } \\
\text { Floorspace by } \\
\text { State (million of }\end{array}$ & $\begin{array}{r}\text { Portion of } \\
\text { U.S. } \\
\text { Commercial } \\
\text { Floornpece }\end{array}$ & $\begin{array}{l}\text { State } \\
\text { Lighting } \\
\text { Code }^{1}\end{array}$ \\
\hline \multicolumn{7}{|c|}{ New Enghend } \\
\hline & ME & 1,222 & $9 \%$ & 297 & $0.5 \%$ & 1980 \\
\hline & VT & 567 & $4 \%$ & 138 & $0.2 \%$ & 1980 \\
\hline & NH & 1.107 & $8 \%$ & 209 & $0.4 \%$ & 1975 \\
\hline & MA & 5,913 & $45 \%$ & 1,438 & $2.3 \%$ & own \\
\hline & $\mathbf{R I}$ & 998 & $8 \%$ & 243 & $0.4 \%$ & own \\
\hline & $\mathbf{C T}$ & 3,239 & $25 \%$ & 788 & $1.2 \%$ & NC \\
\hline & & 13,046 & $100 \%$ & 3,173 & $5.0 \%$ & \\
\hline \multicolumn{7}{|c|}{ Middle Atlantic } \\
\hline . & NY & 17,950 & $48 \%$ & 4,946 & $7.8 \%$ & own \\
\hline & PA & 12,040 & $32 \%$ & 3,318 & $5.3 \%$ & 1975 \\
\hline & NJ & 7.736 & $21 \%$ & 2.132 & $3.4 \%$ & none \\
\hline & Sub-Tocal & 37,726 & $100 \%$ & 10,396 & $16.5 \%$ & \\
\hline Regional & & 50,772 & & 13,569 & $21.5 \%$ & \\
\hline \multicolumn{7}{|c|}{ Midwest } \\
\hline \multicolumn{7}{|c|}{ Eart North Central } \\
\hline & MI & 9,273 & $22 \%$ & 2,342 & $3.7 \%$ & so \\
\hline & WI & 4,867 & $12 \%$ & 1,229 & $1.9 \%$ & own \\
\hline & $\mathrm{OH}$ & 10,907 & $26 \%$ & 2,754 & $4.4 \%$ & so \\
\hline & $\mathbb{N}$ & 5,593 & $13 \%$ & 1,412 & $2.2 \%$ & 1980 \\
\hline & Il & 11,658 & $28 \%$ & 2.944 & $4.7 \%$ & 1980 \\
\hline & Sub-Total & 42,298 & $100 \%$ & 10,681 & $16.9 \%$ & \\
\hline \multicolumn{7}{|c|}{ Weat North Central } \\
\hline & $\mathbf{M N}$ & 4,353 & $24 \%$ & 1,286 & $2.0 \%$ & 1989 \\
\hline & IA & 2,840 & $16 \%$ & 839 & $1.3 \%$ & 1980 \\
\hline & MO & 5,159 & $29 \%$ & 1,524 & $2.4 \%$ & 1975 \\
\hline & ND & 660 & $4 \%$ & 195 & $0.3 \%$ & 1980 \\
\hline & SD & 715 & $4 \%$ & 211 & $0.3 \%$ & none \\
\hline & NE & 1,611 & $9 \%$ & 476 & $0.8 \%$ & 1980 \\
\hline & KS & 2,513 & $14 \%$ & 742 & $1.2 \%$ & none \\
\hline & Sub-Total & 17,851 & $100 \%$ & 5,274 & $8.3 \%$ & \\
\hline Regional & & 60,149 & & 15,955 & $25.3 \%$ & \\
\hline \multicolumn{7}{|c|}{ South } \\
\hline \multicolumn{7}{|c|}{ South Atlentic } \\
\hline & $\mathrm{DE}$ & 673 & $2 \%$ & 157 & $0.2 \%$ & 1989 \\
\hline & MD & 4,694 & $11 \%$ & 1,098 & $1.7 \%$ & none \\
\hline & DC & 604 & $1 \%$ & 141 & $0.2 \%$ & NC \\
\hline & wV & 1,857 & $4 \%$ & 435 & $0.7 \%$ & so \\
\hline & VA & 6,098 & $14 \%$ & 1,427 & $2.3 \%$ & so \\
\hline & NC & 6.571 & $15 \%$ & 1,538 & $2.4 \%$ & general \\
\hline & SC & 3,512 & $8 \%$ & 822 & $1.3 \%$ & 1980 \\
\hline & GA & 6,436 & $15 \%$ & 1,506 & $2.4 \%$ & own \\
\hline & FL & 12,671 & $29 \%$ & 2,965 & $4.7 \%$ & own \\
\hline & Sub-Tocal & 43,116 & $100 \%$ & 10,090 & $16.0 \%$ & \\
\hline
\end{tabular}

'Dates denole versions of ASHRAE buildine code; "SO" denotes stales that only have lighing switching requirements; "NC" denotes states that are not categorized.

C - 3 


\begin{tabular}{|c|c|c|c|c|c|c|}
\hline \multirow{2}{*}{ Trable C.I } & \multicolumn{6}{|c|}{ 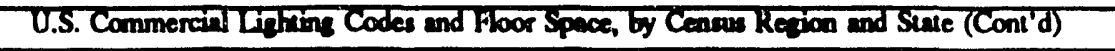 } \\
\hline & $\begin{array}{l}\text { Region d } \\
\text { Sunte }\end{array}$ & $\begin{array}{r}\text { Population } \\
\text { (1989) }\end{array}$ & $\begin{array}{r}\text { Population } \\
\text { Distribution } \\
\text { within } \\
\text { Region }\end{array}$ & $\begin{array}{l}\text { Commescin } \\
\text { Floorpece by } \\
\text { Stule (million af) }\end{array}$ & $\begin{array}{r}\text { Portion of } \\
\text { U.S. } \\
\text { Commencial } \\
\text { Floorepece }\end{array}$ & $\begin{array}{l}\text { Sute } \\
\text { Lighting } \\
\text { Code }^{1}\end{array}$ \\
\hline & $\mathbf{K} \mathbf{Y}$ & 3,2127 & $24 \%$ & T,039 & $1.6 \%$ & so \\
\hline & TN & 4,940 & $32 \%$ & 1,377 & $2.2 \%$ & 1975 \\
\hline & $\mathbf{A L}$ & 4,118 & 27\% & 1,148 & $1.8 \%$ & genenal \\
\hline & MS & 2.621 & $17 \%$ & 731 & $1.2 \%$ & 1975 \\
\hline & -Total & 15,406 & $100 \%$ & 4.295 & $6.8 \%$ & \\
\hline \multicolumn{7}{|c|}{$\begin{array}{l}\text { West South } \\
\text { Central }\end{array}$} \\
\hline & $\mathbf{A R}$ & 2.406 & 9\% & 682 & $1.1 \%$ & own \\
\hline & LA & 4,382 & $16 \%$ & 1,242 & $2.0 \%$ & none \\
\hline & OK & 3.224 & $12 \%$ & 914 & $1.4 \%$ & 1989 \\
\hline & $T X$ & 16,991 & $63 \%$ & 4,816 & $7.6 \%$ & 1989 \\
\hline \multicolumn{2}{|c|}{ Sub-Total } & 27,003 & $100 \%$ & 7,654 & $12.1 \%$ & \\
\hline Regional Total & & 85,525 & & 22,039 & $34.9 \%$ & \\
\hline \multicolumn{7}{|l|}{ West } \\
\hline \multicolumn{7}{|l|}{ Mountain } \\
\hline & MT & 806 & $6 \%$ & 262 & $0.4 \%$ & 1980 \\
\hline & WY & 475 & $4 \%$ & 154 & $0.2 \%$ & 1980 \\
\hline & ID & 1,014 & $8 \%$ & 329 & $0.5 \%$ & 1980 \\
\hline & $\mathbf{U T}$ & 1,707 & $13 \%$ & 554 & $0.9 \%$ & 1980 \\
\hline & CO & 3,317 & $25 \%$ & 1,077 & $1.7 \%$ & 1975 \\
\hline & $\mathbf{A Z}$ & 3,556 & $26 \%$ & 1,155 & $1.8 \%$ & 1980 \\
\hline & NM & 1,528 & $11 \%$ & 496 & $0.8 \%$ & none \\
\hline & NV & 1.111 & $8 \%$ & 361 & $0.6 \%$ & 1980 \\
\hline & b-Total & 13,514 & $100 \%$ & 4,388 & $6.9 \%$ & \\
\hline \multicolumn{7}{|l|}{ Pacific } \\
\hline & WA & 4,761 & $12 \%$ & 899 & $1.4 \%$ & own \\
\hline & OR & 2,820 & $7 \%$ & 533 & $0.8 \%$ & own \\
\hline & CA & 29,063 & $76 \%$ & 5,490 & $8.7 \%$ & own \\
\hline & AK & 527 & $1 \%$ & 100 & $0.2 \%$ & none \\
\hline & HI & 1,112 & $3 \%$ & 210 & $0.3 \%$ & 1980 \\
\hline & b-Total & 38,283 & $100 \%$ & 7,232 & $11.4 \%$ & \\
\hline Regional Total & & 51.797 & & 11,620 & $18.4 \%$ & \\
\hline U.S. Total & & 248,243 & & 63,183 & $100 \%$ & \\
\hline \multicolumn{7}{|l|}{ Subtotals: } \\
\hline 37 & \multicolumn{3}{|c|}{$\begin{array}{l}\text { Stales with pre-1989 ASHRAE } \\
\text { code }^{2}\end{array}$} & 36.077 & $57 \%$ & \\
\hline 4 & \multicolumn{3}{|c|}{$\begin{array}{l}\text { States with } 1989 \\
\text { ASHRAE code }\end{array}$} & 7,174 & $11 \%$ & \\
\hline 10 & \multicolumn{3}{|c|}{ States with own code } & 19,932 & $32 \%$ & \\
\hline
\end{tabular}

\footnotetext{
Tates denote verions of ASHRARE building code; "SO" denotes states that only have highting switching requirements; "NC" denotes ates that are not calegorized.

${ }^{2}$ Includes states that have switching requirements only, general lighting standands, or no lighting standards in their building codes.
} 
Table C.2 1989 National Commercial Building Charecteristics

\begin{tabular}{|c|c|c|c|c|c|c|}
\hline $\begin{array}{l}\text { Building } \\
\text { Type }\end{array}$ & $\begin{array}{l}\text { Floor Space } \\
\text { (million sq. ft) }\end{array}$ & $\begin{array}{l}\text { Floor Spece } \\
\text { Including } \\
\text { Vecent } \\
\text { (million eq ft) }\end{array}$ & Percent & $\begin{array}{l}\text { Total } \\
\text { Buildings } \\
\text { Occupied } \\
\text { (thousands) }\end{array}$ & $\begin{array}{l}\text { Total Including } \\
\text { Vacant } \\
\text { (million sq } \mathrm{ft} \text { ) }\end{array}$ & $\begin{array}{l}\text { Average } \\
\text { Building Size } \\
\text { (million sq } \mathrm{ft} \text { ) }\end{array}$ \\
\hline Small Office & 5,901 & 6,317 & $10 \%$ & 340 & 366 & 17,000 \\
\hline Large Office & 5,901 & 6,317 & $10 \%$ & 340 & 366 & 17,000 \\
\hline Restaurant & 1,167 & 1,249 & $2 \%$ & 241 & 260 & 5,000 \\
\hline Retril & 12,365 & 13,237 & $21 \%$ & 1,278 & 1,379 & 10,000 \\
\hline Grocery & 792 & 848 & $1 \%$ & 102 & 110 & 8,000 \\
\hline Warehouse & 9.253 & 9,905 & $16 \%$ & 618 & 667 & 15,000 \\
\hline School & 3,259 & 3,489 & $6 \%$ & 114 & 123 & 29,000 \\
\hline College & 5,231 & 5,599 & $9 \%$ & 201 & 217 & 26,000 \\
\hline Health & 2.054 & 2,199 & $3 \%$ & 123 & 133 & 17,000 \\
\hline Lodging & 3,476 & 3,721 & $6 \%$ & 118 & 127 & 29,000 \\
\hline Miscelleneous & 9,624 & 10,303 & $16 \%$ & 720 & 777 & 13,000 \\
\hline Total & 59.023 & 63,184 & $100 \%$ & 4,194 & 4,527 & \\
\hline
\end{tabular}

Source: Energy Information Agency, U.S. Department of Energy (CBECS 1989). 
Table C3 Average Change in IES Illuminance Values, by Building Type, 1972 to 1987

\begin{tabular}{|c|c|c|c|c|}
\hline Building Type and Task Category & $\begin{array}{c}1972 \text { IES } \\
\text { (footcendles) }\end{array}$ & $\begin{array}{l}1981 \& 1987 \\
\text { IES } \\
\text { (footcendles) }\end{array}$ & $\begin{array}{l}\text { Percent } \\
\text { Change }\end{array}$ & $\begin{array}{c}\text { Average } \\
\text { Percent } \\
\text { Change }\end{array}$ \\
\hline \multicolumn{5}{|l|}{ Offices } \\
\hline \multicolumn{5}{|l|}{ General and Private Officas } \\
\hline Reading pencil handwriting & 100 & 75 & $-25 \%$ & \\
\hline Reading ink handwriting & 70 & 30 & $-57 \%$ & \\
\hline Reading printed material & 30 & 30 & $0 \%$ & \\
\hline Typing/VDT & 70 & 75 & $7 \%$ & \\
\hline Conference Rooms & 30 & 30 & $0 \%$ & \\
\hline \multicolumn{5}{|l|}{ Drafting } \\
\hline Detuiled & 200 & 150 & $-25 \%$ & \\
\hline Rough & 150 & 75 & $-50 \%$ & $-21 \%$ \\
\hline
\end{tabular}

Restaurent

Food Service

$\begin{array}{lcccc}\text { Cashier } & 50 & 30 & -40 \% \\ \text { Cleaning } & 20 & 15 & -25 \% & \\ \text { Intimate dining } & 10 & 7.5 & -25 \% & \\ \text { Leisure dining } & 30 & 7.5 & -75 \% & \\ \text { Quick service dining } & 100 & 100 & 0 \% & -33 \%\end{array}$

Retail

Circulation

30

$30 \quad 0 \%$

Merchandise

Service (low activity)

100

$30-70 \%$

Self-service (high activity)

200

100

$-50 \%$

Feature Display

Service (low activity)

500

150

$-70 \%$

Self-service (high activity)

1000

500

$-50 \%$

Show Cases

Service (low activity)

200

30

$-85 \%$

Self-Service (high activity)

500

100

$-80 \%$

Show windows

Daytime general

200

200

$0 \%$

Nighttime general (main)

200

200

$0 \%$

Nightime general (secondary)

100

100

$0 \%$

Alteration room

150

150

$0 \%$

Dressing areas

50

30

$-40 \%$

Fitting rooms

200

150

$-25 \%$

Siock rooms

30

30

$0 \%$

$-34 \%$

C - 6 
Table C3. Average Change in IES Illuminance Values, by Building Type, 1972 to 1987 (cont'd)

\begin{tabular}{|c|c|c|c|c|}
\hline Building Type and Category & $\begin{array}{c}1972 \text { IES } \\
\text { (footcendles) }\end{array}$ & $\begin{array}{l}1981 \& 1987 \\
\text { IES } \\
\text { (footcandles) }\end{array}$ & $\begin{array}{l}\text { Percent } \\
\text { Change }\end{array}$ & $\begin{array}{l}\text { Average } \\
\text { Percent } \\
\text { Change }\end{array}$ \\
\hline \multicolumn{5}{|l|}{ Grocery } \\
\hline Circulation & 30 & 30 & $0 \%$ & \\
\hline Merchandise (self-service) & 200 & 100 & $-50 \%$ & $-25 \%$ \\
\hline \multicolumn{5}{|l|}{ Warchouse } \\
\hline \multicolumn{5}{|l|}{ Storage } \\
\hline Innctive & 5 & 7.5 & $50 \%$ & \\
\hline Active: rough, bully & 10 & 15 & $50 \%$ & \\
\hline Active: modium & 20 & 15 & $-25 \%$ & \\
\hline Active: small & 50 & 30 & $-40 \%$ & $9 \%$ \\
\hline \multicolumn{5}{|l|}{ School } \\
\hline Reading & & 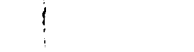 & & \\
\hline Resding printed material & 30 & 30 & $0 \%$ & \\
\hline Reading pencil writing & 70 & 75 & $7 \%$ & \\
\hline Reading chalkboards & 150 & 75 & $-50 \%$ & \\
\hline Science Laboratories & 100 & 75 & $-25 \%$ & $-17 \%$ \\
\hline \multicolumn{5}{|l|}{ College } \\
\hline \multicolumn{5}{|l|}{ Dormitories } \\
\hline General & 10 & 7.5 & $-25 \%$ & \\
\hline Reading & 30 & 30 & $0 \%$ & \\
\hline Study desk & 70 & 75 & $7 \%$ & \\
\hline Typing/VDT & 70 & 75 & $7 \%$ & $-10 \%$ \\
\hline \multicolumn{5}{|l|}{ Health } \\
\hline \multicolumn{5}{|l|}{ Patient Rooms } \\
\hline General & 20 & 7.5 & $-63 \%$ & \\
\hline Reading & 30 & 30 & $0 \%$ & \\
\hline Observation & 2 & 3 & $50 \%$ & \\
\hline Examination & 100 & 75 & $-25 \%$ & \\
\hline Toilets & 30 & 30 & $0 \%$ & \\
\hline Emergency Operating Rooms & 100 & 75 & $-25 \%$ & \\
\hline Examination Rooms & 50 & 30 & $-40 \%$ & $-15 \%$ \\
\hline \multicolumn{5}{|l|}{ Lodging } \\
\hline Bedrooms & 30 & 30 & $0 \%$ & \\
\hline Bathrooms & 30 & 30 & $0 \%$ & \\
\hline Corridors, Elevators, Stuirs & 20 & 15 & $-25 \%$ & \\
\hline Lobby & 10 & 15 & $50 \%$ & \\
\hline Front Desk & 50 & 75 & $50 \%$ & \\
\hline Linen Room & 20 & 15 & $-25 \%$ & $8 \%$ \\
\hline
\end{tabular}




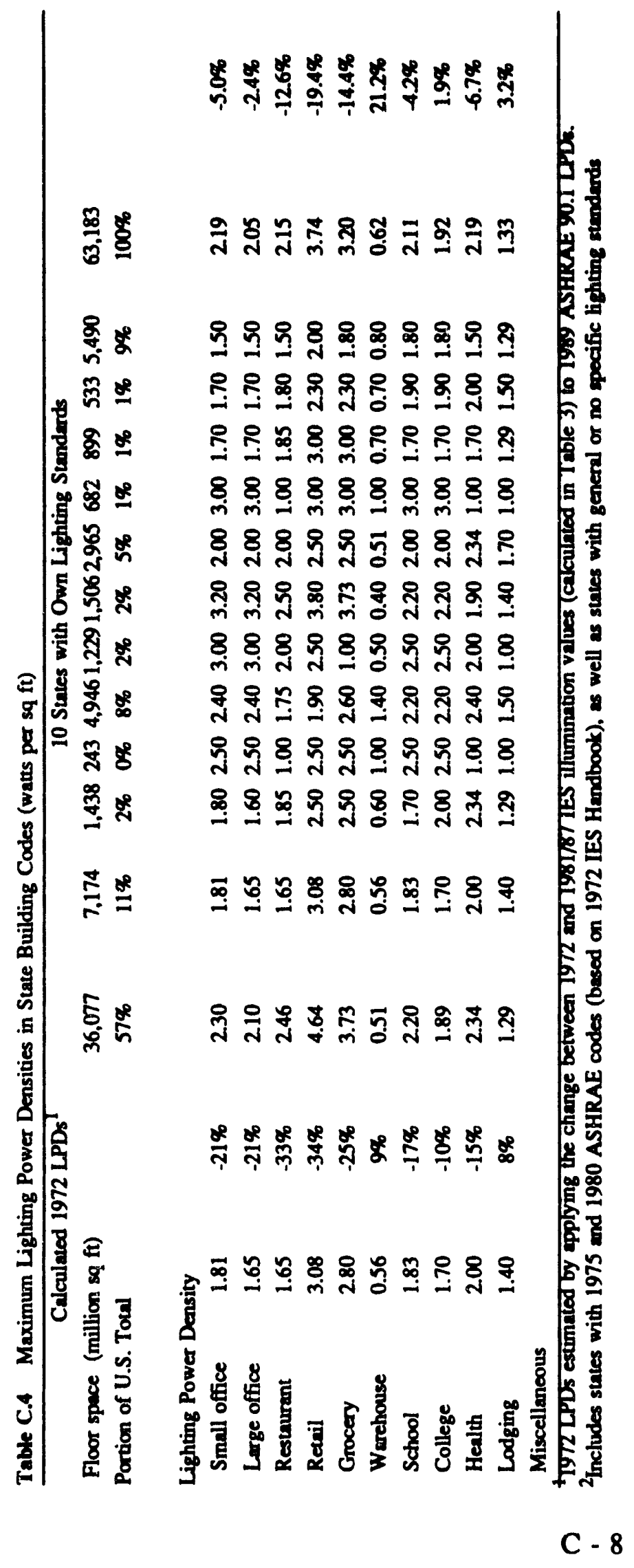




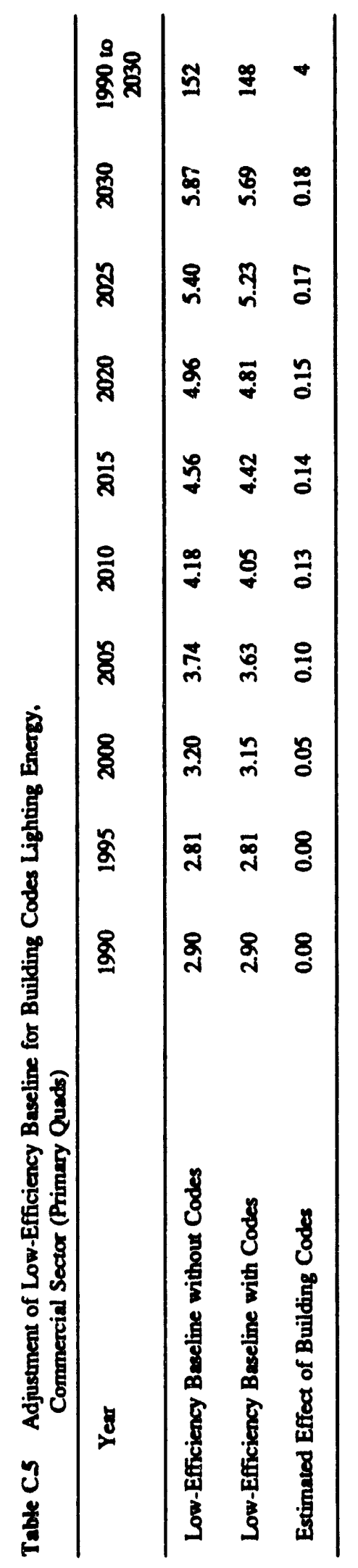

C - 9 


\section{APPENDIX D LIGHTING TECHNOLOGY SPREADSHEETS FOR THE COMMERCIAL SECTOR}

This appendix contains the spreadsheets used in the development of the inputs to the COMMEND model for the commercial sector baselines and policy cases.

Table D.1 presents the data used in the baseline calibration for the existing lighting stock and for new lighting equipment for the years 1986 and 1995. These are classified as 1986 Stock, 1986 Sales, 1995 Stock, and 1995 Sales ("sales" parameters may also be termed "marginal"). Energy Use Intensities (EUIs) and Lighting Power Densities (LPDs)--by technology type and totals--are presented for each building type as well as floor space-weighted averages for all building types. Annual lighting hours and technology shares for fluorescent, incandescent, and HID stock are given to illustrate the development of the technology-type LPDs. See Section 4.3 for a detailed description of the data sources and the process of baseline development. The table continues with presentation of EUIs and LPDs for each policy case. For elaboration on the development of the policy case inputs to COMMEND, see Section 4.4.

Table D. 2 shows the data used for the COMMEND calibration process for the fluorescent lighting stock and sales for 1986 and 1995 . For the major lamp/ballast combinations, normalized wattages and market shares are listed. In this table, the total number of lamp/ballast units are first allocated to end-uses (4-foot, 8-foot, or 8-foot high output lamps/ballasts). Each end-use is divided among ballast technologies (standard, energy-efficient magnetic, cathode cutout, or electronic). Finally, each ballast technology is further divided among lamp technologies (standard, reduced wattage, or T8). The end-use, ballast technology, and lamp technology shares are then multiplied to obtain a market share for each lamp/ballast combination. The sum of each combination's market share accounts for nearly the entire lamp/ballast market (the remaining segment of the fluorescent stock, which accounts for less than one percent of the market, is not affected by the policies analyzed). The table shows the calculation of the Weighted-Average Watt $(W A W)$, which is the sum of the products of each lamp/ballast's normalized wattage and its market share (actual wattages are used for the Eliminate Highest Wattage Fluorescent policy case; see Section 3.2.4 for details). The WAW for 1986 sales, 1995 stock, and 1995 sales decreases from the 1986 stock WAW due to increased market share of more efficient lamp/ballast and fixture technologies. The fractions of the 1986 stock WAW are shown at the bottom of the 1986 sales, 1995 stock, and 1995 sales tables. ${ }^{1}$ Sources of the data are the Lighting Research Institute's supply/demand survey of lamp manufacturers, ballast manufacturers, and NALMCO; the Bureau of Census 1987 Census of Manufacturers, Electric Lighting and Wiring Equipment; and 1986 NBECS.

\footnotetext{
${ }^{1}$ Note that 1986 stock and 1986 sales are nearly identical. It is assumed that by 1986 the 34 -watt fluorescent lamp had penetrated well into the lighting equipment stock, since the lamp was introduced in the 1970s and the turnover rate for fluorescent lamps is about 3.5 years.
} 
Table D. 3 shows the data used for the COMMEND calibration process for incandescent lighting. Since the service life of incandescents is relatively short (less than 3 years), stock and sales are considered to be identical. The 1995 WAW is calculated based on the normalized wattage and market share of each major lamp type (actual wattages are used for the Eliminate Highest Wattage Fluorescent policy case; see Section 3.2.4 for details). The fraction of the Edison socket lamp stock that is compact fluorescent is also shown at the bottom of each table. Sources of the data are the same as those for Table D.2, in addition to manufacturer estimates.

Table D.4 shows the baseline market shares for fixtures. The fixture stock is classified by fixture type: troffer, wraparound, parabolic, and other. The first three categories comprise most of the four-foot fluorescent fixture stock, while most eight-foot fixtures fall into the "other" category. Eight-foot fixtures, including industrial, strip, and wall fixtures, are not affected by the fixture policies. Sources of the data are the Bureau of Census, NEMA, and the Lighting Research Institute.

Tables D.5 and D.6 show the development of the WAW for the fluorescent and incandescent policy cases. Similar in structure to Tables D.2 and D.3, the tables list the major lamp//ballast) types, and the actual or normalized wattages and market shares of each type. The fraction of the baseline WAW is given for each policy case. This fraction is applied to the baseline LPDs to generate the policy case LPDs and EUIs shown in Table D.1.

Table D.7 shows the development of the WAW for the fixture policy cases. The structure of the table is similar to that of Table D.4. See Section 3.3 for a description of the development of fixture wattages for the two policy cases. 


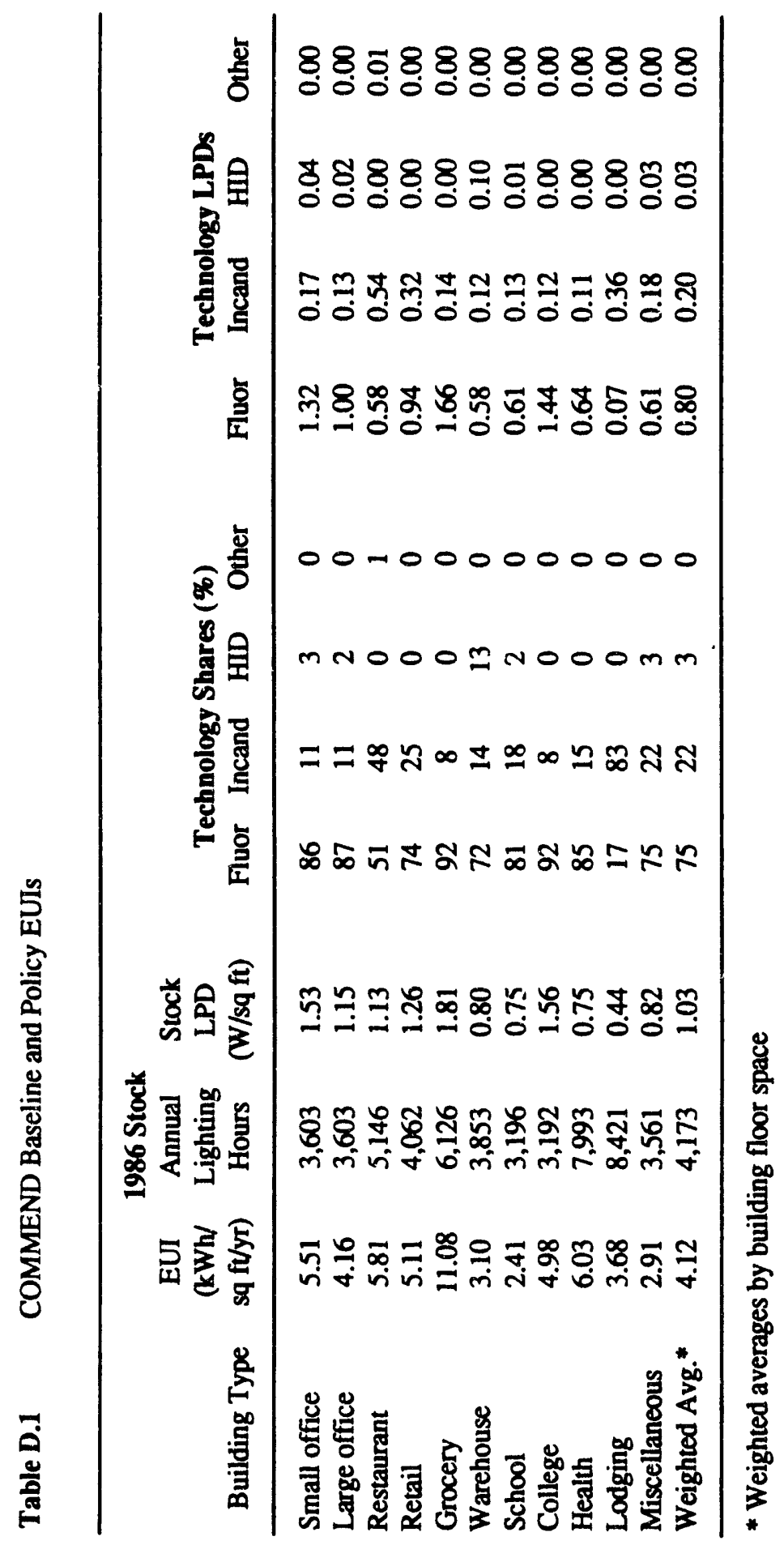

D - 3 


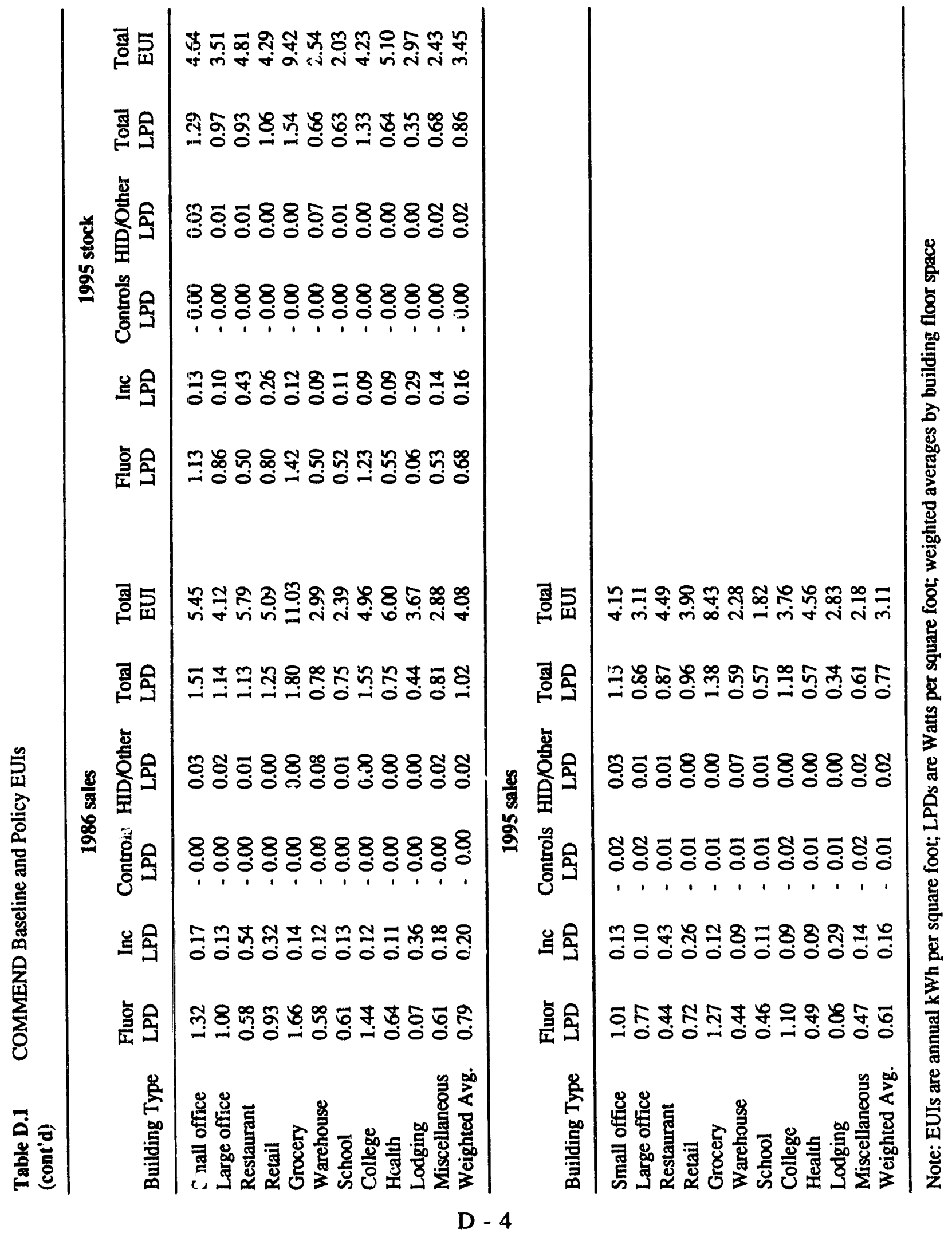




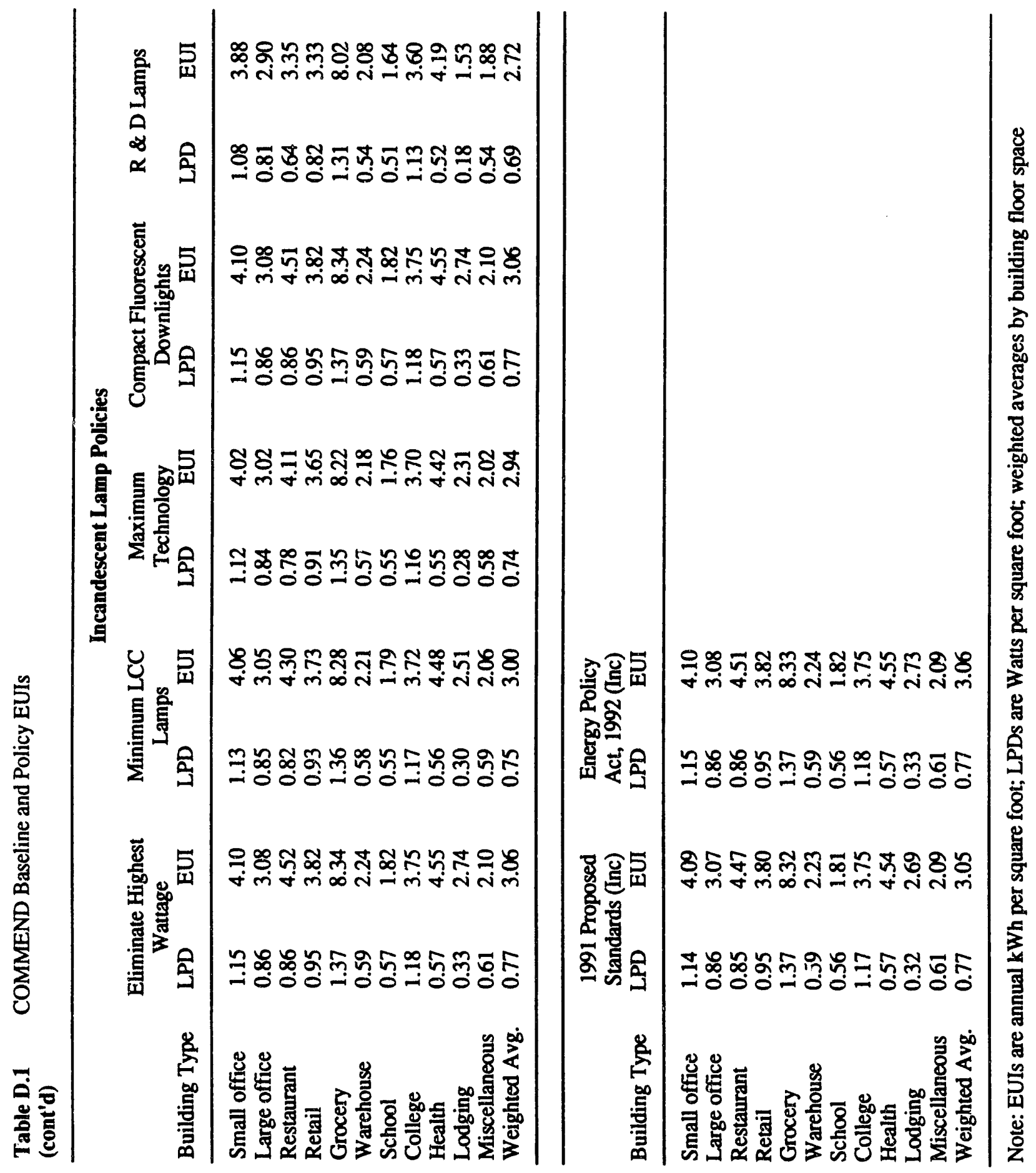

D -5 


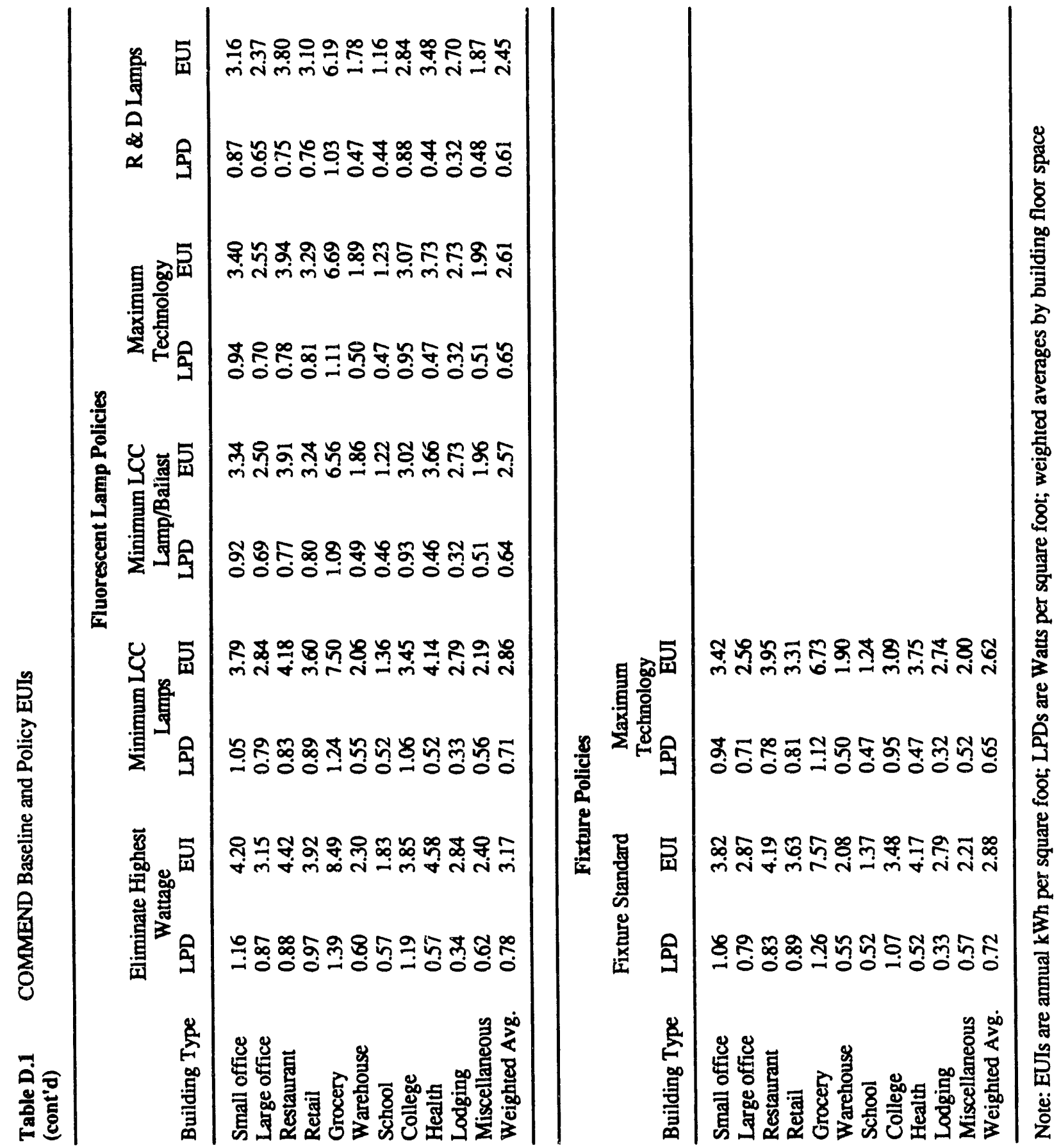

D - 6 


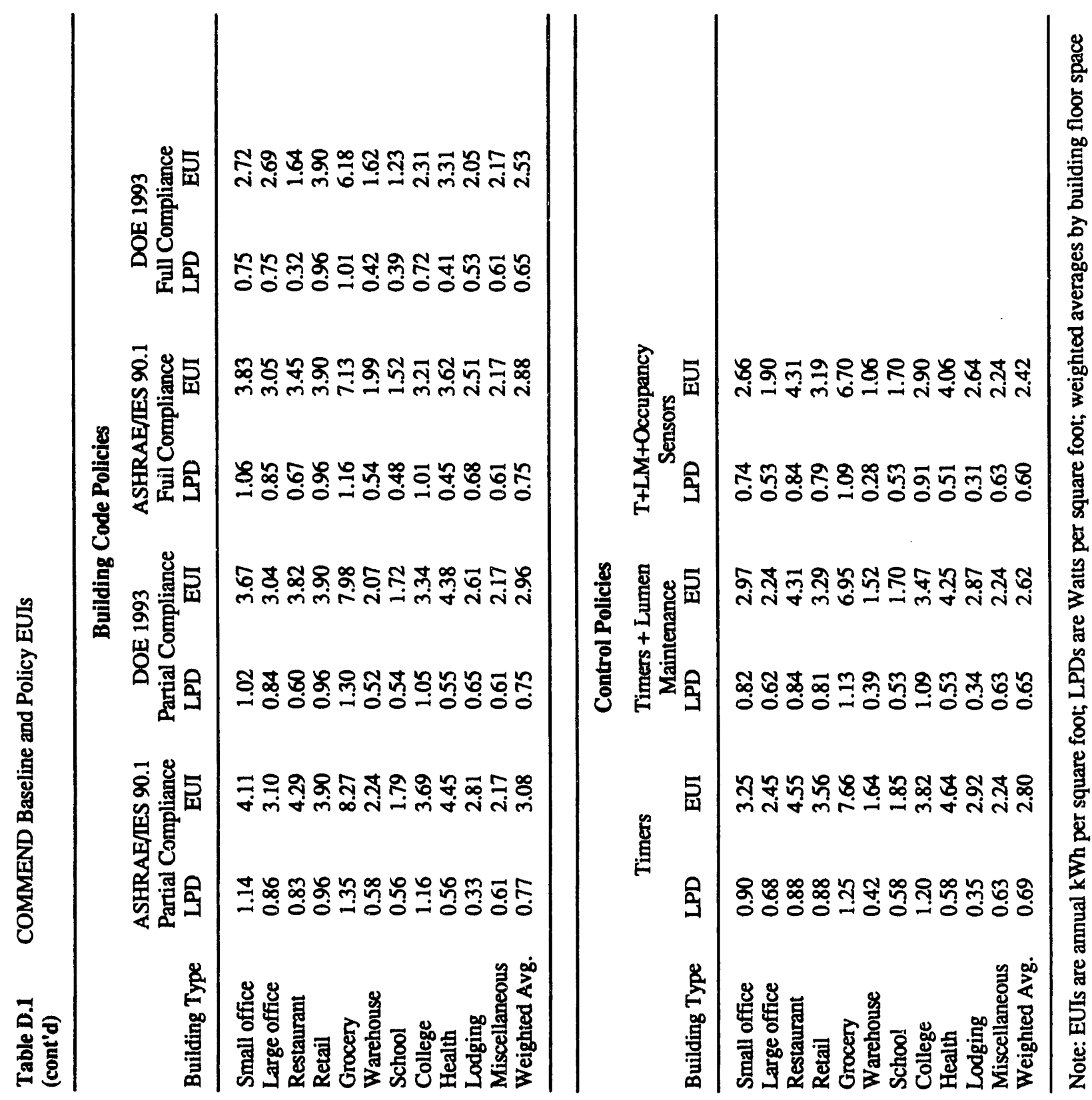

D - 7 


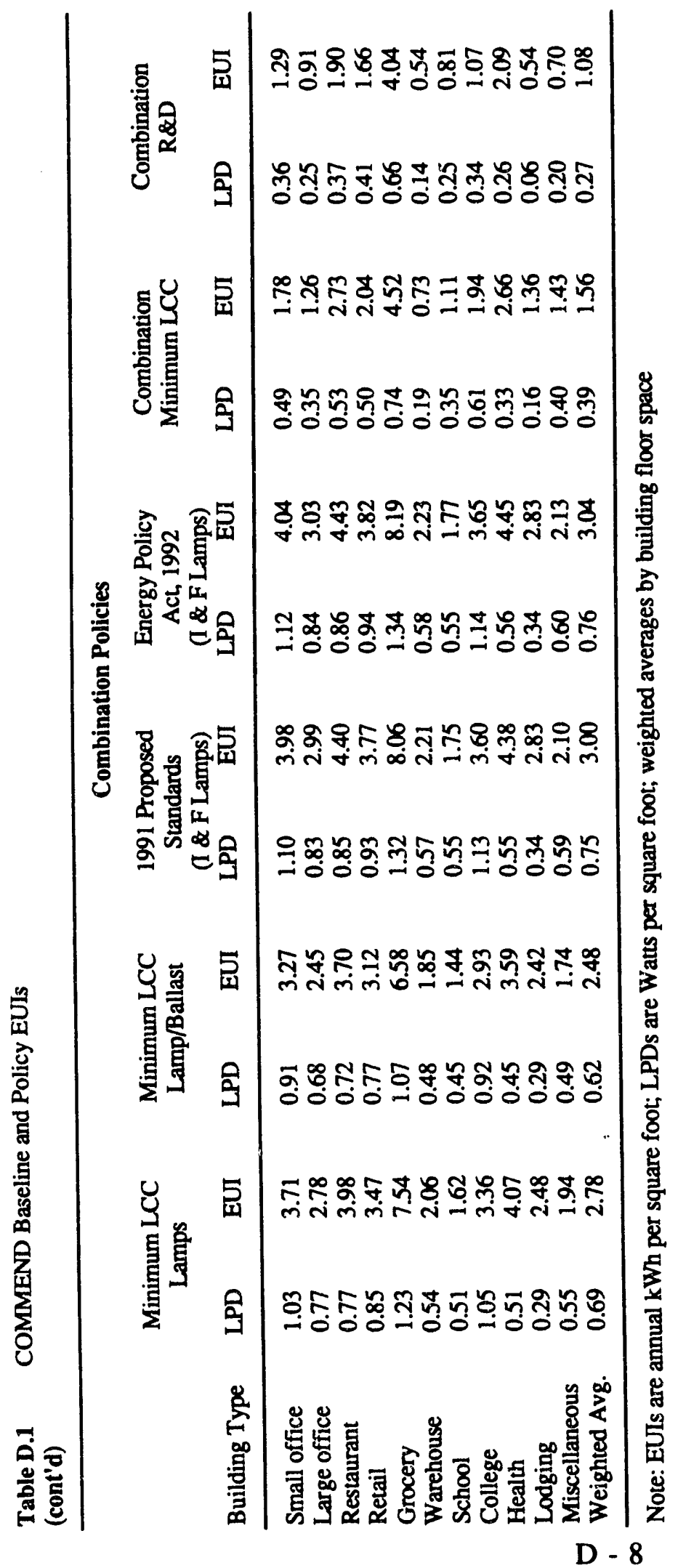


Table D.2 Baseline Market Shares, Fluorescent Lamp/Ballast Combinations 1986 Stock

\begin{tabular}{|c|c|c|c|c|c|c|c|c|}
\hline \multirow[b]{3}{*}{ Technology } & \multirow[b]{3}{*}{$\begin{array}{r}\text { ANSI } \\
\text { Watts * }\end{array}$} & \multirow[b]{3}{*}{$\begin{array}{l}\text { Fixture } \\
\text { Watts * }\end{array}$} & \multirow{3}{*}{$\begin{array}{r}\text { End-Use } \\
\text { Share } \\
(\%)\end{array}$} & \multirow{2}{*}{\multicolumn{2}{|c|}{ Technology Shares }} & \multirow{3}{*}{$\begin{array}{r}\text { Market } \\
\text { Share \# } \\
(\%)\end{array}$} & \multirow{3}{*}{$\begin{array}{c}\text { Weighted } \\
\text { Average } \\
\text { Watt @ } \\
\text { (WAW) }\end{array}$} & \multirow[b]{3}{*}{ Source } \\
\hline & & & & & & & & \\
\hline & & & & $\begin{array}{r}\text { Ballast } \\
(\%)\end{array}$ & $\begin{array}{r}\text { Lamp } \\
(\%)\end{array}$ & & & \\
\hline 4-Foot Lamps & & & 78 & & & & & $(1)$ \\
\hline Standard Ballast & & & & 35 & & & & \\
\hline Standard F40 T12 & 43 & 43 & & & 86 & 24 & 10 & (1) \\
\hline Reduced Wattage 34W T12 & 42 & 48 & & & 14 & 4 & 2 & \\
\hline EE Magnetic Ballast & & & & 65 & & & & (2) \\
\hline Standard F40 T12 & 40 & 39 & & & 86 & 44 & 17 & \\
\hline Reduced Wattage 34W T12 & 37 & 42 & & & 14 & 7 & 3 & \\
\hline T 8 & 32 & 34 & & & 0 & 0 & 0 & \\
\hline Cathode Cutout Ballast & & & & $\mathbf{0}$ & & & & (3) \\
\hline Standard F40 T12 & 36 & 36 & & & 86 & 0 & 0 & \\
\hline Reduced Wattage 34W T12 & 34 & 39 & & & 14 & $\mathbf{0}$ & 0 & \\
\hline T 8 & 33 & 37 & & & 0 & 0 & 0 & \\
\hline Electronic Ballast & & & & $\mathbf{0}$ & & & & (1) \\
\hline Standard F40 T12 & 33 & 33 & & & 86 & 0 & 0 & \\
\hline Reduced Wattage 34W T12 & 30 & 35 & & & 14 & 0 & 0 & \\
\hline T 8 & 26 & 28 & & & $\mathbf{0}$ & 0 & 0 & \\
\hline 8-Foot Lamps & & & 13 & & & & & (1) \\
\hline Standard Ballast & & & & 35 & & & & \\
\hline Standard F96 & 84 & 84 & & & 55 & 3 & 2 & (2) \\
\hline Reduced Wattage F96 & 72 & 81 & & & 45 & 2 & 2 & (2) \\
\hline EE Magnetic Ballast & & & & 65 & & & & (2) \\
\hline Standard F96 & 79 & 79 & & & 55 & 5 & 4 & (2) \\
\hline Reduced Wattage F96 & 68 & 76 & & & 45 & 4 & 3 & (2) \\
\hline Electronic Ballast & & & & $\mathbf{0}$ & & & & (1) \\
\hline Standard F96 & 66 & 66 & & & 55 & $\mathbf{0}$ & $\mathbf{0}$ & (2) \\
\hline Reduced Wattage F96 & 55 & 62 & & & 45 & 0 & $\mathbf{0}$ & (2) \\
\hline 8-Foot High Output Lamps & & & 8 & & & & & (1) \\
\hline Standard Ballast & & & & 35 & & & & \\
\hline Standard F96 & 127 & 127 & & & 55 & 1 & 2 & (2) \\
\hline Reduced Wattage F96 & 117 & 125 & & & 45 & 1 & 1 & (2) \\
\hline EE Magnetic Ballast & & & & 65 & & & & (2) \\
\hline Standard F96 & 119 & 119 & & & 55 & 3 & 3 & (2) \\
\hline Reduced Wattage F96 & 105 & 117 & & & 45 & 2 & 3 & (2) \\
\hline Electronic Ballast & & & & $\mathbf{0}$ & & & & (1) \\
\hline Standard F96 & 95 & 95 & & & 55 & 0 & 0 & (2) \\
\hline Reduced Wattage F96 & 86 & 95 & & & 45 & 0 & 0 & (2) \\
\hline Total & & & 99 & & & 99 & 52 & \\
\hline
\end{tabular}

\# The total fluorescent technology market that the lamp/ballast combination comprises

@ The sum of the products of each lamp/ballast's normalized wattage and its market share

Sources:

(1) Bureau of Census data

(2) NBECS 1986

(3) LBL estimate 
Table D.2 Baseline Market Shares, Fluorescent Lamp/Ballast Combinations (cont'd) 1986 Sales

\begin{tabular}{|c|c|c|c|c|c|c|c|c|}
\hline \multirow[b]{2}{*}{ Technology } & \multirow[b]{2}{*}{$\begin{array}{r}\text { ANSI } \\
\text { Watts * }\end{array}$} & \multirow[b]{2}{*}{$\begin{array}{l}\text { Fixture } \\
\text { Watts * }\end{array}$} & \multirow[b]{2}{*}{$\begin{array}{r}\text { End-Use } \\
\text { Share } \\
(\%)\end{array}$} & \multicolumn{2}{|c|}{ Technology Shares } & \multicolumn{3}{|c|}{ Weighted } \\
\hline & & & & $\begin{array}{c}\text { Technolog: } \\
\text { Ballast } \\
(\%)\end{array}$ & $\begin{array}{r}\text { Shares } \\
\text { Lamp } \\
(\%) \\
\end{array}$ & $\begin{array}{r}\text { Market } \\
\text { Share \# } \\
(\%) \\
\end{array}$ & $\begin{array}{c}\text { Average } \\
\text { Watt@ } \\
\text { (WAW) } \\
\end{array}$ & Source \\
\hline 4-Foot Lamps & & & 78 & & & & & $(1)$ \\
\hline Standard Ballast & & & & 35 & & & & \\
\hline Standard F40 T12 & 43 & 43 & & & 86 & 23 & 10 & (1) \\
\hline Reduced Wattage 34W T12 & 42 & 48 & & & 14 & 4 & 2 & \\
\hline EE Magnetic Ballast & & & & 65 & & & & (2) \\
\hline Standard F40 T12 & 40 & 39 & & & 86 & 44 & 17 & \\
\hline Reduced Wattage 34W T12 & 37 & 42 & & & 14 & 7 & 3 & \\
\hline T 8 & 32 & 34 & & & 0 & 0 & 0 & \\
\hline Cathode Cutout Ballast & & & & 0 & & & & (3) \\
\hline Standard F40 T12 & 36 & 36 & & & 86 & 0 & 0 & \\
\hline Reduced Wattage 34W T12 & 34 & 39 & & & 14 & $\mathbf{0}$ & 0 & \\
\hline T 8 & 33 & 37 & & & 0 & 0 & 0 & \\
\hline Electronic Ballast & & & & 1 & & & & (1) \\
\hline Standard F40 T12 & 33 & 33 & & & 86 & 1 & 0 & \\
\hline Reduced Wattage 34W T 12 & 30 & 35 & & & 14 & 0 & 0 & \\
\hline T 8 & 26 & 28 & & & $\mathbf{0}$ & $\mathbf{0}$ & 0 & \\
\hline 8-Foot Lamps & & & 13 & & & & & (1) \\
\hline Standard Ballast & & & & 35 & & & & \\
\hline Standard F96 & 84 & 84 & & & 55 & 2 & 2 & (2) \\
\hline Reduced Wattage F96 & 72 & 81 & & & 45 & 2 & 2 & (2) \\
\hline EE Magnetic Ballast & & & & 65 & & & & (2) \\
\hline Standard F96 & 79 & 79 & & & 55 & 5 & 4 & (2) \\
\hline Reduced Wattage F96 & 68 & 76 & & & 45 & 4 & 3 & (2) \\
\hline Electronic Ballast & & & & 1 & & & & (1) \\
\hline Standard F96 & 66 & 66 & & & 55 & 0 & 0 & (2) \\
\hline Reduced Wattage F96 & 55 & 62 & & & 45 & 0 & 0 & (2) \\
\hline 8-Foot High Output Lamps & & & 8 & & & & & (1) \\
\hline Standard Ballast & & & & 35 & & & & \\
\hline Standard F96 & 127 & 127 & & & 55 & 1 & 2 & (2) \\
\hline Reduced Wattage F96 & 117 & 125 & & & 45 & 1 & 1 & (2) \\
\hline EE Magnetic Baliast & & & & 65 & & & & (2) \\
\hline Standard Fyo & 119 & 119 & & & 55 & 3 & 3 & (2) \\
\hline Reduced Wattage P96 & 105 & 117 & & & 45 & 2 & 3 & (2) \\
\hline Electronic Ballast & & & & 1 & & & & (1) \\
\hline Standard F96 & 95 & 95 & & & 55 & 0 & 0 & (2) \\
\hline Reduced Wattage F96 & 86 & 95 & & & 45 & 0 & 0 & (2) \\
\hline $\begin{array}{l}\text { Total } \\
\text { Fraction of } 1986 \text { Stock }\end{array}$ & & & 99 & & & 99 & $\begin{array}{r}52 \\
1.00 \\
\end{array}$ & \\
\hline
\end{tabular}

* Normalized by lumen output

\# The total fluorescent technology market that the lamp/ballast combination comprises

@ The sum of the products of each lamp/ballast's normalized wattage and its market share

Sources:
(1) Bureau of Census data
(2) NBECS 1986
(3) LBL estimate

D -10 
Table D.2 Baseline Market Shares, Fluorescent Lamp/Ballast Combinations (cont'd) 1995 Stock

\begin{tabular}{|c|c|c|c|c|c|c|c|c|}
\hline \multirow[b]{2}{*}{ Technology } & \multirow[b]{2}{*}{$\begin{array}{r}\text { ANSI } \\
\text { Watts * }\end{array}$} & \multirow[b]{2}{*}{$\begin{array}{l}\text { Fixture } \\
\text { Watts * }\end{array}$} & \multirow[b]{2}{*}{$\begin{array}{r}\text { End-Use } \\
\text { Share } \\
(\%) \\
\end{array}$} & \multicolumn{2}{|c|}{ Technology Shares } & \multicolumn{3}{|c|}{ Weighted } \\
\hline & & & & $\begin{array}{c}\text { Technolo } \\
\text { Ballast } \\
(\%)\end{array}$ & $\begin{array}{r}\text { Shares } \\
\text { Lamp } \\
(\%) \\
\end{array}$ & $\begin{array}{r}\text { Market } \\
\text { Share \# } \\
\left(\mathscr{\%}_{0}\right)\end{array}$ & $\begin{array}{c}\text { Average } \\
\text { Watt@ } \\
\text { (WAW) }\end{array}$ & Source \\
\hline 4-Foot Lamps & & & 80 & & & & & (1) \\
\hline Standard Ballast & & & & 24 & & & & (2) \\
\hline Standard F40 T12 & 43 & 43 & & & 26 & 5 & 2 & (3) \\
\hline Reduced Wattage 34W T12 & 42 & 48 & & & 74 & 14 & 7 & (3) \\
\hline EE Magnetic Ballast & & & & 72 & & & & (4) \\
\hline Standard F40 T12 & 40 & 39 & & & 22 & 12 & 5 & (3) \\
\hline Reduced Wattage 34W T12 & 37 & 42 & & & 62 & 35 & 15 & (3) \\
\hline T 8 & 32 & 34 & & & 16 & 9 & 3 & (3) \\
\hline Cathode Cutout Ballast & & & & $\mathbf{0}$ & & & & (4) \\
\hline Standard F40 T12 & 36 & 36 & & & 22 & 0 & 0 & (3) \\
\hline Reduced Wattage $34 \mathrm{~W}$ T12 & 34 & 39 & & & 62 & 0 & 0 & (3) \\
\hline T 8 & 33 & 37 & & & 16 & 0 & 0 & (3) \\
\hline Electronic Ballast & & & & 4 & & & & (4) \\
\hline Standard F40 T12 & 33 & 33 & & & 22 & 1 & 0 & (3) \\
\hline Reduced Wattage 34W T12 & 30 & 35 & & & 62 & 2 & 1 & (3) \\
\hline T 8 & 26 & 28 & & & 16 & 0 & 0 & (3) \\
\hline 8-Foot Lamps & & & 11 & & & & & (1) \\
\hline Standard Ballast & & & & 23 & & & & (2) \\
\hline Standard F96 & 84 & 84 & & & 10 & 0 & 0 & (5) \\
\hline Reduced Wattage F96 & 72 & 81 & & & 90 & 2 & 2 & (5) \\
\hline EE Magnetic Ballast & & & & 70 & & & & (6) \\
\hline Standard Std F96 & 79 & 79 & & & 10 & 1 & 1 & (5) \\
\hline Reduced Wattage F96 & 68 & 76 & & & 90 & 7 & 5 & (5) \\
\hline Electronic Ballast & & & & 6 & & & & (6) \\
\hline Standard F96 & 66 & 66 & & & 10 & 0 & 0 & (5) \\
\hline Reduced Wattage F96 & 55 & 62 & & & 90 & 1 & 0 & (5) \\
\hline 8-Foot High Output Lamps & & & 5 & & & & & (1) \\
\hline Standard Ballast & & & & 24 & & & & (2) \\
\hline Standard F96 & 127 & 127 & & & 55 & 1 & 1 & (5) \\
\hline Reduced Wattage F96 & 117 & 125 & & & 45 & 1 & 1 & (5) \\
\hline EE Magnetic Ballast & & & & 71 & & & & (6) \\
\hline Standard F96 & 119 & 119 & & & 55 & 2 & 2 & (5) \\
\hline Reduced Wattage F96 & 105 & 117 & & & 45 & 2 & 2 & (5) \\
\hline Electronic Ballast & & & & 5 & & & & (6) \\
\hline Standard F96 & 95 & 95 & & & 55 & 0 & 0 & (5) \\
\hline Reduced Wattage F96 & 86 & 95 & & & 45 & 0 & 0 & (5) \\
\hline $\begin{array}{l}\text { Total } \\
\text { Fraction of } 1986 \text { Stock } \\
\end{array}$ & & & 95 & & & 95 & $\begin{array}{r}47 \\
0.91 \\
\end{array}$ & \\
\hline
\end{tabular}

* Normalized by lumen output

\# The total fluorescent technology market that the lamp/ballast combination comprises

@ The sum of the products of each lamp/ballast's normalized wattage and its market share

Sources:

(1) LRI Lamp Manufacturer Survey

(2) LBL estimate: $25 \%$ of 1995 magnetic ballast stock

(3) LRI NALMCO Survey for T8s; $26 \%$ of "other" allocated to standard F40, $74 \%$ to reduced wattage $34 \mathrm{~W}$

(4) LRI Ballast Manufacturer Survey for magnetic ballasts; $10 \%$ of "other" allocated to cathode cutout, $90 \%$ to electronic ballasts

(5) LRI NALMCO Survey

(6) LRI Ballast Manufacturer Survey 
Table D.2 Baseline Market Shares, Fluorescent Lamp/Ballast Combinations (cont'd) 1995 Sales

\begin{tabular}{|c|c|c|c|c|c|c|c|c|}
\hline \multirow[b]{2}{*}{ Technology } & \multirow[b]{2}{*}{$\begin{array}{r}\text { ANSI } \\
\text { Watts * }\end{array}$} & \multirow[b]{2}{*}{$\begin{array}{l}\text { Fixture } \\
\text { Watts * }\end{array}$} & \multirow[b]{2}{*}{$\begin{array}{r}\text { End-Use } \\
\text { Share } \\
(\%)\end{array}$} & \multicolumn{2}{|c|}{ Technology Shares } & \multicolumn{3}{|c|}{ Weighted } \\
\hline & & & & $\begin{array}{c}\text { Technolo } \\
\text { Ballast } \\
(\%)\end{array}$ & $\begin{array}{r}\text { Shares } \\
\text { Lamp } \\
(\%)\end{array}$ & $\begin{array}{r}\text { Market } \\
\text { Share \# } \\
(\%)\end{array}$ & $\begin{array}{c}\text { Average } \\
\text { Watt@ } \\
\text { (WAW) }\end{array}$ & Source \\
\hline 4-Foot Lamps & & & 80 & & & & & (1) \\
\hline Standard Ballast & & & & 0 & & & & (2) \\
\hline Standard F40 T12 & 43 & 43 & & & 25 & 0 & 0 & (3) \\
\hline Reduced Wattage 34W T12 & 42 & 48 & & & 75 & 0 & 0 & (3) \\
\hline EE Magnetic Ballast & & & & 54 & & & & (4) \\
\hline Standard F40 T12 & 40 & 39 & & & 20 & 9 & 3 & (3) \\
\hline Reduced Wattage 34W T12 & 37 & 42 & & & 60 & 26 & 11 & (3) \\
\hline T 8 & 32 & 34 & & & 20 & 9 & 3 & (3) \\
\hline Cathode Cutout Ballest & & & & 9 & & & & (4) \\
\hline Standard F40 T12 & 36 & 36 & & & 20 & 1 & 1 & (3) \\
\hline Reduced Wattage 34W T12 & 34 & 39 & & & 60 & 4 & 2 & (3) \\
\hline T 8 & 33 & 37 & & & 20 & 2 & 1 & (3) \\
\hline Electronic Ballast & & & & 37 & & & & (4) \\
\hline Standard F40 T12 & 33 & 33 & & & 20 & 6 & 2 & (3) \\
\hline Reduced Wattage $34 \mathrm{~W}$ T 12 & 30 & 35 & & & 60 & 18 & 6 & (3) \\
\hline T 8 & 26 & 28 & & & 20 & 6 & 2 & (3) \\
\hline 8-Foot Lamps & & & 11 & & & & & (1) \\
\hline Standard Ballast & & & & 0 & & & & (2) \\
\hline Standard F96 & 84 & 84 & & & 10 & 0 & 0 & (5) \\
\hline Reduced Wattage P96 & 72 & 81 & & & 90 & 0 & $\mathbf{0}$ & (5) \\
\hline EE Magnetic Ballast & & & & 76 & & & & (6) \\
\hline Standard F96 & 79 & 79 & & & 10 & 1 & & (5) \\
\hline Reduced Wattage F96 & 68 & 76 & & & 90 & 7 & 5 & (5) \\
\hline Electronic Ballast & & & & 24 & & & & (6) \\
\hline Standard F96 & 66 & 66 & & & 10 & 0 & 0 & (5) \\
\hline Reduced Wattage F96 & 55 & 62 & & & 90 & 2 & 1 & (5) \\
\hline 8-Foot High Output Lamps & & & 4 & & & & & (1) \\
\hline Standard Ballast & & & & 0 & & & & (2) \\
\hline Standard F96 & 127 & 127 & & & 56 & 0 & 0 & (5) \\
\hline Reduced Wattage F96 & 117 & 125 & & & 44 & 0 & 0 & (5) \\
\hline EE Magnetic Ballast & & & & 82 & & & & (6) \\
\hline Standard F96 & 119 & 119 & & & 56 & 2 & 2 & (5) \\
\hline Reduced Wattage F96 & 105 & 117 & & & 44 & 2 & 2 & (5) \\
\hline Electronic Ballast & & & & 18 & & & & (6) \\
\hline Standard F96 & 95 & 95 & & & 56 & 0 & $\mathbf{0}$ & (5) \\
\hline Reduced Wattage F96 & 86 & 95 & & & 44 & 0 & 0 & (5) \\
\hline $\begin{array}{l}\text { Total } \\
\text { Fraction of } 1986 \text { Stock }\end{array}$ & & & 95 & & & 95 & $\begin{array}{r}42 \\
0.81\end{array}$ & \\
\hline
\end{tabular}

* Normalized by lumen output

\# The total fluorescent technology market that the lamp/ballast combination comprises

@ The sum of the products of each lamp/ballast's normalized wattage and its market share

Sources:

(1) LRI Lamp Manufacturer Survey

(2) 1990 Ballast Standard

(3) LRI NALMCO Survey for T8s; $25 \%$ of "other" allocated to standard F40, $75 \%$ to reduced wattage $34 \mathrm{~W}$

(4) LRI Ballast Manufacturer Survey for magnetic ballasts; $20 \%$ of "other" allocated to cathode cutout, $80 \%$ to electronic ballasts

(5) LRI NALMCO Survey

(6) LRI Ballast Manufacturer Survey

$$
\text { D }-12
$$


Table D.3 Baseline Market Shares, Incandescent and Compact Fluorescent Lamps 1986 Stock

\begin{tabular}{|c|c|c|c|c|c|c|}
\hline Technology & Watts * & $\begin{array}{r}\text { End-Use } \\
\text { Share } \\
(\%) \\
\end{array}$ & $\begin{array}{r}\text { Technology } \\
\text { Share } \\
(\%) \\
\end{array}$ & $\begin{array}{r}\text { Market } \\
\text { Share \# } \\
(\%)\end{array}$ & $\begin{array}{c}\text { Weighted } \\
\text { Average } \\
\text { Watt@ } \\
\text { (WAW) }\end{array}$ & Source \\
\hline Generd Service & & 80 & & & & (1) \\
\hline$>150$ & 200 & & 2 & 2 & 3 & (1) \\
\hline 15-150 Standard & 75 & & 93 & $7 \overline{4}$ & 56 & \\
\hline Reduced Wattage & 71 & & 5 & 4 & 3 & (2) \\
\hline Halogen & 66 & & 0 & 0 & 0 & \\
\hline Coated Filament (R\&D) & 24 & & 0 & $\mathbf{0}$ & 0 & \\
\hline Reflector & & 10 & & & & (1) \\
\hline Standard Par & 150 & & 33 & 3 & 5 & (3) \\
\hline Standard R & 150 & & 42 & 4 & 6 & (3) \\
\hline Reduced Wattage PAR/R & 120 & & 20 & 2 & 2 & (2) \\
\hline Halogen & 90 & & 5 & 1 & 0 & (1) \\
\hline Halogen Infrared (IR) & 60 & & 0 & 0 & 0 & \\
\hline Coated Filament (R\&D) & 40 & & 0 & 0 & 0 & \\
\hline Other & & 10 & & & & (1) \\
\hline Standard & 100 & & 100 & 10 & 10 & \\
\hline Total & & 100 & & 100 & 86 & \\
\hline
\end{tabular}

* Normalized by lumen output

\# The share of the total incandescent lamp market that the particular technology comprises

@ The sum of the products of each technology's wattage and its market share

Sources:

(1) Census data

(2) LBL estimate

(3) $44 \%$ of Census "others" allocated to standard par, $56 \%$ to standard reflector lamp 
Table D.3 Baseline Market Shares, Incandescent and Compact Fluorescent Lamps (cont'd) 1995 Stock

\begin{tabular}{|c|c|c|c|c|c|c|}
\hline Technology & Watts * & $\begin{array}{r}\text { End-Use } \\
\text { Share } \\
(\%)\end{array}$ & $\begin{array}{r}\text { Technology } \\
\text { Share } \\
(\%)\end{array}$ & $\begin{array}{r}\text { Market } \\
\text { Share \# } \\
(\%)\end{array}$ & $\begin{array}{l}\text { Weighted } \\
\text { Average } \\
\text { Watt @ } \\
\text { (WAW) }\end{array}$ & Source \\
\hline General Service & & 80 & & & & $(1)$ \\
\hline$>150$ & 200 & & 2 & 2 & 3 & (1) \\
\hline 15-150 Standard & 75 & & 43 & 34 & 26 & \\
\hline Reduced Wattage & 71 & & 50 & 40 & 28 & (2) \\
\hline Halogen & 66 & & 5 & 4 & 3 & (2) \\
\hline Coated Filament (R\&D) & 24 & & 0 & 0 & 0 & \\
\hline Reflector & & 10 & & & & (1) \\
\hline Standard Par & 150 & & 13 & 1 & 2 & (3) \\
\hline Standard R & 150 & & 17 & 2 & 3 & (3) \\
\hline Reduced Wattage PAR/R & 120 & & 30 & 3 & 4 & (2) \\
\hline Halogen & 90 & & 30 & 3 & 3 & (2) \\
\hline Halogen Infrared (IR) & 60 & & 10 & 1 & 1 & (2) \\
\hline Coated Filament (R\&D) & 40 & & 0 & 0 & 0 & \\
\hline Other & & 10 & & & & (1) \\
\hline Standard & 100 & & 100 & 10 & 10 & \\
\hline Total & & 100 & & 100 & 81 & \\
\hline $\begin{array}{l}\text { Total Incandescent } \\
\text { Compact Fluorescent } \\
\text { Combined }\end{array}$ & $\begin{array}{l}81 \\
18\end{array}$ & & & $\begin{array}{l}80 \\
20\end{array}$ & $\begin{array}{r}65 \\
4 \\
69\end{array}$ & (4) \\
\hline Fraction of 1986 Stock & & & & & 0.80 & \\
\hline \multicolumn{7}{|c|}{$\begin{array}{l}\text { \# The share of the total incandescent lamp market that the particular technology comprises } \\
\text { @ The sum of the products of each technology's wattage and its market share }\end{array}$} \\
\hline $\begin{array}{l}\text { Sources: } \\
\text { (1) Census data } \\
\text { (2) LBL estimate } \\
\text { (3) } 44 \% \text { of Census "others" } \\
\text { (4) LRI Lamp Manufacture }\end{array}$ & to stand & PAR, 56 & to standard & & & \\
\hline
\end{tabular}

D -14 
Table D.4 Baseline Market Shares, Fluorescent Fixtures 1986 Stock and 1986 Sales

\begin{tabular}{|c|c|c|c|c|c|c|}
\hline Technology & $\begin{array}{l}\text { Fixture } \\
\text { Watts * }\end{array}$ & $\begin{array}{r}\text { End-Use } \\
\text { Share } \\
(\%)\end{array}$ & $\begin{array}{r}\text { Techno } \\
\text { Fixture } \\
(\%)\end{array}$ & $\begin{array}{r}\text { Shares } \\
\text { Lamp } \\
(\%)\end{array}$ & $\begin{array}{r}\text { Market } \\
\text { Share \# } \\
(\%)\end{array}$ & $\begin{array}{c}\text { Weighted } \\
\text { Average } \\
\text { Watts@ } \\
\text { (WAW) }\end{array}$ \\
\hline 4-Foot Fixtures * & & 77 & & & & \\
\hline Lensed Troffer & 133 & & 69 & NA & 53 & 70 \\
\hline Wraparound & 94 & & 26 & NA & 20 & 19 \\
\hline Parabolic & 117 & & 6 & $\mathbf{N A}$ & 4 & 5 \\
\hline 8-Foot Fixtures & & 23 & & & & \\
\hline Strip & & & 70 & & & \\
\hline $18^{\prime}$ lamp & 78 & & & 22 & 4 & 3 \\
\hline 28 lamp & 152 & & & 78 & 12 & 19 \\
\hline Industrial & & & 17 & & & \\
\hline $\begin{array}{l}18^{\prime} \text { HO lamp } \\
28^{\prime} \text { HO lamp }\end{array}$ & $\begin{array}{l}119 \\
233\end{array}$ & & & $\begin{array}{l}13 \\
87\end{array}$ & $\begin{array}{l}1 \\
3\end{array}$ & $\begin{array}{l}1 \\
8\end{array}$ \\
\hline Wall & & & 13 & & & \\
\hline 18 lamp & 78 & & & 50 & 2 & 1 \\
\hline $28^{\prime}$ lamp & 152 & & & 50 & 2 & 2 \\
\hline Total & & 100 & & & 100 & 128 \\
\hline
\end{tabular}

\begin{tabular}{|c|c|c|c|c|c|c|}
\hline Technology & $\begin{array}{l}\text { Fixture } \\
\text { Watts * }\end{array}$ & $\begin{array}{r}\text { End-Use } \\
\text { Share } \\
(\%)\end{array}$ & $\begin{array}{l}\text { Techno } \\
\text { Fixture } \\
(\%)\end{array}$ & $\begin{array}{r}\text { Shares } \\
\text { Lamp } \\
(\%)\end{array}$ & $\begin{array}{r}\text { Market } \\
\text { Share \# } \\
(\%)\end{array}$ & $\begin{array}{l}\text { Weighted } \\
\text { Averrge } \\
\text { Watts @ } \\
\text { (WAW) }\end{array}$ \\
\hline 4-Foot Fixtures ** & & 77 & & & & \\
\hline $\begin{array}{l}\text { Lensed Troffer } \\
\text { Wraparound } \\
\text { Parabolic }\end{array}$ & $\begin{array}{r}133 \\
94 \\
117\end{array}$ & & $\begin{array}{l}54 \\
22 \\
23\end{array}$ & $\begin{array}{l}\mathbf{N A} \\
\mathbf{N A} \\
\mathbf{N A}\end{array}$ & $\begin{array}{l}42 \\
17 \\
18\end{array}$ & $\begin{array}{l}56 \\
16 \\
21\end{array}$ \\
\hline $\begin{array}{l}\text { 8-Foot Fixtures } \\
\text { Strip }\end{array}$ & & 23 & 70 & & & \\
\hline $\begin{array}{r}18^{\prime} \text { lamp } \\
28^{\prime} \text { lamp } \\
\text { Industrial }\end{array}$ & $\begin{array}{r}78 \\
152\end{array}$ & & 17 & $\begin{array}{l}22 \\
78\end{array}$ & $\begin{array}{r}4 \\
12\end{array}$ & $\begin{array}{r}3 \\
19\end{array}$ \\
\hline $\begin{array}{l}18^{\prime} \text { HO lamp } \\
28^{\prime} \text { HO lamp } \\
\text { Wall }\end{array}$ & $\begin{array}{l}119 \\
233\end{array}$ & & 13 & $\begin{array}{l}13 \\
87\end{array}$ & $\begin{array}{l}1 \\
3\end{array}$ & $\begin{array}{l}1 \\
8\end{array}$ \\
\hline $\begin{array}{l}18^{\prime} \text { lamp } \\
28^{\prime} \text { lamp }\end{array}$ & $\begin{array}{r}78 \\
152\end{array}$ & & & $\begin{array}{l}50 \\
50\end{array}$ & $\begin{array}{l}2 \\
2\end{array}$ & $\begin{array}{l}1 \\
2\end{array}$ \\
\hline $\begin{array}{l}\text { Total } \\
\text { Fraction of } 1986 \text { Stock }\end{array}$ & & & & & 100 & $\begin{array}{r}127 \\
0.99\end{array}$ \\
\hline
\end{tabular}

* Normalized by lumen output

\# The share of the total fixture market that the particular technology comprises

@ The sum of the products of each technology's wattage and its market share

** Wattages for a 2-lamp fixture with energy-efficient magnetic ballast and standard lamp

D -15 
Table D.4 Baseline Market Shares, Fluorescent Fixtures (cont'd) 1995 Stock and 1995 Sales

\begin{tabular}{|c|c|c|c|c|c|c|}
\hline Technology & $\begin{array}{l}\text { Fixture } \\
\text { Watts * }\end{array}$ & $\begin{array}{r}\text { End-Use } \\
\text { Share } \\
(\%)\end{array}$ & $\begin{array}{r}\text { Techno } \\
\text { Fixture } \\
(\%)\end{array}$ & $\begin{array}{r}\text { Shares } \\
\text { Lamp } \\
(\%)\end{array}$ & $\begin{array}{r}\text { Market } \\
\text { Share \# } \\
(\%)\end{array}$ & $\begin{array}{r}\text { Weighted } \\
\text { Average } \\
\text { Watts@ } \\
\text { (WAW) }\end{array}$ \\
\hline $\begin{array}{l}\text { 4-Foot Fixtures } \\
\text { Lensed Troffer } \\
\text { Wraparound } \\
\text { Parabolic }\end{array}$ & $\begin{array}{r}133 \\
94 \\
114\end{array}$ & 77 & $\begin{array}{l}44 \\
25 \\
31\end{array}$ & $\begin{array}{l}\text { NA } \\
\text { NA } \\
\text { NA }\end{array}$ & $\begin{array}{l}34 \\
19 \\
24\end{array}$ & $\begin{array}{l}45 \\
18 \\
27\end{array}$ \\
\hline $\begin{array}{l}\text { 8-Foot Fixtures } \\
\text { Strip }\end{array}$ & & 23 & 70 & & & \\
\hline $\begin{array}{r}18 \text { lamp } \\
28 \text { lamp } \\
\text { Industrial }\end{array}$ & $\begin{array}{r}78 \\
152\end{array}$ & & & $\begin{array}{l}22 \\
78\end{array}$ & $\begin{array}{r}4 \\
12\end{array}$ & $\begin{array}{r}3 \\
19\end{array}$ \\
\hline $\begin{array}{l}18^{\prime} \text { HO lamp } \\
28^{\prime} \text { HO lamp } \\
\text { Wall }\end{array}$ & $\begin{array}{l}119 \\
233\end{array}$ & & & $\begin{array}{l}13 \\
87\end{array}$ & $\begin{array}{l}1 \\
3\end{array}$ & $\begin{array}{l}1 \\
8\end{array}$ \\
\hline $\begin{array}{l}18^{\prime} \text { lamp } \\
28^{\prime} \text { lamp }\end{array}$ & $\begin{array}{r}78 \\
152\end{array}$ & & & $\begin{array}{l}50 \\
50\end{array}$ & $\begin{array}{l}2 \\
2\end{array}$ & $\begin{array}{l}1 \\
2\end{array}$ \\
\hline $\begin{array}{l}\text { Total } \\
\text { Fraction of } 1986 \text { Stock }\end{array}$ & & 100 & & & 100 & $\begin{array}{r}124 \\
0.97\end{array}$ \\
\hline
\end{tabular}

\begin{tabular}{|c|c|c|c|c|c|c|}
\hline Technology & $\begin{array}{l}\text { Fixture } \\
\text { Watts * }\end{array}$ & $\begin{array}{r}\text { End-Use } \\
\text { Share } \\
(\%)\end{array}$ & $\begin{array}{l}\text { Technol } \\
\text { Fixture } \\
(\%)\end{array}$ & $\begin{array}{r}\text { Shares } \\
\text { Lamp } \\
(\%)\end{array}$ & $\begin{array}{r}\text { Market } \\
\text { Share \# } \\
(\%)\end{array}$ & $\begin{array}{c}\text { Weighted } \\
\text { Average } \\
\text { Watts @ } \\
\text { (WAW) }\end{array}$ \\
\hline 4-Foot Fixtures ** & & 77 & & & & \\
\hline Lensed Troffer & 133 & & 28 & NA & 22 & 29 \\
\hline Wraparound & 94 & & 30 & NA & 23 & 21 \\
\hline Parabolic & 109 & & 42 & NA & 33 & 35 \\
\hline 8-Foot Fixtures & & 23 & & & & \\
\hline Strip & & & 70 & & & \\
\hline $18^{\prime}$ lamp & 78 & & & 22 & 4 & 3 \\
\hline $28^{\prime}$ lamp & 152 & & & 78 & 12 & 19 \\
\hline \multicolumn{7}{|l|}{ Industrial } \\
\hline $18^{\prime}$ HO lamp & 119 & & & 13 & 1 & 1 \\
\hline 2 8' HO lamp & 233 & & & 87 & 3 & 8 \\
\hline \multicolumn{7}{|l|}{ Wall } \\
\hline 18 lamp & 78 & & & 50 & 2 & 1 \\
\hline 28 lamp & 152 & & & 50 & 2 & 2 \\
\hline $\begin{array}{l}\text { Total } \\
\text { Fraction of } 1986 \text { Stock }\end{array}$ & & 100 & & & 100 & $\begin{array}{r}119 \\
0.93\end{array}$ \\
\hline
\end{tabular}

* Normalized by lumen output

\# The share of the total fixture market that the particular technology comprises

@ The sum of the products of each technology's wattage and its market share

** Wattages for a 2-lamp fixture with energy-efficient magnetic ballast and standard lamp

D -16 
Table D.5 Fluorescent Policy Case Market Shares, 1995 Sales Basecase

\begin{tabular}{|c|c|c|c|c|c|c|c|c|}
\hline Technology & $\begin{array}{l}\text { Fixture } \\
\text { Watts * }\end{array}$ & $\begin{array}{l}\text { Equip } \\
\text { Cost * }\end{array}$ & $\begin{array}{r}\text { End.Use } \\
\text { Share } \\
\left(\%_{0}\right) \\
\end{array}$ & $\begin{array}{c}\text { Technology } \\
\text { Ballast } \\
(\%) \\
\end{array}$ & $\begin{array}{r}\text { Shares } \\
\text { Lamp } \\
(\%) \\
\end{array}$ & $\begin{array}{r}\text { Market } \\
\text { Share } \\
(\%) \\
\end{array}$ & $\begin{array}{c}\text { Weighted } \\
\text { Average } \\
\text { Watt* } \\
\text { (WAW) } \\
\end{array}$ & $\begin{array}{r}\text { Weighted } \\
\text { Average } \\
\text { Cost * } \\
\text { (WAC) } \\
\end{array}$ \\
\hline 4-Foot Lamps & & & & & & & & \\
\hline EE Magnetic Ballast & & & & 54 & & & & \\
\hline Standard F40 T12 & 39 & $\$ 33.41$ & & & 20 & 9 & 3 & 3 \\
\hline Reduced Wattage 34W T12 & 42 & $\$ 39.78$ & & & 60 & 26 & 11 & 10 \\
\hline T 8 & 34 & $\$ 38.94$ & & & 20 & 9 & 3 & 3 \\
\hline Cathode Cutout Ballast & & & & 9 & & & & \\
\hline Standard F40 T12 & 36 & $\$ 36.66$ & & & 20 & 1 & 1 & 1 \\
\hline Reduced Wattage 34 W T12 & 39 & $\$ 43.52$ & & & 60 & 4 & 2 & 2 \\
\hline T 8 & 37 & $\$ 42.21$ & & & 20 & 2 & 1 & 1 \\
\hline Electronic Ballast & & & & 37 & & & & \\
\hline Standard F40 T12 & 33 & $\$ 38.68$ & & & 20 & 6 & 2 & 2 \\
\hline Reduced Wattage 34W T12 & 35 & $\$ 45.84$ & & & 60 & 18 & 6 & 8 \\
\hline $\mathrm{T} 8$ & 28 & $\$ 52.46$ & & & 20 & 6 & 2 & 3 \\
\hline 8-Foot Lamps & & & 11 & & & & & \\
\hline EE Magnetic Ballast & & & & 76 & & & & \\
\hline Standard F96 & 79 & $\$ 46.08$ & & & 10 & 1 & 1 & 0 \\
\hline Reduced Wattage F96 & 76 & $\$ 61.41$ & & & 90 & 7 & 5 & 4 \\
\hline Electronic Ballast & & & & 24 & & & & \\
\hline Standard F96 & 66 & $\$ 49.93$ & & & 10 & $\mathbf{0}$ & $\mathbf{0}$ & 0 \\
\hline Reduced Wattage F96 & 62 & $\$ 65.72$ & & & 90 & 2 & 1 & 1 \\
\hline 8-Foot High Output Lamps & & & 4 & & & & & \\
\hline EE Magnetic Ballast & & & & 82 & & & & \\
\hline Standard F96 & 119 & $\$ 64.31$ & & & 10 & $\mathbf{0}$ & $\mathbf{0}$ & $\mathbf{0}$ \\
\hline Reduced Wattage F96 & 117 & $\$ 76.44$ & & & 90 & 3 & 4 & 2 \\
\hline Electronic Ballast & & & & 18 & & & & \\
\hline Standard F96 & 95 & $\$ 66.29$ & & & 10 & $\mathbf{0}$ & $\mathbf{0}$ & 0 \\
\hline Reduced Wathage F96 & 95 & $\$ 78.64$ & & & 90 & 1 & 1 & 1 \\
\hline $\begin{array}{l}\text { Total } \\
\text { WAC / WAW }\end{array}$ & & & 95 & & & 95 & 42 & $\begin{array}{r}43 \\
1.01\end{array}$ \\
\hline
\end{tabular}


Table D.5 Fluorescent Policy Case Market Shares, 1995 Sales (cont'd) Eliminare Highest Wattage Fluorescent Lamp

\begin{tabular}{|c|c|c|c|c|c|c|c|c|}
\hline Technology & $\begin{array}{r}\text { Fixture } \\
\text { Watts }\end{array}$ & $\begin{array}{r}\text { Equip } \\
\text { Cost }\end{array}$ & $\begin{array}{r}\text { End-Use } \\
\text { Share } \\
(\%)\end{array}$ & $\begin{array}{c}\text { Technolog } \\
\text { Ballast } \\
(\%)\end{array}$ & $\begin{array}{r}\text { Shares } \\
\text { Lamp } \\
(\%) \\
\end{array}$ & $\begin{array}{r}\text { Market } \\
\text { Share } \\
(\%)\end{array}$ & $\begin{array}{r}\text { Weighted } \\
\text { Average } \\
\text { Watt } \\
\text { (WAW) }\end{array}$ & $\begin{array}{r}\text { Weighted } \\
\text { Average } \\
\text { Cost } \\
\text { (WAC) }\end{array}$ \\
\hline 4-Foot Lamps & & & 80 & & & & & \\
\hline EE Magnetic Ballast: & & & & 54 & & & & \\
\hline Standard F40 T12 & 40 & $\$ 21.29$ & & & 0 & $\mathbf{0}$ & $\mathbf{0}$ & 0 \\
\hline Reduced Wattage 344W T12 & 37 & $\$ 21.84$ & & & 80 & 34 & 13 & 7 \\
\hline T 8 & 32 & $\$ 23.14$ & & & 20 & 9 & 3 & 2 \\
\hline Cathode Cutout Ballsst & & & & 9 & & & & \\
\hline Standard F40 T12 & 36 & $\$ 24.42$ & & & $\mathbf{0}$ & $\mathbf{0}$ & 0 & 0 \\
\hline Reduced Wattage 3:4W T12 & 34 & $\$ 24.97$ & & & 80 & 6 & 2 & 1 \\
\hline T 8 & 33 & $\$ 26.13$ & & & 20 & 2 & 0 & 0 \\
\hline Electronic Ballast & & & & 37 & & & & \\
\hline Standard F40 T12 & 33 & $\$ 26.44$ & & & 0 & 0 & 0 & 0 \\
\hline Reduced Wattage 34W T12 & 30 & $\$ 26.99$ & & & 80 & 24 & 7 & 6 \\
\hline T 8 & 26 & $\$ 27.75$ & & & 20 & 6 & 2 & 2 \\
\hline 8-Foot Lamps & & & 11 & & & & & \\
\hline EE Magnetic Ballast & & & & 76 & & & & \\
\hline Standard F96 & 79 & $\$ 36.63$ & & & 0 & 0 & 0 & 0 \\
\hline Reduced Wattage F96 & 68 & $\$ 38.77$ & & & 100 & 8 & 5 & 3 \\
\hline Electronic Ballast & & & & 24 & & & & \\
\hline Standard F96 & 66 & $\$ 40.48$ & & & 0 & 0 & 0 & 0 \\
\hline Reduced Wattage F96 & 55 & $\$ 42.62$ & & & 100 & 2 & 1 & 1 \\
\hline 8-Foot High Output Lamps & & & 4 & & & & & \\
\hline EE Magnetic Ballast & & & & 82 & & & & \\
\hline Standard F96 & 119 & $\$ 46.42$ & & & 0 & 0 & 0 & 0 \\
\hline Reduced Wattage F96 & 105 & $\$ 49.38$ & & & 100 & 4 & 4 & 2 \\
\hline Electronic Ballast & & & & 18 & & & & \\
\hline Standard F96 & 95 & $\$ 48.39$ & & & 0 & 0 & 0 & 0 \\
\hline Reduced Wattage F96 & 86 & $\$ 51.36$ & & & 100 & 1 & 1 & 0 \\
\hline Total & & & 95 & & & 95 & 38 & 26 \\
\hline WAC / WA W & & & & & & & & 0.68 \\
\hline Fraction of Baseline WAW & & & & & & & 0.98 & \\
\hline
\end{tabular}

D -18 
Table D.5 Fluorescent Policy Case Market Shares, 1995 Sales (cont'd) Minimum LCC Fluorescent Lamp

\begin{tabular}{|c|c|c|c|c|c|c|c|c|}
\hline Technology & $\begin{array}{r}\text { Fixture } \\
\text { Watts * }\end{array}$ & $\begin{array}{l}\text { Equip } \\
\text { Cost * }\end{array}$ & $\begin{array}{r}\text { End-Use } \\
\text { Share } \\
(\%) \\
\end{array}$ & $\begin{array}{c}\text { Technolog } \\
\text { Ballast } \\
(\%)\end{array}$ & $\begin{array}{r}\text { Shares } \\
\text { Lamp } \\
(\%) \\
\end{array}$ & $\begin{array}{r}\text { Market } \\
\text { Share } \\
(\%) \\
\end{array}$ & $\begin{array}{l}\text { Weighted } \\
\text { Average } \\
\text { Watt * } \\
\text { (WAW) }\end{array}$ & $\begin{array}{r}\text { Weighted } \\
\text { Average } \\
\text { Cost * } \\
\text { (WAC) }\end{array}$ \\
\hline 4-Foot Lamps & & & 80 & & & & & \\
\hline EE Magnetic Ballast & & & & 54 & & & & \\
\hline Standard F40 T12 & 39 & $\$ 33.41$ & & & 0 & 0 & 0 & 0 \\
\hline Reduced Wattage 34 W T12 & 42 & $\$ 39.78$ & & & 0 & 0 & $\mathbf{0}$ & 0 \\
\hline T 8 & 34 & $\$ 38.94$ & & & 100 & 43 & 15 & 17 \\
\hline Cathode Cutout Ballast & & & & 9 & & & & \\
\hline Standard F40 T12 & 36 & $\$ 36.66$ & & & 0 & 0 & 0 & 0 \\
\hline Reduced Wattage 34W T12 & 39 & $\$ 43.52$ & & & 0 & 0 & 0 & 0 \\
\hline T 8 & 37 & $\$ 42.21$ & & & 100 & 7 & 3 & 3 \\
\hline Electronic Ballast & & & & 37 & & & & \\
\hline Standard F40 T12 & 33 & $\$ 38.68$ & & & 0 & 0 & 0 & 0 \\
\hline Reduced Wattage 34W T12 & 35 & $\$ 45.84$ & & & $\mathbf{0}$ & $\mathbf{0}$ & 0 & 0 \\
\hline T 8 & 28 & $\$ 52.46$ & & & 100 & 30 & 8 & 16 \\
\hline 8-Foot Lamps & & & 11 & & & & & \\
\hline EE Magnetic Ballast & & & & 76 & & & & \\
\hline Standard F96 & 79 & $\$ 46.08$ & & & 0 & $\mathbf{0}$ & 0 & 0 \\
\hline Reduced Wattage F96 & 76 & $\$ 61.41$ & & & 100 & 8 & 6 & 5 \\
\hline Electronic Ballast & & & & 24 & & & & \\
\hline Standard F96 & 66 & $\$ 49.93$ & & & 0 & 0 & 0 & 0 \\
\hline Reduced Wattage F96 & 62 & $\$ 65.72$ & & & 100 & 2 & 2 & 2 \\
\hline 8-Foot High Output Lamps & & & 4 & & & & & \\
\hline EE Magnetic Ballast & & & & 82 & & & & \\
\hline Standard F96 & 119 & $\$ 64.31$ & & & 0 & 0 & 0 & 0 \\
\hline Reduced Wattage F96 & 117 & $\$ 76.44$ & & & 100 & 4 & 4 & 3 \\
\hline Electronic Ballast & & & & 18 & & & & \\
\hline Standard F96 & 95 & $\$ 66.29$ & & & 0 & 0 & 0 & 0 \\
\hline Reduced Wattage F96 & 95 & $\$ 78.64$ & & & 100 & 1 & 1 & 1 \\
\hline $\begin{array}{l}\text { Total } \\
\text { WAC / WA W } \\
\text { Fraction of Brseline WAW }\end{array}$ & & & 95 & & & 95 & $\begin{array}{r}38 \\
099\end{array}$ & $\begin{array}{r}45 \\
1.19\end{array}$ \\
\hline
\end{tabular}


Table D.5 Fluorescent Policy Case Market Shares, 1995 Sales (cont'd) Minimum LCC Fluorescent Lamp/Ballast

\begin{tabular}{|c|c|c|c|c|c|c|c|c|}
\hline Technology & $\begin{array}{l}\text { Fixture } \\
\text { Watts * }\end{array}$ & $\begin{array}{l}\text { Equip } \\
\text { Cost * }\end{array}$ & $\begin{array}{r}\text { End-Use } \\
\text { Share } \\
(\%)\end{array}$ & $\begin{array}{c}\text { Technolog } \\
\text { Ballast } \\
(\%)\end{array}$ & $\begin{array}{r}\text { Shares } \\
\text { Lamp } \\
(\%)\end{array}$ & $\begin{array}{r}\text { Market } \\
\text { Share } \\
(\%)\end{array}$ & $\begin{array}{l}\text { Weighted } \\
\text { Average } \\
\text { Watt* } \\
\text { (WAW) }\end{array}$ & $\begin{array}{r}\text { Weighted } \\
\text { Average } \\
\text { Cost }{ }^{*} \\
\text { (WAC) }\end{array}$ \\
\hline 4-Foot Lamps & & & 80 & & & & & \\
\hline EE Magnetic Ballast & & & & 0 & & & & \\
\hline Standard F40 T12 & 39 & $\$ 33.41$ & & & $\mathbf{0}$ & 0 & 0 & 0 \\
\hline Reduced Wattage 34W T12 & 42 & $\$ 39.78$ & & & $\mathbf{0}$ & $\mathbf{0}$ & 0 & 0 \\
\hline T 8 & 34 & $\$ 38.94$ & & & 100 & $\mathbf{0}$ & 0 & 0 \\
\hline Cathode Cutout Ballast & & & & 0 & & & & \\
\hline Standard F40 T12 & 36 & $\$ 36.66$ & & & 0 & $\mathbf{0}$ & $\mathbf{0}$ & 0 \\
\hline Reduced Wattage 34 W T 12 & 39 & $\$ 43.52$ & & & $\mathbf{0}$ & $\mathbf{0}$ & 0 & 0 \\
\hline T 8 & 37 & $\$ 42.21$ & & & 100 & 0 & 0 & 0 \\
\hline Electronic Ballast & & & & 100 & & & & \\
\hline Standard F40 T12 & 33 & $\$ 38.68$ & & & 0 & 0 & 0 & 0 \\
\hline Reduced Wattage 34 W T 12 & 35 & $\$ 45.84$ & & & 0 & $\mathbf{0}$ & 0 & 0 \\
\hline T 8 & 28 & $\$ 52.46$ & & & 100 & 80 & 22 & 42 \\
\hline 8-Foot Lamps & & & 11 & & & & & \\
\hline EE Magnetic Ballast & & & & 0 & & & & \\
\hline Standard F96 & 79 & $\$ 46.08$ & & & 0 & $\mathbf{0}$ & 0 & 0 \\
\hline Reduced Wattage F96 & 76 & $\$ 61.41$ & & & 100 & 0 & 0 & 0 \\
\hline Electronic Ballast & & & & 100 & & & & \\
\hline Standard F96 & 66 & $\$ 49.93$ & & & 0 & $\mathbf{0}$ & 0 & 0 \\
\hline Reduced Wattage F96 & 62 & $\$ 65.72$ & & & 100 & 11 & 6 & 7 \\
\hline 8-Foot High Output Lamps & & & 4 & & & & & \\
\hline EE Magnetic Ballast & & & & 0 & & & & \\
\hline Standard F96 & 119 & $\$ 64.31$ & & & 0 & 0 & 0 & 0 \\
\hline Reduced Wattage F96 & 117 & $\$ 76.44$ & & & 100 & 0 & 0 & 0 \\
\hline Electronic Ballast & & & & 100 & & & & \\
\hline Standard F96 & 95 & $\$ 66.29$ & & & 0 & 0 & 0 & 0 \\
\hline Reduced Wattage F96 & 95 & $\mathbf{5 7 8 . 6 4}$ & & & 100 & 4 & 4 & 3 \\
\hline $\begin{array}{l}\text { Total } \\
\text { WAC / WAW }\end{array}$ & & & 95 & & & 95 & 33 & $\begin{array}{r}52 \\
1.60\end{array}$ \\
\hline Fraction of Baseline WAW & & & & & & & 0.85 & \\
\hline
\end{tabular}

D - 20 
Table D.5 Fluorescent Policy Case Market Shares, 1995 Sales (cont'd) Maximum Technology Fluorescent Lamp

\begin{tabular}{|c|c|c|c|c|c|c|c|c|}
\hline Technology & $\begin{array}{r}\text { Fixture } \\
\text { Watts * } \\
\end{array}$ & $\begin{array}{l}\text { Equip } \\
\text { Cost * }\end{array}$ & $\begin{array}{r}\text { End-Use } \\
\text { Share } \\
(\%) \\
\end{array}$ & $\begin{array}{c}\text { Technolog } \\
\text { Ballast } \\
(\%)\end{array}$ & $\begin{array}{r}\text { Shares } \\
\text { Lamp } \\
(\%) \\
\end{array}$ & $\begin{array}{r}\text { Market } \\
\text { Share } \\
(\%) \\
\end{array}$ & $\begin{array}{r}\text { Weighted } \\
\text { Average } \\
\text { Watt * } \\
\text { (WAW) } \\
\end{array}$ & $\begin{array}{r}\text { Weighted } \\
\text { Average } \\
\text { Cost } \\
\text { (WAC) }\end{array}$ \\
\hline 4-Foot Lamps & & & 80 & & & & & \\
\hline EE Magnetic Ballast & & & & 0 & & & & \\
\hline Standard F40 T12 & 39 & $\$ 33.41$ & & & 0 & 0 & 0 & 0 \\
\hline Reduced Wattage 34W T12 & 42 & $\$ 39.78$ & & & $\mathbf{0}$ & 0 & 0 & 0 \\
\hline T 8 & 34 & $\$ 38.94$ & & & 100 & 0 & $\mathbf{0}$ & 0 \\
\hline Cathode Cutout Ballast & & & & 0 & & & & \\
\hline Standard F40 T12 & 36 & $\$ 36.66$ & & & 0 & 0 & 0 & 0 \\
\hline Reduced Wattage 34W T12 & 39 & $\$ 43.52$ & & & 0 & 0 & 0 & 0 \\
\hline T 8 & 37 & $\$ 42.21$ & & & 100 & 0 & 0 & 0 \\
\hline Electronic Ballast & & & & 100 & & & & \\
\hline Standard F40 T12 & 33 & $\$ 38.68$ & & & 0 & 0 & 0 & 0 \\
\hline Reduced Wattage 34W T 12 & 35 & $\$ 45.84$ & & & 0 & 0 & 0 & 0 \\
\hline T 8 & 28 & $\$ 52.46$ & & & 0 & 0 & 0 & 0 \\
\hline Max Tech 4-Foot & 29 & $\$ 54.09$ & & & 100 & 80 & 23 & 43 \\
\hline 8-Foot Lamps & & & 11 & & & & & \\
\hline EE Magnetic Ballast & & & & 0 & & & & \\
\hline Standard F96 & 79 & $\$ 46.08$ & & & 0 & 0 & $\mathbf{0}$ & 0 \\
\hline Reduced Wattage F96 & 76 & $\$ 61.41$ & & & 100 & 0 & 0 & 0 \\
\hline Electronic Ballast & & & & 100 & & & & \\
\hline Standard F96 & 66 & $\$ 49.93$ & & & 0 & 0 & 0 & 0 \\
\hline Reduced Wattage F96 & 62 & $\$ 65.72$ & & & 0 & 0 & 0 & 0 \\
\hline T 8 & 58 & $\$ 80.13$ & & & 100 & 11 & 6 & 8 \\
\hline 8-Foot High Output Lamps & & & 4 & & & & & \\
\hline EE Magnetic Ballast & & & & $\mathbf{0}$ & & & & \\
\hline Standard F96 & 119 & $\$ 64.31$ & & & 0 & 0 & 0 & 0 \\
\hline Reduced Wattage F96 & 117 & $\$ 76.44$ & & & 100 & 0 & 0 & 0 \\
\hline Electronic Ballast & $\cdot$ & & & 100 & & & & \\
\hline Standard F96 & 95 & $\$ 66.29$ & & & 0 & 0 & 0 & 0 \\
\hline Reduced Wattage F96 & 95 & $\$ 78.64$ & & & 100 & 4 & 4 & 3 \\
\hline $\begin{array}{l}\text { Total } \\
\text { WAC / WAW } \\
\text { Fraction of Baseline WAW }\end{array}$ & & & 95 & & & 95 & $\begin{array}{r}34 \\
0.87\end{array}$ & $\begin{array}{r}55 \\
1.65\end{array}$ \\
\hline
\end{tabular}

D -21 
Table D.5 Fluorescent Policy Case Market Shares, 1995 Sales (cont'd) R\&D Fluorescent Lamp

\begin{tabular}{|c|c|c|c|c|c|c|c|c|}
\hline Technology & $\begin{array}{l}\text { Fixture } \\
\text { Watts * }\end{array}$ & $\begin{array}{l}\text { Equip } \\
\text { Cost * }\end{array}$ & $\begin{array}{r}\text { End-Use } \\
\text { Share } \\
(\%)\end{array}$ & $\begin{array}{c}\text { Technolog } \\
\text { Ballast } \\
(\%)\end{array}$ & $\begin{array}{r}\text { Shares } \\
\text { Lamp } \\
(\%)\end{array}$ & $\begin{array}{r}\text { Market } \\
\text { Share } \\
(\%)\end{array}$ & $\begin{array}{l}\text { Weighted } \\
\text { Average } \\
\text { Watt * } \\
\text { (WAW) }\end{array}$ & $\begin{array}{r}\text { Weighted } \\
\text { Average } \\
\text { Cost } \\
\text { (WAC) }\end{array}$ \\
\hline 4-Foot Lamps & & & 80 & & & & & \\
\hline EE Magnetic Ballast & & & & 0 & & & & \\
\hline Standard F40 T12 & 39 & $\$ 33.41$ & & & $\mathbf{0}$ & 0 & 0 & 0 \\
\hline Reduced Wattage 34W T12 & 42 & $\$ 39.78$ & & & 0 & $\mathbf{0}$ & $\mathbf{0}$ & 0 \\
\hline T 8 & 34 & $\$ 38.94$ & & & 100 & 0 & 0 & 0 \\
\hline Cathode Cutout Ballast & & & & 0 & & & & \\
\hline Standard F40 T12 & 36 & $\$ 36.66$ & & & $\mathbf{0}$ & 0 & $\mathbf{0}$ & 0 \\
\hline Reduced Wattage 34W T12 & 39 & $\$ 43.52$ & & & 0 & $\mathbf{0}$ & $\mathbf{0}$ & 0 \\
\hline T 8 & 37 & $\$ 42.21$ & & & 100 & 0 & $\mathbf{0}$ & $\mathbf{0}$ \\
\hline Electronic Ballast & & & & 100 & & & & \\
\hline Standard F40 T12 & 33 & $\$ 38.68$ & & & 0 & $\mathbf{0}$ & $\mathbf{0}$ & $\mathbf{0}$ \\
\hline Reduced Wattage $34 \mathrm{~W}$ T12 & 35 & $\$ 45.84$ & & & $\mathbf{0}$ & $\mathbf{0}$ & $\mathbf{0}$ & 0 \\
\hline T 8 & 28 & $\$ 52.46$ & & & 0 & 0 & $\mathbf{0}$ & 0 \\
\hline R\&D & 26 & $\$ 31.07$ & & & 100 & 80 & 21 & 25 \\
\hline 8-Foot Lamps & & & 11 & & & & & \\
\hline EE Magnetic Ballast & & & & $\mathbf{0}$ & & & & \\
\hline Standard F96 & 79 & $\$ 46.08$ & & & 0 & 0 & 0 & 0 \\
\hline Reduced Wattage F96 & 76 & $\$ 61.41$ & & & 100 & 0 & 0 & 0 \\
\hline Electronic Ballast & & & & 100 & & & & \\
\hline Standard F96 & 66 & $\$ 49.93$ & & & $\mathbf{0}$ & 0 & 0 & 0 \\
\hline Reduced Wattage F96 & 62 & $\$ 65.72$ & & & 0 & 0 & 0 & 0 \\
\hline R\&D & 46 & $\$ 40.11$ & & & 100 & 11 & 5 & 4 \\
\hline 8-Foot High Output Lamps & & & 4 & & & & & \\
\hline EE Magnetic Ballast & & & & $\mathbf{0}$ & & & & \\
\hline Standard F96 & 119 & $\$ 64.31$ & & & $\mathbf{0}$ & 0 & 0 & 0 \\
\hline Reduced Wattage F96 & 117 & $\$ 76.44$ & & & 100 & 0 & 0 & 0 \\
\hline Electronic Ballast & & & & 100 & & & & \\
\hline Standard F96 & 95 & $\$ 66.29$ & & & 0 & 0 & 0 & 0 \\
\hline Reduced Wattage F96 & 95 & $\$ 78.64$ & & & 100 & 4 & 4 & 3 \\
\hline $\begin{array}{l}\text { Total } \\
\text { WAC / WAW }\end{array}$ & & & 95 & & & 95 & 30 & $\begin{array}{r}33 \\
1.09\end{array}$ \\
\hline Fraction of Baseline WAW & & & & & & & 0.77 & \\
\hline
\end{tabular}

* Normalized by lumen output 
Table D.5 Fluorescent Policy Case Market Shares, 1995 Sales (cont'd) Minimum LCC Combination

\begin{tabular}{|c|c|c|c|c|c|c|c|c|}
\hline Technology & $\begin{array}{l}\text { Fixture } \\
\text { Watts * }\end{array}$ & $\begin{array}{l}\text { Equip } \\
\text { Cost * }\end{array}$ & $\begin{array}{r}\text { End-Use } \\
\text { Share } \\
(\%) \\
\end{array}$ & $\begin{array}{c}\text { Technolog } \\
\text { Ballast } \\
(\%)\end{array}$ & $\begin{array}{r}\text { Shares } \\
\text { Lamp } \\
(\%) \\
\end{array}$ & $\begin{array}{r}\text { Market } \\
\text { Share } \\
(\%)\end{array}$ & $\begin{array}{r}\text { Weighted } \\
\text { Average } \\
\text { Watt } \\
\text { (WAW) }\end{array}$ & $\begin{array}{r}\text { Weighted } \\
\text { Average } \\
\text { Cost } \\
\text { (WAC) }\end{array}$ \\
\hline 4-Foot Lamps & & & 80 & & & & & \\
\hline EE Magnetic Ballast & & & & $\mathbf{0}$ & & & & \\
\hline Standard F40 T12 & 39 & $\$ 33.41$ & & & $\mathbf{0}$ & $\mathbf{0}$ & $\mathbf{0}$ & 0 \\
\hline Reduced Wattage 34W T12 & 42 & $\$ 39.78$ & & & 0 & 0 & $\mathbf{0}$ & 0 \\
\hline T 8 & 34 & $\$ 38.94$ & & & 100 & $\mathbf{0}$ & $\mathbf{0}$ & 0 \\
\hline Cathode Cutout Ballast & & & & 0 & & & & \\
\hline Standard F40 T12 & 36 & $\$ 36.66$ & & & 0 & 0 & $\mathbf{0}$ & 0 \\
\hline Reduced Wattage 34W T12 & 39 & $\$ 43.52$ & & & 0 & 0 & 0 & $\mathbf{0}$ \\
\hline T 8 & 37 & $\$ 42.21$ & & & 100 & 0 & $\mathbf{0}$ & $\mathbf{0}$ \\
\hline Electronic Ballast & & & & 100 & & & & \\
\hline Standard F40 T12 & 33 & $\$ 38.68$ & & & 0 & $\mathbf{0}$ & $\mathbf{0}$ & 0 \\
\hline Reduced Wattage 34W T12 & 35 & $\$ 45.84$ & & & 0 & 0 & $\mathbf{0}$ & $\mathbf{0}$ \\
\hline T 8 & 28 & $\$ 52.46$ & & & 0 & $\mathbf{0}$ & 0 & 0 \\
\hline T 8 in High-Efficiency Fixture & 26 & $\$ 67.46$ & & & 100 & 80 & 21 & 54 \\
\hline 8-Foot Lamps & & & 11 & & & & & \\
\hline EE Magnetic Ballast & & & & $\mathbf{0}$ & & & & \\
\hline Standard F96 & 79 & $\$ 46.08$ & & & 0 & 0 & 0 & 0 \\
\hline Reduced Wattage F96 & 76 & $\$ 61.41$ & & & 100 & $\mathbf{0}$ & $\mathbf{0}$ & $\mathbf{0}$ \\
\hline Electronic Ballast & & & & 100 & & & & \\
\hline Standard F96 & 66 & $\$ 49.93$ & & & $\mathbf{0}$ & $\mathbf{0}$ & $\mathbf{0}$ & 0 \\
\hline Reduced Wattage F96 & 53 & $\$ 65.72$ & & & 100 & 11 & 6 & 7 \\
\hline 8-Foot High Output Lamps & & & 4 & & & & & \\
\hline EE Magnetic Ballast & & & & $\mathbf{0}$ & & & & \\
\hline Standard F96 & 119 & $\$ 64.31$ & & & 0 & 0 & $\mathbf{0}$ & 0 \\
\hline Reduced Wattage F96 & 117 & $\$ 76.44$ & & & 100 & 0 & 0 & $\mathbf{0}$ \\
\hline Electronic Ballast & & & & 100 & & & & \\
\hline Standard F96 & 95 & $\$ 66.29$ & & & 0 & 0 & $\mathbf{0}$ & 0 \\
\hline Reduced Wattage P96 & 80 & $\$ 78.64$ & & & 100 & 4 & 4 & 3 \\
\hline $\begin{array}{l}\text { Total } \\
\text { WAC / WAW }\end{array}$ & & & 95 & & & 95 & 30 & $\begin{array}{r}65 \\
2.17\end{array}$ \\
\hline Fraction of Baseline WAW & & & & & & & 0.77 & \\
\hline
\end{tabular}

D - 23 
Table D.5 Fluorescent Policy Case Market Shares, 1995 Sales (cont'd) R\&D Combination

\begin{tabular}{|c|c|c|c|c|c|c|c|c|}
\hline Technology & $\begin{array}{c}\text { Fixture } \\
\text { Watts * }\end{array}$ & $\begin{array}{l}\text { Equip } \\
\text { Cost * }\end{array}$ & $\begin{array}{r}\text { End-Use } \\
\text { Share } \\
(\%)\end{array}$ & $\begin{array}{c}\text { Technolog } \\
\text { Ballast } \\
(\%)\end{array}$ & $\begin{array}{r}\text { Shares } \\
\text { Lamp } \\
(\%) \\
\end{array}$ & $\begin{array}{r}\text { Market } \\
\text { Share } \\
(\%) \\
\end{array}$ & $\begin{array}{r}\text { Weighted } \\
\text { Average } \\
\text { Watt * } \\
\text { (WAW) } \\
\end{array}$ & $\begin{array}{r}\text { Weighted } \\
\text { Average } \\
\text { Cost } \\
\text { (WAC) } \\
\end{array}$ \\
\hline 4-Foot Lamps & & & 80 & & & & & \\
\hline EE Magnetic Ballast & & & & 0 & & & & \\
\hline Standard F40 T12 & 39 & $\$ 33.41$ & & & 0 & 0 & 0 & 0 \\
\hline Reduced Wattage 34W T12 & 42 & $\$ 39.78$ & & & $\mathbf{0}$ & 0 & 0 & 0 \\
\hline T 8 & 34 & $\$ 38.94$ & & & 100 & 0 & 0 & 0 \\
\hline Cathode Cutout Ballast & & & & 0 & & & & \\
\hline Standard F40 T12 & 36 & $\$ 36.66$ & & & $\mathbf{0}$ & $\mathbf{0}$ & $\mathbf{0}$ & 0 \\
\hline Reduced Wattage 34W T12 & 39 & $\$ 43.52$ & & & 0 & 0 & 0 & 0 \\
\hline T 8 & 37 & $\$ 42.21$ & & & 100 & 0 & 0 & 0 \\
\hline Electronic Ballast & & & & 100 & & & & \\
\hline Standard F40 T12 & 33 & $\$ 38.68$ & & & 0 & 0 & 0 & 0 \\
\hline Reduced Wattage 34W T12 & 35 & $\$ 45.84$ & & & 0 & $\mathbf{0}$ & $\mathbf{0}$ & $\mathbf{0}$ \\
\hline T 8 & 28 & $\$ 52.46$ & & & 0 & 0 & 0 & 0 \\
\hline VHF Super-Efficient Fixture & 20 & $\$ 77.46$ & & & 100 & 80 & 16 & 62 \\
\hline 8-Foot Lamps & & & 11 & & & & & \\
\hline EE Magnetic Ballast & & & & 0 & & & & \\
\hline Standard F96 & 79 & $\$ 46.08$ & & & 0 & 0 & 0 & 0 \\
\hline Reduced Wattage F96 & 76 & $\$ 61.41$ & & & 100 & 0 & 0 & 0 \\
\hline Electronic Ballast & & & & 100 & & & & \\
\hline Standard F96 & 66 & $\$ 49.93$ & & & 0 & 0 & 0 & 0 \\
\hline Reduced Wattage F96 & 62 & $\$ 65.72$ & & & 0 & $\mathbf{0}$ & 0 & $\mathbf{0}$ \\
\hline R\&D & 46 & $\$ 40.11$ & & & 100 & 11 & 5 & 4 \\
\hline 8-Foot High Output Lamps & & & 4 & & & & & \\
\hline EE Magnetic Ballast & & & & 0 & & & & \\
\hline Standard F96 & 119 & $\$ 64.31$ & & & 0 & $\mathbf{0}$ & 0 & 0 \\
\hline Reduced Wattage F96 & 117 & $\$ 76.44$ & & & 100 & 0 & 0 & 0 \\
\hline Electronic Ballast & & & & 100 & & & & \\
\hline Standard F96 & 95 & $\$ 66.29$ & & & 0 & $\mathbf{0}$ & 0 & 0 \\
\hline Reduced Wattage F96 & 95 & $\$ 78.64$ & & & 100 & 4 & 4 & 3 \\
\hline $\begin{array}{l}\text { Total } \\
\text { WAC / WAW }\end{array}$ & & & 95 & & & 95 & 25 & $\begin{array}{r}70 \\
2.78\end{array}$ \\
\hline Fraction of Baseline WAW & & & & & & & 0.65 & \\
\hline
\end{tabular}


Table D.6 Incandescent Policy Case Market Shares, 1995 Sales Baseline

\begin{tabular}{|c|c|c|c|c|c|c|c|}
\hline Technology & Watts * & $\begin{array}{l}\text { Equip } \\
\text { Cost * }\end{array}$ & $\begin{array}{r}\text { End-Use } \\
\text { Share } \\
(\%)\end{array}$ & $\begin{array}{r}\text { Technology } \\
\text { Share } \\
(\%)\end{array}$ & $\begin{array}{r}\text { Market } \\
\text { Share } \\
(\%)\end{array}$ & $\begin{array}{l}\text { Weighted } \\
\text { Average } \\
\text { Watt * } \\
\text { (WAW) }\end{array}$ & $\begin{array}{r}\text { Weighted } \\
\text { Average } \\
\text { Cost * } \\
\text { (WAC) }\end{array}$ \\
\hline Genera Service & & & 80 & & & & \\
\hline$>150$ & 200 & $\$ 163$ & & 2 & 2 & 3 & 3 \\
\hline 15-150 Standard & 75 & $\$ 153$ & & 43 & 34 & 26 & 53 \\
\hline Reduced Wattage & 71 & $\$ 167$ & & 50 & 40 & 28 & 67 \\
\hline Halogen & 66 & $\$ 50$ & & 5 & 4 & 3 & 2 \\
\hline Coated Filament (R\&D) & 24 & $\$ 136$ & & 0 & 0 & 0 & 0 \\
\hline Reflector & & & 10 & & & & \\
\hline Standard PAR & 150 & $\$ 114$ & & 13 & 1 & 2 & 2 \\
\hline Standard $\mathbf{R}$ & 150 & $\$ 103$ & & 17 & 2 & 3 & 2 \\
\hline Reduced Wattage PAR/R & 120 & $\$ 137$ & & 30 & 3 & 4 & 4 \\
\hline Halogen & 90 & $\$ 167$ & & 30 & 3 & 3 & 5 \\
\hline Halogen Infrared (IR) & 60 & $\$ 156$ & & 10 & 1 & 1 & 2 \\
\hline Coated Filament (R\&D) & 40 & $\$ 146$ & & 0 & 0 & 0 & 0 \\
\hline Other & & & 10 & & & & \\
\hline Standard & 100 & $\$ 113$ & & 100 & 10 & 10 & 11 \\
\hline Total & & & 100 & & 100 & 81 & 149 \\
\hline Total Incandescent & 81 & $\$ 149$ & & & 80 & 65 & 119 \\
\hline Total Compact Fluorescent & 18 & $\$ 35$ & & & 20 & 4 & 7 \\
\hline Total Combined & & & & & 100 & 69 & 126 \\
\hline
\end{tabular}

D -25 
Table D.6 Incandescent Policy Case Market Shares, 1995 Saies (cont'd) Eliminate Highest Wattage Incandescent Lamp

\begin{tabular}{|c|c|c|c|c|c|c|c|}
\hline Technology & Watts * & $\begin{array}{l}\text { Equip } \\
\text { Cost * }\end{array}$ & $\begin{array}{r}\text { End-Use } \\
\text { Share } \\
(\%)\end{array}$ & $\begin{array}{r}\text { Technology } \\
\text { Share } \\
(\%) \\
\end{array}$ & $\begin{array}{r}\text { Market } \\
\text { Share } \\
(\%)\end{array}$ & $\begin{array}{l}\text { Weighted } \\
\text { Average } \\
\text { Watt* } \\
\text { (WAW) }\end{array}$ & $\begin{array}{r}\text { Weighted } \\
\text { Average } \\
\text { Cost * } \\
\text { (WAC) }\end{array}$ \\
\hline GeneraI Service & & & 80 & & & & \\
\hline$>150$ & 200 & $\$ 163$ & & 2 & 2 & 3 & 3 \\
\hline 15-150 Standard & 75 & $\$ 153$ & & 0 & $\mathbf{0}$ & 0 & 0 \\
\hline Reduced Wattage & 71 & $\$ 167$ & & 89 & 74 & 53 & 124 \\
\hline Halogen & 66 & $\$ 50$ & & 9 & 4 & 3 & 2 \\
\hline Coated Filament (R\&D) & 24 & $\$ 136$ & & 0 & 0 & 0 & 0 \\
\hline Reflector & & & 10 & & & & \\
\hline Standard PAR & 150 & $\$ 114$ & & $\mathbf{0}$ & 0 & 0 & 0 \\
\hline Standard $\mathbf{R}$ & 150 & $\$ 103$ & & $\mathbf{0}$ & 0 & 0 & $\mathbf{0}$ \\
\hline Reduced Wattage PAR/R & 120 & $\$ 137$ & & 43 & 6 & 7 & 8 \\
\hline Halogen & 90 & $\$ 167$ & & 43 & 3 & 3 & 5 \\
\hline Halogen Infrared (IR) & 60 & $\$ 156$ & & 14 & 1 & 1 & 2 \\
\hline Coated Filament (R\&D) & 40 & $\$ 146$ & & $\mathbf{0}$ & 0 & 0 & 0 \\
\hline Other & & & 10 & & & & \\
\hline Standard & 100 & $\$ 113$ & & 100 & 10 & 10 & 11 \\
\hline Total & & & & 100 & 100 & 79 & 155 \\
\hline $\begin{array}{l}\text { Total Incandescent } \\
\text { Total Compact Fluorescent } \\
\text { Total Combined }\end{array}$ & $\begin{array}{l}79 \\
18\end{array}$ & $\begin{array}{r}\$ 155 \\
\$ 35\end{array}$ & & & $\begin{array}{r}80 \\
20 \\
100\end{array}$ & $\begin{array}{r}63 \\
4 \\
67\end{array}$ & $\begin{array}{r}124 \\
7 \\
131\end{array}$ \\
\hline Fraction of Baseline WAW & & & & & & 0.97 & \\
\hline
\end{tabular}

* Normalized by lumen output 
Table D.6 Incandescent Policy Case Market Shares, 1995 Sales (cont'd) Minimum LCC Incandescent Lamp

\begin{tabular}{|c|c|c|c|c|c|c|c|}
\hline Technology & Watts * & $\begin{array}{l}\text { Equip } \\
\text { Cost * }\end{array}$ & $\begin{array}{r}\text { End-Use } \\
\text { Share } \\
(\%) \\
\end{array}$ & $\begin{array}{r}\text { Technology } \\
\text { Share } \\
(\%) \\
\end{array}$ & $\begin{array}{r}\text { Market } \\
\text { Share } \\
(\%) \\
\end{array}$ & $\begin{array}{l}\text { Weighted } \\
\text { Average } \\
\text { Watt* } \\
\text { (WAW) } \\
\end{array}$ & $\begin{array}{r}\text { Weighted } \\
\text { Average } \\
\text { Cost* } \\
\text { (WAC) } \\
\end{array}$ \\
\hline Genera Service & & & & & & & \\
\hline$>150$ & 200 & $\$ 163$ & & 2 & 2 & 3 & 3 \\
\hline 15-150 Standard & 75 & $\$ 153$ & & 0 & 0 & 0 & 0 \\
\hline Reduced Wattage & 71 & $\$ 167$ & & $\mathbf{0}$ & 0 & 0 & $\mathbf{0}$ \\
\hline Halogen & 66 & $\$ 50$ & & 98 & 78 & 52 & 39 \\
\hline Coated Filament (R\&D) & 24 & $\$ 136$ & & 0 & 0 & 0 & 0 \\
\hline Reflector & & & 10 & & & & \\
\hline Standard PAR & 150 & $\$ 114$ & & 0 & 0 & 0 & 0 \\
\hline Standard R & 150 & $\$ 103$ & & 0 & 0 & 0 & 0 \\
\hline Reduced Wattage PAR/R & 120 & $\$ 137$ & & 0 & 0 & 0 & 0 \\
\hline Halogen & 90 & $\$ 167$ & & 0 & 0 & 0 & $\mathbf{0}$ \\
\hline Halogen Infrared (IR) & 60 & $\$ 156$ & & 100 & 10 & 6 & 16 \\
\hline Coated Filament (R\&D) & 40 & $\$ 146$ & & 0 & 0 & 0 & 0 \\
\hline Other & & & 10 & & & & \\
\hline Standard & 100 & $\$ 113$ & & 100 & 10 & 10 & 11 \\
\hline Total & & & 100 & & 100 & 71 & 69 \\
\hline Total Incandescent & 71 & $\$ 69$ & & & 80 & 57 & 55 \\
\hline Total Compact Fluorescent & 18 & $\$ 36$ & & & 20 & 4 & 7 \\
\hline Total Combined & & & & & 100 & 60 & 62 \\
\hline Fraction of Baseline WAW & & & & & & 0.88 & \\
\hline
\end{tabular}

D -27 
Table D.6 Incandescent Policy Case Market Shares, 1995 Sales

(cont'd) Maximum Technology Incandescent Lamp

\begin{tabular}{|c|c|c|c|c|c|c|c|}
\hline Technology & Watts * & $\begin{array}{l}\text { Equip } \\
\text { Cost * }\end{array}$ & $\begin{array}{r}\text { End-Use } \\
\text { Share } \\
(\%)\end{array}$ & $\begin{array}{r}\text { Technology } \\
\text { Share } \\
(\%)\end{array}$ & $\begin{array}{r}\text { Market } \\
\text { Share } \\
(\%)\end{array}$ & $\begin{array}{l}\text { Weighted } \\
\text { Average } \\
\text { Watt } \\
\text { (WAW) }\end{array}$ & $\begin{array}{l}\text { Weighted } \\
\text { Average } \\
\text { Cost * } \\
\text { (WAC) }\end{array}$ \\
\hline General Service & & & 80 & & & & \\
\hline$>150$ & 200 & $\$ 163$ & & 2 & 2 & 3 & 3 \\
\hline 15-150 Standard & 75 & $\$ 153$ & & 0 & 0 & 0 & 0 \\
\hline Reduced Wattage & 71 & $\$ 167$ & & 0 & 0 & 0 & 0 \\
\hline Halogen & 66 & $\$ 50$ & & 0 & 0 & 0 & 0 \\
\hline Coated Filarnent (R\&D) & 57 & $\$ 136$ & & 98 & 78 & 45 & 107 \\
\hline Reflector & & & 10 & & & & \\
\hline Standard PAR & 150 & $\$ 114$ & & 0 & 0 & 0 & $\mathbf{0}$ \\
\hline Standard R & 150 & $\$ 103$ & & 0 & 0 & 0 & $\mathbf{0}$ \\
\hline Reduced Wattage PAR/R & 120 & $\$ 137$ & & 0 & 0 & 0 & $\mathbf{0}$ \\
\hline Halogen & 90 & $\$ 167$ & & 0 & $\mathbf{0}$ & 0 & $\mathbf{0}$ \\
\hline Halogen Infrared (IR) & 60 & $\$ 156$ & & 100 & 10 & 6 & 16 \\
\hline Coated Filament (R\&D) & 40 & $\$ 146$ & & 0 & 0 & 0 & 0 \\
\hline Other & & & 10 & & & & \\
\hline Standard & 100 & $\$ 113$ & & 100 & 10 & 10 & 11 \\
\hline Total & & & 100 & & 100 & 64 & 136 \\
\hline Total Incandescent & 64 & $\$ 136$ & & & 80 & 51 & 109 \\
\hline Total Compact Fluorescent & 18 & $\$ 36$ & & & 20 & $\begin{array}{r}4 \\
55\end{array}$ & 7 \\
\hline Total Combined & & & & & 100 & 55 & 116 \\
\hline Fraction of Baseline WAW & & & & & & 0.80 & \\
\hline
\end{tabular}

* Normalized by lamen output 
Table D.6 Incandescent Policy Case Market Shares, 1995 Sales (cont'd) Compact Fluorescent Downlights

\begin{tabular}{|c|c|c|c|c|c|c|c|}
\hline Technology & Watts * & $\begin{array}{l}\text { Equip } \\
\text { Cost * }\end{array}$ & $\begin{array}{r}\text { End-Use } \\
\text { Share } \\
(\%)\end{array}$ & $\begin{array}{r}\text { Technology } \\
\text { Share } \\
(\%) \\
\end{array}$ & $\begin{array}{r}\text { Market } \\
\text { Share } \\
(\%) \\
\end{array}$ & $\begin{array}{r}\text { Weighted } \\
\text { Average } \\
\text { Watt } \\
\text { (WAW) }\end{array}$ & $\begin{array}{r}\text { Weighted } \\
\text { Average } \\
\text { Cost * } \\
\text { (WAC) } \\
\end{array}$ \\
\hline General Service & & & 80 & & & & \\
\hline $\begin{array}{l}>150 \\
15-150 \text { Standard }\end{array}$ & $\begin{array}{r}200 \\
75\end{array}$ & $\begin{array}{l}\$ 163 \\
\$ 153\end{array}$ & & $\begin{array}{r}2 \\
43\end{array}$ & $\begin{array}{r}2 \\
34\end{array}$ & $\begin{array}{r}3 \\
26\end{array}$ & $\begin{array}{r}3 \\
53\end{array}$ \\
\hline Reduced Wattage & 71 & $\$ 167$ & & 50 & 40 & 28 & 67 \\
\hline Halogen & 66 & $\$ 50$ & & 5 & 4 & 3 & 2 \\
\hline Coated Filament (R\&D) & 24 & $\$ 136$ & & 0 & 0 & 0 & 0 \\
\hline Reflector & & & 10 & & & & \\
\hline Standard PAR & 150 & $\$ 114$ & & 13 & 1 & 2 & 2 \\
\hline Standard R & 150 & $\$ 103$ & & 17 & 2 & 3 & 2 \\
\hline Reduced Wattage PAR/R & 120 & $\$ 137$ & & 30 & 3 & 4 & 4 \\
\hline Halogen & 90 & $\$ 167$ & & 30 & 3 & 3 & 5 \\
\hline Halogen Infrared (IR) & 60 & $\$ 156$ & & 10 & 1 & 1 & 2 \\
\hline Coated Filament (R\&D) & 40 & $\$ 146$ & & 0 & 0 & 0 & 0 \\
\hline Other & & & 10 & & & & \\
\hline Standard & 100 & $\$ 113$ & & 100 & 10 & 10 & 11 \\
\hline Total & & & 100 & & 100 & 81 & 149 \\
\hline Total Incandescent & 81 & $\$ 149$ & & & 77 & 63 & 115 \\
\hline Total Compact Fluorescent & 18 & $\$ 36$ & & & 23 & 4 & 8 \\
\hline Total Combined & & & & & 100 & 67 & 123 \\
\hline Fraction of Baseline WAW & & & & & & 0.97 & \\
\hline
\end{tabular}


Table D.6 Incandescent Policy Case Market Shares, 1995 Sales (cont'd) R\&D

\begin{tabular}{|c|c|c|c|c|c|c|c|}
\hline Technology & Watts * & $\begin{array}{l}\text { Equip } \\
\text { Cost * }\end{array}$ & $\begin{array}{r}\text { End.Use } \\
\text { Share } \\
(\%) \\
\end{array}$ & $\begin{array}{r}\text { Technology } \\
\text { Share } \\
(\%) \\
\end{array}$ & $\begin{array}{r}\text { Market } \\
\text { Share } \\
(\%) \\
\end{array}$ & $\begin{array}{l}\text { Weighted } \\
\text { Average } \\
\text { Watt * } \\
\text { (WAW) }\end{array}$ & $\begin{array}{l}\text { Weighted } \\
\text { Average } \\
\text { Cost } \\
\text { (WAC) }\end{array}$ \\
\hline General Service & & & 80 & & & & \\
\hline$>150$ & 200 & $\$ 163$ & & 2 & 2 & 3 & 3 \\
\hline 15-150 Standard & 75 & $\$ 153$ & & 0 & 0 & 0 & 0 \\
\hline Reduced Wattage & 71 & $\$ 167$ & & 0 & 0 & 0 & 0 \\
\hline Halogen & 66 & $\$ 50$ & & 0 & 0 & 0 & 0 \\
\hline Coated Filament (R\&D) & 24 & $\$ 136$ & & 98 & 78 & 19 & 107 \\
\hline Reflector & & & 10 & & & & \\
\hline Standard PAR & 150 & $\$ 114$ & & $\mathbf{0}$ & $\mathbf{0}$ & 0 & 0 \\
\hline Standard R & 150 & $\$ 103$ & & 0 & 0 & $\mathbf{0}$ & 0 \\
\hline Reduced Wattage PAR/R & 120 & $\$ 137$ & & $\mathbf{0}$ & $\mathbf{0}$ & 0 & $\mathbf{0}$ \\
\hline Halogen & 90 & $\$ 167$ & & 0 & 0 & 0 & $\mathbf{0}$ \\
\hline Halogen Infrared (IR) & 60 & $\$ 156$ & & $\mathbf{0}$ & 0 & 0 & 0 \\
\hline Coated Filament (R\&D) & 40 & $\$ 146$ & & 100 & 10 & 4 & 15 \\
\hline Other & & & 10 & & & & \\
\hline Standard & 100 & $\$ 113$ & & 100 & 10 & 10 & 11 \\
\hline Total & & & 100 & & 100 & 36 & 135 \\
\hline Total Incandescent & 36 & $\$ 135$ & & & 80 & 29 & 108 \\
\hline Total Compact Fluorescent & 18 & $\$ 36$ & & & 20 & 4 & $\begin{array}{r}7 \\
115\end{array}$ \\
\hline Fraction of Baseline WAW & & & & & & 0.47 & \\
\hline
\end{tabular}

* Normalized by lumen output

D -30 
Table D.6 Incandescent Policy Case Market Shares, 1995 Sales (cont'd) 1991 Proposed Standards (Incandescent)

\begin{tabular}{|c|c|c|c|c|c|c|c|}
\hline Technology & Watts * & $\begin{array}{l}\text { Equip } \\
\text { Cost }\end{array}$ & $\begin{array}{r}\text { End-Use } \\
\text { Share } \\
(\%) \\
\end{array}$ & $\begin{array}{r}\text { Technology } \\
\text { Share } \\
(\%)\end{array}$ & $\begin{array}{r}\text { Market } \\
\text { Share } \\
(\%)\end{array}$ & $\begin{array}{l}\text { Weighted } \\
\text { Average } \\
\text { Watt * } \\
\text { (WAW) }\end{array}$ & $\begin{array}{l}\text { Weighted } \\
\text { Average } \\
\text { Cost * } \\
\text { (WAC) }\end{array}$ \\
\hline General Service & & & 80 & & & & \\
\hline$>150$ & 200 & $\$ 163$ & & 2 & 2 & 3 & 3 \\
\hline 15-150 Standard & 75 & $\$ 153$ & & 0 & 0 & 0 & 0 \\
\hline Reduced Wattage & 71 & $\$ 167$ & & 89 & 74 & 53 & 124 \\
\hline Halogen & 66 & $\$ 50$ & & 9 & 4 & 3 & 2 \\
\hline Coated Filament (R\&D) & 24 & $\$ 136$ & & 0 & 0 & 0 & 0 \\
\hline Reflector & & & 10 & & & & \\
\hline Standard PAR & 150 & $\$ 114$ & & 0 & 0 & 0 & 0 \\
\hline Standard R & 150 & $\$ 103$ & & 0 & 0 & 0 & 0 \\
\hline Reduced Wattage PAR/R & 120 & $\$ 137$ & & $\mathbf{0}$ & 0 & 0 & 0 \\
\hline Halogen & 90 & $\$ 167$ & & 75 & 9 & 8 & 15 \\
\hline Halogen Infrared (IR) & 60 & $\$ 156$ & & 25 & 1 & 1 & 2 \\
\hline Coated Filament (R\&D) & 40 & $\$ 146$ & & 0 & 0 & 0 & 0 \\
\hline Other & & & 10 & & & & \\
\hline Standard & 100 & $\$ 113$ & & 100 & 10 & 10 & 11 \\
\hline Total & & & 100 & & 100 & 77 & 157 \\
\hline $\begin{array}{l}\text { Total Incandescent } \\
\text { Total Compact Fluorescent } \\
\text { Total Combined }\end{array}$ & $\begin{array}{l}77 \\
18\end{array}$ & $\begin{array}{r}\$ 157 \\
\$ 336\end{array}$ & & . & $\begin{array}{r}80 \\
20 \\
100\end{array}$ & $\begin{array}{r}62 \\
4 \\
65\end{array}$ & $\begin{array}{r}125 \\
7 \\
133\end{array}$ \\
\hline Fraction of Baseline WAW & & & & & & 0.95 & \\
\hline
\end{tabular}

* Normalized by lumen output 
Table D.6 Incandescent Policy Case Market Shares, 1995 Sales (cont'd) Minimum LCC Combination

\begin{tabular}{|c|c|c|c|c|c|c|c|}
\hline Technology & Watts * & $\begin{array}{l}\text { Equip } \\
\text { Cost }\end{array}$ & $\begin{array}{r}\text { End-Use } \\
\text { Share } \\
(\%) \\
\end{array}$ & $\begin{array}{r}\text { Technology } \\
\text { Share } \\
(\%) \\
\end{array}$ & $\begin{array}{r}\text { Market } \\
\text { Share } \\
(\%)\end{array}$ & $\begin{array}{r}\text { Weighted } \\
\text { Average } \\
\text { Watt * } \\
\text { (WAW) }\end{array}$ & $\begin{array}{r}\text { Weighted } \\
\text { Average } \\
\text { Cost } \\
\text { (WAC) }\end{array}$ \\
\hline General Service & & & 80 & & & & \\
\hline$>150$ & 200 & $\$ 163$ & & 2 & 2 & 3 & 3 \\
\hline 15-150 Standard & 75 & $\$ 153$ & & 0 & 0 & 0 & 0 \\
\hline Reduced Wattage & 71 & $\$ 167$ & & 0 & 0 & 0 & 0 \\
\hline Halogen & 66 & $\$ 50$ & & 98 & 78 & 52 & 39 \\
\hline Coated Filament (R\&D) & 24 & $\$ 136$ & & 0 & 0 & 0 & 0 \\
\hline Reflector & & & 10 & & & & \\
\hline Standard PAR & 150 & $\$ 114$ & & 0 & 0 & 0 & 0 \\
\hline Standard R & 150 & $\$ 103$ & & 0 & 0 & 0 & 0 \\
\hline Reduced Wattage PAR/R & 120 & $\$ 137$ & & 0 & 0 & 0 & 0 \\
\hline Halogen & 90 & $\$ 167$ & & 0 & 0 & 0 & 0 \\
\hline Halogen Infrared (IR) & 60 & $\$ 156$ & & 100 & 10 & 6 & 16 \\
\hline Coated Filament (R\&D) & 40 & $\$ 146$ & & 0 & 0 & 0 & 0 \\
\hline Other & & & 10 & & & & \\
\hline Standard & 100 & $\$ 113$ & & 100 & 10 & 10 & 11 \\
\hline Total & & & 100 & & 100 & 71 & 69 \\
\hline $\begin{array}{l}\text { Total Incandescent } \\
\text { Total Compact Fluorescent } \\
\text { Total Combined }\end{array}$ & $\begin{array}{l}71 \\
18\end{array}$ & $\begin{array}{l}\$ 69 \\
\$ 67\end{array}$ & & & $\begin{array}{r}33 \\
67 \\
100\end{array}$ & $\begin{array}{l}23 \\
12 \\
35\end{array}$ & $\begin{array}{l}23 \\
45 \\
68\end{array}$ \\
\hline Fraction of Baseline WAW & & & & & & 0.52 & \\
\hline
\end{tabular}

* Normalized by lumen output 
Table D.6 Incandescent Policy Case Market Shares, 1995 Sales (cont'd) R\&D Combination

\begin{tabular}{|c|c|c|c|c|c|c|c|}
\hline Technology & Watts * & $\begin{array}{l}\text { Equip } \\
\text { Cost* }\end{array}$ & $\begin{array}{r}\text { End-Use } \\
\text { Share } \\
(\%) \\
\end{array}$ & $\begin{array}{r}\text { Technology } \\
\text { Share } \\
(\%)\end{array}$ & $\begin{array}{r}\text { Market } \\
\text { Share } \\
(\%)\end{array}$ & $\begin{array}{l}\text { Weighted } \\
\text { Average } \\
\text { Watt } \\
\text { (WAW) }\end{array}$ & $\begin{array}{r}\text { Weighted } \\
\text { Average } \\
\text { Cost * } \\
\text { (WAC) }\end{array}$ \\
\hline General Service & & & 80 & & & & \\
\hline$>150$ & 200 & $\$ 163$ & & 2 & 2 & 3 & 3 \\
\hline 15-150 Standard & 75 & $\$ 153$ & & 0 & 0 & 0 & 0 \\
\hline Reduced Wattage & 71 & $\$ 167$ & & 0 & 0 & 0 & 0 \\
\hline Halogen & 66 & $\$ 50$ & & 0 & 0 & 0 & 0 \\
\hline Coated Filament (R\&D) & 24 & $\$ 136$ & & 98 & 78 & 19 & 107 \\
\hline Reflector & & & 10 & & & & \\
\hline Standard PAR & 150 & $\$ 114$ & & 0 & 0 & 0 & 0 \\
\hline Standard $\mathrm{R}$ & 150 & $\$ 103$ & & 0 & 0 & 0 & 0 \\
\hline Reduced Wattage PAR/R & 120 & $\$ 137$ & & 0 & 0 & 0 & 0 \\
\hline Halogen & 90 & $\$ 167$ & & 0 & 0 & 0 & 0 \\
\hline Halogen Infrared (IR) & 60 & $\$ 156$ & & 0 & 0 & 0 & 0 \\
\hline Coated Filament (R\&D) & 40 & $\$ 146$ & & 100 & 10 & 4 & 15 \\
\hline Other & & & 10 & & & & \\
\hline Standard & 100 & $\$ 113$ & & 100 & 10 & 10 & 11 \\
\hline Total & & & 100 & & 100 & 36 & 135 \\
\hline Total Incandescent & 36 & $\$ 135$ & & & 10 & 4 & 14 \\
\hline Total Compact Fuorescent & 18 & $\$ 44$ & & & 90 & 16 & 40 \\
\hline Total Combined & & & & & 100 & 20 & 53 \\
\hline Fraction of Baseline WAW & & & & & & 0.29 & \\
\hline
\end{tabular}

* Normalized by lumen output 
Table D.7 Fixture Policy Case Market Shares, 1995 Sales Baseline

\begin{tabular}{|c|c|c|c|c|c|c|}
\hline Technology & $\begin{array}{l}\text { Fixture } \\
\text { Watts * }\end{array}$ & $\begin{array}{r}\text { End-Use } \\
\text { Share } \\
(\%)\end{array}$ & $\begin{array}{l}\text { Techno } \\
\text { Fixture } \\
(\%)\end{array}$ & $\begin{array}{r}\text { Shares } \\
\text { Lamp } \\
(\%)\end{array}$ & $\begin{array}{r}\text { Market } \\
\text { Share \# } \\
(\%)\end{array}$ & $\begin{array}{l}\text { Weighted } \\
\text { Average } \\
\text { Watt@ } \\
\text { (WAW) }\end{array}$ \\
\hline 4-Foot Fixtures ** & & 77 & & & & \\
\hline Lensed Troffer & 133 & & 28 & NA & 22. & 29 \\
\hline Wraparound & 94 & & 30 & NA & 23 & 21 \\
\hline Parabolic & 109 & & 42 & NA & 33 & 35 \\
\hline 8-Foot Fixtures & & 23 & & & & \\
\hline Strip & & & 70 & & & \\
\hline $18^{\prime}$ lamp & 78 & & & 22 & 4 & 3 \\
\hline 28 lamp & 152 & & & 78 & 12 & 19 \\
\hline Industrial & & & 17 & & & \\
\hline $18^{\prime}$ HO lamp & 119 & & & 13 & 1 & 1 \\
\hline $28^{\prime}$ HO lamp & 233 & & & 87 & 3 & 8 \\
\hline Wall & & & 13 & & & \\
\hline 18 lamp & 78 & & & 50 & 2 & 1 \\
\hline $28^{\prime}$ lamp & 152 & & & 50 & 2 & 2 \\
\hline Total & & 100 & & & 100 & 119 \\
\hline
\end{tabular}

* Normalized by lumen output

\# The share of the total fixture market that the particular technology comprises

@ The sum of the products of each technology's wattage and its market share

** Wattages for a 2-lamp fixture with energy-efficient magnetic ballast and standard lamp 
Table D.7 Fixture Policy Case Market Shares, 1995 Sales (cont'd) Luminaire Efficiency Standard

\begin{tabular}{|c|c|c|c|c|c|c|}
\hline Technology & $\begin{array}{l}\text { Fixture } \\
\text { Watts * }\end{array}$ & $\begin{array}{r}\text { End-Use } \\
\text { Share } \\
(\%)\end{array}$ & $\begin{array}{l}\text { Technol } \\
\text { Fixture } \\
(\%)\end{array}$ & $\begin{array}{r}\text { Shares } \\
\text { Lamp } \\
(\%)\end{array}$ & $\begin{array}{r}\text { Market } \\
\text { Share \# } \\
(\%)\end{array}$ & $\begin{array}{r}\text { Weighted } \\
\text { Average } \\
\text { Watt@ } \\
\text { (WAW) }\end{array}$ \\
\hline 4-Foot Fixtures ** & & 77 & & & & \\
\hline Lensed Troffer & 127 & & 28 & NA & 22 & 28 \\
\hline Wraparound & 91 & & 30 & NA & 23 & 21 \\
\hline Parabolic & 104 & & 42 & NA & 33 & 34 \\
\hline 8-Foot Fixtures & & 23 & & & & \\
\hline Strip & & & 70 & & & \\
\hline 18 lamp & 78 & & & 22 & 4 & 3 \\
\hline 28 lamp & 152 & & & 78 & 12 & 19 \\
\hline Industrial & & & 17 & & & \\
\hline $18^{\prime}$ HO lamp & 119 & & & 13 & 1 & 1 \\
\hline $28^{\prime}$ HO lamp & 233 & & & 87 & 3 & 8 \\
\hline Wall & & & 13 & & & \\
\hline 18 lamp & 78 & & & 50 & 2 & 1 \\
\hline 2. $8^{\prime}$ lamp & 152 & & & 50 & 2 & 2 \\
\hline $\begin{array}{l}\text { Total } \\
\text { Fraction of Buseline WAW }\end{array}$ & ' & 100 & & & 100 & $\begin{array}{r}116 \\
0.97\end{array}$ \\
\hline
\end{tabular}

* Normalized by lumen output

\# The share of the total fixture market that the particular technology comprises

@ The sum of the products of each technology's wattage and its market share

** Wattages for a 2-lamp fixture with energy-efficient magnetic ballast and standard lamp 
Table D.7 Fixture Policy Case Market Shares, 1995 Sales (cont'd) Maximum Technology

\begin{tabular}{|c|c|c|c|c|c|c|}
\hline Technology & $\begin{array}{l}\text { Fixture } \\
\text { Watts * }\end{array}$ & $\begin{array}{r}\text { End-Use } \\
\text { Share } \\
(\%)\end{array}$ & $\begin{array}{r}\text { Techno } \\
\text { Fixture } \\
(\%)\end{array}$ & $\begin{array}{r}\text { Shares } \\
\text { Lamp } \\
(\%)\end{array}$ & $\begin{array}{r}\text { Market } \\
\text { Share \# } \\
(\%)\end{array}$ & $\begin{array}{r}\text { Weighted } \\
\text { Average } \\
\text { Watt@ } \\
\text { (WAW) }\end{array}$ \\
\hline 4-Foot Fixtures ** & & 77 & & & & \\
\hline Lensed Troffer & 106 & & 28 & NA & 22 & 23 \\
\hline Wraparound & 75 & & 30 & NA & 23 & 17 \\
\hline Parabolic & 86 & & 42 & NA & 33 & 28 \\
\hline 8-Foot Fixtures & & 23 & & & & \\
\hline Strip & & & 70 & & & \\
\hline 18 lamp & 78 & & & 22 & 4 & 3 \\
\hline 28 lamp & 152 & & & 78 & 12 & 19 \\
\hline Industrial & & & 17 & & & \\
\hline $18^{\prime}$ HO lamp & 119 & & & 13 & 1 & 1 \\
\hline 28 HO lamp & 233 & & & 87 & 3 & 8 \\
\hline Wall & & & 13 & & & \\
\hline $18^{\prime}$ lamp & 78 & & & 50 & 2 & 1 \\
\hline 28 lamp & 152 & & & 50 & 2 & 2 \\
\hline $\begin{array}{l}\text { Total } \\
\text { Fraction of Baseline WAW }\end{array}$ & & & & & 100 & $\begin{array}{r}102 \\
0.88\end{array}$ \\
\hline
\end{tabular}

* Normalized by lumen output

\# The share of the total fixture market that the particular technology comprises

@ The sum of the products of each technology's wattage and its market share

** Watlages for a 2-lamp fixture with energy-efficient magnetic ballast and standard lamp 


\section{APPENDIX E THE DEMAND FORECASTING MODELS}

\section{E.1 EPRI COMMEND END USE FORECASTING MODEL'}

COMMEND has been developed by the Electuic Power Research Institute for use by its member utilities and energy analysts. The main analysis uses are load forecasting for power system planning, demand-side management planning, and market planning. The COMMEND framework segments the commercial market by building type and end use. The framework is illustrated in Figure E-1.

Building types define the primary market segments. This approach is useful because energy-use patterns differ strongly across building types. These differences reflect different operating hours, types of energy-using activities, types of energy-using equipment, and energy-using technologies.

Figure E.1 COMMEND Framework

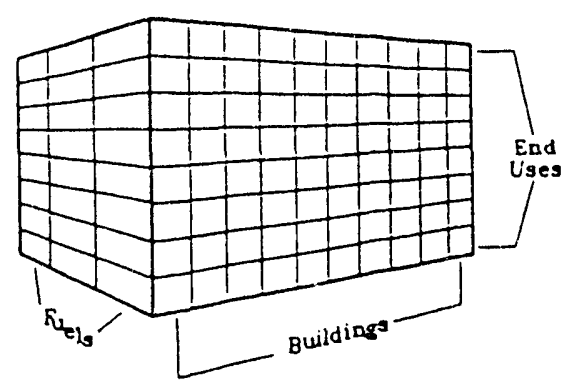
Uses for Market Data
- Forecasting
- Demand-Side Planning
- Integrated Planning
- Marketing

$\begin{array}{ll}\text { BUILDINGS } & \text { END USES } \\ \text { Small Office } & \text { Space Heal } \\ \text { Large Office } & \text { Cooling } \\ \text { Restaurant } & \text { Ventilation } \\ \text { Retail } & \text { Mater Heat } \\ \text { Grocery } & \text { Cooking } \\ \text { Farebouse } & \text { Retrigeration } \\ \text { Scbools } & \text { Lighting } \\ \text { Colleges } & \text { Miscellaneous } \\ \text { Heallb } & \\ \text { Lodging } & \\ \text { Mliscellaneous } & \end{array}$

FUELS

Electricity

Natural Gas

Fuel oil

Miscellaneous

\footnotetext{
'This appendix is adapted from "COMMEND End-Use Planning System," by J. Stuart McMenamin, Regional Economic Rescarch, Inc., San Diego, CA.
} 
The COMMEND framework also tracks buildings according to the building vintage. This allows fuel and efficiency decisions to be analyzed separately for new construction versus retrofits and replacements.

In many applications, building types are further split on the basis of size. The most common example of this is the separate treatment of large versus small office buildings. This separate treatment is prompted by the fact that large buildings have different thermal properties and tend to utilize different types of HVAC technologies than do smaller buildings.

\section{E.1.1 Central Energy Equation}

The COMMEND framework provides an analysis structure for describing energy-use patterns:

- $\quad$ Floor space (square feet of building space)

- $\quad$ Energy intensity (annual energy per square foot)

- Fuel share (percent of area served by an end use and fuel type)

- $\quad$ Energy-use index (annual energy per square foot for an end use)

- Peak-day fractions (share of annual energy)

- $\quad$ End-use load profiles

These are the key concepts used in commercial sector energy analysis. By developing data for these concepts, a complete profile of the commercial sector can be produced.

For each market segment, the central energy equation in COMMEND defines current energy use as the produce of three factors. These are floor space, fuel share, and energy use index (EUI). For a single building/end-use segment, the central equation is:

\section{Annual Energy Use $=$ EUI $\times \mathrm{S} \times \mathrm{F}$}

where $F$ is square footage of floor space,

$S$ is average share of space served by the end use and fuel, and

EUI is average energy use for served space in $\mathrm{kWh} / \mathrm{sq}$. $\mathrm{ft}$-yr.

In this definition, the floor space is the total amount across all building vintages, and the share and EUI values are averages across buildings of all vintages. As an average, the EUI value embodies both average equipment efficiencies and average usage levels across the customer base in the segment In national-scale COMMEND calculations, energy use is summed over each building type, vintage, and fuel type for each year. But in the model, EUIs are given and analyzed by building type. 


\section{E.1.2 Load Shapes}

The COMMEND framework also deals with daily energy use and with peak-day load shapes. The approach used relies on fixed fractions. The first set of fractions indicates the share of annual energy use that occurs on the winter and summer peak days. These are referred to as peak-day fractions. The second set of fractions contains load profiles for each electric end use. These fractions are used to spread annual energy use from the daily total to hours of the day. Combined, these values allow the translation of annual energy usage levels to peak-day loads.

\section{E.1.3 Example of Market Profiles}

Figure E. 2 provides an illustration of the types of results that can be obtained from COMMEND. The data presented here reflect actual results that have been developed from the COMMEND 3.1 national data base. These data have been scaled down to reflect about 1 percent of the U.S. total.

Figure E.2 1986 Commercial Energy Sales by End Use (1\% of U.S. Total)
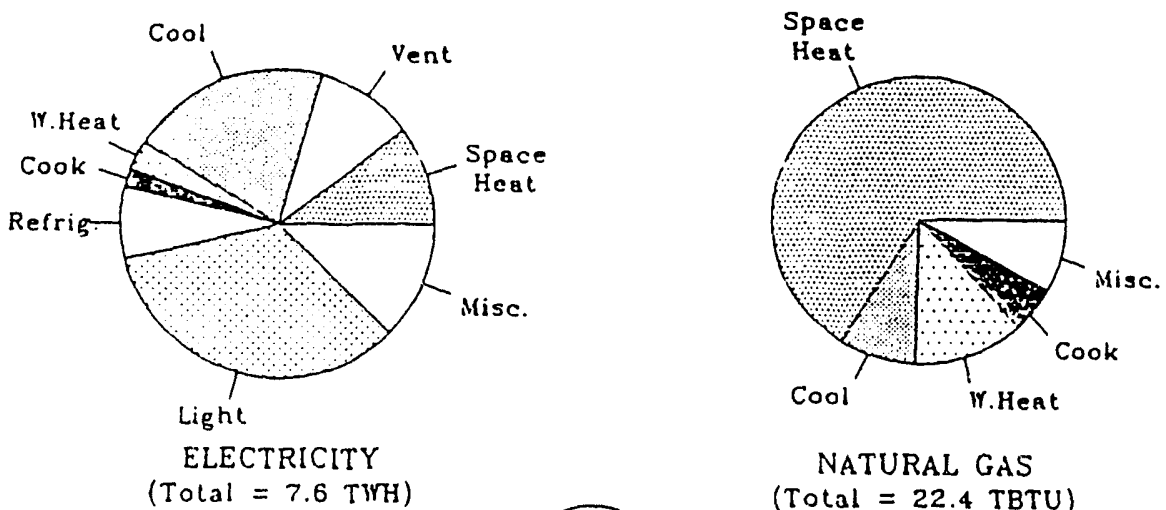

NATURAL GAS

(Tolal $=7.6 \mathrm{TirH})$

(Total $=22.4$ TBTU $)$

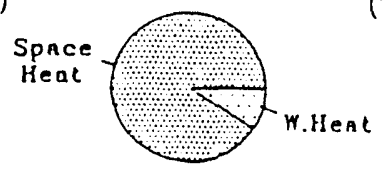

FUEL OIL

(Total $=3.4$ TBTU $)$ 


\section{E.1.4 COMMEND Forecasting Framework}

For the base year, the market profiles discussed above provide a detailed depiction of energy-use patterns at the end-use level. The purpose of the COMMEND forecasting framework is to project these detailed profiles into the future. Figure E.3 illustrates the COMMEND framework. By forecasting at the end-use level, it is possible to isolate the influences on energy sales of economic growth, changes in fuel shares, changes in efficiencies, and changes in usage levels. This approach allows consideration of key issues in future markets, such as fuel competition, technology competition, building standards, and customer behavior.

Figure E.3 COMMEND Framework for Long-Term Forecasting

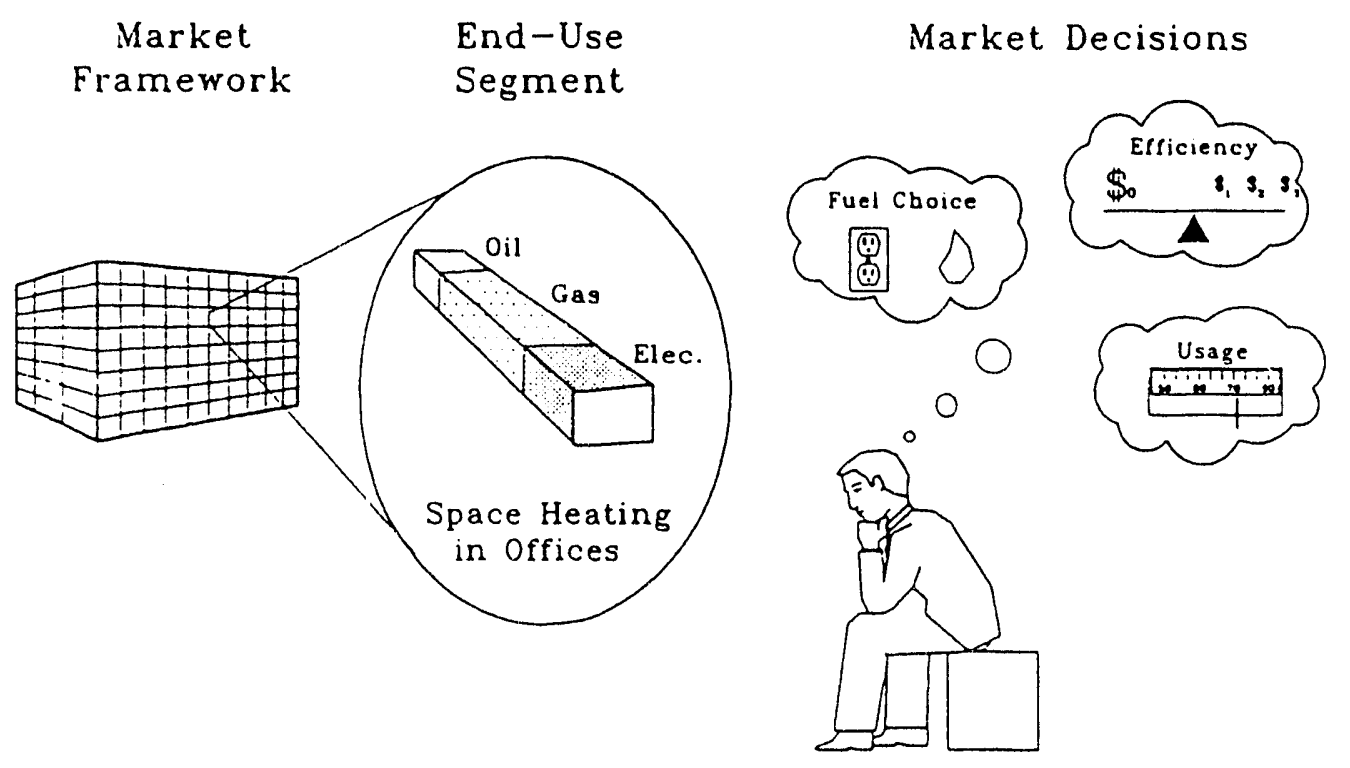


Within each market segment or model cell, COMMEND computes energy sales using the central energy equation. All end-use models use this type of definition as a starting point. The definition is not a static one, since each of the model components will change over time. These changes reflect economic decisions in the commercial market, such as the decision to build, the choice of construction materials, the type of energy-using equipment to install, and the eventual usage pattern of this equipment. The challenge in end-use modeling is to provide an abstract model that captures the main influences on these decisions, and that projects over time the basic trends in each component.

COMMEND's general framework is presented in Figure E.4. The remainder of this discussion focuses on version 3.2 and briefly describes each model component, forecast logic, and forecast results.

Figure E.4 COMMEND Forecast Framework

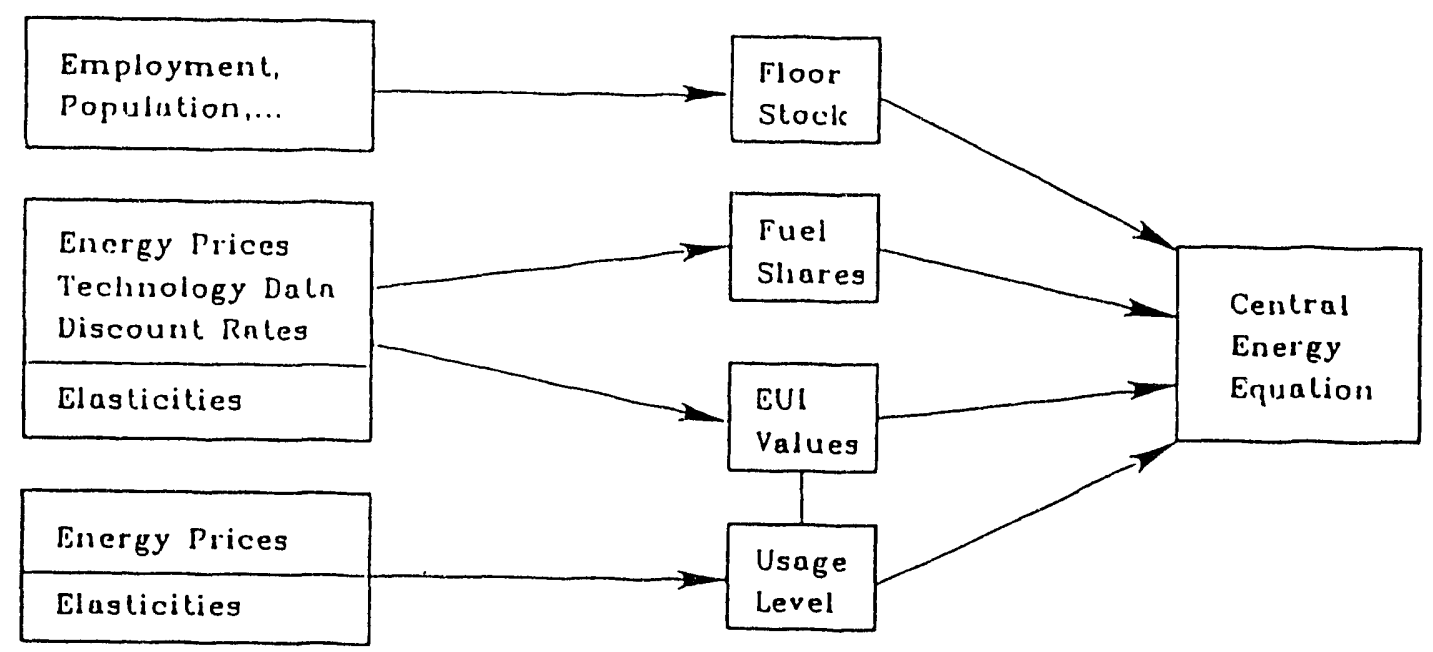




\section{E.1.5 Floor Space}

The floor space component of COMMEND is used to organize information about the existing floor space and to forecast future floor space levels. The floor space outlook embodies assumptions about growth in economic activity for the commercial sector. This outlook will be tightly linked to population growth, employment growth, and regional income.

Data about historical stock are input to the model. The key input values are

- $\quad$ Base year floor space (e.g., 1986)

- A historical floor space series from a distant year to the base year (e.g., from 1941 to 1986). This series can be developed in the model using historical additions, scale variables (such as employment or population), or a combination of both.

- Survival functions describing building survival and decay over time.

A flexible forecasting framework is provided. Two general approaches can be used.

- In the flow approach, annual building construction is projected directly. The stock is inferred as the old stock, survived for one more year, plus the new additions.

- In the stock approach, the final stock is projected directly. Additions are inferred as the amount of construction required to produce the projected stock value.

With either approach, the user provides forecasting equations, including estimated coefficients and exogenous variable forecasts. Typically, the exogenous variables come directly from a service territory economic model. Variables that are used are (a) employment in the commercial SIC codes, (b) population by age group, (c) regional income, and (d) construction industry conditions, such as interest rates. Within this general framework, simple and complex forecast approaches can be implemented. See section 2.1.2 for a description of how floorspace growth is modeled in this study.

\section{E.1.6 Modeling Share, EUI, and Usage Decisions}

Fuel shares and EUI values reflect the outcome of choices among energy technologies. These choices are investment decisions made by building owners, designers, and contractors at the time of construction or equipment replacement. Decisions involved include:

- The decision to include the end use (for example, to have air conditioning or water heating present). This decision impacts the end-use penetration across all fuels.

- The decision to use a generic technology (such as an electric heat pump or a gas 
furnace). This determines the fuel share for each fuel.

- The decision to select a specific technology (an equipment brand and model), along with structure characteristics and initial usage patterns. This determines the EUI for each fuel.

Once a building is constructed and equipment is in place, changes in usage levels reflect daily decisions about the frequency and intensity of equipment use. These decisions are determined by the behavior of building managers and occupants.

COMMEND 3.2 uses a probabilistic choice approach for fuel and efficiency choice. In this application, the model outcome is the probability that a specific system is installed in a particular building. The probability will depend on the following:

- The capital cost of all system options,

- The operating costs of all system options, and

- Characteristics of the building and other relevant factors.

The probabilistic approach is appealing because it is not possible to observe all the factors that affect equipment decisions. Therefore, it is not possible to predict these decisions perfectly. This philosophy modifies the model's life-cycle cost (LCC) minimization approach. A pure LCC minimization approach would posit that each choice is known precisely, based on a complete set of cost information and pure economic optimization.

The probability approach does not have the knife's-edge property associated with LCC minimization. For example, a change in fuel prices alters operating costs, which in turn reorients the probabilities. These shifts will be sudden and dramatic only if estimated parameters suggest a high sensitivity to operating costs.

Key inputs to the modeling process are grouped into technology data, economic dat: and standards and DSM data. These are described below.

Technology Data. Technology data center on equipment costs and efficiencies. The main technology inputs are:

- $\quad$ Equipment Costs. Average installed system costs for all end uses by building type are entered in $\$ /$ square foot.

- Efficiency Ranges. For each generic technology, the range of available suboptions is described. The range for each system is described as a curve segment. Parameters of the segment are EUI range percentages, and a tradeoff elasticity between outlay and energy use. The implied cost range is computed internally. This is referred to as the generic technology curve approach (see Figure 2.4). These data describe the opportunity for price-induced efficiency changes. 
- Efficiency and Cost Trends. For each generic technology, trend values that alter equipment efficiencies and installed costs may be specified. These impacts can be used to evaluate the impacts of naturally-occurring technology improvements.

- Thermal Interactions. Thermal interaction elasticities are used to describe the impact of changes in lighting and miscellaneous loads on HVAC energy use. Separate parameters give the impact of changes in building thermal characteristics on HVAC energy use.

The equipment cost data determine the relationship between capital costs and operating costs, whict. is important in determining the importance of energy prices in equipment decisions. In this study, analysis of HVAC interactions is given in Appendix $\mathrm{H}$.

Economic Data. The economic data describe decision makers and decision rules. These data are defined as follows:

- Decision Maker Data. Decision makers are described by a block distribution of discount rates. These distributions may differ across building types. The decision makers have price expectations which are based on a single distributed lag adjustment mechanism. This implies that price expectations are formed on the basis of past price events.

- Efficiency Option Elasticities. These parameters give the sensitivity of market shares to life-cycle cost, where life-cycle cost includes both initial equipment cost and the present value of operating costs. These sensitivities are used to model efficiency choice for all end uses.

- Fuel Choice Option Elasticities. Like the efficiency option elasticities, these parameters give the sensitivity of market shares to life-cycle cost, where life-cycle cost includes both initial equipment cost and the present value of operating costs. These sensitivities are to model market shares of competing fuels and technologies.

- Automatic Calibration. The technology data and decision data are combined to compute implied efficiency elasticities and to calibrate fuel choice equations. These equations are calibrated to marginal shares in new construction.

- Utilization Elasticities. These parameters indicate the sensitivity of equipment usage to energy prices, as well as weather data, operating hours, vacancy rates and other factors. These parameters are used to simulate changes in usage levels over time. The assumed elasticity for lighting is -0.18 .

- Replacement Factors. Fuel share inertial parameters apply to fuel choice decisions in appliance replacement. They reflect the presence of barriers to fuel conversion 
when equipment is replaced. EUI inertial factors apply to efficiency changes at the time of equipment replacement.

- Retrofit Penetration Changes. These parameters control changes in the penetration of end uses in existing structures.

- Office Equipment and Miscellaneous Equipment EUI Growth. These parameters allow office equipment and miscellaneous equipment EUIs to grow independently for each building type in the forecast period.

Standards and DSM Data. This section includes data related to equipment efficiency standards, thermal efficiency standards and DSM program impacts. These inputs are described briefly below.

- Efficiency Standards. This section contains data that identify the timing of efficiency standards and that describe the impact of these standards on (a) equipment efficiency ranges and (b) the level of thermal efficiency in new construction. (This option is used in the component standards analysis; see Figure 2.7.)

- Efficiency Incentives. This section allows introduction of incentive or rebate payments for equipment that meets specified efficiency requirements. (This option is not used in this analysis because it does not allow rebates to be given to only efficient technologies.)

- Specific DSM Program Impacts. This section allows imposition of program impacts by building type, end use and fuel

- General DSM Program Impacts. This section allows imposition of impacts by building and fuel. Specific end uses are not identified.

Forecast Logic

Given the model parameters, the key steps in the forecast logic are summarized as follows:

- Compute price forecast

- $\quad$ Compute floor space forecast

- Compute efficiency/cost changes

-- Trends and standards move curves

-- Simulated elasticities give changes along curves

- Compute share changes

- Compute replacement impacts

-- Shares

-- Average EUIs 
- $\quad$ Compute utilization impacts

- Apply central energy equation.

Forecast Results

COMMEND 3.2 forecast results are summarized below.

- $\quad$ Price forecast

- Floor space forecast

- $\quad$ Energy sales forecast

- $\quad$ Sales forecast by building type

- Sales forecast by end use

- Summer peak demand forecast

- Winter peak demand forecast.

Figure E.5 presents an example of forecast results using the COMMEND 3.1 national data base.

Figure E.5 Forecast of Electricity Sales by End Use (GWh) (1 percent of U.S. Total)

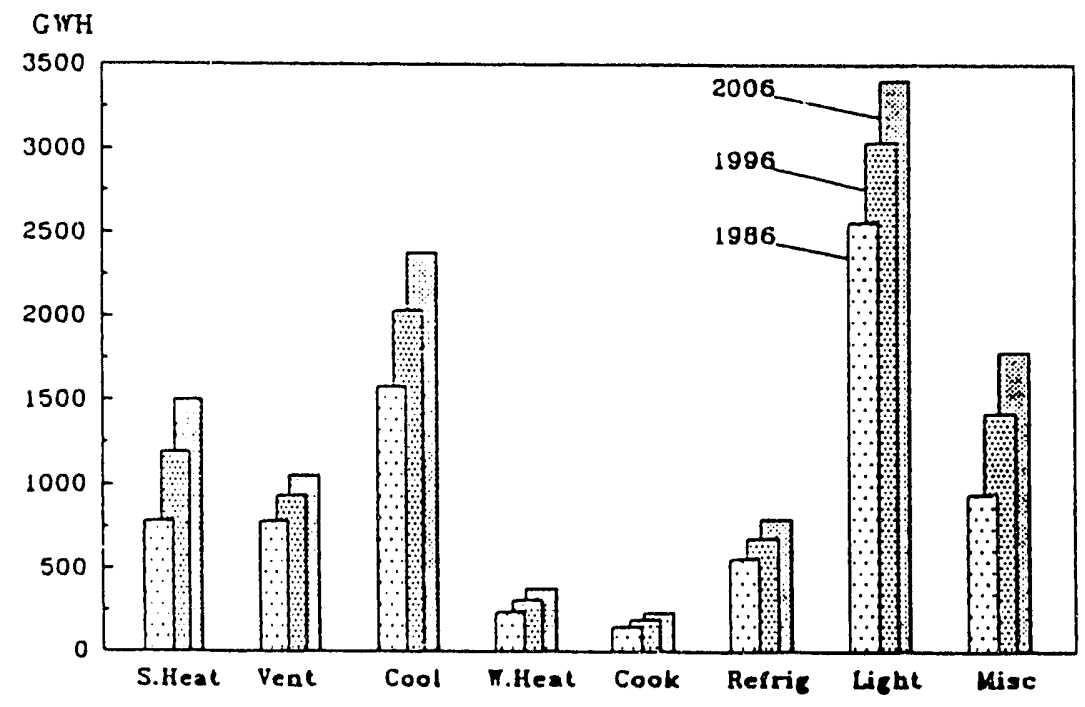




\section{E.1.7. Future COMMEND Model Development}

In addition to software development, future improvements should focus on data collection and analysis. Many of the parameters in COMMEND that directly affect energy consumption require updating and further supporting research. For example, the heating and cooling interaction elasticities could be refined through sensitivity runs using DOE-2, and fuel shares by building type and end use could be updated using the 1989 CBECS building characteristics data. Further, consumption data from 1989 CBECS could be incorporated in further calibration of model parameters as these data become available. Finally, the technology-specific framework in COMMEND 4.0 will require development of technology-level data; these data are not available in the current version. As a result, confirmation, improvement, and expansion of the default data in COMMEND are necessary steps for accurate poicy analysis at the technology level.

\section{E.2 LBL RESIDENTIAL ENERGY MODEL (LBL-REM)}

\section{E.2.1 Purpose}

The LBL-REM models the appliance purchase choices made in households, as well as these households' subsequent usage behavior and energy consumption.

Engineering, economic, and demographic data are used in LBL-REM. These include engineering data for appliances and data regarding alternative building shell construction measures and costs, unit energy consumption and efficiency of appliances, age distribution of existing appliance stock, and retirement functions. Economic data include projected energy prices and household income; and models of energy investment, appliance purchase, and usage behavior (including fuel and technology choice for each end-use). Demographic data include number of households by type, projected housing starts and demolitions, and appliance holdings.

\section{E.2.2 Historical Development}

Early energy-demand modeling focused on engineering estimates or on the relationship between energy consumption and economic growth. In the 1970s, Oak Ridge National Laboratory (ORNL) developed the first model to integrate these two important aspects of energy demand, the Engineering-Economic Model of Residential Energy Use. The ORNL Model was brought to LBL in 1979 and adapted to the analysis of federal appliance conservation standards. 
Further extensive changes were made at LBL from 1979 to the present, resulting in the LBLREM. Many of these changes have already been documented. ${ }^{2,3}$

\section{E.2.3 Structure of the Model}

The LBL-REM segments annual energy consumption into house types, end-uses, and fuel types. The house types include single-family, multifamily, and mobile homes. Calculations are performed separately for existing and new housing construction each year during the forecast period, 1980-2015. The end-uses are space heating (including room and central), air conditioning, water heating, refrigeration, freezing, cooking, dish washing, clothes washing, clothes drying, lighting, and miscellaneous. Up to four fuels are considered, as appropriate to each end-use: electricity, natural gas (utility gas), heating oil, and LPG. The national version of the model, which treats the country as a single region, is used in the analysis.

The model projects five types of activities: technology/fuel choice, building shell thermal integrity choice, appliance efficiency choice, usage behavior, and turnover of buildings and appliances.

\section{E.2.4 Housing Stock Submodel}

This submodel prepares data about the housing stock projection for the main model. The initial number of occupied households, by type, is taken from the 1980 Census of Population and Housing and an exogenous projection of housing stants is obtained. The housing sui model determines the projected housing stock each year, 1981-2030, by house type, basus nn the projected age distribution of the population in each state.

\section{E.2.5 Efficiency Choice Algorithm}

In the absence of other policies, efficiency improvements are projected as a function of designs available (technological change) and of electricity price. If energy prices increase, the life-cycle cost of more efficient designs will increase more slowly than that of less efficient designs, making the more efficient designs more attractive. When the life-cycle cost of a more efficient design falls below the life-cycle cost of the current average design, then the more efficient design is projected to be purchased. Conversely, if energy prices decline, the model projects no further efficiency change. No market discount rate was calculated for lighting equipment, since this was an analysis of standards policies.

\footnotetext{
2US DOE. 1990. Technical Support Document: Energy Conservation Standards for Consumer Products: Dishwashers, Clothes Washers, and Clothes Dryers, DOE/CE-0299P, December 1990.

${ }^{3}$ US DOE. 1988. Technical Support Documens for the Analysis of Efficiency Standards on Refrigerators, Refrigerator-freezers, Freezers, Small Gas Furnaces, and Televisions. DOE/CE-00239, November 1988.
} 


\section{E.2.6 Modeling Efficiency Standards}

The LBL-REM projects the average efficiency of new products purchased each year, in the absence of additional Federal regulations, as described above. A distribution of unit energy consumption (UEC) is constructed around the projected average unit energy consumption for each product class, based on efficiency distributions previously observed in the marketplace. Standards would eliminate at least part of the distribution. A new distribution is constructed in which all sales below the standards are increased in efficiency to meet the standards. The new shipment-weighted average efficiency then characterizes the efficiency of new units in that year. The same process is applied to all years after implementation of the policy. The model is then run again, for the policy case, with adjusted average efficiencies, to calculate any changes in market shares, usage behavior, or investment in efficiency thermal improvements that may occur as a result of standards, and to calculate the net energy savings.

\section{E.2.7 Turnover of Appliance Stocks}

The initial age distribution of appliances in the stock is characterized, based on industry data about historical annual shipments and retirements. The fraction of total stock of each product type that is retired each year is based on the number of years since purchase for each age cohort. Each age cohort is associated with an average efficiency; when older appliances retire, they are also typically recognized as less efficient.

The number of potential purchasers of an appliance in new homes is equal to the number of new homes constructed each year. The number of potential purchasers in existing houses is equal to the number of retiring appliances, plus some fraction of those households that did not previously own the product.

\section{E.2.8 Calculation of Market Shares}

Potential buyers may make no purchase or may buy any competing technology within an end-use. Long-term market share elasticities have been assumed with respect to equipment price, operating expense, and income. Standards are expected to create lower operating expenses and increased equipment prices. The percentage changes in these quantities are used, together with the elasticities, to determine changes in market share resulting from standards. Higher equipment cost will decrease market shares, while lower operating expense will increase market shares. The net result depends on the policy case selected, and the associated equipment price and operating expense.

\section{E.2.9 Usage Behavior}

For some products, changing the operating expense results in changes in usage behavior. These changes are modeled using usage elasticities in operating expense and income. For lighting equipment, these elasticities are assumed to be zero. 


\section{E.2.10 Energy Consumption Calculations}

The total energy consumption per house for each end-use and fuel by house type and vintage (existing or new) is the product of the UEC (accounting for efficiency changes), and usage factor. The corresponding energy consumption for all households is the consumption per house times the number of households of that type and vintage, times the fraction of households that own the equipment. ${ }^{4}$

Aggregate energy consumption is obtained by summing over intermediate results. For example, national electricity consumption for lighting equipment in a particular year is the sum (over house types, classes, and vintages) of electricity consumption by lighting. National residential electricity consumption in that year is the sum over all end-uses, of electricity consumption.

The Consumer Analysis assumes that decisions on the purchase and use of equipment depend on operating expenses, household income, and equipment prices. Manufacturers are projected to respond to the demand for more efficient products by incorporating technologically feasible and cost-effective design options in new units. Exogenous forecasts of population growth, housing starts, personal income and energy prices from published sources are assumed to be correct.

\section{E.2.11 Data Sources}

The LBL-REM takes energy efficiencies of new equipment from the Engineering Analysis. The purchase price of these products is derived as described in Section 3.2.6 and Appendix B. Data on housing and equipment stocks as well as historical data on housing starts come from the 1980 census. Exogenous projections of population, housing starts, income, and energy prices are taken from the Bureau of Census, Data Resources, Inc., and DOE/EIA, respectively.

\section{E.2.12 Model Outputs}

The principal outputs from the LBL-REM for each year are:

- energy consumption by end-use and fuel;

- $\quad$ per-unit equipment prices and operating expense by product;

- $\quad$ total residential energy consumption by fuel;

\footnotetext{
'For space conditioning (heating and cooling), two additional terms are multiplied by the intermediate results: relative floor area (square feet of conditioned space), and relative thermal integrity (a measure of the effect of building shell characteristics on energy consumption).

${ }^{5}$ For appliance analysis, not lighting
} 
- projected annual shipments of residential equipment;

- differences in these quantities between a base case and each policy case.

These outputs are provided annually (or for selected years) and cumulative for the period 1995-2030. Energy savings are provided annually from implementation of standards to the end of the period. Net present value (NPV) of policies is evaluated for each regulated product, and for the end-use(s) comprising the regulated and competing products.

Cost-Benefit Analysis. The costs and benefits of the policies from a national perspective are quantified by calculating a net present value. The NPV is the sum of discounted savings in operating expense minus the sum of discounted increases in equipment prices. 


\section{APPENDIX F COMMERCIAL SECTOR POLICY ANALYSIS RESULTS}

Forecast EUIs and lighting energy consumption for each commercial sector policy group -fluorescent lamps, incandescent lamps, fixtures, controls, mandatory combination equipment standards, voluntary combination equipment standards, building codes (system performance standards), and incentive policies -- are presented graphically. Results are shown for each policy case modeled within the policy group (see Figure 2.2). For each group, average commercial indoor lighting EUIs are plotted in the top figure and lighting energy use (in primary quads and TWh) in the bottom figure. Results from the High-Efficiency Baseline are followed by those from the Low-Efficiency Baseline. Each graph contains EUIs and consumption projections presented in five-year intervals from 1985 through 2030. The EUIs for the policy cases are lower than those for the baseline forecasts, resulting in the cumulative lighting energy savings presented in Tables 4.3 and 4.6.

These results are for lighting electricity only and do not include impacts of heating and cooling interactions. 
Figure F.1

Fluorescent Lamps, High-Efficiency Baseline

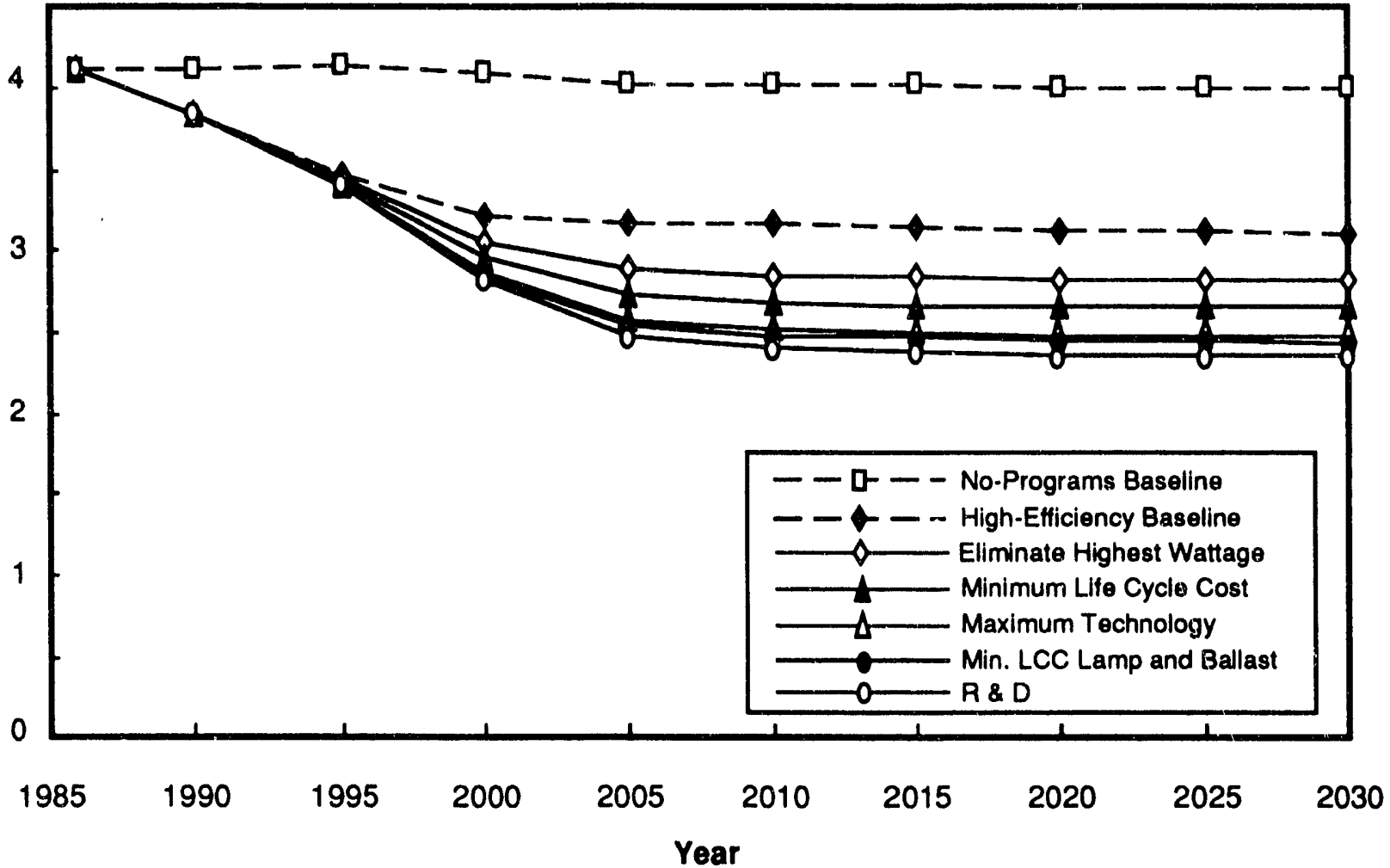

Figure F.2

Fluorescent Lamps, High-Efficiency Baseline

Primary Quads

Commercial Indoor Lighting Energy

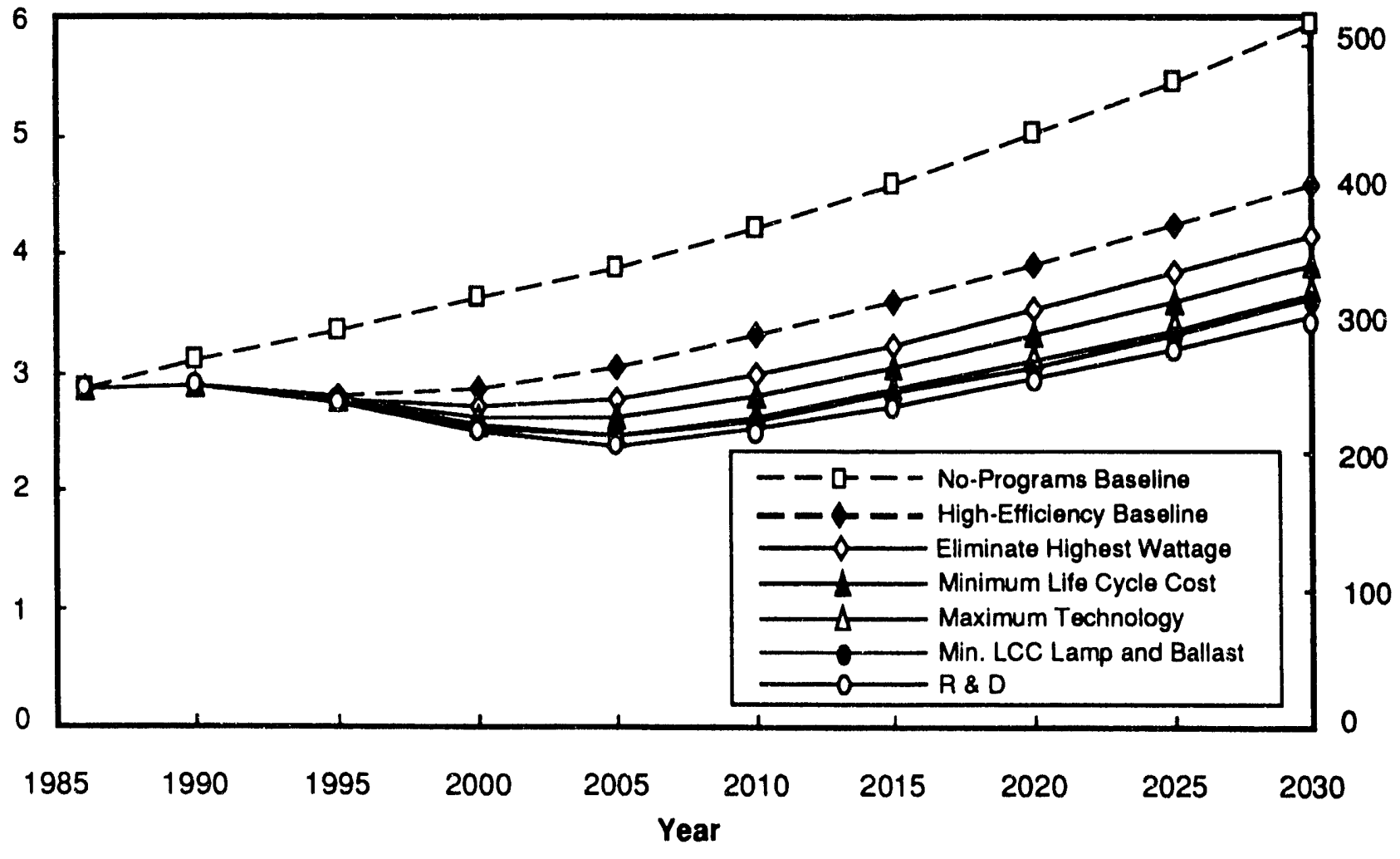


Figure F.3

Fluorescent Lamps, Low-Efficiency Baseline

kWh/sq. ft. - yr.

Average Commercial Indoor Lighting EUls

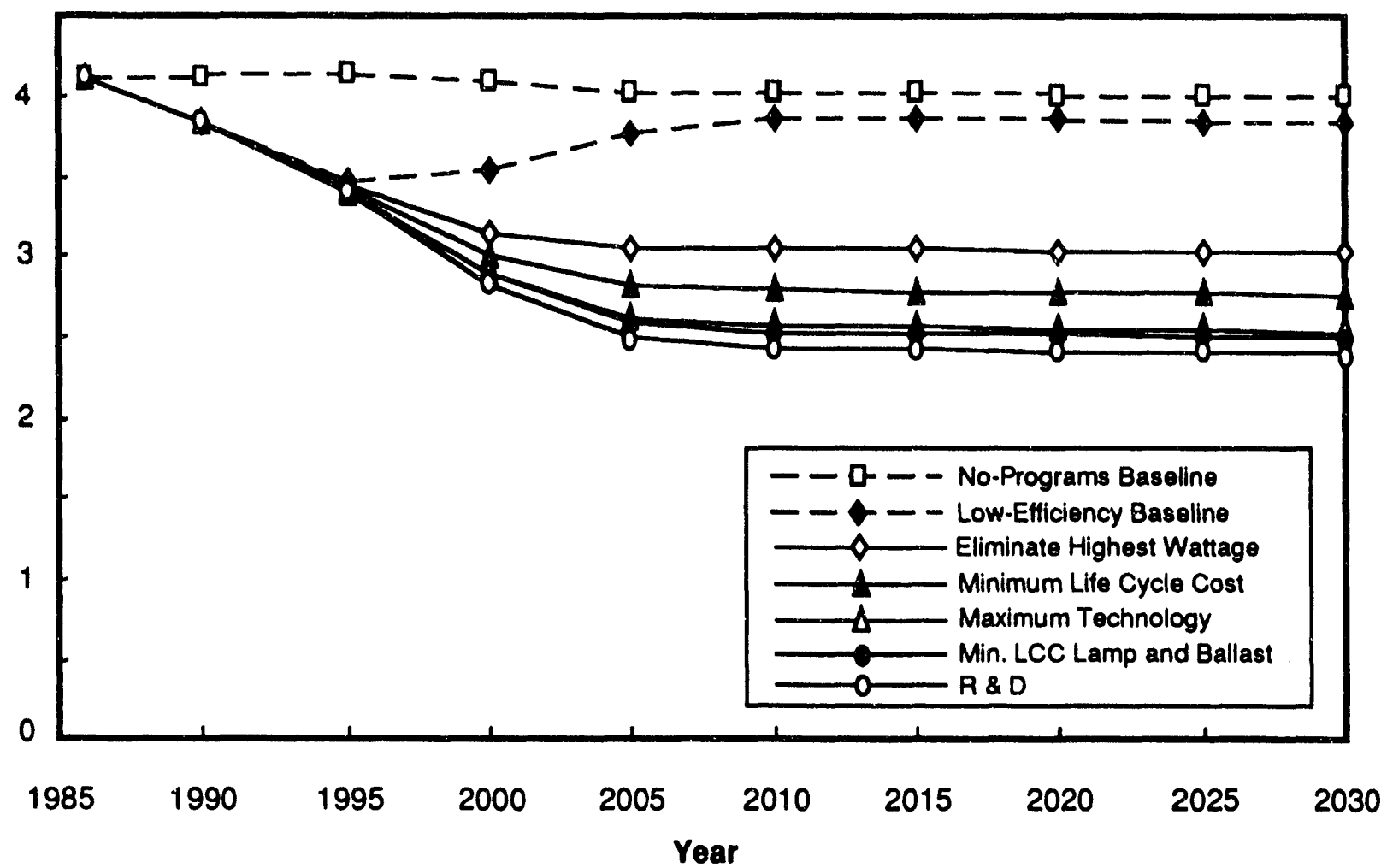

Figure F.4

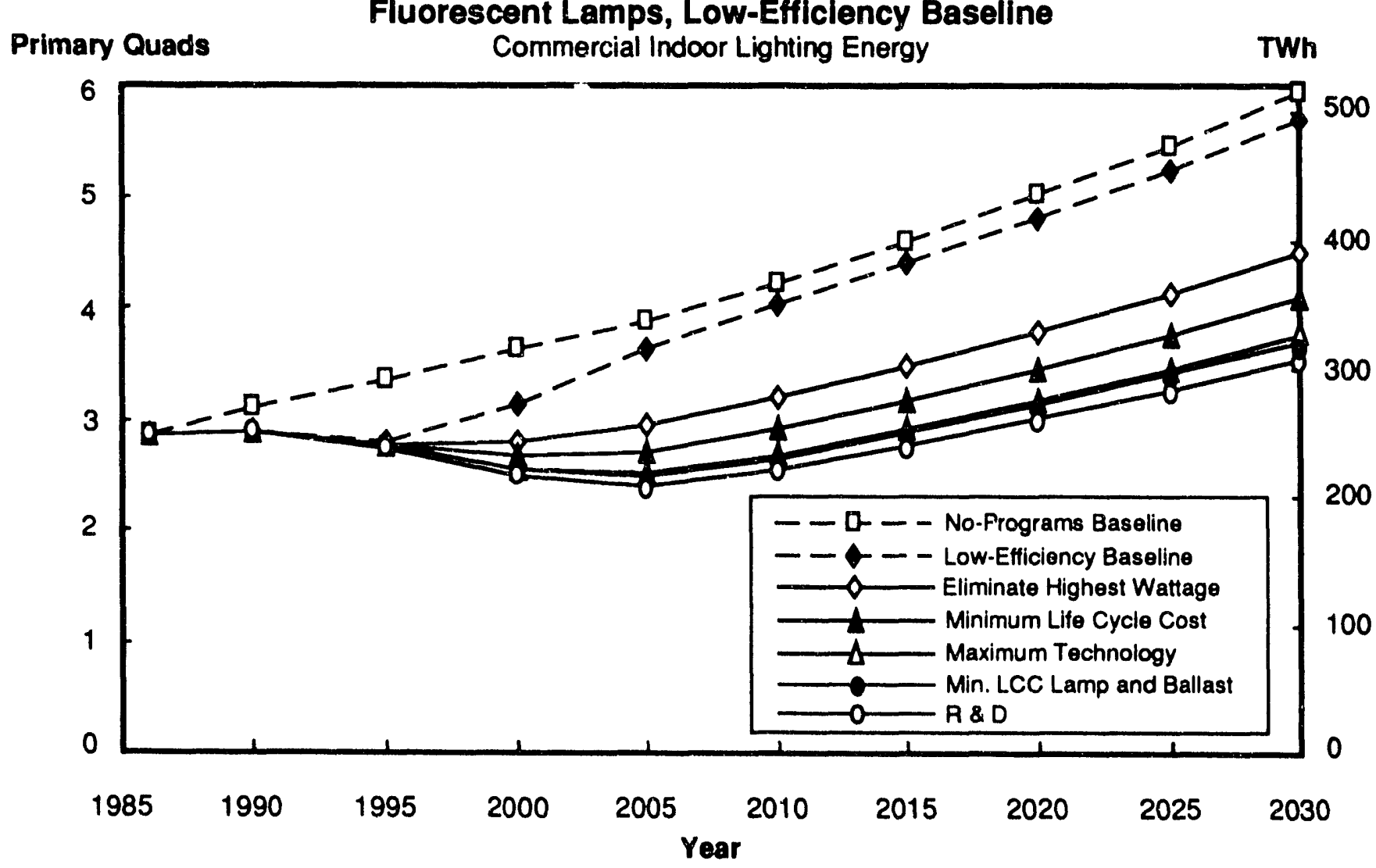


Figure F.5

kWh/sq. tt. - yr.

Incandescent Lamps, High-Efficiency Baseline

Average Commercial Indoor Lighting EUls

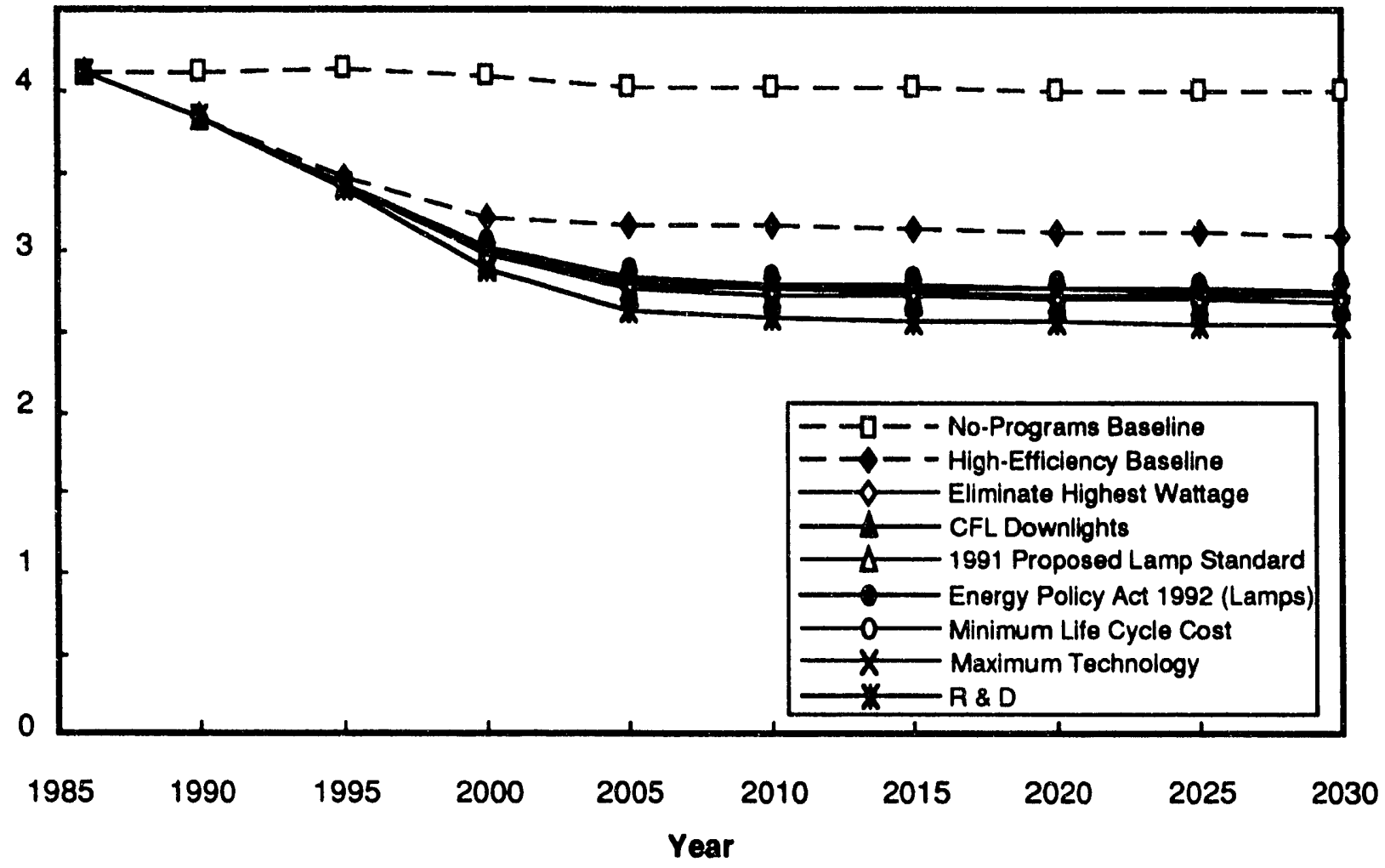

Figure F.6

Primary Quads

Incandescent Lamps, High-Efficiency Baseline

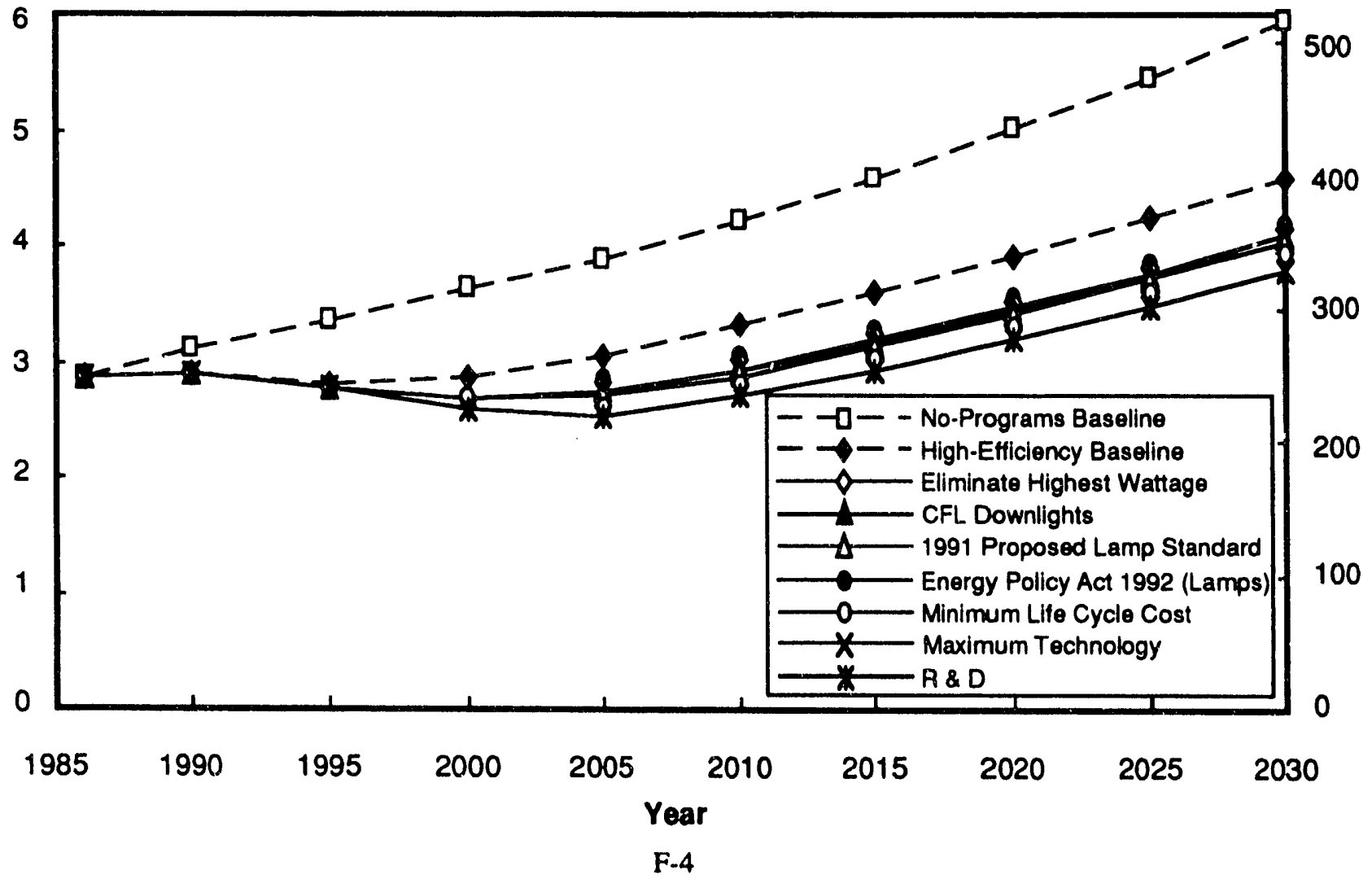


Figure F.7

kWh/sq. ft. - yr. $\quad \begin{gathered}\text { Incandescent Lamps, Low-Efflciency Baselline } \\ \text { Average Commercial Indoor Lighting EUls }\end{gathered}$

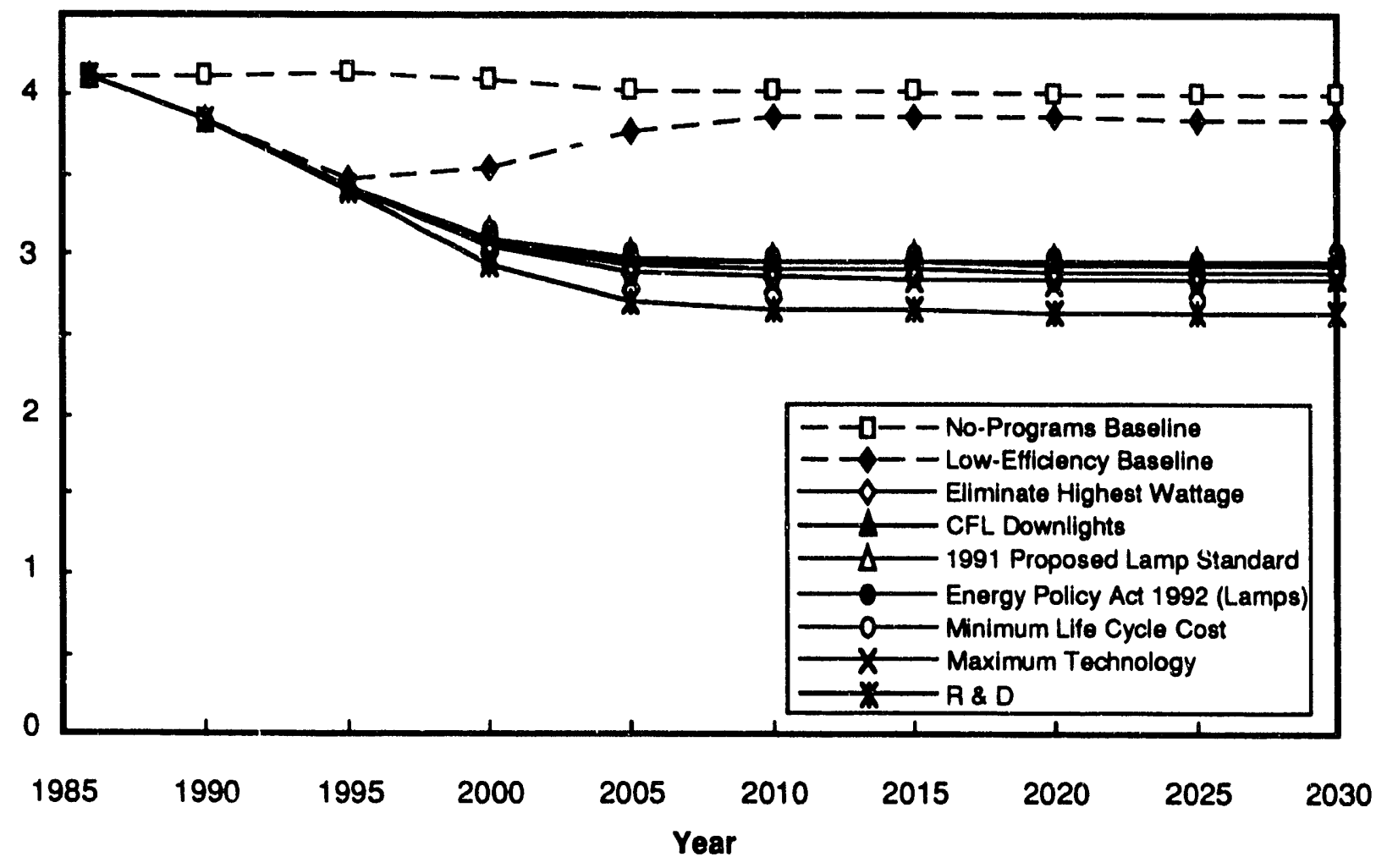

Figure F.8

Primary Quads

Incandescent Lamps, Low-Efficiency Baseline

Commercial Indoor Lighting Energy

TWh

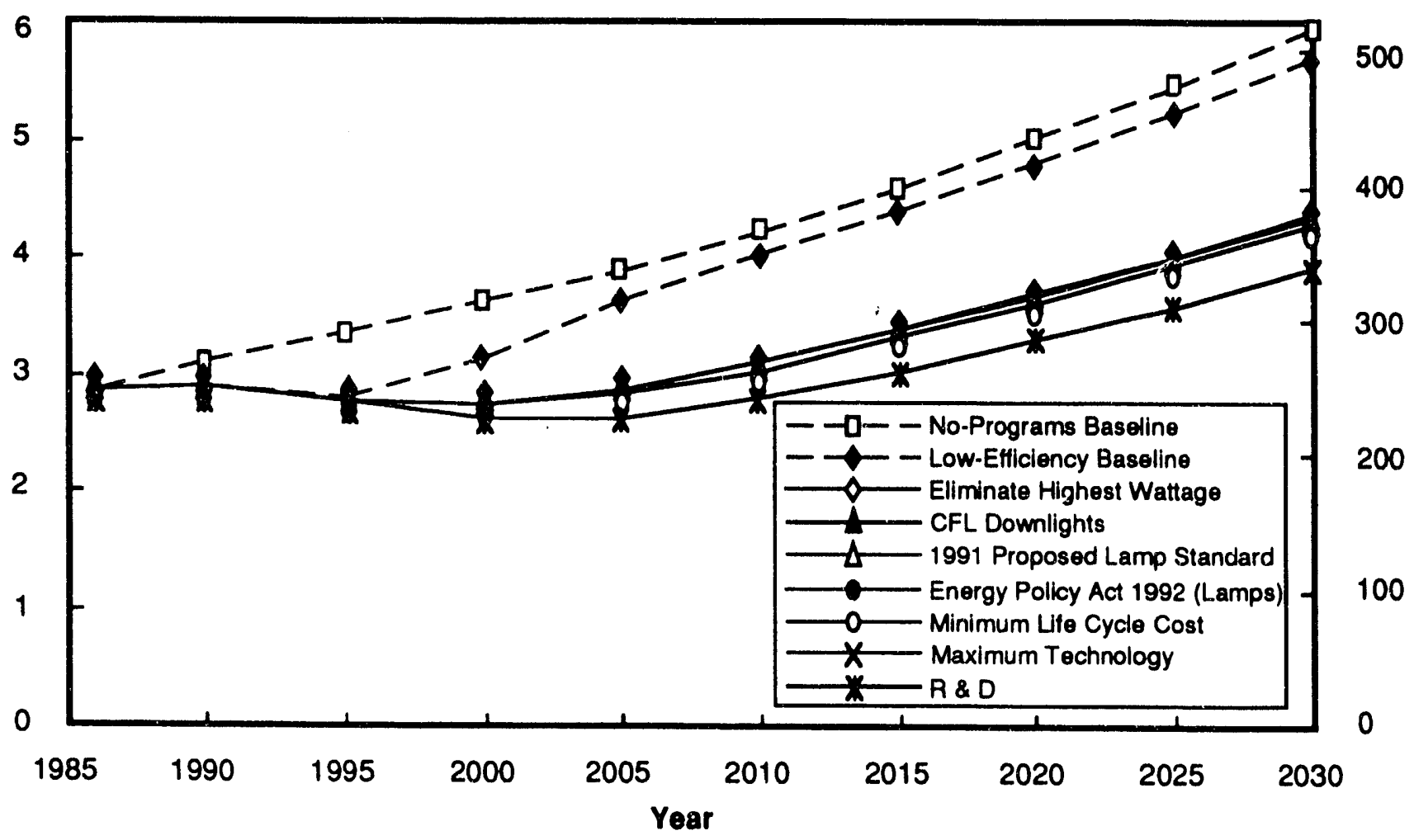


Figure F.9

Fixtures, High-Efficlency Baseline

kWh/sq. ft. - yr.

Average Commercial Indoor Lighting EUls

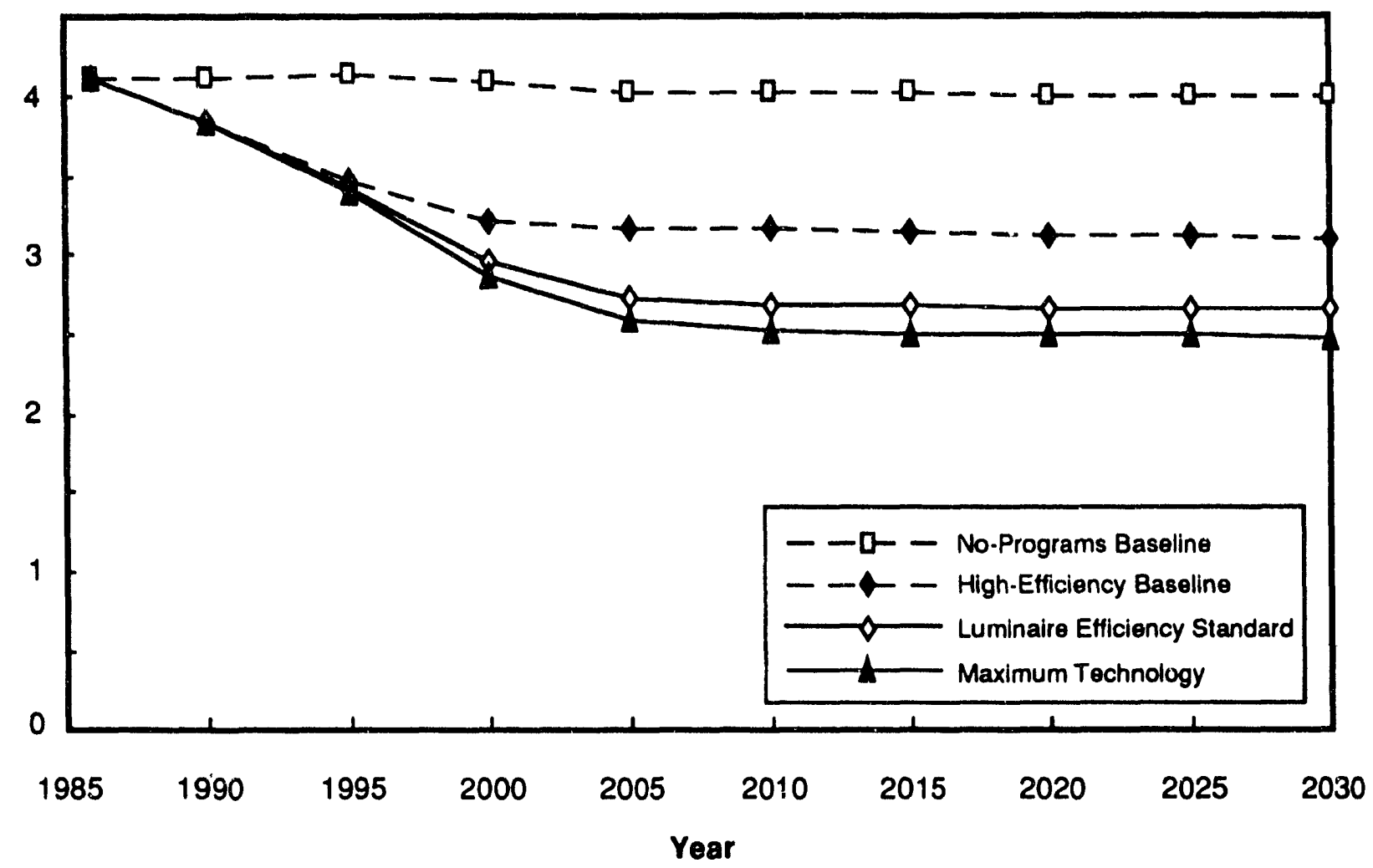

Figure F.10

Fixtures, High-Efficiency Baseline

Primary Quads

Commercial Indoor Lighting Energy

TWh

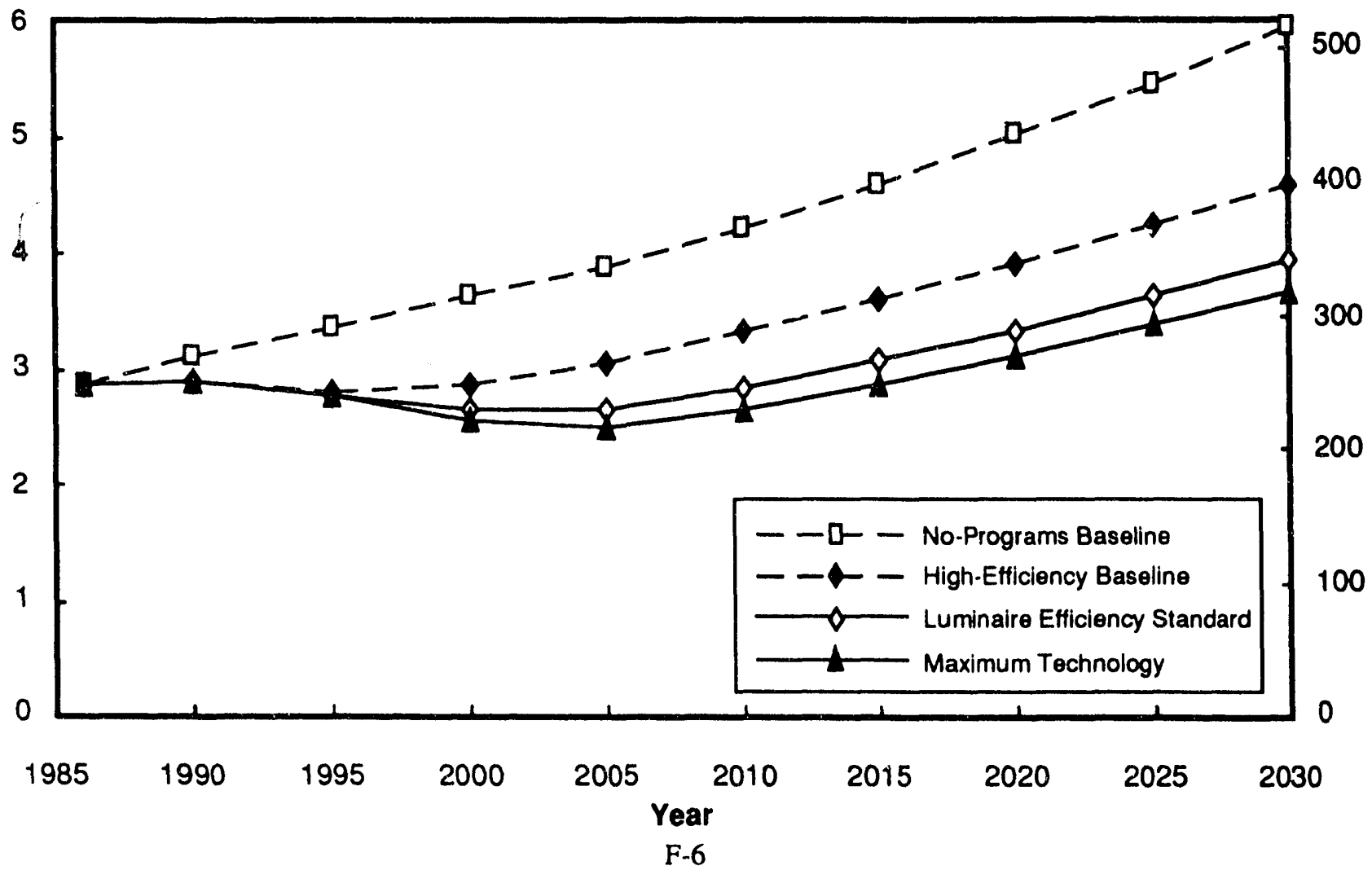


Figure F.11

kWh/sq. ft. - yr.

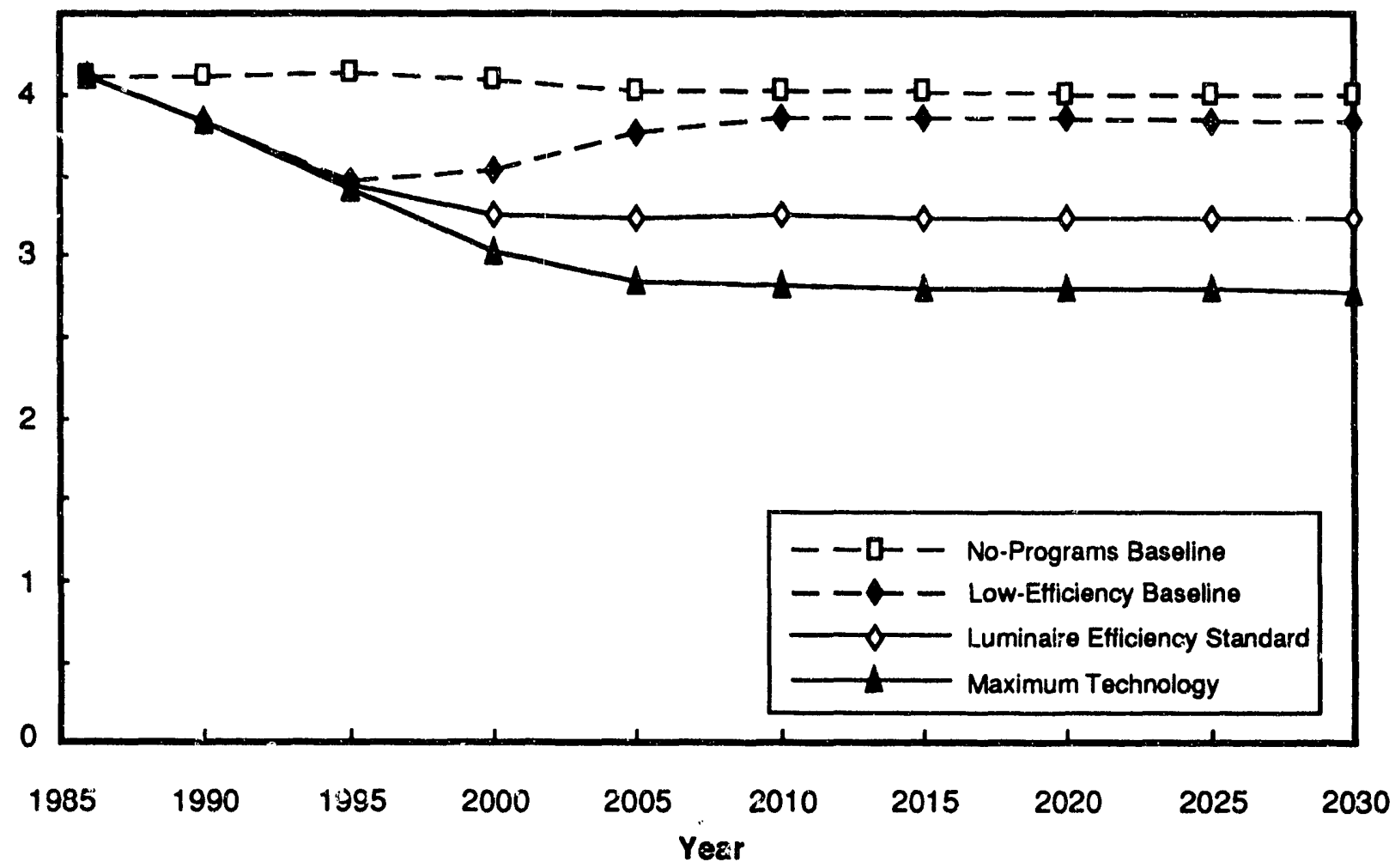

Figure F.12

Primary Cuads

Fixtures, Low-Efficiency Baseline

Commercial Indoor Llghting Energy

TWh

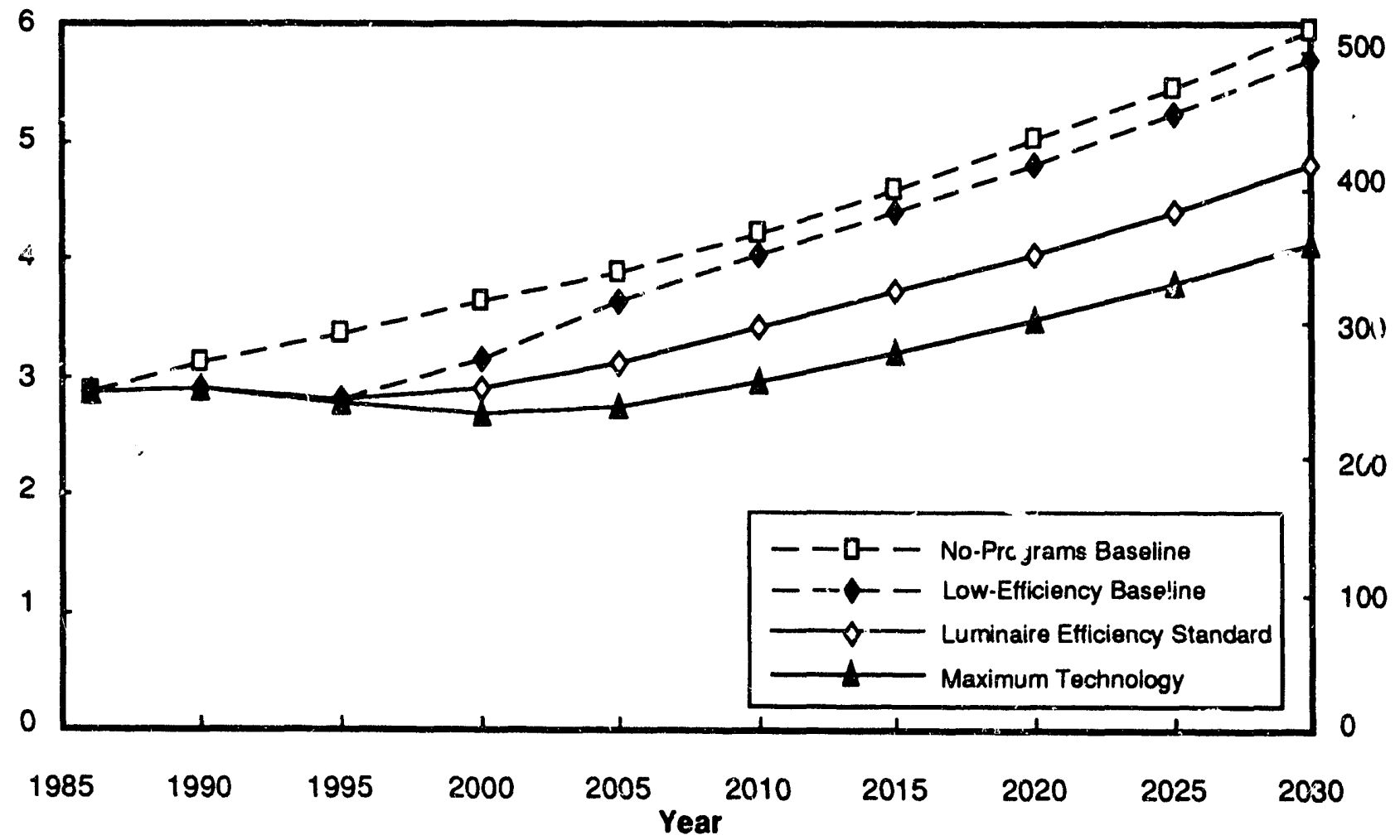


Figure F.13

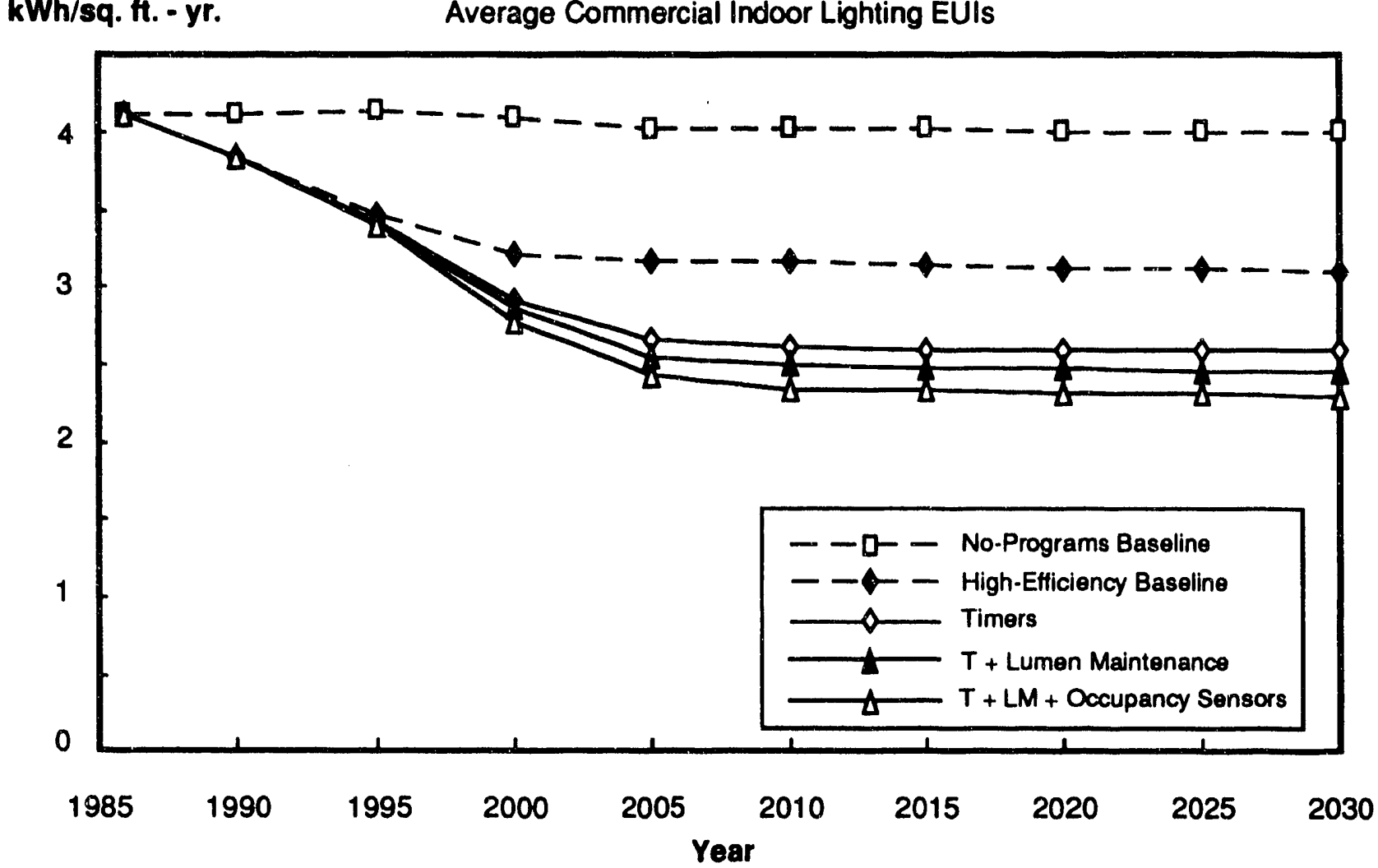

Figure F.14

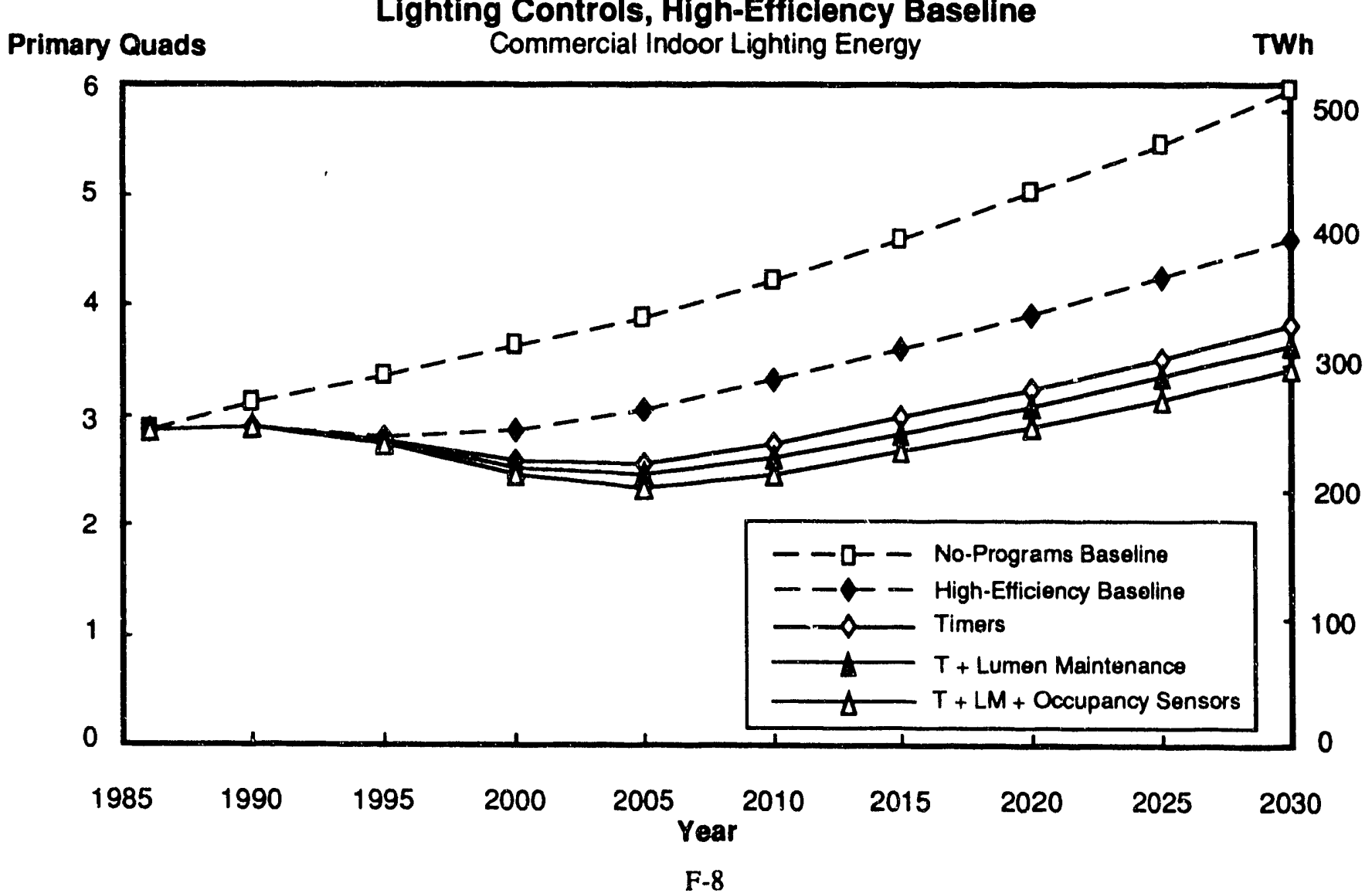




\section{Lighting Controls, Low-Efficlency Baseline \\ Average Commercial Indoor Llghting EUls}

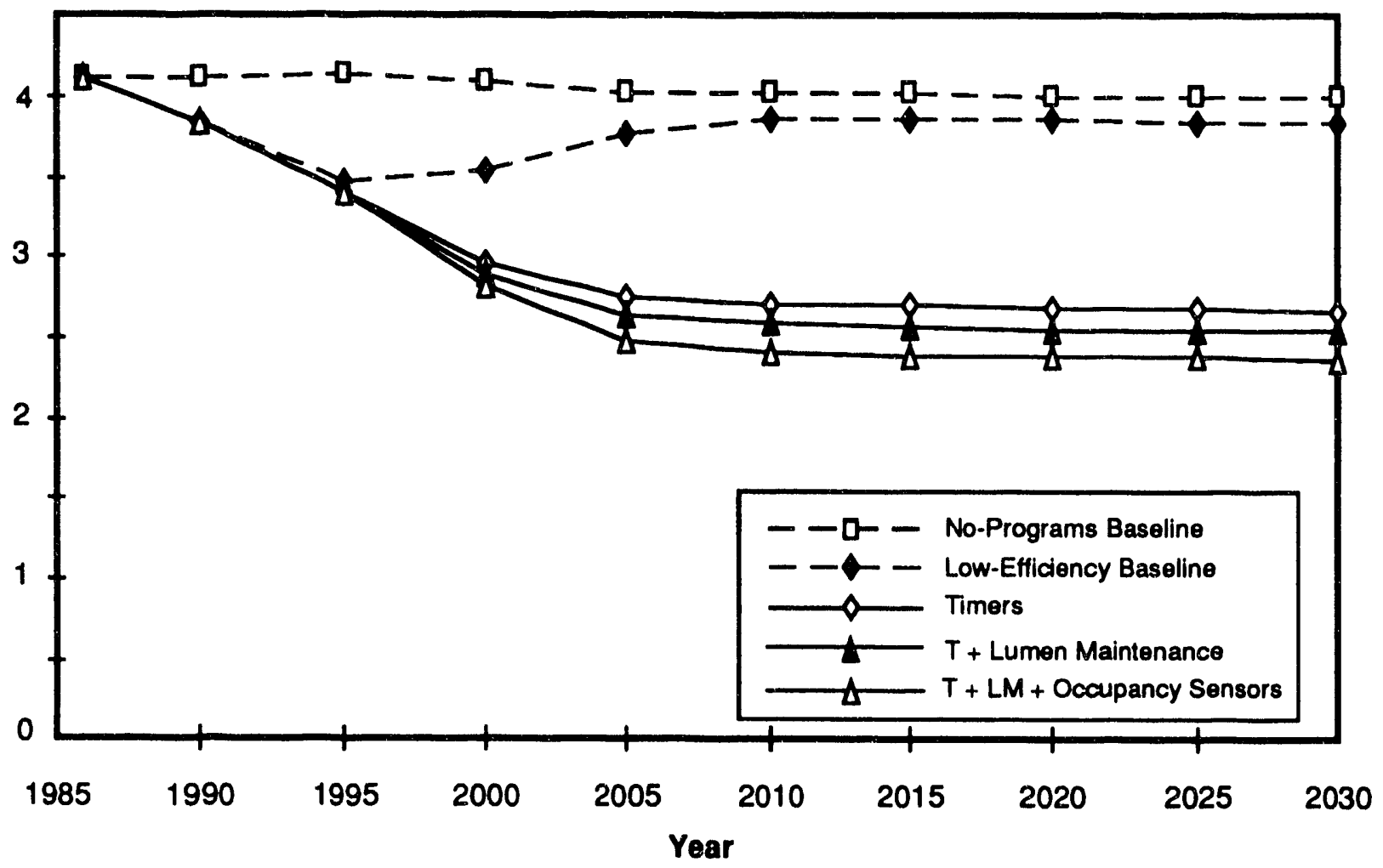

Figure F.16

Primary Quads

Lighting Controls, Low-Efficiency Baseline

Commercial Lighting Energy

TWh

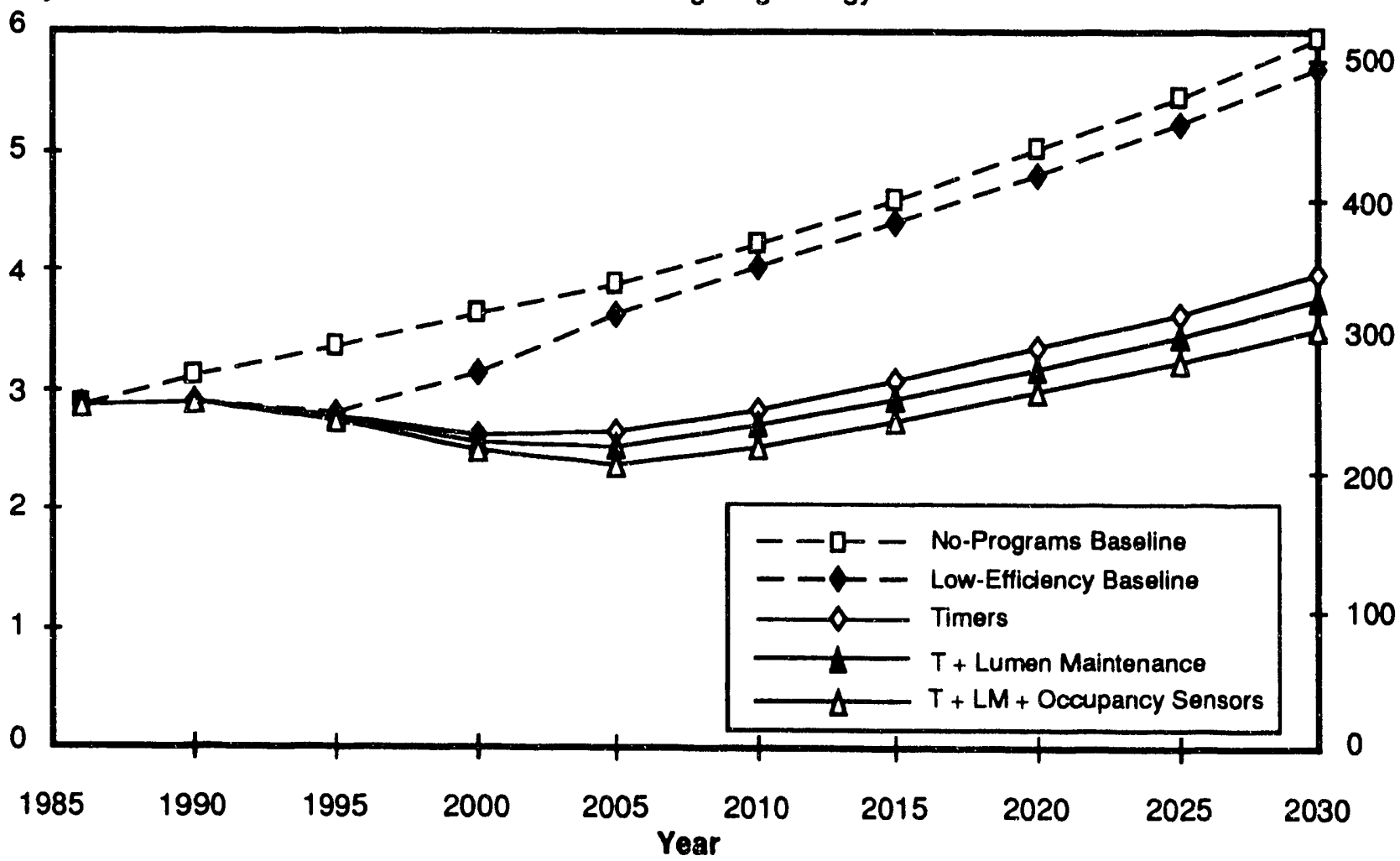


Figure F.17

Mandatory Combination Equipment Standards, High-Efficlency Baseline

kWh/sq. ft.-yr.
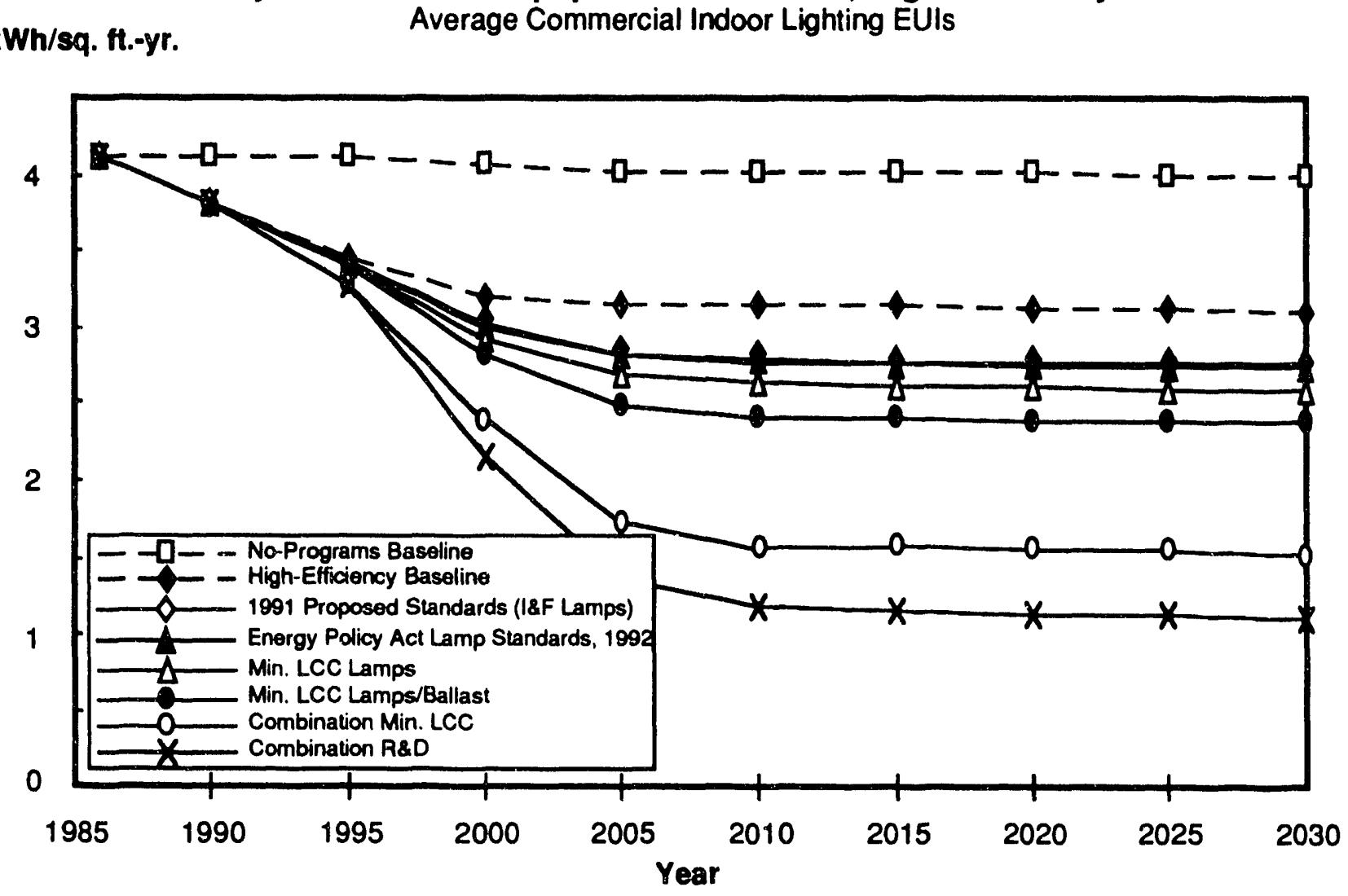

Figure F.18

Mandatory Combination Equipment Standards, High-Efficiency Baseline

Primary Quads

TWh

6

Commercial Indoor Lighting Energy 
Figure F.19

Mandatory Combination Equipment Standards, Low-Efficiency Baseline

kWh/sq. ft.-yr. Average Commercial Indoor Lighting EUls

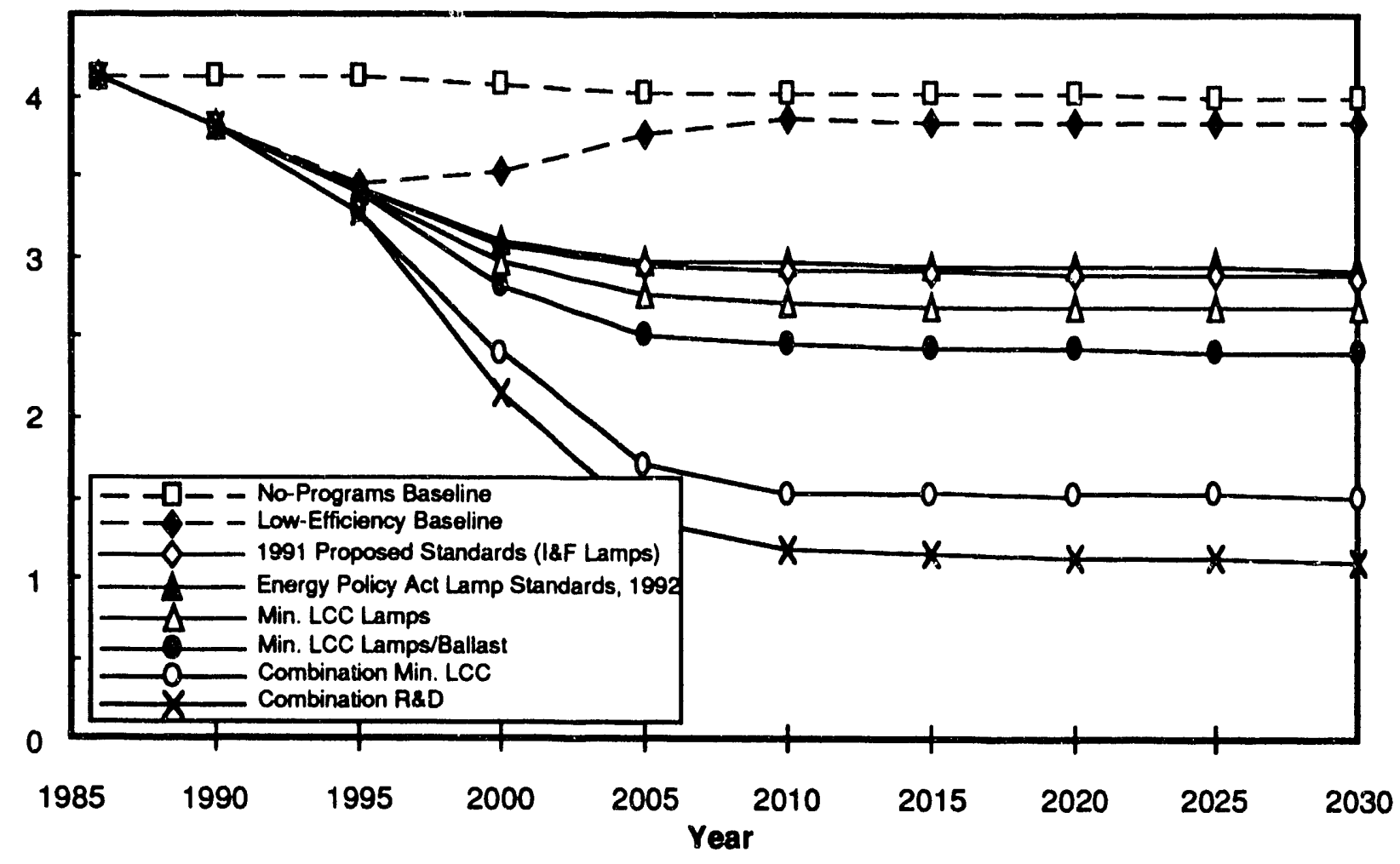

Figure F.20

Mandatory Combination Equipment Standards, Low-Efficiency Baseline

Primary Quads

Commercial Indoor Lighting Energy

TWh

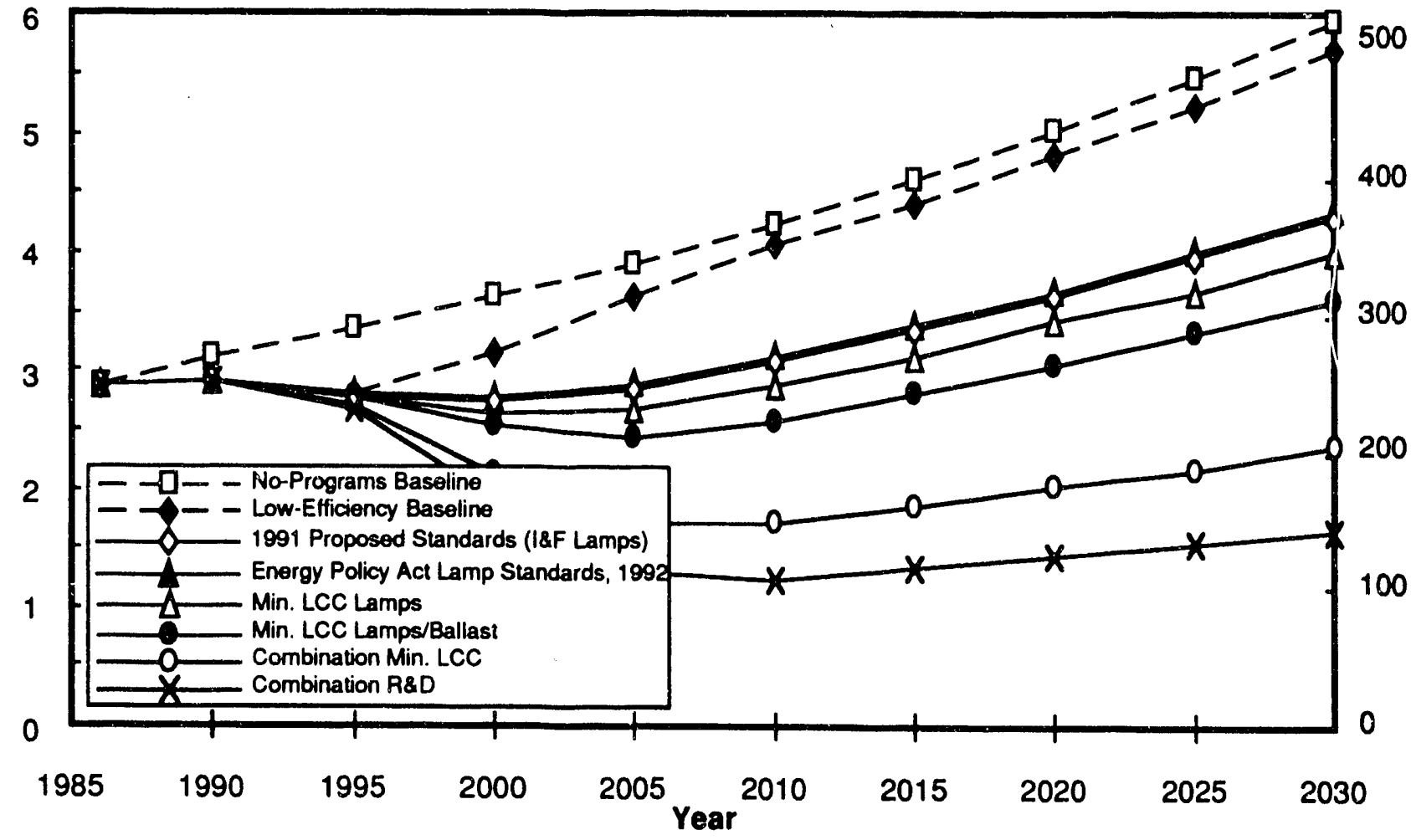


Voluntary Combination Equipment Standards, High-Efficiency Baseline kWh/sq. tt.-yr.

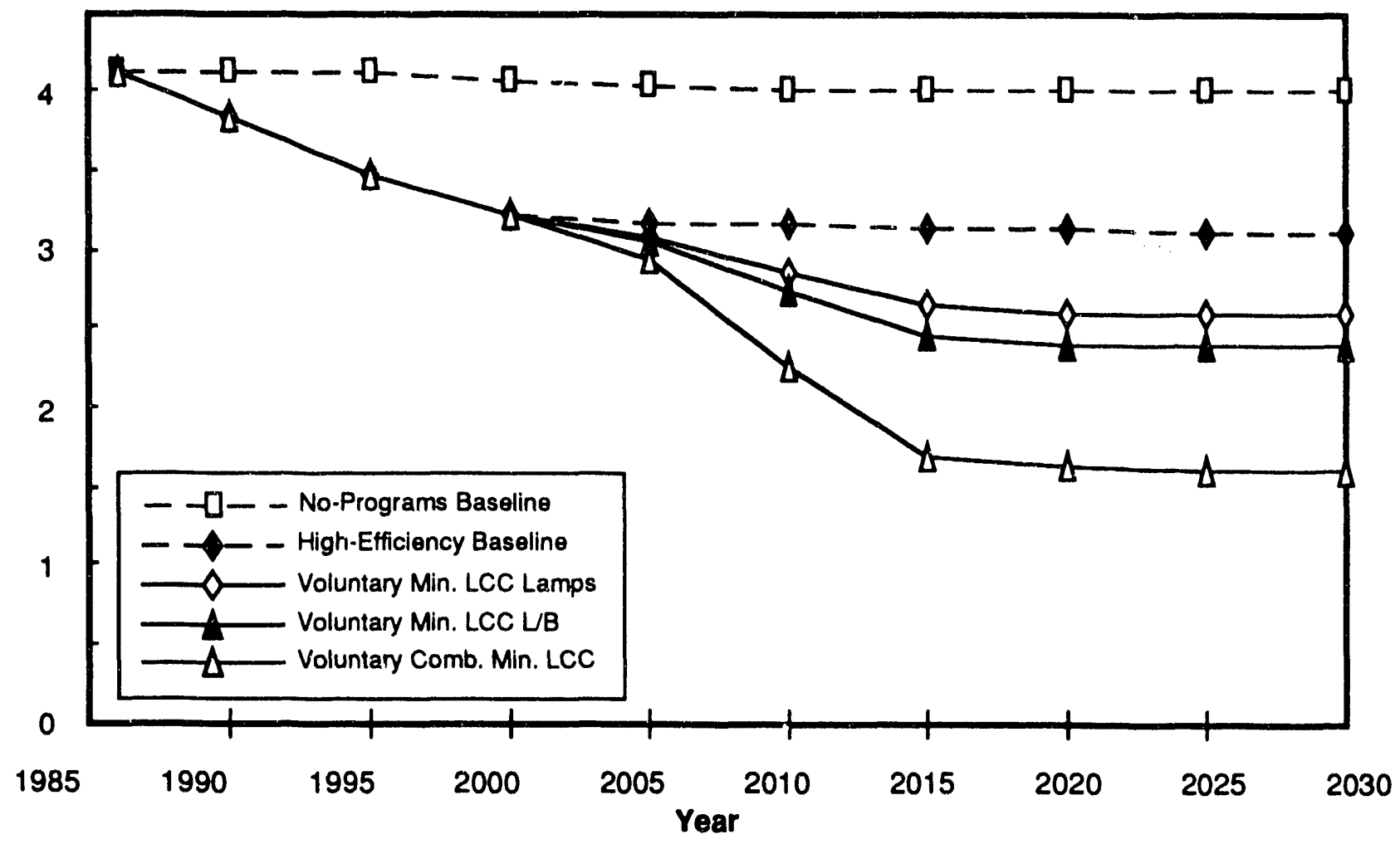

Figure F.22

Voluntary Combination Equipment Standards, High-Efficiency Baseline Primary Quads Commercial Indoor Lighting Energy

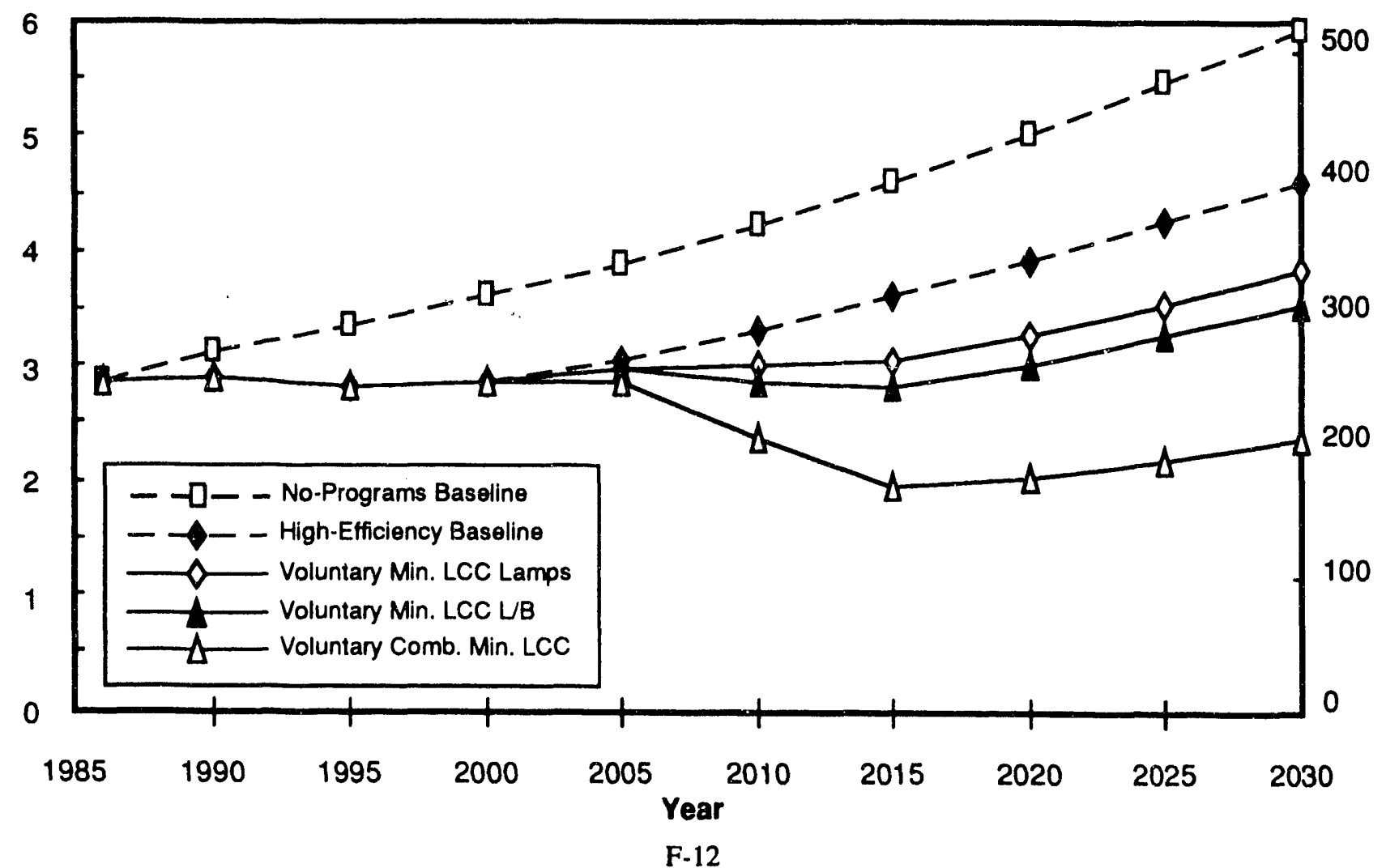


Voluntary Combination Equipment Standards, Low-Efficiency Baseline kWh/sq. tt.-yr.

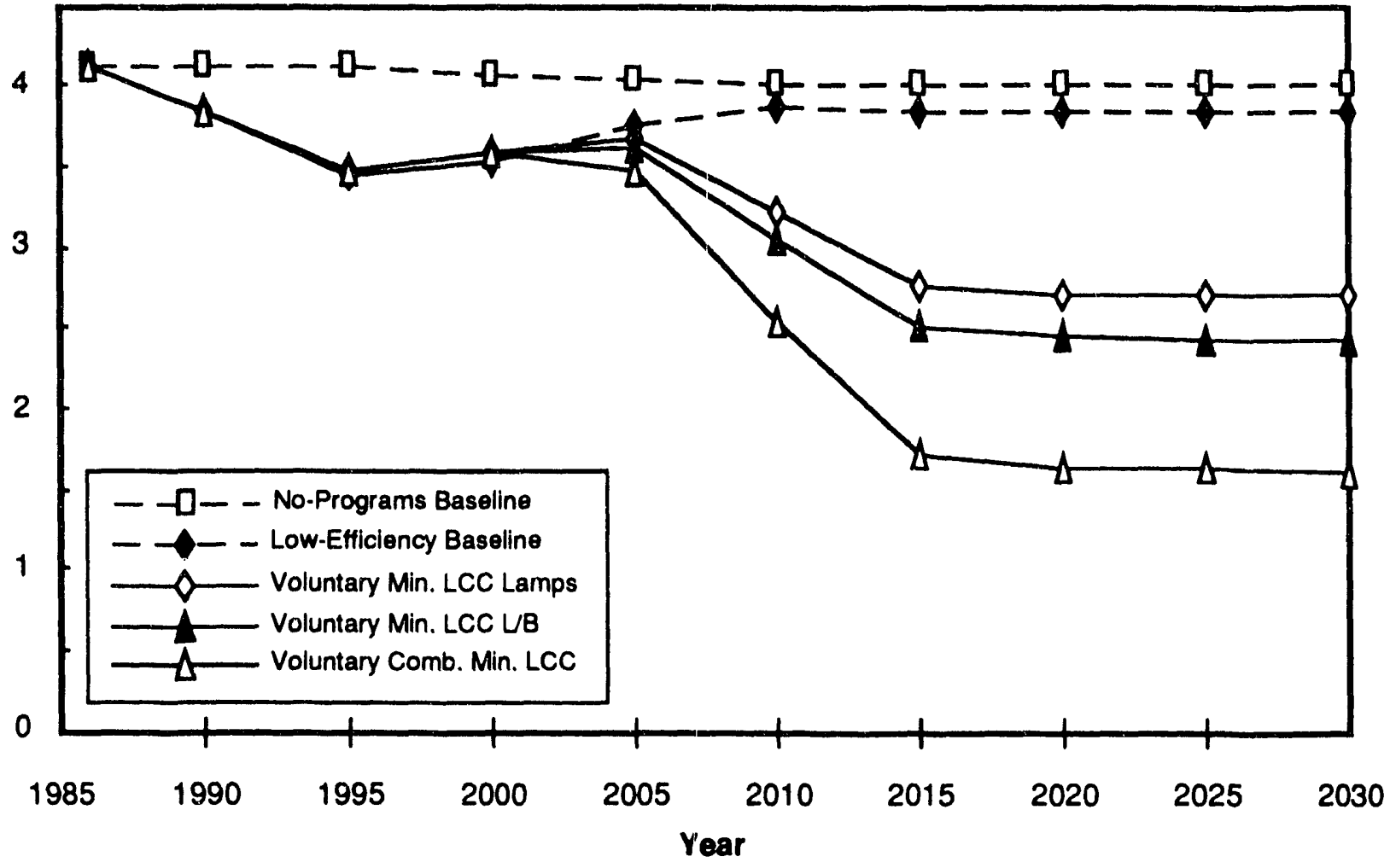

Figure F.24

Voluntary Combination Equipment Standards, Low-Efficiency Baseline Primary Quads Commercial Indoor Lighting Energy

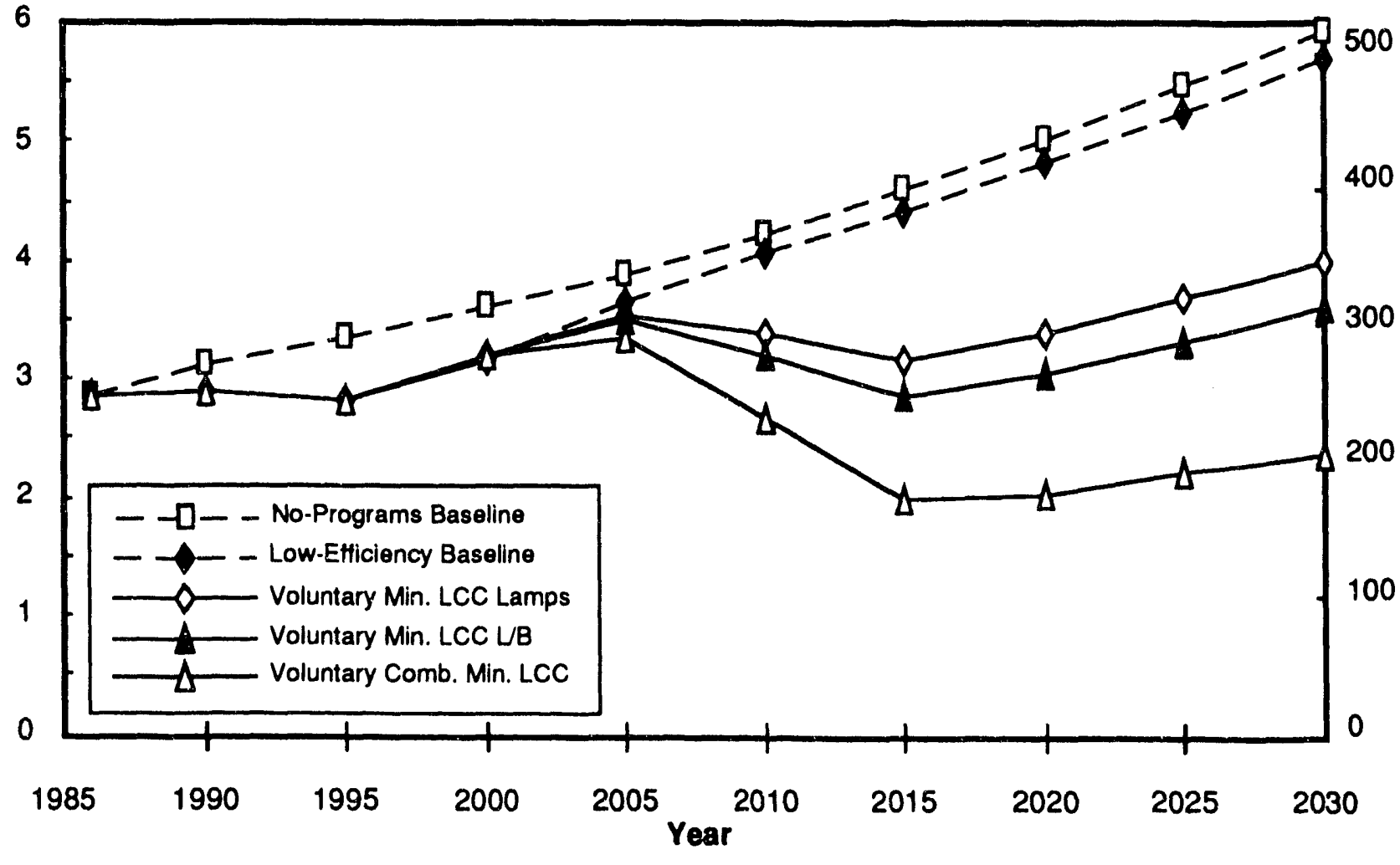


Figure F.25

Building Codes, High-Efficiency Baseline

kWh/sq. tt. - yr. Average Commercial Indoor Lighting EUls

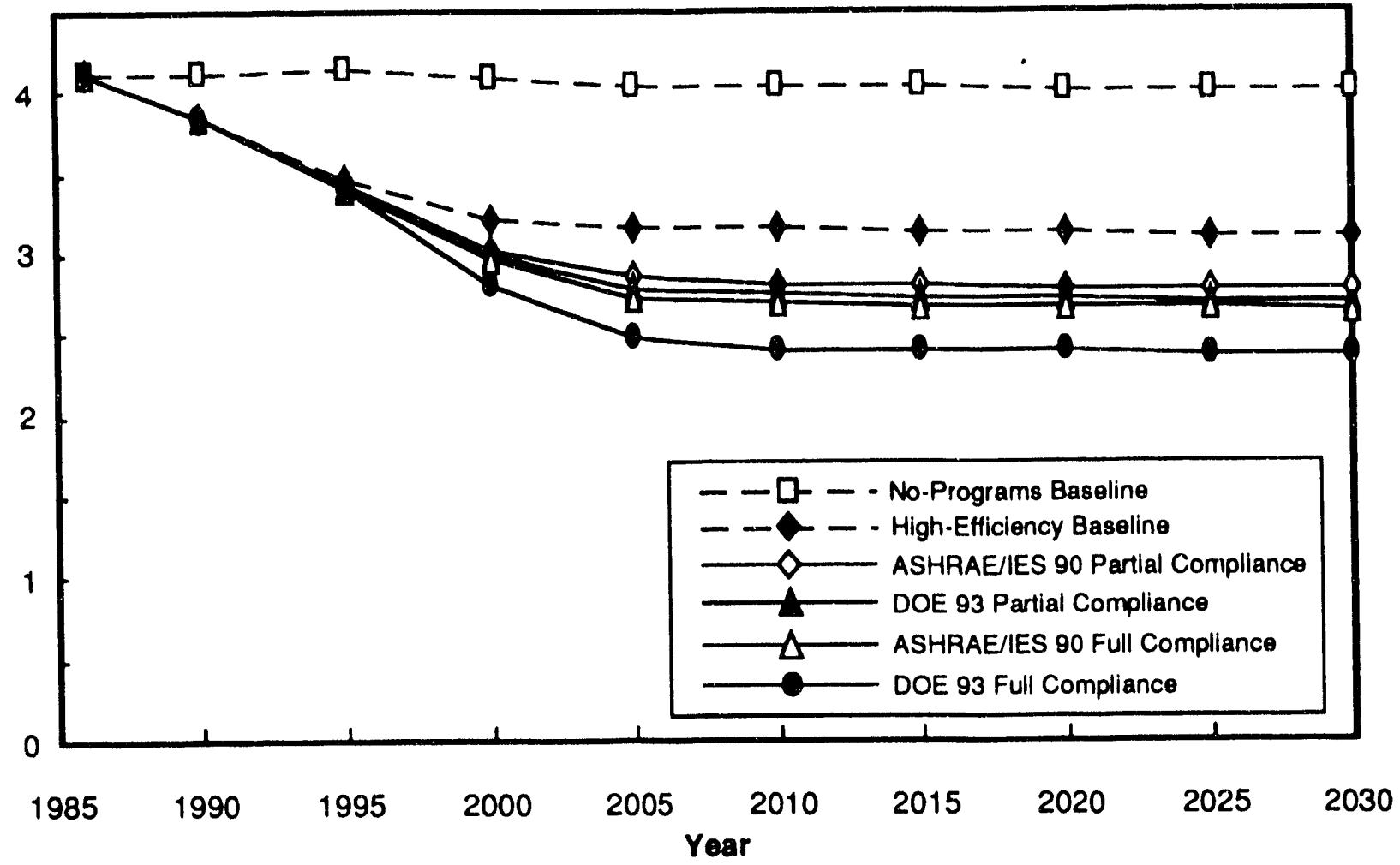

Figure F.26

Building Codes, High-Efficiency Baseline

Primary Quads

Commercial Indoor Llghting Energy

TWh

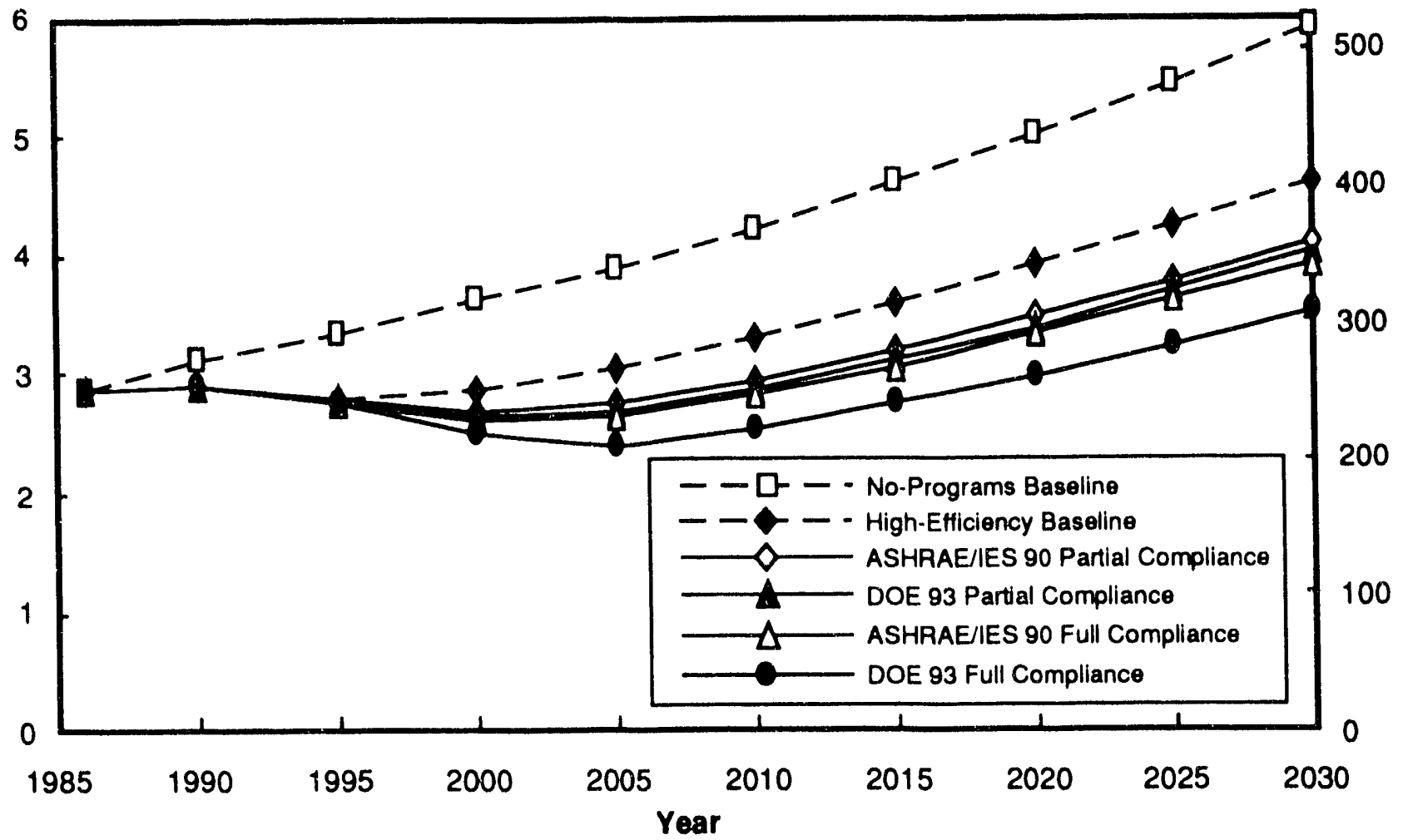

F-14 
kWh/sq. ft. - yr.

Building Codes, Low-Etficiency Baseline

Average Commercial Indoor Lighting EUls

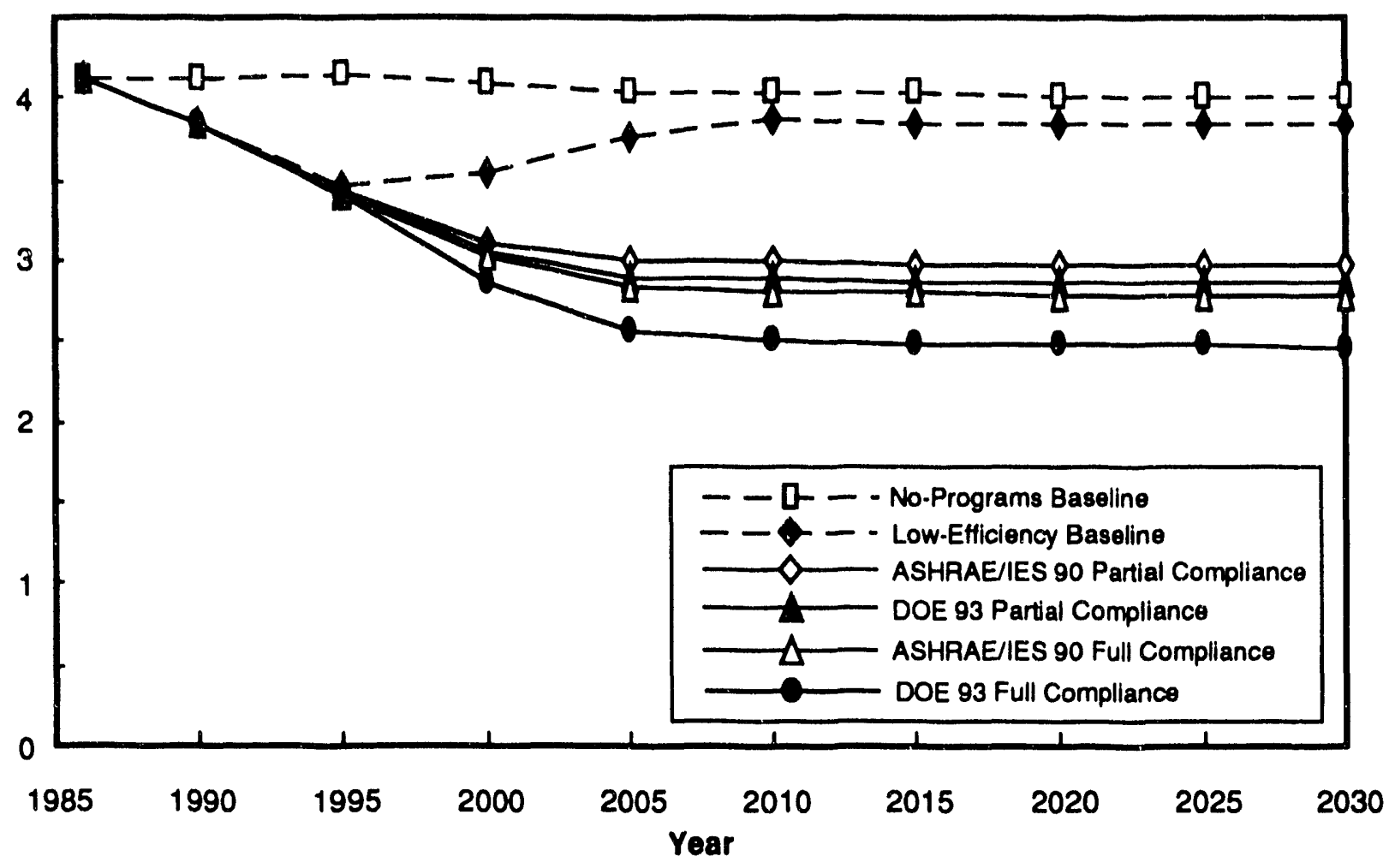

Figure F.28

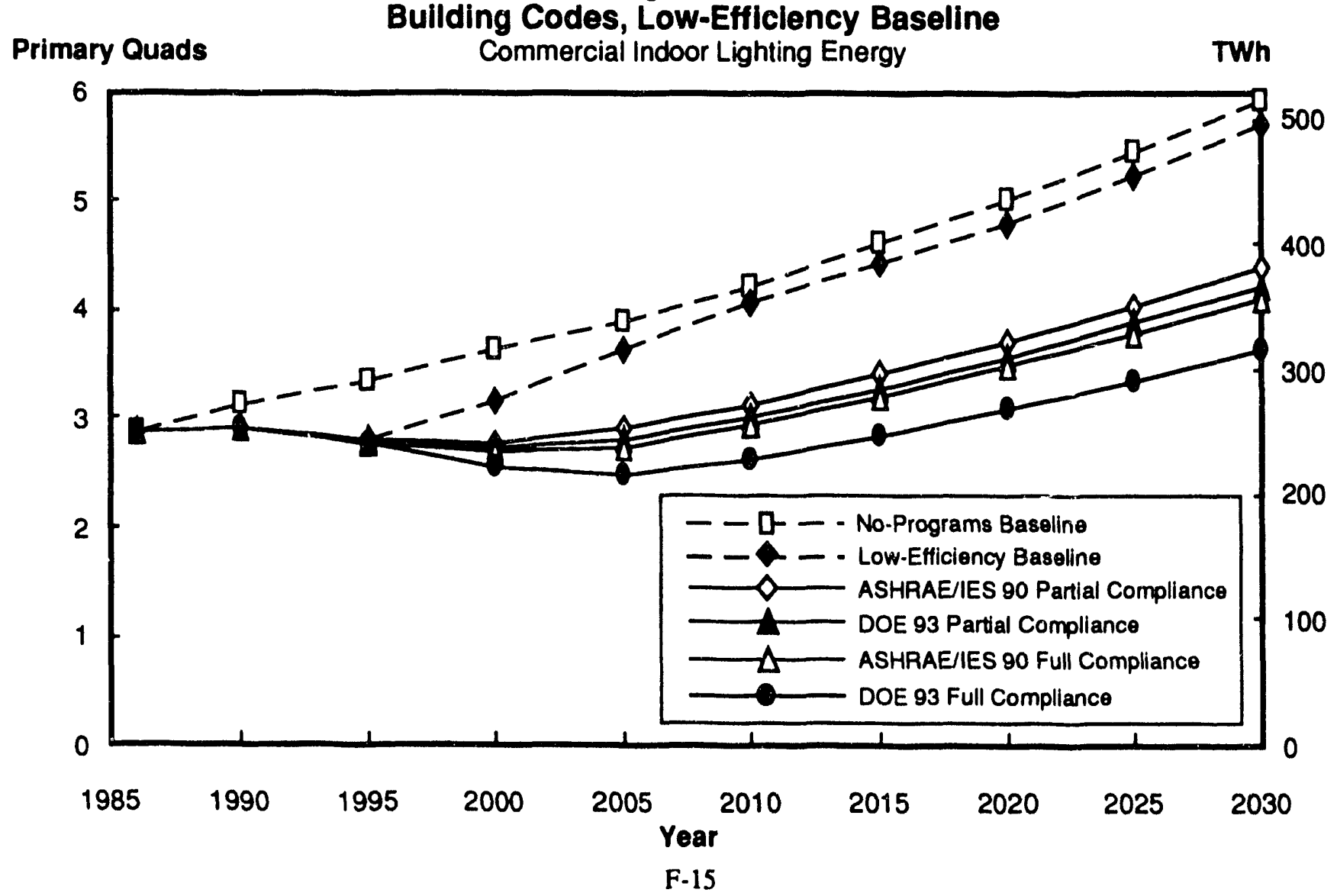


Figure F.29

Incentive Policies, High-Efflciency Baseline

kWh/sq. tt.-yr.

Average Commercial Indoor Lighting EUls

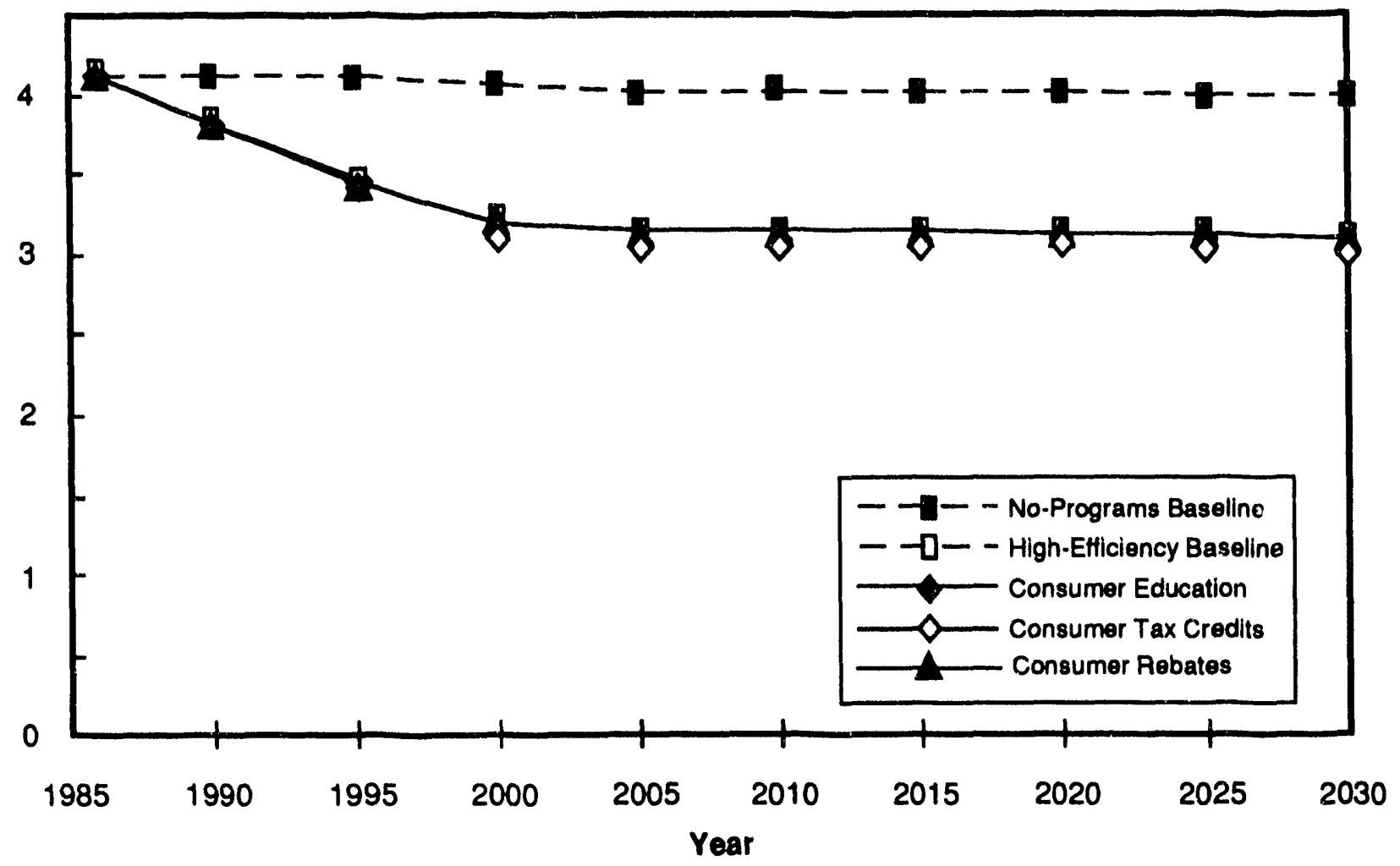

Figure F.30

Incentive Policies, High-Efficiency Baseline

Primary Quads

Commercial Indoor Lighting Energy

TWh

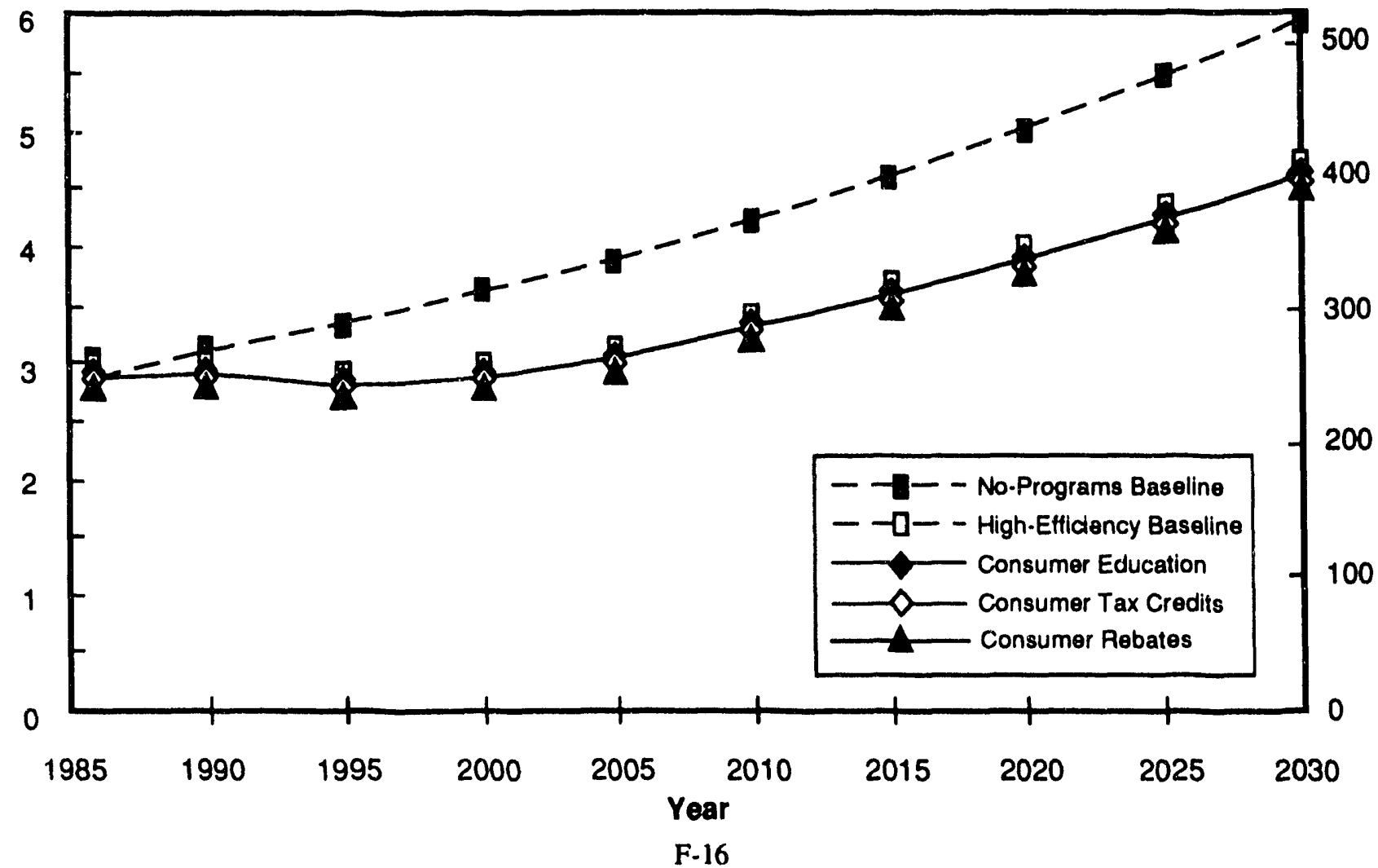


kWh/sq. ft.-yr.

\section{Incentive Pollcles, Low-Efficlency Baseline}

Average Commercial Indoor Lighting EUls

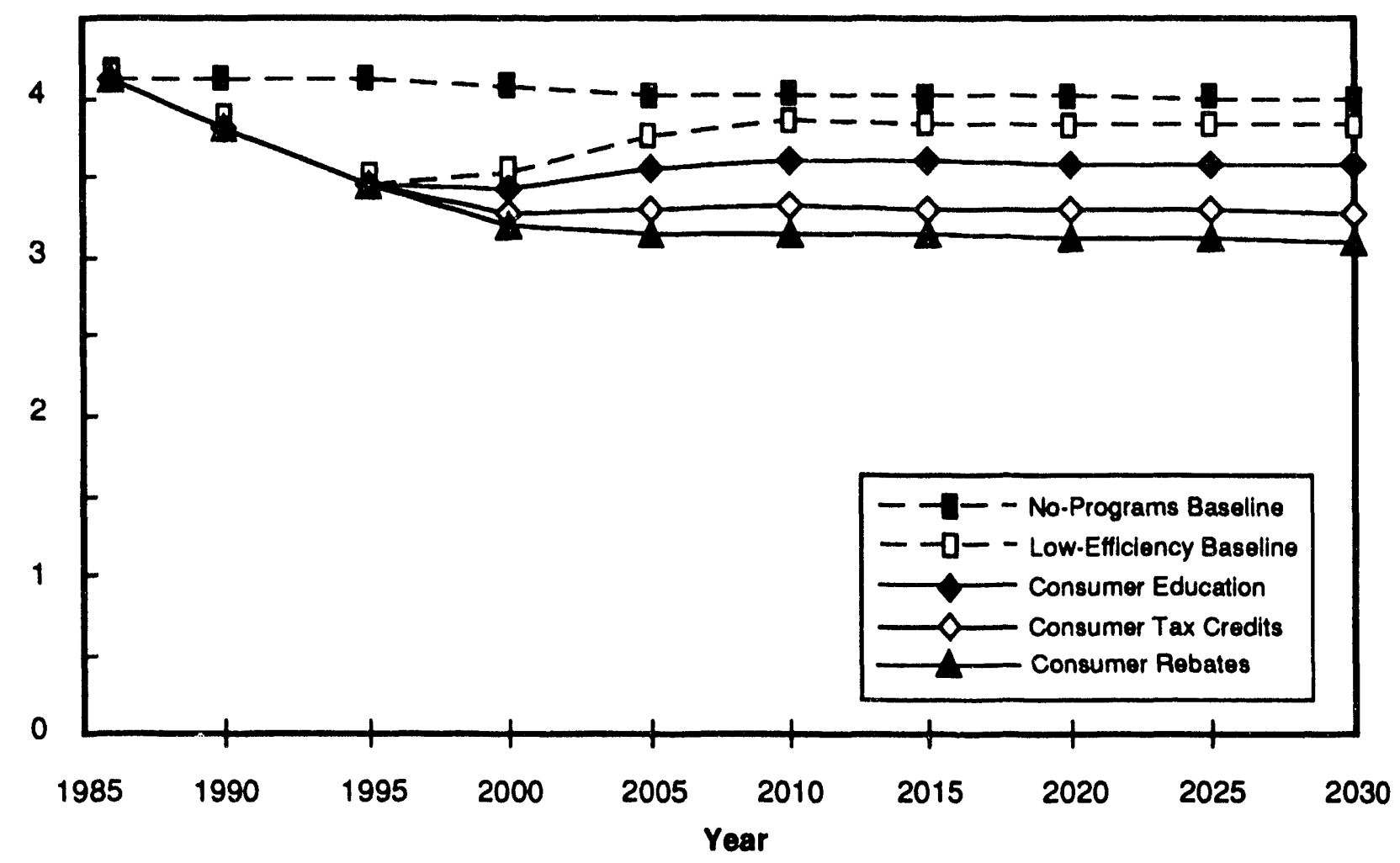

Figure F.32

Incentive Policies, Low-Efficlency Baseline

Primary Quads

Commercial Indoor Lighting Energy

TWh

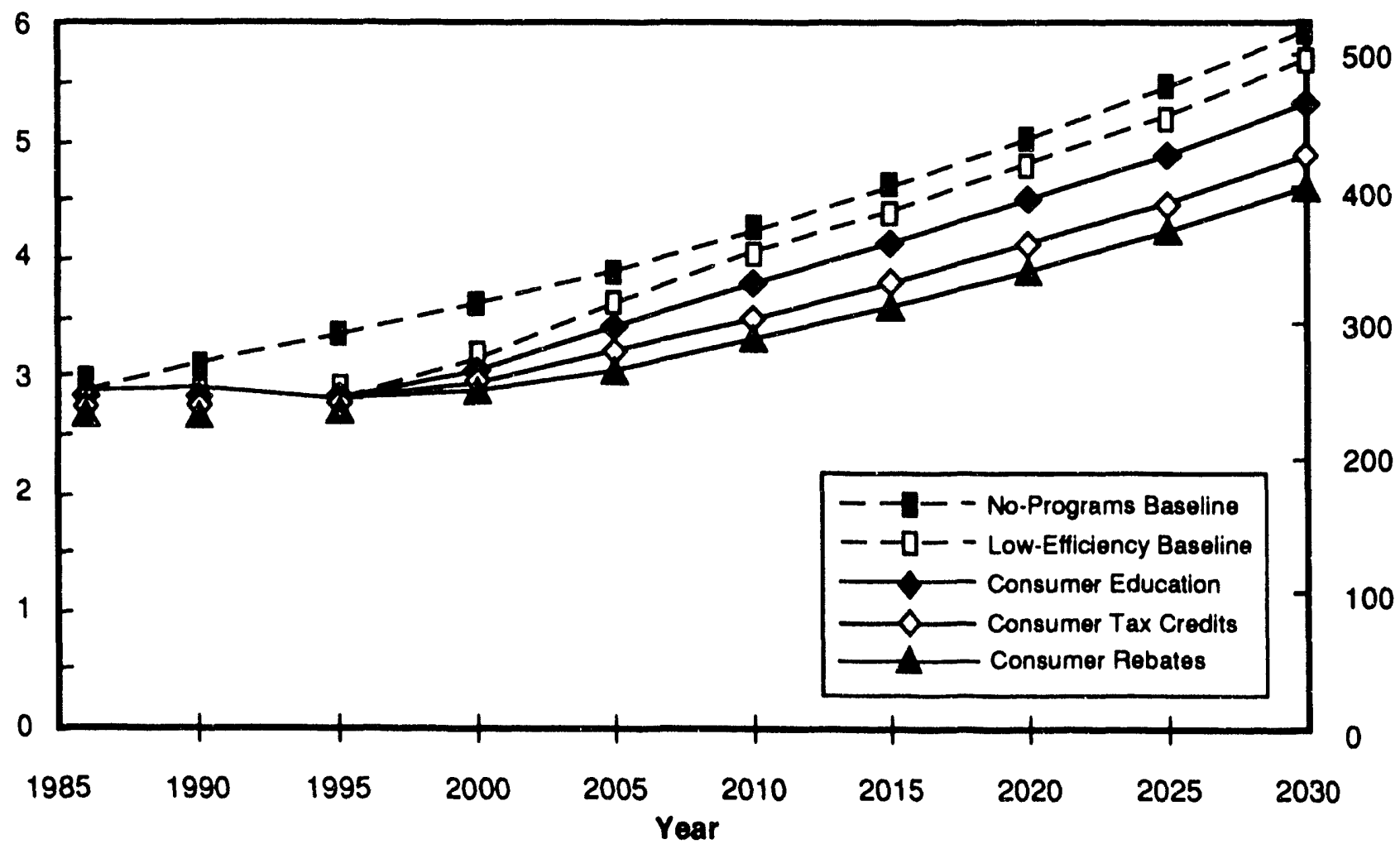

F-17 


\section{APPENDIX G EXISTING ENERGY CODES ADDRESSING LIGHTING}

\section{G.1 ENERGY CODES: LIGHTING PERFORMANCE AND EQUIPMENT STANDARDS}

A detailed state-by-state listing of lighting codes is provided in Table C.1. This appendix describes some of these codes in detail.

\section{G.1.1 Energy Policy Act of 1992: Regulations on Lighting Equipment}

\section{Lamps}

Fluorescent Lamps. The law sets standards for common 4-foot, 8-foot, and 8-foot high-output fluorescent lamps. The metric is a combination of efficacy (lumens/watt) and CRI (color rendering index) that in effect means that the 34-watt T12 lamp is the least expensive option for compliance. (Other more efficacious lamps such as the T8 lamp also comply). The standards affect all lamps domestically manufactured or assembled as well as imported products. The transition period is 3 years for 4 -foot lamps and 18 months for 8 -foot lamps. One year after the transition period, no lamps may be sold that fail to meet the standard. There are several categories of exempted lamps.

Incandescent Reflector Lamps. The law sets standards for common spot and flood light reflector lamps. The metric is efficacy, and in effect for many applications halogen reflector lamps (or better) must be used to qualify. However, a technicality discovered after the legislation was passed allows the 65-watt reduced-wattage PAR lamp to comply. Elliptical reflector lamps are exempted and thus may also be used. The transition period for these lamps is 3 years.

Incandescent General Service Lamps. There is no standard on these lamps. In an earlier version of the legislation, these lamps were regulated. NEMA and the organizations advocating standards negotiated and agreed that general service lamps would not have mandatory standards at this time. Instead, there will be a labeling program for general service lamps sold in the US, designed by the Federal Trade Commission. This program takes effect 18 months after enactment of the legislation.

High Intensity Discharge (HID) Lamps. Within 18 months of enactment, DOE will prescribe testing requirements for those HID lamps for which it determines there are significant potential energy savings. Within 18 months of the establishment of the testing requirements, DOE will prescribe standards for the HID lamps selected. The standards will take effect 3 years after the standard is published, and the Federal Trade Commission will prescribe labeling requirements for these lamps. 


\section{Future Lamp Standards}

Within three years of the enactment date, DOE will study the need for amendment to the fluorescent and incandescent reflector standards. Any revised standards will take effect 4.5 years after enactment. This update procedure will be repeated 8 years after enactment.

Within 2 years of the date the incandescent labeling program takes effect, DOE will study the need for standards on additional fluorescent and incandescent lamps, including general service incandescents.

\section{Fluorescent Luminaires}

DOE, in consultation with NEMA, industry representatives, and other appropriate organizations, will design a luminaire rating and labeling system. This will be in place within one year after the legislation takes effect. If such a system is not established within two years, DOE will develop a rating program for luminaires in consultation with NIST (National Institute of Standards and Technology).

\section{G.1.2 ASHRAE/IES 90.1 and DOE-1988 and -1993 Building Codes}

The current DOE building code is identical to ASHRAE/IES-90.1 in specification of ballast efficiency, exterior LPD standards, and minimum number of control points. In addition, the current code contains the ASHRAE interior LPDs for building types and specific tasks. These LPDs in the DOE code will be lowered, effective in 1993 (the 1993 standards are shown directly below the current DOE standards in Table G.1).

\section{G.1.3 Performance and Component Standards at the State Level}

The lighting performance standards states that have codified in their building codes vary greatly, from no standards at all to independently-developed standards. Most states have building codes modeled after one of the versions of the ASHRAE code. The basis for each states' building code is listed in Table G.2.'

Building codes and/or component standards developed by individual states are summarized in the following sections.

\footnotetext{
${ }^{1}$ Data compiled from The 1991 Energy Directory. The National Conference of States on Building Codes and Standards (NCSBCS). The classifications are rough and have not been verified by the individual states.
}

$$
\text { G - } 2
$$


Table G.1 Lighting Power Density Allowance, Interior Lighting Prescriptive Approach (W/f $\left.{ }^{2}\right)$, ASHRAE/IES 90.1 and DOE 1993 Codes

\begin{tabular}{|c|c|c|c|c|c|c|c|}
\hline \multirow[b]{2}{*}{$\begin{array}{l}\text { Building Type/Area } \\
\text { Function }\end{array}$} & \multicolumn{6}{|c|}{ Gross Lighted Area Ranges } & \multirow[b]{2}{*}{$\begin{array}{l}\text { Effective } \\
\text { Date }\end{array}$} \\
\hline & $\begin{array}{c}0 \text { to } \\
2,000 \mathrm{ft}^{2}\end{array}$ & $\begin{array}{l}2,001 \text { to } \\
10,000 \mathrm{ft}^{2}\end{array}$ & $\begin{array}{l}10,001 \mathrm{to} \\
25,000 \mathrm{ft}^{2}\end{array}$ & $\begin{array}{l}25,001 \mathrm{to} \\
50,000 \mathrm{ft}^{2}\end{array}$ & $\begin{array}{l}50,001 \text { to } \\
250,000 \mathrm{ft}^{2}\end{array}$ & 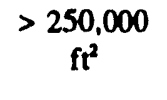 & \\
\hline \multicolumn{8}{|l|}{ Food Service } \\
\hline ASHRAE 90/DOE ${ }^{2}$ & 1.50 & 1.38 & 1.34 & 1.32 & 1.31 & 1.30 & 1988 \\
\hline DOE 93 & 0.92 & 0.85 & 0.82 & 0.81 & 0.81 & 0.80 & 1993 \\
\hline \multicolumn{8}{|l|}{ Leisure Dining/Bar } \\
\hline ASHRAE 90/DOE 88 & 2.20 & 1.91 & 1.71 & 1.56 & 1.46 & 1.40 & 1988 \\
\hline DOE 93 & 1.60 & 1.55 & 1.52 & 1.48 & 1.44 & 1.40 & 1993 \\
\hline \multicolumn{8}{|l|}{ Offices } \\
\hline ASHRAE 90/DOE 88 & 1.90 & 1.81 & 1.72 & 1.65 & 1.57 & 1.50 & 1988 \\
\hline DOE 93 & 1.40 & 1.34 & 1.27 & 1.22 & 1.16 & 1.11 & 1993 \\
\hline \multicolumn{8}{|l|}{ Retail $^{3}$} \\
\hline ASHRAE 90/DOE 88 & 3.30 & 3.08 & 2.83 & 2.50 & 2.28 & 2.10 & 1988 \\
\hline DOE 93 & 2.70 & 2.52 & 2.32 & 2.05 & 1.87 & 1.72 & 1993 \\
\hline \multicolumn{8}{|l|}{ Mall Concourse } \\
\hline ASHRAE 90/DOE 88 & 1.60 & 1.58 & 1.52 & 1.46 & 1.43 & 1.40 & 1988 \\
\hline DOE 93 & 0.69 & 0.68 & 0.65 & 0.63 & 0.61 & 0.60 & 1993 \\
\hline \multicolumn{8}{|l|}{ Service Establishment } \\
\hline ASHRAE 90/DOE 88 & 2.60 & 2.37 & 2.08 & 1.92 & 1.80 & 1.70 & 1988 \\
\hline DOE 93 & 2.81 & 2.03 & 1.78 & 1.65 & 1.54 & 1.46 & 1993 \\
\hline \multicolumn{8}{|l|}{ Garages } \\
\hline ASHRAE 90/DOE 88 & 0.30 & 0.28 & 0.24 & 0.22 & 0.21 & 0.20 & 1988 \\
\hline DOE 93 & 0.25 & 0.24 & 0.23 & 0.22 & 0.21 & 0.20 & 1993 \\
\hline \multicolumn{8}{|l|}{ Schools } \\
\hline ASHRAE 90/DOE 88 & 1.80 & 1.80 & 1.72 & 1.65 & 1.57 & 1.50 & 1988 \\
\hline DOE 93 & 1.33 & 1.33 & 1.27 & 1.22 & 1.16 & 1.11 & 1993 \\
\hline \multicolumn{8}{|l|}{ Jr. High/High School } \\
\hline ASHRAE 90/DOE 88 & $1.90^{\circ}$ & 1.90 & 1.88 & 1.83 & 1.76 & 1.70 & 1988 \\
\hline DOE 93 & 1.40 & 1.40 & 1.39 & 1.35 & 1.30 & 1.26 & 1993 \\
\hline \multicolumn{8}{|l|}{ Technical/Vocational } \\
\hline ASHRAE 90/DOE 88 & 2.40 & 2.33 & 2.17 & 2.01 & 1.84 & 1.70 & 1988 \\
\hline DOE 93 & 1.77 & 1.72 & 1.60 & 1.49 & 1.36 & 1.26 & 1993 \\
\hline \multicolumn{8}{|l|}{ Warehouse/Storage } \\
\hline ASHRAE 90/DOE 88 & 0.80 & 0.66 & 0.56 & 0.48 & 0.43 & 0.40 & 1988 \\
\hline DOE 93 & 0.60 & 0.50 & 0.42 & 0.36 & 0.32 & 0.30 & 1993 \\
\hline
\end{tabular}

${ }^{2}$ LPDs for the ASHRAE/IES 90.1 and the DOE 1988 code are identical.

'Includes general, merchandising, and display lighting.

G - 3 


\begin{tabular}{|c|c|c|c|c|c|c|c|}
\hline No Criteria & $\begin{array}{l}\text { Switching } \\
\text { Criteria } \\
\text { Only }\end{array}$ & $\begin{array}{l}\text { Criteria } \\
\text { included in } \\
\text { General } \\
\text { Building } \\
\text { Performance }\end{array}$ & $\begin{array}{c}\text { Criteria based } \\
\text { on ASHRAE } \\
1980 \text { (1983, } \\
86,89 \text { MEC) }\end{array}$ & $\begin{array}{c}\text { Criteria based } \\
\text { on ASHRAE } \\
1975 \text { (1977 } \\
\text { MEC) }\end{array}$ & $\begin{array}{c}\text { Criteria } \\
\text { based on } \\
\text { ASHRAE } \\
1989\end{array}$ & $\begin{array}{l}\text { States with } \\
\text { own criteria }\end{array}$ & $\begin{array}{c}\text { Not } \\
\text { classified }\end{array}$ \\
\hline $\begin{array}{l}\text { Alaska } \\
\text { Kansas } \\
\text { Louisiana } \\
\text { Maryland } \\
\text { New } \\
\text { Mexico } \\
\text { South } \\
\text { Dakota }\end{array}$ & $\begin{array}{l}\text { Kentucls' } \\
\text { Michigan } \\
\text { Ohio } \\
\text { Vurginia } \\
\text { West } \\
\text { Virginia }\end{array}$ & $\begin{array}{l}\text { Alabama } \\
\text { North } \\
\text { Carolina }\end{array}$ & $\begin{array}{l}\text { Arizona } \\
\text { Hawaii } \\
\text { Idaho } \\
\text { lowa } \\
\text { Illinois } \\
\text { Indiana } \\
\text { Maine } \\
\text { Montana } \\
\text { Nebraska } \\
\text { Nevada } \\
\text { North Dakota } \\
\text { South } \\
\text { Carolina } \\
\text { Utah } \\
\text { Vermont } \\
\text { Wyoming }\end{array}$ & $\begin{array}{l}\text { Coloredo } \\
\text { Missouri } \\
\text { Mississippi } \\
\text { New Hampshire } \\
\text { Pennsylvania } \\
\text { Tennessee }\end{array}$ & $\begin{array}{l}\text { Delaware } \\
\text { Minnesota } \\
\text { Oklahoma } \\
\text { Texas }\end{array}$ & $\begin{array}{l}\text { Arkansas } \\
\text { California } \\
\text { Florida } \\
\text { Georgia } \\
\text { Massachusetts } \\
\text { New York } \\
\text { Oregon } \\
\text { Rhode Island } \\
\text { Washington } \\
\text { Wisconsin }\end{array}$ & $\begin{array}{l}\text { Connecticut } \\
\text { District of } \\
\text { Columbia } \\
\text { New Jersey }\end{array}$ \\
\hline
\end{tabular}

\section{G.1.4 Massachusetts State Standards}

\section{Performance Standards}

Massachusetts' lighting power specifications are very similar to ASHRAE's. Twelve of ASHRAE's exterior lighting LPDs are included in the code. The interior lighting LPDs are similar to the general building type LPDs in ASHRAE, but there are only five building size categories. Massachusetts' power adjustment factors for lighting controls are identical to those in ASHRAE, but allow for fewer combinations of controls.

\section{Equipment Standards}

\section{Lamps}

The Massachusetts legislature passed a statute requiring the Executive Office of Energy Resources (MEOER) to develop standards for energy-efficient lamps, to be enforced at the point of sale. MEOER has devuloped minimum efficacy (lumens per watt) and color rendering index (CRI) standards for fluorescent lamps and general service incandescent and reflector incandescent lamps. The standards were established for four types of fluorescent lamps (F40, F40/U, F96, F96/HO) sold mainly for commercial and industrial uses. The efficacy standards were developed to eliminate stanảard lamps using halophosphors. A lower CRI standard was developed for reduced-wattage ("energy saving") lamps to allow them to meet the standard. The rationale for designing the CRI standard to allow continued use of reduced-wattage lamps is that most new lamps that will be purchased in Massachusetts will be used in existing fixtures, so that the lamp

$$
\text { G }-4
$$


standard should allow for energy efficiency gains from replacing lamps without requiring the retrofit of lighting fixtures. A point-of-sale standard that allows the purchase of energy-saving lamps does not prevent the installation of such lamps in new construction.

Efficacy standards have been developed for five wattage categories of general service incandescent lamps between 30 and 160 watts. Within each wattage category are three separate efficacy standards for lamps with different lifetimes, for a total of 18 efficacy standards. Massachusetts has also adopted five efficacy standards for incandescent reflector lamps based on lamp wattage. Lamps for special purposes or for which no energy efficient substitutes are available within each lamp category are exempt.

Although the standards legislation has passed, these standards have not gone into effect. There was strong opposition from the lamp industry, and the final bill has not been signed into law by the governor. The Massachusetts legislature also delayed extension of standards to residential uses, fearing that efficient lamps were not cost effective for residential users and were not commercially available, although a consultants' report found otherwise. The state has been considering residential lamp standards, as well as HID lamp standards. ${ }^{\star}$

The current Massachusetts building code includes the recently-adopted national ballast standards.

\section{Fixtures}

In addition, Massachusetts is considering establishing by 1993 standards for fluorescent fixtures sold in the state. Incandescent and HID fixture standards would be regulated by 1993 and 1994, respectively. These standards would apply to fixture manufacturers and therefore would affect fixtures in all building types.

\section{Controls}

Massachusetts has requirements for a minimum number of control points similar to the requirements in ASHRAE.

\section{G.1.5 New York State Standard's}

\section{Performance Standards}

The New York building code outlines LPDs and base room cavity ratios (RCR) for 14 building types. Separate LPDs are not given for different building sizes (as in ASHRAE). Installed lighting wattage can be above the appropriate LPD if the overall RCR of the building exceeds

\footnotetext{
4S. Nadel. 1990. "Efficiency Standards for Lamps, Motors and Lighting Fixtures," Proceedings of the ACEEE 1990 Summer Siudty. p. 7:135.
}

$$
\text { G }-5
$$


the base RCR. The room cavity ratio is calculated based on the dimensions of the room. The code also includes four of ASHRAE's LPDs for exterior lighting.

\section{Equipment Standards}

\section{Lamps}

In 1991, New York State adopted lighting component standards for commercial buildings as part of its building code for new construction and major renovation. The standards were developed by the State Energy Office (NYSEO). New York's standards based on lamp efficacy are identical to those adopted by Massachusetts. However, the New York standards are part of the state building code and therefore apply to lamps used in new construction only. For this reason, NYSEO developed a single CRI standard of 67; this single CRI standard prevents the use of reduced-wattage lamps in new construction.

New York's standards also do not exempt any lamps that use colors for specialized use; all lamps subject to the standard must have the minimum $67 \mathrm{CRI}$. The New York code incorporates the national fluorescent ballast standards and has added a standard for three-lamp F40 ballasts. All three-lamp fixtures must either be tandem-wired or use three-lamp ballasts.

\section{Fixtures}

The code also includes minimum efficiency standards for fixtures designed for fluorescent, HID reflector and general service incandescent lamps. The fixture standards for fluorescent lamp fixtures are based on fixture type (parabolic louver, wraparound, etc.) and lumen distribution characteristics (narrow, moderate, or wide). Fixtures that do not meet the standards can still be used if they are offset by more efficient fixtures elsewhere in the building. The code provides a table of average lamp/ballast efficacies to use in determining fixture efficiency "debits" and "credits." The code includes higher efficiency standards for fixtures manufactured after 1994. Fixtures for compact fluorescent lamps and lamps of lower than 30 volts, "job-specific" fixtures, and chandelier fixtures are exempt from the efficiency standards.

\section{Controls}

The code has some requirements for controls but not the minimum number of control points specified in ASHRAE.

\section{G.1.6 California State Standards}

\section{Performance Standards}

The California Energy Commission adopted a new energy building code in May of 1991, effective July 1992. The code requires compliance with a performance standard by one of three methods: the complete building method, the tailored method, or the area category method. The

$$
\text { G - } 6
$$


complete building method must be used for buildings with a single end use, and the applicant must submit lighting plans for the entire building. The code provides a single LPD for each of the eleven building types regardless of building size, as shown in Table G.3. The LPDs are analogous to the ASHRAE 90/DOE 88 prescriptive LPDs in Table G.1.

Table G.3 Complete Building Method California Tite 24 Lighting Power Density Values

\begin{tabular}{lc}
\hline \multicolumn{1}{c}{ Building Type } & Allowed Lighting Power (W/sq.ft) \\
\hline General Commercial and Industrial Work Buildings & 1.2 \\
Grocery Store & 1.8 \\
Industrial and Commercial Storage Buildings & 0.8 \\
Medical Buildings and Clinics & 1.5 \\
Office Building & 1.5 \\
Religious Worship, Auditorium, and Convention & 2.0 \\
Centers & \\
Restaurants & 1.5 \\
Retail and Wholesale Store & 2.0 \\
Schools & 1.8 \\
Theaters & 1.5 \\
All Others & 0.8 \\
\hline
\end{tabular}

When buildings contain many separate end use areas, the area category method, or the more detailed tailored method, must be used. The code lists LPDs for 22 area functions under the method. Under the tailored method, LPDs are provided for nine illuminance categories, corresponding to various task types. Three LPDs based on Room Cavity Ratio (RCR) are provided for each of five of the categories, while two LPDs, based on task area or throw distance (distance between fixture and center of lighted plane on a feature display) are provided for each of the remaining four categories. The code provides illuminance categories for some building areas, such as retail. The code refers to ANSI/IES RP-1, 1982 for illuminance categories for specific office tasks, ${ }^{5}$ and the IES Handbook for the illuminance categories of all other building areas. ${ }^{6}$ The LPDs for retail areas higher than 15 feet can be increased by multipliers provided in the code.

The calculated installed LPD can be lowered for each area of the building that utilizes one of a number of lighting controls. Power adjustment factors are provided for the use of occupancy sensors, dimming systems, lumen maintenance controls, tuning, automatic time switch control

\footnotetext{
${ }^{5}$ Office Lighting American National Standard Practice.

${ }^{6}$ Illuminating Engineering Society of North America (John Kaufman ed.) 1981, 1987. IES Lighting Handbook. (1981 and 1987 Reference Volumes.) New York.
}

$$
\text { G - } 7
$$


devices, daylighting controls, or some combinations of these controls. Factors for daylighting controls are based on the window to wall ratio (or percent of exterior roof area for skylights) of the room controlled and the degree of visible light transmittance (VLT) of the window (or skylight) glazing.

The new code includes three additional changes to the previous lighting control requirements. First, automatic shut-off controls are required for all buildings larger than 5,000 square feet. Second, only controls that have been certified by the state can be installed. Third, multiple switches are required in spaces with connected loads greater than 1.2 watts per square foot. In addition, the photocell control of exterior lighting is required.

\section{Equipment Standards}

California currently has no component standards (the state established standards for fluorescent ballasts in 1978, which became national standards effective in 1991). The CEC held a workshop in January, 1990, to consider adopting lamp standards similar to those in Massachusetts, as well as lowering the LPDs for lighting in Title 24. However, the CEC decided to forego lamp or fixture standards at this time, and concentrate on performance standards (building codes) only.

\section{G.1.7 Minnesota State Standards}

\section{Performance Standards}

Minnesota's performance standards are presently based on ASHRAE/IES 90.1. Public hearings were held in February 1992 on the proposed adoption of the Model Energy Code. A legal ruling on adopting the revisions is pending. The state plans to include lighting efficiency standards included in the DOE-93 code, which result in lighting power densities lower than those in ASHRAE/IES 90.1.

\section{Equipment Standards}

\section{Lamps}

Minnesota recently passed HF2134 which adopts energy efficiency standards for incandescent lamps. Under the statute's provisions, the State Department of Public Service will require that reduced-wattage substitutes be used for 40-, 60-, 75-, 100-, and 150-watt incandescent lamps. Minimum efficacies will be established for lamps, and the efficacy of a reduced-wattage lamp must meet or exceed that of the standard lamp which it replaces. The rule will be mandatory in all instances where reduced-wattage equivalents are available from at least two manufacturers. A lamp in a category subject to the standards may not be sold in the state unless it meets or exceeds the standard. 


\section{G.1.8 Northwest Power Planning Council Standards}

The Model Conservation Standards (MCS) are voluntary commercial and residential building codes developed by the Northwest Power Planning Council (NPPC), which covers the states of Idaho, Montana, Oregon, and Washington.

The MCS commercial code includes LPDs for a number of building types. For rooms with ceilings higher than 20 feet, LPDs may be increased by two percent per foot. Although no member state has adopted the MCS commercial code, Washington and Oregon have commercial lighting codes similar to the MCS.

Washington and Oregon have adopted the MCS residential code; however, this code has no lighting standards.

The MCS commercial code was updated in 1991 to reflect the LPDs in DOE-93. Many feel that the MCS contains the most stringent LPDs in the country.

\section{G.1.9 Washington State Standards}

\section{Performance Standards}

Washington has LPDs for the same building categories as the NPPC MCS. In general, Washington's interior LPDs are slightly lower than those in the MCS, with one notable exception: office buildings (LPD is 1.7 rather than 1.5). For rooms with ceilings higher than 20 feet, LPDs may be increased by two percent per foot. Lighting for stage or entertainment areas, medical and dental uses, kitchens and food preparation areas, and areas specifically designed for the visually handicapped are exempt from the LPD standards. The code includes exterior lighting LPDs for building perimeters ( 7.5 watts per square foot of perimeter), parking structures, and surface parking and circulation areas.

The Washington code also includes ASHRAE's power adjustment factors for occupancy sensors, continuous dimming, stepped controls, lumen maintenance controls, daylighting controls plus occupancy sensors, and occupancy sensors plus lumen maintenance controls. The code also has certain requirements for multiple switching and automatic controls for exterior lighting.

\section{Equipment Standards}

None 


\section{G.1.10 Oregon State Standards}

\section{Performance Standards}

Oregon's code has LPDs, exemptions, and power adjustment factors similar to, but not as detailed as those in Washington's code. Oregon is currently considering lowering the LPDs in its code to the level of those in DOE-93.

\section{Equipment Standards}

None

\section{G.1.11 Wisconsin State Standards}

\section{Performance Standards}

Wisconsin's code contains LPDs for work areas only; no LPDs for general building types are given. The LPDs for interior lighting tend to be higher than ASHRAE's. There is no separate budget for exterior lighting; some exterior lighting LPDs (perimeter facade, parking) are listed with interior lighting LPDs. The code includes LPDs for many areas of apartment buildings, such as bathrooms, closets, kitchens and living/sleeping areas. There are no adjustment factors for controls.

\section{Equipment Standards}

None

\section{G.1.12 Florida State Standards}

\section{Performance Standards}

Florida has LPDs for a number of building types and areas, but no adjustment factors for controls. There are no separate LPDs for exterior lighting; exterior lighting is included in calculating the total watts per square foot of building space.

\section{Equipment Standards}

Florida's code includes the national efficiency standards for fluorescent ballasts.

\section{G.1.13 Georgia State Standards}

\section{Performance Standards}

Georgia has separate lighting budgets for exterior and interior lighting. The exterior LPDs are

$$
\text { G }-10
$$


in general higher than those in ASHRAE. The code provides LPDs for specific task areas only; there are no LPDs for general building types. Although the code contains many of the same interior LPD categories as in ASHRAE (such as athletic areas), the values of Georgia's LPDs vary from ASHRAE's. There are no adjustment factors for controls. For commercial construction, the state is considering approval of ASHRAE/IES 90.1. This code could become effective in 1992.

\section{Equipment Standards}

None

\section{G.1.14 Other State Activities}

New Hampshire. New Hampshire is considering adoption of ASHRAE/IES Standard 90.1.

Pennsylvania. Legislators in Pennsylvania are currently reviewing various building energy codes and standards in an effort to revise the state energy code included in Pennsylvania Act 222.

Vermont. The state legislature is considering the development of lamp standards.

\section{G.1.15 Seattle City Standards}

\section{Performance Standards}

The City of Seattle has systems and component performance approaches with separate LPDs for interior and exterior lighting. LPDs are separated by building type, similar to the approach in Washington's code; the office LPD is lower than Washington's (1.5 rather than 1.7).

\section{G.2 COMPLIANCE WITH BUILDING CODES}

The effectiveness of lighting performance standards incorporated in local building codes depends on the degree to which builders comply with the codes. Code compliance can be determined at two stages: at the planning stage, by checking the final design plans for buildings, and after building completion, by site checks at completed buildings.

Architectural plans demonstrate intent to comply with the requirements of local building codes. However, construction cost overruns and other factors can result in many changes to the building design. Observers note that energy conservation measures required by code are typically disregarded before other code requirements, such as handicapped access and safety measures. Therefore, an architectural plan that passes code inspection does not ensure that the completed building complies with the energy code.

On-site inspection after construction would ensure that completed buildings reflect the 
architectural plans and comply with all measures required by code. However, detailed inspections would prove quite costly, especially for performance (rather than prescriptive) standards. In addition, many code requirements, such as thermal insulation levels, are difficult to confirm once the building is completed. There is little literature on the rates of actual compliance with the lighting requirements of local building codes. Identified studies in this area are summarized below.

California has been monitoring the effectiveness of local government enforcement of its building code (Title 24) for a number of years. ${ }^{7}$ The annual monitoring reports document three types of error that may bring a building out of compliance with the lighting power density standards in Title 24: (1) incorrect calculations of the designed wattage for compliance; (2) plans that show higher installed wattage than shown in the calculations; (3) actual installed wattage that exceeds the calculated wattage and/or the wattage included in the final plan. The latest report (fiscal year 1990) monitored the compliance of 49 non-residential buildings. The report found that three (or six percent) of the buildings inspected had installed lighting wattages in excess of the approved plans; however, it does not follow that these buildings were necessarily out of compliance with the energy requirements of Title 24 . In fiscal 1989, the actual installed wattages of eight out of 44 buildings, or 18 percent, exceeded the calculated wattages on the final plans. In fiscal year 1988 , the actual installed wattages of five out of 50 buildings, or 10 percent, of the buildings inspected exceeded the wattages in the plan. The report notes that local building inspectors claim that they do not have enough time to count lighting fixtures and calculate the installed lighting power density to enforce Title $24 .{ }^{8.9}$

A 1985 study of compliance with Oregon's commercial energy code found that about one-half of the 65 commercial buildings examined met the interior lighting unit power densities of the code. The study noted that at that time the lighting standards were described in a document separate from the building code. Only 44 percent of the architects and engineers, and only 29 percent of the code officials, were even aware of the additional lighting standards. ${ }^{10}$

More recently, Washington and Oregon have completed follow-up studies of 70 commercial buildings in Washington, and 71 commercial buildings in Oregon. These studies were designed to evaluate the degree to which new commercial buildings comply with energy codes, including

\footnotetext{
${ }^{7}$ See Section G.1.6 for a description of California Title 24 lighting requirements.

${ }^{8} \mathrm{CMJ}$ Engineering. 1987-88 and 1988-89. Building Energy Monitoring Final Report. Prepared by CMJ Engineering, Sacramerito, CA, for the Califomia Energy Commission, Sacramento, CA.

${ }^{9}$ C. Jetsen, CMJ Engineering, Sacramento, CA. Personal communication, October 1991.

${ }^{10}$ Church/Davis Architects. 1985. Commercial Building Code Compliance in Oregon. Prepared by Church/Davis, for the Oregon Department of Energy, Salem, OR.
}

$$
\text { G - } 12
$$


lighting. ${ }^{11.12}$ The buildings were drawn from a pool which included all new commercial buildings permitted for construction in Washington and Oregon in 1990. The sample was stratified into two groups, large $\left(>40,000 \mathrm{ft}^{2}\right)$ and small $\left(<40,000 \mathrm{ft}^{2}\right)$, to reflect the importance of large buildings. About half of the buildings studied were found to comply with all aspects of the states' energy codes. Compliance on individual sections of the code exceeded 70 percent, and where the code provisions were simple and straightforward (e.g., HVAC) compliance exceeded 95 percent. In Oregon, 28 percent of the buildings studied failed on lighting, more than on any other system, and in Washington the failure rate on lighting was 24 percent of buildings studied. When weighted by floor area, the results show much higher lighting compliance than by project, with highest compliance among office buildings, schools, and warehouses, and lowest compliance among retail, restaurant, and lodging buildings. Lighting systems which failed to comply often did so because changes to the design were made during construction. In many of the larger buildings, the lighting systems were not yet completed at the time of the study. The analysis of compliance in these buildings was based on lighting specifications.

A recent analysis of 18 commercial buildings in Massachusetts and Rhode Island compared the actual installed lighting power densities of the buildings to the LPDs allowed under Massachusetts' new lighting code (which is based on ASHRAE 90.1). Although each building was approved before the new code was adopted, eight buildings had met the code voluntarily. ${ }^{13}$

Seattle's Major Projects Rule (MPR) requires large commercial buildings to exceed the state prescriptive energy code requirements by ten percent. A recent analysis of the MPR compared the subsystems of six buildings constructed under the MPR guidelines with those in 11 control buildings constructed to meet the requirements of Washington and Oregon prescriptive codes. All of the MPR and control buildings met the lighting unit power density requirements of the state building codes. ${ }^{14}$

The Bonneville Power Administration (BPA) reviewed selected local government's efforts to enforce Chapter 53, the energy efficiency section of the Oregon building code. The study found that plan review of Chapter 53 requirements is not administered uniformly by the municipalities studied. Lighting standards were singled out as not being adequately enforced.

\footnotetext{
"Baylon, D. 1992. "Commercial Building Energy Code Compliance in Washington and Oregon." Proceedings of the ACEEE 1992 Summer Study on Energy Efficient Buildings, vol. 6, p. 6.1.

${ }^{12}$ Baylon, D., M. Frankel and C. Clark. 1992. Energy Code Compliance in Commercial Buildings in Washington and Oregon. Washington State Energy Office, Olympia, WA and Oregon Department of Energy, Salem, OR.

${ }^{13}$ S. Nadel and F. Davis. 1990. "Is ASHRAE/IES Standard 90.1P Being Followed?" Lighting Design and Applications.

14Ecotope. 1989. Major Projects Rule, Phase II Evaluation. Prepared by Ecotope, Seattle, WA, for Seattle City Light, Seatue, WA.
} 
A Washington state study tabulates the number of local governments that perform on-site inspections for specific residential code measures (there are no lighting requirements in residential code). Jurisdictions were more likely to inspect certain requirements of the code: 93 percent of all jurisdictions inspected for wall insulation, while only 45 percent inspected for the proper thermostat. ${ }^{15}$ A similar study was done on compliance with the commercial code for BPA. $^{16}$

The New York State Energy Office has received the first draft of an analysis of statewide compliance with its energy code. The final report will examine the approved plans and perform on-site inspections for residential buildings only. The report will also contain the results of surveys of code officials and building designers throughout the state. ${ }^{17}$

The findings of these studies indicate that enforcement of building codes is inadequate. Lack of enforcement compromises the effectiveness of building codes in promoting energy efficiency. More research is necessary to accurately measure the impact of poor code enforcement on energy efficiency.

\footnotetext{
${ }^{15}$ Washington State Building Code Council. 1991. Washington State Energy Code Enforcement Study. Olympia, WA.

${ }^{16} \mathrm{O}^{\prime}$ Neill and Company. 1988. Evaluation of the Enforcement Costs of the Washington State Commercial Energy Code. Prepared by O'Neill and Company for the Bonneville Power Administration.

${ }^{17}$ W. Saxonis, New York State Energy Office, Albany, NY. Personal communication, October 1991.

G -14
} 


\section{APPENDIX H LIGHTING INTERACTIONS WITH HEATING, VENTILATING, AND AIR-CONDITIONING ENERGY USE}

\section{H.1 INTRODUCTION}

Rules of thumb and engineering studies on individual commercial buildings often suggest that energy saved in lighting translates into additional net savings in space-conditioning energy. This section presents results of a preliminary attempt to evaluate the issue on a national scale. The results run contrary to conventional assumptions, and may appear counter-intuitive upon first inspection. Further technical work is being performed to resolve the issue.

"Waste" heat from lighting can represent useful energy during periods when space heating is required but can lead to increased energy use when air conditioning is required. Raising the efficiency of lighting systems can thus be expected have a net-positive or negative-effect on the energy required for space conditioning, depending on many variables. Based on the uncertainties discussed below, and the lack of a definitive supporting analysis and consensus among analysts, these effects are not incorporated in the results presented in Sections 4 and 5 and Appendix F. However, the issue is important enough to warrant the following discussion and quantitative illustrations.

The net effect of interactions among lighting systems and heating, air-conditioning, and ventilation systems (HVAC) depends on a spectrum of technical and economic factors. Technical factors include the extent to which lighting savings occur during periods when the building requires space conditioning and the relative efficiencies (by fuel and equipment) with which heating and cooling are provided. Other (non-lighting) sources of internal heat gains must also be quantified; their value depends on the building's thermal integrity and operating schedule. Given the inefficiency of producing electricity compared to other forms of delivered energy (e.g., natural gas, coal, or oil), the net energy-use results also depend on whether energy impacts are counted in terms of primary or site energy. Moreover, system-wide peak-demand impacts may differ from energy impacts depending on the coincidence of lighting energy use with the total load faced by the utility and on whether the utility peak tends to occur during the cooling season or the heating season.

Relevant economic factors include the mix and costs of the energy sources affected (electricity and fossil fuels) and the respective tariff structures and time-of-day/year differentiation in energy prices. Because of the generally higher cost of electricity compared to fossil fuel, cooling savings can have relatively more weight in terms of financial impacts. Moreover, in summer-peaking regions, avoided demand charges associated with reduced cooling loads can be substantially greater than charges (if any) linked to heating loads. In addition, reduced or increased HVAC loads can influence system sizing and thus the cost of the HVAC equipment 
in a building. Consideration of equipment costs pertains only to new buildings or buildings where HVAC equipment is being replaced.

To accurately capture the technical effects in a given building and location, it is necessary to employ a dynamic (e.g., hourly) building energy simulation model. To evaluate national impacts, the analysis must correctly account for distinct building types and regional variations in weather, building envelope and equipment efficiencies, and economic variables. For forecasting purposes, technical and economic variables must be projected over time. Given the rapid changes possible over time for each variable, the analysis is fairly complicated. For example, if it is anticipated that the energy efficiency of space conditioning increases over time, then the net impact of HVAC interactions will diminish as overall demand for purchased space-conditioning energy is lower.

Existing estimates reflect a lack of consensus on the issue. Most previous studies project a considerable net HVAC benefit (in other words, the cooling benefit exceeds the heating penalty) for commercial buildings and relatively small penalties for residential buildings. In one national estimate, direct electricity savings from lighting efficiency improvements increase by 35 to 45 percent in commercial buildings due to HVAC effects while a net reduction of about five percent is found in residential buildings. ${ }^{1}$ The EPA's Green Lights Program assumes a 20 percent net benefit for commercial buildings.

For the commercial sector, qualitatively different results emerged from a recent $L B L$ investigation that used a state-of-the-art buildings energy simulation model (DOE-2). ${ }^{2}$ This study examined representative large U.S. office buildings and found a net reduction in lighting source energy savings for a cold northern climate (Chicago, IL) and small net benefits in a hot climate (Charleston, SC). The corresponding payback time adjustments were extremely small, only a few months in most cases. This "counter-intuitive" result combined with negative net impacts resulting from COMMEND modeling has led to further investigation described in Section H.3.

\section{H.2 COMMERCIAL SECTOR RESULTS}

The COMMEND 3.2 model used in preparing this study contains a framework for estimating lighting-HVAC interactions based on default values and user inputs. However, this model version lacks an adequate basis to specify with confidence the technical and economic parameters necessary to represent the entire country and dynamic trends up to the year 2030 (e.g., changing equipment efficiencies). The COMMEND software to improve this for version 4.0 is still under development (see Appendix E). Furthermore, the results are strongly influenced by underlying assumptions about energy prices; relative electricity/fuel prices affect the choice of heating equipment. Energy price forecasts used in this study reflect those employed in the AEO and the

\footnotetext{
${ }^{1}$ A. Lovins and R. Sardinsky. 1988. The State of the Art: Lighting, Rocky Mountain Institute, Snowmass, Colorado.

${ }^{2}$ E. Franconi and F. Rubinstein. 1992. "Considering Lighting System Performance and HVAC Interactions in Lighting Retrofit Analyses," IEEE Industrial Applications Society Annual Meeting, Houston, TX, vol. 2, p. 1858.
}

$\mathrm{H}-2$ 
National Energy Strategy where electricity prices remain almost constant in real terms while fossil fuel prices increase considerably. This set of price relationships-stemming from an assumed tripling of coal use in the electric power sector-leads to projections of significant increases in electric heating in commercial buildings. This, in turn, gives rise to increasing heating penalties over time. Improvements in envelope efficiency, which would reduce spaceconditioning demand, are not driven by energy prices in the model.

COMMEND 3.2 models the heating and cooling energy impacts through a set of lighting/HVAC coincidence factors. Cooling coincidence factors range from 0.4 to 0.6 , depending on the building type (i.e., 40 percent to 60 percent of lighting energy appears as increased cooling loads). The corresponding coincidence factors for heating range from 0.2 to 0.3 . The remaining 20 percent or so of lighting energy is used when neither heating nor cooling systems are in operation or is delivered to unconditioned plenum space. A table of HVAC equipment efficiencies is used in a COMMEND post-processor to estimate energy use impacts. The equipment efficiencies are held constant in the model rather than allowed to change dynamically over time. To remedy this, electric heating Coefficients of Performance (COPs) are adjusted in this analysis to reflect the increased penetration of heat pumps assumed by the model. The penetration of heat pumps versus electric resistance heating is also influenced by embedded default assumptions about equipment costs.

Efficiency parameters and fuel-share assumptions have a strong effect on the result of HVAC-lighting interactions analyses. Within the COMMEND analysis described above, the following assumptions are made: approximately 35 percent heat pump penetration for space heating (COP 2.0) by the year 2030; gas and oil heating efficiency 70 percent, and cooling efficiency (COP) approximately 3.5. By the year 2030, 39 percent of the commercial building stock (and 46 percent of newly constructed buildings) is electrically heated.

Using the COMMEND default values, there is a slight reduction in effective lighting energy savings due to HVAC interactions in commercial buildings. In other words, there is a net penalty in which the increase in heating primary energy use resulting from lighting energy reductions exceeds the savings in cooling primary energy use. The effect ranges from 3 percent to 6 percent depending on the policy case. On the other hand, lighting energy savings lead to indirect HVAC-related reductions in utility peak demand of about 30 percent beyond the reductions due directly to lighting. This arises due to the summer-peaking nature of the national power system. 


\section{H.2.1 COMMEND Results in Perspective}

Parametric DOE-2 and COMMEND runs have been performed to test the plausibility of the COMMEND version 3.2 default coincidence factors.

Figure H-1 displays a range of predicted HVAC-Lighting interaction effects. Limiting cases are defined by hourly DOE-2 simulations of cooling benefits (only) in the above-mentioned office buildings in Charleston, NC and by heating penalties (only) in an office building in Chicago, IL. Combined heating-cooling interactions for these locations range from a 9 percent net benefit in Charleston to a 13 percent penalty (i.e. reduction in lighting savings) in Chicago. The COMMEND results are within the bounds of these limiting cases.

As a check on the COMMEND default coincidence factors, DOE- 2 has also been used to develop floorspace-weighted heating and cooling coincidence factors representative of the entire US commercial buildings stock (based on 11 building types in 8 climate zones). This resulted in a range of coincidence factors varying by building type. When these factors are used in COMMEND 3.2, the resulting US average impacts range from a one percent net benefit for a hypothetical buildings stock heated entirely with electric-resistance systems to a 5 percent net benefit for a buildings stock heated entirely with electric heat pumps (see Figure H.1). The intermediate case ( 3 percent benefit) reflects the mix of heat pumps and resistance heating predicted by COMMEND. Recall that using COMMEND's default coincidence factors resulted in a net penalty, ranging from 3 to 6 percent of primary lighting energy savings, depending on the policy case examined. While the net HVAC impact using the newer set of coincidence factors shifts from slightly negative to slightly positive, these results are far from the large net benefits assumed by many analysts. The results should be treated as preliminary. Further work is underway to refine the COMMEND model for the forthcoming version 4.0 (1993).

\section{H.3 RESIDENTIAL SECTOR RESULTS}

As with the commercial sector, interactions between residential lighting and space-conditioning energy use are complex. It is especially difficult to extrapolate building-specific relationships to the entire U.S. housing stock and into the future.

The results of a limited investigation of the issue are presented below, based on 1990-vintage, single-family detached, single-zone dwellings. Three cities-Chicago, Washington, D.C., and Fort Worth-are studied. The cities represent a variety of climates, but the results cannot be used to definitively develop average U.S. coincidence factors. Thermal integrity of the homes is assumed to match the 1990 ASHRAE $90.2 \mathrm{P}$ voluntary standard. This is not synonymous with actual practice, or with how homes will be designed throughout the forecast period of 1990 to 2030. The simulations yielded the counter-intuitive result that the coincidence factors do not diminish with increasing thermal integrity, even though increases in insulation levels imply that the effective heating season would be shortened. 
Figure H.1

Range of HVAC-Lighting Interaction Effects

(DOE-2 and COMMEND Results)

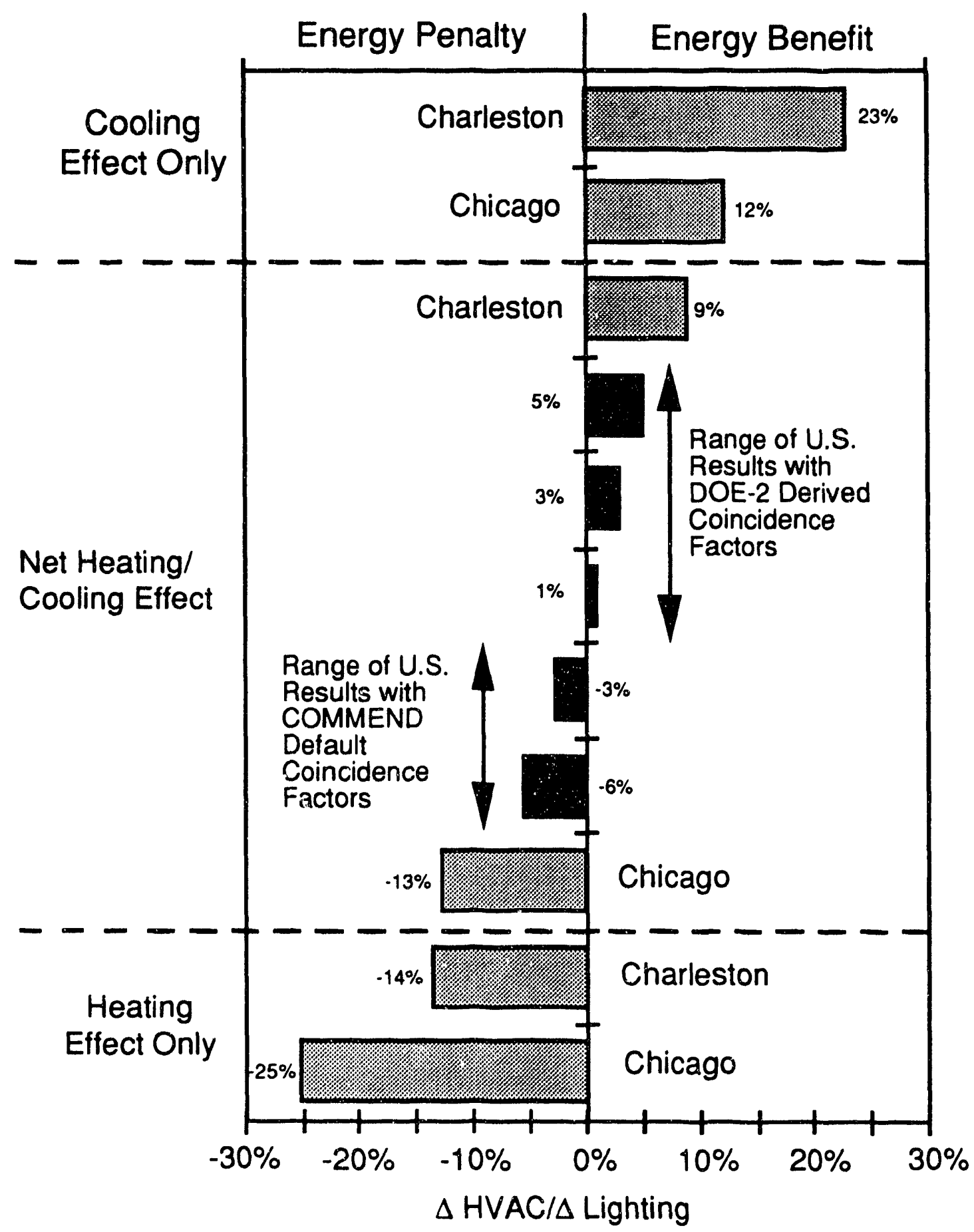

DOE-2 Simulations

COMMEND Runs 
Simulations with DOE-2, assuming a 25 percent reduction in lighting energy use, lead to lighting coincidence factors that are inferred from the changes in heating and cooling loads predicted by the model (Table H.1). The translation of these loads to energy impacts depends on the mix of space-conditioning system types, fuels, and efficiencies.

Table H.1 Coincidence of Lighting Energy Use with Heating and Cooling Periods, Residential Sector ${ }^{3}$

\begin{tabular}{lccc}
\hline Location & $\begin{array}{c}\text { Coincidence of lighting } \\
\text { and heating periods }\end{array}$ & $\begin{array}{c}\text { Coincidence of lighting } \\
\text { and cooling periods }\end{array}$ & $\begin{array}{c}\text { Non-coincidence of } \\
\text { lighting and heating or } \\
\text { cooling }\end{array}$ \\
\hline Washington, D.C. & $50 \%$ & $25 \%$ & $25 \%$ \\
Chicago, II. & $57 \%$ & $18 \%$ & $25 \%$ \\
Fort Worth, TX & $37 \%$ & $31 \%$ & $32 \%$ \\
Weighted Avg.* & & & $27 \%$ \\
(Chicago \& Fort Worth) & $48 \%$ & $24 \%$ & $27 \%$ \\
\hline
\end{tabular}

* The average for the two cities is weighted, by the housing stock in the U.S. Federal regions; those classified as "Northern" are assigned to Chicago and those as "Southern" to Forth Worth.

As in the commercial sector, there is a net penalty in which the increase in heating primary energy use exceeds the savings in cooling energy use. The effect ranges from 9 to 13 percent of direct lighting energy savings, depending on the policy case examined. In terms of peak electric power demand, there is a net benefit ranging from 25 to 50 percent.

\footnotetext{
${ }^{3}$ Ritschard, R.L., J.W. Hanford, and A.O. Sezgen. 1992. "Single-family Heating and Cooling Requirements: Assumptions, Methods, and Summary Report." Draft. Gas Research Institute Report No. GRI-9/0236, Chicago, IL.

H -6
} 

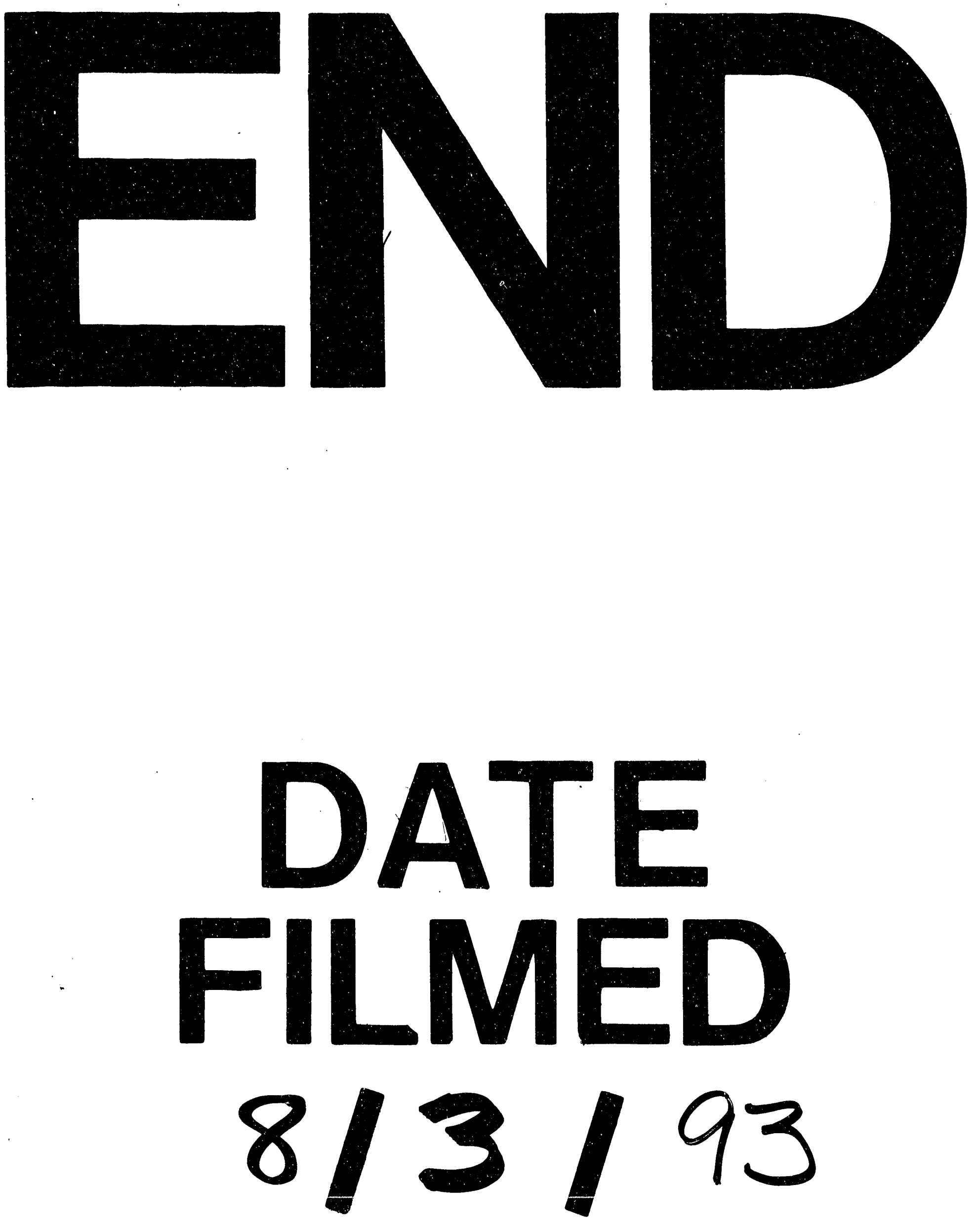
